\title{
Synthesis and Characterization of $\mathrm{Ru}(\mathrm{II})$ Complexes as Potential Catalysts in Olefin Hydroarylation
}

\author{
Evan Elizabeth Joslin \\ Atlanta, GA \\ B.A. Chemistry, Agnes Scott College, 2008
}

A Dissertation presented to the Graduate Faculty

of the University of Virginia in Candidacy for the Degree of

Doctor of Philosophy

Department of Chemistry

University of Virginia

July 2013 


\begin{abstract}
JOSLIN, EVAN E. Synthesis and Characterization of Ru(II) Complexes as Potential Catalysts in Olefin Hydroarylation. (Under the direction of Professor T. Brent Gunnoe).

The production of alkyl arenes from benzene and simple olefins is a continually growing market. However, current acid base technologies (i.e., Friedel-Crafts \& Zeolites) have significant drawbacks. For example, Friedel-Crafts alkylation of arenes exhibits extensive polyalkylation, and thus requires an additional high temperature transalkylation process to increase the selectivity for monoalkylated products. Furthermore, Friedel Crafts is selective for the Markovnikov addition products when a-olefins are employed. Additionally, the ability to recycle the catalyst is impossible due to degradation during product isolation. Our strategy is to use transition metal catalysts for olefin hydroarylation that proceeds via an alternative mechanism which combines both olefin insertion and $\mathrm{C}-\mathrm{H}$ activation which could potentially overcome these challenges.
\end{abstract}

Extension to previous studies conducted by our group on a series of complexes with the motif $\mathrm{TpRu}(\mathrm{L}) \mathrm{Ph}(\mathrm{NCMe})[\mathrm{Tp}=$ hydridotris(pyrazolyl)borate, $\mathrm{L}=$ neutral two electron donor] were investigated. These studies demonstrated that an electron poor metal center was needed to strike promote olefin insertion over olefin $\mathrm{C}-\mathrm{H}$ activation. Therefore, the electron donating properties of $\mathrm{P}\left(\mathrm{OCH}_{2}\right)_{2}\left(\mathrm{OCCH}_{3}\right)$ where explored using cyclic voltammetry of a variety of $\mathrm{Ru}(\mathrm{II})$ complexes contain a wide range of phosphites and phosphines. It was determined that the metal center is less electron rich with $\mathrm{P}\left(\mathrm{OCH}_{2}\right)_{2}\left(\mathrm{OCCH}_{3}\right)$ than $\mathrm{L}=\mathrm{PMe}_{3}, \mathrm{P}\left(\mathrm{OCH}_{2}\right)_{3} \mathrm{CEt}, \mathrm{PPh}_{3}$, and $\mathrm{P}(\mathrm{OMe})_{3}$; however, the metal center is still more electron rich than when $\mathrm{L}=\mathrm{CO}$. The $\mathrm{Ru}(\mathrm{II})$ complex 
$\mathrm{TpRu}\left[\mathrm{P}\left(\mathrm{OCH}_{2}\right)_{2}\left(\mathrm{OCCH}_{3}\right)\right](\mathrm{NCMe}) \mathrm{Ph}$ has been synthesized and isolated. This complex was shown to be both capable of activating $\mathrm{C}-\mathrm{H}$ bonds and an active catalyst for ethylene hydrophenylation.

Additionally, rather than varying the electron density of the metal center via the neutral two electron ligand one could alter the electron density by replacing the anionic Tp ligand with neutral analogues, such as tri(pyrazolyl)alkanes. Complexes with tris(pyrazolyl)alkanes were synthesized, characterized and tested for olefin hydrophenylation the results of these experiments will be discussed herein. 


\section{ACKNOWLEDGMENTS}

I would first like to thank all my professors from the Agnes Scott Chemistry Department who helped me learn the fundamentals of chemistry and show me how much I enjoyed the subjected and guided me to pursue it. In particular, Dr. Venable who gave me the opportunity to do research in his inorganic lab and helped me realized that I would rather go to graduate school rather than medical school. I would also like to thank Dr. Venable for all the encouragement during the last five years when I started to wonder if I would be able to complete this long road.

Thank you to all the staff of the Chemistry Department at UVA for making my time here have more laughs and be a lot less stressful. In particular thanks to Danny and the stockroom guys for helping me with the groups purchase and for all the sports talk. Thanks to Jeff Ellena for helping me all the times that I "broke" the NMR or need help running a new experiment. Thanks to Dr. Tom Cundari and Claire at the University of North Texas for all the calculations to help support my experimental data. Additionally, thank you to Dr. Sabat for looking at all my lousy crystals and being to willing to try to solve them even when there was thought to be no hope. Finally, thank you to Dr. Bill Myers for all the discussions and mass spect. data collected.

I would also like to thank my committee members, Dr. Dean Harman, Dr. Robert Davis, and Dr. James Marshall. Thank you for taking the time out of your busy schedules to read my dissertation, annual reports, and to answer my questions. Additionally, Dean thank you for all your helpful suggestions in both research and teaching and allowing me to shadow you while taught. 
Thanks to all my Agnes Scott friends (Jaxen, Aly, Diana, Diane, and Dana) and to all my Virginia friends (there are just too many to name, I am bound to forget one) for hanging in with me these last five years even in times when it seemed like I had fallen off the face of the earth. In particular, thank you to Scott Donald for all the conversations, pep me ups, laughs and tennis games. I hope you are planning to have guest in California because I am coming to VISIT! Additionally, thanks to all my teammates during intramurals, kickball, Saturday basketball or any other activity I am missing. Without these breaks from chemistry I wouldn't have been able to make it through!

To my fellow Gunnoers, thank you for all the memories. Samantha, thank you for always being there and listening to all my crazy stories no matter how busy you are and always making me smile with your squeal. I have enjoyed all the football games that we have attended (maybe one day Virginia will win more). Brad, from our times in Brent office (because of course you lost rock, paper, scissors to Joanna!) to both of us finishing up it has been a great rollercoaster. Even though there have been times that I find you more annoying than some of my own sibling (e.g., candidacy exam time) you can always make me laugh and have answered all my questions and I am extremely thankful. Joanna, thank you for all the girl power talks that we had my first fours years and helping to encourage me to continue on. To the current members of the Gunnoe group: JJ, Steve, Kathleen, Mike, Tristan, Ben, Shaun, Zuming, George, Ted, Bridget, Anna, Tomas, Nate, Michael thanks for all the memories and of course the most important thing make sure to keep the Gunnoe group superior to the Harman group! To past members: Brandon, Tamara, Jeremy, Mark, Sam, Zorida, Max and Chong thanks for those enjoyable 
moments in lab and certain ones in particular thanks for helping me learn how to be a scientist and how not to blow myself up in lab, I couldn't have done it without all your help.

Coach Brent thanks for all the support during these last five years. Thank you for always pushing me and helping me understand that I can do more than I think. Thank you for your patience as a teacher. Your optimism, enthusiasm, and passion for science helped me in the times when I thought that my chemistry would never work. Thank you for letting me coach basketball with you the past two seasons. It has been so much fun to see Leah and the other girls start to understand basketball and improve. I have greatly enjoyed all of our talks on how to teach $3^{\text {rd }} / 4^{\text {th }}$ girls basketball along with all our times talking about running. I know you can make that 6-minute mile you just have to run it on an outside track rather than an indoor one-less turning is the key! Thanks for everything and I could not be happy for picking you to be my advisor in graduate school.

A huge thanks to Shawn Fahl and his family for all their love and support. Shawn, thank you for all the times of talking me down when I thought things could not get worse and for encouraging me to continue. Thank you for putting up with all my quarks no matter how crazy they might be. Thanks for the smiles, laughs and terrific memories so far, from me throwing the EMPTY beer can at you, to the Huskey Research Exhibition, all the sporting events to Paris I could not have found someone more supportive and who I enjoy spending time with anywhere.

Finally and the most important thank you to my family for always believing in me and encouraging me that I can do most anything I put my mind to. Mom and Dad, you are 
the most terrific parents that any one could ask for, I could not have been luckier. Thank you for always believing in me and encouraging me to continue. Thank you for all the phone calls and visits to Charlottesville when I needed a distraction. Love you more! 


\section{TABLE OF CONTENTS}

LIST OF SCHEMES.................................................................IX

LIST OF FIGURES............................................................

LIST OF TABLES........................................................XVII

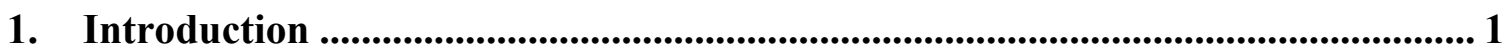

1.1. Current Methods for Industrial Synthesis of Alkyl Arenes................................ 2

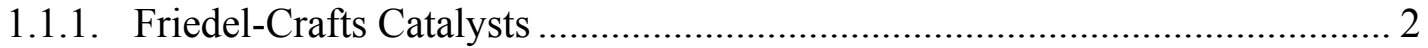

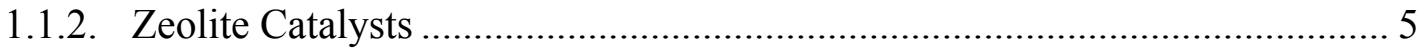

1.2. Transition Metal Catalyzed C-C Bond Forming Reactions ............................9

1.3. Transition Metal Mediated C-H Activation for the Synthesis of Alkyl Arenes

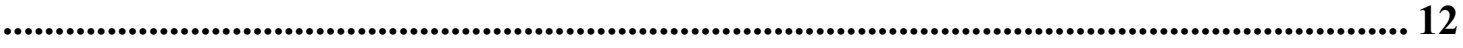

1.4. Examples of Transition Metal Catalysts for Olefin Hydroarylation ............... 15

1.4.1. Transition Metal C-H Activation by an Acid Catalyzed Pathway............... 15

1.4.2. Non-Acid Catalyzed Transition Metal Promoted C-H Activation of

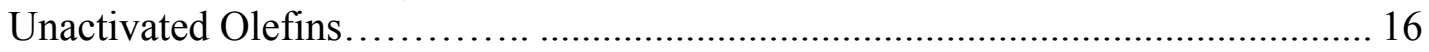

1.5. Summary and Thesis Aims ..................................................................... 34

1.6. References ............................................................................................................. 36

2. Structural and Electronic Properties of Ru(II) Complexes Containing ........... 41

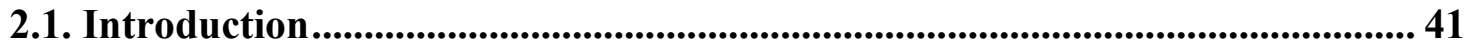

2.2. Results and Discussion.............................................................................. 44

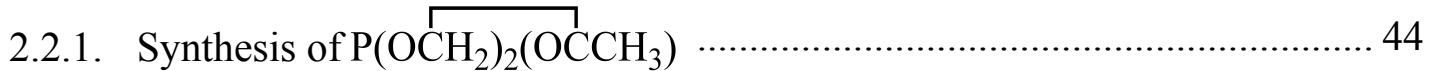

2.2.2. Synthesis and Characterization of $\mathrm{TpRu}(\mathrm{L})\left(\mathrm{PPh}_{3}\right) \mathrm{Cl}$ Complexes ................ 45

2.2.3. Synthesis and Characterization $\left(\eta^{6}-\mathrm{C}_{6} \mathrm{H}_{6}\right) \mathrm{Ru}(\mathrm{L}) \mathrm{Cl}_{2}$ Complexes ................... 52

2.2.4. Synthesis and Characterization of $\left(\eta^{6}-p\right.$-cymene $) \mathrm{Ru}(\mathrm{L}) \mathrm{Cl}_{2}$ Complexes. ..... 59

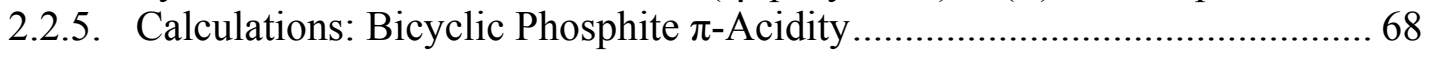

2.3. Conclusions ......................................................................................................... 71

2.4. Experimental Section......................................................................................... 72

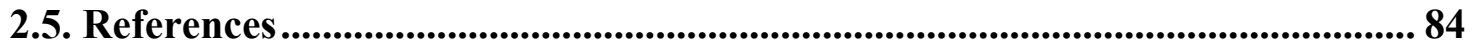

3. Aromatic C-H Activation and Catalytic Hydroarylation of Ethylene Using $\mathrm{TpRu}\left[\mathrm{P}\left(\mathrm{OCH}_{2}\right)_{2}\left(\mathrm{OCCH}_{3}\right)\right](\mathrm{NCMe}) \mathrm{Ph}$...................................................................... 89

3.1. Introduction............................................................................................ 89

3.2. Results and Discussion................................................................................. 91

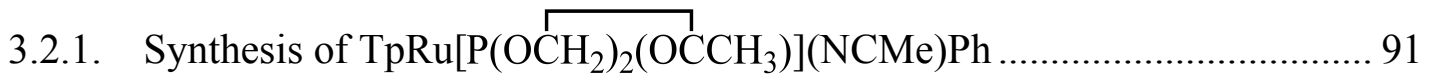

3.2.2. Stoichiometric Benzene Activation .......................................................... 99

3.2.3. Catalytic Hydrophenylation of Ethylene by $\mathrm{TpRu}\left[\mathrm{P}\left(\mathrm{OCH}_{2}\right)_{2}\left(\mathrm{OCCH}_{3}\right)\right]$ (NCMe)Ph (4) 
3.2.4. Catalytic Hydroarylation by $\mathrm{TpRu}\left[\mathrm{P}\left(\mathrm{OCH}_{2}\right)_{2}\left(\mathrm{OCCH}_{3}\right)\right](\mathrm{NCMe}) \mathrm{Ph}$ (4) using

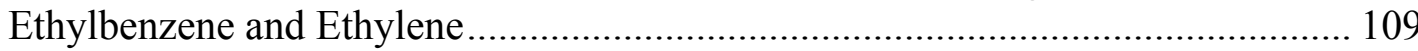

3.2.5. Attempted Hydrophenylation of Monosubstituted Olefins......................... 110

3.2.6. DFT Calculations of Ethylene Hydrophenylation by

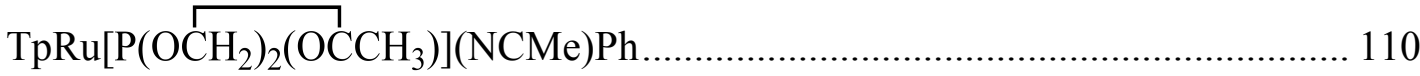

3.2.7. Comparison of $\mathrm{TpRu}(\mathrm{L})(\mathrm{NCMe}) \mathrm{Ph}$ Catalysts ............................................ 113

3.3. Summary and Conclusions .............................................................................. 118

3.4. Experimental .................................................................................................... 119

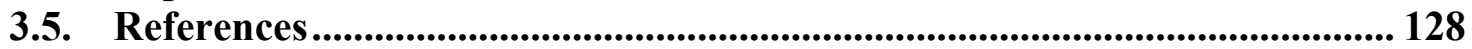

4. Catalytic Decomposition Pathway for $\mathrm{TpRu}(\mathrm{CO})(\mathrm{NCMe}) \mathrm{Ph}$............................. 130

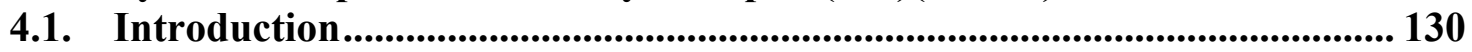

4.2. Results and Discussion.......................................................................................... 132

4.2.1. Kinetics of Decomposition of $\mathrm{TpRu}(\mathrm{CO})(\mathrm{NCMe}) \mathrm{Ph}$ in THF .................. 132

4.2.2. Competing Decompostion Reactions: Dependence on Ethylene

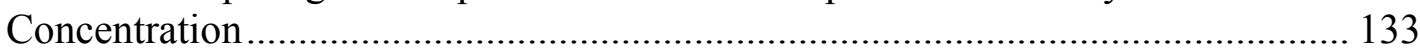

4.2.3. Competing Deactivation Pathways: Dependence on Catalyst Loading..... 136

4.3. Conclusions ........................................................................................................... 137

4.4. Experimental ............................................................................................................ 138

4.5. References................................................................................................................... 141

5. Synthesis and Characterization of $(\mathrm{L}) \mathrm{Ru}(\mathrm{II})$ complexes $(\mathrm{L}=$ neutral 6-electron

donor) for Olefin Hydroarylation.............................................................................. 142

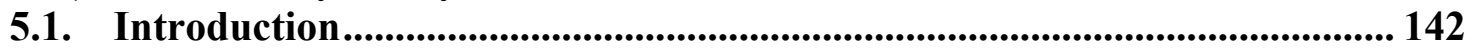

5.2. Results and Discussion...................................................................................... 145

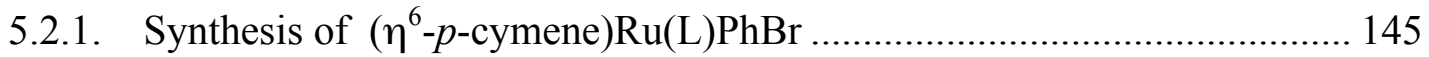

5.2.2. Olefin hydrophenylation using $\left(\eta^{6}-p\right.$-cymene $) \mathrm{Ru}(\mathrm{L}) \mathrm{PhBr}$........................ 152

5.2.3. Synthesis of $\left\{\left[\mathrm{C}(\mathrm{pz})_{4}\right] \mathrm{Ru}\left[\mathrm{P}\left(\mathrm{OCH}_{2}\right)_{3} \mathrm{CEt}\right] \mathrm{Ph}(\mathrm{NCMe})\right\}[\mathrm{Y}]$ Complexes ...... 153

5.2.4. Synthesis of $\left\{\left[\mathrm{HC}\left(\mathrm{pz}^{\prime}\right)_{3}\right] \mathrm{Ru}\left[\mathrm{P}\left(\mathrm{OCH}_{2}\right)_{3} \mathrm{CEt}\right] \mathrm{Ph}(\mathrm{NCMe})\right\}[\mathrm{Y}]$ Complexes (pz'

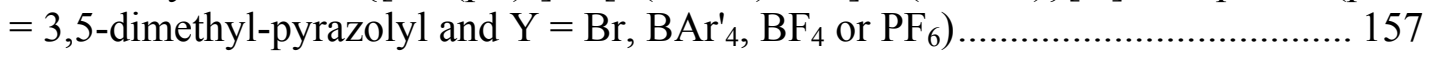

5.2.5. Attempted Synthesis of $\left\{\left[\mathrm{C}(\mathrm{pz})_{4}\right] \mathrm{Ru}\left[\mathrm{P}\left(\mathrm{OCH}_{2}\right)_{3} \mathrm{CEt}\right] \mathrm{Ph}(\mathrm{NCMe})\right\}\left[\mathrm{BAr}_{4}^{\prime}\right] .162$

5.3. Conclusions....................................................................................................... 175

5.4. Experimental Section ......................................................................................... 176

5.5. Acknowledgements for High-Resolution Mass Spectroscopy Data............. 193

5.6. References................................................................................................................. 193

6. Summary and Future Outlook ................................................................................. 196

6.1. Olefin Hydroarylation with $\mathrm{TpRu}(\mathrm{L}) \mathrm{Ph}(\mathrm{NCMe})$............................................. 196

6.2. Olefin Hydroarylation with $\mathrm{Ru}$ (II) Complex contain neutral 6-electron donor ligands........................................................................................................................ 199

6.3. Onward to Rhodium ............................................................................................... 200

6.4. References................................................................................................................ 202 


\section{LIST OF SCHEMES}

\section{CHAPTER 1}

Scheme 1.1. Alkyl arenes produced from benzene and olefins. ................................... 2

Scheme 1.2. Overall reaction for Friedel-Crafts alkylation............................................ 3

Scheme 1.3. Mechanism for Friedel-Crafts alkylation reaction. ..................................... 3

Scheme 1.4. Mechanism for Friedel-Crafts alkylation reaction with a-olefins................. 5

Scheme 1.5. Product shape selectivity of $p$-xylene is favorable due to pore size

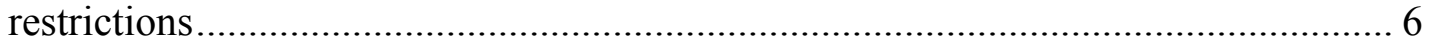

Scheme 1.6. General reaction scheme for cross-coupling reactions utilizing palladium. 10

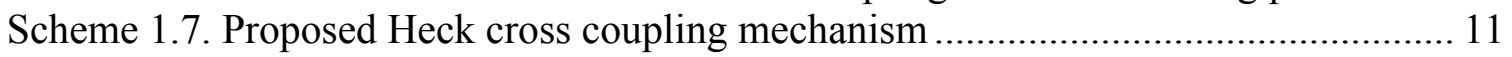

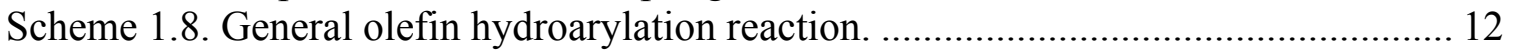

Scheme 1.9. Cycle for transition metal catalyzed olefin hydroarylation......................... 13

Scheme 1.10. Potential competing side reactions for olefin hydroarylation. ................... 14

Scheme 1.11. Proposed catalytic cycle for addition of arenes to alkynes. ...................... 17

Scheme 1.12. Proposed mechanism for ethylene hydrophenylation with (dmpp)Pt....... 19

Scheme 1.13. Proposed mechanism for the formation of diethylbenzene by

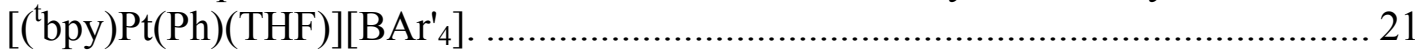

Scheme 1.14. Trans-Cis isomerization of (acac $)_{2} \mathrm{Ir}(\mathrm{Ph}) \mathrm{L}\left(\mathrm{L}=\mathrm{H}_{2} \mathrm{O}\right.$ or $\left.\mathrm{C}_{5} \mathrm{H}_{5} \mathrm{~N}\right) \ldots \ldots \ldots \ldots . . .22$

Scheme 1.15. Proposed Olefin Hydroarylation Catalytic Cycle by $\mathrm{TpRu}(\mathrm{L})(\mathrm{NCMe})(\mathrm{R})$.

Scheme 1.16. Allyl formation through $\mathrm{C}-\mathrm{H}$ olefin activation for $\mathrm{TpRu}(\mathrm{L})$ complexes... 29

Scheme 1.17. Competition between ethylene $\mathrm{C}-\mathrm{H}$ activation and ethylene insertion. .... 29

Scheme 1.18. Regioselective of a-olefin hydroarylation............................................ 30

Scheme 1.19. Olefin coordination inhibited due to steric bulk of $\mathrm{P}(\mathrm{pyr})_{3} \ldots \ldots \ldots \ldots \ldots \ldots \ldots . . . . . . . . . . .31$

Scheme 1.20. Intramolecular $\mathrm{C}-\mathrm{H}$ activation of $\mathrm{TpRu}\left[\mathrm{P}(\mathrm{pyr})_{3}\right](\mathrm{NCMe}) \mathrm{Ph}$ to yield

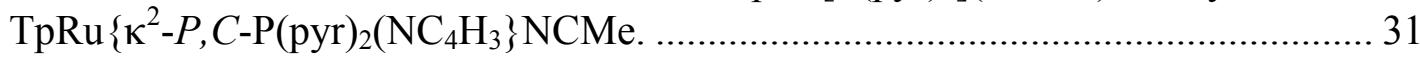

Scheme 1.21. Calculated Gibbs Free Energy $(\mathrm{kcal} / \mathrm{mol})$ for benzene $\mathrm{C}-\mathrm{H}$ activation by $\mathrm{TpRu}(\mathrm{L})(\mathrm{NCMe}) \mathrm{Ph}\left[\mathrm{L}=\mathrm{CO}, \mathrm{P}\left(\mathrm{OCH}_{2}\right)_{3} \mathrm{CEt}, \mathrm{PMe}_{3}\right.$ and $\left.\mathrm{P}(\mathrm{pyr})_{3}\right]$.

\section{CHAPTER 2}

Scheme 2.1. Comparison of acyclic and bicyclic phosphites based on the hinge effect. . 42

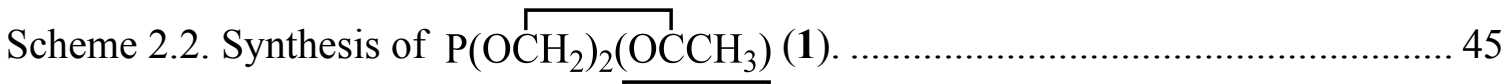

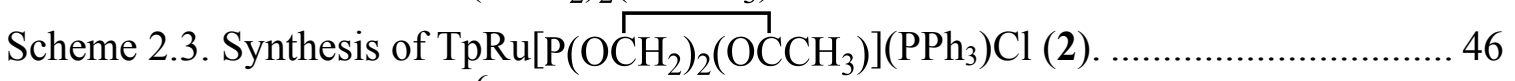

Scheme 2.4. Synthesis of $\left(\eta^{6}-\mathrm{C}_{6} \mathrm{H}_{6}\right) \mathrm{Ru}(\mathrm{L}) \mathrm{Cl}_{2}\left(\mathrm{~L}=\mathrm{PMe}_{3}, \mathrm{P}\left(\mathrm{OCH}_{2}\right)_{3} \mathrm{CEt}\right.$ and

$\left.\mathrm{P}\left(\mathrm{OCH}_{2}\right)_{2}\left(\mathrm{OCCH}_{3}\right)\right]$

Scheme 2.5. Synthesis of $\left(\eta^{6}-p\right.$-cymene $) \mathrm{Ru}(\mathrm{L}) \mathrm{Cl}_{2}\left(\mathrm{~L}=\mathrm{P}\left(\mathrm{OCH}_{2}\right)_{3} \mathrm{CEt}\right.$,

$\mathrm{P}\left(\mathrm{OCH}_{2}\right)_{2}\left(\mathrm{OCCH}_{3}\right), \mathrm{P}(\mathrm{OMe})_{3}$, and $\left.\mathrm{PPh}_{3}\right]$.

Scheme 2.6. Proposed mechanism for exchange reaction of $\mathrm{L}$ with $\mathrm{P}(\mathrm{OMe})_{3}$ to form $\left(\eta^{6}-\right.$ p-cymene $) \mathrm{Ru}\left[\mathrm{P}(\mathrm{OMe})_{3}\right] \mathrm{Cl}_{2}$ in $\mathrm{CDCl}_{3}$ at $60^{\circ} \mathrm{C}$. 


\section{CHAPTER 3}

Scheme 3.1. Ethylene C-H activation vs ethylene insertion in olefin hydroaylation cycle. 90

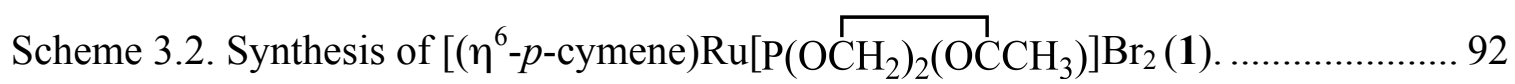

Scheme 3.3. Synthesis of $\left[\left(\eta^{6}-p\right.\right.$-cymene $) \mathrm{Ru}\left[\mathrm{P}\left(\mathrm{OCH}_{2}\right)_{2}\left(\mathrm{OCCH}_{3}\right)\right] \mathrm{PhBr} \ldots \ldots \ldots \ldots \ldots \ldots . . . . . . . . . . . . . . .94$

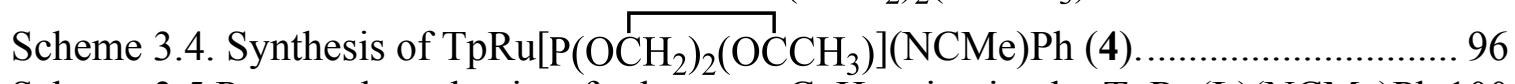

Scheme 3.5 Proposed mechanism for benzene $\mathrm{C}-\mathrm{H}$ activation by $\mathrm{TpRu}(\mathrm{L})(\mathrm{NCMe}) \mathrm{Ph} .100$

Scheme 3.6. Stoichiometric C-D benzene of complex 4 . 101

Scheme 3.7. Proposed Catalytic Cycle for the Hydrophenylation of Ethylene using $\mathrm{TpRu}(\mathrm{L})(\mathrm{NCMe})_{3} \mathrm{Ph}\left[\mathrm{L}=\mathrm{CO}, \mathrm{P}\left(\mathrm{OCH}_{2}\right)_{3} \mathrm{CEt}\right.$ or $\left.\mathrm{P}\left(\mathrm{OCH}_{2}\right)_{2}\left(\mathrm{OCCH}_{3}\right)\right] \ldots \ldots \ldots \ldots \ldots . . . . . . . . .104$

Scheme 3.8. TpRu[P(OCH$\left.)_{2}\left(\mathrm{OCCH}_{3}\right)\right]\left(\eta^{3}-\mathrm{C}_{3} \mathrm{H}_{4} \mathrm{Me}\right)(\mathbf{5})$ and minor products caused by multiple ethylene insertions.

Scheme 3.9. Formation of 1,3- and 1,4-diethylbenzene............................................ 110

Scheme 3.10. Calculated Gibbs free energies $(\mathrm{kcal} / \mathrm{mol})$ for hydrophenylation of ethylene by $\mathrm{TpRu}\left[\mathrm{P}\left(\mathrm{OCH}_{2}\right)_{2}\left(\mathrm{OCCH}_{3}\right)\right](\mathrm{NCMe}) \mathrm{Ph}$.

Scheme 3.11. Calculated Gibb's free energies $(\mathrm{kcal} / \mathrm{mol})$ for ethylene hydrophenylation catalytic cycle by $\mathrm{TpRu}(\mathrm{L})(\mathrm{NCMe}) \mathrm{Ph}\left[\mathrm{L}=\mathrm{CO}, \mathrm{PMe}_{3}, \mathrm{P}\left(\mathrm{OCH}_{2}\right)_{3} \mathrm{CEt}, \mathrm{P}(\mathrm{pyr})_{3}\right.$ and $\left.\mathrm{P}\left(\mathrm{OCH}_{2}\right)_{2}\left(\mathrm{OCCH}_{3}\right)\right]$

Scheme 3.12. Calculated Gibbs Free Energies $(\mathrm{kcal} / \mathrm{mol})$ for benzene $\mathrm{C}-\mathrm{H}$ activation and formation of ethylbenzene by $\mathrm{TpRu}(\mathrm{L})\left(\eta^{2}-\mathrm{C}_{2} \mathrm{H}_{4}\right)\left(\mathrm{CH}_{2} \mathrm{CH}_{2} \mathrm{Ph}\right)$. 117

\section{CHAPTER 4}

Scheme 4.1. Proposed catalytic cycle for olefin hydroarylation with $\mathrm{TpRu}(\mathrm{II})$ complexes.

Scheme 4.2. Competing deactivation pathways during catalysis for $\mathrm{TpRu}(\mathrm{CO})(\mathrm{NCMe}) \mathrm{Ph}$.

\section{CHAPTER 5}

Scheme 5.1. Synthesis of $\left(\eta^{6}-p\right.$-cymene $) \mathrm{Ru}(\mathrm{L}) \mathrm{Br}_{2}\left[\mathrm{~L}=\mathrm{P}\left(\mathrm{OCH}_{2}\right)_{3} \mathrm{CEt}(\mathbf{1})\right.$ or $\left.\mathrm{PMe}_{3}(\mathbf{3})\right]$.

Scheme 5.2. Synthesis of $\left(\eta^{6}-p\right.$-cymene $) \mathrm{Ru}(\mathrm{L}) \mathrm{PhBr}\left[\mathrm{L}=\mathrm{P}\left(\mathrm{OCH}_{2}\right)_{3} \mathrm{CEt}(2)\right.$ or $\left.\mathrm{PMe}_{3}(\mathbf{4})\right]$.

Scheme 5.3. Synthesis of $\left(\kappa^{3}-N, C^{5}, N\right) \mathrm{C}(\mathrm{pz})_{4} \mathrm{Ru}\left[\mathrm{P}\left(\mathrm{OCH}_{2}\right)_{3} \mathrm{CEt}\right](\mathrm{NCMe}) \mathrm{Br}(\mathbf{6}) \ldots \ldots \ldots \ldots . . . . .156$

Scheme 5.4. C-H activation of 5-position of the Tp pyrazolyl ring in $\operatorname{Tp} \operatorname{Ir}\left(\mathrm{PPh}_{3}\right)\left(\mathrm{C}_{2} \mathrm{H}_{4}\right)$.

Scheme 5.5. Synthesis of $\left\{\left[\mathrm{HC}\left(\mathrm{pz}^{\prime}\right)_{3}\right] \mathrm{Ru}\left[\mathrm{P}\left(\mathrm{OCH}_{2}\right)_{3} \mathrm{CEt}\right] \mathrm{Ph}(\mathrm{NCMe})\right\}[\mathrm{Br}](7) \ldots \ldots \ldots \ldots . . . .158$

Scheme 5.6. Synthesis of $\left\{\left[\mathrm{HC}\left(\mathrm{pz}^{\prime}\right)_{3}\right] \mathrm{Ru}\left[\mathrm{P}\left(\mathrm{OCH}_{2}\right)_{3} \mathrm{CEt}\right] \mathrm{Ph}(\mathrm{NCMe})\right\}\left[\mathrm{BAr}_{4}^{\prime}\right](\mathbf{8}) \ldots \ldots . . .161$

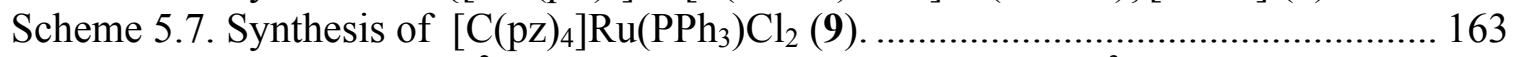

Scheme 5.8. Synthesis of $\left[\kappa^{2}-\mathrm{C}(\mathrm{pz})_{4}\right] \mathrm{Ru}\left[\mathrm{P}\left(\mathrm{OCH}_{2}\right)_{3} \mathrm{CEt}\right] \mathrm{Cl}_{2}$ and $\left[\kappa^{3}-\right.$ $\left.\mathrm{C}(\mathrm{pz})_{4}\right] \mathrm{Ru}\left[\mathrm{P}\left(\mathrm{OCH}_{2}\right)_{3} \mathrm{CEt}\right] \mathrm{Cl}_{2}(\mathbf{1 0})$....... 
Scheme 5.9. Synthesis of $\left\{\left[\mathrm{C}(\mathrm{pz})_{4}\right] \mathrm{Ru}\left[\mathrm{P}\left(\mathrm{OCH}_{2}\right)_{3} \mathrm{CEt}\right] \mathrm{Cl}(\mathrm{NCMe})\right\}[\mathrm{Cl}](\mathbf{1 1}) \ldots \ldots \ldots \ldots . . . . .166$

Scheme 5.10. Synthesis of $\left\{\left[\mathrm{C}(\mathrm{pz})_{4}\right] \mathrm{Ru}\left[\mathrm{P}\left(\mathrm{OCH}_{2}\right)_{3} \mathrm{CEt}\right] \mathrm{Cl}(\mathrm{NCMe})\right\}\left[\mathrm{BAr}{ }_{4}\right](\mathbf{1 2}) \ldots \ldots . . .167$

Scheme 5.11. Synthesis of $\left\{\left[\mathrm{C}(\mathrm{pz})_{4}\right] \mathrm{Ru}\left[\mathrm{P}\left(\mathrm{OCH}_{2}\right)_{3} \mathrm{CEt}\right](\mathrm{OTf})(\mathrm{NCMe})\right\}\left[\mathrm{BAr}_{4}\right](\mathbf{1 3}) \ldots 170$

Scheme 5.12. Synthesis of $\left\{\left[\mathrm{C}(\mathrm{pz})_{4}\right] \mathrm{Ru}\left[\mathrm{P}\left(\mathrm{OCH}_{2}\right)_{3} \mathrm{CEt}\right](\mathrm{Me})(\mathrm{NCMe})\right\}\left[\mathrm{BAr}_{4}\right]$ (14)..... 173

Scheme 5.13. Synthesis of $\left\{\left[\left(N, C^{5}, N\right) \mathrm{C}(\mathrm{pz})_{4}\right] \mathrm{Ru}\left[\mathrm{P}\left(\mathrm{OCH}_{2}\right)_{3} \mathrm{CEt}\left[(\mathrm{NCMe})_{2}\right\}\left[\mathrm{BAr}_{4}\right](\mathbf{1 5})\right.\right.$. 


\section{LIST OF FIGURES}

\section{CHAPTER 1}

Figure 1.1. Depiction of a ZSM-5 zeolite catalyst (A) Structure looking from the top at Zeolite channels (B) Looking side on at zeolite material- four pores are marked for orientation ( $a, b, c$ and d). Copyright 2009 Wiley. Used with permission from Macquarrie, D. J., Industrial Friedel-Crafts Chemistry, Catalytic Asymmetric Friedel-Crafts Alkylations, Wiley-VCH.

Figure 1.2. Depiction of a Y zeolite. Copyright 2010 Wiley. Used with permission from Broach, R.W. Zeolite Types and Structures, Zeolites in Industrial Separation and Catalysis, Wiley-VCH

Figure 1.3. (dmpp)Pt catalyst precursors for olefin hydroarylation................................ 18

Figure 1.4. [('bpy) $\mathrm{Pt}(\mathrm{Ph}) \mathrm{L}]\left[\mathrm{BAr}{ }_{4}\right]$ catalyst for olefin hydroarylation............................. 20

Figure 1.5. bis-acac- $O, O$-Ir(III) ( $(\mathrm{acac}=$ acetylacetonato or 2,4-pentanedione $)$ and bishfac- $O, O$-Rh(III) (hfac- $O, O=$ b-diketonate $\kappa^{2}-O, O-1,1,1,5,5,5-$

hexafluoroacetylacetonate) complexes for olefin hydroarylation of benzene.......... 22

Figure 1.6. Catalyst design motif for $\mathrm{Ru}(\mathrm{II})$ complexes for olefin hydroarylation........... 24

Figure 1.7. $\mathrm{TpRu}(\mathrm{L}) \mathrm{Ph}(\mathrm{NCMe})$ catalyst first examined for olefin hydroarylation. ......... 25

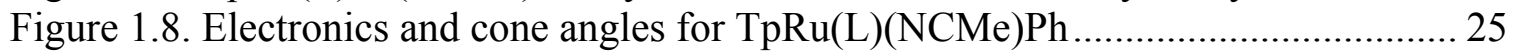

Figure 1.9. C-H activation transition state, "oxidative hydrogen migration".................. 28

\section{CHAPTER 2}

Figure 2.1. Tolman's method for measuring cone angle for phosphines/phosphites ....... 41

Figure 2.2. Anticipated impact of $\mathrm{O}-\mathrm{P}-\mathrm{O}$ bond angle of $\sigma^{*}(\mathrm{P}-\mathrm{O})$ orbital energy and,

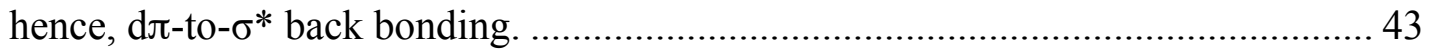

Figure 2.3. Examples of bicyclic phosphites.................................................................... 44

Figure 2.4. ${ }^{1} \mathrm{H}$ NMR spectrum of $\mathrm{TpRu}\left[\mathrm{P}\left(\mathrm{OCH}_{2}\right)_{2}\left(\mathrm{OCCH}_{3}\right)\right]\left(\mathrm{PPh}_{3}\right) \mathrm{Cl}(2)$ in $\mathrm{CDCl}_{3} \ldots . . .46$

Figure 2.5. ${ }^{13} \mathrm{C}$ NMR spectrum of TpRu[P(OCH $\left.)_{2}\left(\mathrm{OCCH}_{3}\right)\right]\left(\mathrm{PPh}_{3}\right) \mathrm{Cl}(2)$ in $\mathrm{CDCl}_{3} \ldots . .47$

Figure 2.6. ORTEP of TpRu[ $\left.\mathrm{P}\left(\mathrm{OCH}_{2}\right)_{2}\left(\mathrm{OCCH}_{3}\right)\right]\left(\mathrm{PPh}_{3}\right) \mathrm{Cl}(\mathbf{2})(50 \%$ probability with

hydrogen atoms omitted) ……………………………................................ 49

Figure 2.7. Calculation of cone angles using crystallographic data ................................ 50

Figure 2.8. ${ }^{1} \mathrm{H}$ NMR spectrum of $\mathrm{TpRu}\left[\mathrm{P}(\mathrm{OMe})_{3}\right]\left(\mathrm{PPh}_{3}\right) \mathrm{Cl}(\mathbf{5})$ in $\mathrm{CDCl}_{3} \ldots \ldots \ldots \ldots \ldots \ldots \ldots . . .51$

Figure 2.9. ${ }^{13} \mathrm{C}$ NMR spectrum of $\mathrm{TpRu}\left[\mathrm{P}(\mathrm{OMe})_{3}\right]\left(\mathrm{PPh}_{3}\right) \mathrm{Cl}(\mathbf{5})$ in $\mathrm{CDCl}_{3} \ldots \ldots \ldots \ldots \ldots \ldots . . . .51$

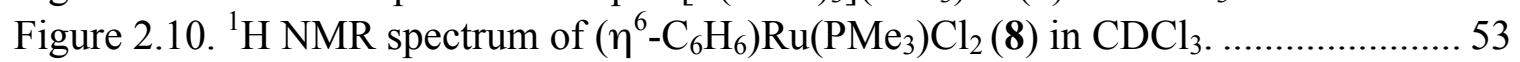

Figure 2.11. ${ }^{13} \mathrm{C}$ NMR spectrum of $\left(\eta^{6}-\mathrm{C}_{6} \mathrm{H}_{6}\right) \mathrm{Ru}\left(\mathrm{PMe}_{3}\right) \mathrm{Cl}_{2}(\mathbf{8})$ in $\mathrm{CDCl}_{3} \ldots \ldots \ldots \ldots \ldots \ldots \ldots . . .53$

Figure 2.12. ${ }^{1} \mathrm{H}$ NMR spectrum of $\left(\eta^{6}-\mathrm{C}_{6} \mathrm{H}_{6}\right) \mathrm{Ru}\left[\mathrm{P}\left(\mathrm{OCH}_{2}\right)_{3} \mathrm{CEt}\right] \mathrm{Cl}_{2}$ (9) in DMSO......... 54

Figure 2.13. ${ }^{13} \mathrm{C}$ NMR spectrum of $\left(\eta^{6}-\mathrm{C}_{6} \mathrm{H}_{6}\right) \mathrm{Ru}\left[\mathrm{P}\left(\mathrm{OCH}_{2}\right)_{3} \mathrm{CEt}\right] \mathrm{Cl}_{2}(9)$ in DMSO ......... 54

Figure 2.14. ${ }^{1} \mathrm{H}$ NMR spectrum of $\left(\eta^{6}-\mathrm{C}_{6} \mathrm{H}_{6}\right) \mathrm{Ru}\left[\mathrm{P}\left(\mathrm{OCH}_{2}\right)_{2}\left(\mathrm{OCCH}_{3}\right)\right] \mathrm{Cl}_{2}(\mathbf{1 1})$ in $\mathrm{CD}_{2} \mathrm{Cl}_{2}$.

Figure 2.15. ${ }^{13} \mathrm{C}$ NMR spectrum of $\left(\eta^{6}-\mathrm{C}_{6} \mathrm{H}_{6}\right) \mathrm{Ru}\left[\mathrm{P}\left(\mathrm{OCH}_{2}\right)_{2}\left(\mathrm{OCCH}_{3}\right) \mathrm{Cl}_{2}(\mathbf{1 1})\right.$ in $\mathrm{CD}_{2} \mathrm{Cl}_{2}$. 
Figure 2.16. ORTEP diagram of $\left(\eta^{6}-\mathrm{C}_{6} \mathrm{H}_{6}\right) \mathrm{Ru}\left[\mathrm{P}\left(\mathrm{OCH}_{2}\right)_{2}\left(\mathrm{OCCH}_{3}\right)\right] \mathrm{Cl}_{2}(\mathbf{1 1})(50 \%$ probability with hydrogen atoms omitted) ........................................................ 56

Figure 2.17. ${ }^{1} \mathrm{H}$ NMR spectrum of $\left(\eta^{6}-p\right.$-cymene $) \mathrm{Ru}\left[\mathrm{P}\left(\mathrm{OCH}_{2}\right)_{3} \mathrm{CEt}\right] \mathrm{Cl}_{2}(\mathbf{1 2})$ in $\mathrm{CDCl}_{3} .60$

Figure 2.18. ${ }^{13} \mathrm{C}$ NMR spectrum of $\left(\eta^{6}-p\right.$-cymene $) \mathrm{Ru}\left[\mathrm{P}\left(\mathrm{OCH}_{2}\right)_{3} \mathrm{CEt}\right] \mathrm{Cl}_{2}(\mathbf{1 2})$ in $\mathrm{CDCl}_{3} .60$

Figure 2.19. ${ }^{1} \mathrm{H}$ NMR spectrum of $\left(\eta^{6}-p\right.$-cymene $) \mathrm{Ru}\left[\mathrm{P}\left(\mathrm{OCH}_{2}\right)_{2}\left(\mathrm{OCCH}_{3}\right)\right] \mathrm{Cl}_{2}(\mathbf{1 3})$ in $\mathrm{CDCl}_{3}$.

Figure 2.20. ${ }^{13} \mathrm{C}$ NMR spectrum of $\left(\eta^{6}-p\right.$-cymene $) \mathrm{Ru}\left[\mathrm{P}\left(\mathrm{OCH}_{2}\right)_{2}\left(\mathrm{OCCH}_{3}\right)\right] \mathrm{Cl}_{2}(\mathbf{1 3})$ in $\mathrm{CDCl}_{3}$

Figure 2.21. ORTEP of $\left(\eta^{6}-p\right.$-cymene $) \mathrm{Ru}\left[\mathrm{P}\left(\mathrm{OCH}_{2}\right)_{3} \mathrm{CEt}\right] \mathrm{Cl}_{2}(\mathbf{1 2})(50 \%$ probability with hydrogen atoms omitted)

Figure 2.22. Representative kinetic plots for the exchange reaction of $\mathrm{L}$ in $\left(\eta^{6}-p\right.$ cymene $) \mathrm{Ru}(\mathrm{L}) \mathrm{Cl}_{2}\left[\mathrm{~L}=\mathrm{P}\left(\mathrm{OCH}_{2}\right)_{2}\left(\mathrm{OCCH}_{3}\right), \mathrm{P}\left(\mathrm{OCH}_{2}\right)_{3} \mathrm{CEt}\right.$ or $\left.\mathrm{PPh}_{3}\right]$ complexes with $\mathrm{P}(\mathrm{OMe})_{3}$ (40 equivalents relevant to concentration of $\mathrm{Ru}$ complex) in $\mathrm{CDCl}_{3}$ at 60 ${ }^{\circ} \mathrm{C}$

Figure 2.23. Plot of $k_{\text {obs }}$ versus concentration of $\mathrm{PPh}_{3}$ for the exchange of $\mathrm{PPh}_{3}$ with $\mathrm{P}(\mathrm{OMe})_{3}$ upon reaction of $\left(\eta^{6}\right.$-p-cymene $) \mathrm{Ru}\left(\mathrm{PPh}_{3}\right) \mathrm{Cl}_{2}(\mathbf{1 5})$ with excess $\mathrm{P}(\mathrm{OMe})_{3}$ in $\mathrm{CDCl}_{3}$ at $60^{\circ} \mathrm{C}$.

Figure 2.24. Plot of $k_{\text {obs }}$ versus concentration of $\mathrm{P}(\mathrm{OMe})_{3}$ for the exchange of $\mathrm{PPh}_{3}$ with $\mathrm{P}(\mathrm{OMe})_{3}$ upon reaction of $\left(\eta^{6}-p\right.$-cymene $) \mathrm{Ru}\left(\mathrm{PPh}_{3}\right) \mathrm{Cl}_{2}(\mathbf{1 5})$ with excess $\mathrm{P}(\mathrm{OMe})_{3}$ in $\mathrm{CDCl}_{3}$ at $60^{\circ} \mathrm{C}$

Figure 2.25. Rate law for exchange reaction of $\mathrm{L}$ in $\left(\eta^{6}-p\right.$-cymene $) \mathrm{Ru}(\mathrm{L}) \mathrm{Cl}_{2}[\mathrm{~L}=$ $\mathrm{P}\left(\mathrm{OCH}_{2}\right)_{2}\left(\mathrm{OCCH}_{3}\right), \mathrm{P}\left(\mathrm{OCH}_{2}\right)_{3} \mathrm{CEt}$ or $\left.\mathrm{PPh}_{3}\right]$ complexes with $\mathrm{P}(\mathrm{OMe})_{3}$ to form $\left(\eta^{6}-p\right.$ cymene $) \mathrm{Ru}\left[\mathrm{P}(\mathrm{OMe})_{3}\right] \mathrm{Cl}_{2}$ in $\mathrm{CDCl}_{3}$ at $60{ }^{\circ} \mathrm{C}$ 68

Figure 2.26. Orientations of $\mathrm{P}(\mathrm{OMe})_{3}$ ligand defined by the torsion $\mathrm{Au}-\mathrm{P}-\mathrm{O}-\mathrm{Me}$ (viewed along the $\mathrm{Au}-\mathrm{P}$ bond) that were modeled using DFT calculations. 70

\section{CHAPTER 3}

Figure 3.1. ${ }^{1} \mathrm{H}$ NMR spectrum of $\left(\eta^{6}-p\right.$-cymene $) \mathrm{Ru}\left[\mathrm{P}\left(\mathrm{OCH}_{2}\right)_{2}\left(\mathrm{OCCH}_{3}\right)\right] \mathrm{Br}_{2}(\mathbf{1})$ in $\mathrm{CDCl}_{3}$

Figure 3.2. ${ }^{13} \mathrm{C}$ NMR spectrum of $\left(\eta^{6}-p\right.$-cymene $) \mathrm{Ru}\left[\mathrm{P}\left(\mathrm{OCH}_{2}\right)_{2}\left(\mathrm{OCCH}_{3}\right)\right] \mathrm{Br}_{2}(\mathbf{1})$ in $\mathrm{CDCl}_{3}$

Figure 3.3. ${ }^{1} \mathrm{H}$ NMR spectrum of $\left(\eta^{6}-p\right.$-cymene $) \mathrm{Ru}\left[\mathrm{P}\left(\mathrm{OCH}_{2}\right)_{2}\left(\mathrm{OCCH}_{3}\right)\right](\mathrm{Ph}) \mathrm{Br}(2)$ in $\mathrm{CDCl}_{3}$

Figure 3.4. ${ }^{13} \mathrm{C}$ NMR spectrum of $\left(\eta^{6}-p\right.$-cymene $) \mathrm{Ru}\left[\mathrm{P}\left(\mathrm{OCH}_{2}\right)_{2}\left(\mathrm{OCCH}_{3}\right)\right](\mathrm{Ph}) \mathrm{Br}(2)$ in $\mathrm{CDCl}_{3}$

Figure 3.5. ${ }^{1} \mathrm{H}$ NMR spectrum of $(\mathrm{NCMe})_{3} \mathrm{Ru}\left[\mathrm{P}\left(\mathrm{OCH}_{2}\right)_{2}\left(\mathrm{OCCH}_{3}\right)\right] \mathrm{PhBr}(3)$ in $\mathrm{CD}_{3} \mathrm{CN}$.

Figure 3.6. ${ }^{1} \mathrm{H}$ NMR spectrum of $\mathrm{TpRu}\left[\mathrm{P}\left(\mathrm{OCH}_{2}\right)_{2}\left(\mathrm{OCCH}_{3}\right)\right](\mathrm{NCMe}) \mathrm{Ph}(4)$ in $\mathrm{C}_{6} \mathrm{D}_{6} \ldots 97$ 
Figure 3.7. ${ }^{13} \mathrm{C}$ NMR spectrum of $\mathrm{TpRu}\left[\mathrm{P}\left(\mathrm{OCH}_{2}\right)_{2}\left(\mathrm{OCCH}_{3}\right)\right](\mathrm{NCMe}) \mathrm{Ph}(4)$ in $\mathrm{C}_{6} \mathrm{D}_{6} \ldots 97$ Figure 3.8. ORTEP of TpRu[P(OCH $\left.)_{2}\left(\mathrm{OCCH}_{3}\right)\right](\mathrm{NCMe}) \mathrm{Ph}(4)$ (50\% probability, hydrogen atoms omitted for clarity) 98

Figure 3.9. Representative plot of $\mathrm{C}-\mathrm{D}$ activation of $\mathrm{C}_{6} \mathrm{D}_{6}$ by $\mathrm{TpRu}\left[\mathrm{P}\left(\mathrm{OCH}_{2}\right)_{2}\left(\mathrm{OCCH}_{3}\right)\right](\mathrm{NCMe}) \mathrm{Ph}(4)$ in $\mathrm{C}_{6} \mathrm{D}_{6}$ at $60{ }^{\circ} \mathrm{C}$ monitored by ${ }^{1} \mathrm{H} \mathrm{NMR}$ spectroscopy $\left(k_{\mathrm{obs}}=7.0(2) \times 10^{-6} \mathrm{~s}^{-1}, \mathrm{R}^{2}=0.99\right)$. The plot shows relative amount of protio-phenyl ligand (integrated against an internal standard) of $\mathbf{4}$ as a function of time.

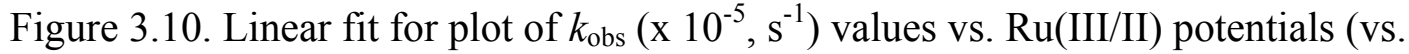

NHE, $V$ ) for the $\mathrm{C}-\mathrm{D}$ activation of $\mathrm{C}_{6} \mathrm{D}_{6}$ by $\mathrm{TpRu}(\mathrm{L})(\mathrm{NCMe}) \mathrm{Ph}$ at $60{ }^{\circ} \mathrm{C}$ with 0.065 mmol of added NCMe $\left(\mathrm{R}^{2}=0.92, \mathrm{~m}=-1.29 \mathrm{~s}^{-1} \mathrm{~V}^{-1}\right)$.

Figure 3.11. Comparison of catalytic hydrophenylation of ethylene by complex $4\left(90^{\circ} \mathrm{C}\right)$ at variable ethylene pressures.

Figure 3.12. Comparison of catalytic hydrophenylation of ethylene by complex 4 (15 psi $\left.\& 90{ }^{\circ} \mathrm{C}\right)$ through $4 \mathrm{~h}$ with mininal decomposition of catalyst present $\left(\mathrm{R}^{2}=0.99\right.$ when trendline is forced through 0,0 ). 105

Figure 3.13. Comparison of catalytic hydrophenylation of ethylene by complex 4 at 15 psi of ethylene and variable temperature. 106

Figure 3.14. ${ }^{1} \mathrm{H}$ NMR spectrum of $\mathrm{TpRu}\left[\mathrm{P}\left(\mathrm{OCH}_{2}\right)_{2}\left(\mathrm{OCCH}_{3}\right)\right]\left(\eta^{3}-\mathrm{C}_{3} \mathrm{H}_{4} \mathrm{Me}\right)(\mathbf{5})$ in $\mathrm{C}_{6} \mathrm{D}_{6}$. 108

Figure 3.15. ${ }^{13} \mathrm{C}$ NMR spectrum of $\mathrm{TpRu}\left[\mathrm{P}\left(\mathrm{OCH}_{2}\right)_{2}\left(\mathrm{OCCH}_{3}\right)\right]\left(\eta^{3}-\mathrm{C}_{3} \mathrm{H}_{4} \mathrm{Me}\right)(\mathbf{5})$ in $\mathrm{C}_{6} \mathrm{D}_{6}$. 108

Figure 3.16. Low-Resolution Mass Spectrometry of TpRu[P(OCH$\left.)_{2}\left(\mathrm{OCCH}_{3}\right)\right]\left(\eta^{3}-\right.$ $\mathrm{C}_{3} \mathrm{H}_{4} \mathrm{Me}$ ) (5) in $\mathrm{C}_{6} \mathrm{D}_{6}$ from $\mathrm{m} / \mathrm{z}=490$ to 600 .

Figure 3.17. Transition state for benzene $\mathrm{C}-\mathrm{H}$ activation (TS2, Scheme 3.10) by $\mathrm{TpRu}(\mathrm{L})(\mathrm{NCMe}) \mathrm{Ph}$. See Table 3.3 for calculated distances.

Figure 3.18. Plot of TOF vs. Ru(III/II) potential for catalytic hydrophenylation of ethylene by $\mathrm{TpRu}(\mathrm{L})(\mathrm{NCMe}) \mathrm{Ph}\left(\mathrm{L}=\mathrm{P}\left(\mathrm{OCH}_{2}\right)_{3} \mathrm{CEt}, \mathrm{P}\left(\mathrm{OCH}_{2}\right)_{2}\left(\mathrm{OCCH}_{3}\right)\right.$ or $\left.\mathrm{CO}\right)$ using $0.025 \mathrm{~mol} \%$ of catalyst, $15 \mathrm{psi}$ of ethylene at $90{ }^{\circ} \mathrm{C}$. TOF calculated after 4 hours of reaction $\left(\mathrm{R}^{2}=0.97\right)$.

\section{CHAPTER 4}

Figure 4.1. First order plot of $\ln ([\mathrm{TpRu}(\mathrm{CO})(\mathrm{NCMe}) \mathrm{Ph}])$ vs time determined from ${ }^{1} \mathrm{H}$ NMR spectroscopy (using the internal standard HMDS) for the decomposition of $\mathrm{TpRu}(\mathrm{CO})(\mathrm{NCMe}) \mathrm{Ph}$ in $\mathrm{THF}-d_{8}$ at $75^{\circ} \mathrm{C}$.

Figure 4.2. Second order plot of the $[\mathrm{TpRu}(\mathrm{CO})(\mathrm{NCMe}) \mathrm{Ph}]^{-1}$ vs time $\left(\mathrm{R}^{2}=0.98\right)$ determined from ${ }^{1} \mathrm{H}$ NMR spectroscopy (using the internal standard HMDS) for the decomposition of $\mathrm{TpRu}(\mathrm{CO})(\mathrm{NCMe}) \mathrm{Ph}$ in $\mathrm{THF}-d_{8}$ at $75^{\circ} \mathrm{C}$.

Figure 4.3. Comparison of catalytic hydrophenylation of ethylene at various pressures (1 atm, 25 and $50 \mathrm{psi}$ ) by $\mathrm{TpRu}(\mathrm{CO})(\mathrm{NCMe}) \mathrm{Ph}$ at $0.01 \mathrm{~mol} \% \mathrm{Ru}$ and $90{ }^{\circ} \mathrm{C}$. 
Figure 4.4. Comparison of catalytic hydrophenylation of ethylene at various Ru mol \% loadings $(0.001-0.3 \mathrm{~mol} \%)$ by $\mathrm{TpRu}(\mathrm{CO}) \mathrm{Ph}(\mathrm{NCMe})$ at $1 \mathrm{~atm}$ and $90^{\circ} \mathrm{C}$.

\section{CHAPTER 5}

Figure 5.1. Examples of some scorpionate ligands. 142

Figure 5.2. Comparison of experimental Ru(III/II) (V vs NHE) potentials for

$\mathrm{TpRu}(\mathrm{L}) \mathrm{Ph}(\mathrm{NCMe})$ to predicted $\mathrm{Ru}(\mathrm{III} / \mathrm{II})(\mathrm{V}$ vs NHE) potentials for $\mathrm{EpRu}(\mathrm{L}) \mathrm{Ph}(\mathrm{NCMe})$.

Figure 5.3. ${ }^{1} \mathrm{H}$ NMR spectrum of $\left(\eta^{6}-p\right.$-cymene $) \mathrm{Ru}\left[\mathrm{P}\left(\mathrm{OCH}_{2}\right)_{3} \mathrm{CEt}\right] \mathrm{Br}_{2}(\mathbf{1})$ in $\mathrm{CDCl}_{3} \ldots 146$

Figure 5.4. ${ }^{13} \mathrm{C}$ NMR spectrum of $\left(\eta^{6}-p\right.$-cymene $) \mathrm{Ru}\left[\mathrm{P}\left(\mathrm{OCH}_{2}\right)_{3} \mathrm{CEt}\right] \mathrm{Br}_{2}(\mathbf{1})$ in $\mathrm{CDCl}_{3} . .147$

Figure 5.5. ${ }^{1} \mathrm{H}$ NMR spectrum of $\left(\eta \eta^{6}-p\right.$-cymene $) \mathrm{Ru}\left(\mathrm{PMe}_{3}\right) \mathrm{Br}_{2}(3)$ in $\mathrm{CDCl}_{3} \ldots \ldots \ldots \ldots . . . . .147$

Figure 5.6. ${ }^{13} \mathrm{C}$ NMR spectrum of $\left(\eta{ }^{6}-p\right.$-cymene $) \mathrm{Ru}\left(\mathrm{PMe}_{3}\right) \mathrm{Br}_{2}(3)$ in $\mathrm{CDCl}_{3} \ldots \ldots \ldots \ldots . . .148$

Figure 5.7. ORTEP of $\left(\eta^{6}-p\right.$-cymene) $\mathrm{Ru}\left[\mathrm{P}\left(\mathrm{OCH}_{2}\right)_{3} \mathrm{CEt}\right] \mathrm{PhBr}(2)$ (35\% probability with hydrogen atoms omitted) .

Figure 5.8. ${ }^{1} \mathrm{H}$ NMR spectrum of $\left(\eta^{6}-p\right.$-cymene $) \mathrm{Ru}\left[\mathrm{P}\left(\mathrm{OCH}_{2}\right)_{3} \mathrm{CEt}\right] \mathrm{PhBr}(2)$ in $\mathrm{CDCl}_{3}$.

Figure 5.9. ${ }^{13} \mathrm{C}$ NMR spectrum of $\left(\eta^{6}-p\right.$-cymene $) \mathrm{Ru}\left[\mathrm{P}\left(\mathrm{OCH}_{2}\right)_{3} \mathrm{CEt}\right] \mathrm{PhBr}(2)$ in $\mathrm{CDCl}_{3}$.

Figure 5.10. ORTEP of $\left(\eta^{6}-p\right.$-cymene $) \operatorname{Ru}\left(\mathrm{PMe}_{3}\right) \operatorname{PhBr}(4)(35 \%$ probability with hydrogen atoms omitted) 150

Figure 5.11. ${ }^{1} \mathrm{H}$ NMR spectrum of $\left(\eta^{6}-p\right.$-cymene $) \mathrm{Ru}\left(\mathrm{PMe}_{3}\right) \mathrm{PhBr}(4)$ in $\mathrm{CDCl}_{3} \ldots \ldots \ldots . .151$

Figure 5.12. ${ }^{13} \mathrm{C}$ NMR spectrum of $\left(\eta^{6}-p\right.$-cymene $) \mathrm{Ru}\left(\mathrm{PMe}_{3}\right) \mathrm{PhBr}(4)$ in $\mathrm{CDCl}_{3} \ldots \ldots \ldots .152$

Figure 5.13. ${ }^{1} \mathrm{H}$ NMR spectrum of $(\mathrm{NCMe})_{3} \mathrm{Ru}\left[\mathrm{P}\left(\mathrm{OCH}_{2}\right)_{3} \mathrm{CEt}\right] \mathrm{PhBr}(\mathbf{5})$ in $\mathrm{CD}_{3} \mathrm{CN} \ldots . .154$

Figure 5.14. The reaction of $\left(\eta^{6}-p\right.$-cymene $) \mathrm{Ru}\left[\mathrm{P}\left(\mathrm{OCH}_{2}\right)_{3} \mathrm{CEt}\right] \mathrm{PhBr}(\mathbf{2})$ and $\mathrm{C}(\mathrm{pz})_{4}$ in $\mathrm{NCMe}$ at $90^{\circ} \mathrm{C}$.

Figure 5.15. ${ }^{1} \mathrm{H}$ NMR spectrum of $\left(\kappa^{3}-N, C^{5}, N\right) \mathrm{C}(\mathrm{pz})_{4} \mathrm{Ru}\left[\mathrm{P}\left(\mathrm{OCH}_{2}\right)_{3} \mathrm{CEt}\right](\mathrm{NCMe}) \mathrm{Br}(\mathbf{6})$ in $\mathrm{CD}_{2} \mathrm{Cl}_{2}$ 156

Figure 5.16. ${ }^{13} \mathrm{C}$ NMR spectrum of $\left(\kappa^{3}-N, C^{5}, N\right) \mathrm{C}(\mathrm{pz})_{4} \mathrm{Ru}\left[\mathrm{P}\left(\mathrm{OCH}_{2}\right)_{3} \mathrm{CEt}\right](\mathrm{NCMe}) \mathrm{Br}(\mathbf{6})$ in $\mathrm{CD}_{2} \mathrm{Cl}_{2}$. 157

Figure 5.17. ${ }^{1} \mathrm{H}$ NMR spectrum of $\left\{\left[\mathrm{HC}\left(\mathrm{pz}^{\prime}\right)_{3}\right] \mathrm{Ru}\left[\mathrm{P}\left(\mathrm{OCH}_{2}\right)_{3} \mathrm{CEt}\right] \mathrm{Ph}(\mathrm{NCMe})\right\}[\mathrm{Br}](7)$ in $\mathrm{CD}_{2} \mathrm{Cl}_{2}$

Figure 5.18. ${ }^{13} \mathrm{C}$ NMR spectrum for $\left\{\left[\mathrm{HC}\left(\mathrm{pz}^{\prime}\right)_{3}\right] \mathrm{Ru}\left[\mathrm{P}\left(\mathrm{OCH}_{2}\right)_{3} \mathrm{CEt}\right] \mathrm{Ph}(\mathrm{NCMe})\right\}[\mathrm{Br}](7)$ in $\mathrm{CD}_{2} \mathrm{Cl}_{2}$

Figure 5.19. ${ }^{1} \mathrm{H}$ NMR spectrum of $\left\{\left[\mathrm{HC}\left(\mathrm{pz}^{\prime}\right)_{3}\right] \mathrm{Ru}\left[\mathrm{P}\left(\mathrm{OCH}_{2}\right)_{3} \mathrm{CEt}\right] \mathrm{Ph}(\mathrm{NCMe})\right\}\left[\mathrm{BAr}_{4}^{\prime}\right](\mathbf{8})$ in $\mathrm{CD}_{2} \mathrm{Cl}_{2}$

Figure 5.20. ${ }^{13} \mathrm{C}$ NMR spectrum of $\left\{\left[\mathrm{HC}\left(\mathrm{pz}^{\prime}\right)_{3}\right] \mathrm{Ru}\left[\mathrm{P}\left(\mathrm{OCH}_{2}\right)_{3} \mathrm{CEt}\right] \mathrm{Ph}(\mathrm{NCMe})\right\}\left[\mathrm{BAr}_{4}^{\prime}\right](\mathbf{8})$ in $\mathrm{CD}_{2} \mathrm{Cl}_{2}$ 162

Figure 5.21. ${ }^{1} \mathrm{H}$ NMR spectrum of $\left[\mathrm{C}(\mathrm{pz})_{4}\right] \mathrm{Ru}\left(\mathrm{PPh}_{3}\right) \mathrm{Cl}_{2}(9)$ in $\mathrm{CDCl}_{3} \ldots \ldots \ldots \ldots \ldots \ldots \ldots \ldots . . . \ldots 163$

Figure 5.22. ${ }^{13} \mathrm{C}$ NMR spectrum of $\left[\mathrm{C}(\mathrm{pz})_{4}\right] \mathrm{Ru}\left(\mathrm{PPh}_{3}\right) \mathrm{Cl}_{2}(\mathbf{9})$ in $\mathrm{CDCl}_{3} \ldots \ldots \ldots \ldots \ldots \ldots \ldots \ldots . . .163$

Figure 5.23. ${ }^{1} \mathrm{H}$ NMR spectrum of $\left[\mathrm{C}(\mathrm{pz})_{4}\right] \mathrm{Ru}\left[\mathrm{P}\left(\mathrm{OCH}_{2}\right)_{3} \mathrm{CEt}\right] \mathrm{Cl}_{2}(\mathbf{1 0})$ in $\mathrm{CD}_{2} \mathrm{Cl}_{2} \ldots \ldots . .165$

Figure 5.24. ${ }^{13} \mathrm{C}$ NMR spectrum of $\left[\mathrm{C}(\mathrm{pz})_{4}\right] \mathrm{Ru}\left[\mathrm{P}\left(\mathrm{OCH}_{2}\right)_{3} \mathrm{CEt}\right] \mathrm{Cl}_{2}(\mathbf{1 0})$ in $\mathrm{CD}_{2} \mathrm{Cl}_{2} \ldots . . .165$

Figure 5.25. ${ }^{1} \mathrm{H}$ NMR spectrum of $\left\{\left[\mathrm{C}(\mathrm{pz})_{4}\right] \mathrm{Ru}\left[\mathrm{P}\left(\mathrm{OCH}_{2}\right)_{3} \mathrm{CEt}\right] \mathrm{Cl}(\mathrm{NCMe})\right\}[\mathrm{Cl}](\mathbf{1 1})$ in $\mathrm{CD}_{2} \mathrm{Cl}_{2}$. 
Figure 5.26. ${ }^{13} \mathrm{C}$ NMR spectrum of $\left\{\left[\mathrm{C}(\mathrm{pz})_{4}\right] \mathrm{Ru}\left[\mathrm{P}\left(\mathrm{OCH}_{2}\right)_{3} \mathrm{CEt}\right] \mathrm{Cl}(\mathrm{NCMe})\right\}[\mathrm{Cl}](\mathbf{1 1})$ in $\mathrm{CD}_{2} \mathrm{Cl}_{2}$. 167

Figure 5.27. ORTEP of $\left\{\left[\mathrm{C}(\mathrm{pz})_{4}\right] \mathrm{Ru}\left[\mathrm{P}\left(\mathrm{OCH}_{2}\right)_{3} \mathrm{CEt}\right] \mathrm{Cl}(\mathrm{NCMe})\right\}\left[\mathrm{BAr}_{4}{ }_{4}\right](\mathbf{1 2})(35 \%$ probability with hydrogen atoms and $\mathrm{BAr}_{4}$ omitted) ........................................ 168

Figure 5.28. ${ }^{1} \mathrm{H}$ NMR spectrum of $\left\{\left[\mathrm{C}(\mathrm{pz})_{4}\right] \mathrm{Ru}\left[\mathrm{P}\left(\mathrm{OCH}_{2}\right)_{3} \mathrm{CEt}\right] \mathrm{Cl}(\mathrm{NCMe})\right\}\left[\mathrm{BAr}_{4}{ }_{4}\right](\mathbf{1 2})$ in $\mathrm{CD}_{2} \mathrm{Cl}_{2}$ 169

Figure 5.29. ${ }^{13} \mathrm{C}$ NMR spectrum of $\left\{\left[\mathrm{C}(\mathrm{pz})_{4}\right] \mathrm{Ru}\left[\mathrm{P}\left(\mathrm{OCH}_{2}\right)_{3} \mathrm{CEt}\right] \mathrm{Cl}(\mathrm{NCMe})\right\}\left[\mathrm{BAr}_{4}\right]$ (12) in $\mathrm{CD}_{2} \mathrm{Cl}_{2}$.

Figure 5.30. ${ }^{1} \mathrm{H}$ NMR spectrum of $\left\{\left[\mathrm{C}(\mathrm{pz})_{4}\right] \mathrm{Ru}\left[\mathrm{P}\left(\mathrm{OCH}_{2}\right)_{3} \mathrm{CEt}\right](\mathrm{OTf})(\mathrm{NCMe})\right\}\left[\mathrm{BAr}_{4}{ }_{4}\right]$

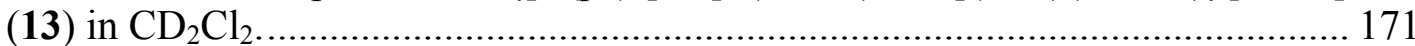

Figure 5.31. ${ }^{13} \mathrm{C}$ NMR spectrum of $\left\{\left[\mathrm{C}(\mathrm{pz})_{4}\right] \mathrm{Ru}\left[\mathrm{P}\left(\mathrm{OCH}_{2}\right)_{3} \mathrm{CEt}\right](\mathrm{OTf})(\mathrm{NCMe})\right\}\left[\mathrm{BAr}_{4}{ }_{4}\right]$ (13) in $\mathrm{CD}_{2} \mathrm{Cl}_{2}$.

Figure 5.32. ${ }^{1} \mathrm{H}$ NMR spectrum of $\left\{\left[\mathrm{C}(\mathrm{pz})_{4}\right] \mathrm{Ru}\left[\mathrm{P}\left(\mathrm{OCH}_{2}\right)_{3} \mathrm{CEt}\right](\mathrm{Me})(\mathrm{NCMe})\right\}\left[\mathrm{BAr}_{4}\right]$ (14)

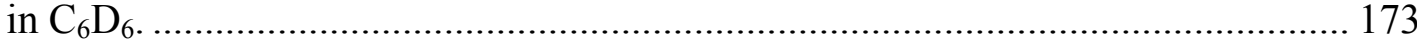

Figure 5.33. ${ }^{1} \mathrm{H}$ NMR spectrum of $\left\{\left[\left(N, C^{5}, N\right) \mathrm{C}(\mathrm{pz})_{4}\right] \mathrm{Ru}\left[\mathrm{P}\left(\mathrm{OCH}_{2}\right)_{3} \mathrm{CEt}\left[(\mathrm{NCMe})_{2}\right\}\left[\mathrm{BAr}_{4}{ }_{4}\right]\right.\right.$

Figure 5.34. ${ }^{13} \mathrm{C}$ NMR spectrum of $\left\{\left[\left(N, C^{5}, N\right) \mathrm{C}(\mathrm{pz})_{4}\right] \mathrm{Ru}\left[\mathrm{P}\left(\mathrm{OCH}_{2}\right)_{3} \mathrm{CEt}\left[\left(\mathrm{NCMe}_{2}\right\}\left[\mathrm{BAr}_{4}^{\prime}\right]\right.\right.\right.$ (15) in $\mathrm{C}_{6} \mathrm{D}_{6}$ 175

\section{CHAPTER 6}

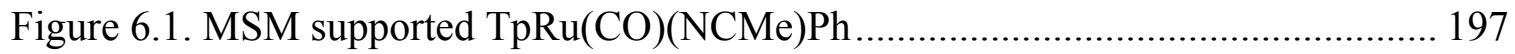

Figure 6.2. Examples of tris(pyrazolyl)alkanes........................................................ 199

Figure 6.3. Calculated $\Delta \mathrm{G}^{\ddagger}(\mathrm{kcal} / \mathrm{mol})$ for benzene $\mathrm{C}-\mathrm{H}$ activation via a two-step reaction

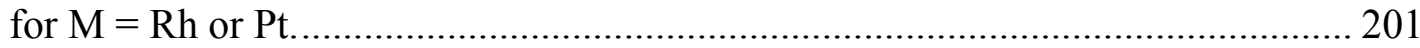

Figure 6.4. Potential Rh(I) catalyst for olefin hydroarylation. ...................................... 201 


\section{LIST OF TABLES}

\section{CHAPTER 1}

Table 1.1. Olefin hydroarylation with $\mathrm{TpRu}(\mathrm{CO})(\mathrm{NCMe}) \mathrm{Ph}$ as catalyst (unless otherwise noted, reaction conditions are $90{ }^{\circ} \mathrm{C}, 25 \mathrm{psi}$ of gas, $0.1 \mathrm{~mol} \%$ of Ru, $4 \mathrm{~h} .{ }^{\mathrm{a}} 50$ equiv. based on Ru, after $6 \mathrm{~h}$ ).

Table 1.2. Calculated $\mathrm{D} G^{\ddagger}{ }_{\text {insertion }}(\mathrm{kcal} / \mathrm{mol})$ for ethylene insertion and $\mathrm{D} G^{\ddagger} \mathrm{CH}$ activation $(\mathrm{kcal} / \mathrm{mol})$ of ethylene for $\mathrm{TpRu}(\mathrm{L})\left(\eta^{2}-\mathrm{C}_{2} \mathrm{H}_{4}\right) \mathrm{Ph}$ complexes.

\section{CHAPTER 2}

Table 2.1. Coupling constants observed for the ligand in the ${ }^{1} \mathrm{H}$ NMR spectrum of

$$
\mathrm{TpRu}\left[\mathrm{P}\left(\mathrm{OCH}_{2}\right)_{2}\left(\mathrm{OCCH}_{3}\right)\right]\left(\mathrm{PPh}_{3}\right) \mathrm{Cl}(2)
$$

Table 2.2. Selected Crystallographic Data for TpRu( $\left.\mathrm{PPh}_{3}\right)\left[\mathrm{P}\left(\mathrm{OCH}_{2}\right)_{2}\left(\mathrm{OCCH}_{3}\right)\right] \mathrm{Cl}$ (2),

$\left(\eta^{6}-\mathrm{C}_{6} \mathrm{H}_{6}\right) \mathrm{Ru}\left[\mathrm{P}\left(\mathrm{OCH}_{2}\right)_{2}\left(\mathrm{OCCH}_{3}\right)\right] \mathrm{Cl}_{2}(\mathbf{1 1})$ and $\left(\eta^{6}-p-\right.$

cymene) $\mathrm{Ru}\left[\mathrm{P}\left(\mathrm{OCH}_{2}\right)_{2}\left(\mathrm{OCCH}_{3}\right)\right] \mathrm{Cl}_{2}(\mathbf{1 2})$.

Table 2.3. $\mathrm{Ru}(\mathrm{III} / \mathrm{II})$ potentials for $\mathrm{TpRu}(\mathrm{L})\left(\mathrm{PPh}_{3}\right) \mathrm{Cl}$ complexes. Data from cyclic voltammetry in NCMe with reversible potentials $\left(E_{1 / 2}\right)$ reported vs NHE (in V). ... 51

Table 2.4. $\mathrm{Ru}(\mathrm{III} / \mathrm{II})$ potentials for $\left(\eta^{6}-\mathrm{C}_{6} \mathrm{H}_{6}\right) \mathrm{Ru}(\mathrm{L}) \mathrm{Cl}_{2}$ complexes. Data from cyclic voltammetry in NCMe with potentials reported vs NHE (in V).............................. 58

Table 2.5. Comparison of bond lengths from crystallographic data for $\left(\eta^{6}-p-\right.$ cymene $) \mathrm{Ru}(\mathrm{L}) \mathrm{Cl}_{2}$ complexes.

Table 2.6. $\mathrm{Ru}(\mathrm{III} / \mathrm{II})$ potentials for $\left(\mathrm{h}^{6}-p\right.$-cymene $) \mathrm{Ru}(\mathrm{L}) \mathrm{Cl}_{2}$ complexes. Data from cyclic voltammetry in NCMe with potentials reported vs NHE (in V) 64

Table 2.7. Data from DFT calculations of $\mathrm{P}\left(\mathrm{OCH}_{2}\right)_{2}\left(\mathrm{OCCH}_{3}\right)(\mathbf{1}), \mathrm{P}(\mathrm{OMe})_{3}$, $\mathrm{P}\left(\mathrm{OCH}_{2}\right)_{3} \mathrm{CEt}$ and $\mathrm{PF}_{3}$. 70

\section{CHAPTER 3}

Table 3.1. Selective Crystallographic Data for $\mathrm{TpRu}\left[\mathrm{P}\left(\mathrm{OCH}_{2}\right)_{2}\left(\mathrm{OCCH}_{3}\right)\right]$ $(\mathrm{NCMe}) \mathrm{Ph} \cdot \mathrm{CH}_{2} \mathrm{Cl}_{2}(4)$.

Table 3.2. $\mathrm{Ru}(\mathrm{III} / \mathrm{II})$ Potentials and Rate Constants for the Activation of $\mathrm{C}_{6} \mathrm{D}_{6}$ at $60{ }^{\circ} \mathrm{C}$ by $\mathrm{TpRu}(\mathrm{L})(\mathrm{NCMe}) \mathrm{Ph}$ 102

Table 3.3. Calculated Distances $(\AA)$ for C-H Activation Transition State (TS2, Scheme

3.10) for $\mathrm{TpRu}(\mathrm{L})(\mathrm{NCMe}) \mathrm{Ph}$ (see Figure 3.17 for labels).

Table 3.4. Comparison of TON and TOF for Ethylbenzene Production from Catalytic

Hydrophenylation of Ethylene by $\mathrm{TpRu}(\mathrm{L})(\mathrm{NCMe}) \mathrm{Ph}$ Complexes.

Table 3.5. Calculated $\mathrm{D} G^{\ddagger}$ insertion $(\mathrm{kcal} / \mathrm{mol})$ for Ethylene Insertion (TS1, Scheme 3.10) and $\mathrm{D} G^{\ddagger} \mathrm{CH}$ activation $(\mathrm{kcal} / \mathrm{mol})$ of ethylene for $\mathrm{TpRu}(\mathrm{L})\left(\eta^{2}-\mathrm{C}_{2} \mathrm{H}_{4}\right) \mathrm{Ph}$ Complexes. ... 116

Table 3.6. Allyl Coupling Diagram for TpRu[P(OCH$\left.)_{2}\left(\mathrm{OCCH}_{3}\right)\right]\left(\eta^{3}-\mathrm{C}_{3} \mathrm{H}_{4} \mathrm{Me}\right)(\mathbf{5}) \ldots 127$ 


\section{CHAPTER 4}

Table 4.1. Comparison of TON and TOF for Ethylbenzene Production from Catalytic Hydrophenylation of Ethylene by $\mathrm{TpRu}(\mathrm{L})(\mathrm{NCMe}) \mathrm{Ph}$ Complexes...................... 132

Table 4.2. Comparison of $\mathrm{TpRu}(\mathrm{CO})\left(\eta^{3}-\mathrm{C}_{3} \mathrm{H}_{4} \mathrm{Me}\right)$ yield during catalysis at $0.01 \mathrm{~mol} \%$ $\mathrm{Ru}$ at varying pressures of ethylene at $90{ }^{\circ} \mathrm{C}$.................................................... 136

Table 4.3. Comparison of $\mathrm{TpRu}(\mathrm{CO})\left(\eta^{3}-\mathrm{C}_{3} \mathrm{H}_{4} \mathrm{Me}\right)$ concentration during catalysis as a function of catalyst loading....

\section{CHAPTER 5}

Table 5.1. Selected Crystallographic Data for $\left(\eta^{6}-p\right.$-cymene $) \mathrm{Ru}\left[\mathrm{P}\left(\mathrm{OCH}_{2}\right)_{3} \mathrm{CEt}\right] \mathrm{PhBr}(2)$, and $\left(\eta^{6}-p\right.$-cymene $) \mathrm{Ru}\left(\mathrm{PMe}_{3}\right) \mathrm{PhBr}(4)$.

Table 5.2. Selected Crystallographic Data for $\left\{\left[\mathrm{C}(\mathrm{pz})_{4}\right] \mathrm{Ru}\left[\mathrm{P}\left(\mathrm{OCH}_{2}\right)_{3} \mathrm{CEt}\right] \mathrm{Cl}(\mathrm{NCMe})\right\}\left[\mathrm{BAr}_{4}\right](\mathbf{1 2})$. 168

Table 5.3. Attempted alkylation of $\left\{\left[\mathrm{C}(\mathrm{pz})_{4}\right] \mathrm{Ru}\left[\mathrm{P}\left(\mathrm{OCH}_{2}\right)_{3} \mathrm{CEt}\right] \mathrm{Cl}(\mathrm{NCMe})\right\}\left[\mathrm{BAr}_{4}\right]_{(12)}$.

Table 5.4. Attempted alkylation of $\left\{\left[\mathrm{C}(\mathrm{pz})_{4}\right] \mathrm{Ru}\left[\mathrm{P}\left(\mathrm{OCH}_{2}\right)_{3} \mathrm{CEt}\right](\mathrm{OTf})(\mathrm{NCMe})\right\}\left[\mathrm{BAr}_{4}\right]$ (13) 


\section{Introduction}

The use of transition metal catalysts to provide less energy-intensive and more atom economical synthetic pathways for the production of substituted aromatic substrates has recently become an area of increased attention. As the demand continues to grow in the United States and throughout the world for plastics, elastomers, detergents, pharmaceuticals, and other materials derived from simple aromatic precursors more efficient ways to produce these commodities is needed (Scheme 1.1) ${ }^{1-5}$ Benzene, toluene, and xylene from petroleum feedstock serve as the chemical building blocks to these desired compounds. As a result of their widespread use, the demand for these three chemicals is substantial. For example, in 2004, the world demand for benzene was $36.4 \mathrm{x}$ $10^{6} \mathrm{t}(\mathrm{t}=$ tonnes $)$, and the demand is expected to continue to increase $4 \%-6 \%$ per year. ${ }^{4}$ The United States was the second largest consumer of benzene with $9.7 \times 10^{6} \mathrm{t}$ consumed in 2004 . Approximately $75 \%$ of benzene is converted to alkyl arenes. ${ }^{4,6}$ In particular, the worldwide consumption of ethylbenzene has continued to increase as the demand for

plastics and elastomers rises. In 2004, the United States produced approximately $5.1 \mathrm{x}$ $10^{6} \mathrm{t}$ of ethylbenzene, of which approximately $99 \%$ was converted to styrene. Approximately $65 \%$ of styrene is used to synthesize polystyrene. ${ }^{3,4}$ 


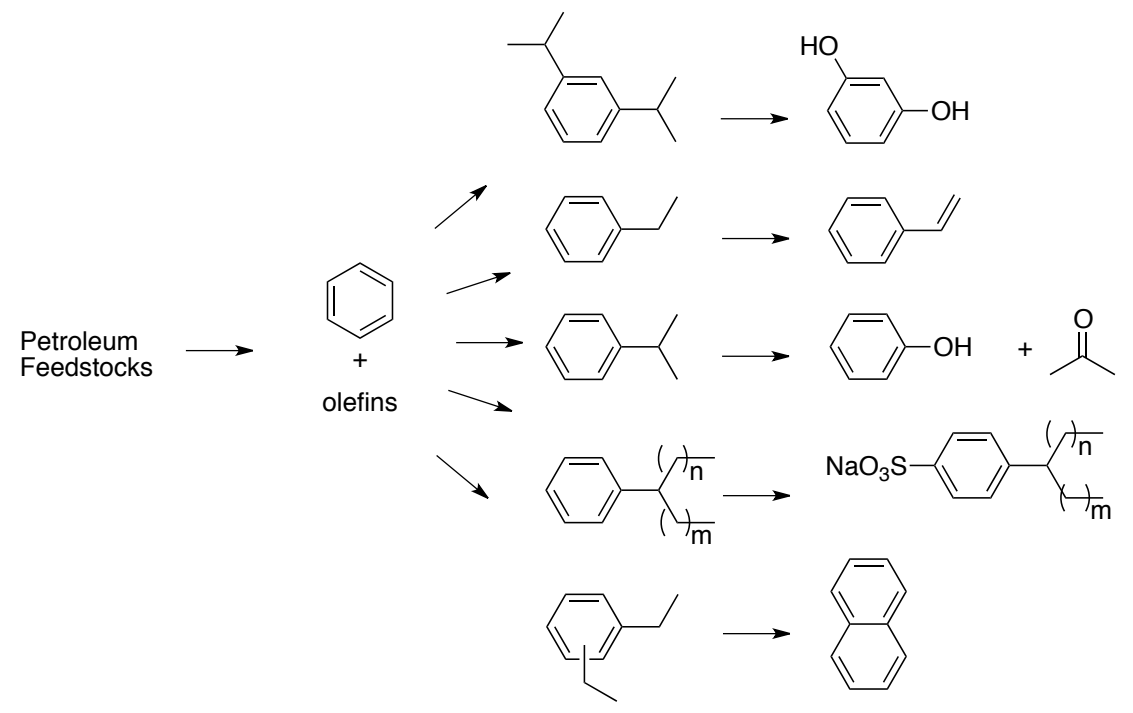

Scheme 1.1. Alkyl arenes produced from benzene and olefins.

With the increasing demand for benzene derivatives and new government environmental restrictions (i.e., The United States Clean Air Act), older, more conventional methods, (i.e., Friedel-Crafts alkylation, vide infra) must be improved and alternative industrial methods for the production of alkyl arenes must be developed. In addition, new catalyst technologies can provide routes to new compounds that are not currently accessible.

\subsection{Current Methods for Industrial Synthesis of Alkyl Arenes}

\subsubsection{Friedel-Crafts Catalysts}

In the late 1870s, Charles Friedel and James M. Crafts discovered that aromatic rings (e.g., benzene) can be functionalized with alkyl-halides (i.e., $\mathrm{MeCl}$ ) in the presence of an aluminum halide (e.g., $\mathrm{AlCl}_{3}$ ). This was a prominent discovery since alkyl-halides by themselves are not sufficiently electrophilic to react with the functionally inert $\mathrm{C}-\mathrm{H}$ 
bond in benzene $(\mathrm{BDE}=\sim 110 \mathrm{kcal} / \mathrm{mol})$ or other aromatic substrates to produce alkyl arenes. ${ }^{7-11}$ Later, it was found that alkenes (e.g., ethylene), in the presence of a Lewis acid (often in combination with a Brønsted, acid, e.g., HF) could perform a similar reaction (Scheme 1.2). The ability to functionalize $\mathrm{C}-\mathrm{H}$ bonds of benzene provided an opportunity to manipulate some of the basic building blocks from fossil resources to produce valueadded chemicals.

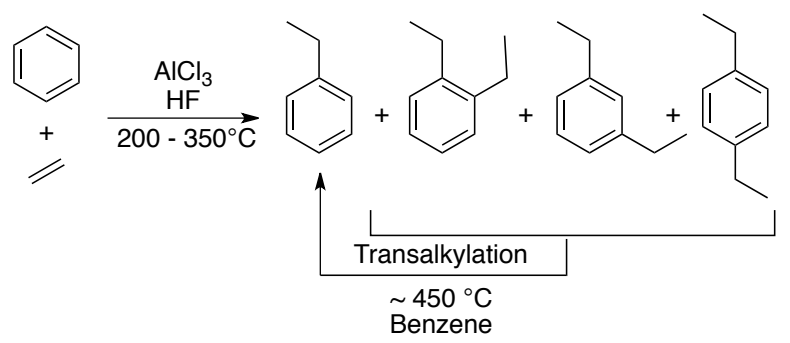

Scheme 1.2. Overall reaction for Friedel-Crafts alkylation.

The Friedel-Crafts mechanism is considered an electrophilic aromatic substitution reaction (Scheme 1.3)..$^{6,8,10-15}$ The reaction proceeds by initial protonation of the alkene by the Brønsted acid to produce a carbocation. The electrons from the benzene ring subsequently attack the carbocation to form a new $\mathrm{C}-\mathrm{C}$ bond and yield a Wheland intermediate. Finally, the $\left[\mathrm{AlCl}_{3} \mathrm{X}\right]^{-}$deprotonates the Wheland intermediate generating the desired alkyl arene and regenerating the starting Brønsted and Lewis acids.

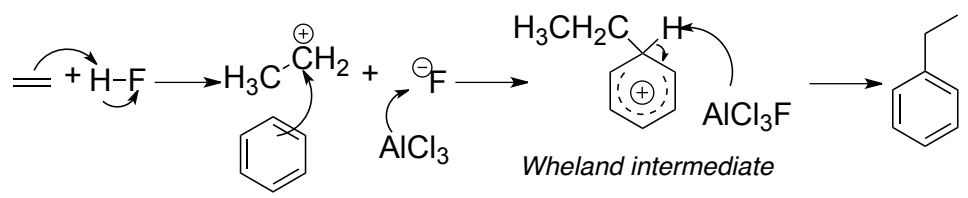

Scheme 1.3. Mechanism for Friedel-Crafts alkylation reaction. 
Starting in the 1930s, the majority of the ethylbenzene was produced from ethylene and benzene using Friedel-Crafts alkylation in the presence of an $\mathrm{AlCl}_{3}-\mathrm{HCl}$ catalyst under mild temperatures and pressures $\left(160{ }^{\circ} \mathrm{C}\right.$ and $\sim 1$ atm $) .{ }^{4,8,13}$ However, due to the nature of the mechanism many drawbacks arise. One significant drawback is polyalkylation to produce di/tri-substituted ethylbenzenes, which inherently limits the purity of the final reaction solution. Polyalkylation is a result of the ethylbenzene product being more reactive than the starting material by approximately $2-5$ times. ${ }^{8}$ To increase the yield of ethylbenzene the di/tri-substituted benzenes are reacted with benzene in a transalkylation process (Scheme 1.2); however, this process is energy intensive. ${ }^{8}$ Additionally, since the reaction occurs in the liquid phase, it therefore requires the use of non-corrosive vessels, which can be costly. Additional drawbacks include the production of stoichiometric amounts of halogenated waste as a result of the inability to recycle the catalyst due to neutralization during product workup. Later, to be more environmentally friendly, industries started to substitute $\mathrm{HF}$ for $\mathrm{AlCl}_{3}$ primarily because of the volatility of $\mathrm{HF}$ enables it to be reused and recycled more readily. ${ }^{5}$ However, the use of HF as a catalyst still suffers from drawback such as extreme toxicity if a leak in the production stream occurs.

Due to the formation of a carbocation, when $\alpha$-olefins are used the Markovnikov (i.e., branched) species is obtained (Scheme 1.4). Historically, highly branched alkyl arenes were used in detergents; however, their slow decomposition rate led to pollution of water sources causing industry to implement the use of "linear" alkyl arene sulfonates 
starting in the 1960s (Scheme 1.1). A linear alkyl benzene is defined as an molecule with the chemical formula of $\mathrm{C}_{6} \mathrm{H}_{5} \mathrm{C}_{n} \mathrm{H}_{2 n}+1$ where $\mathrm{n}=10-14 .{ }^{13}$ This increase in demand for linear alkyl arenes has caused alternative processes to be explored and developed (see Section 1.1.2). ${ }^{8,12}$ Another drawback of Friedel-Crafts alkylation is that in the presence of aromatic substrates containing electron-withdrawing substituents the reaction does not proceed, thus limiting the substrate scope.

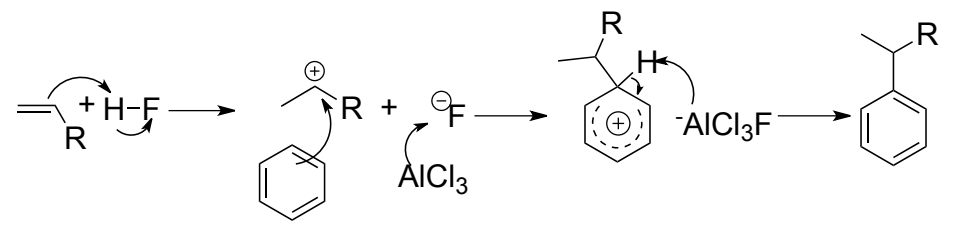

Scheme 1.4. Mechanism for Friedel-Crafts alkylation reaction with $\alpha$-olefins.

\subsubsection{Zeolite Catalysts}

Due to the drawbacks with liquid phase Friedel-Crafts catalysis, alternative techniques have been developed. One way to improve the drawbacks of waste production (e.g., salt formation), low yields, corrosion of the reaction vessel and formation of polyalkylated species in the production of alkyl arenes is the use of solid supports. The first use of solid support was in the 1940s when amorphous silica-alumina gel was employed enabling the reaction to occur in the gas phase. ${ }^{13,16}$ This technology quickly evolved, and the use of zeolite catalyst was first explored on the industrial scale in 1976 by Mobil-Badger. ${ }^{13,17-20}$ Today, zeolites are one of the most utilized catalyst for heterogeneous catalysis. ${ }^{2,21}$ 
Zeolites are surfaces that consist of porous crystalline aluminosilicates and are constructed most commonly using $\mathrm{SiO}_{4}{ }^{4-}$ and $\mathrm{AlO}_{4}{ }^{5-}$; however, they also can be made using other elements such as boron, gallium, iron or titanium. ${ }^{4,22}$ Zeolites are beneficial to industry because of their wide range of properties including the ability to vary pore size, which can control selectivity, high surface area, high thermal and hydrothermal stability, and the ability to vary the chemical properties of the active sites which can increase selectivity. ${ }^{2,23}$

As stated above, one of the advantages of zeolites is the ability to vary the pore size and control selectivity based on size and or shape. There are three main ways that the effects of pore shape can influence selectivity: 1) Reactant shape selectivity, which involves biasing one reaction over a competing side reaction by using size exclusion toward the entrance to the pore. 2) Product shape selectivity, which biases which product is released from the pore dependent on the size (Scheme 1.5). 3) Transition state selectivity, where one transition state is favored because of the geometry of the pore. ${ }^{4,24}$ The pores of zeolites are typically well defined and range from $0.5-1 \mathrm{~nm}$ in diameter. ${ }^{5}$ Additionally, zeolites can have different orientations of the pores such as zig-zag or straight.

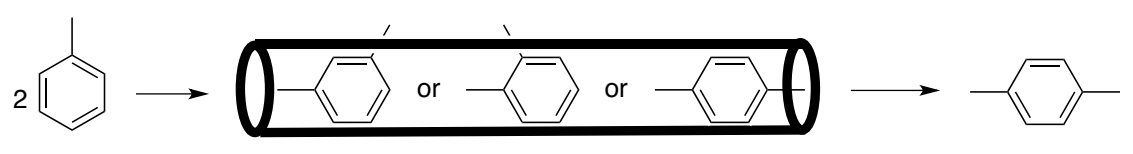

Scheme 1.5. Product shape selectivity of $p$-xylene is favorable due to pore size restrictions. ${ }^{24}$ 
In 1976, the first zeolite catalyst for the production of ethylbenzene, known as ZSM-5, was developed (Figure 1.1)..$^{3,4,6,13,14,23,25}$ ZSM-5 zeolite is one of the three widely used industrial catalysts, the other two are zeolite Y and zeolite A. ${ }^{22}$ ZSM-5 zeolites are constructed of five rings with channels connecting them, which are straight and zigzag ten-ring channels yielding an orthorhombic space group. Due to their high $\mathrm{Si}$ :Al ratios ( $\geq$ 10:1) these zeolites are hydrophobic and organophilic. ${ }^{22}$ Using ZSM-5 aromatic alkylation is carried out in the gas phase. Under a constant ethylene stream the catalyst is active between 40 - 60 days, after which regeneration is necessary due to coke deposits in the pores. ${ }^{26}$ The reaction is conducted under high temperatures $\left(390-450{ }^{\circ} \mathrm{C}\right)$ and pressures (1.5 to $2 \mathrm{MPa}){ }^{4}$ Polyalkylated species are recycled back into the original reactor vessel and undergo transalkylation.
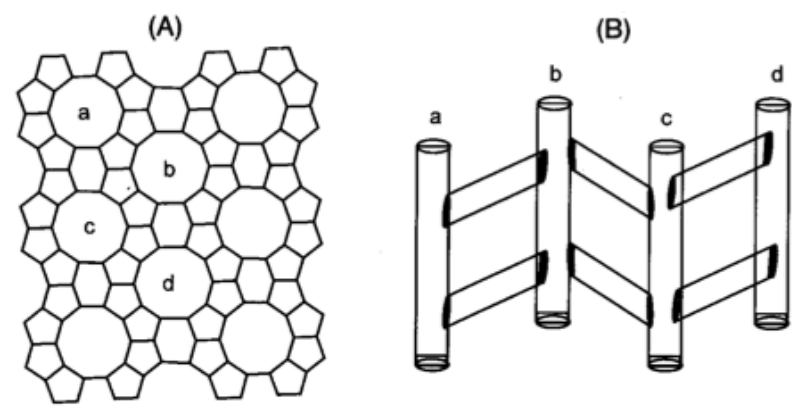

Figure 1.1. Depiction of a ZSM-5 zeolite catalyst (A) Structure looking from the top at Zeolite channels (B) Looking side on at zeolite material- four pores are marked for orientation (a,b,c and d). Copyright 2009 Wiley. Used with permission from Macquarrie, D. J., Industrial Friedel-Crafts Chemistry, Catalytic Asymmetric Friedel-Crafts Alkylations, Wiley-VCH. ${ }^{5}$

Approximately 10 years later two new zeolite systems were developed, which moved the transalkylation reaction to a separate reactor. Lummus-UOP modified the 
ZSM-5 zeolites to form Zeolite $\mathrm{Y}$. Zeolite $\mathrm{Y}$ is a three dimension 12 ring pore system which forms large cavities called "supercages" (Figure 1.2). As a result they could run the alkylation and transalkylation reaction in the liquid phase and could reduce the temperature for the reaction $\left(\sim 270{ }^{\circ} \mathrm{C}\right)$ with $3.8 \mathrm{MPa}$ of ethylene. Due to the reduced temperature compared to catalysis with ZSM-5 zeolites the overall energy consumption is decreased, which increases the lifetime of the catalyst. Higher selectivity for the desired monoalkylated products is also observed for the liquid phase reaction. ${ }^{3}$ Around the same time, Mobil-Badger reported a third generation manufacturing ethylbenzene process using ZSM-5. Similar to the Lummus-UOP process, transalkylation occurs in a separate reactor allowing for an increase in zeolite cycle life to approximately three years. Later in the mid-1990s, three more heterogeneous zeolite catalysts were used. These included CDtech ED (1994) and the Lummus-UOP-EBONE (1996) (EBZ-500 zeolite), both of which conduct alkylation and transalkylation in the liquid phase, and the Mobil's EBMAX process (1995) that uses MCM-22 based zeolite catalyst where the reaction occurs in a mix phase reactor with alkylation in the liquid phase and transalkylation in the vapor phase. However, the reaction was later changed to a liquid phase reaction., Currently, technology continues to improve. Mobil has been awarded 33 licenses for ethylbenzene Zeolite technology. ${ }^{21,23}$ 


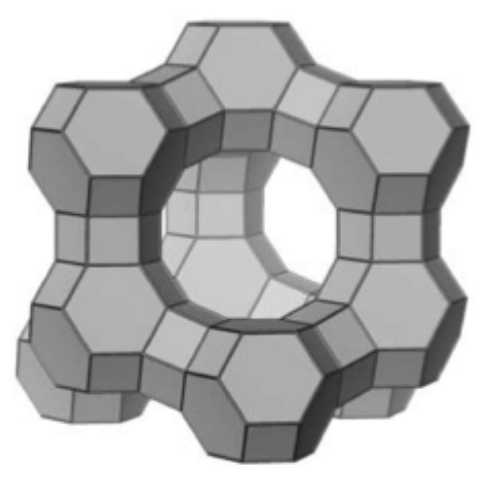

Figure 1.2. Depiction of a Y zeolite. Copyright 2010 Wiley. Used with permission from Broach, R.W. Zeolite Types and Structures, Zeolites in Industrial Separation and Catalysis, Wiley-VCH. ${ }^{22}$

\subsection{Transition Metal Catalyzed C-C Bond Forming Reactions}

Carbon-Carbon bond forming reactions are important and are incorporated by the petrochemical industry to convert hydrocarbons derived from natural gas or petroleum into higher-value molecules as well as by synthetic organic chemistry for the preparation

of complex molecules. ${ }^{27-32} \mathrm{~A}$ wide range of transition metals have been used to promote $\mathrm{C}-\mathrm{C}$ bond formation. The most widely used transition metal is palladium, but coupling reactions also occur in the presence of copper, nickel, rhodium, or cobalt. ${ }^{33}$ These $\mathrm{C}-\mathrm{C}$ bonding forming reactions (i.e., Suzuki, Negishi, Stille, and Sonogashira), sometimes termed cross-coupling reactions, typically involve three distinct steps 1) carbon-halide oxidative addition 2) transmetallation and 3) reductive elimination (Scheme 1.6). ${ }^{33}$ 


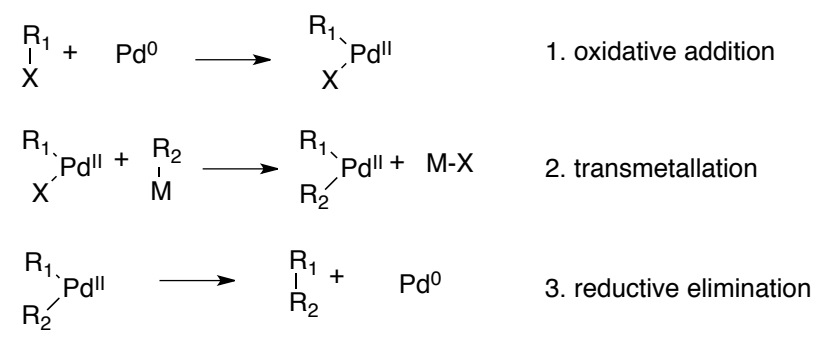

Scheme 1.6. General reaction scheme for cross-coupling reactions utilizing palladium.

Although there are many variations of $\mathrm{C}-\mathrm{C}$ coupling reactions, three important cross coupling processes include Negishi (mid 1970's), Stille (late 1970s), Suzuki (early 1980s) and Heck (mid 1970's) reactions. The 2010 Nobel Prize in Chemistry, was jointly awarded to Heck, Suzuki and Negishi. ${ }^{34-36}$ The most common Pd catalyst is $\operatorname{Pd}\left(\mathrm{PPh}_{3}\right)_{4}$; however, $\mathrm{Pd}(\mathrm{II})$ salts such as $\mathrm{PdCl}_{2}\left(\mathrm{PPh}_{3}\right)_{2}$ or $\mathrm{Pd}(\mathrm{OAc})_{2}$ can also be employed with $\mathrm{PPh}_{3}$ since the $\operatorname{Pd}(\mathrm{II})$ species is reduced to $\operatorname{Pd}(0)$ in situ. ${ }^{27,37}$ The Negishi reaction occurs between aryl zinc reagents and aryl halides or triflates. The reaction is tolerant to many functional groups including esters, amines, ketones and aldehydes ${ }^{27}$ Stille incorporated aryl-stannanes rather than aryl-zincs, which led to increased tolerance to functional groups. The reaction conditions are typically mild; however, a major drawback is the toxicity of organotin reagents. ${ }^{32,38}$ Another variations of late transition metal catalyzed CC cross coupling is the Suzuki-Miyaura reaction. This reaction uses boronic acids with aryl-halides, arylboranes or bornic acid esters. However, all of these coupling reactions suffer from the need for halogenated/activated substrates, which result in halogenated waste and a stoichiometric organometallic reagent. ${ }^{39}$ 
Another important cross coupling reaction is the Heck reaction, which functions by a different catalytic cycle than the cross coupling reactions discussed above. The Heck reaction does incorporate a transmetallation step. The proposed catalytic cycle involves an initial alkyl halide oxidative addition to $\operatorname{Pd}(0)$ to produce a $\mathrm{Pd}(\mathrm{II})$ complex (Scheme 1.7). Subsequent olefin coordination and migratory insertion leads to an intermediate Pdalkyl species. The desired product is released from the metal center after the $\beta$-hydride elimination step. Reductive elimination of HX, which is captured by a base, regenerates the $\operatorname{Pd}(0)$ catalyst. These reactions are conducted in polar solvents at temperatures of 100$140{ }^{\circ} \mathrm{C}$. The majority of Heck reactions incorporate phosphorous-based palladium complexes; however, many studies have looked at different palladium catalysts such as those ligated with $\mathrm{NHC} .^{38,40}$ One major reason for the research on alternative palladium catalysts is because the phosphorous palladium catalysts are toxic, air sensitive and expensive. $^{38}$

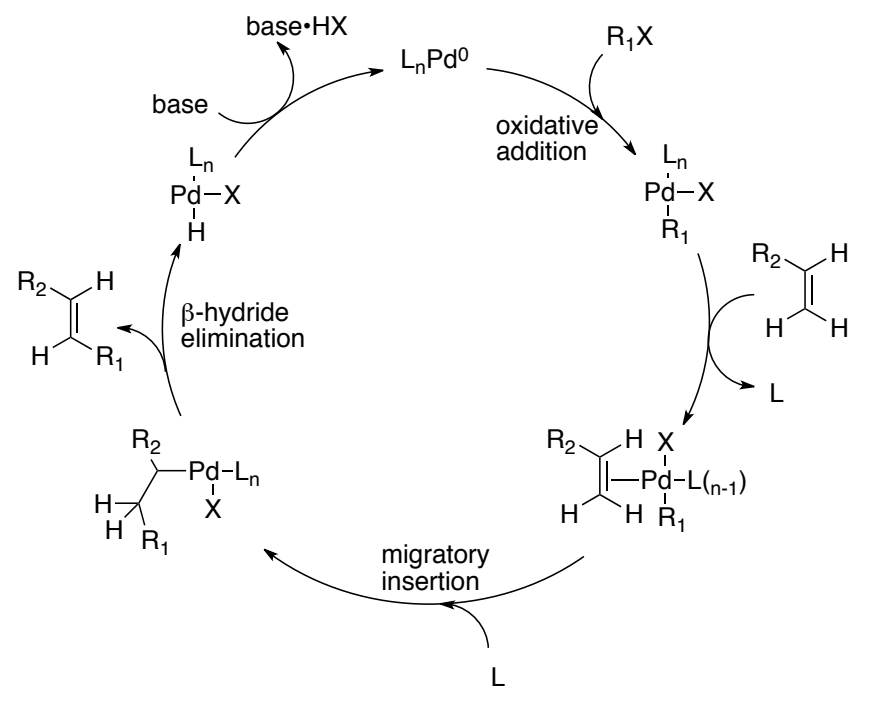

Scheme 1.7. Proposed Heck cross coupling mechanism. ${ }^{38}$ 
Although cross coupling reactions are valuable to synthetic chemists, application to industrial scale processes is difficult. For example, the production of halogenated waste is a hindrance. ${ }^{41}$ Additionally, the use of large amounts of Pd that give relatively low turnover numbers is an issue. Finally, the inability to recycle the catalyst efficiently is an issue. ${ }^{41}$

\subsection{Transition Metal Mediated C-H Activation for the Synthesis of Alkyl Arenes}

Transition metal mediated non-Friedel-Crafts olefin hydroarylation (Scheme 1.8) is generally believed to precede through the mechanism shown in Scheme 1.9. The cycle proceeds via $\eta^{2}$-coordination of the olefin to the metal center, followed by olefin insertion into the $\mathrm{M}$-aryl bond, which generates an open coordination site. Arene coordination is followed by $\mathrm{C}-\mathrm{H}$ activation, and alkyl arene dissociation regenerates the starting catalyst. $^{42-46}$

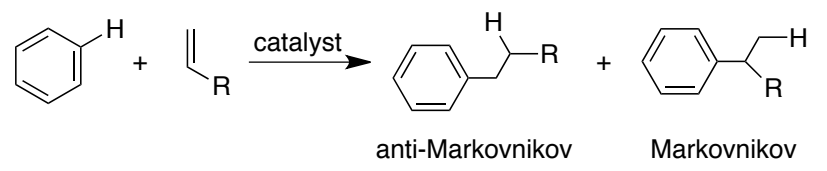

Scheme 1.8. General olefin hydroarylation reaction. 


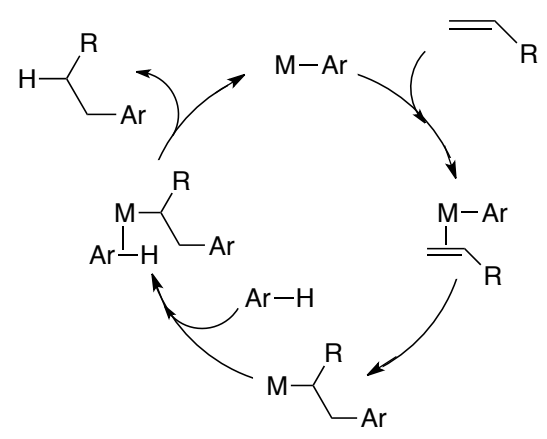

Scheme 1.9. Cycle for transition metal catalyzed olefin hydroarylation.

Examples of catalytic metal-mediated $\mathrm{C}-\mathrm{H}$ functionalization of aromatic substrates have increased substantially in recent years. ${ }^{47-60}$ Although several transition metal catalysts for olefin hydroarylation using substrates functionalized with heteroatomic groups are known, ${ }^{55,57,61-66}$ examples of transition metal catalysts that convert unactivated hydrocarbons (e.g., benzene, ethylene or propene) to alkyl or vinyl arenes are relatively rare ${ }^{67-71}$ Catalysts based on ruthenium, iridium and platinum complexes have been utilized to promote olefin hydroarylation using simple hydrocarbons. ${ }^{42-45,56,62,67-70,72-76}$

There are multiple potential benefits of olefin hydroarylation that proceeds by the cycle shown in Scheme 1.9.

1. Transition metal catalyzed olefin hydroarylation of $\alpha$-olefins could afford selectivity for linear products (Scheme 1.8).

2. Selectivity for mono-alkyl arenes might be achieved, which is not possible with Friedel-Crafts catalyst since the products formed in the reactions are typically $\sim 5$ times more reactive than the starting materials. ${ }^{8}$ 
3. Regioselectivity for dialkyl arenes is possible. In contrast, Friedel-Crafts catalysts are not selective for a second alkylation of benzene. The lack of selectivity for Friedel-Crafts alkylation is due the poor directing ability of an alkyl group.

4. Direct oxidative olefin hydroarylation (potentially with $\mathrm{O}_{2}$ ) to give vinyl arenes such as styrene could provide a direct synthesis of styrene from benzene and ethylene.

A substantial challenge to developing transition metal catalysis for olefin hydroarylation is avoiding potential competing side reactions. Four undesirable reactions include: 1. $\mathrm{C}-\mathrm{H}$ activation of the olefin, 2. $\beta$-hydride elimination from the M-alkyl species (note: desirable if vinyl arenes are the target), 3. olefin oligomerzation/polymerization and 4. irreversible oxidative addition (Scheme 1.10).

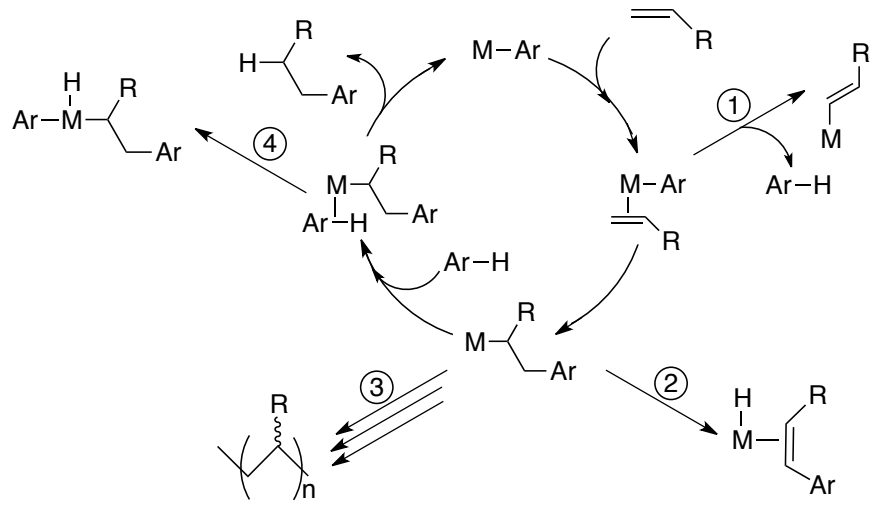

Scheme 1.10. Potential competing side reactions for olefin hydroarylation.

Considering these side reactions can provide some guidance to catalyst design. In order to have a catalyst that readily inserts the olefin into the metal-phenyl bond a less electron rich metal center is desired due to decreased backbonding between the metal and 
olefin $\pi^{*}$ orbitals. However, if the metal center is too electron deficient, such as a $\mathrm{d}^{0}$ complex, oligomerization/polymerization could compete with arene $\mathrm{C}-\mathrm{H}$ activation leading to deactivation of the catalyst. Avoiding $\beta$-hydride elimination is likely to be a challenge. Thus, if alkyl arenes are desired, the most viable strategy is to suppress olefin displacement and render $\beta$-hydride elimination reversible. Finally, if the metal center is too electron rich, irreversible oxidative addition could occur. ${ }^{45,59}$

\subsection{Examples of Transition Metal Catalysts for Olefin Hydroarylation}

\subsubsection{Transition Metal C-H Activation by an Acid Catalyzed Pathway}

Tilley and coworkers have reported olefin hydroarylation using [2-(2pyridyl)indole] $\mathrm{Pt}(\mathrm{Cl})\left(\mathrm{C}_{2} \mathrm{H}_{4}\right){ }^{72}$ Attempted catalysis using [2-(2-pyridyl) $\mathrm{Pt}(\mathrm{Cl})\left(\mathrm{C}_{2} \mathrm{H}_{4}\right)$ in benzene with norbornene resulted in no reaction. Yet, the addition of 1 equiv. AgOTf at elevated temperatures $\left(115^{\circ} \mathrm{C}\right)$ for $20 \mathrm{~h}$, produced exo-phenylnorbornane. The use of $\mathrm{AgBF}_{4}$ allowed a lower temperature $\left(80^{\circ} \mathrm{C}\right)$ and increased the yield of the reaction with a 92\% yield after $2 \mathrm{~h}$ versus a 79\% yield after 20 hours in the case of AgOTf. These data suggest that the Ag salt is not just a chloride abstraction agent but potentially also increases the rate of hydrophenylation. Catalysis with ethylene and benzene to produce

ethylbenzene was not successful, and only ethylene polymerization occurred. Upon further examination of the mechanism, it is believed that the reaction proceeds through an acid-catalyzed mechanism. ${ }^{72}$

Recently, Tilley, Bergman and coworkers published a mechanistic study on olefin hydroarylation for (COD)Pt(OTf $)_{2}$ and ('bpy)PtOTf ${ }_{2}$ (bpy = 4,4'-di-tert-butyl-2,2'- 
bipyridyl). ${ }^{62}$ Norborene was initially studied, and the best yield (41\%) was obtained using 9-fold excess of benzene at $110{ }^{\circ} \mathrm{C}$ for $5 \mathrm{~h}$. Additionally, hydroarylation of cyclic alkenes was studied. The reaction of a 9-fold excess of benzene at $100{ }^{\circ} \mathrm{C}$ for $24 \mathrm{~h}$ with cyclohexene produced cyclohexylbenzene in $36 \%$ yield, but dicyclohexylbenzene $(21 \%$ yield) was also observed. It was found that $\mathrm{Pt}(\mathrm{COD})(\mathrm{OTf})_{2}$ and ('bpy) $\mathrm{Pt}(\mathrm{OTf})_{2}$ could achieve olefin hydroarylation with the best yield being obtained from the reaction between cyclohexene and mesitylene; but the reaction is catalyzed by HOTf rather than by Pt.

\subsubsection{Non-Acid Catalyzed Transition Metal Promoted C-H Activation of Unactivated Olefins}

The ability to produce alkyl benzenes through olefin hydroarylation using a transition metal as catalyst in the presence of an acid source is well documented in the literature. ${ }^{56}$ Fujiwara and coworkers have extensively studied Pd complexes for aromatic C-H functionalization. ${ }^{61,77,78}$ For example, in 2000, $\mathrm{Pt}\left(\mathrm{PtCl}_{2} / \mathrm{AgOAc}\right)$ and $\mathrm{Pd}\left(\mathrm{Pd}(\mathrm{OAc})_{2}\right)$ catalysts for regio- and stereoselective addition of arenes to alkynes and alkenes in trifluoroacetic acid (HTFA) were reported by Fugiwara and coworkers ${ }^{61}$ It was found that both $\mathrm{Pt}(\mathrm{II})$ and $\mathrm{Pd}(\mathrm{II})$ were more active than $\mathrm{RhCl}_{3} / 3 \mathrm{AgOAc}, \mathrm{RuCl}_{3} / 3 \mathrm{AgOAc}$ and $\mathrm{Ni}(\mathrm{OAc})_{2}$. Although no detailed mechanistic studies were conducted since the reaction is being conducted in HTFA, it was proposed that $\left[\mathrm{Pd}\left(\mathrm{O}_{2} \mathrm{CCF}_{3}\right)\right]^{+}$is generated in situ and is the active catalyst. This cationic species is proposed to undergo electrophilic metalation with the arene to form a $\sigma$-aryl-Pd complex, $\mathrm{Ar}-\mathrm{PdO}_{2} \mathrm{CCF}_{3}$. Then an $\eta^{2}$-alkyne-Pd 
complex is formed. Insertion of the alkyne into the Ar-Pd bond and protonation by HTFA forms the product and regenerates the catalyst (Scheme 1.11).

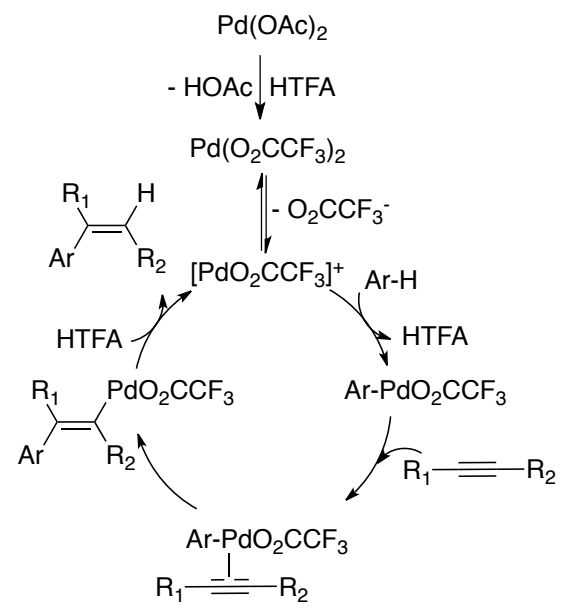

Scheme 1.11. Proposed catalytic cycle for addition of arenes to alkynes.

To survey the versatility of $\mathrm{PtCl}_{2} / \mathrm{AgOAc}$ and $\mathrm{Pd}(\mathrm{OAc})_{2}$ as catalysts, the addition of a variety of arenes to substituted alkynes was studied. ${ }^{61}$ Using more electron-donating groups on the arene improves the yield of reactions with bulky molecules. One major advantage observed was the chemoselectivity for substrates with traditionally reactive functional groups on the arene $(-\mathrm{OH},-\mathrm{Br},-\mathrm{CHO}$ or vinyl groups $)$ and alkynes $(-\mathrm{CHO},-$ $\left.\mathrm{COMe},-\mathrm{CO}_{2} \mathrm{H},-\mathrm{CO}_{2} \mathrm{Et},-\mathrm{CO}_{2} \mathrm{Me}\right)$ and the reaction predominantly yields cis product. Furthermore, $\mathrm{Pd}(\mathrm{II})$ was found to be a more active than $\mathrm{Pt}(\mathrm{II})$; however, $\mathrm{Pt}(\mathrm{II})$ was longer lived, gave higher yields, exhibited better selectivity and fewer by-products such as products from multiple alkyne insertions or coupling of two arenes. 
Goldberg and co-workers reported in 2008 that $\left.[\mathrm{dmpp}] \mathrm{Pt}\left(\mathrm{SMe}_{2}\right) \mathrm{Ph}\right]$ and [(dmpp)PtMe 3 ( $\mathrm{dmpp}=3,5$-dimethyl-2-(2-pyridyl)pyrrolide) are capable of catalytic olefin hydroarylation of unactivated substrates (Figure 1.3). ${ }^{68}$ The reaction of ethylene and benzene in the presence of either $\left.[\mathrm{dmpp}] \mathrm{Pt}\left(\mathrm{SMe}_{2}\right) \mathrm{Ph}\right]$ or $\left[(\mathrm{dmpp}) \mathrm{PtMe}_{3}\right]$ at $\sim 100{ }^{\circ} \mathrm{C}$ resulted in 36 and 26 TON of ethylbenzene, respectively. When propylene was used under similar conditions, the Markovnikov product was formed over the antiMarkovnikov product in approximately an 85:15 ratio for both Pt catalysts.
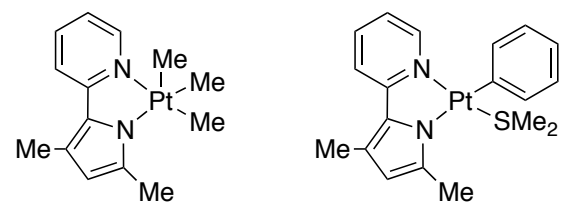

Figure 1.3. (dmpp)Pt catalyst precursors for olefin hydroarylation.

The mechanism of olefin hydroarylation with the (dmpp)Pt catalyst is not likely a Friedel-Crafts reaction. Evidence against a Friedel-Crafts pathway includes formation of the linear product for reactions with $\alpha$-olefins (although not selectively) and selectivity for the functionalization of meta and para positions when substituted arenes were used. Friedel-Crafts reactions generally are not selective for dialkylation. The proposed catalytic cycle is shown in Scheme 1.12. The reaction is initiated with the formation of a phenyl-ethylene complex, which is followed by olefin insertion into the Pt-Ph bond. Cyclometalation results in the formation of a five-coordinated platinum species. Reductive elimination and solvent coordination yields a four coordinate $\mathrm{Pt}^{\mathrm{II}}$ species with 
coordinated ethylbenzenyl. This complex is likely in rapid equilibrium with a 5coordinate hydride species, which was determined using isotopic studies. The isotopic studies yielded a significant amount of deuterium incorporation $\left(\mathrm{D}_{0}-\mathrm{D}_{6}\right)$ into the ethylbenzene fragment when reactions were performed in a 1:1 solution of $\mathrm{C}_{6} \mathrm{D}_{6}: \mathrm{C}_{6} \mathrm{H}_{6}$ under ethylene pressure. The catalytic cycle is completed by coordination of ethylene and dissociation of ethylbenzene (Scheme 1.12).

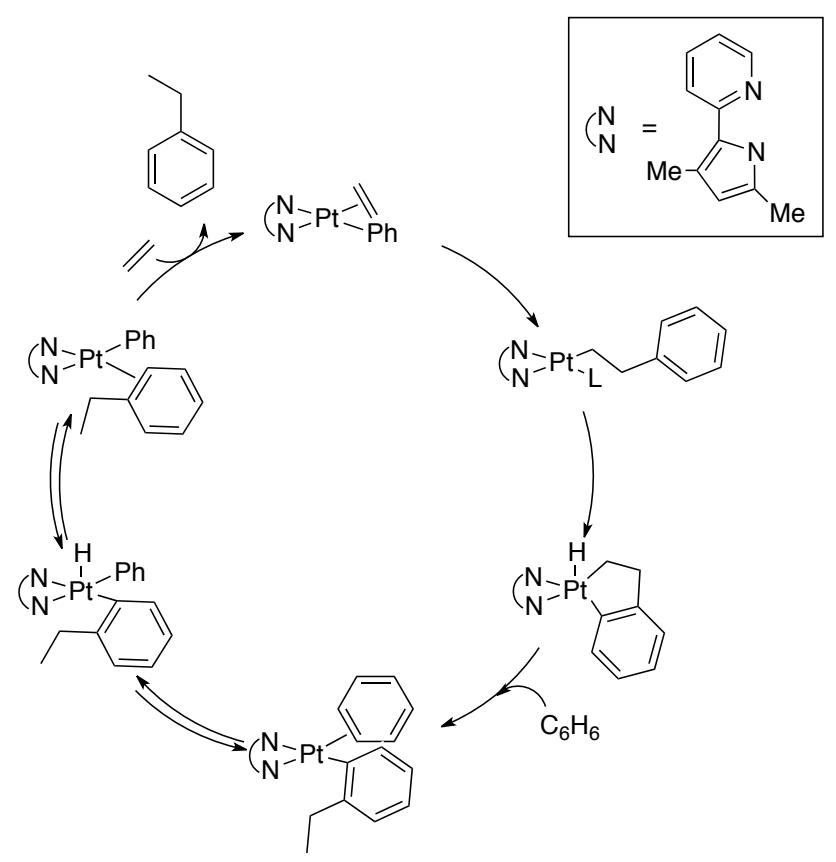

Scheme 1.12. Proposed mechanism for ethylene hydrophenylation with (dmpp)Pt.

Recently, our group has published that [('bpy) $\mathrm{Pt}(\mathrm{Ph}) \mathrm{L}]\left[\mathrm{BAr}{ }_{4}\right]\left(\mathrm{L}=\mathrm{NCMe}, \mathrm{NC}_{5} \mathrm{~F}_{5}\right.$ or THF and $\mathrm{Ar}^{\prime}=3,5$-bis(trifluoromethyl)phenyl) is capable of catalyzing olefin hydroarylation. ${ }^{70,73}$ 


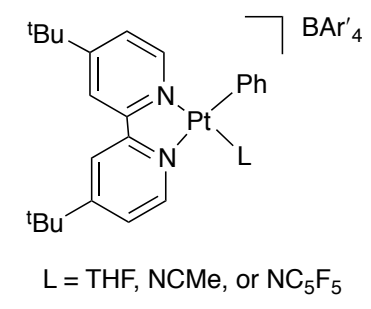

Figure 1.4. $[(\mathrm{bpy}) \mathrm{Pt}(\mathrm{Ph}) \mathrm{L}]\left[\mathrm{BAr}_{4}\right]$ catalyst for olefin hydroarylation.

Catalytic reactions with $\left[\left({ }^{\mathrm{t} b p y}\right) \mathrm{Pt}(\mathrm{Ph})(\mathrm{THF})\right]\left[\mathrm{BAr}_{4}^{\prime}\right](0.025 \mathrm{~mol} \%$ relative to benzene) in benzene under $0.1 \mathrm{MPa}$ of ethylene at $100{ }^{\circ} \mathrm{C}$ for $16 \mathrm{~h}$ yielded $53 \mathrm{TON}$ of ethylbenzene and approximately 11 total TON of diethylbenzenes with an ortho:meta:para ratio of 1:2.6:1.6. Replacing the THF with $\mathrm{NCMe}$ or $\mathrm{NC}_{5} \mathrm{~F}_{5}$ inhibited the rate of the reaction most likely due to the stronger interaction between the metal and the ligand. For example, only $21 \mathrm{TON}$ and $20 \mathrm{TON}$ of ethylbenzene were observed after 16 hours for the $\mathrm{N}$-donor ligands respectively, with diethylbenzene also being observed. Upon further studying the impact of temperature and ethylene pressure on catalysis, it was found that increasing temperature increases the rate of olefin insertion and that increased ethylene pressures inhibits catalysis.

Further mechanistic studies were conducted to elucidate the cause of a relatively large quantity of polyalkylated benzene species that are formed. This was of particular interest since, as stated above, a major drawback to Friedel-Crafts catalysis is the production of polyalkylated species and the need of high temperatures for subsequent transalkylation. It is proposed that the production of dialkylated benzene using $\left[\left({ }^{\prime} \mathrm{bpy}\right) \mathrm{Pt}(\mathrm{Ph})(\mathrm{THF})\right]\left[\mathrm{BAr}_{4}\right]$ as the catalyst is a result of a second aromatic $\mathrm{C}-\mathrm{H}$ activation competing with ethylbenzene dissociation (Scheme 1.13). Currently, alternative platinum 
catalysts are being synthesized in our laboratories to investigate the structure and activity relationship of platinum catalysts with similar motifs on olefin hydroarylation.

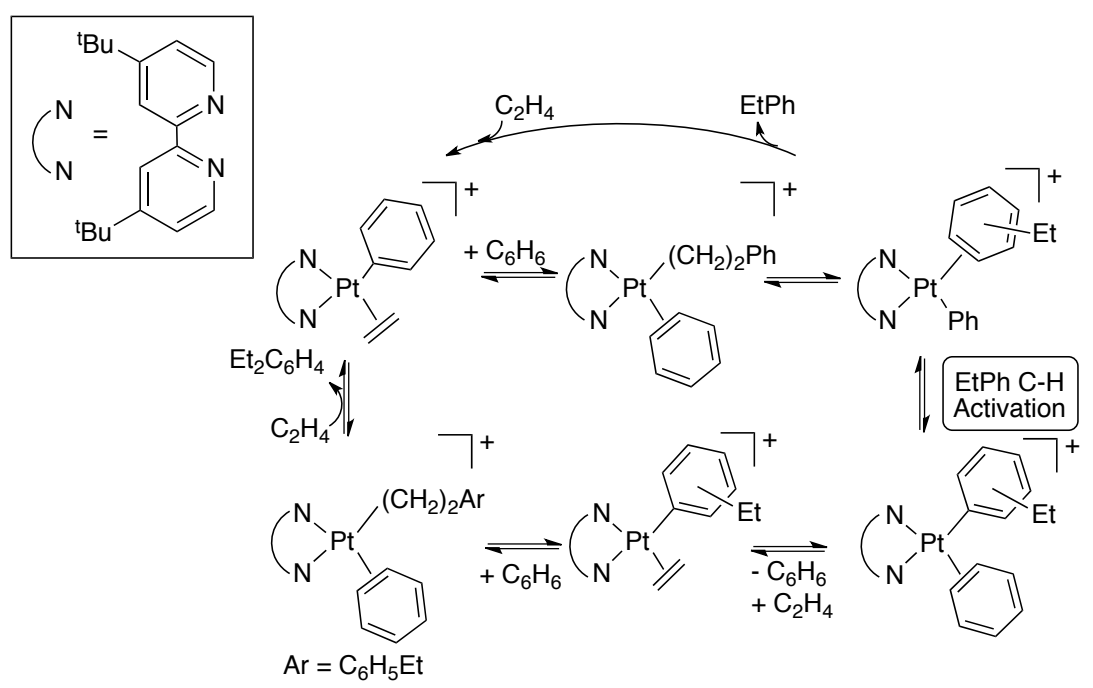

Scheme 1.13. Proposed mechanism for the formation of diethylbenzene by $[(' \mathrm{bpy}) \mathrm{Pt}(\mathrm{Ph})(\mathrm{THF})]\left[\mathrm{BAr}_{4}\right]$.

In 2000, Periana and coworkers reported catalytic hydroarylation of olefins using the dinuclear complex, $\operatorname{Ir}\left(\mu\right.$-acac-O $\left., \mathrm{O}, \mathrm{C}^{3}\right)($ acac-O, $\mathrm{O})\left(\right.$ acac- $\left.\left.\mathrm{C}^{3}\right)\right]_{2}($ acac $=$ acetylacetonato or 2,4-pentanedione) (Figure 1.5). ${ }^{79}$ When reactions were performed with $\operatorname{Ir}(\mu$-acac$\left.\mathrm{O}, \mathrm{O}, \mathrm{C}^{3}\right)($ acac-O, $\mathrm{O})\left(\right.$ acac- $\left.\left.\mathrm{C}^{3}\right)\right]_{2}$ in the presence of benzene and $1.96 \mathrm{MPa}$ of ethylene at $180{ }^{\circ} \mathrm{C}, 455 \mathrm{TO}$ of ethylbenzene were observed after $3 \mathrm{~h}$. When the reaction was performed with $0.78 \mathrm{MPa}$ of propylene at $180{ }^{\circ} \mathrm{C}$ for 20 minutes formation of $n$ propylbenzene and cumene was observed in a 61:39 ratio with 13 total TOs. ${ }^{44,79}$ In 2002, 
Periana and coworkers reported that mononuclear $\operatorname{Ir}(\mathrm{III})$ catalyst with acac ligands are also active (Figure 1.5). ${ }^{69}$
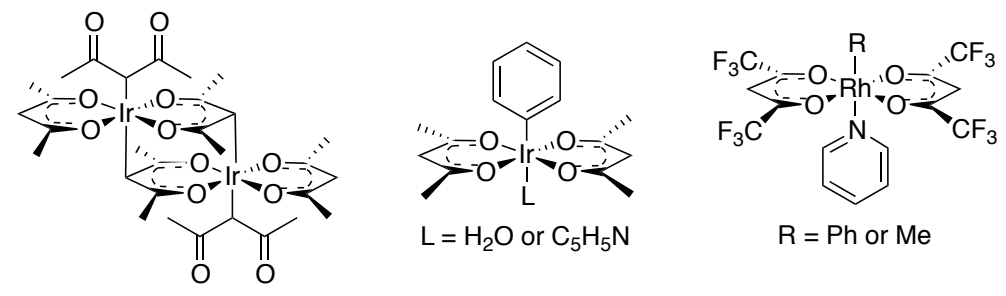

Figure 1.5. bis-acac- $O, O$ - $\operatorname{Ir}(\mathrm{III})$ (acac $=$ acetylacetonato or 2,4-pentanedione) and bishfac- $O, O$-Rh(III) $\quad\left(\right.$ hfac- $O, O \quad=\quad \beta$-diketonate $\quad \kappa^{2}-O, O-1,1,1,5,5,5-$ hexafluoroacetylacetonate) complexes for olefin hydroarylation of benzene.

Upon reaction of the mononuclear Ir complexes with propylene under similar reaction conditions as the dinuclear complex $\operatorname{Ir}\left(\mu\right.$-acac-O,O, $\left.\mathrm{C}^{3}\right)($ acac-O,O$)\left(\right.$ acac- $\left.\left.\mathrm{C}^{3}\right)\right]_{2}$ the same 61:39 linear to branched ratio was observed. For catalysis using $(\operatorname{acac})_{2} \operatorname{Ir}(\mathrm{Ph}) \mathrm{L}(\mathrm{L}=$ $\mathrm{H}_{2} \mathrm{O}$ or $\mathrm{C}_{5} \mathrm{H}_{5} \mathrm{~N}$ ) it has been proposed that the initial step in the catalytic process is trans to cis isomerization of the $\mathrm{Ph}$ and "L" (Scheme 1.14) followed by olefin coordination and insertion into the $\mathrm{Ir}-\mathrm{Ph}$ bond. Subsequent coordination of benzene, $\mathrm{C}-\mathrm{H}$ activation and coordination of another equivalent of olefin to release the product and regenerate the active catalyst completes the catalytic cycle..$^{44,69}$

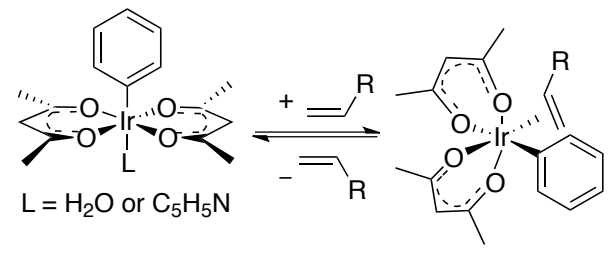

Scheme 1.14. Trans-Cis isomerization of (acac) $)_{2} \mathrm{Ir}(\mathrm{Ph}) \mathrm{L}\left(\mathrm{L}=\mathrm{H}_{2} \mathrm{O}\right.$ or $\left.\mathrm{C}_{5} \mathrm{H}_{5} \mathrm{~N}\right)$. 
Periana and coworkers reported a rhodium catalyst as an extension of their bis-Iracac system. ${ }^{80}$ Due to calculations showing that the rate of olefin insertion can be enhanced with a less- $\pi$ basic metal center, they replaced the $-\mathrm{CH}_{3}$ groups of acac with the strongly electron-withdrawing perfluoromethyl groups (Figure 1.5) ${ }^{42,45}$ Attempts to make the cis-(hfac- $O, O)_{2} \operatorname{Ir}(\mathrm{Ph})(\mathrm{py})$ analog were unsuccessful; trans-(hfac- $\left.O, O\right)_{2} \mathrm{Rh}\left(\mathrm{CH}_{3}\right)(\mathrm{py})$ and trans-(hfac- $O, O)_{2} \mathrm{Rh}(\mathrm{Ph})(\mathrm{py}) \quad\left(\mathrm{hfac}-O, O=\beta\right.$-diketonate $\kappa^{2}-O, O-1,1,1,5,5,5-$ hexafluoroacetylacetonate) were isolated. Heating trans-(hfac- $O, O)_{2} \mathrm{Rh}\left(\mathrm{CH}_{3}\right)(\mathrm{py})$ in benzene or mesitylene (1,3,5-trimethylbenzene) at $190{ }^{\circ} \mathrm{C}$ lead to the formation of cis$(\text { hfac- } O, O)_{2} \mathrm{Rh}(\mathrm{R})(\mathrm{py})(\mathrm{R}=$ phenyl or ethyl-3,5-dimethylbenzene) with release of methane, which demonstrates that trans-(hfac-O,O $)_{2} \mathrm{Rh}\left(\mathrm{CH}_{3}\right)(\mathrm{py})$ is capable of activating $\mathrm{sp}^{2}$ and $\mathrm{sp}^{3} \mathrm{C}-\mathrm{H}$ bonds. To study if cis-(hfac- $\left.O, O\right)_{2} \mathrm{Rh}\left(\mathrm{CH}_{3}\right)(\mathrm{py})$ is capable of catalytic $\mathrm{C}-$ $\mathrm{H}$ activation, the complex was placed in a $1: 1$ mixture of toluene- $d_{8}$ and $\mathrm{C}_{6} \mathrm{H}_{6}$ at $190{ }^{\circ} \mathrm{C}$. The reaction yielded a rate of H/D exchange of $2.0 \times 10^{-3} \mathrm{~s}^{-1}$, which is approximately the same rate (taking in consideration the difference in reaction conditions) as the cis-(acac$O, O)_{2} \operatorname{Ir}(\mathrm{Ph})(\mathrm{py})$. Reacting benzene and styrene in the presence of cis-(hfac$O, O)_{2} \mathrm{Rh}(\mathrm{Ph})(\mathrm{py})$ at $90{ }^{\circ} \mathrm{C}$ lead to stoichiometric amounts of the anti-Markovnikov product dihydrostilbene; however, at longer reaction times polystyrene was formed. Thus, olefin insertion is too facile leading to multiple insertions to generate polymeric product. Catalytic activity with other olefins, e.g., ethylene, was not studied due to the poor activity of of $c i s-(\mathrm{hfac}-\mathrm{O}, \mathrm{O})_{2} \mathrm{Rh}(\mathrm{Ph})(\mathrm{py})$ with benzene and styrene. 
Our group has published a series of $\mathrm{Ru}(\mathrm{II})$ catalysts for olefin hydroarylation through a mechanism involving metal mediated $\mathrm{C}-\mathrm{H}$ activation (Scheme 1.15). ${ }^{43,46,71,81,82}$ A main objective of these studies was to look at the effects of sterics and electronics on catalysis. The catalyst are $\mathrm{TpRu}(\mathrm{L})(\mathrm{NCMe}) \mathrm{Ph}(\mathrm{Tp}=$ hydridotris(pyrazolyl)borate; $\mathrm{L}=$ $\mathrm{CO}, \mathrm{PMe}_{3}, \mathrm{P}(\mathrm{pyr})_{3}$, and $\mathrm{P}\left(\mathrm{OCH}_{2}\right)_{3} \mathrm{CEt} ; \mathrm{pyr}=N$-pyrroyl $)$. Thus the catalyst motif uses a neutral two-electron donor ligand, L, which allows tuning of steric and electronic properties. Additionally, a labile ligand in the equatorial plane is needed so when the catalyst precursor is placed in the presence of an olefin, ligand dissociation and olefin coordination can occur to initiate the catalytic cycle (Figure 1.6). Finally, the $\kappa^{3}-$ coordinated Tp ligand was used. The facial coordination mode restricts orientation for the $\mathrm{R}$-group and the ethylene to a cis conformation, which is need for olefin insertion and $\mathrm{C}-$ $\mathrm{H}$ activation.

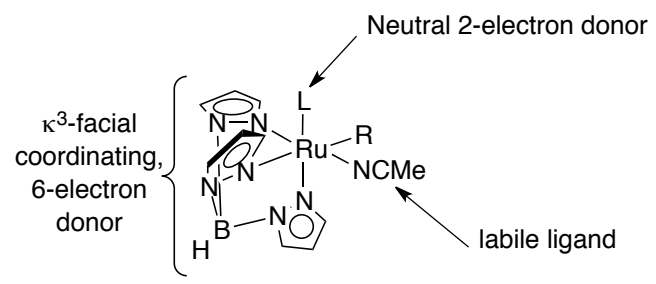

Figure 1.6. Catalyst design motif for $\mathrm{Ru}(\mathrm{II})$ complexes for olefin hydroarylation.

Synthetic targets $\mathrm{TpRu}(\mathrm{L})(\mathrm{NCMe}) \mathrm{Ph}(\mathrm{Tp}=$ hydridotris(pyrazolyl)borate; $\mathrm{L}=\mathrm{CO}$, $\mathrm{PMe}_{3}, \mathrm{P}(\text { pyr })_{3}$, and $\mathrm{P}\left(\mathrm{OCH}_{2}\right)_{3} \mathrm{CEt}$; pyr $=N$-pyrroyl $)$ are shown in Figure 1.7 and Figure 1.8 . 

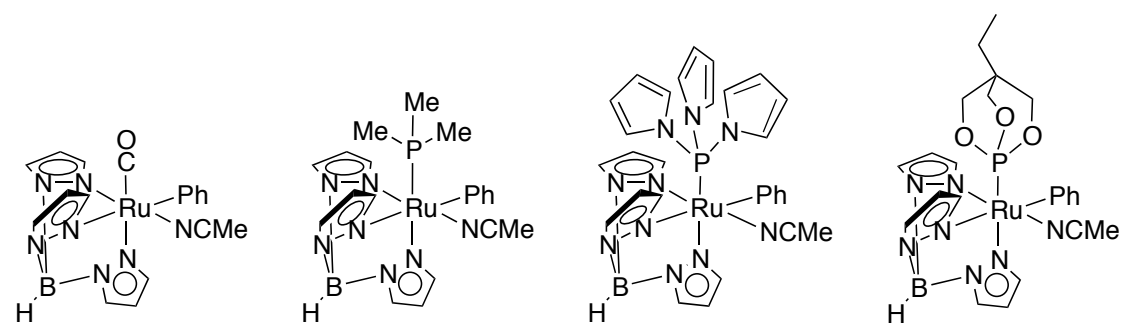

Figure 1.7. $\mathrm{TpRu}(\mathrm{L}) \mathrm{Ph}(\mathrm{NCMe})$ catalyst first examined for olefin hydroarylation.

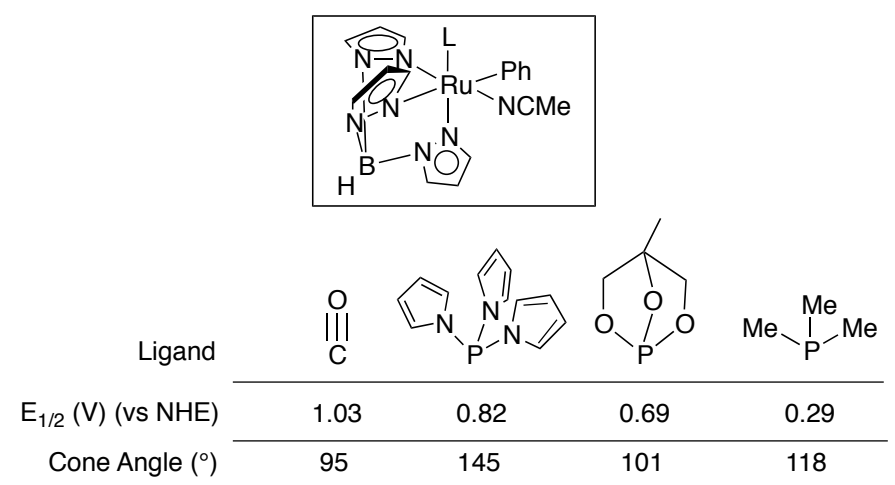

Figure 1.8. Electronics and cone angles for $\mathrm{TpRu}(\mathrm{L})(\mathrm{NCMe}) \mathrm{Ph}^{83,84}$

The first catalyst for olefin hydroarylation developed in our group was $\mathrm{TpRu}(\mathrm{CO})(\mathrm{NCMe}) \mathrm{Ph} .^{71,85}$ This catalyst is to our knowledge the most active transition metal catalyst for olefin hydroarylation proceeding through a mechanism that involves $\mathrm{C}-\mathrm{H}$ activation and olefin insertion. At $0.1 \mathrm{~mol} \% \mathrm{Ru}, 25 \mathrm{psi}$ of ethylene and $90{ }^{\circ} \mathrm{C}, 51$ turnovers (TO) of ethylbenzene were observed after 4 hours with a total of 77 TO after 24 $\mathrm{h}$ before catalyst deactivation to NMR silent materials. When propylene ( $25 \mathrm{psi}$ ) was used as the olefin with $0.1 \mathrm{~mol} \% \mathrm{Ru}$ at $90{ }^{\circ} \mathrm{C}$ both cumene and $n$-propylbenzene were observed in a 1:1.6 ratio (Table 1.1). The selectivity for $n$-propylbenzene over cumene supports a non-Friedel-Crafts mechanism. In additional, the reaction of benzene and 1- 
hexene at $90{ }^{\circ} \mathrm{C}$ with $1 \mathrm{~mol} \%$ of $\mathrm{Ru}$ catalyst) yielded only 2-phenylhexane and 1phenylhexane in a 1:1.6 ratio demonstrating catalyst selectivity for the linear product over the branch and no evidence for isomerization of hexene to yield the internal 3phenylhexane.

Table 1.1. Olefin hydroarylation with $\mathrm{TpRu}(\mathrm{CO})(\mathrm{NCMe}) \mathrm{Ph}$ as catalyst (unless otherwise noted, reaction conditions are $90{ }^{\circ} \mathrm{C}, 25 \mathrm{psi}$ of gas, $0.1 \mathrm{~mol} \%$ of $\mathrm{Ru}, 4 \mathrm{~h}$. ${ }^{\mathrm{a}} 50$ equiv. based on $\mathrm{Ru}$, after $6 \mathrm{~h}$ ).

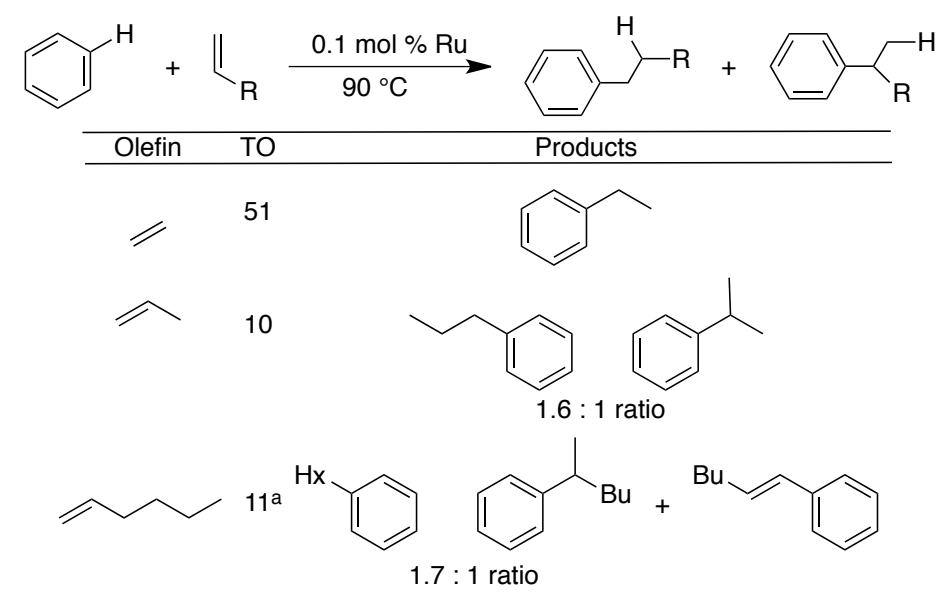

Experimental and computational studies performed by Prof. Thomas Cundari at University of North Texas support the mechanism depicted in Scheme 1.15. ${ }^{71}$ Initial, NCMe dissociation followed by olefin coordination forms the catalytic active species. Olefin insertion into the $\mathrm{Ru}-\mathrm{Ph}$ bond followed by coordination of ethylene leads to formation of a phenethyl/ethylene species (the proposed catalytic resting state). Dissociation of ethylene and subsequent coordination of benzene and $\mathrm{C}-\mathrm{H}$ activation through what is considered a "oxidative hydrogen migration" transition state, ${ }^{42,45}$ similar 
to $\sigma$-bond metathesis with non- $\mathrm{d}^{0}$ metals (Figure 1.9), leads to formation of the alkylated species. Replacement of ethylbenzene with ethylene regenerates the active catalyst. Kinetic isotope studies were completed. Monitoring the product isotopic distribution (i.e., $M_{W}=111$ vs 112 ) for catalytic reactions using a 1:1 solution of $\mathrm{C}_{6} \mathrm{H}_{6}: \mathrm{C}_{6} \mathrm{D}_{6}$ under ethylene pressure lead to a kinetic isotopic effect (KIE) of 2.1(1). Additionally, the KIE for stoichiometric benzene activation by $\mathrm{TpRu}(\mathrm{CO})(\mathrm{NCMe}) \mathrm{Me}$ to produce $\mathrm{TpRu}(\mathrm{CO})(\mathrm{NCMe}) \mathrm{Ph}$ was studied. A KIE of 2.5(5) was determined, which is in agreement with the catalytic benzene activation KIE demonstrating that benzene $\mathrm{C}-\mathrm{H}$ bond activation is the rate-limiting step of the catalytic cycle.

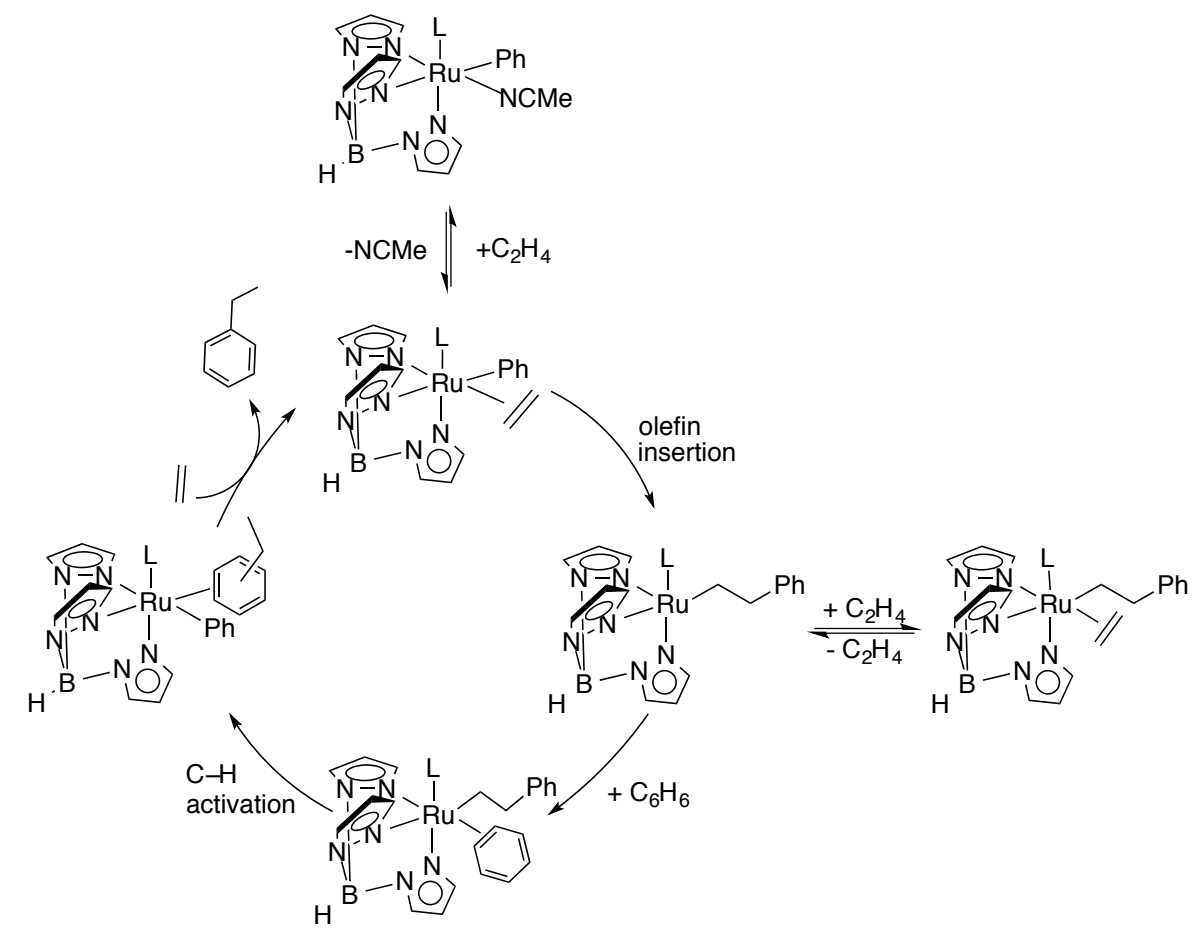

Scheme 1.15. Proposed Olefin Hydroarylation Catalytic Cycle by $\mathrm{TpRu}(\mathrm{L})(\mathrm{NCMe})(\mathrm{R})$. 


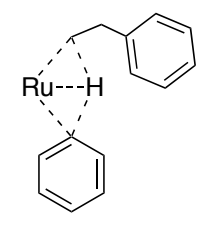

Figure 1.9. C-H activation transition state, "oxidative hydrogen migration".

To study the effect of increased electron density at the metal center, $\mathrm{TpRu}\left(\mathrm{PMe}_{3}\right)(\mathrm{NCMe}) \mathrm{Ph}$ was synthesized and probed for benzene $\mathrm{C}-\mathrm{H}$ activation as well as catalytic ethylene hydrophenylation. ${ }^{82}$ This complex does not catalyze olefin hydroarylation. Under extreme olefin hydroarylation conditions $\left(0.100 \mathrm{~mol} \% \mathrm{Ru}, 180{ }^{\circ} \mathrm{C}\right.$ and $800 \mathrm{psi}$ of ethylene) the reaction yields only $3.6 \mathrm{TO}$ of ethylbenzene in $12 \mathrm{~h}$ with 2.5 TO of styrene; however, $\mathrm{TpRu}\left(\mathrm{PMe}_{3}\right)(\mathrm{NCMe}) \mathrm{Ph}$ is not stable under these conditions; therefore, another species is accomplishing the production of ethylbenzene and styrene.

The increased electron density on the metal center of $\mathrm{TpRu}\left(\mathrm{PMe}_{3}\right)(\mathrm{NCMe}) \mathrm{Ph}$ was found to increase the barrier to olefin insertion and cause the ethylene $\mathrm{C}-\mathrm{H}$ activation to compete with ethylene insertion. Ethylene $\mathrm{C}-\mathrm{H}$ activation yields a vinyl species upon which a subsequent equivalent of ethylene could coordinate and insert into the $\mathrm{Ru}-\mathrm{C}_{\mathrm{vinyl}}$ bond. Isomerization of the species leads to an $\eta^{3}$-allyl complex, $\mathrm{TpRu}\left(\mathrm{PMe}_{3}\right)\left(\eta^{3}-\right.$ $\mathrm{C}_{3} \mathrm{H}_{4} \mathrm{Me}$ ). This complex has been shown to be inactive in catalyzing olefin hydroarylation (Scheme 1.17, Scheme 1.16). Therefore for $\mathrm{TpRu}(\mathrm{L})(\mathrm{NCMe}) \mathrm{Ph}$ catalyst, if the metal center is too electron-rich olefin insertion is inhibited and the rate of olefin $\mathrm{C}-\mathrm{H}$ activation competes with olefin insertion. 


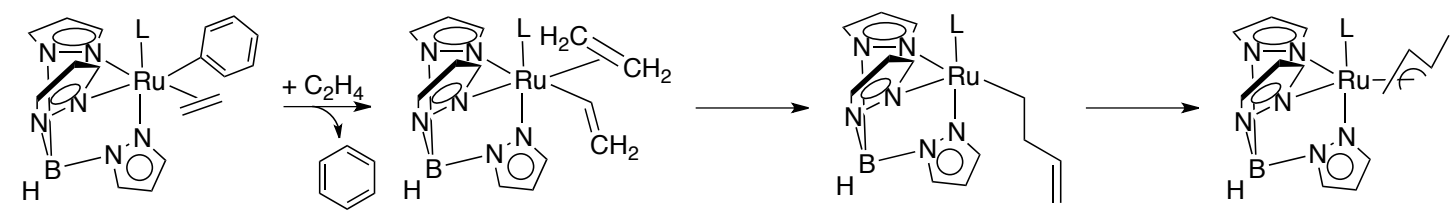

Scheme 1.16. Allyl formation through $\mathrm{C}-\mathrm{H}$ olefin activation for $\mathrm{TpRu}(\mathrm{L})$ complexes.

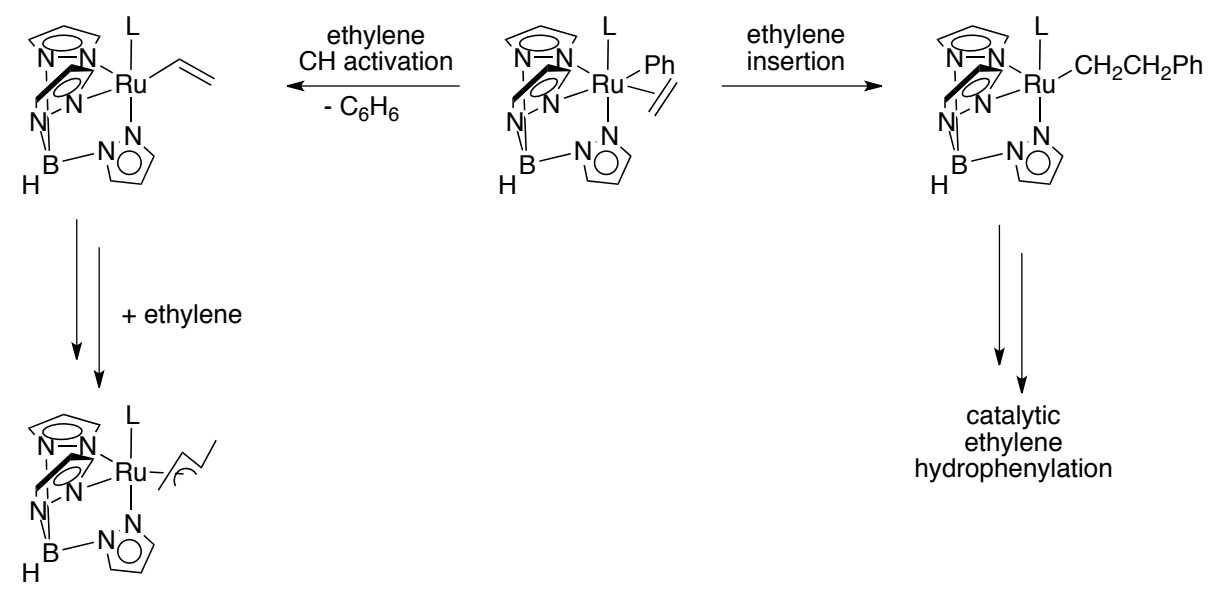

Scheme 1.17. Competition between ethylene $\mathrm{C}-\mathrm{H}$ activation and ethylene insertion.

As stated above, $\mathrm{TpRu}\left(\mathrm{PMe}_{3}\right)(\mathrm{NCMe}) \mathrm{Ph}$ was found to be too electron-donating and unable to accomplish catalytic olefin hydroarylation; furthermore, the less electron rich complex $\mathrm{TpRu}(\mathrm{CO})(\mathrm{NCMe}) \mathrm{Ph}$ is capable of olefin hydroarylation (TON 77 after 24 h). Thus, we sought a phosphite/phosphine that would be similar in electron donating ability as CO. Studies have shown that tris- $N$-pyrrolyl $\left[\mathrm{P}(\mathrm{pyr})_{3}\right]$ phosphine has a similar overall donating ability as $\mathrm{CO}^{84} \mathrm{TpRu}\left[\mathrm{P}(\mathrm{pyr})_{3}\right](\mathrm{NCMe}) \mathrm{Ph}$ was synthesized and tested to determine if steric bulk would help control the regioselectivity of hydroarylation when $\alpha$ olefins were employed while having a metal center that was similar in electron density as the $\mathrm{CO}$ (Scheme 1.18). ${ }^{81}$ 


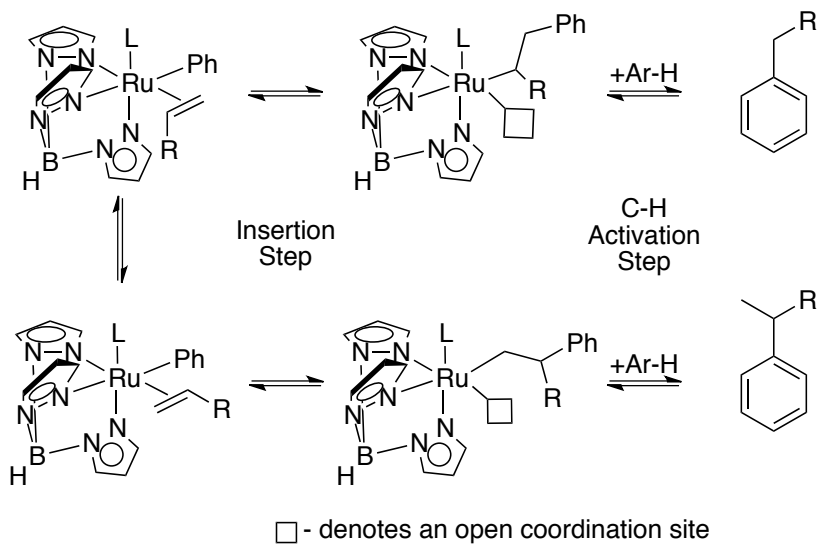

Scheme 1.18. Regioselective of $\alpha$-olefin hydroarylation.

$\mathrm{TpRu}\left[\mathrm{P}(\mathrm{pyr})_{3}\right](\mathrm{NCMe}) \mathrm{Ph}$ is not a catalyst for olefin hydroarylation. Upon examining a wide range of temperatures $\left(90{ }^{\circ} \mathrm{C}-180{ }^{\circ} \mathrm{C}\right)$ and pressures of ethylene $(15$ psi - 700 psi), production of ethylbenzene was not observed until 80 psi of ethylene at $120{ }^{\circ} \mathrm{C}\left(0.2 \mathrm{TO}\right.$ of ethylbenzene). Under $100 \mathrm{psi}$ of ethylene at $180{ }^{\circ} \mathrm{C}$ near stoichiometric amounts of ethylbenzene were produced. $\mathrm{TpRu}\left[\mathrm{P}(\mathrm{pyr})_{3}\right](\mathrm{NCMe}) \mathrm{Ph}$ is not stable under these conditions. Due to the lack of catalytic activity observed with $\mathrm{TpRu}\left[\mathrm{P}(\mathrm{pyr})_{3}\right](\mathrm{NCMe}) \mathrm{Ph}$, reactions were conducted to determine if the steric bulk of the $\mathrm{P}(\mathrm{pyr})_{3}$ was inhibiting catalytic activity. TpRu$\left[\mathrm{P}(\mathrm{pyr})_{3}\right](\mathrm{NCMe}) \mathrm{Ph}$ was placed in an THF$d_{8}$ under 80 psi of ethylene at $60{ }^{\circ} \mathrm{C}$ for 5 days. The formation of $\mathrm{TpRu}\left[\mathrm{P}(\mathrm{pyr})_{3}\right]\left(\eta^{2}-\right.$ $\left.\mathrm{C}_{2} \mathrm{H}_{4}\right) \mathrm{Ph}$ was not observed. Hence, it is speculated that the steric bulk of the $\mathrm{P}(\mathrm{pyr})_{3}$ ligand inhibits ethylene coordination (Scheme 1.19). DFT calculations performed by Dr. Cundari's group at the University of North Texas support the experimental results. Calculations showed that coordination of ethylene to $\mathrm{TpRu}\left[\mathrm{P}(\mathrm{pyr})_{3}\right] \mathrm{Ph}$ is less favorable 
than both $\mathrm{TpRu}(\mathrm{CO}) \mathrm{Ph}$ and $\mathrm{TpRu}\left(\mathrm{PMe}_{3}\right) \mathrm{Ph}$ by $8.9 \mathrm{kcal} / \mathrm{mol}$ and $5.1 \mathrm{kcal} / \mathrm{mol}$, respectively.
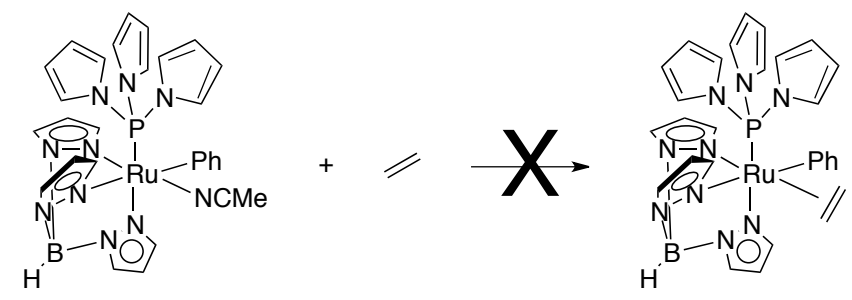

Scheme 1.19. Olefin coordination inhibited due to steric bulk of $\mathrm{P}(\mathrm{pyr})_{3}$.

Intramolecular $\mathrm{C}-\mathrm{H}$ activation of one pyrrolyl ring of the $\mathrm{P}(\mathrm{pyr})_{3}$ was also observed under certain conditions with $\mathrm{TpRu}\left[\mathrm{P}(\mathrm{pyr})_{3}\right](\mathrm{NCMe}) \mathrm{Me}$. Heating $\mathrm{TpRu}\left[\mathrm{P}(\mathrm{pyr})_{3}\right](\mathrm{NCMe}) \mathrm{Me}$ in $\mathrm{C}_{6} \mathrm{H}_{6}$ lead to the production of $\mathrm{TpRu}\left[\mathrm{P}(\mathrm{pyr})_{3}\right](\mathrm{NCMe}) \mathrm{Ph}$, $\mathrm{CH}_{3} \mathrm{D}$ and an insoluble NMR inactive species. Similar to $\mathrm{TpRu}(\mathrm{CO})(\mathrm{NCMe}) \mathrm{Me}$, the addition of $\mathrm{NCMe}$ to the reaction of $\mathrm{TpRu}\left[\mathrm{P}(\mathrm{pyr})_{3}\right](\mathrm{NCMe}) \mathrm{Me}$ in $\mathrm{C}_{6} \mathrm{D}_{6}$ inhibited decomposition; but, it also lead to the formation of a new species (minor), $\mathrm{TpRu}\left\{\kappa^{2}-\right.$ $\left.\mathrm{P}, \mathrm{C}, \mathrm{P}-\mathrm{P}(\mathrm{pyr})_{2}\left(\mathrm{NC}_{4} \mathrm{H}_{3}\right)\right\} \mathrm{NCMe}$, due to intramolecular $\mathrm{C}-\mathrm{H}$ activation of the 2-position of the pyrrolyl (Scheme 1.20).
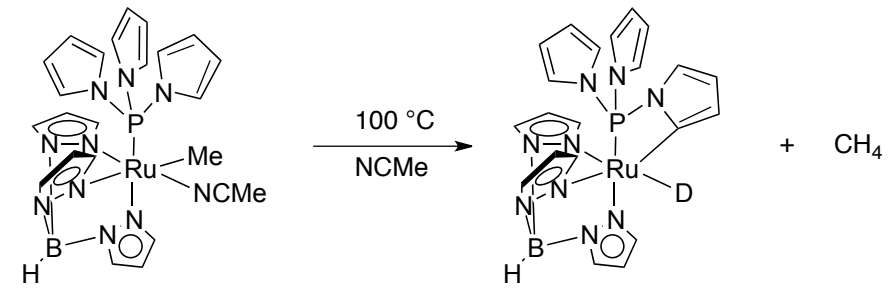

Scheme 1.20. Intramolecular $\mathrm{C}-\mathrm{H}$ activation of $\mathrm{TpRu}\left[\mathrm{P}(\mathrm{pyr})_{3}\right](\mathrm{NCMe}) \mathrm{Ph}$ to yield $\mathrm{TpRu}\left\{\kappa^{2}-P, C-\mathrm{P}(\mathrm{pyr})_{2}\left(\mathrm{NC}_{4} \mathrm{H}_{3}\right\} \mathrm{NCMe}\right.$. 
For accessible $\mathrm{CH}$ bonds [e.g., $\mathrm{P}(\mathrm{OMe})_{3}$ or $\mathrm{PPh}_{3}$ ], intramolecular $\mathrm{CH}$ activation and cyclometallation of the phosphite can inhibit catalysis. Thus, we initially probed $\mathrm{TpRu}\left[\mathrm{P}\left(\mathrm{OMe}_{3}\right)\right](\mathrm{NCMe}) \mathrm{R}$; however, cyclometallation of the phosphite inhibited catalysis. ${ }^{86}$ Therefore, the neutral bicyclic phosphite $\mathrm{P}\left(\mathrm{OCH}_{2}\right)_{3} \mathrm{CEt}$ was explored since the cyclic structure of $\mathrm{P}\left(\mathrm{OCH}_{2}\right)_{3} \mathrm{CEt}$ would prohibit cyclometallation. Furthermore, it is less donating than $\mathrm{PMe}_{3}$ and less bulky than $\mathrm{P}(\mathrm{pyr})_{3}$; however, since the ligand is more sterically bulk than $\mathrm{CO}$ it was hypothesized that regioselectivity with $\alpha$-olefins could be achieved.

Under optimal catalyst conditions $\left(0.1 \mathrm{~mol} \%, 90{ }^{\circ} \mathrm{C}\right.$ and $10 \mathrm{psi}$ of ethylene $)$ $\mathrm{TpRu}\left[\mathrm{P}\left(\mathrm{OCH}_{2}\right)_{3} \mathrm{CEt}\right](\mathrm{NCMe}) \mathrm{Ph}$ gives $10 \mathrm{TO}$ of ethylbenzene after $28 \mathrm{~h}$. Increasing the pressure of ethylene (e.g., 50 psi) decreases the TO which indicates an inverse dependence on ethylene concentration that is consistent with the proposed mechanism shown in Scheme 1.15. Unfortunately, relatively rapid catalyst deactivation through formation of $\mathrm{TpRu}\left[\mathrm{P}\left(\mathrm{OCH}_{2}\right)_{3} \mathrm{CEt}\right]\left(\eta^{3}-\mathrm{C}_{3} \mathrm{H}_{4} \mathrm{Me}\right)$ was observed. Thus, $\mathrm{TpRu}\left[\mathrm{P}\left(\mathrm{OCH}_{2}\right)_{3} \mathrm{CEt}\right](\mathrm{NCMe}) \mathrm{Ph}$ is too electron-rich and olefin $\mathrm{C}-\mathrm{H}$ activation is competitive with olefin insertion.

The Gibbs free energies of each step of the catalytic cycle for $\mathrm{TpRu}(\mathrm{L})(\mathrm{NCMe}) \mathrm{Ph}$ were examined using DFT calculations \{B3LYP/CEP-31G(d) level of theory) (Scheme 1.21). According to both calculations and experimental results there is a direct correlation between steric bulk of $\mathrm{L}$ and the $\Delta \mathrm{G}$ for ethylene coordination and insertion. For example, the $\Delta \mathrm{Gs}$ for ethylene coordination are negative when $\mathrm{L}=\mathrm{CO}(-7.9 \mathrm{kcal} / \mathrm{mol})$, 
$\mathrm{PMe}_{3}(-4.1 \mathrm{kcal} / \mathrm{mol})$ or $\mathrm{P}\left(\mathrm{OCH}_{2}\right)_{3} \mathrm{CEt}(-6.1 \mathrm{kcal} / \mathrm{mol})$; however, $\mathrm{L}=\mathrm{P}(\mathrm{pyr})_{3}$ ethylene coordination is overall endergonic at $+1 \mathrm{kcal} / \mathrm{mol}^{43}$

To understand the propensity of $\mathrm{TpRu}(\mathrm{L})(\mathrm{NCMe}) \mathrm{Ph}\left(\mathrm{L}=\mathrm{PMe}_{3}\right.$ or $\mathrm{P}\left(\mathrm{OCH}_{2}\right)_{3} \mathrm{CEt}$ to form $\mathrm{TpRu}(\mathrm{L})\left(\eta^{3}-\mathrm{C}_{3} \mathrm{H}_{4} \mathrm{Me}\right), \Delta \Delta G^{\ddagger}$ s for ethylene $\mathrm{C}-\mathrm{H}$ activation and ethylene insertion from $\mathrm{TpRu}(\mathrm{L})\left(\eta^{2}-\mathrm{C}_{2} \mathrm{H}_{4}\right) \mathrm{Ph}$ were calculated. Calculations demonstrate a clear trend. As the electron density of the metal center increases, the $\Delta \Delta G^{\ddagger}$ for ethylene $\mathrm{C}-\mathrm{H}$ activation and ethylene insertion decrease. When $\mathrm{L}=\mathrm{PMe}_{3}$ the difference in energies $\left(\Delta \Delta G^{\ddagger}\right)$ is 3.1 $\mathrm{kcal} / \mathrm{mol}$; whereas, $\mathrm{L}=\mathrm{CO}$ has a significantly larger $\Delta \Delta G^{\ddagger}$ at $8.6 \mathrm{kcal} / \mathrm{mol}$ (Table 1.2).

Table 1.2. Calculated $\Delta G_{\text {insertion }}^{\ddagger}(\mathrm{kcal} / \mathrm{mol})$ for ethylene insertion and $\Delta G^{\ddagger}{ }_{\text {CH activation }}$ $(\mathrm{kcal} / \mathrm{mol})$ of ethylene for $\mathrm{TpRu}(\mathrm{L})\left(\eta^{2}-\mathrm{C}_{2} \mathrm{H}_{4}\right) \mathrm{Ph}$ complexes.

\begin{tabular}{|c|c|c|c|}
\hline $\mathrm{L}$ & $\begin{array}{c}\Delta G_{\text {insertion }}^{\ddagger} \\
\text { of } \mathrm{C}_{2} \mathrm{H}_{4}\end{array}$ & $\begin{array}{c}\Delta G_{\text {C-H activation }}^{\ddagger} \\
\text { of } \mathrm{C}_{2} \mathrm{H}_{4}\end{array}$ & $\Delta \Delta G^{\ddagger}$ \\
\hline $\mathrm{PMe}_{3}$ & 23.9 & 27.0 & 3.1 \\
\hline $\mathrm{P}(\mathrm{pyr})_{3}$ & 23.2 & 28.6 & 5.4 \\
\hline $\mathrm{P}\left(\mathrm{OCH}_{2}\right)_{3} \mathrm{CEt}$ & 20.1 & 27.3 & 7.4 \\
\hline $\mathrm{CO}$ & 26.4 & 17.8 & 8.6 \\
\hline
\end{tabular}

Furthermore, calculations show that the rate limiting step for ethylene hydrophenylation is the benzene $\mathrm{C}-\mathrm{H}$ activation step, which is consistent with experimental results. ${ }^{46}$ However, the calculated $\Delta \Delta G^{\ddagger}$ for ethylene insertion $\left(\Delta \Delta G^{\ddagger}\right.$ of $\sim 6.2 \mathrm{kcal} / \mathrm{mol})$ is larger than the $\Delta \Delta G^{\ddagger}$ for benzene $\mathrm{C}-\mathrm{H}$ activation $(\sim 4.4 \mathrm{kcal} / \mathrm{mol})$ as the ligand $\mathrm{L}$ is varied (Scheme 1.21). Therefore, varying the donor ability of $\mathrm{L}$ has a greater impact on the rate of olefin insertion compared to the rate of benzene $\mathrm{C}-\mathrm{H}$ activation. 


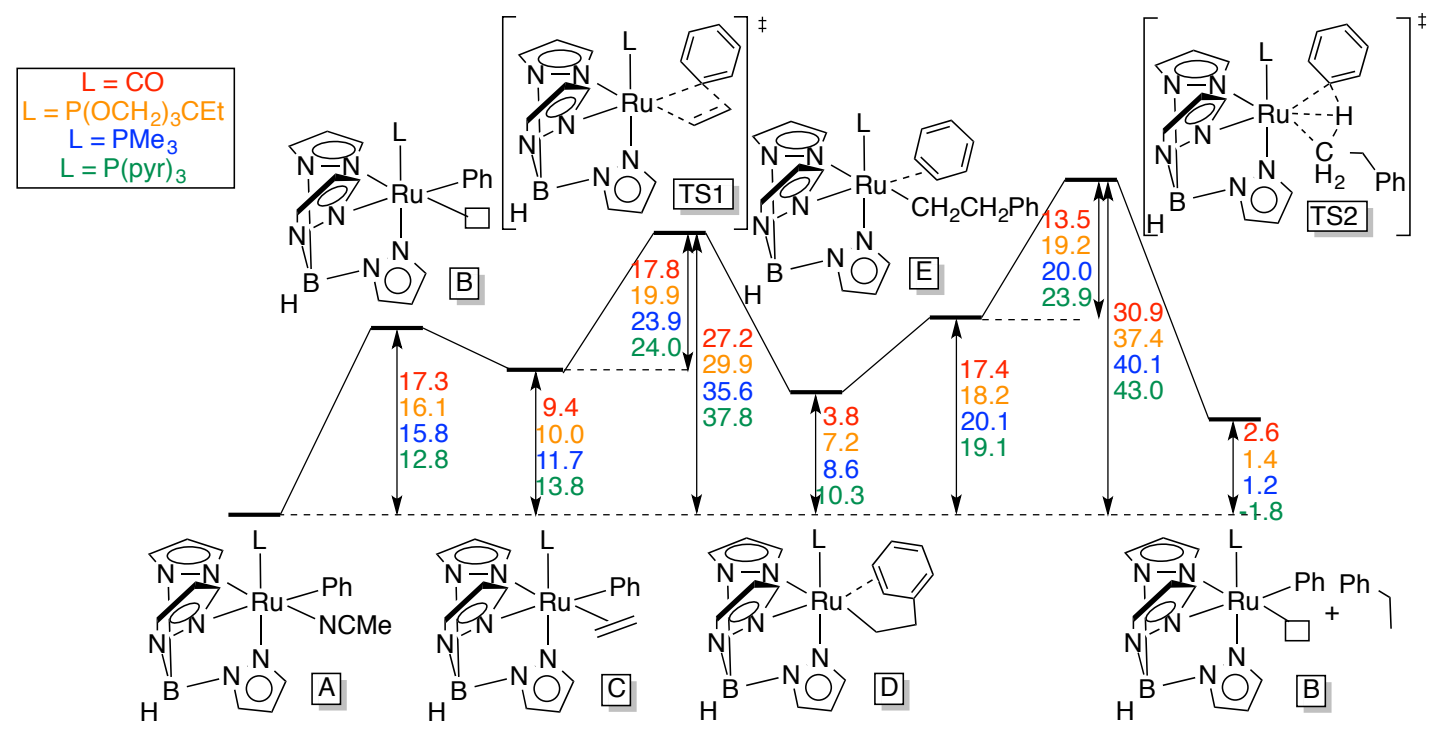

Scheme 1.21. Calculated Gibbs Free Energy ( $\mathrm{kcal} / \mathrm{mol}$ ) for benzene $\mathrm{C}-\mathrm{H}$ activation by $\mathrm{TpRu}(\mathrm{L})(\mathrm{NCMe}) \mathrm{Ph}\left[\mathrm{L}=\mathrm{CO}, \mathrm{P}\left(\mathrm{OCH}_{2}\right)_{3} \mathrm{CEt}, \mathrm{PMe}_{3}\right.$ and $\left.\mathrm{P}(\mathrm{pyr})_{3}\right]$.

\subsection{Summary and Thesis Aims}

Through the studies of the $\mathrm{TpRu}(\mathrm{L})(\mathrm{NCMe}) \mathrm{Ph}\left(\mathrm{L}=\mathrm{CO}, \mathrm{PMe}_{3}, \mathrm{P}(\mathrm{pyr})_{3}\right.$, and $\left.\mathrm{P}\left(\mathrm{OCH}_{2}\right)_{3} \mathrm{CEt}\right)$ complexes, a few important trends were observed. 1) If the ancillary ligand is too sterically bulky (e.g. $\mathrm{P}(\mathrm{pyr})_{3}$ cone angle $145^{\circ}$ ), olefin coordination is inhibited and the catalytic olefin hydroarylation cannot be accessed. 2) Metal centers which are too electronic rich, cause olefin $\mathrm{C}-\mathrm{H}$ activation to become competitive with olefin insertion and lead to the formation of a TpRu(L) $\left(\eta^{3}-\mathrm{C}_{3} \mathrm{H}_{4} \mathrm{Me}\right)$. 3) The ancillary ligand's electron influence is relatively small on the activation barrier for benzene $\mathrm{C}-\mathrm{H}$ activation (with more electron-donating ligands), slightly reducing the free energy of activation; however, steric influence can have a substantial effect on the rate of olefin insertion vs. $\mathrm{C}-\mathrm{H}$ activation. 
Presented herein is an extension of the previous work on olefin hydroarylation using $\mathrm{Ru}(\mathrm{II})$ metal centers. Chapter 2 discusses the studies of the bicyclic phosphite ligand $\mathrm{P}\left(\mathrm{OCH}_{2}\right)_{2}\left(\mathrm{OCCH}_{3}\right)$ coordinated to $\mathrm{Ru}(\mathrm{II})$. This ligand is predicted to be less electron donating but sterically similar to $\mathrm{P}\left(\mathrm{OCH}_{2}\right)_{3} \mathrm{CEt}$ and was hoped to lead to a better $\mathrm{TpRu}(\mathrm{II})$ olefin hydroarylation catalyst. Chapter 3 delineates the use of $\mathrm{P}\left(\mathrm{OCH}_{2}\right)_{2}\left(\mathrm{OCCH}_{3}\right)$ in synthesis of the $\mathrm{Ru}(\mathrm{II})$ catalyst $\mathrm{TpRu}\left[\mathrm{P}\left(\mathrm{OCH}_{2}\right)_{2}\left(\mathrm{OCCH}_{3}\right)\right.$ ](NCMe) $\mathrm{Ph}$ and its ability to catalyze olefin hydroarylation compared to the previously reported $\mathrm{TpRu}(\mathrm{L})(\mathrm{NCMe}) \mathrm{Ph}\left[\mathrm{L}=\mathrm{CO}, \mathrm{PMe}_{3}, \mathrm{P}(\mathrm{pyr})_{3}\right.$, and $\left.\mathrm{P}\left(\mathrm{OCH}_{2}\right)_{3} \mathrm{CEt}\right]$ complexes. Chapter 4 describes a more in-depth study of our $\mathrm{TpRu}(\mathrm{CO})(\mathrm{NCMe}) \mathrm{Ph}$ catalyst, and the effects of catalyst loading and ethylene concentration on olefin hydroarylation. As studies with the $\mathrm{TpRu}(\mathrm{II})$ catalyst have shown that the electron density of the metal center has more of an impact on olefin insertion versus $\mathrm{C}-\mathrm{H}$ activation, a more electron poor system was sought. Thus, Chapter 5 discusses the synthesis and screening of other neutral sixelectron-donor motifs including $\left(\eta^{6}\right.$-p-cymene $) \mathrm{Ru}(\mathrm{L}) \mathrm{PhBr} \quad\left[\mathrm{L}=\mathrm{P}(\mathrm{OMe})_{3}\right.$ or $\left.\mathrm{P}\left(\mathrm{OCH}_{2}\right)_{3} \mathrm{CEt}\right], \mathrm{C}(\mathrm{pz}) 4 \mathrm{Ru}\left[\mathrm{P}\left(\mathrm{OCH}_{2}\right)_{3} \mathrm{CEt}\right](\mathrm{NCMe}) \mathrm{R}\left[\mathrm{BAr}_{4}^{\prime}\right]\left(\mathrm{C}(\mathrm{pz})_{4}=\kappa^{3}-N, N, N\right.$-tetrakis $(1-$ pyrazolyl)methane) and $\mathrm{HC}\left(\mathrm{pz}_{3}{ }_{3}\right) \mathrm{Ru}\left[\mathrm{P}\left(\mathrm{OCH}_{2}\right)_{3} \mathrm{CEt}\right](\mathrm{NCMe}) \mathrm{Ph} \quad\left(\mathrm{pz}{ }^{\prime}=3,5\right.$-dimethylpyrazole) for catalytic hydroarylation. 


\subsection{References}

(1) Somorjai, G. A.; Rioux, R. M. Catal. Today 2005, 100, 201.

(2) Corma, A. Chem. Rev. 1997, 97, 2373.

(3) Gerzeliev, I. M.; Khadzhiev, S. N.; Sakharova, I. E. Petrol Chem+ 2011, 51,39 .

(4) Perego, C.; Pollesel, P. In Advances in Nanoporous Materials; Stefan, E., Ed.; Elsevier: 2010; Vol. 1, p 97.

(5) Macquarrie, D. J. In Catalytic Asymmetric Friedel-Crafts Alkylations; Wiley-VCH: 2009, p 271.

(6) Perego, C.; Ingallina, P. Green Chem. 2004, 6, 274.

(7) Brown, H. C.; Pearsall, H. W.; Eddy, L. P.; Wallace, W. J.; Grayson, M.; Nelson, K. L. Industrial \& Engineering Chemistry 1953, 45, 1462.

(8) Olah, G. A.; Molnar, A. Hydrocarbon Chemistry; 2nd ed.; WileyInterscience: New York, 2003.

(9) You, S.-L.; Cai, Q.; Zeng, M. Chem. Soc. Rev. 2009, 38, 2190.

(10) Roberts, R. M.; Khalaf, A. A. Friedel-Crafts Alkylation Chemistry: A Century of Discovery; Marcel Dekker, Inc. : New York, 1984.

(11) Corma, A.; Garcia, H. Chem. Rev. 2003, 103, 4307.

(12) Kocal, J. A.; Vora, B. V.; Imai, T. Appl. Catal., A 2001, 221, 295.

(13) Perego, C.; Ingallina, P. Catal. Today 2002, 73, 3.

(14) Degnan, T. F.; Smith, C. M.; Venkat, C. R. Appl. Catal., A 2001, 221, 283.

(15) Cejka, J.; Wichterlova, B. Catal. Rev. 2002, 375.

(16) O'Kelly, A. A.; Kellett, J., III; Plucker, J. J. Ind. Eng. Chem. 1947, 39, 154.

(17) Fechete, I.; Wang, Y.; Védrine, J. C. Catal. Today 2012, 189, 2.

(18) Haag, W. O. Catalysis by Zeolites - Science and Technology; Elsevier, 1994; Vol. 84. 
(19) O'Connor, C. T.; Van Steen, E.; Dry, M. E. New Catalytic Applications of Zeolites for Petrochemicals; Elsevier, 1996; Vol. 102.

(20) Weitkamp, J. New Directions in Zeolite Catalysis; Elsevier, 1991; Vol. 65.

(21) Tanabe, K.; Hölderich, W. F. Appl. Catal., A 1999, 181, 399.

(22) Broach, R. W. In Zeolites in Industrial Separation and Catalysis; WileyVCH: 2010,p 27.

(23) Martínez, C.; Corma, A. Coord. Chem. Rev. 2011, 255, 1558.

(24) Degnan, T. F. J. Catal. 2003, 216, 32.

(25) Kulprathipanja, S. Zeolites in Industrial Separation and Catalysis; John Wiley \& Sons.

(26) Guisnet, M.; Ribeiro, F. R. Deactivation and Regeneration of Zeolite Catalysts; Imperial College Press: London, 2011.

(27) Stanforth, S. P. Tetrahedron 1998, 54, 263.

(28) Negishi, E.-I.; Anastasia, L. Chem. Rev. 2003, 103, 1979.

(29) Beletskaya, I. P.; Cheprakov, A. V. Chem. Rev. 2000, 100, 3009.

(30) Corbet, J.-P.; Mignani, G. Chem. Rev. 2006, 106, 2651.

(31) Shen, H. C. Selected Applications of Transition Metal-Catalyzed CarbonCarbon Cross-Coupling Reactions in the Pharmaceutical Industry; John Wiley \& Sons, Inc., 2012.

(32) Caron, S.; Ghosh, A.; Gut Ruggeri, S.; Ide, N. D.; Nelson, J. D.; Ragan, J. A. Selected Metal-Mediated Cross-Coupling Reactions; John Wiley \& Sons, Inc., 2011.

(33) Carey, F. A.; Sundberg, R. J. Advanced Organic Chemistry; 5th ed.; Springer, 2007.

(34) Negishi, E.-i. Angew. Chem. Int. Ed. 2011, 50, 6738.

(35) Colacot, T. J. Platinum Met. Rev. 2011, 55, 84.

(36) Lipshutz, B. H.; Taft, B. R.; Abela, A. R.; Ghorai, S.; Krasovskiy, A.; Duplais, C. Platinum Met. Rev. 2012, 56, 62. 
(37) Miyaura, N.; Suzuki, A. Chem.Rev. 1995, 95, 2457.

(38) Fortman, G. C.; Nolan, S. P. Chem. Soc. Rev. 2011, 40, 5151.

(39) Kuhl, N.; Hopkinson, M. N.; Wencel-Delord, J.; Glorius, F. Angew. Chem. Int. Ed. 2012, 51, 10236.

(40) Fu, G. C. Acc. Chem. Res. 2008, 41, 1555.

(41) Cornils, B.; Herrmann, W. A. In Applied Homogeneous Catalysis with Organometallic Compounds; Wiley-VCH Verlag GmbH: 2008, p 599.

(42) Oxgaard, J.; Periana, R. A.; Goddard, W. A. J. Am. Chem. Soc. 2004, 126, 11658.

(43) Foley, N. A.; Lee, J. P.; Ke, Z. F.; Gunnoe, T. B.; Cundari, T. R. Acc. Chem. Res. 2009, 42, 585 .

(44) Oxgaard, J.; Muller, R. P.; Goddard, W. A.; Periana, R. A. J. Am. Chem. Soc. 2004, 126, 352 .

(45) Oxgaard, J.; Goddard, W. A. J. Am. Chem. Soc. 2004, 126, 442.

(46) Foley, N. A.; Ke, Z. F.; Gunnoe, T. B.; Cundari, T. R.; Petersen, J. L. Organometallics 2008, 27, 3007.

(47) Lewis, J. C.; Bergman, R. G.; Ellman, J. A. Acc. Chem. Res. 2008, 41, 1013.

(48) Colby, D. A.; Bergman, R. G.; Ellman, J. A. Chem. Rev. 2010, 110, 624.

(49) Engle, K. M.; Mei, T.-S.; Wasa, M.; Yu, J.-Q. Acc. Chem. Res. 2012, 45, 788.

(50) Chen, X.; Engle, K. M.; Wang, D.-H.; Yu, J.-Q. Angew. Chem. Int. Ed. 2009, 48, 5094.

(51) Neufeldt, S. R.; Sanford, M. S. Acc. Chem. Res. 2012, 45, 936.

(52) Daugulis, O.; Do, H.-Q.; Shabashov, D. Acc.Chem.Res. 2009, 42, 1074.

(53) Hartwig, J. F. Acc. Chem. Res. 2011, 45, 864.

(54) Hickman, A. J.; Sanford, M. S. ACS Catalysis 2011, 1, 170. 
(55) Baxter, R. D.; Sale, D.; Engle, K. M.; Yu, J.-Q.; Blackmond, D. G. J. Am. Chem. Soc. 2012, 134, 4600.

(56) Goj, L. A.; Gunnoe, T. B. Curr. Org. Chem. 2005, 9, 671.

(57) Ritleng, V.; Sirlin, C.; Pfeffer, M. Chem.Rev. 2002, 102, 1731.

(58) Nadres, E. T.; Daugulis, O. J. Am. Chem. Soc. 2011, 134, 7.

(59) Lin, B. L.; Bhattacharyya, K. X.; Labinger, J. A.; Bercaw, J. E. Organometallics 2009, 28, 4400 .

(60) Sevov, C. S.; Hartwig, J. F. J. Am. Chem. Soc. 2013, 135, 2116.

(61) Jia, C.; Piao, D.; Oyamada, J.; Lu, W.; Kitamura, T.; Fujiwara, Y. Science 2000, 287, 1992.

(62) Bowring, M. A.; Bergman, R. G.; Tilley, T. D. Organometallics 2011, 30, 1295.

(63) Jia, C. G.; Kitamura, T.; Fujiwara, Y. Acc. Chem. Res. 2001, 34, 633.

(64) Kakiuchi, F.; Murai, S. Acc. Chem. Res. 2002, 35, 826.

(65) Colby, D. A.; Bergman, R. G.; Ellman, J. A. Chem Rev 2010, 110, 624.

(66) Kubota, A.; Emmert, M. H.; Sanford, M. S. Org Lett 2012, 14, 1760.

(67) Andreatta, J. R.; McKeown, B. A.; Gunnoe, T. B. J. Organomet. Chem. 2011, 696, 305 .

(68) Luedtke, A. T.; Goldberg, K. I. Angew. Chem., Int. Ed. 2008, 47, 7694.

(69) Periana, R. A.; Liu, X. Y.; Bhalla, G. Chem. Commun. 2002, 3000.

(70) McKeown, B. A.; Foley, N. A.; Lee, J. P.; Gunnoe, T. B. Organometallics 2008, 27, 4031 .

(71) Lail, M.; Bell, C. M.; Conner, D.; Cundari, T. R.; Gunnoe, T. B.; Petersen, J. L. Organometallics 2004, 23, 5007.

(72) Karshtedt, D.; Bell, A. T.; Tilley, T. D. Organometallics 2004, 23, 4169.

(73) McKeown, B. A.; Gonzalez, H. E.; Friedfeld, M. R.; Gunnoe, T. B.; Cundari, T. R.; Sabat, M. J. Am. Chem. Soc. 2011, 133, 19131. 
(74) Karshtedt, D.; McBee, J. L.; Bell, A. T.; Tilley, T. D. Organometallics 2006, $25,1801$.

(75) Jones, W. D.; Maguire, J. A.; Rosini, G. P. Inorg. Chim. Acta 1998, 270, 77.

(76) Cucciolito, M. E.; D'Amora, A.; Tuzi, A.; Vitagliano, A. Organometallics 2007, 26, 5216 .

(77) Jia, C. G.; Lu, W. J.; Oyamada, J.; Kitamura, T.; Matsuda, K.; Irie, M.; Fujiwara, Y. J.Am. Chem. Soc. 2000, 122, 7252.

(78) Jia, C. G.; Lu, W. J.; Kitamura, T.; Fujiwara, Y. Org Lett 1999, 1, 2097.

(79) Matsumoto, T.; Taube, D. J.; Periana, R. A.; Taube, H.; Yoshida, H. J. Am. Chem. Soc. 2000, 122, 7414.

(80) Tenn III, W. J.; Conley, B. L.; Bischof, S. M.; Periana, R. A. J. Organomet. Chem. 2011, 696, 551.

(81) Foley, N. A.; Lail, M.; Gunnoe, T. B.; Cundari, T. R.; Boyle, P. D.; Petersen, J. L. Organometallics 2007, 26, 5507.

(82) Foley, N. A.; Lail, M.; Lee, J. P.; Gunnoe, T. B.; Cundari, T. R.; Petersen, J. L. J. Am. Chem. Soc. 2007, 129, 6765.

(83) Tolman, C. A. Chem.Rev. 1977, 77, 313.

(84) Moloy, K. G.; Petersen, J. L. J. Am. Chem. Soc. 1995, 117, 7696.

(85) Lail, M.; Arrowood, B. N.; Gunnoe, T. B. J. Am. Chem. Soc. 2003, 125, 7506.

(86) Unpublished results from a former Gunnoe group member. 


\section{Structural and Electronic Properties of Ru(II) Complexes Containing $\mathbf{P}\left(\mathrm{OCH}_{2}\right)_{2}\left(\mathrm{OCCH}_{3}\right)$.}

\subsection{Introduction}

Phosphorous-based compounds offer a wide range of steric properties and basicities due to the variety of accessible substituents, ${ }^{1-16}$ and many phosphorous-based compounds bind strongly to transition metals. As a result of their coordinating ability and highly tunable stereoelectronic character, phosphorous-based compounds are among the most heavily utilized class of ligands in coordination chemistry and homogeneous catalysis..$^{1-3,5-7,9,16-19}$ Several studies have quantified the steric and donor properties of a wide range of phosphorous-based ligands. ${ }^{6,8,10-16,20-22}$ For example, the classic work by Tolman established the comparison of the steric properties of phosphorus ligands using cone angles ${ }^{6}$ The donor abilities of phosphorous ligands have been studied using $\mathrm{CO}$ absorption energies for metal carbonyl complexes with phosphorous ligands [e.g., $\mathrm{Ni}(\mathrm{CO})_{3} \mathrm{~L}$ where $\mathrm{L}=$ phosphite, phosphine, etc..$^{6}$

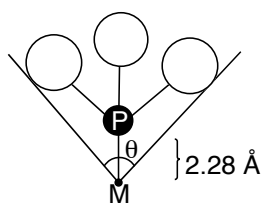

Figure 2.1. Tolman's method for measuring cone angle for phosphines/phosphites. ${ }^{6}$

Bicyclic phosphites have been investigated and compared to acyclic phosphites. In general, the steric profiles of bicyclic phosphites are constrained relative to acyclic compounds, and cyclic phosphites exhibit reduced basicity relative to acyclic phosphites. 
Verkade has proposed the "hinge" effect to explain the influence of the bicyclic phosphites' rigidity on basicity (Scheme 2.1). ${ }^{3,23-26}$ Uncoordinated phosphites adopt a trigonal pyramidal geometry, while coordination (or protonation) of the phosphite results in a shift toward tetrahedral geometry. Upon coordination to a metal center, the $\mathrm{O}-\mathrm{P}-\mathrm{O}$ and the $\mathrm{P}-\mathrm{O}-\mathrm{C}$ angles of an acyclic phosphite can adjust independently. But, reorganization of bicyclic phosphites upon metal ligation is more restricted because adjustment of the $\mathrm{O}-\mathrm{P}-\mathrm{O}$ angle influences the $\mathrm{P}-\mathrm{O}-\mathrm{C}$ angle. For coordinated phosphites, bicyclic phosphites exhibit a smaller $\mathrm{P}-\mathrm{O}-\mathrm{C}$ angle compared to the acyclic phosphites (i.e., $\mathrm{d}^{\prime}<\mathrm{c}^{\prime}$ in Scheme 2.1). Verkade has proposed that these changes result in a reduction of the $p$-orbital overlap between $\mathrm{O}$ and $\mathrm{P}$, which increases the positive charge on the $\mathrm{P}$ atom and decreases the basicity relative to acyclic phosphites. Thus, the donor ability of bicyclic phosphites is reduced relative to related acyclic phosphites. ${ }^{27,28}$

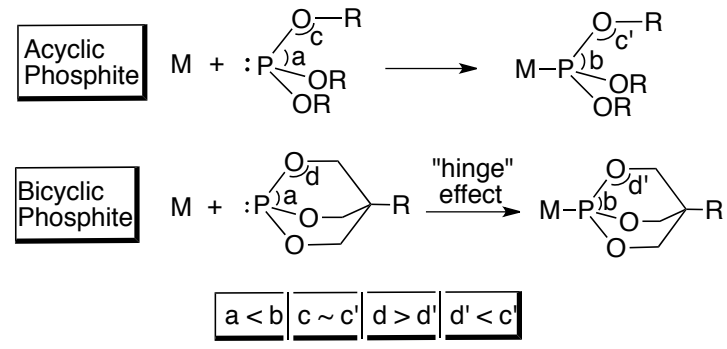

Scheme 2.1. Comparison of acyclic and bicyclic phosphites based on the hinge effect.

The hinge effect looks at the influence of the $p$-orbital; however, another orbital that can contribute to the $\pi$-acidity of phosphites is the vacant $\mathrm{P}-\mathrm{O} \sigma^{*}$ orbital, which has 
been proposed to play a role in $\mathrm{d} \pi$-to-P orbital back-bonding. ${ }^{1}$ Specifically with the bicyclic phosphites, the energy level of the $\sigma^{*}$ orbital can be related to the $\mathrm{O}-\mathrm{P}-\mathrm{O}$ bond angles. As the $\mathrm{O}-\mathrm{P}-\mathrm{O}$ angle is constrained the overlap between the metal and the $\mathrm{P}-\mathrm{O} \sigma-$ orbitals decreases which raises the energy of the $\sigma$-orbital lowers the energy of the $\mathrm{P}-\mathrm{O}$ $\sigma^{*}$. The decrease energy of the $\mathrm{P}-\mathrm{O} \sigma^{*}$ provides better overlap with the metal $\mathrm{d} \pi$ orbitals. As a result, more electron density can be donated from the metal center to the ligand decreasing the electron density on the metal center (Figure 2.2).

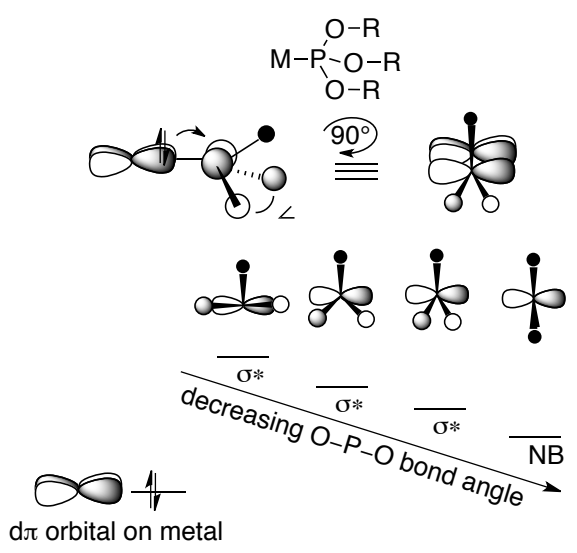

Figure 2.2. Anticipated impact of $\mathrm{O}-\mathrm{P}-\mathrm{O}$ bond angle of $\sigma^{*}(\mathrm{P}-\mathrm{O})$ orbital energy and, hence, $\mathrm{d} \pi-$ to- $\sigma^{*}$ back bonding.

A few bicyclic phosphites have been prepared and studied, and similar to acyclic phosphorous-based ligands their steric and donor properties are variable (Figure 2.3). ${ }^{6,29}$ While several examples of transition metal complexes with bicyclic phosphite ligands are known, including nickel, cobalt, iron, chromium, molybdenum and tungsten complexes, 2-4,30-32 however to our knowledge, no example of a structurally characterized transition metal complex with $\mathrm{P}\left(\mathrm{OCH}_{2}\right)_{2}\left(\mathrm{OCCH}_{3}\right) \quad$ (1) (4-methyl-2,6,7-trioxa-1- 
phosphabicyclo[2,2,1]heptane) is known. The structure of the phosphate $\mathrm{O}=$ $\mathrm{P}\left(\mathrm{OCH}_{2}\right)_{2}\left(\mathrm{OCCH}_{3}\right)$ has been reported. ${ }^{29}$ Verkade et al. have studied a variety of polycyclic phosphorous compounds including their coordination to transition metals. 2,3,24,27,29,30 Based on trends in basicity, it is anticipated that $\mathbf{1}$ would be less donating to metal centers than the more commonly studied bicyclic phosphite $\mathrm{P}\left(\mathrm{OCH}_{2}\right)_{3} \mathrm{CEt}^{28}$

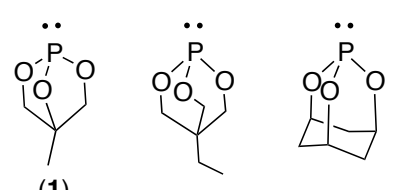

Figure 2.3. Examples of bicyclic phosphites.

Phosphorous-based ligands are generally considered good donor ligands; however, we felt that phosphite 1 might provide a relatively weakly donating phosphorus-based ligand. In order to study phosphite $\mathbf{1}$ and compare its donor ability to other phosphorous-based ligands as well as other non-phosphorous based ligands (e.g., $\mathrm{CO}$ ), we sought suitable transition metal systems that would allow the coordination of several phosphorous-based ligands.

\subsection{Results and Discussion}

\subsubsection{Synthesis of $\mathrm{P}\left(\mathrm{OCH}_{2}\right)_{2}\left(\mathrm{OCCH}_{3}\right)$}

The preparation of 1 from 2-methyl-1,2,3-propanetriol has been reported. ${ }^{33}$ Our attempts to synthesize and cleanly isolate $\mathbf{1}$ using this procedure were not successful. In addition, using alternate procedures reported for similar bicyclic phosphorous species did 
not result in the clean isolation of $\mathbf{1} .^{24,30,34,35}$ Thus, we developed a modified procedure that involves the in situ generation and subsequent reaction of $\mathbf{1}$ without isolation. ${ }^{36,37}$ The reaction of 2-methyl-1,2,3-propane with 3 equivalents of $\mathrm{NaH}$ followed by addition of $\mathrm{PCl}_{3}$ leads to the formation of compound $\mathbf{1}$, as evidenced by a single resonance at 115 ppm in the ${ }^{31} \mathrm{P}$ NMR spectrum (Scheme 2.2).

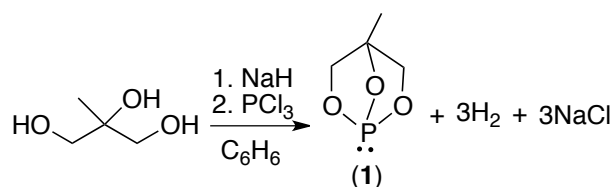

Scheme 2.2. Synthesis of $\mathrm{P}\left(\mathrm{OCH}_{2}\right)_{2}\left(\mathrm{OCCH}_{3}\right)$ (1).

\subsubsection{Synthesis and Characterization of $\mathrm{TpRu}(\mathrm{L})\left(\mathrm{PPh}_{3}\right) \mathrm{Cl}$ Complexes}

The addition of $\mathrm{TpRu}\left(\mathrm{PPh}_{3}\right)_{2} \mathrm{Cl}$ to a benzene solution of $\mathbf{1}$ followed by reflux results in the formation of $\mathrm{TpRu}\left[\mathrm{P}\left(\mathrm{OCH}_{2}\right)_{2}\left(\mathrm{OCCH}_{3}\right)\right]\left(\mathrm{PPh}_{3}\right) \mathrm{Cl}$ (2) (Scheme 2.3). For 2, the methylene hydrogen atoms are diastereotopic as indicated by three resonances (one missing due to coincidental overlap) due to the two $\mathrm{CH}_{2}$ groups $(3.93,3.45,3.50 \mathrm{ppm})$ with ${ }^{2} J_{\mathrm{HH}}=8 \mathrm{~Hz}$ and ${ }^{3} J_{\mathrm{HP}}$ between $8 \mathrm{~Hz}$ and $3.6 \mathrm{~Hz}$. Furthermore, a ${ }^{4} J_{\mathrm{HH}}$ of $1.4 \mathrm{~Hz}$ is observed for two of the methylene hydrogen atoms (Figure 2.4, Figure 2.5, Table 2.1). The observation of 9 unique $\mathrm{Tp}$ resonances is also consistent with an asymmetric complex. 


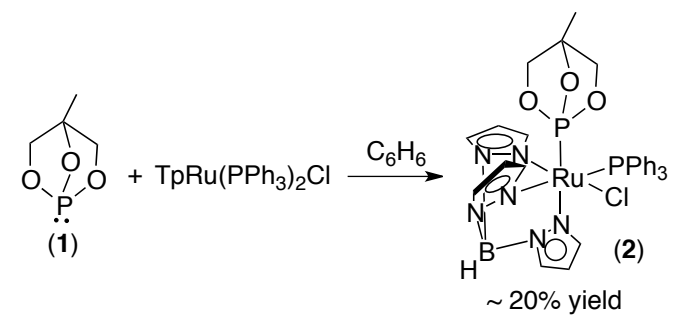

Scheme 2.3. Synthesis of $\mathrm{TpRu}\left[\mathrm{P}\left(\mathrm{OCH}_{2}\right)_{2}\left(\mathrm{OCCH}_{3}\right)\right]\left(\mathrm{PPh}_{3}\right) \mathrm{Cl}(\mathbf{2})$.

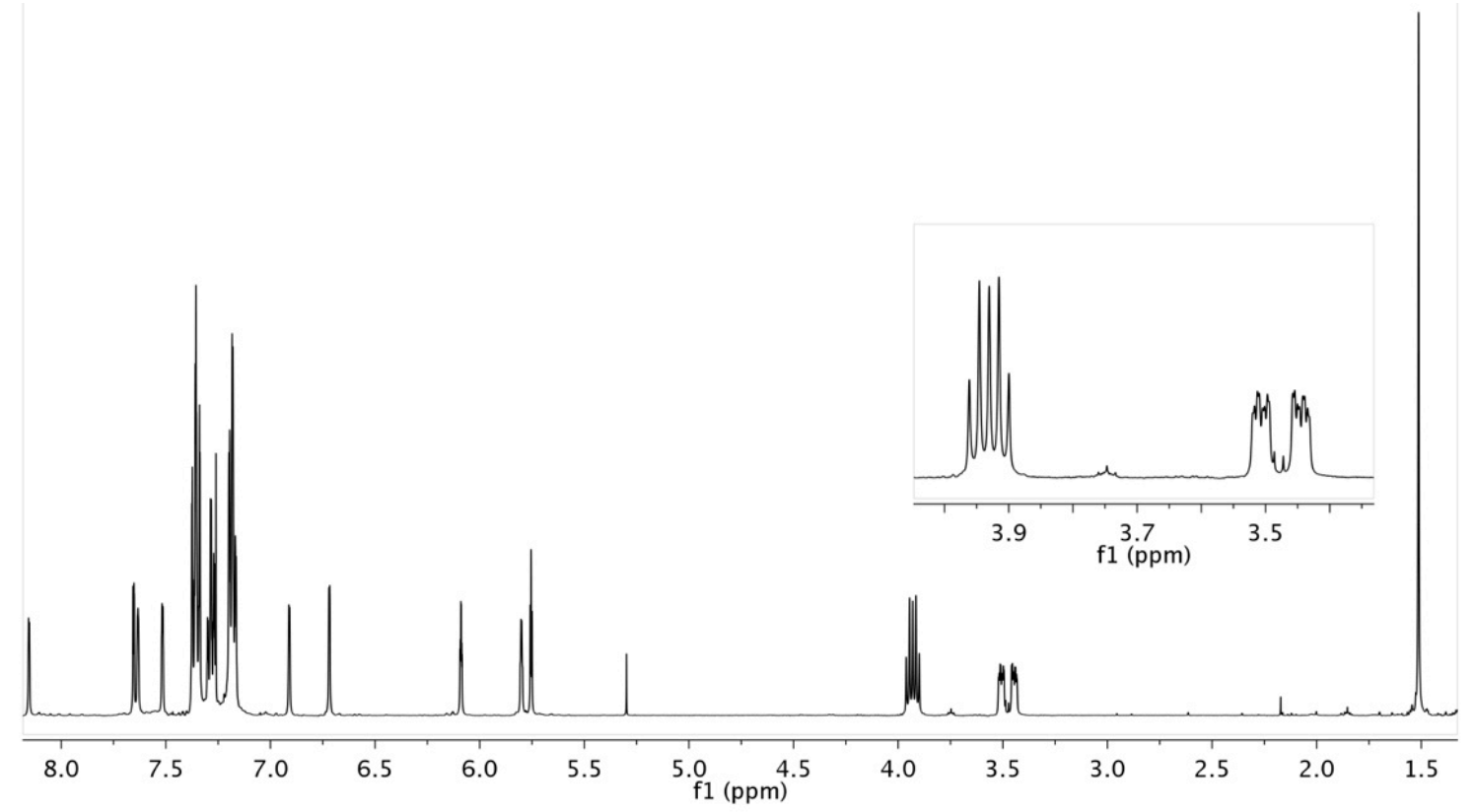

Figure 2.4. ${ }^{1} \mathrm{H}$ NMR spectrum of $\mathrm{TpRu}\left[\mathrm{P}\left(\mathrm{OCH}_{2}\right)_{2}\left(\mathrm{OCCH}_{3}\right)\right]\left(\mathrm{PPh}_{3}\right) \mathrm{Cl}(\mathbf{2})$ in $\mathrm{CDCl}_{3}$. 


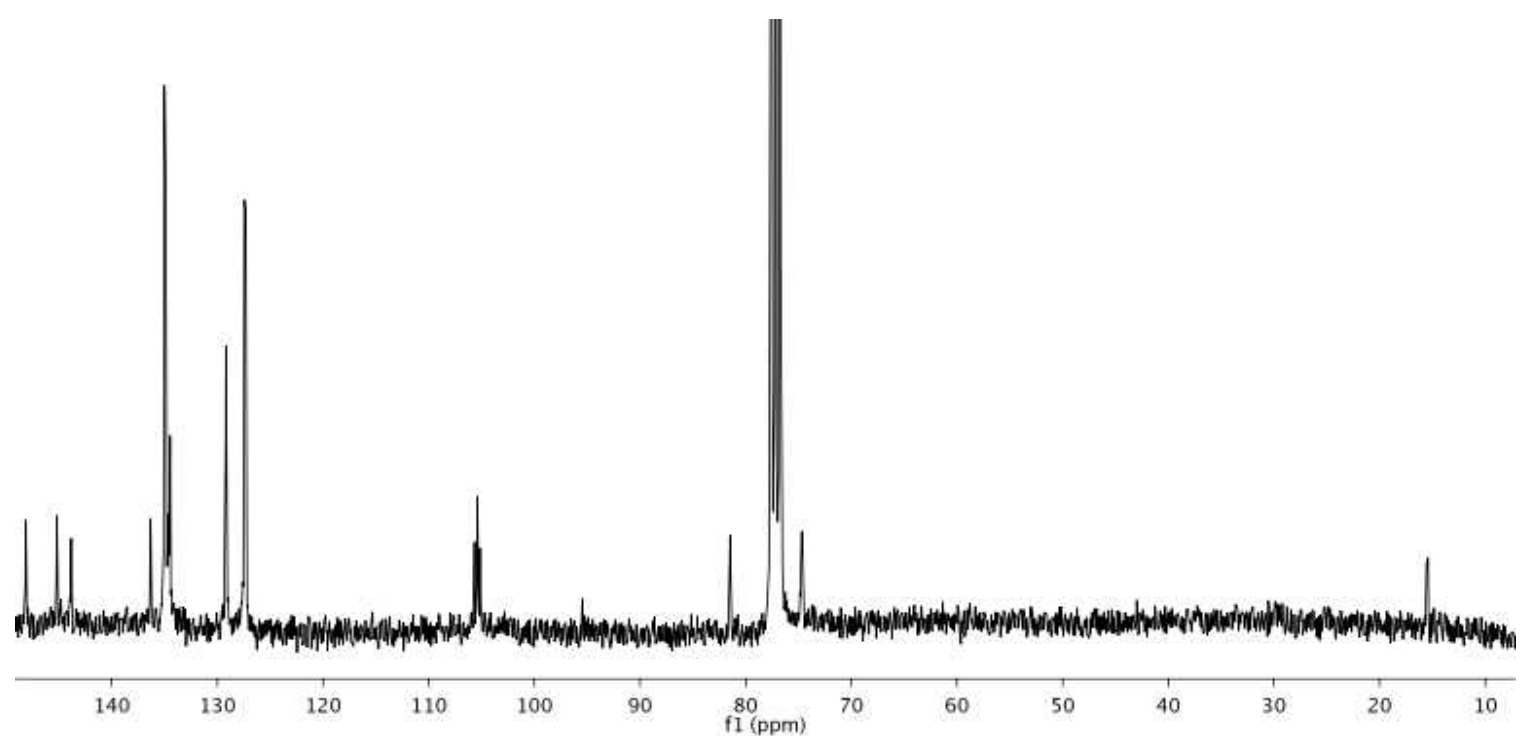

Figure 2.5. ${ }^{13} \mathrm{C}$ NMR spectrum of $\mathrm{TpRu}\left[\mathrm{P}\left(\mathrm{OCH}_{2}\right)_{2}\left(\mathrm{OCCH}_{3}\right)\right]\left(\mathrm{PPh}_{3}\right) \mathrm{Cl}(\mathbf{2})$ in $\mathrm{CDCl}_{3}$.

Table 2.1. Coupling constants observed for the $\mathrm{P}\left(\mathrm{OCH}_{2}\right)_{2}\left(\mathrm{OCCH}_{3}\right)$ ligand in the ${ }^{1} \mathrm{H}$ $\mathrm{NMR}$ spectrum of $\mathrm{TpRu}\left[\mathrm{P}\left(\mathrm{OCH}_{2}\right)_{2}\left(\mathrm{OCCH}_{3}\right)\right]\left(\mathrm{PPh}_{3}\right) \mathrm{Cl}(2)$.

\begin{tabular}{|c|c|c|c|c|}
\hline \multirow{5}{*}{ 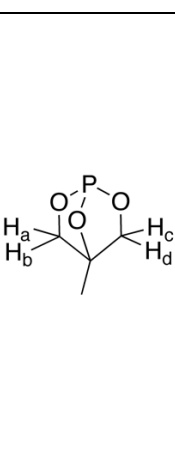 } & & ${ }^{2} J_{\mathrm{HH}}$ & ${ }^{3} J_{\mathrm{HP}}$ & ${ }^{4} J_{\mathrm{HH}}$ \\
\hline & $\mathrm{H}_{\mathrm{a}}$ & $8.0 \mathrm{~Hz}^{\mathrm{b}}$ & $8.0 \mathrm{~Hz}$ & $-^{\mathrm{a}}$ \\
\hline & $\mathrm{H}_{\mathrm{b}}$ & $8.0 \mathrm{~Hz}^{\mathrm{b}}$ & $3.6 \mathrm{~Hz}$ & $1.4 \mathrm{~Hz}$ \\
\hline & $\mathrm{H}_{\mathrm{c}}$ & $8.0 \mathrm{~Hz}$ & $8.0 \mathrm{~Hz}$ & $-^{a}$ \\
\hline & $\mathrm{H}_{\mathrm{d}}$ & $8.0 \mathrm{~Hz}$ & $3.6 \mathrm{~Hz}$ & $1.4 \mathrm{~Hz}$ \\
\hline
\end{tabular}

${ }^{a}$ A third coupling constant was not resolved for these resonances. ${ }^{\text {b } 2} J_{\mathrm{HaHb}}{ }^{\mathrm{c} 2} J_{\mathrm{HcHd}}$.

An X-ray diffraction study was performed on a crystal of complex 2 (Figure 2.6, Table 2.2). A search of the Cambridge Structural Database revealed no other examples of structures with phosphite 1. We have previously reported the structure of $\mathrm{TpRu}\left[\mathrm{P}\left(\mathrm{OCH}_{2}\right)_{3} \mathrm{CEt}\right]\left(\mathrm{PPh}_{3}\right) \mathrm{Cl}(\mathbf{3}){ }^{31}$ The Ru$-\mathrm{P}_{\text {phosphite }}$ bond lengths for complexes $\mathbf{2}$ and $\mathbf{3}$ 
are 2.191(1) $\AA$ and 2.2025(8) Å respectively. Thus, phosphite 1 exhibits a slightly shorter $\mathrm{Ru}-\mathrm{P}_{\text {phosphite }}$ bond distance than $\mathrm{P}\left(\mathrm{OCH}_{2}\right)_{3} \mathrm{CEt}$. The average $\mathrm{P}_{\text {phosphite }}-\mathrm{O}$ bond distance for complex 2 is $1.627(3) \AA$, whereas complex 3 has a shorter average $\mathrm{P}_{\text {phosphite }}-\mathrm{O}$ bond length of $1.605(2) \AA$. The longer $\mathrm{P}-\mathrm{O}$ bond distances for 1 [compared to $\mathrm{P}\left(\mathrm{OCH}_{2}\right)_{3} \mathrm{CEt}$ ] are anticipated if ligand $\mathbf{1}$ functions as a better $\pi$-acid than $\mathrm{P}\left(\mathrm{OCH}_{2}\right)_{3} \mathrm{CEt}$ and the dpbackbonding involves the $\mathrm{P}-\mathrm{O} \sigma^{*}$ orbitals. $^{1}$ Complex 2 exhibits one larger $\left[100.2(1)^{\circ}\right]$ and two smaller $\left[94.6(1)^{\circ}\right.$ and $\left.95.0(1)^{\circ}\right] \mathrm{O}-\mathrm{P}-\mathrm{O}$ bond angles. The $\mathrm{O} 2-\mathrm{P} 1-\mathrm{Ru}$ angle in complex 2 is $126.2(1)^{\circ}$, whereas the $\mathrm{O} 3-\mathrm{P} 1-\mathrm{Ru}$ and $\mathrm{O} 1-\mathrm{P} 1-\mathrm{Ru}$ angles are $116.80(1)^{\mathrm{o}}$ and $118.49(1)^{\mathrm{o}}$. The O3- $\mathrm{P}_{\text {phosphite }}-\mathrm{Ru}$ angles $\left[118.33(9)^{\mathrm{o}}, 113.34(9)^{\mathrm{o}}\right.$ and $\left.118.79(9)^{\mathrm{o}}\right]$ of $\mathbf{3}$ are similar to the same angles with $\mathrm{O} 1$ and $\mathrm{O} 3$ of complex 2 . For the $\mathrm{C}_{\text {phosphite }}-\mathrm{O}-\mathrm{P}_{\text {phosphite }}$ angles, complex 2 has one angle smaller than the other two $\left[97.5(2)^{\mathbf{o}}\right.$ vs. $107.3(2)^{\mathbf{o}}$ and $\left.107.4(2)^{\circ}\right]$. For complex 3, all the angles for $\mathrm{C}_{\text {phosphite }}-\mathrm{O}-\mathrm{P}_{\text {phosphite }}$ are similar at $116.9(2)^{\mathbf{o}}$, $115.8(2)^{\circ}$ and $116.5(2)^{\circ}$. Thus, the $\mathrm{C}_{\text {phosphite }}-\mathrm{O}-\mathrm{P}_{\text {phosphite }}$ angles of $\mathbf{2}$ are smaller than $\mathbf{3}$, which is consistent with a more pronounced "hinge" effect for $\mathbf{1}$ compared to $\mathrm{P}\left(\mathrm{OCH}_{2}\right)_{3} \mathrm{CEt}$. Cone angles were calculated from crystallographic data for the phosphite ligands of complexes 2 and $\mathbf{3}$. Using the $\mathrm{P} 1-\mathrm{Ru}-\mathrm{O}$ angles and the van der Waals radius for oxygen, the cone angle for complex 2 was determined to be $104^{\circ}$, whereas complex 3 is slightly larger at $108^{\circ}$ (Figure 2.7). Those cone angles cannot be directly compared to Tolman's published cone angles since the M-P bond length in the crystallographic data was not adjusted to be $2.28 \AA .^{14}$ The cone angle of $\mathrm{P}(\mathrm{OMe})_{3}$ is $107^{\circ}$. 


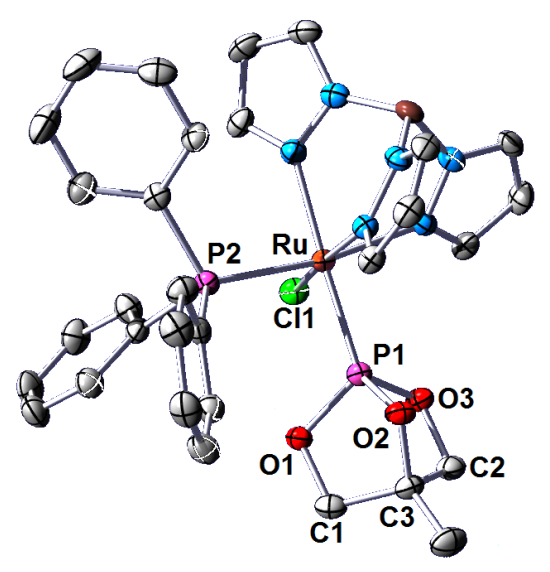

Figure 2.6. ORTEP of $\mathrm{TpRu}\left[\mathrm{P}\left(\mathrm{OCH}_{2}\right)_{2}\left(\mathrm{OCCH}_{3}\right)\right]\left(\mathrm{PPh}_{3}\right) \mathrm{Cl}(\mathbf{2})$ (50\% probability with hydrogen atoms omitted.). Selected bond lengths $(\AA)$ : Ru-P1, 2.191(1); Ru-P2, 2.342(1); $\mathrm{P}-\mathrm{O} 1,1.627(3)$; $\mathrm{P}-\mathrm{O} 2,1.632(3)$; $\mathrm{P}-\mathrm{O} 3,1.620(3)$. Selected bond angles $\left(^{\circ}\right)$ : $\mathrm{P} 1-\mathrm{Ru}-\mathrm{P} 2$, 94.1(4); O3-P1-O1, 100.2(1); O3-P1-O2, 94.6(1); O1-P1-O2, 95.0(1); O1-P1-Ru, 118.5(1); O2-P1-Ru, 126.2(1); O3-P1-Ru, 116.8(1); C1-O1-P1, 107.3(2); C3-O2-P1, 97.5(2); C2-O3-P1, 107.4(2).

Table 2.2. Selected Crystallographic Data for $\mathrm{TpRu}\left(\mathrm{PPh}_{3}\right)\left[\mathrm{P}\left(\mathrm{OCH}_{2}\right)_{2}\left(\mathrm{OCCH}_{3}\right)\right] \mathrm{Cl}$ (2), $\left(\eta^{6}-\mathrm{C}_{6} \mathrm{H}_{6}\right) \mathrm{Ru}\left[\mathrm{P}\left(\mathrm{OCH}_{2}\right)_{2}\left(\mathrm{OCCH}_{3}\right)\right] \mathrm{Cl}_{2}(\mathbf{1 1})$ and $\left(\eta^{6}-p\right.$-cymene $) \mathrm{Ru}\left[\mathrm{P}\left(\mathrm{OCH}_{2}\right)_{2}\left(\mathrm{OCCH}_{3}\right)\right.$ $\mathrm{Cl}_{2}(\mathbf{1 2})$.

\begin{tabular}{|c|c|c|c|}
\hline & complex $\mathbf{2} \cdot \mathrm{CH}_{2} \mathrm{Cl}_{2}$ & complex $11 \bullet\left(\mathrm{CHCl}_{3}\right)_{2}$ & complex $12 \cdot\left(\mathrm{CH}_{2} \mathrm{Cl}_{2}\right)_{2}$ \\
\hline empirical formula & $\mathrm{C}_{32} \mathrm{H}_{34} \mathrm{BCl}_{3} \mathrm{~N}_{6} \mathrm{O}_{3} \mathrm{P}_{2} \mathrm{Ru}$ & $\mathrm{C}_{12} \mathrm{H}_{15} \mathrm{Cl}_{8} \mathrm{O}_{3} \mathrm{PRu}$ & $\mathrm{C}_{18} \mathrm{H}_{29} \mathrm{Cl}_{6} \mathrm{O}_{3} \mathrm{PRu}$ \\
\hline Fw & 830.82 & 622.88 & 638.15 \\
\hline cryst syst & monoclinic & monoclinic & monoclinic \\
\hline space group & $P 2_{1} / \mathrm{c}$ & $P 2_{1} / \mathrm{c}$ & $P 2_{1} / \mathrm{n}$ \\
\hline $\mathrm{a}, \AA$ & $14.5126(3)$ & $10.219(1)$ & $10.7611(3)$ \\
\hline $\mathrm{b}, \AA$ & $13.5883(3)$ & $10.518(1)$ & $10.4473(3)$ \\
\hline $\mathrm{c}, \AA$ & $17.8390(4)$ & $20.162(2)$ & $22.4999(6)$ \\
\hline $\mathrm{b}, \mathrm{deg}$ & $93.643(1)$ & $99.416(1)$ & $99.312(1)$ \\
\hline $\mathrm{V}, \AA^{3}$ & $3510.8(1)$ & $2137.9(4)$ & $2496.2(1)$ \\
\hline $\mathrm{Z}$ & 4 & 4 & 4 \\
\hline $\mathrm{D}_{\text {calcd }}, \mathrm{mg} / \mathrm{m}^{3}$ & 1.572 & 1.935 & 1.698 \\
\hline $\mathrm{R} 1, \mathrm{wR} 2(\mathrm{I}>2(\mathrm{I}))$ & $0.0346,0.0994$ & $0.0492,0.1298$ & $0.0253,0.0965$ \\
\hline GOF & 0.833 & 1.056 & 0.863 \\
\hline
\end{tabular}




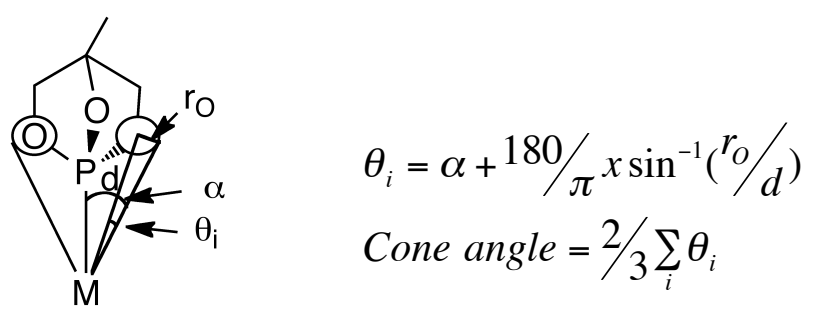

Figure 2.7. Calculation of cone angles using crystallographic data. ${ }^{14}$

In addition to 2 and 3, TpRu( $\left.\mathrm{PMe}_{3}\right)\left(\mathrm{PPh}_{3}\right) \mathrm{Cl}(\mathbf{4})$ and $\mathrm{TpRu}\left[\mathrm{P}(\mathrm{OMe})_{3}\right]\left(\mathrm{PPh}_{3}\right) \mathrm{Cl}$ (5). ${ }^{38} \mathrm{TpRu}\left[\mathrm{P}(\mathrm{OMe})_{3}\right]\left(\mathrm{PPh}_{3}\right)(\mathbf{5})$ were synthesized and isolated in the same manner as complexes 2 and 3 by refluxing in $\mathrm{C}_{6} \mathrm{H}_{6}$. The ${ }^{1} \mathrm{H}$ NMR spectrum shows a doublet at 3.24 ppm with a coupling constant of ${ }^{3} J_{\mathrm{HP}}=10.3 \mathrm{~Hz}$ for the coordinated $\mathrm{P}(\mathrm{OMe})_{3}$ ligand (Figure 2.8, Figure 2.9). The relative donor-ability of 1 [compared to $\mathrm{PMe}_{3}, \mathrm{P}(\mathrm{OMe})_{3}$ and $\left.\mathrm{P}\left(\mathrm{OCH}_{2}\right)_{3} \mathrm{CEt}\right]$ was probed by comparing the $\mathrm{Ru}(\mathrm{III} / \mathrm{II})$ redox potentials of $\mathrm{TpRu}(\mathrm{L})\left(\mathrm{PPh}_{3}\right) \mathrm{Cl} \quad\left[\mathrm{L}=\mathrm{P}\left(\mathrm{OCH}_{2}\right)_{2}\left(\mathrm{OCCH}_{3}\right)\right.$ (2), $\mathrm{P}\left(\mathrm{OCH}_{2}\right)_{3} \mathrm{CEt}$ (3), $\mathrm{PMe}_{3}$ (4) and $\left.\mathrm{P}(\mathrm{OMe})_{3}(\mathbf{5})\right]$ complexes (Table 2.3). ${ }^{31,38}$ The $\mathrm{Ru}(\mathrm{III} / \mathrm{II})$ potentials indicate the following trend in overall donor ability: $\mathrm{PMe}_{3}>\mathrm{P}(\mathrm{OMe})_{3}>\mathrm{P}\left(\mathrm{OCH}_{2}\right)_{3} \mathrm{CEt}>1$. The $\mathrm{Ru}(\mathrm{III} / \mathrm{II})$ potentials of complexes $\mathbf{2}$ and $\mathbf{3}$ differ by $0.13 \mathrm{~V}(1.08 \mathrm{~V}$ and $0.95 \mathrm{~V}$, respectively) with the potential of $\mathbf{2}$ positive compared to the potential of $\mathbf{3}$, thus supporting the hypothesis that ligand $\mathbf{1}$ is less donating overall than $\mathrm{P}\left(\mathrm{OCH}_{2}\right)_{3} \mathrm{CEt}$. 


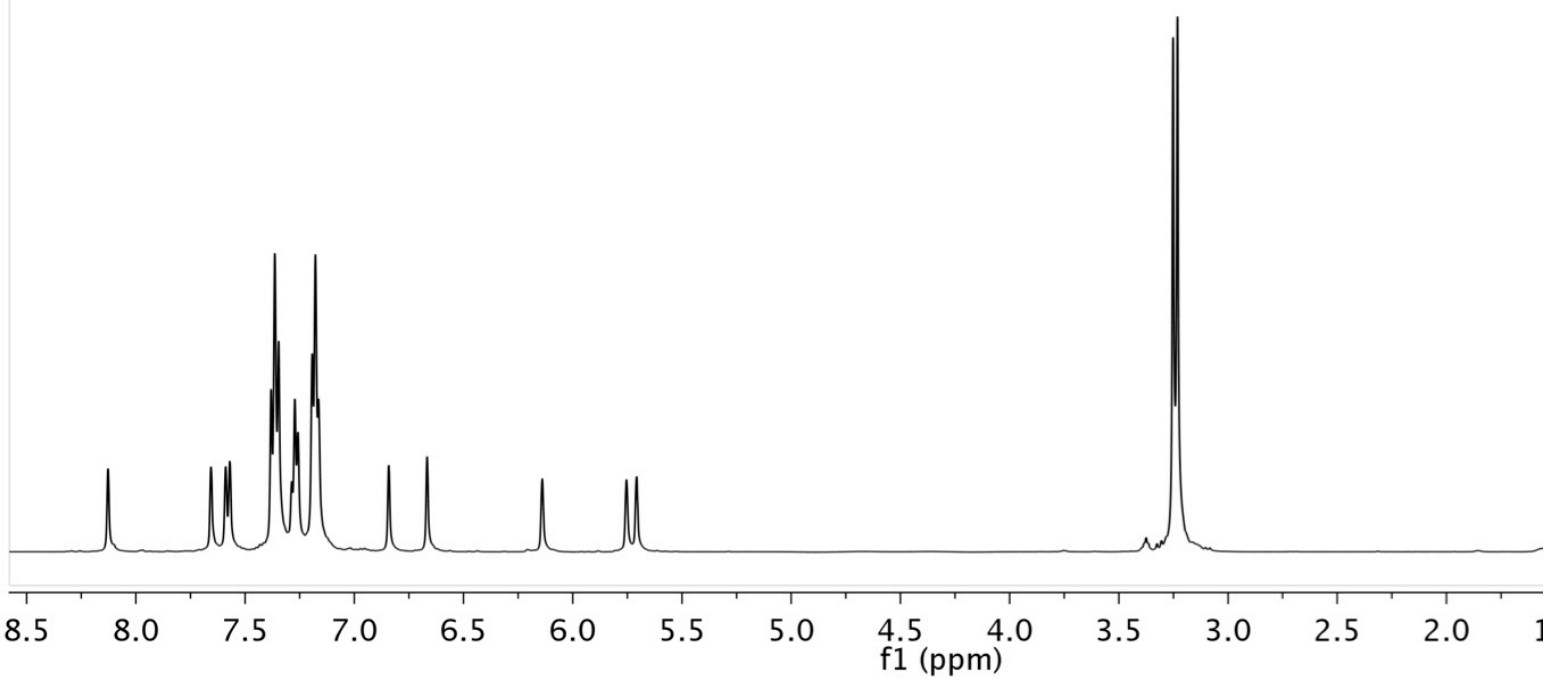

Figure 2.8. ${ }^{1} \mathrm{H} \mathrm{NMR}$ spectrum of $\mathrm{TpRu}\left[\mathrm{P}(\mathrm{OMe})_{3}\right]\left(\mathrm{PPh}_{3}\right) \mathrm{Cl}(\mathbf{5})$ in $\mathrm{CDCl}_{3}$.

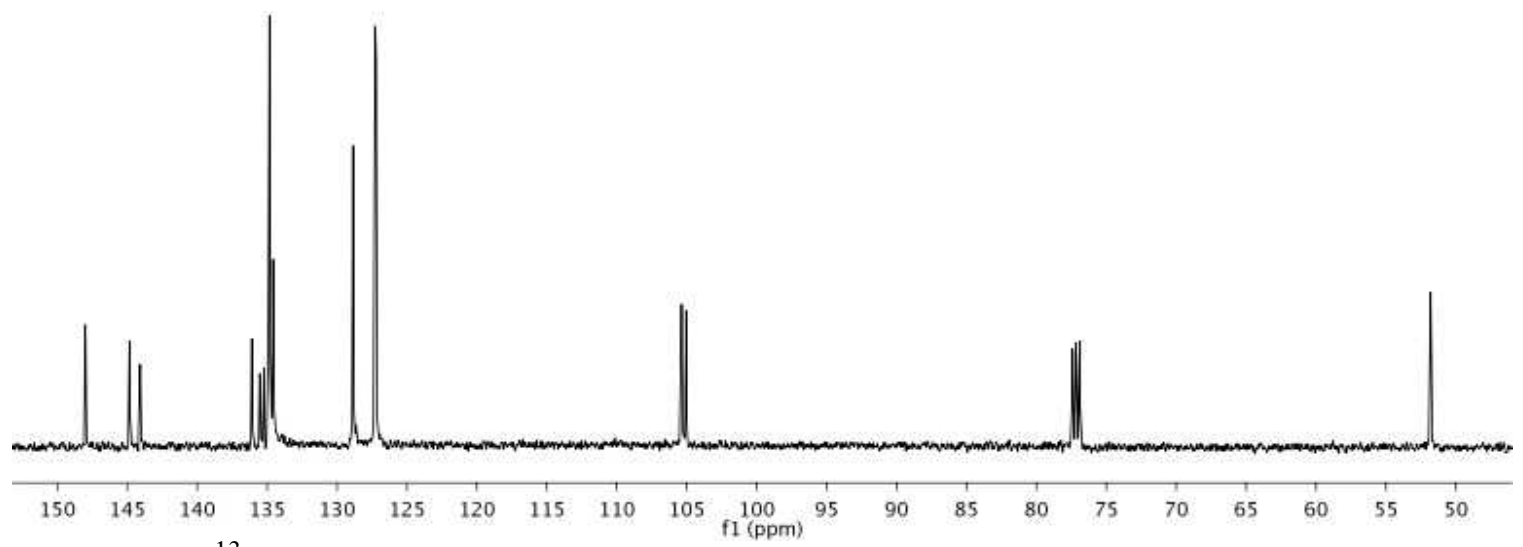

Figure 2.9. ${ }^{13} \mathrm{C} \mathrm{NMR}$ spectrum of $\mathrm{TpRu}\left[\mathrm{P}(\mathrm{OMe})_{3}\right]\left(\mathrm{PPh}_{3}\right) \mathrm{Cl}(\mathbf{5})$ in $\mathrm{CDCl}_{3}$.

Table 2.3. $\mathrm{Ru}(\mathrm{III} / \mathrm{II})$ potentials for $\mathrm{TpRu}(\mathrm{L})\left(\mathrm{PPh}_{3}\right) \mathrm{Cl}$ complexes. Data from cyclic voltammetry in NCMe with reversible potentials $\left(\mathrm{E}_{1 / 2}\right)$ reported vs NHE (in V).

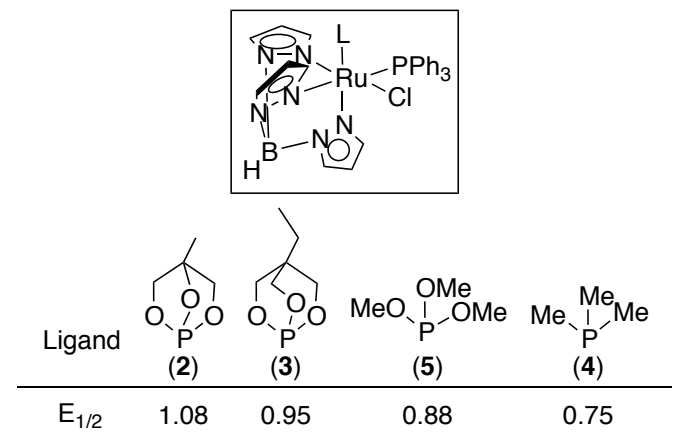




\subsubsection{Synthesis and Characterization $\left(\eta^{6}-\mathrm{C}_{6} \mathrm{H}_{6}\right) \mathrm{Ru}(\mathrm{L}) \mathrm{Cl}_{2}$ Complexes}

To gain further insight into the donor ability of $\mathbf{1}$, we prepared a series of $\left(\eta^{6}-\right.$ $\left.\mathrm{C}_{6} \mathrm{H}_{6}\right) \mathrm{Ru}(\mathrm{L}) \mathrm{Cl}_{2}$ complexes $\left[\mathrm{L}=\mathrm{PPh}_{3}(6), \mathrm{P}(\mathrm{OMe})_{3}(7), \mathrm{PMe}_{3}(8), \mathrm{P}\left(\mathrm{OCH}_{2}\right)_{3} \mathrm{CEt}(\mathbf{9}), \mathrm{CO}\right.$ (10) and $\mathrm{P}\left(\mathrm{OCH}_{2}\right)_{2}\left(\mathrm{OCCH}_{3}\right)$ (11)]. ${ }^{39-45}$ Our main reasons for selecting this ligand set are the literature precedent and the ease of synthesis. The syntheses of complexes $\mathbf{6 , 7}$ and $\mathbf{1 0}$ have been previously reported. ${ }^{39,40}$ Complexes $\mathbf{8 ,} \mathbf{9}$ and $\mathbf{1 1}$ were synthesized by stirring commercially available $\left[\left(\eta^{6}-\mathrm{C}_{6} \mathrm{H}_{6}\right) \mathrm{Ru}(\mathrm{Cl})(\mu-\mathrm{Cl})\right]_{2}$ with excess $\mathrm{L}$ in dichloromethane (Scheme 2.4). ${ }^{1} \mathrm{H}$ NMR spectroscopy of $\left(\eta^{6}-\mathrm{C}_{6} \mathrm{H}_{6}\right) \mathrm{Ru}\left(\mathrm{PMe}_{3}\right) \mathrm{Cl}_{2}(\mathbf{8})$ shows a singlet for the $\eta^{6}$-coordinated benzene and a distinct doublet at $1.65 \mathrm{ppm}$ with a ${ }^{2} J_{\mathrm{HP}}$ of $11.4 \mathrm{~Hz}$ for $\mathrm{PMe}_{3}$ (Figure 2.10, Figure 2.11). Complex 9 differs from complexes $\mathbf{8}$ and $\mathbf{1 1}$ in that it lacks solubility in dichloromethane and thus precipates during synthesis. Similar to

complex 8, the ${ }^{1} \mathrm{H}$ NMR spectrum of $\left(\eta^{6}-\mathrm{C}_{6} \mathrm{H}_{6}\right) \mathrm{Ru}\left[\mathrm{P}\left(\mathrm{OCH}_{2}\right)_{3} \mathrm{CEt}\right] \mathrm{Cl}_{2}(\mathbf{9})$ has a singlet for the coordinated $\eta^{6}$-benzene. A doublet is also observed for the methylene groups of the phosphite, with the ethyl-tail of the phosphite, $\mathrm{P}\left(\mathrm{OCH}_{2}\right)_{3} \mathrm{CEt}$, giving the characteristic quartet and triplet (Figure 2.12, Figure 2.13). The ${ }^{1} \mathrm{H}$ NMR spectrum of complex 11 shows a singlet for coordinated $\eta^{6}$-benzene. Additionally, the methylene hydrogen atoms of the phosphite are diastereotopic, similar to complex 2, and give us two distinct resonances, a triplet and a doublet; while a singlet is observed for the methyl group (Figure 2.14, Figure 2.15). 


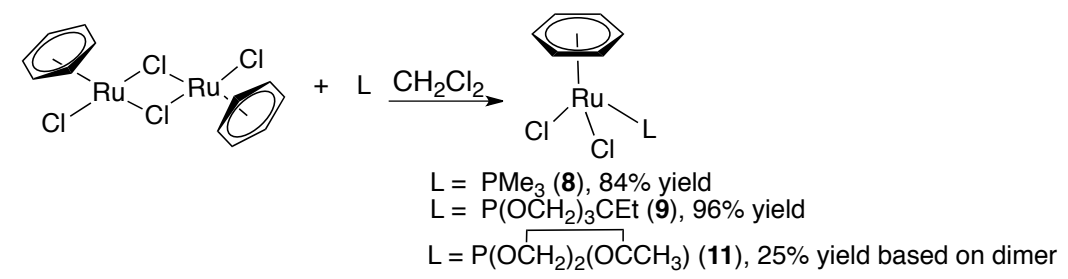

Scheme 2.4. Synthesis of $\left(\eta^{6}-\mathrm{C}_{6} \mathrm{H}_{6}\right) \mathrm{Ru}(\mathrm{L}) \mathrm{Cl}_{2}$ (L $=\mathrm{PMe}_{3}, \mathrm{P}\left(\mathrm{OCH}_{2}\right)_{3} \mathrm{CEt}$ and $\left.\mathrm{P}\left(\mathrm{OCH}_{2}\right)_{2}\left(\mathrm{OCCH}_{3}\right)\right]$.

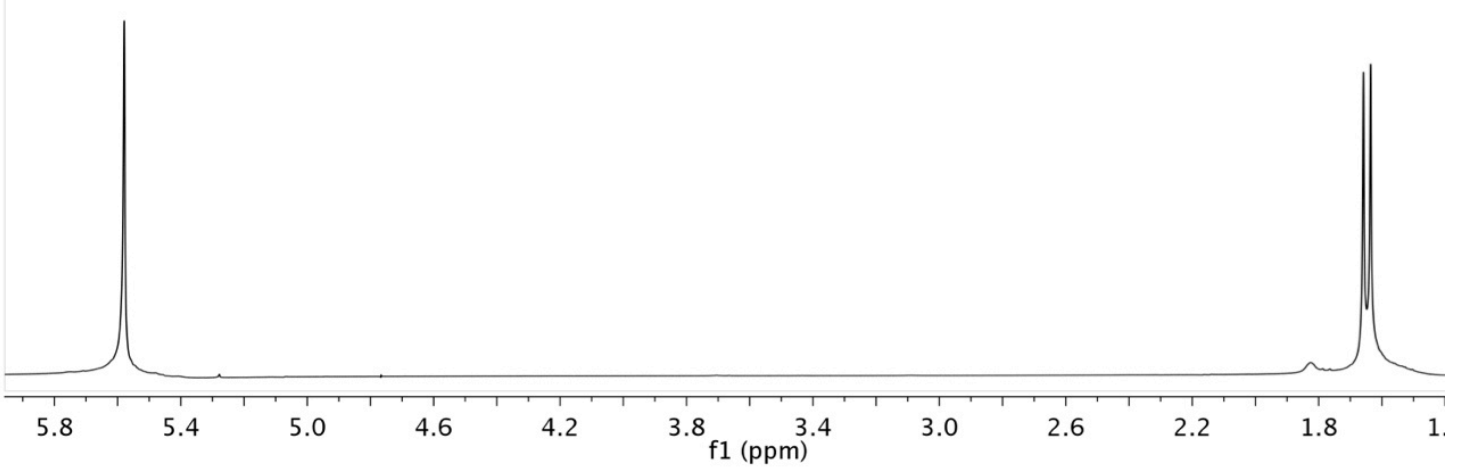

Figure 2.10. ${ }^{1} \mathrm{H}$ NMR spectrum of $\left(\eta^{6}-\mathrm{C}_{6} \mathrm{H}_{6}\right) \mathrm{Ru}\left(\mathrm{PMe}_{3}\right) \mathrm{Cl}_{2}(\mathbf{8})$ in $\mathrm{CDCl}_{3}$.

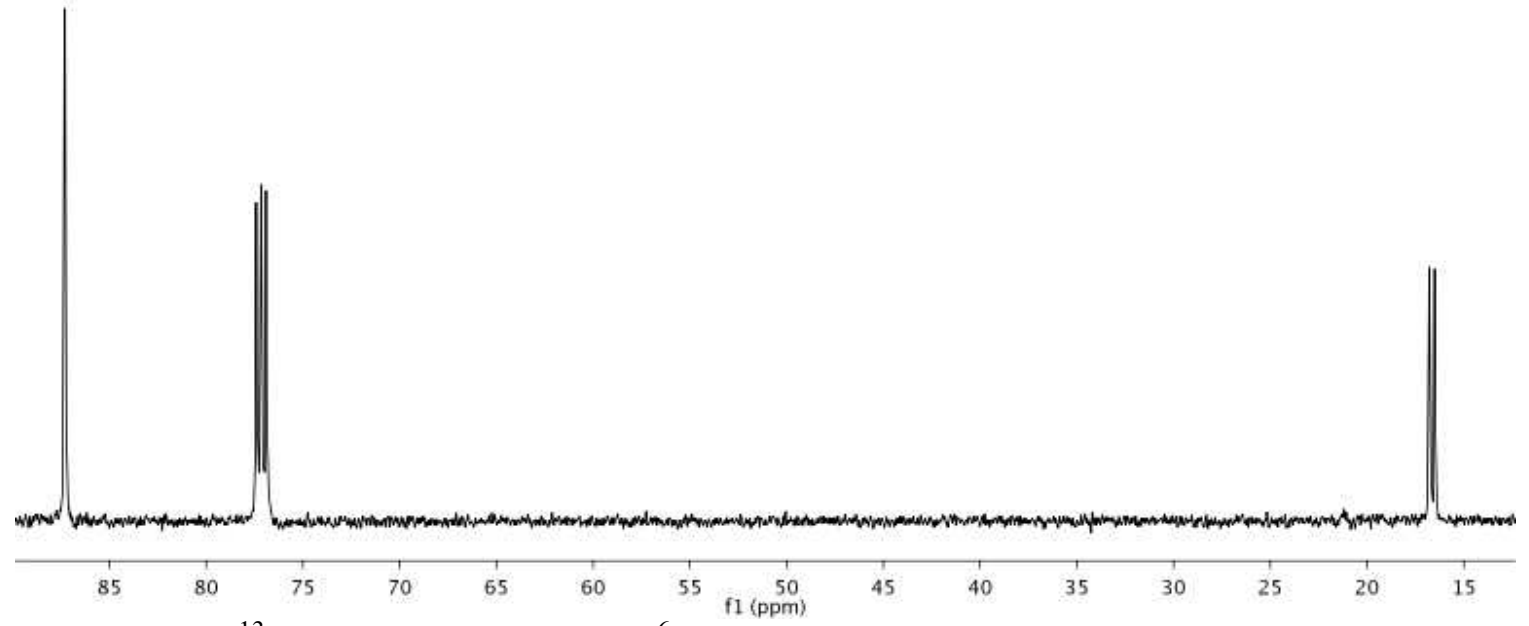

Figure 2.11. ${ }^{13} \mathrm{C}$ NMR spectrum of $\left(\eta^{6}-\mathrm{C}_{6} \mathrm{H}_{6}\right) \mathrm{Ru}\left(\mathrm{PMe}_{3}\right) \mathrm{Cl}_{2}(\mathbf{8})$ in $\mathrm{CDCl}_{3}$. 


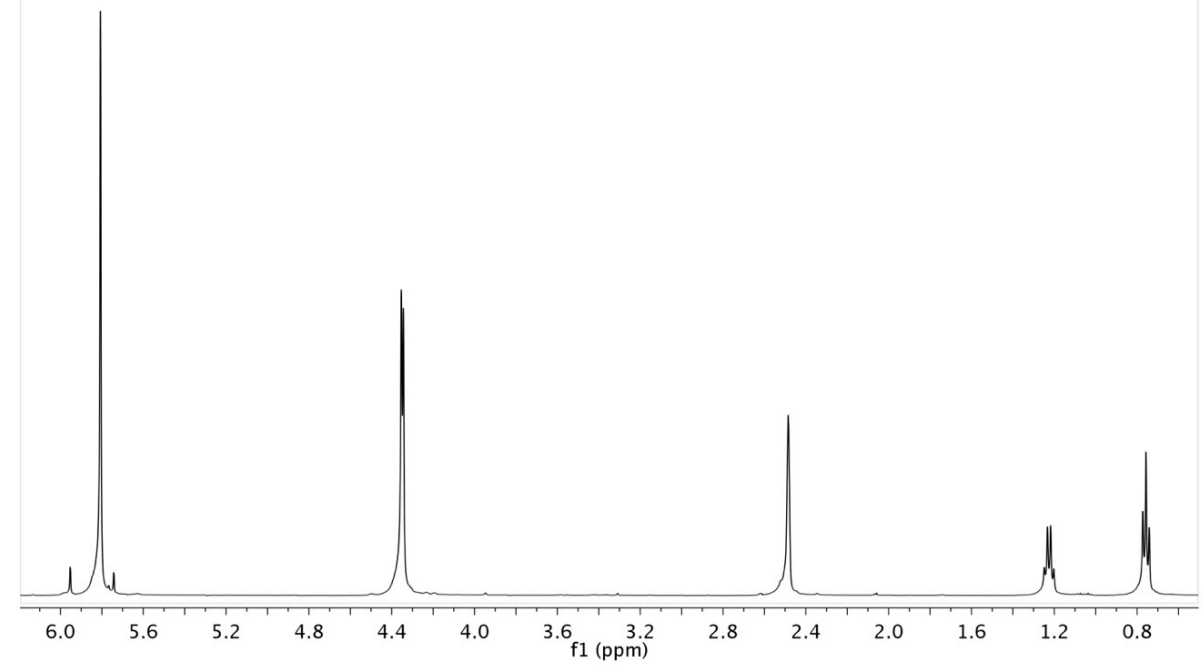

Figure 2.12. ${ }^{1} \mathrm{H}$ NMR spectrum of $\left(\eta^{6}-\mathrm{C}_{6} \mathrm{H}_{6}\right) \mathrm{Ru}\left[\mathrm{P}\left(\mathrm{OCH}_{2}\right)_{3} \mathrm{CEt}\right] \mathrm{Cl}_{2}(9)$ in DMSO.

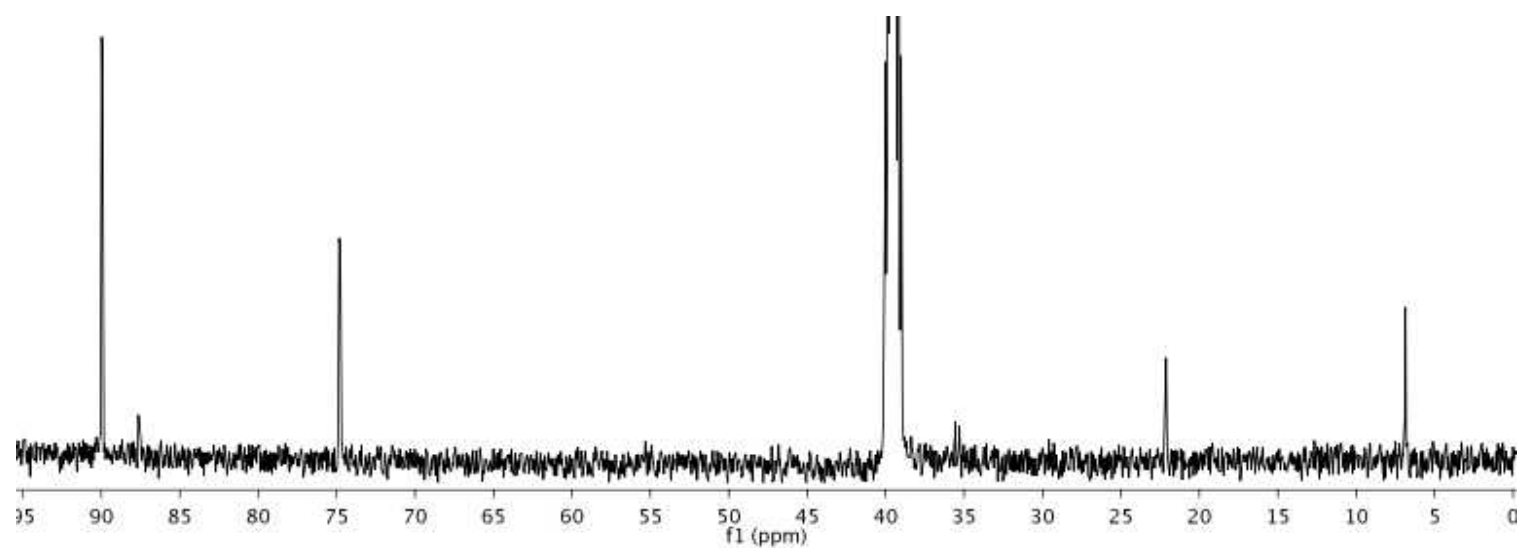

Figure 2.13. ${ }^{13} \mathrm{C}$ NMR spectrum of $\left(\eta^{6}-\mathrm{C}_{6} \mathrm{H}_{6}\right) \mathrm{Ru}\left[\mathrm{P}\left(\mathrm{OCH}_{2}\right)_{3} \mathrm{CEt}\right] \mathrm{Cl}_{2}(9)$ in DMSO. 


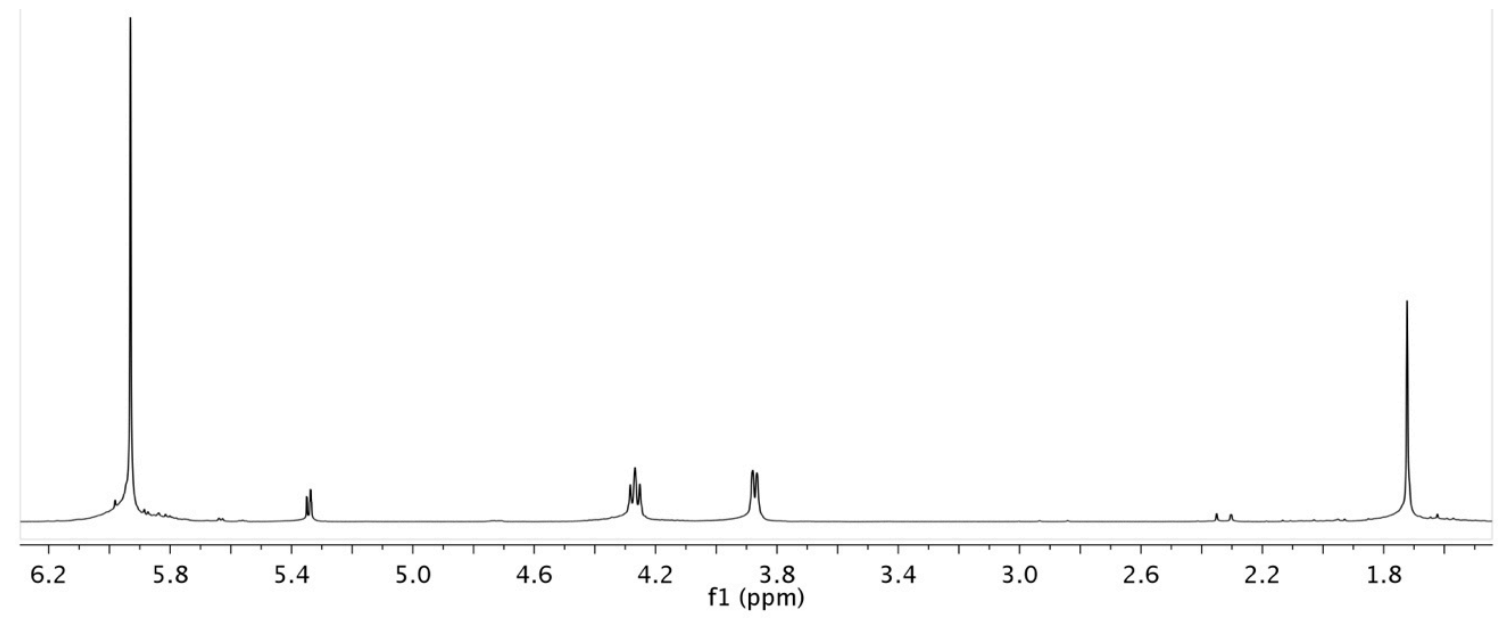

Figure 2.14. ${ }^{1} \mathrm{H}$ NMR spectrum of $\left(\eta^{6}-\mathrm{C}_{6} \mathrm{H}_{6}\right) \mathrm{Ru}\left[\mathrm{P}(\stackrel{\mathrm{OCH}}{2})_{2}\left(\mathrm{OCCH}_{3}\right)\right] \mathrm{Cl}_{2}(\mathbf{1 1})$ in $\mathrm{CD}_{2} \mathrm{Cl}_{2}$.

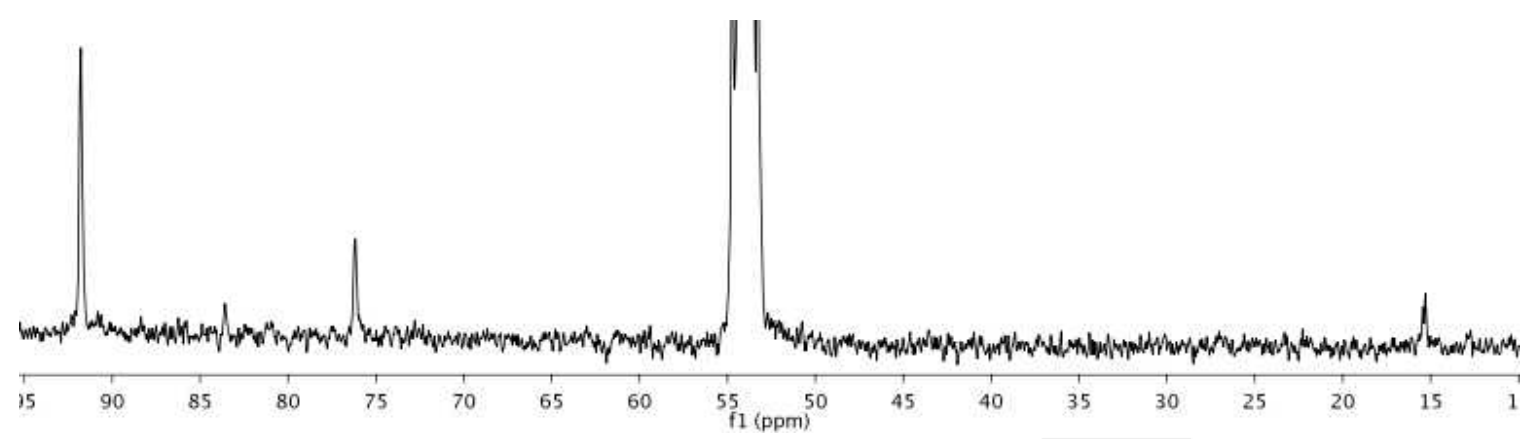

Figure 2.15. ${ }^{13} \mathrm{C}$ NMR spectrum of $\left(\eta^{6}-\mathrm{C}_{6} \mathrm{H}_{6}\right) \mathrm{Ru}\left[\mathrm{P}\left(\mathrm{OCH}_{2}\right)_{2}\left(\mathrm{OCCH}_{3}\right)\right] \mathrm{Cl}_{2}$ (11) in $\mathrm{CD}_{2} \mathrm{Cl}_{2}$.

A single crystal of $\mathbf{1 1}$ suitable for an X-ray diffraction study was grown (Figure 2.16). The phosphite ligand of $\mathbf{1 1}$ has features that are similar to complex $\mathbf{2}$. For example, there are one larger $\left[102.5(1)^{\circ}\right]$ and two smaller $\left[95.77(9)^{\circ}\right.$ and $\left.96.38(1)^{\circ}\right] \mathrm{O}-\mathrm{P}-\mathrm{O}$ bond angles which is a consequence of the removal of the methylene group from one of the tethered arms. The C3-O1-P1 angle $\left[96.89(1)^{\circ}\right]$ is substantially smaller by approximately $10^{\circ}$ than the other two C-O-P angles, which are $106^{\circ}$. The cone angle of 
$\mathrm{P}\left(\mathrm{OCH}_{2}\right)_{2}\left(\mathrm{OCCH}_{3}\right)$ calculated from the structure of complex $\mathbf{1 1}$ is $104^{\circ}$, which is identical to that determined using the structure of complex 2. The average $\mathrm{P}-\mathrm{O}$ bond distances for $\mathbf{1 1}[1.613(2) \AA]$ are longer than those for the $\mathrm{P}\left(\mathrm{OCH}_{2}\right)_{3} \mathrm{CEt}$ complex $\mathbf{3}$ [1.605(2) $\AA]$, but not as long as those of complex 2 [1.627(3) $\AA$ ]. Table 2.4 shows some comparative geometric data of complexes 2,11 and the previously reported complex ( $\eta^{6}-$ $\left.\mathrm{C}_{6} \mathrm{H}_{6}\right) \mathrm{Ru}\left[\mathrm{P}(\mathrm{OMe})_{3}\right] \mathrm{Cl}_{2}(7){ }^{41}$

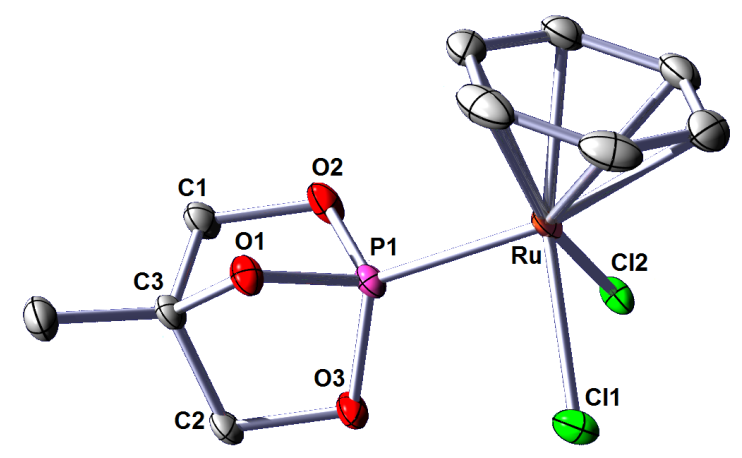

Figure 2.16. ORTEP diagram of $\left(\eta^{6}-\mathrm{C}_{6} \mathrm{H}_{6}\right) \mathrm{Ru}\left[\mathrm{P}\left(\mathrm{OCH}_{2}\right)_{2}\left(\mathrm{OCCH}_{3}\right)\right] \mathrm{Cl}_{2} \quad$ (11) $\quad(50 \%$ probability with hydrogen atoms omitted.) Selected bond lengths ( $\AA$ ): Ru-P1, 2.2453(7); $\mathrm{P} 1-\mathrm{O} 1,1.615(2)$; P1-O2, 1.616(2), P1-O3, 1.607(2); Avg. $\mathrm{C}_{(\mathrm{C} 6 \mathrm{H} 6)}-\mathrm{Ru}, 2.198(1)$. Selected bond angles $\left({ }^{\circ}\right)$ : O1-P1-O2, 95.77(9); O3-P1-O1, 96.38(1); O3-P1-O2 102.5(1); $\mathrm{Cl1}-\mathrm{Ru}-\mathrm{Cl} 2$, 87.33(2); $\mathrm{P} 1-\mathrm{Ru}-\mathrm{Cl1}$, 88.66(2); $\mathrm{P} 1-\mathrm{Ru}-\mathrm{Cl} 2$, 84.03(2); C3-O1P1 96.89(1); C1-O2-P1 106.58(1); C2-O3-P1 106.24(1). 
Table 2.4. Selected bond lengths and angles comparing $\mathrm{TpRu}\left[\mathrm{P}\left(\mathrm{OCH}_{2}\right)_{2}\left(\mathrm{OCCH}_{3}\right)\right.$ ]$\left(\mathrm{PPh}_{3}\right) \mathrm{Cl}(\mathbf{2}),\left(\eta^{6}-\mathrm{C}_{6} \mathrm{H}_{6}\right) \mathrm{Ru}\left(\mathrm{PMe}_{3}\right) \mathrm{Cl}_{2}(\mathbf{7})$ and $\left(\eta^{6}-\mathrm{C}_{6} \mathrm{H}_{6}\right) \mathrm{Ru}\left[\mathrm{P}\left(\mathrm{OCH}_{2}\right)_{2}\left(\mathrm{OCCH}_{3}\right)\right] \mathrm{Cl}_{2}(\mathbf{1 1})$. The structure of 7 has been previously reported. ${ }^{41}$

\begin{tabular}{|c|l|l|l|l|}
\hline Complex & $\mathrm{O}-\mathrm{P}-\mathrm{O}\left({ }^{\circ}\right)$ & $\mathrm{C}-\mathrm{O}-\mathrm{P}\left(^{\circ}\right)$ & $\mathrm{O}-\mathrm{P}-\mathrm{Ru}\left({ }^{\circ}\right)$ & $\mathrm{P}-\mathrm{O}(\AA)$ \\
\hline $\mathbf{2}$ & $100.2(1)$ & $97.5(2)$ & $118.5(1)$ & $1.627(3)$ \\
& $94.6(1)$ & $107.3(2)$ & $126.2(1)$ & $1.632(3)$ \\
& $95.0(1)$ & $107.4(2)$ & $116.8(1)$ & $1.620(3)$ \\
\hline $\mathbf{7}$ & $107.0(2)$ & $123.1(3)$ & $111.2(1)$ & $1.565(3)$ \\
& $98.7(2)$ & $131.4(3)$ & $123.4(1)$ & $1.569(3)$ \\
& $97.5(2)$ & $119.4(3)$ & $115.7(1)$ & $1.594(3)$ \\
\hline $\mathbf{1 1}$ & $102.5(1)$ & $96.89(1)$ & $121.20(7)$ & $1.615(2)$ \\
& $95.77(9)$ & $106.58(1)$ & $120.98(6)$ & $1.616(2)$ \\
& $96.38(1)$ & $106.24(1)$ & $115.31(8)$ & $1.607(2)$ \\
\hline
\end{tabular}

The $\left(\eta^{6}-\mathrm{C}_{6} \mathrm{H}_{6}\right) \mathrm{Ru}(\mathrm{L}) \mathrm{Cl}_{2}$ complexes were studied using cyclic voltammetry to determine if a similar trend observed for the $\mathrm{TpRu}(\mathrm{L})\left(\mathrm{PPh}_{3}\right) \mathrm{Cl}$ complexes held true for a broader range of phosphites/phosphines with the metal center containing $\mathrm{P}\left(\mathrm{OCH}_{2}\right)_{2}\left(\mathrm{OCCH}_{3}\right)$ is the least electron rich. For $\left(\eta^{6}-\mathrm{C}_{6} \mathrm{H}_{6}\right) \mathrm{Ru}^{\text {II }}$ complexes, irreversible $\mathrm{Ru}(\mathrm{III} / \mathrm{II})$ potentials are often observed (Table 2.4), possibly due to dissociation of the benzene ligand in the oxidized $\mathrm{Ru}(\mathrm{III})$ state. ${ }^{44}$ For the $\left(\eta^{6}-\mathrm{C}_{6} \mathrm{H}_{6}\right) \mathrm{Ru}(\mathrm{L}) \mathrm{Cl}_{2}$ complexes studied herein, some complexes exhibit quasi-reversible $\mathrm{Ru}(\mathrm{III} / \mathrm{II})$ potentials while others have chemically irreversible potentials. In order to standardize comparisons, we use $\mathrm{E}_{\mathrm{p}, \mathrm{a}}$ and $\mathrm{E}_{\mathrm{p}, \mathrm{c}}$ in the discussions below. The carbonyl complex $\left(\eta^{6}-\mathrm{C}_{6} \mathrm{H}_{6}\right) \mathrm{Ru}(\mathrm{CO}) \mathrm{Cl}_{2}(\mathbf{1 0})$, with $E_{p, a}=+1.78 \mathrm{~V}$ (vs NHE), was used as a benchmark to compare the donor ability of $\mathbf{1}$ because of the known strong $\pi$-acidity of the CO ligand. The $\mathrm{E}_{\mathrm{p}, \mathrm{a}}$ for complex $11(1.50 \mathrm{~V})$ is $0.28 \mathrm{~V}$ more negative than the $\mathrm{E}_{\mathrm{p}, \mathrm{a}}$ for the $\mathrm{CO}$ complex $\mathbf{1 0}$, indicating that the phosphite 1 is more donating than $\mathrm{CO}$. Consistent with the $\mathrm{TpRu}(\mathrm{L})\left(\mathrm{PPh}_{3}\right) \mathrm{Cl}$ complexes, 
the $\mathrm{Ru}(\mathrm{III} / \mathrm{II})$ potentials for the $\left(\eta^{6}-\mathrm{C}_{6} \mathrm{H}_{6}\right) \mathrm{Ru}(\mathrm{L}) \mathrm{Cl}_{2}$ complexes indicate the following trend in overall donating ability: $\mathrm{PMe}_{3}\left(\right.$ complex 8) $>\mathrm{P}(\mathrm{OMe})_{3}($ complex 7) $>$ $\mathrm{P}\left(\mathrm{OCH}_{2}\right)_{3} \mathrm{CEt}($ complex 6$) \approx \mathrm{PPh}_{3}\left(\right.$ complex 9) $>\mathrm{P}\left(\mathrm{OCH}_{2}\right)_{2}\left(\mathrm{OCCH}_{3}\right)($ complex 11) $>\mathrm{CO}$ (complex 10). Of the phosphines and phosphites studied, complex 11 yields a metal center with the most positive potential with $\mathrm{E}_{\mathrm{p}, \mathrm{a}}=1.50 \mathrm{~V}$.

Table 2.4. $\mathrm{Ru}(\mathrm{III} / \mathrm{II})$ potentials for $\left(\eta^{6}-\mathrm{C}_{6} \mathrm{H}_{6}\right) \mathrm{Ru}(\mathrm{L}) \mathrm{Cl}_{2}$ complexes. Data from cyclic voltammetry in NCMe with potentials reported vs NHE (in V).

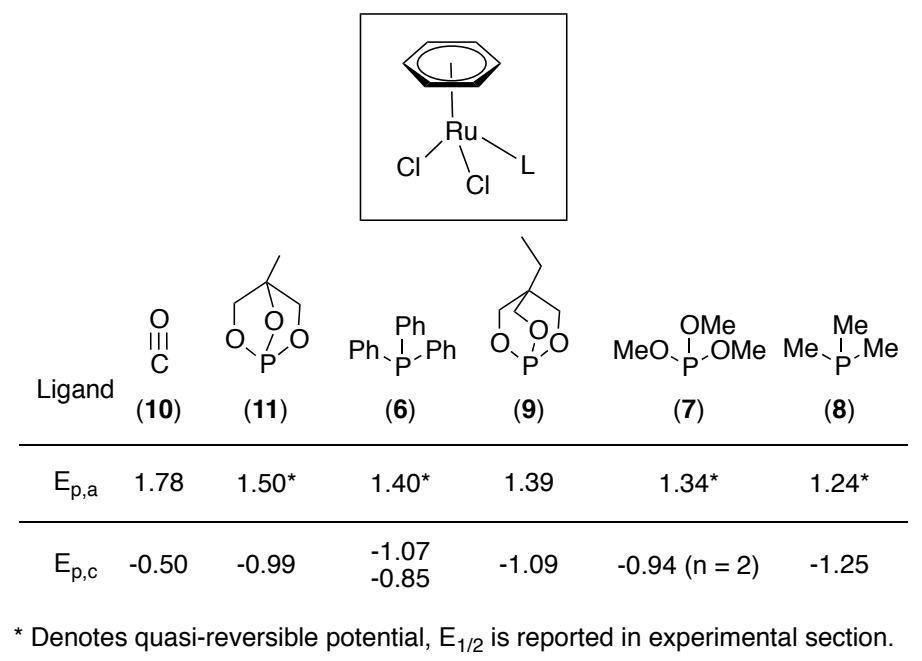

In addition to the $\mathrm{Ru}(\mathrm{III} / \mathrm{II})$ potentials, a cathodic wave $\left(\mathrm{E}_{\mathrm{p}, \mathrm{c}}\right)$ is observed for each $\left(\eta^{6}-\mathrm{C}_{6} \mathrm{H}_{6}\right) \mathrm{Ru}(\mathrm{L}) \mathrm{Cl}_{2}$ complex (Table 2.4). The $\mathrm{P}(\mathrm{OMe})_{3}$ complex 7 displays a two-electron reduction at $-0.94 \mathrm{~V} .{ }^{46}$ Two one-electron reductions are observed for complex 6 , at $\mathrm{E}_{\mathrm{p}, \mathrm{a}}=$ $-0.85 \mathrm{~V}$ and $-1.07 \mathrm{~V}$. All of the other complexes exhibit one single-electron reduction. As the electron density of the metal center decreases, one would expect the $E_{p, c}$ to become less negative. Indeed, complexes $\mathbf{1 0}$ and $\mathbf{1 1}$ have the least negative reduction potentials, $-0.50 \mathrm{~V}$ and $-0.99 \mathrm{~V}$, respectively. 


\subsubsection{Synthesis and Characterization of $\left(\eta^{6}-p\right.$-cymene $) \mathrm{Ru}(\mathrm{L}) \mathrm{Cl} \mathrm{l}_{2}$ Complexes.}

Another group of metal complexes containing phosphites/phosphines is $\left(\eta^{6}-p-\right.$ cymene $) \mathrm{Ru}(\mathrm{L}) \mathrm{Cl}_{2}{ }^{5,47-49}$ Similar to the $\left(\eta^{6}-\mathrm{C}_{6} \mathrm{H}_{6}\right) \mathrm{Ru}(\mathrm{L}) \mathrm{Cl}_{2}$, the complexes $\left(\eta^{6}-p\right.$ cymene $) \mathrm{Ru}\left[\mathrm{P}\left(\mathrm{OCH}_{2}\right)_{3} \mathrm{CEt}\right] \mathrm{Cl}_{2}(\mathbf{1 2}),\left(\eta^{6}-p\right.$-cymene $) \mathrm{Ru}\left[\mathrm{P}\left(\mathrm{OCH}_{2}\right)_{2}\left(\mathrm{OCCH}_{3}\right)\right] \mathrm{Cl}_{2}(\mathbf{1 3}),\left(\eta^{6}-p\right.$ cymene $) \mathrm{Ru}\left[\mathrm{P}(\mathrm{OMe})_{3}\right] \mathrm{Cl}_{2}(\mathbf{1 4})$ and $\left(\eta^{6}-p\right.$-cymene $) \mathrm{Ru}\left(\mathrm{PPh}_{3}\right) \mathrm{Cl}_{2}$ (15) were synthesized by the reaction of $\left[\left(\eta^{6}-p \text {-cymene) } \mathrm{Ru}(\mathrm{Cl})(\mu-\mathrm{Cl})\right]_{2}\right.$ with excess $\mathrm{L}$ in dichloromethane (Scheme 2.5). The ${ }^{1} \mathrm{H}$ NMR spectrum of the bicyclic phosphite, complex 12, displays 2 doublets (each $2 \mathrm{H}$ ) for the $\mathrm{CH}$ groups of the $p$-cymene ligand. Upfield of the $\mathrm{CH}$ group of the $p$ cymene, the distinct septet for the $\mathrm{CH}$ of the isopropyl group is observed. The methyl group of the $p$-cymene is observed as a singlet upfield at approximately 2.2 ppm with the doublet from the isopropyl $\mathrm{CH}_{3}$ groups overlapping with the quartet of the phosphite. Similar to the $\left(\eta^{6}-\mathrm{C}_{6} \mathrm{H}_{6}\right) \mathrm{Ru}\left[\mathrm{P}\left(\mathrm{OCH}_{2}\right)_{3} \mathrm{CEt}\right] \mathrm{Cl}_{2}$ species, the phosphite yields a doublet for the methylene hydrogens and a quartet and triplet for the ethyl-group (Figure 2.17, Figure 2.18). The ${ }^{1} \mathrm{H}$ NMR spectrum of complex $\mathbf{1 3}$ displays similar resonances for the $p$ cymene ligand (Figure 2.19, Figure 2.20).

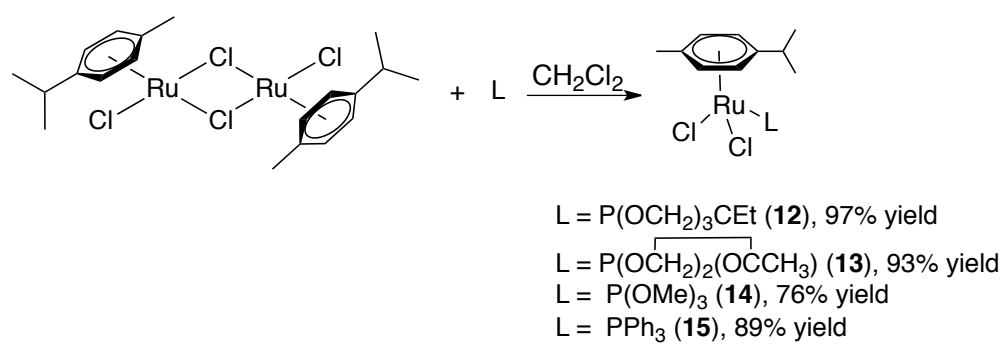

Scheme 2.5. Synthesis of $\left(\eta^{6}-p\right.$-cymene $) \mathrm{Ru}(\mathrm{L}) \mathrm{Cl}_{2} \quad\left(\mathrm{~L}=\mathrm{P}\left(\mathrm{OCH}_{2}\right)_{3} \mathrm{CEt}\right.$, $\mathrm{P}\left(\mathrm{OCH}_{2}\right)_{2}\left(\mathrm{OCCH}_{3}\right), \mathrm{P}(\mathrm{OMe})_{3}$, and $\left.\mathrm{PPh}_{3}\right]$. 


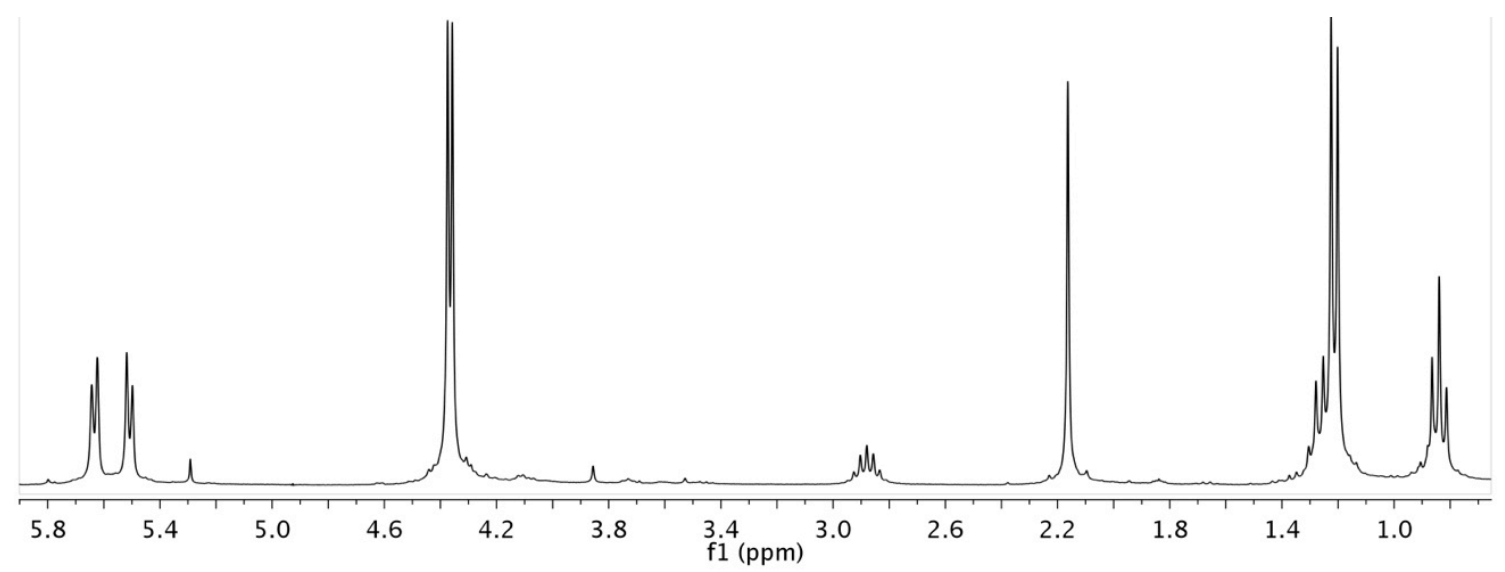

Figure 2.17. ${ }^{1} \mathrm{H}$ NMR spectrum of $\left(\eta^{6}-p\right.$-cymene $) \mathrm{Ru}\left[\mathrm{P}\left(\mathrm{OCH}_{2}\right)_{3} \mathrm{CEt}\right] \mathrm{Cl}_{2}(\mathbf{1 2})$ in $\mathrm{CDCl}_{3}$.

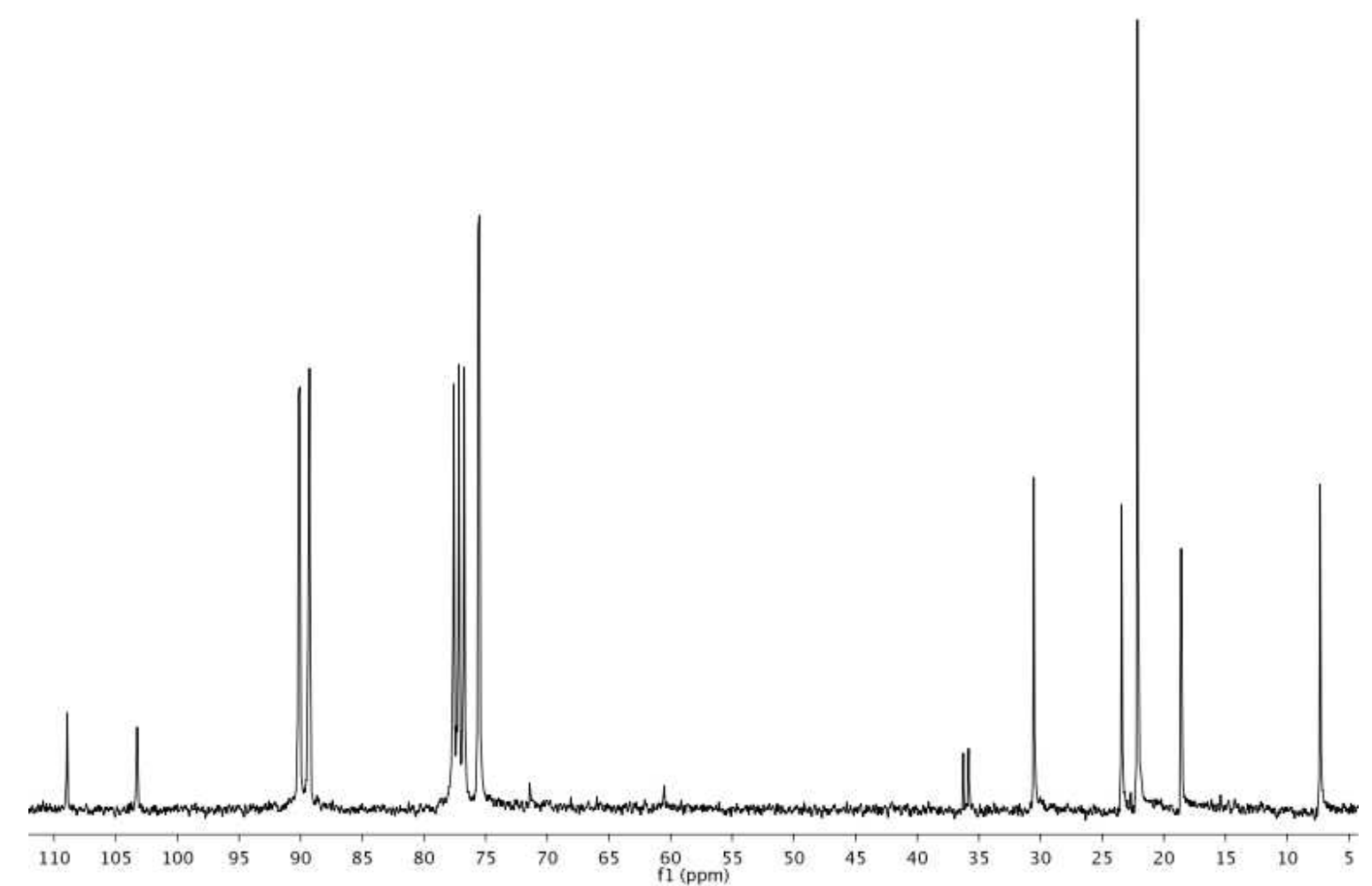

Figure 2.18. ${ }^{13} \mathrm{C}$ NMR spectrum of $\left(\eta^{6}\right.$-p-cymene $) \mathrm{Ru}\left[\mathrm{P}\left(\mathrm{OCH}_{2}\right)_{3} \mathrm{CEt}\right] \mathrm{Cl}_{2}(\mathbf{1 2})$ in $\mathrm{CDCl}_{3}$. 


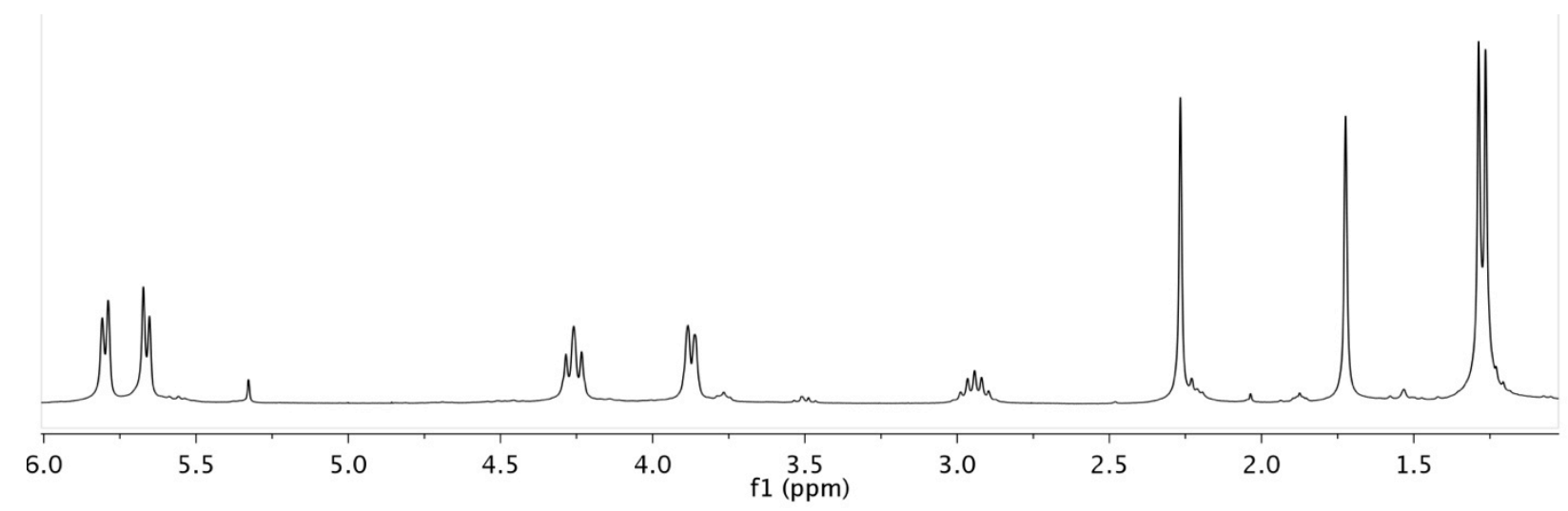

Figure 2.19. ${ }^{1} \mathrm{H}$ NMR spectrum of $\left(\eta^{6}-p\right.$-cymene $) \mathrm{Ru}\left[\mathrm{P}\left(\mathrm{OCH}_{2}\right)_{2}\left(\mathrm{OCCH}_{3}\right)\right] \mathrm{Cl}_{2}(\mathbf{1 3})$ in $\mathrm{CDCl}_{3}$.

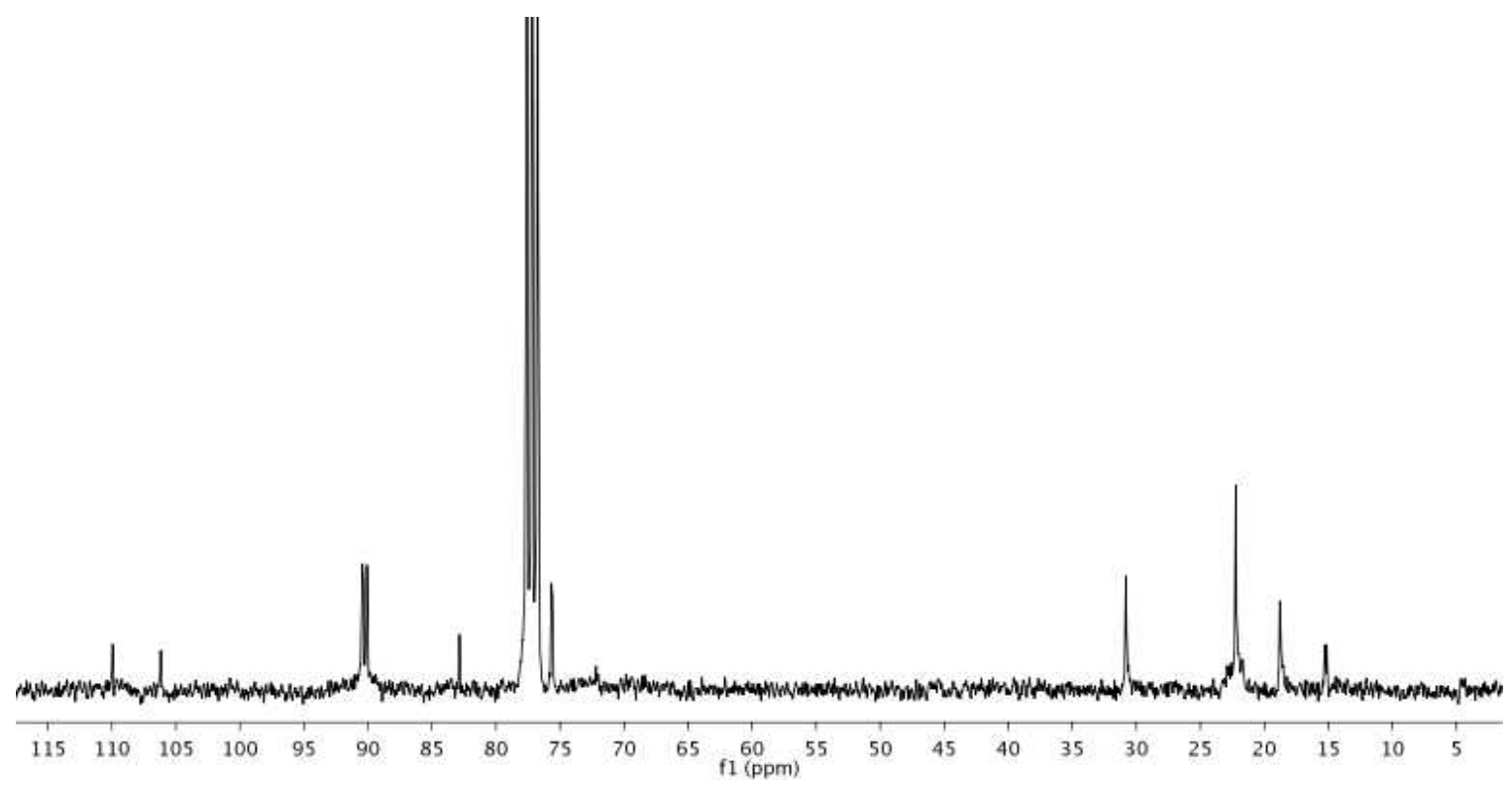

Figure 2.20. ${ }^{13} \mathrm{C}$ NMR spectrum of $\left(\eta^{6}-p\right.$-cymene $) \mathrm{Ru}\left[\mathrm{P}\left(\mathrm{OCH}_{2}\right)_{2}\left(\mathrm{OCCH}_{3}\right)\right] \mathrm{Cl}_{2}(\mathbf{1 3})$ in $\mathrm{CDCl}_{3}$. 
A single crystal suitable for X-ray diffraction was grown of complex 12 (Figure 2.21). Using previously reported data for $\left(\eta^{6}-p\right.$-cymene $) \mathrm{Ru}\left[\mathrm{P}\left(\mathrm{OCH}_{2}\right)_{3} \mathrm{CEt}\right] \mathrm{Cl}_{2}[\mathrm{~L}=$ $\mathrm{P}\left(\mathrm{OCH}_{2}\right)_{3} \mathrm{CEt}$ (12), $\left.\mathrm{P}(\mathrm{OPh})_{3}, \mathrm{PPh}_{3}(\mathbf{1 5}), \mathrm{P}\left(\mathrm{NC}_{4} \mathrm{H}_{4}\right)_{3}\right], 5,47,49$ the $\mathrm{Ru}-\mathrm{P}$ bond distance increases with the following trend $\mathrm{P}\left(\mathrm{OCH}_{2}\right)_{3} \mathrm{CEt}(\mathbf{1 2})<\mathrm{P}(\mathrm{OPh})_{3}<\mathrm{PPh}_{3}(\mathbf{1 5})<$ $\mathrm{P}\left(\mathrm{NC}_{4} \mathrm{H}_{4}\right)_{3}$ (Table 2.5). When comparing the $\mathrm{O}-\mathrm{P}-\mathrm{O}$ bond angles of complexes $\mathrm{TpRu}[$ $\left.\mathrm{P}\left(\mathrm{OCH}_{2}\right)_{2}\left(\mathrm{OCCH}_{3}\right)\right]\left(\mathrm{PPh}_{3}\right) \mathrm{Cl}(\mathbf{2}),\left(\eta^{6}-\mathrm{C}_{6} \mathrm{H}_{6}\right) \mathrm{Ru}\left[\mathrm{P}\left(\mathrm{OCH}_{2}\right)_{2}\left(\mathrm{OCCH}_{3}\right)\right] \mathrm{Cl}_{2}(\mathbf{1 1})$, and $\left(\eta^{6}-p\right.$ cymene) $\mathrm{Ru}\left[\mathrm{P}\left(\mathrm{OCH}_{2}\right)_{3} \mathrm{CEt}\right] \mathrm{Cl}_{2}$ (12), the removal of the methylene group from $\mathrm{P}\left(\mathrm{OCH}_{2}\right)_{3} \mathrm{CEt}$ to form phosphite $1, \mathrm{P}\left(\mathrm{OCH}_{2}\right)_{2}\left(\mathrm{OCCH}_{3}\right)$, results in a substantial decrease in the $\mathrm{O}-\mathrm{P}-\mathrm{O}$ bond angle where the methylene group is removed by approximately $5^{\circ}$ for complexes 2 and 11. The Ru-P bond length for $\left(\eta^{6}-p\right.$-cymene $) \mathrm{Ru}\left[\mathrm{P}\left(\mathrm{OCH}_{2}\right)_{3} \mathrm{CEt}\right] \mathrm{Cl}_{2}(\mathbf{1 2})$ $[2.2529(4) \AA]$ is longer than that for $\mathrm{TpRu}\left[\mathrm{P}\left(\mathrm{OCH}_{2}\right)_{2}\left(\mathrm{OCCH}_{3}\right)\right]\left(\mathrm{PPh}_{3}\right) \mathrm{Cl}(2)$ [2.191(1) $\left.\AA\right]$ and $\left(\eta^{6}-\mathrm{C}_{6} \mathrm{H}_{6}\right) \mathrm{Ru}\left[\mathrm{P}\left(\mathrm{OCH}_{2}\right)_{2}\left(\mathrm{OCCH}_{3}\right)\right] \mathrm{Cl}_{2}(\mathbf{1 1})[2.2453(7) \AA]$. Additionally, the average P-O bond lengths for complex 2 [1.627(3) $\AA]$ and $\mathbf{1 1}$ [1.613(2) $\AA]$ are longer than for complex 12 [1.597(2) $\AA$ ], consistent with phosphite 1 being a better $\pi$-acid than $\mathrm{P}\left(\mathrm{OCH}_{2}\right)_{3} \mathrm{CEt}$. 


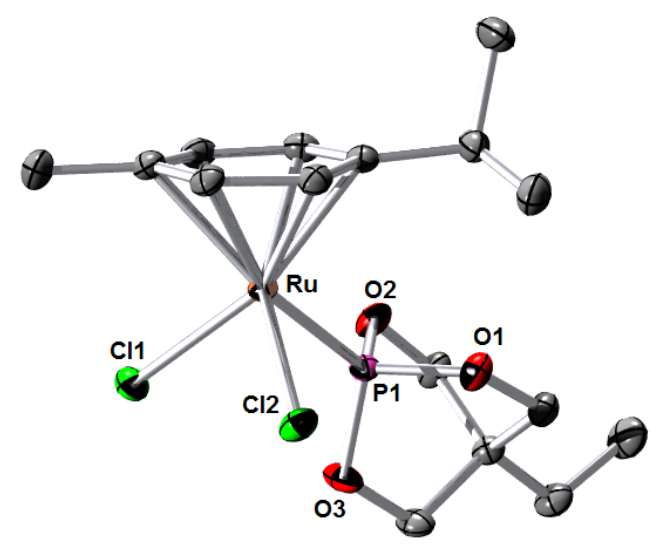

Figure 2.21. ORTEP of $\left(\eta^{6}-p\right.$-cymene $) \mathrm{Ru}\left[\mathrm{P}\left(\mathrm{OCH}_{2}\right)_{3} \mathrm{CEt}\right] \mathrm{Cl}_{2}(\mathbf{1 2})(50 \%$ probability with hydrogen atoms omitted.) Selected bond lengths $(\AA)$ : Ru-P1, 2.2529(4); P1-O1, 1.599(1); P1-O2, 1.599(1), P1-O3, 1.594(1). Selected bond angles $\left(^{\circ}\right)$ : O3-P1-O2, 102.82(6); O3-P1-O1, 102.37(6); O2-P1-O1, 102.31(6); Cl(1)-Ru-Cl2, 88.59(1); P1$\mathrm{Ru}-\mathrm{Cl1}$, 88.10(1); P1-Ru-Cl2, 83.91(1).

Table 2.5. Comparison of bond lengths from crystallographic data for $\left(\eta^{6}-p-\right.$ cymene $) \mathrm{Ru}(\mathrm{L}) \mathrm{Cl}_{2}$ complexes.

\begin{tabular}{|c|c|c|c|c|}
\hline \multicolumn{5}{|c|}{ 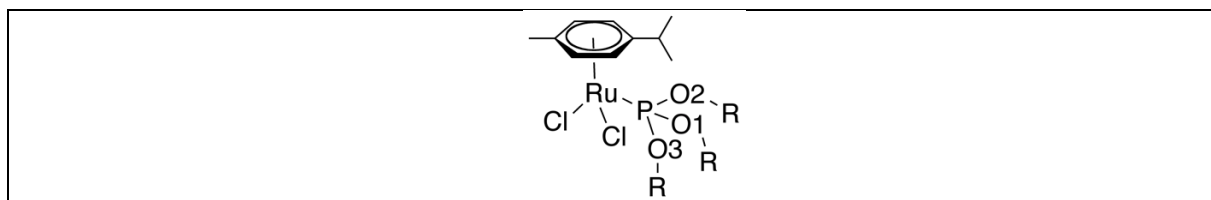 } \\
\hline Ligand "L" & $\mathrm{Ru}-\mathrm{P}(\AA)$ & $\mathrm{P}-\mathrm{O} 1(\AA)$ & $\mathrm{P}-\mathrm{O} 2(\AA)$ & $\mathrm{P}-\mathrm{O} 3(\AA)$ \\
\hline $\mathrm{PPh}_{3}$ & $2.3438(6)$ & $-^{\mathrm{a}}$ & $-^{\mathrm{a}}$ & $-^{\mathrm{a}}$ \\
\hline $\mathrm{P}\left(\mathrm{OCH}_{2}\right)_{3} \mathrm{CEt}$ & $2.2529(4)$ & $1.599(1)$ & $1.599(1)$ & $1.594(1)$ \\
\hline $\mathrm{P}\left(\mathrm{NC}_{4} \mathrm{H}_{4}\right)_{3}$ & $2.396(2)$ & $-^{\mathrm{a}}$ & $-^{\mathrm{a}}$ & $-{ }^{\mathrm{a}}$ \\
\hline $\mathrm{P}(\mathrm{OPh})_{3}$ & $2.2642(8)$ & $1.596(2)$ & $1.607(2)$ & $1.584(2)$ \\
\hline
\end{tabular}

${ }^{\mathrm{a}}$ No oxygen atom in P-based ligand.

The $\left(\eta^{6}-p\right.$-cymene $) \mathrm{Ru}(\mathrm{L}) \mathrm{Cl}_{2}$ complexes $\mathbf{1 2 - 1 5}$ were studied using cyclic voltammetry (Table 2.6). It was determined that the least electron density on the metal center is observed for complex 13 containing $\mathrm{P}\left(\mathrm{OCH}_{2}\right)_{2}\left(\mathrm{OCCH}_{3}\right)$ with quasi-reversible $\mathrm{Ru}(\mathrm{III} / \mathrm{II})$ wave at $\mathrm{E}_{1 / 2}=1.44 \mathrm{~V}$, and $\mathrm{E}_{\mathrm{p}, \mathrm{c}}=-1.05 \mathrm{~V}$. This observation is consistent with 
data collected for the $\left(\eta^{6}-\mathrm{C}_{6} \mathrm{H}_{6}\right) \mathrm{Ru}(\mathrm{L}) \mathrm{Cl}_{2}$ systems (see above). Intriguingly, both metal centers containing cyclic phosphites (complex 12 and 13) are less electron-rich than the acyclic phosphites, unlike the $\eta^{6}-\mathrm{C}_{6} \mathrm{H}_{6}$ systems in which the bicyclic phosphite, $\mathrm{P}\left(\mathrm{OCH}_{2}\right)_{3} \mathrm{CEt}$ and $\mathrm{PPh}_{3}$ are basically identical. Unlike the $\left(\eta^{6}-\mathrm{C}_{6} \mathrm{H}_{6}\right) \mathrm{Ru}(\mathrm{L}) \mathrm{Cl}_{2}$ systems, all of the $\eta^{6}$-p-cymene systems show reversible waves. The same trend as shown with $\mathrm{TpRu}\left(\mathrm{PPh}_{3}\right)_{2} \mathrm{Cl}$ and $\left(\eta^{6}-\mathrm{C}_{6} \mathrm{H}_{6}\right) \mathrm{Ru}(\mathrm{L}) \mathrm{Cl}_{2}$ complexes of the metal center being the least electron rich with $\mathrm{L}=\mathrm{P}\left(\mathrm{OCH}_{2}\right)_{2}\left(\mathrm{OCCH}_{3}\right)$ and the most electron rich with the phosphines studied is apparent using both $\mathrm{E}_{1 / 2}$ and $\mathrm{E}_{\mathrm{p}, \mathrm{a}}$ for the $\left(\eta^{6}-p\right.$-cymene $) \mathrm{Ru}(\mathrm{L}) \mathrm{Cl}_{2}$ complexes.

Table 2.6. $\mathrm{Ru}(\mathrm{III} / \mathrm{II})$ potentials for $\left(\eta^{6}-p\right.$-cymene $) \mathrm{Ru}(\mathrm{L}) \mathrm{Cl}_{2}$ complexes. Data from cyclic voltammetry in NCMe with potentials reported vs NHE (in V).

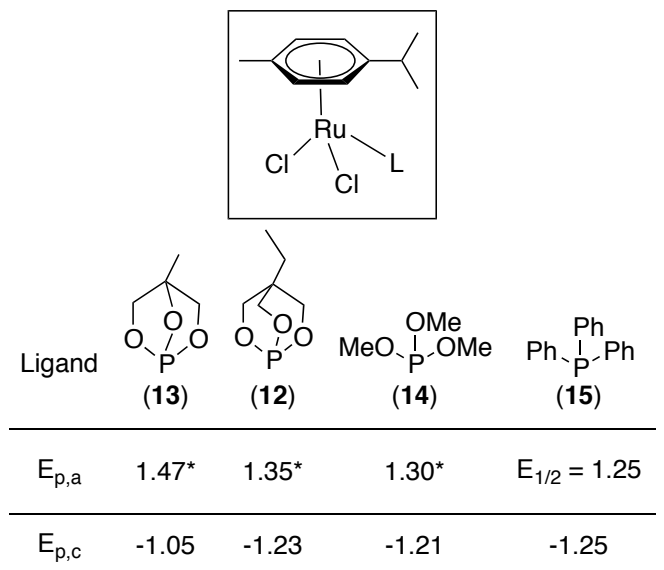

* Denotes quasi-reversible potential, $\mathrm{E}_{1 / 2}$ is reported in experimental section.

Kinetic Studies for Phosphine/Phosphite Exchange. As a final probe of the properties of 1 as a ligand, we compared the rate of ligand exchange using $\mathrm{P}(\mathrm{OMe})_{3}$ for $\left(\eta^{6}\right.$ - $p$-cymene $) \mathrm{Ru}(\mathrm{L}) \mathrm{Cl}_{2}$ complexes $\left[\mathrm{L}=\mathbf{1}, \mathrm{P}\left(\mathrm{OCH}_{2}\right)_{3} \mathrm{CEt}\right.$ and $\left.\mathrm{PPh}_{3}\right]$. The exchange rates 
were determined under pseudo-first-order conditions by monitoring $\left({ }^{1} \mathrm{H}\right.$ NMR spectroscopy) the disappearance of $\left(\eta^{6}-p\right.$-cymene $) \mathrm{Ru}(\mathrm{L}) \mathrm{Cl}_{2}$ in the presence of excess $\mathrm{P}(\mathrm{OMe})_{3}$ to form $\left(\eta^{6}-p\right.$-cymene $) \mathrm{Ru}\left[\mathrm{P}(\mathrm{OMe})_{3}\right] \mathrm{Cl}_{2}$. In all cases the reaction proceeded to quantitative conversion. Figure 2.22 displays plots of concentration of Ru complex vs time for $\mathbf{1 2}, \mathbf{1 3}$ and $\mathbf{1 5}$. The $k_{\mathrm{obs}}$ values for each reaction were determined by fitting the plots to first-order decays, which gives the following relative $k_{\text {obs }}$ magnitudes: $\left(\eta^{6}-p\right.$ cymene $) \mathrm{Ru}\left(\mathrm{PPh}_{3}\right) \mathrm{Cl}_{2}(\mathbf{1 5})\left[k_{\mathrm{obs}}=0.0045(3) \mathrm{s}^{-1}\right]>\left(\eta^{6}-p\right.$-cymene $) \mathrm{Ru}\left[\mathrm{P}\left(\mathrm{OCH}_{2}\right)_{2}\left(\mathrm{OCCH}_{3}\right)\right.$ ] $\mathrm{Cl}_{2}(\mathbf{1 3})\left[k_{\mathrm{obs}}=0.0030(1) \mathrm{s}^{-1}\right]>>\left(\eta^{6}-p\right.$-cymene $) \mathrm{Ru}\left[\mathrm{P}\left(\mathrm{OCH}_{2}\right)_{3} \mathrm{CEt}\right] \mathrm{Cl}_{2}(\mathbf{1 2})\left[k_{\mathrm{obs}}=8.5(6)\right.$ $\left.\times 10^{-5} \mathrm{~s}^{-1}\right]$.
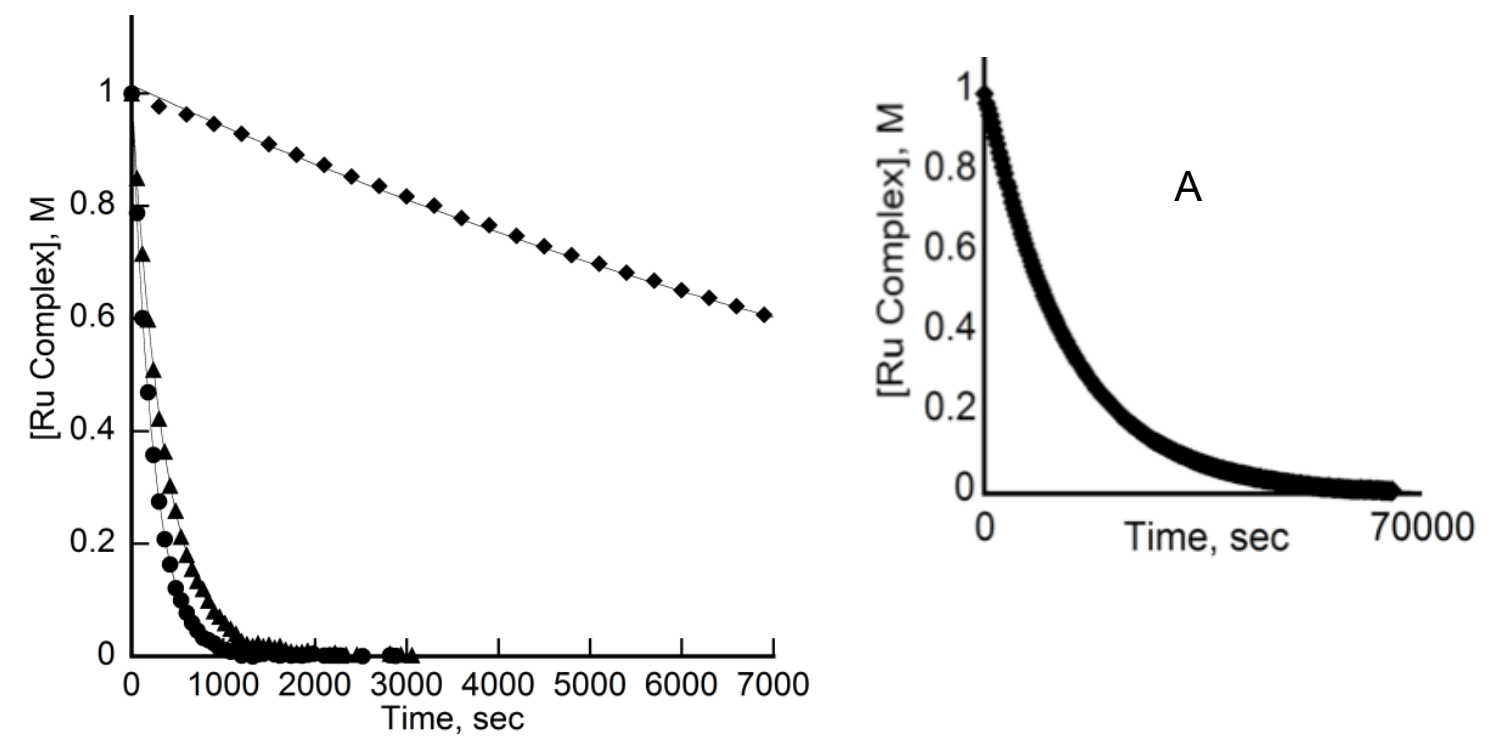

Figure 2.22. Representative kinetic plots for the exchange reaction of $L$ in $\left(\eta^{6}-p\right.$ cymene $) \mathrm{Ru}(\mathrm{L}) \mathrm{Cl}_{2}\left[\mathrm{~L}=\mathrm{P}\left(\mathrm{OCH}_{2}\right)_{2}\left(\mathrm{OCCH}_{3}\right), \mathrm{P}\left(\mathrm{OCH}_{2}\right)_{3} \mathrm{CEt}\right.$ or $\left.\mathrm{PPh}_{3}\right]$ complexes with $\mathrm{P}(\mathrm{OMe})_{3}$ (40 equivalents relevant to concentration of $\mathrm{Ru}$ complex) in $\mathrm{CDCl}_{3}$ at $60{ }^{\circ} \mathrm{C}[\mathrm{L}$ $=\boldsymbol{\Delta} \mathrm{P}\left(\mathrm{OCH}_{2}\right)_{2}\left(\mathrm{OCCH}_{3}\right)(\mathbf{1 3})\left[k_{\mathrm{obs}}=0.0030(1) \mathrm{s}^{-1}, \mathrm{R}^{2}=0.99\right], \cdot \mathrm{PPh}_{3}(\mathbf{1 5})\left[k_{\mathrm{obs}}=\right.$ $\left.\left.0.0045(3) \mathrm{s}^{-1}, \mathrm{R}^{2}=0.99\right)\right], \mathrm{P}\left(\mathrm{OCH}_{2}\right)_{3} \mathrm{CEt}(\mathbf{1 2})\left[k_{\mathrm{obs}}=0.000085(6) \mathrm{s}^{-1}, \mathrm{R}^{2}=0.99\right]$. Plot $\mathrm{A}$ represents the exchange reaction for $\mathrm{L}=\mathrm{P}\left(\mathrm{OCH}_{2}\right)_{3} \mathrm{CEt}$. 
Figure 2.23 shows a plot of $k_{\text {obs }}$ vs concentration of $\mathrm{PPh}_{3}$ for the reaction of $\mathbf{1 5}$ with $\mathrm{P}(\mathrm{OMe})_{3}$. Increasing the concentration of $\mathrm{PPh}_{3}$ decreases the rate of ligand exchange indicating an inverse rate dependence on concentration of $\mathrm{PPh}_{3}$. Figure 2.24 displays a plot of $k_{\mathrm{obs}}$ Vs concentration of $\mathrm{P}(\mathrm{OMe})_{3}$ for the reaction of 15 with $\mathrm{P}(\mathrm{OMe})_{3}$. The rate of reaction initially increases, and saturation is observed at higher concentrations of $\mathrm{P}(\mathrm{OMe})_{3}$. Scheme 2.6 shows a potential reaction pathway for the conversion of $\mathbf{1 2}, \mathbf{1 3}$ or 15 and $\mathrm{P}(\mathrm{OMe})_{3}$ to $\left(\eta^{6}-p\right.$-cymene $) \mathrm{Ru}\left[\mathrm{P}(\mathrm{OMe})_{3}\right] \mathrm{Cl}_{2}$ that is consistent with the kinetic data for the reaction of $\mathbf{1 5}$ and $\mathrm{P}(\mathrm{OMe})_{3}$. Since 12, 13 and 15 are 18-electron complexes, a ligand exchange by a dissociative pathway is reasonable. Under saturation conditions $\left\{\right.$ where $\left.k_{2}\left[\mathrm{P}(\mathrm{OMe})_{3}\right]>k_{-1}[\mathrm{~L}]\right\}$, the rate law can be reduced to rate $=k_{1}[\mathrm{Ru}$ complex $]$ where $k_{\mathrm{obs}}=k_{1}$, which is the rate constant for dissociation of L (Figure 2.25). Thus, the $k_{\text {obs }}$ values derived from the kinetic plots in Figure 2.22 should provide relative rates of dissociation of $\mathrm{L}$ from $\left(\eta^{6}-p\right.$-cymene $) \mathrm{Ru}(\mathrm{L}) \mathrm{Cl}_{2}$ complexes. The $k_{\mathrm{obs}}$ values indicate that the rate of dissociation of $\mathbf{1}$ from $\left(\eta^{6}-p\right.$-cymene $) \mathrm{Ru}\left[\mathrm{P}\left(\mathrm{OCH}_{2}\right)_{2}\left(\mathrm{OCCH}_{3}\right)\right] \mathrm{Cl}_{2}(\mathbf{1 3})$ is similar to that of $\mathrm{PPh}_{3}$ from $\left(\eta^{6}-p\right.$-cymene $) \mathrm{Ru}\left(\mathrm{PPh}_{3}\right) \mathrm{Cl}_{2}(15)$, and that 1 and $\mathrm{PPh}_{3}$ dissociate more rapidly than $\mathrm{P}\left(\mathrm{OCH}_{2}\right)_{3} \mathrm{CEt}$ from $\left(\eta^{6}\right.$-p-cymene $) \mathrm{Ru}\left[\mathrm{P}\left(\mathrm{OCH}_{2}\right)_{3} \mathrm{CEt}\right] \mathrm{Cl}_{2}(\mathbf{1 2})$. 


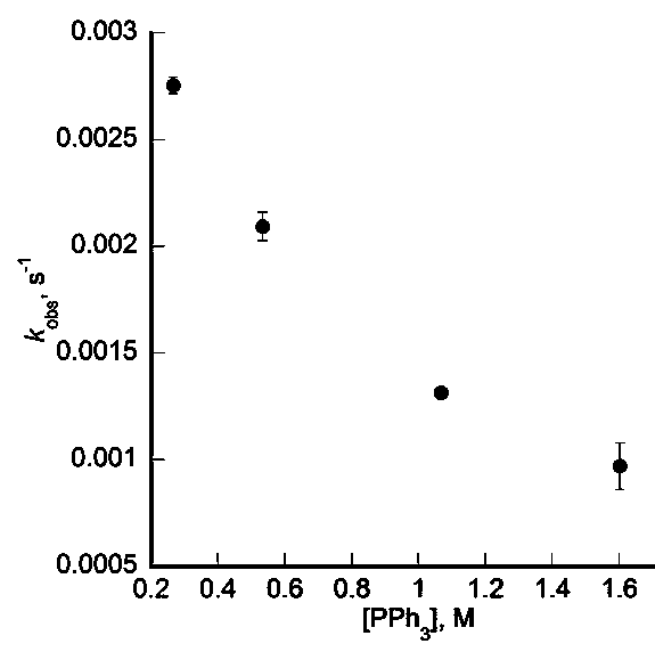

Figure 2.23. Plot of $k_{\text {obs }}$ versus concentration of $\mathrm{PPh}_{3}$ for the exchange of $\mathrm{PPh}_{3}$ with $\mathrm{P}(\mathrm{OMe})_{3}$ upon reaction of $\left(\eta^{6}-p\right.$-cymene $) \mathrm{Ru}\left(\mathrm{PPh}_{3}\right) \mathrm{Cl}_{2}(15)$ with excess $\mathrm{P}(\mathrm{OMe})_{3}$ in $\mathrm{CDCl}_{3}$ at $60^{\circ} \mathrm{C}$.

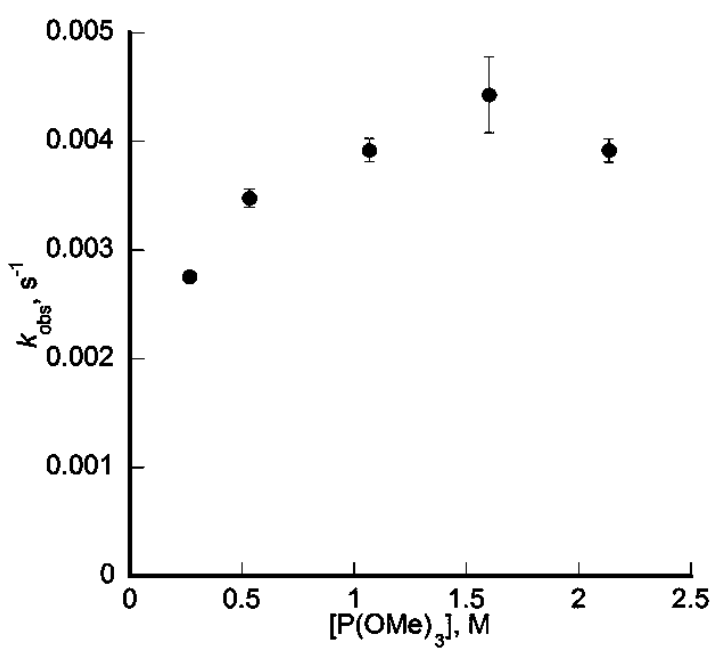

Figure 2.24. Plot of $k_{\text {obs }}$ versus concentration of $\mathrm{P}(\mathrm{OMe})_{3}$ for the exchange of $\mathrm{PPh}_{3}$ with $\mathrm{P}(\mathrm{OMe})_{3}$ upon reaction of $\left(\eta^{6}-p\right.$-cymene $) \mathrm{Ru}\left(\mathrm{PPh}_{3}\right) \mathrm{Cl}_{2}(15)$ with excess $\mathrm{P}(\mathrm{OMe})_{3}$ in $\mathrm{CDCl}_{3}$ at $60^{\circ} \mathrm{C}$. 


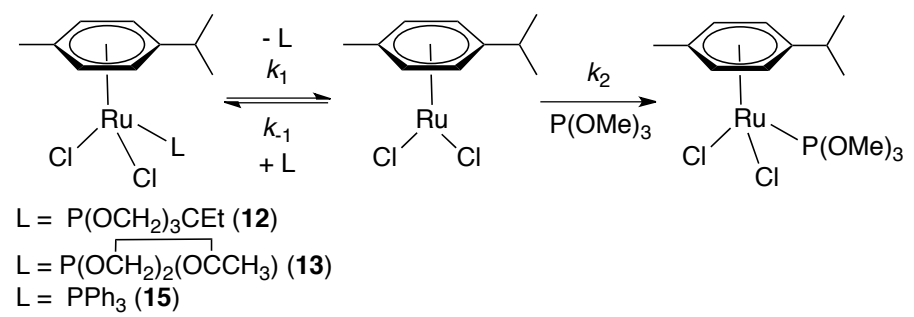

Scheme 2.6. Proposed mechanism for exchange reaction of $\mathrm{L}$ with $\mathrm{P}(\mathrm{OMe})_{3}$ to form $\left(\eta^{6}\right.$ p-cymene $) \mathrm{Ru}\left[\mathrm{P}(\mathrm{OMe})_{3}\right] \mathrm{Cl}_{2}$ in $\mathrm{CDCl}_{3}$ at $60{ }^{\circ} \mathrm{C}$.

$$
\text { Rate }=\frac{k_{1} k_{2}\left[\mathrm{P}(\mathrm{OMe})_{3}\right][\mathrm{Ru}-\text { Complex }]}{k_{-1}[\mathrm{~L}]+k_{2}\left[\mathrm{P}(\mathrm{OMe})_{3}\right]}
$$

Figure 2.25. Rate law for exchange reaction of $\mathrm{L}$ in $\left(\eta^{6}-p\right.$-cymene $) \mathrm{Ru}(\mathrm{L}) \mathrm{Cl}_{2}[\mathrm{~L}=$ $\mathrm{P}\left(\mathrm{OCH}_{2}\right)_{2}\left(\mathrm{OCCH}_{3}\right), \mathrm{P}\left(\mathrm{OCH}_{2}\right)_{3} \mathrm{CEt}$ or $\left.\mathrm{PPh}_{3}\right]$ complexes with $\mathrm{P}(\mathrm{OMe})_{3}$ to form $\left(\eta^{6}-p\right.$ cymene $) \mathrm{Ru}\left[\mathrm{P}(\mathrm{OMe})_{3}\right] \mathrm{Cl}_{2}$ in $\mathrm{CDCl}_{3}$ at $60{ }^{\circ} \mathrm{C}$.

\subsubsection{Calculations: Bicyclic Phosphite $\pi$-Acidity}

To further understand the bonding between $\mathbf{1}$ and transition metals, DFT calculations were carried out to compare bonding of 1 to $\mathrm{P}(\mathrm{OMe})_{3}, \mathrm{P}\left(\mathrm{OCH}_{2}\right)_{3} \mathrm{CEt}$ and $\mathrm{PF}_{3}$. The calculations were performed by Claire L. McMullin of Tom Cundari's group (University of North Texas). The role of the $\mathrm{P}-\mathrm{X}\left(\mathrm{X}=\mathrm{O}, \mathrm{C}\right.$, halide, etc.) $\sigma^{*}$ orbitals in $\pi$ acidity of phosphorus ligands has been documented. ${ }^{9,50,51}$ The energies of the $\mathrm{PX}_{3} \sigma^{*}$ orbitals are a function of the substituent $\mathrm{X}$ as well as the $\mathrm{X}-\mathrm{P}-\mathrm{X}$ bond angle. ${ }^{1,9}$ Smaller $\mathrm{X}-\mathrm{P}-\mathrm{X}$ angles are suggested to result in better $\pi$-acceptor ligands as $\sigma^{*}$ LUMOs are 
lower in energy due to the reduced overlap between the $3 p$ phosphorus orbitals with $\sigma$ orbitals of the $\mathrm{X}$ substituents (see Figure 2.2). Thus, the decreased $\mathrm{O}-\mathrm{P}-\mathrm{O}$ bond angles of bicyclic phosphites that result from the cyclic structure are expected to decrease the energy of the $\mathrm{P}-\mathrm{O} \sigma^{*}$ orbitals and, as a result, enhance $\pi$-acidity.

Structures were optimized for a linear gold(I) complex $[\mathrm{AuCl}(\mathrm{L})]$ where $\mathrm{L}=\mathbf{1}$, $\mathrm{P}(\mathrm{OMe})_{3}, \mathrm{P}\left(\mathrm{OCH}_{2}\right)_{3} \mathrm{CEt}$ or $\mathrm{PF}_{3}$ and for the free ligand $\mathrm{L} . \mathrm{AuCl}(\mathrm{L})$ is an established organometallic fragment by Fey et al. used to parameterize ligand electronic and steric effects. $^{52}$ While the experimental studies herein are focused on $\mathrm{Ru}(\mathrm{II})$, the $\mathrm{d}^{10}$ configuration of the $\mathrm{Au}(\mathrm{I})$ complex allowed for easier delineation of $\sigma$-donor and $\pi$ acceptor electronic effects without steric influence from cis ligands. The free ligand HOMO and LUMO energies $\left(E_{\mathrm{HOMO}}\right.$ and $\left.E_{\mathrm{LUMO}}\right)$ are given in Figure 2.12 , along with the $\mathrm{Au}-\mathrm{P}$ bond length and phosphine substituent angles $(\mathrm{X}-\mathrm{P}-\mathrm{X})$ from the $[\mathrm{AuCl}(\mathrm{L})]$ complexes.

Care was taken when modeling the conformation of $\mathrm{P}(\mathrm{OMe})_{3},{ }^{53}$ with the lowest energy conformers in low and high coordinate compounds investigated $\left(\mathrm{ag}^{+} \mathrm{g}^{+}\right.$and $\mathrm{ag}^{-} \mathrm{g}^{+}$ respectively), as well as the most similar $\mathrm{P}(\mathrm{OMe})_{3}$ conformation to $\mathbf{1}$, where the $\mathrm{OMe}$ groups are all anti to the metal-phosphorus bond (aaa) (Figure 2.26). Consideration of confirmations is important to ensure that possible anomeric effects are not neglected, ${ }^{54}$ as delocalization of the phosphorus lone pair into a $\mathrm{C}-\mathrm{O} \sigma^{*}$ orbital is known to be more favorable if the substituent has an anti configuration. ${ }^{55}$ The anomeric effect is lessened when the phosphite is coordinated to a metal center. ${ }^{53}$ 
Table 2.7. Data from DFT calculations of $\mathrm{P}\left(\mathrm{OCH}_{2}\right)_{2}\left(\mathrm{OCCH}_{3}\right)(\mathbf{1}), \mathrm{P}(\mathrm{OMe})_{3}$, $\mathrm{P}\left(\mathrm{OCH}_{2}\right)_{3} \mathrm{CEt}$ and $\mathrm{PF}_{3}$.

\begin{tabular}{|l|c|c|c|c|c|c|}
\hline Ligand & Orientation & $\begin{array}{c}E_{\text {HOMO }} \\
{[\text { hartree }]}\end{array}$ & $\begin{array}{c}E_{\text {LUMO }} \\
{[\text { hartree }]}\end{array}$ & $\begin{array}{c}\text { Au-P } \\
{[\AA]}\end{array}$ & $\begin{array}{c}\text { Average } \\
\mathrm{X}-\mathrm{P}-\mathrm{X} \\
{\left[{ }^{\circ}\right]}\end{array}$ & $\begin{array}{c}\text { Relative } \\
\text { Free } \\
\text { Energy } \\
{\left[\mathrm{kcal} \mathrm{mol}^{-1}\right]}\end{array}$ \\
\hline $\mathrm{P}\left(\mathrm{OCH}_{2}\right)_{2}\left(\mathrm{OCCH}_{3}\right)(\mathbf{1})$ & & -0.2343 & -0.0428 & 2.21 & 97.4 & - \\
\hline $\mathrm{P}(\mathrm{OMe})_{3}$ & $a g^{+} g^{+}$ & -0.2190 & -0.0235 & 2.24 & 102.5 & 0.0 \\
\hline $\mathrm{P}(\mathrm{OMe})_{3}$ & $a g g^{+}$ & -0.2230 & -0.0241 & 2.24 & 102.7 & 1.0 \\
\hline $\mathrm{P}(\mathrm{OMe})_{3}$ & $a a a$ & -0.2215 & -0.0118 & 2.23 & 105.6 & 7.6 \\
\hline $\mathrm{P}\left(\mathrm{OCH}_{2}\right)_{3} \mathrm{CEt}$ & & -0.2296 & -0.0196 & 2.22 & 102.2 & - \\
\hline $\mathrm{PF}_{3}$ & & -0.3089 & -0.0709 & 2.20 & 99.5 & - \\
\hline
\end{tabular}

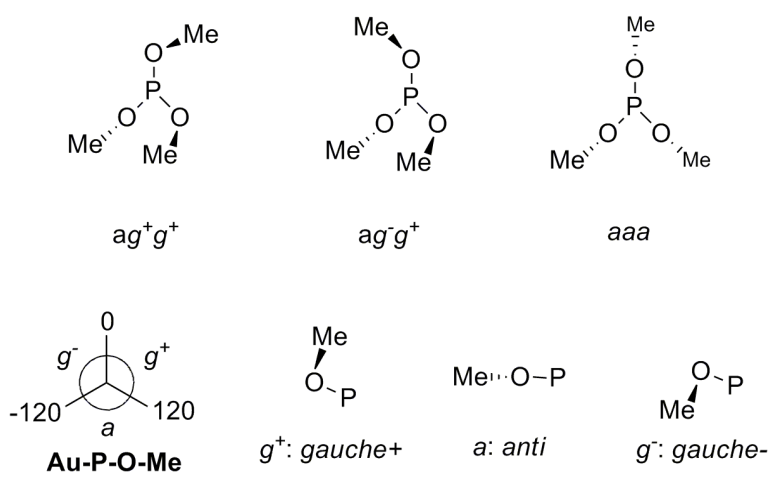

Figure 2.26. Orientations of $\mathrm{P}(\mathrm{OMe})_{3}$ ligand defined by the torsion $\mathrm{Au}-\mathrm{P}-\mathrm{O}-\mathrm{Me}$ (viewed along the $\mathrm{Au}-\mathrm{P}$ bond) that were modeled using DFT calculations.

The descriptor $E_{\mathrm{LUMO}}$ has been shown in Ligand Knowledge Base research to be related to the $\pi$-accepting character of a phosphorus ligand. ${ }^{52}$ As the results in Table 2.7 indicate, the energy of the LUMO ( $\left.E_{\mathrm{LUMO}}\right)$ is significantly lower for $\mathbf{1}$ compared to the $\mathrm{P}(\mathrm{OMe})_{3}$ conformers, which directly correlates to the size of the $\mathrm{O}-\mathrm{P}-\mathrm{O}$ angle. Likewise, the $E_{\mathrm{LUMO}}$ of $\mathbf{1}$ is lower than that calculated for $\mathrm{P}\left(\mathrm{OCH}_{2}\right)_{3} \mathrm{CEt}$. The calculated X-P-X 
angles of 1 and $\mathrm{PF}_{3}$ are smallest, supporting the hypothesis that small $\mathrm{X}-\mathrm{P}-\mathrm{X}$ angles lower the $E_{\mathrm{LUMO}}$ and thereby increase the ligand's $\pi$-acidity. The LUMO energy for $\mathrm{PF}_{3}$ is likely lower than that for $\mathbf{1}$ as a result of the more strongly withdrawing fluorine substituents of $\mathrm{PF}_{3}$, which is consistent with the known strong $\pi$-acceptor ability of $\mathrm{PF}_{3}$. Structural parameters from the linear $\mathrm{Au}(\mathrm{I})$ calculations also show a clear correlation between the $E_{\mathrm{LUMO}}$ and $\mathrm{Au}-\mathrm{P}$ bond lengths. Again for $\mathbf{1}, \mathrm{Au}-\mathrm{P}$ is shorter $(\sim 0.02 \AA)$ than that observed in the equivalent $\mathrm{P}(\mathrm{OMe})_{3}$ and $\mathrm{P}\left(\mathrm{OCH}_{2}\right)_{3} \mathrm{CEt}$ complexes, further corroborating a higher $\pi$-acidity character for phosphite $\mathbf{1}$ than the others included in this study and placing it below $\mathrm{PF}_{3}$ on the $\pi$-acidity scale.

\subsection{Conclusions}

Crystallographic and cyclic voltammetry data have been used to demarcate the properties of 1 compared with other phosphine and phosphite ligands, as well as carbon monoxide, using three types of ruthenium complexes, $\operatorname{TpRu}(\mathrm{L})\left(\mathrm{PPh}_{3}\right) \mathrm{Cl}, \quad\left(\eta^{6}-\right.$ $\left.\mathrm{C}_{6} \mathrm{H}_{6}\right) \mathrm{Ru}(\mathrm{L}) \mathrm{Cl}_{2}$ and $\left(\eta^{6}-p\right.$-cymene $) \mathrm{Ru}(\mathrm{L}) \mathrm{Cl}_{2}$. Data clearly indicate that the formal removal of one methylene group from the bicyclic phosphite $\mathrm{P}\left(\mathrm{OCH}_{2}\right)_{3} \mathrm{CEt}$, which gives the phosphite $\mathrm{P}\left(\mathrm{OCH}_{2}\right)_{2}\left(\mathrm{OCCH}_{3}\right)(\mathbf{1})$, results in a reduction in electron density at the metal center. For all three types of Ru complexes, redox potentials with $\mathbf{1}$ in the coordination sphere are shifted positive by $0.11 \mathrm{~V}$ to $0.13 \mathrm{~V}$ compared to analogous complexes with $\mathrm{P}\left(\mathrm{OCH}_{2}\right)_{3} \mathrm{CEt}$. Furthermore, when $\mathrm{L}=\mathbf{1}$, the metal is less electron-rich (as determined by cyclic voltammetry) than metals coordinated by all other phosphorus ligands studied including $\mathrm{P}(\mathrm{OMe})_{3}, \mathrm{PMe}_{3}, \mathrm{PPh}_{3}$ and $\mathrm{P}\left(\mathrm{OCH}_{2}\right)_{3} \mathrm{CEt}$. It can be concluded that $\mathbf{1}$ is overall 
more weakly donating than the acyclic phosphite $\mathrm{P}(\mathrm{OMe})_{3}$. The source of these differences is more difficult to pinpoint. Verkade et al. have rationalized differences in basicity of cyclic vs acyclic phosphites (and related ligands) with the hinge effect, $3,23-26$ which involves differences in $\mathrm{O}-\mathrm{P} \pi$-overlap as function of $\mathrm{O}-\mathrm{P}-\mathrm{O}$ and $\mathrm{P}-\mathrm{O}-\mathrm{C}$ bond angles (see above). In addition, differences in $\mathrm{O}-\mathrm{P}-\mathrm{O}$ bond angles (for cyclic vs acyclic phosphites) might impact $\mathrm{O}-\mathrm{P} \sigma$-overlap and, hence, the energy of $\mathrm{P}-\mathrm{O} \sigma^{*}$ orbitals, which could influence ligand $\pi$-acidity. DFT calculations are consistent with this suggestion and indicate a lower energy LUMO for $\mathbf{1}$ compared to $\mathrm{P}(\mathrm{OMe})_{3}$ and $\mathrm{P}\left(\mathrm{OCH}_{2}\right)_{3} \mathrm{CEt}$.

\subsection{Experimental Section}

General Methods. Unless otherwise noted, all synthetic procedures were performed under anaerobic conditions in a nitrogen-filled glovebox or by using standard Schlenk techniques. Glovebox purity was maintained by periodic nitrogen purges and was monitored by an oxygen analyzer $\left[\mathrm{O}_{2}(\mathrm{~g})<15 \mathrm{ppm}\right.$ for all reactions]. Tetrahydrofuran was dried by distillation from sodium/benzophenone. Pentane was distilled over $\mathrm{P}_{2} \mathrm{O}_{5}$. Acetonitrile and diethyl ether were dried by distillation from $\mathrm{CaH}_{2}$. Hexanes, benzene and methylene chloride were purified by passage through a column of activated alumina. Benzene- $d_{6}$, acetonitrile- $d_{3}$, methylene chloride- $d_{2}$ and chloroform- $d_{1}$ were stored under a $\mathrm{N}_{2}$ atmosphere over $4 \AA$ molecular sieves. ${ }^{1} \mathrm{H}$ NMR spectra were recorded on a Varian Mercury Plus $300 \mathrm{MHz}$ Spectrometer or Varian Inova $500 \mathrm{MHz}$ Spectrometer, and ${ }^{13} \mathrm{C}$ NMR spectra were recorded on a Varian Inova $500 \mathrm{MHz}$ Spectrometer (operating 
frequency $125 \mathrm{MHz}$ ). All ${ }^{1} \mathrm{H}$ and ${ }^{13} \mathrm{C}$ NMR spectra are referenced against residual proton signals $\left({ }^{1} \mathrm{H}\right.$ NMR $)$ or the ${ }^{13} \mathrm{C}$ resonances of the deuterated solvent $\left({ }^{13} \mathrm{C}\right.$ NMR $) .{ }^{31} \mathrm{P}$ NMR spectra were obtained on a Varian $300 \mathrm{MHz}$ (operating frequency $121 \mathrm{MHz}$ ) spectrometer and referenced against an external standard of $\mathrm{H}_{3} \mathrm{PO}_{4}(\delta=0)$. Resonances due to the Tp ligand in ${ }^{1} \mathrm{H}$ NMR spectra are listed by chemical shift and multiplicity only (all coupling constants for the Tp ligand are $\sim 2 \mathrm{~Hz}$ ).

Electrochemical experiments were performed under a nitrogen atmosphere using a BAS Epsilon Potentiostat. Cyclic voltammograms were recorded in NCMe using a standard three electrode cell from -1700 to $1700 \mathrm{mV}$ at $100 \mathrm{mV} / \mathrm{s}$ [with the exception of $\left(\eta^{6}-\mathrm{C}_{6} \mathrm{H}_{6}\right) \mathrm{Ru}(\mathrm{CO}) \mathrm{Cl}_{2}$, which was scanned from -1700 to $2500 \mathrm{mV}$ at a scan rate of 100 $\mathrm{mV} / \mathrm{s}$ ] with a glassy carbon working electrode and tetrabutylammonium hexafluorophosphate as electrolyte. All potentials are reported versus NHE (normal hydrogen electrode) using ferrocene as the internal standard.

High-resolution electrospray ionization mass spectrometry (ESI-MS) analyses were obtained on a Bruker BioTOF-Q spectrometer at the University of Richmond. Samples were dissolved in acetonitrile and then mixed 3:1 with $0.1 \mathrm{M}$ aqueous sodium trifluoroacetate $(\mathrm{NaTFA})$ using $\left[\mathrm{Na}(\mathrm{NaTFA})_{\mathrm{x}}\right]^{+}$clusters as an internal standard. These data are reported using the most intense peaks from the isotopic envelope for $[\mathrm{M}+\mathrm{Na}]^{+}$. The data are listed as $m / z$ with the intensity relative to the most abundant peak of the isotopic envelope given in parentheses for both the calculated and observed peaks. The difference between calculated and observed peaks is reported in ppm. In all cases, observed isotopic envelopes were consistent with the composition reported. 
The preparation, isolation and characterization of $\mathrm{TpRu}\left[\mathrm{P}\left(\mathrm{OCH}_{2}\right)_{3} \mathrm{CEt}\right]\left(\mathrm{PPh}_{3}\right) \mathrm{Cl}(\mathbf{3}),{ }^{31}$ $\mathrm{TpRu}\left(\mathrm{PMe}_{3}\right)\left(\mathrm{PPh}_{3}\right) \mathrm{Cl}(\mathbf{4}),{ }^{38}\left(\eta^{6}-\mathrm{C}_{6} \mathrm{H}_{6}\right) \mathrm{Ru}(\mathrm{CO}) \mathrm{Cl}_{2}(\mathbf{1 1}),{ }^{39}\left(\eta^{6}-\mathrm{C}_{6} \mathrm{H}_{6}\right) \mathrm{Ru}\left(\mathrm{PPh}_{3}\right) \mathrm{Cl}_{2}(\mathbf{6}),{ }^{40}$ and $\left(\eta^{6}-\mathrm{C}_{6} \mathrm{H}_{6}\right) \mathrm{Ru}\left[\mathrm{P}(\mathrm{OMe})_{3}\right] \mathrm{Cl}(7)^{40}$ have been previously reported. $\mathrm{P}\left(\mathrm{OCH}_{2}\right)_{3} \mathrm{CEt}$ was obtained from a commercial source and purified by reconstitution in hexanes followed by filtration through Celite. The filtrate was concentrated to dryness to yield pure material.

Calculations. DFT calculations were performed using the standard Becke-Perdew (BP86) density functional ${ }^{56-60}$ in conjunction with the double- $\zeta 6-31+\mathrm{G}(\mathrm{d})$ basis set for all atoms excluding gold, for which the Los Alamos National Laboratory LANL2DZ ${ }^{61}$ basis set, augmented by diffuse and contracted $\mathrm{f}$ functions taken from Pyykkö and Mendizabal ${ }^{62}$ and the $6 \mathrm{p}$ functions of Couty and Hall, ${ }^{63}$ was employed. All calculations were performed using the Gaussian 09 suite of programs. ${ }^{64}$

$\mathbf{C}\left(\mathbf{C H}_{3}\right)(\mathbf{O H})\left(\mathbf{C H}_{2} \mathbf{O H}\right)_{2}$. The synthesis of $\mathrm{C}\left(\mathrm{CH}_{3}\right)(\mathrm{OH})\left(\mathrm{CH}_{2} \mathrm{OH}\right)_{2}$ has been previously reported..$^{36} \mathrm{We}$ used an alternate procedure. The reaction was performed in a vented hood. $\mathrm{H}_{2} \mathrm{O}_{2}(30 \%, 8.51 \mathrm{~mL}, 0.0826 \mathrm{~mol})$ was added to formic acid $(88 \%, 34.7$ $\mathrm{mL}, 0.808 \mathrm{~mol}$ ), and the mixture was stirred at room temperature for 5 minutes. The flask was placed in an ice bath, and 2-methyl-2-propen-1-ol $(5.0 \mathrm{~mL}, 0.059 \mathrm{~mol})$ was added slowly using an addition funnel. The reaction was heated at $40{ }^{\circ} \mathrm{C}$ for $1 \mathrm{~h}$. The solution was allowed to cool to room temperature. After $16 \mathrm{~h}$ at room temperature, the solution was concentrated in vacuo, and the residual oil was cooled in an ice bath and treated drop wise with $10 \mathrm{~mL}$ of cold $\mathrm{NaOH}(13.3 \mathrm{M})$. The resulting mixture was heated for $1 \mathrm{~h}$ at 40 ${ }^{\circ} \mathrm{C}$, which resulted in a yellow solution. After the addition of acetone $(\sim 50 \mathrm{~mL})$, the top 
layer was removed using a pipette. The acetone addition/extraction was repeated three times, and all extractions were combined. The combined fractions were concentrated under reduced pressure. The remaining pale yellow viscous oil was dissolved in a minimal amount of methanol, and diethyl ether was added to induce precipitation. The mixture was filtered using a fine porosity frit, and the solid was discarded. This step was repeated multiple times until no precipitate was observed upon the addition of diethyl ether. The filtrates were combined and concentrated in vacuo to give a brownish-yellow oil. The oil was purified by column chromatography on silica using 1:2 methanol:ethyl acetate as eluent. The solution was concentrated to dryness to yield a brownish-yellow oil (4.206 g, 67\%). The sample was dried by azeotropic distillation in benzene. ${ }^{1} \mathrm{H}$ NMR $\left(\mathrm{D}_{2} \mathrm{O}, 300 \mathrm{MHz}, \delta\right) 3.47\left(\mathrm{~s}, 4 \mathrm{H}, \mathrm{CH}_{2}\right), 1.13\left(\mathrm{~s}, 3 \mathrm{H}, \mathrm{CH}_{3}\right) .{ }^{13} \mathrm{C} \mathrm{NMR}\left(125 \mathrm{MHz}, \mathrm{CD}_{3} \mathrm{OD}\right.$,

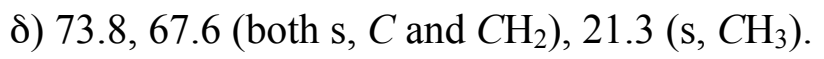

$\mathbf{P}\left(\mathrm{OCH}_{2}\right)_{2}\left(\mathbf{O C C H}_{3}\right)$ (1). The synthesis of $\mathrm{P}\left(\mathrm{OCH}_{2}\right)_{2}\left(\mathrm{OCCH}_{3}\right)$ has been previously reported. ${ }^{33}$ We used a modified procedure. $\mathrm{C}\left(\mathrm{CH}_{3}\right)(\mathrm{OH})\left(\mathrm{CH}_{2} \mathrm{OH}\right)_{2}(1.032 \mathrm{~g}, 9.725 \mathrm{mmol})$ was added to benzene $(200 \mathrm{~mL})$ in a $400 \mathrm{~mL}$ beaker. $\mathrm{NaH}(0.695 \mathrm{~g}, 29.0 \mathrm{mmol})$ was added to the reaction vessel, and the reaction mixture was stirred at room temperature for 1.25 h. $\mathrm{PCl}_{3}(775 \mu \mathrm{L}, 8.89 \mathrm{mmol})$ was added slowly via syringe, and the reaction was stirred at room temperature for over night. The heterogeneous mixture was filtered through a fine porosity frit. Attempts to isolate pure $\mathbf{1}$ lead to decomposition. Thus, for coordination to $\mathrm{Ru}, \mathbf{1}$ was generated as described above and added to the $\mathrm{Ru}$ precursor without isolation. ${ }^{31} \mathrm{P}\left\{{ }^{1} \mathrm{H}\right\} \mathrm{NMR}\left(121 \mathrm{MHz}, \mathrm{C}_{6} \mathrm{D}_{6}, \delta\right): 115.5\left[P\left(\mathrm{OCH}_{2}\right)_{2}\left(\mathrm{OCCH}_{3}\right)\right]$. 
TpRu[ $\left.\mathbf{P}\left(\mathrm{OCH}_{2}\right)_{2}\left(\mathbf{O C C H}_{3}\right)\right]\left(\mathbf{P P h}_{3}\right) \mathbf{C l}$ (2). A benzene solution of phosphite $\mathbf{1}$ (150 $\mathrm{mL}, 2.98 \mathrm{mmol})$ was added to $\mathrm{TpRu}\left(\mathrm{PPh}_{3}\right)_{2} \mathrm{Cl}(0.510 \mathrm{~g}, 0.564 \mathrm{mmol})$. The solution was refluxed for $3 \mathrm{~h}$ to give a bright yellow solution. The solution was filtered through Celite, and the volatiles were removed from the filtrate in vacuo. The resulting solid was dissolved in minimal THF. Hexanes were added to induce precipitation of a yellow solid, which was collected on a fine porosity frit and dried in vacuo. The solid was dissolved in $\mathrm{CH}_{2} \mathrm{Cl}_{2}$ and loaded onto a silica column. The column was washed with hexanes, and the eluent was discarded. The column was then eluted with $\mathrm{Et}_{2} \mathrm{O}$. The eluent was collected and reduced in vacuo to $\sim 2 \mathrm{~mL}$. Hexanes were added to induce precipitation of a yellow solid, which was collected on a fine porosity frit and dried in vacuo $(0.0933 \mathrm{~g}, 19.5 \%$ yield). Crystals of 2 were obtained by slow evaporation of a $\mathrm{CH}_{2} \mathrm{Cl}_{2}$ solution layered with hexanes. ${ }^{1} \mathrm{H}$ NMR $\left(500 \mathrm{MHz}, \mathrm{CDCl}_{3}, \delta\right.$ ): 8.15, 7.65, 7.63, 7.52 (each a d, each $1 \mathrm{H}, \mathrm{Tp} 3$ and 5), 7.38-7.15 (overlapping m's, $\left.15 \mathrm{H}, \mathrm{P}\left(\mathrm{C}_{6} H_{5}\right)_{3}\right), 6.91,6.72$ (each a d, each $1 \mathrm{H}, \mathrm{Tp} 3$ and 5), $6.09\left(\mathrm{dt}, 1 \mathrm{H},{ }^{5} J_{\mathrm{HP}}=1.0 \mathrm{~Hz}, \mathrm{Tp} 4\right), 5.80\left(\mathrm{dt}, 1 \mathrm{H},{ }^{5} J_{\mathrm{HP}}=1.3 \mathrm{~Hz}, \mathrm{Tp} 4\right), 5.75(\mathrm{t}, 1 \mathrm{H}$, Tp 4), $3.93\left(\mathrm{dd}, 2 \mathrm{H},{ }^{2} J_{\mathrm{HH}}=8.0 \mathrm{~Hz},{ }^{3} J_{\mathrm{HP}}=8.0 \mathrm{~Hz}, \mathrm{P}\left(\mathrm{OCH}_{2}\right)_{2}\left(\mathrm{OCCH}_{3}\right)\right.$; Note: assignment of coupling constants was based on decoupling experiments), 3.50 (ddd, $1 \mathrm{H},{ }^{2} J_{\mathrm{HH}}=8.0$ $\left.\mathrm{Hz},{ }^{3} J_{\mathrm{HP}}=3.6 \mathrm{~Hz},{ }^{4} J_{\mathrm{HH}}=1.4 \mathrm{~Hz}, \mathrm{P}\left(\mathrm{OCH}_{2}\right)_{2}\left(\mathrm{OCCH}_{3}\right)\right), 3.45\left(\mathrm{ddd}, 1 \mathrm{H},{ }^{2} J_{\mathrm{HH}}=8.0 \mathrm{~Hz}\right.$, $\left.{ }^{3} J_{\mathrm{HP}}=3.6 \mathrm{~Hz},{ }^{4} J_{\mathrm{HH}}=1.4 \mathrm{~Hz}, \mathrm{P}\left(\mathrm{OCH}_{2}\right)_{2}\left(\mathrm{OCCH}_{3}\right)\right), 1.51$ (s, 3H, $\left.\mathrm{P}\left(\mathrm{OCH}_{2}\right)_{2}\left(\mathrm{OCCH}_{3}\right)\right)$. ${ }^{13} \mathrm{C}$ NMR (125 MHz, $\mathrm{CDCl}_{3}, \delta$ ): 148.2, 145.3, 143.9, 136.4 (Tp 3 or 5 position), 135.0 (d, $J_{\mathrm{CP}}=9.0 \mathrm{~Hz}$, ortho or meta of $\left.\mathrm{PPh}_{3}\right), 134.7,134.5\left(\mathrm{Tp} 3\right.$ or 5 or ipso of $\mathrm{PPh}_{3}$ with one singlet missing presumably due to coincidental overlap), 129.3 (para of $\mathrm{PPh}_{3}$ ), 127.4 (d, 
$J_{\mathrm{CP}}=9.0 \mathrm{~Hz}$, ortho or meta of $\left.\mathrm{PPh}_{3}\right), 105.7,105.5,105.2$ (Tp 4 position), 81.6 [ $\mathrm{P}\left(\mathrm{OCH}_{2}\right)_{2}\left(\mathrm{OCCH}_{3}\right)$ ], 74.9-74.7 (overlapping resonances, $\left.\mathrm{P}\left(\mathrm{OCH}_{2}\right)_{2}\left(\mathrm{OCCH}_{3}\right)\right), 15.6(\mathrm{~d}$, $\left.J_{\mathrm{CP}}=10 \mathrm{~Hz}, \mathrm{P}\left(\mathrm{OCH}_{2}\right)_{2}\left(\mathrm{OCCH}_{3}\right)\right) .{ }^{31} \mathrm{P}\left\{{ }^{1} \mathrm{H}\right\} \mathrm{NMR}\left(121 \mathrm{MHz}, \mathrm{CDCl}_{3}, \delta\right): 162.6\left(\mathrm{~d},{ }^{2} J_{\mathrm{PP}}=\right.$ $\left.55 \mathrm{~Hz}, P\left(\mathrm{OCH}_{2}\right)_{2}\left(\mathrm{OCCH}_{3}\right)\right), 44.8\left(\mathrm{~d},{ }^{2} J_{\mathrm{PP}}=55 \mathrm{~Hz}, P \mathrm{Ph}_{3}\right) . \mathrm{CV}(\mathrm{NCMe}): E_{1 / 2}=1.08 \mathrm{~V}$ $\mathrm{Ru}(\mathrm{III} / \mathrm{II})$. Anal. Calcd. for $\mathrm{C}_{22} \mathrm{H}_{35} \mathrm{BClN}_{6} \mathrm{O}_{3} \mathrm{P}_{2} \mathrm{Ru} \bullet \mathrm{CH}_{2} \mathrm{Cl}_{2}$ [NOTE: repeated efforts to dry this sample did not remove residual solvent. Thus, one equivalent of dichloromethane (observed and quantified by ${ }^{1} \mathrm{H}$ NMR spectroscopy) is included in elemental analysis calculations]: C, 46.26; H, 4.12; N, 10.12. Found: C, 46.84; H, 4.19; N, 10.28.

TpRu[P(OMe) $\left.)_{3}\right]\left(\mathbf{P P h}_{3}\right) \mathbf{C l}$ (5). $\mathrm{TpRu}\left(\mathrm{PPh}_{3}\right)_{2} \mathrm{Cl}(0.295 \mathrm{~g}, 0.338 \mathrm{mmol})$ was added to $20 \mathrm{~mL}$ of $\mathrm{C}_{6} \mathrm{H}_{6}$, and $\mathrm{P}(\mathrm{OMe})_{3}(0.0460 \mathrm{~g}, 0.371 \mathrm{mmol})$ was added. The solution was refluxed for $3 \mathrm{~h}$ to give a bright yellow solution. The volatiles were removed in vacuo. The resulting solid was dissolved in minimal THF. Hexanes were added, and the solvent was reduced in vacuo to induce precipitation of a yellow solid, which was collected on a fine porosity frit and dried in vacuo $(0.0557 \mathrm{~g}, 67.0 \%) .{ }^{1} \mathrm{H} \mathrm{NMR}\left(300 \mathrm{MHz}, \mathrm{CDCl}_{3}, \delta\right)$ 8.12, 7.65, 7.58, 7.56 (each a d, each 1H, Tp 3 and 5), 7.41-7.11 (overlapping m’s, 15H, $\left.\mathrm{P}\left(\mathrm{C}_{6} H_{5}\right)_{3}\right), 6.83,6.66$ (each a d, each $1 \mathrm{H}, \mathrm{Tp} 3$ and 5), 6.13, 5.75, 5.70 (each a t, each $1 \mathrm{H}$, Tp 4), $3.24\left(\mathrm{~d},{ }^{3} J_{\mathrm{HP}}=10.3 \mathrm{~Hz}, 9 \mathrm{H}, \mathrm{P}\left(\mathrm{OCH}_{3}\right)_{3}\right) .{ }^{13} \mathrm{C} \mathrm{NMR}\left(125 \mathrm{MHz}, \mathrm{CDCl}_{3}\right) \delta 148.0$, 144.8, 144.1, 136.2, 135.5, 135.2 (Tp 3 or 5 position), 134.9 (d, $J_{\mathrm{CP}}=9 \mathrm{~Hz}$, ortho or meta of $\left.\mathrm{P}\left(\mathrm{C}_{6} \mathrm{H}_{5}\right)_{3}\right), 134.6$ (ipso of $\left.\mathrm{P}\left(\mathrm{C}_{6} H_{5}\right)_{3}\right), 128.9$ (para of $\left.\mathrm{P}\left(\mathrm{C}_{6} \mathrm{H}_{5}\right)_{3}\right), 127.2\left(\mathrm{~d}, J_{\mathrm{CP}}=9 \mathrm{~Hz}\right.$, ortho or meta of $\left.\mathrm{P}\left(\mathrm{C}_{6} \mathrm{H}_{5}\right)_{3}\right)$, 105.2 (coincidental overlap of two Tp 4 position), 104.3 (Tp 4 position), $51.8\left(\mathrm{~d},{ }^{2} J_{\mathrm{CP}}=6.3 \mathrm{~Hz}, \mathrm{CH}_{3}\right) .{ }^{31} \mathrm{P} \mathrm{NMR}\left(121 \mathrm{MHz}, \mathrm{CDCl}_{3}, \delta\right): 145.9\left(\mathrm{~d},{ }^{2} J_{\mathrm{PP}}=\right.$ 
$54 \mathrm{~Hz}, P(\mathrm{OMe})_{3}, 46.1\left(\mathrm{~d},{ }^{2} J_{\mathrm{PP}}=54 \mathrm{~Hz}, P \mathrm{Ph}_{3}\right) . \mathrm{CV}(\mathrm{NCMe}): E_{1 / 2}=0.88 \mathrm{~V} \mathrm{Ru}(\mathrm{III} / \mathrm{II})$. HRMS: $[\mathrm{M}+\mathrm{Na}]^{+}$obsd (\%), calcd (\%), ppm: 756.091 (38), 756.08845 (31.1), 3.4; 757.09061 (50.3), 757.09029 (53), 0.4; 758.09062 (77), 758.08983 (78.8), 1; 759.08946 (100), 759.08712 (100), 3.1; 760.09086 (56.8), 760.08976 (49.2), 1.4; 761.08919 (73.4), 761.08741 (72.6), 2.3; 762.09149 (26.1), 762.0891 (27.9), 3.1.

$\left(\eta^{6}-\mathbf{C}_{6} \mathbf{H}_{6}\right) \mathbf{R u}\left(\mathbf{P P h}_{3}\right) \mathbf{C l}_{2}$ (6). The synthesis and characterization of $\left(\eta^{6}-\right.$ $\left.\mathrm{C}_{6} \mathrm{H}_{6}\right) \mathrm{Ru}\left(\mathrm{PPh}_{3}\right) \mathrm{Cl}_{2}$ have been previously reported. ${ }^{40}{ }^{1} \mathrm{H}$ NMR spectroscopy revealed pure material and was consistent with previously reported data. $\mathrm{CV}(\mathrm{NCMe}): \mathrm{E}_{1 / 2}=1.31 \mathrm{~V}$ $\mathrm{Ru}(\mathrm{III} / \mathrm{II})$ (quasi-reversible); $\mathrm{E}_{\mathrm{p}, \mathrm{c}}=-0.85 \mathrm{~V}$ and $-1.07 \mathrm{~V}$ )

$\left(\eta^{6}-\mathbf{C}_{6} \mathbf{H}_{6}\right) \mathbf{R u}\left[\mathbf{P}(\mathrm{OMe})_{3}\right] \mathbf{C l}$ (7). The synthesis and characterization of $\left(\eta^{6}-\right.$ $\left.\mathrm{C}_{6} \mathrm{H}_{6}\right) \mathrm{Ru}\left[\mathrm{P}(\mathrm{OMe})_{3}\right] \mathrm{Cl}_{2}$ have been previously reported. ${ }^{40}{ }^{1} \mathrm{H}$ NMR spectroscopy revealed clean material and was consistent with previously reported data. $\mathrm{CV}(\mathrm{NCMe}): \mathrm{E}_{1 / 2}=1.30$ $\mathrm{V} \mathrm{Ru(III/II)} \mathrm{(quasi-reversible);} \mathrm{E}_{\mathrm{p}, \mathrm{c}}=-0.94 \mathrm{~V}(\mathrm{n}=2)$.

$\left(\eta^{6}-\mathbf{C}_{6} \mathbf{H}_{6}\right) \mathbf{R u}\left(\mathbf{P M e}_{3}\right) \mathbf{C l}_{2}$ (8). The synthesis of $\left(\eta^{6}-\mathrm{C}_{6} \mathrm{H}_{6}\right) \mathrm{Ru}\left(\mathrm{PMe}_{3}\right) \mathrm{Cl}_{2}$ has been previously reported. ${ }^{42} \mathrm{We}$ used an alternate procedure. $\left[\left(\eta^{6}-\mathrm{C}_{6} \mathrm{H}_{6}\right) \mathrm{Ru}(\mathrm{Cl})(\mathrm{m}-\mathrm{Cl})\right]_{2}(0.140$ g, $0.280 \mathrm{mmol})$ was stirred in $\mathrm{CH}_{2} \mathrm{Cl}_{2}(\sim 30 \mathrm{~mL})$ at room temperature. $\mathrm{PMe}_{3}(0.0470 \mathrm{~g}$, $0.616 \mathrm{mmol}$ ) was added slowly by syringe. The solution was stirred at room temperature for $3 \mathrm{~h}$ during which time the heterogeneous solution became a homogeneous red solution. The solution was filtered through a fine porosity frit. The filtrate was reduced in vacuo to $\sim 5 \mathrm{~mL}$. Hexanes were added to induce an orange precipitate. The mixture was filtered through a fine porosity fritted funnel. The solid was dried in vacuo to yield an 
orange solid ( $0.153 \mathrm{~g}, 83.8 \%)$. Although complex 8 has been previously reported, NMR data were not provided. ${ }^{1} \mathrm{H}$ NMR $\left(500 \mathrm{MHz}, \mathrm{CDCl}_{3}, \delta\right): 5.58\left(\mathrm{~s}, 6 \mathrm{H}, \mathrm{C}_{6} \mathrm{H}_{6}\right), 1.65(\mathrm{~d}, 9 \mathrm{H}$, $\left.{ }^{2} J_{\mathrm{HP}}=11.4 \mathrm{~Hz}, \mathrm{CH}_{3}\right) \cdot{ }^{13} \mathrm{C} \mathrm{NMR}\left(125 \mathrm{MHz}, \mathrm{CDCl}_{3}, \delta\right): 87.2\left(\mathrm{~s}, C_{6} \mathrm{H}_{6}\right), 16.6\left(\mathrm{~d},{ }^{1} J_{\mathrm{PC}}=\right.$ $\left.34.1 \mathrm{~Hz}, \mathrm{CH}_{3}\right){ }^{31} \mathrm{P}\left\{{ }^{1} \mathrm{H}\right\} \mathrm{NMR}\left(121 \mathrm{MHz}, \mathrm{CDCl}_{3}, \delta\right): 7.5\left(\mathrm{~s}, P \mathrm{Me}_{3}\right) . \mathrm{CV}(\mathrm{NCMe}): \mathrm{E}_{1 / 2}=$ $1.19 \mathrm{~V} \mathrm{Ru}(\mathrm{III} / \mathrm{II})$ (quasi-reversible); $\mathrm{E}_{\mathrm{p}, \mathrm{c}}=-1.25 \mathrm{~V}$.

$\left(\eta^{6}-\mathbf{C}_{6} \mathbf{H}_{6}\right) \mathbf{R u}\left[\mathbf{P}\left(\mathbf{O C H}_{2}\right)_{3} \mathbf{C E t}\right] \mathbf{C l}_{2}(9) . \mathrm{P}\left(\mathrm{OCH}_{2}\right)_{3} \mathrm{CEt}(0.248 \mathrm{~g}, 1.53 \mathrm{mmol})$ and $\left[\left(\eta^{6}-\right.\right.$ $\left.\left.\mathrm{C}_{6} \mathrm{H}_{6}\right) \mathrm{Ru}(\mathrm{Cl})(\mu-\mathrm{Cl})\right]_{2}(0.382 \mathrm{~g}, 0.764 \mathrm{mmol})$ were stirred in $\mathrm{CH}_{2} \mathrm{Cl}_{2}(\sim 50 \mathrm{~mL})$ at room temperature overnight to give a heterogeneous mixture. The solid was collected by filtration through a fine porosity frit, washed with $\mathrm{CH}_{2} \mathrm{Cl}_{2}$ and pentane and dried in vacuo to yield a red solid $(0.601 \mathrm{~g}, 95.5 \%) .{ }^{1} \mathrm{H}$ NMR $\left(500 \mathrm{MHz}, \mathrm{DMSO}-d_{6}, \delta\right): 5.82$ (s, $6 \mathrm{H}$, $\left.\mathrm{C}_{6} H_{6}\right), 4.37\left(\mathrm{~d}, 6 \mathrm{H},{ }^{3} J_{\mathrm{HP}}=4.7 \mathrm{~Hz}, \mathrm{P}\left(\mathrm{OCH}_{2}\right)_{3} \mathrm{CCH}_{2} \mathrm{CH}_{3}\right), 1.24\left(\mathrm{q}, 2 \mathrm{H},{ }^{3} J_{\mathrm{HH}}=7.7 \mathrm{~Hz}\right.$, $\left.\mathrm{CCH}_{2} \mathrm{CH}_{3}\right), 0.77\left(\mathrm{t}, 3 \mathrm{H},{ }^{3} \mathrm{~J}_{\mathrm{HH}}=7.6 \mathrm{~Hz},-\mathrm{CCH}_{2} \mathrm{CH}_{3}\right) .{ }^{13} \mathrm{C} \mathrm{NMR}\left(125 \mathrm{MHz}, \mathrm{DMSO}-d_{6}, \delta\right)$ : $90.0\left(\mathrm{~s}, \mathrm{C}_{6} \mathrm{H}_{6}\right), 87.6\left(\mathrm{~s}, \mathrm{P}\left(\mathrm{OCH}_{2}\right)_{3} \mathrm{CCH}_{2} \mathrm{CH}_{3}\right), 74.8\left(\mathrm{~s}, \mathrm{P}\left(\mathrm{OCH}_{2}\right)_{3} \mathrm{CCH}_{2} \mathrm{CH}_{3}\right), 22.1$ (s, $\left.\mathrm{P}\left(\mathrm{OCH}_{2}\right)_{3} \mathrm{CCH}_{2} \mathrm{CH}_{3}\right), 6.9\left(\mathrm{~s}, \mathrm{P}\left(\mathrm{OCH}_{2}\right)_{3} \mathrm{CCH}_{2} \mathrm{CH}_{3}\right) .{ }^{31} \mathrm{P}\left\{{ }^{1} \mathrm{H}\right\}$ NMR (121 MHz, DMSO-d 6 ,

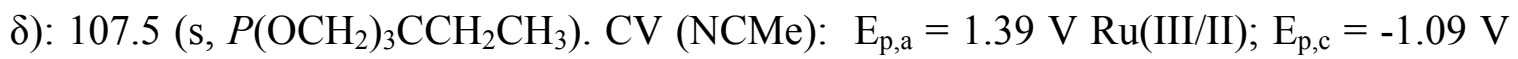
$\mathrm{Ru}(\mathrm{II} / \mathrm{I})$. Anal. Calcd. for $\mathrm{C}_{12} \mathrm{H}_{17} \mathrm{Cl}_{2} \mathrm{O}_{3} \mathrm{PRu} \bullet\left(\mathrm{CH}_{2} \mathrm{Cl}_{2}\right)_{0.25}$ [NOTE: repeated efforts to dry this sample did not remove residual solvent. Thus, 0.25 equivalents of dichloromethane (observed and quantified by ${ }^{1} \mathrm{H}$ NMR spectroscopy) are included in elemental analysis calculations]: C, 33.94; H, 4.08. Found: C, 34.25; H, 4.18.

$\left(\eta^{6}-\mathbf{C}_{6} \mathbf{H}_{6}\right) \mathbf{R u}\left[\mathbf{P}\left(\mathrm{OCH}_{2}\right)_{2}\left(\mathbf{O C C H}_{3}\right)\right] \mathbf{C l}_{2} \mathbf{2}(\mathbf{1 1})$. Compound $\mathbf{1}\left[55 \mathrm{~mL}\right.$ of $\mathbf{1}$ in $\mathrm{C}_{6} \mathrm{H}_{6}(\sim$ $0.0054 \mathrm{M})]$ was added to $\left[\left(\eta^{6}-\mathrm{C}_{6} \mathrm{H}_{6}\right) \mathrm{Ru}(\mathrm{Cl})(\mu-\mathrm{Cl})\right]_{2}(0.505 \mathrm{~g}, 1.01 \mathrm{mmol})$. The solution 
was stirred in $\mathrm{CH}_{2} \mathrm{Cl}_{2}(\sim 100 \mathrm{~mL})$ at room temperature for $2 \mathrm{~h}$ to give an orange solution. The mixture was filtered through a fine porosity frit. The filtrate was added to a $1 / 4$ inch plug of silica gel on top of $1 / 4$ inch of Celite and eluted with $\mathrm{CH}_{2} \mathrm{Cl}_{2}$. The volume of the eluent was reduced in vacuo to $\sim 3 \mathrm{~mL}$. Hexanes were added to the eluent to yield a red precipitate. The solution was filtered through a fine porosity frit and dried in vacuo to give a red solid (0.102 g, 25\% based on Ru dimer). Crystals of 4 were obtained by slow evaporation from a chloroform solution. ${ }^{1} \mathrm{H}$ NMR $\left(500 \mathrm{MHz}, \mathrm{CD}_{2} \mathrm{Cl}_{2}, \delta\right) 5.90(\mathrm{~s}, 6 \mathrm{H}$, $\left.\mathrm{C}_{6} H_{6}\right), 4.26\left(\mathrm{~m}, 2 \mathrm{H}, \mathrm{P}\left(\mathrm{OCH}_{2}\right)_{2}\left(\mathrm{OCCH}_{3}\right)\right), 3.84\left(\mathrm{~d}, 2 \mathrm{H},{ }^{2} J_{\mathrm{HH}}=6.5 \mathrm{~Hz} \mathrm{CH}\right), 1.69(\mathrm{~s}, 3 \mathrm{H}$, $\left.\mathrm{CH}_{3}\right) .{ }^{13} \mathrm{C} \mathrm{NMR}\left(75 \mathrm{MHz}, \mathrm{CDCl}_{3}, \delta\right): 91.5\left(\mathrm{~s}, \mathrm{C}_{6} \mathrm{H}_{6}\right), 83.3\left(\mathrm{~s}, \mathrm{P}\left(\mathrm{OCH}_{2}\right)_{2}\left(\mathrm{OCCH}_{3}\right)\right), 75.9$ $\left(\mathrm{d},{ }^{2} J_{\mathrm{CP}}=5.4 \mathrm{~Hz}, \mathrm{P}\left(\mathrm{OCH}_{2}\right)_{2}\left(\mathrm{OCCH}_{3}\right)\right), 15.0\left(\mathrm{~s}, \mathrm{P}\left(\mathrm{OCH}_{2}\right)_{2}\left(\mathrm{OCCH}_{3}\right)\right){ }^{31} \mathrm{P}\left\{{ }^{1} \mathrm{H}\right\} \mathrm{NMR}(121$ $\left.\mathrm{MHz}, \mathrm{CD}_{2} \mathrm{Cl}_{2}, \delta\right): 139.7 P\left(\mathrm{OCH}_{2}\right)_{2}\left(\mathrm{OCCH}_{3}\right)$. HRMS: $[\mathrm{M}+\mathrm{Na}]^{+}$obsd $(\%)$, calcd $(\%)$, ppm: 403.89292 (36.8), 403.8932 (15.2), 0.7; 405.89292 (36.8), 405.89274 (25.3), 0.4; 406.89271 (100), 406.8917 (100), 2.5; 407.89157 (36.8), 407.89134 (12.8), 0.6; 408.88907 (97.7), 408.89079 (28.8), 4.2; 409.89174 (85.5), 409.8919 (84.2), 0.4; 410.88847 (85.5), 410.88871 (84.2), 0.6. CV (NCMe): $E_{\mathrm{p}, \mathrm{a}}=1.50 \mathrm{~V} \mathrm{Ru}(\mathrm{III} / \mathrm{II}) ; E_{\mathrm{p}, \mathrm{c}}=-$ $0.99 \mathrm{~V} \mathrm{Ru}(\mathrm{II} / \mathrm{I})$.

$\left(\eta^{6}\right.$-p-cymene $) \mathbf{R u}\left[\mathbf{P}\left(\mathbf{O C H}_{2}\right)_{3} \mathbf{C E t}\right] \mathbf{C l}_{2} \quad$ (12). The dimeric complex $\left[\left(\eta^{6}-p\right.\right.$ cymene $) \mathrm{Ru}(\mathrm{Cl})(\mu-\mathrm{Cl})]_{2}(0.102 \mathrm{~g}, 0.166 \mathrm{mmol})$ and $\mathrm{P}\left(\mathrm{OCH}_{2}\right)_{3} \mathrm{CEt}(0.0690 \mathrm{~g}, 0.436 \mathrm{mmol})$ were combined in a round bottom flask with $20 \mathrm{~mL}$ of $\mathrm{CH}_{2} \mathrm{Cl}_{2}$. The reaction mixture was stirred at room temperature for $1 \mathrm{~h}$. The total volume of the solution was reduced in 
vacuo to $\sim 2 \mathrm{~mL}$. Hexanes were added to yield a red-orange precipitate. The solid was collected by filtration through a fine porosity frit and dried in vacuo to yield a red-orange solid (0.3830 g, 83\%). ${ }^{1} \mathrm{H}$ NMR (300 MHz, $\left.\mathrm{CDCl}_{3}, \delta\right) 5.63\left(\mathrm{~d}, 2 \mathrm{H},{ }^{3} \mathrm{~J}_{\mathrm{HH}}=6.0 \mathrm{~Hz}, \mathrm{C}_{6} H_{4}\right)$, $5.51\left(\mathrm{~d}, 2 \mathrm{H},{ }^{3} J_{\mathrm{HH}}=6.0 \mathrm{~Hz}, \mathrm{C}_{6} H_{4}\right), 4.37\left(\mathrm{~d}, 6 \mathrm{H},{ }^{3} J_{\mathrm{HP}}=5.0 \mathrm{~Hz}, \mathrm{P}\left(\mathrm{OCH}_{2}\right)_{3} \mathrm{CCH}_{2} \mathrm{CH}_{3}\right), 2.88$ (sept, $1 \mathrm{H},{ }^{2} J_{\mathrm{HH}}=7 \mathrm{~Hz},\left(\mathrm{CH}_{3} \mathrm{C}_{6} \mathrm{H}_{4}(\mathrm{CH})\left(\mathrm{CH}_{3}\right)_{2}\right), 2.16\left(\mathrm{~s}, 3 \mathrm{H}, \mathrm{C}_{6} \mathrm{H}_{4}-\mathrm{CH}_{3}\right), 1.32-1.15$ (overlapping m's, $8 \mathrm{H}$, coincidental overlap of $\mathrm{P}\left(\mathrm{OCH}_{2}\right)_{3} \mathrm{CCH}_{2} \mathrm{CH}_{3}$ and $\left.\mathrm{C}_{6} \mathrm{H}_{4}-\mathrm{CH}\left(\mathrm{CH}_{3}\right)_{2}\right)$, $0.84\left(\mathrm{t}, 3 \mathrm{H},{ }^{3} J_{\mathrm{HH}}=8 \mathrm{~Hz},\left(\mathrm{P}\left(\mathrm{OCH}_{2}\right){ }_{3} \mathrm{CCH}_{2} \mathrm{CH}_{3}\right) .{ }^{13} \mathrm{C} \mathrm{NMR}\left(75 \mathrm{MHz}, \mathrm{CDCl}_{3}\right) \delta 108.9(\mathrm{~s}\right.$, $\left.C_{6} \mathrm{H}_{4}\right), 103.3\left(\mathrm{~s}, C_{6} \mathrm{H}_{4}\right), 90.1\left(\mathrm{~d},{ }^{2} J_{\mathrm{PC}}=7.1 \mathrm{~Hz}, C_{6} \mathrm{H}_{4}\right), 89.3\left(\mathrm{~d},{ }^{2} J_{\mathrm{PC}}=6.0 \mathrm{~Hz}, C_{6} \mathrm{H}_{4}\right), 75.5$ $\left(\mathrm{d},{ }^{2} J_{\mathrm{CP}}=7.6 \mathrm{~Hz}, \mathrm{P}\left(\mathrm{OCH}_{2}\right)_{3} \mathrm{CCH}_{2} \mathrm{CH}_{3}\right), 36.1\left({ }^{3} J_{\mathrm{CP}}=32.2 \mathrm{~Hz}, \mathrm{P}\left(\mathrm{OCH}_{2}\right)_{3} \mathrm{CCH}_{2} \mathrm{CH}_{3}\right), 30.5$ (s, $\left.\mathrm{C}_{6} \mathrm{H}_{4}-\mathrm{CH}\left(\mathrm{CH}_{3}\right)_{2}\right), 23.4\left(\mathrm{~s}, \mathrm{P}\left(\mathrm{OCH}_{2}\right)_{3} \mathrm{CCH}_{2} \mathrm{CH}_{3}\right), 22.1\left(\mathrm{~s}, \mathrm{C}_{6} \mathrm{H}_{4}-\left(\mathrm{CH}\left(\mathrm{CH}_{3}\right)_{2}\right)\right), 18.6$ (s, $\left.\mathrm{C}_{6} \mathrm{H}_{4}-\mathrm{CH}_{3}\right), 7.3\left(\mathrm{~s}, \mathrm{P}\left(\mathrm{OCH}_{2}\right)_{3} \mathrm{CCH}_{2} \mathrm{CH}_{3}\right) .{ }^{31} \mathrm{P}\left\{{ }^{1} \mathrm{H}\right\}$ NMR (121 MHz, $\left.\mathrm{CD}_{2} \mathrm{Cl}_{2}, \delta\right): 111.8$ $\left(P\left(\mathrm{OCH}_{2}\right)_{2} \mathrm{CEt}\right)$. HRMS: $[\mathrm{M}+\mathrm{Na}]^{+}$obsd (\%), calcd (\%), ppm: 488.9858 (37.6), 488.98503 (32.9), 1.6; 489.98611 (62.9), 489.98504 (42), 2.2; 490.98525 (100), 490.98445 (100), 1.6; 491.98534 (44.5), 491.98404 (32.9), 2.6; 492.9845 (96.7), 492.98449 (94.8), $0 ; 493.98643$ (85.5), 493.98554 (84.2), 1.8; 494.98312 (85.5), 494.98235 (84.2), 1.6. CV (NCMe): $\mathrm{E}_{1 / 2}=1.30 \mathrm{~V} \mathrm{Ru(III/II)} \mathrm{(quasi-reversible);} \mathrm{E}_{\mathrm{p}, \mathrm{c}}=-$ $1.23 \mathrm{~V} \mathrm{Ru}(\mathrm{II} / \mathrm{I})$.

$\left(\eta^{6}\right.$-p-cymene)Ru[P( $\left.\left(\mathrm{OCH}_{2}\right)_{2}\left(\mathrm{OCCH}_{3}\right)\right] \mathrm{Cl}_{2}(13)$. A benzene solution of $\mathbf{1}(0.570$ $\mathrm{g}, 4.25 \mathrm{mmol})$ was added to $\left[\left(\eta^{6}-p \text {-cymene }\right) \mathrm{Ru}(\mathrm{Cl})(\mu-\mathrm{Cl})\right]_{2}(0.369 \mathrm{~g}, 0.603 \mathrm{mmol})$ in $\mathrm{CH}_{2} \mathrm{Cl}_{2}(\sim 75 \mathrm{~mL})$. The solution was stirred at room temperature for 30 minutes to give an orange solution. The solvent volume was reduced in vacuo to $\sim 25 \mathrm{~mL}$. Hexanes were 
added to yield a red precipitate, which formed a red oil. The solution was filtered through Celite. The solid collected on Celite was eluted with $\mathrm{CH}_{2} \mathrm{Cl}_{2}$. The solvent was removed in vacuo. The resulting solid was washed with pentane. The solid was dried to yield a reddish-orange solid $(0.489 \mathrm{~g}, 92.3 \%)$. This crude material was purified on an alumina column with 1:1 $\mathrm{CH}_{2} \mathrm{Cl}_{2}$ :THF as eluent (0.088 mg, 20\%). ${ }^{1} \mathrm{H} \mathrm{NMR}\left(300 \mathrm{MHz}, \mathrm{CDCl}_{3}, \delta\right)$ $5.76\left(\mathrm{~d}, 2 \mathrm{H}, \mathrm{C}_{6} \mathrm{H}_{4},{ }^{3} J_{\mathrm{HH}}=5.9 \mathrm{~Hz}\right), 5.62\left(\mathrm{~d}, 2 \mathrm{H}, \mathrm{C}_{6} H_{4},{ }^{3} J_{\mathrm{HH}}=5.9 \mathrm{~Hz}\right), 4.22$ (apparent t, $\left.2 \mathrm{H}, \mathrm{P}\left(\mathrm{OCH}_{2}\right)_{2}\left(\mathrm{OCCH}_{3}\right),{ }^{2} J_{\mathrm{HH}}=8 \mathrm{~Hz}\right) 3.83\left(\mathrm{~d}, 2 \mathrm{H}, \mathrm{P}\left(\mathrm{OCH}_{2}\right)_{2}\left(\mathrm{OCCH}_{3}\right),{ }^{2} J_{\mathrm{HH}}=7 \mathrm{~Hz}\right)$, 2.90 (sept, $1 \mathrm{H},\left(\mathrm{CH}_{3} \mathrm{C}_{6} \mathrm{H}_{4}(\mathrm{CH})\left(\mathrm{CH}_{3}\right)_{2}{ }^{3} J_{\mathrm{HH}}=7 \mathrm{~Hz}\right), 2.22\left(\mathrm{~s}, 3 \mathrm{H}, \mathrm{C}_{6} \mathrm{H}_{4}-\mathrm{CH}_{3}\right), 1.68(\mathrm{~s}, 3 \mathrm{H}$, $\left.\mathrm{P}\left(\mathrm{OCH}_{2}\right)_{2}\left(\mathrm{OCCH}_{3}\right)\right), 1.23\left(\mathrm{~d}, 6 \mathrm{H}, \mathrm{C}_{6} \mathrm{H}_{4}-\mathrm{CH}\left(\mathrm{CH}_{3}\right)_{2},{ }^{3} J_{\mathrm{HH}}=7 \mathrm{~Hz}\right) .{ }^{13} \mathrm{C} \mathrm{NMR}(75 \mathrm{MHz}$ $\left.\mathrm{CDCl}_{3}, \mathrm{~d}\right) 110.0\left(\mathrm{~s}, C_{6} \mathrm{H}_{4}\right), 106.2\left(\mathrm{~s}, C_{6} \mathrm{H}_{4}\right), 90.5\left(C_{6} \mathrm{H}_{4}\right), 90.4\left(C_{6} \mathrm{H}_{4}\right), 90.1\left(C_{6} \mathrm{H}_{4}\right), 90.1$ $\left(C_{6} \mathrm{H}_{4}\right), \quad 82.9 \quad\left(\mathrm{P}\left(\mathrm{OCH}_{2}\right)_{2}\left(\mathrm{OCCH}_{3}\right)\right), \quad 75.7 \quad\left(\mathrm{~s}, \quad \mathrm{P}\left(\mathrm{OCH}_{2}\right)_{2}\left(\mathrm{OCCH}_{3}\right)\right), \quad 75.6 \quad($ $\left.\mathrm{P}\left(\mathrm{OCH}_{2}\right)_{2}\left(\mathrm{OCCH}_{3}\right)\right), 30.9\left(\mathrm{C}_{6} \mathrm{H}_{4}-\mathrm{CH}\left(\mathrm{CH}_{3}\right)_{2}\right), 22.3$ (s, symm. equivalent $\left.\mathrm{C}_{6} \mathrm{H}_{4}-\mathrm{C}\left(\mathrm{CH}_{3}\right)_{2}\right)$, $18.8\left(\mathrm{~s}, \mathrm{C}_{6} \mathrm{H}_{4}-\mathrm{CH}_{3}\right), 15.3\left(\mathrm{~d},{ }^{3} J_{\mathrm{HH}}=10.4 \mathrm{~Hz}, \mathrm{P}\left(\mathrm{OCH}_{2}\right)_{2}\left(\mathrm{OCCH}_{3}\right)\right) .{ }^{31} \mathrm{P}\left\{{ }^{1} \mathrm{H}\right\} \mathrm{NMR}(121$ $\left.\mathrm{MHz}, \mathrm{CDCl}_{3} \delta\right): 143.6\left(\mathrm{~s}, P\left(\mathrm{OCH}_{2}\right)_{2}\left(\mathrm{OCCH}_{3}\right)\right)$. HRMS: $[\mathrm{M}+\mathrm{Na}]^{+}$obsd $(\%)$, calcd $(\%)$, ppm: 460.95441 (37.4), 460.95328 (46.3), 2.5; 461.95477 (63), 461.95265 (60.9), 4.6; 462.95389 (100), 462.95262 (100), 2.7; 463.95387 (42.9), 463.95148 (48.6), 5.2; 464.95316 (97.1), 464.95168 (91.8), 3.2; 465.95496 (85.5), 465.95309 (84.2), 4; 466.95174 (85.5), 466.95034 (84.2), 3. CV (NCMe): $\mathrm{E}_{1 / 2}=1.44 \mathrm{~V} \mathrm{Ru}(\mathrm{III} / \mathrm{II})$ (quasireversible); $\mathrm{E}_{\mathrm{p}, \mathrm{c}}=-1.05 \mathrm{~V}$. 
$\left(\eta^{6}\right.$-p-cymene) $\mathbf{R u}\left[\mathbf{P}(\mathrm{OMe})_{3}\right] \mathbf{C l}_{2}(\mathbf{1 4})$. The synthesis of complex $\mathbf{1 4}$ has been previously reported. ${ }^{47}$ We used an alternate procedure, which is given below. $\left[\left(\eta^{6}-p\right.\right.$ cymene $) \mathrm{Ru}(\mathrm{Cl})(\mu-\mathrm{Cl})]_{2} \quad(0.0517 \mathrm{~g}, 0.0844 \mathrm{mmol})$ was stirred at room temperature in $\mathrm{CH}_{2} \mathrm{Cl}_{2}(\sim 15 \mathrm{~mL}) . \mathrm{P}(\mathrm{OMe})_{3}(0.0232 \mathrm{~g}, 0.187 \mathrm{mmol})$ was added by syringe. The solution was stirred at room temperature for $2 \mathrm{~h}$ after which time the solution was reduced in vacuo to $\sim 3 \mathrm{~mL}$. Hexanes were added to yield an orange precipitate. The solution was filtered through a fine porosity frit. The solid was washed with pentane and dried in vacuo to yield an orange solid $(0.0553 \mathrm{~g}, 76.1 \%$ yield $) .{ }^{1} \mathrm{H}$ NMR spectroscopy revealed clean material and was consistent with previously reported data. ${ }^{47} \mathrm{CV}(\mathrm{NCMe}): \mathrm{E}_{1 / 2}=$ 1.25 V Ru(III/II) (quasi-reversible); $\mathrm{E}_{\mathrm{p}, \mathrm{c}}=-1.21 \mathrm{~V}$.

$\left(\eta^{6}\right.$-p-cymene)Ru(PPh$) \mathbf{C l}_{2}$ (15). The synthesis of complex 15 has been previously reported. ${ }^{47} \mathrm{We}$ used an alternate procedure, which is given below. $\left[\left(\eta^{6}-p\right.\right.$ cymene $) \mathrm{Ru}(\mathrm{Cl})(\mu-\mathrm{Cl})]_{2} \quad(0.400 \mathrm{~g}, 0.653 \mathrm{mmol})$ and $\mathrm{PPh}_{3}(0.360 \mathrm{~g}, 1.37 \mathrm{mmol})$ were stirred at room temperature for $2 \mathrm{~h}$ in $\mathrm{CH}_{2} \mathrm{Cl}_{2}(\sim 15 \mathrm{~mL})$, after which time the solution was reduced in vacuo to $\sim 3 \mathrm{~mL}$. Hexanes were added to yield an orange precipitate. The mixture was filtered through a fine porosity frit. The solid was washed with pentane and dried in vacuo to yield an orange solid (0.658 g, 88.7\% yield). ${ }^{1} \mathrm{H}$ NMR spectroscopy revealed clean material and was consistent with previously reported data. ${ }^{47} \mathrm{CV}(\mathrm{NCMe})$ : $\mathrm{E}_{1 / 2}=1.25 \mathrm{~V} \mathrm{Ru}(\mathrm{III} / \mathrm{II}) ; \mathrm{E}_{\mathrm{p}, \mathrm{c}}=-1.25 \mathrm{~V}$.

General Procedure for the Measurement of Rates of Exchange. Stock solutions in $\mathrm{CDCl}_{3}$ were prepared in a volumetric flask. Each kinetic experiment was 
performed in triplicate. For each experiment, $\mathrm{CDCl}_{3}$ solutions of $\mathrm{P}(\mathrm{OMe})_{3}$ and/or $\mathrm{PPh}_{3}$ were combined in a screw cap NMR tube with $\mathrm{CDCl}_{3}$ such that the reaction volume before addition of Ru complex totaled $0.40 \mathrm{~mL}$. Immediately before placing the solution into the NMR probe (equilibrated at $58^{\circ} \mathrm{C}$ ), $0.20 \mathrm{~mL}$ of the $\mathrm{Ru}$ complex $(\mathbf{1 2}, 13$ or $\mathbf{1 5})$ (with hexamethyldisiloxane as an internal standard) was added by syringe to give a total volume $0.60 \mathrm{~mL}$. The tube was inverted two times. Reaction progress was monitored by ${ }^{1} \mathrm{H}$ NMR spectroscopy using automated data acquisition. A single transient was used for each time point with $60 \mathrm{~s}$ delay between transients for reactions with solutions of $\mathbf{1 3}$ and 15, and a $600 \mathrm{~s}$ between transients for reactions of complex 12. The rate of the reaction was determined by monitoring the disappearance of starting material [complex 12: 4.37 ppm $\left[\mathrm{d},{ }^{3} J_{\mathrm{HP}}=5.0 \mathrm{~Hz}, \mathrm{P}\left(\mathrm{OCH}_{2}\right)_{3} \mathrm{CCH}_{2} \mathrm{CH}_{3}\right]$; complex 15: $1.87 \mathrm{ppm} \quad[\mathrm{s},(p$-cymene $)$ $\left.\mathrm{C}_{6} \mathrm{H}_{4}-\mathrm{CH}_{3}\right]$, and complex 13: $1.68 \mathrm{ppm}\left[\mathrm{s}, 3 \mathrm{H}, \mathrm{P}\left(\mathrm{OCH}_{2}\right)_{2}\left(\mathrm{OCCH}_{3}\right)\right]$. Each reaction was monitored through at least 3.5 half-lives. Rates were determined by least squares analyses of a plot of starting material vs time (seconds).

\subsection{References}

(1) Crabtree, R. H. The Organometallic Chemistry of the Transition Metals; 4th ed.; Wiley-Interscience: USA, 2005.

(2) Keiter, R. L.; Verkade, J. G. Inorg. Chem. 1970, 9, 404.

(3) Verkade, J. G.; McCarley, D. G.; Hendricker, D. G.; King, R. W. Inorg. Chem. 1965, 4, 228.

(4) Meiners, J. H.; Rix, C. J.; Clardy, J. C.; Verkade, J. G. Inorg. Chem. 1975, 14,705 . 
(5) Serron, S.; Nolan, S. P.; Abramov, Y. A.; Brammer, L.; Petersen, J. L. Organometallics 1998, 17, 104.

(6) Tolman, C. A. Chem. Rev. 1977, 77, 313.

(7) Freixa, Z.; van Leeuwen, P. W. N. M. Dalton Trans. 2003, 1890.

(8) Bunten, K. A.; Chen, L.; Fernandez, A. L.; Poe, A. J. Coord. Chem. Rev. 2002, 233-234, 41 .

(9) Leyssens, T.; Peeters, D.; Orpen, A. G.; Harvey, J. N. Organometallics 2007, 26, 2637.

(10) Downing, J. H.; Smith, M. B. Comprehensive Coordination Chemistry II 2004, $1,253$.

(11) Kuehl, O. Coord. Chem. Rev. 2005, 249, 693.

(12) Sasaki, S.; Yoshifuji, M. Curr. Org. Chem. 2007, 11, 17.

(13) van Leeuwen, P. W. N. M.; Freixa, Z.; Zuidema, E. Phosphorus Ligands in Asymmetric Catalysis 2008, 3, 1433.

(14) Müller, T. E.; Mingos, D. M. P. Transition Met. Chem. 1995, 20, 553.

(15) Gilheany, D. G. In Organophosphorus Compounds; Hartley, F. R., Ed.; John Wiley \& Sons: 1990; Vol. 1, p 9.

(16) Valentine, D. H.; Hillhouse, J. H. Synthesis 2003, 2437.

(17) Meiners, J. H.; Clardy, J. C.; Verkade, J. G. Inorg. Chem. 1975, 14, 632.

(18) Hartwig, J. F. Organotransition Metal Chemisty: from Bonding to Catalysis; University Science Books, 2010.

(19) Valentine, D. H.; Hillhouse, J. H. Synthesis 2003, 317.

(20) Kuehl, O. Can. J. Chem. 2007, 85, 230.

(21) Cao, M.; Do, L. V.; Hoffman, N. W.; Kwan, M. L.; Little, J. K.; McGilvray, J. M.; Morris, C. B.; Soderberg, B. C.; Wierzbicki, A.; Cundari, T. R.; Lake, C. H.; Valente, E. J. Organometallics 2001, 20, 2270.

(22) Fortman, G. C.; Nolan, S. P. Organometallics 2010, 29, 4579. 
(23) Verkade, J. G.; Hutteman, T. J.; Fung, M. K.; King, R. W. Inorg. Chem. 1965, 4,83 .

(24) Heitsch, C. W.; Verkade, J. G. Inorg. Chem. 1962, 1, 392.

(25) Rix, C. J.; Verkade, J. G. Coord. Chem. Rev. 1975, 16, 129.

(26) Verkade, J. G. Bioinorg Chem 1974, 3, 165.

(27) Vande Griend, L. J.; Verkade, J. G.; Pennings, J. F. M.; Buck, H. M. J. Am. Chem. Soc. 1977, 99, 2459.

(28) Verkade, J. G. Coord. Chem. Rev. 1972, 9, 1.

(29) Milbrath, D. S.; Springer, J. P.; Clardy, J. C.; Verkade, J. G. J. Am. Chem. Soc. 1976, 98, 5493.

(30) Huttemann, T. J.; Foxman, B. M.; Sperati, C. R.; Verkade, J. G. Inorg. Chem. 1965, 950 .

(31) Foley, N. A.; Ke, Z. F.; Gunnoe, T. B.; Cundari, T. R.; Petersen, J. L. Organometallics 2008, 27, 3007.

(32) Verkade, J. G.; Piper, T. S. Inorg. Chem. 1963, 2, 944.

(33) Denny, D. B.; Varga, S. L. Phosphorus 1973, 2, 245.

(34) Nifantyev, E. E.; Koroteev, A. M.; Koroteev, M. P.; Meshkov, S. V.; Belsky, V. K.; Bekker, A. R. Phosphorus, Sulfur Silicon Relat. Elem. 1996, 113, 1 .

(35) Wadsworth, W. S.; Emmons, W. D. J. Am. Chem. Soc. 1962, 610.

(36) Wirz, B.; Barner, R.; Hubscher, J. J. Org. Chem. 1993, 58, 3980.

(37) Roebuck, A.; Adkins, H. A. Organic Synthesis; John Wiley \& Sons, Inc. : New York, 1955; Vol. 3.

(38) Slugovc, C.; Sapunov, V. N.; Wiede, P.; Mereiter, K.; Schmid, R.; Kirchner, K. J. Chem. Soc., Dalton Trans. 1997, 4209.

(39) Werner, H.; Brauers, G.; Nurnberg, O. J. Organomet. Chem. 1993, 454, 247.

(40) Zelonka, R. A.; Baird, M. C. Can J Chemistry 1972, 50, 3063. 
(41) Bennett, M. A.; Smith, A. K. J Chem Soc Dalton 1974, 233.

(42) Werner, H.; Werner, R. Chem Ber-Recl 1982, 115, 3766.

(43) Zelonka, R. A.; Baird, M. C. J. Organomet. Chem. 1972, 35, C43.

(44) Elsegood, M. R. J.; Tocher, D. A. Polyhedron 1995, 14, 3147.

(45) Pigge, F. C.; Coniglio, J. J. Curr. Org. Chem. 2001, 5, 757.

(46) Bard, A. J.; Faulkner, L. R. Electrochemical Methods: Fundamentals and Applications; 2nd ed.; John Wiley \& Sons: New York, 2001.

(47) Hodson, E.; Simpson, S. J. Polyhedron 2004, 23, 2695.

(48) Furstner, A.; Liebl, M.; Lehmann, C. W.; Picquet, M.; Kunz, R.; Bruneau, C.; Touchard, D.; Dixneuf, P. H. Chem-Eur J 2000, 6, 1847.

(49) Elsegood, M. R. J.; Smith, M. B.; Sanchez-Ballester, N. M. Acta Crystallogr E 2006, 62, M2838.

(50) Orpen, A. G.; Connelly, N. G. J. Chem. Soc., Chem. Commun. 1985, 1310.

(51) Dias, P. B.; Depiedade, M. E. M.; Simoes, J. A. M. Coord. Chem. Rev. 1994, 135,737 .

(52) Jover, J.; Fey, N.; Harvey, J. N.; Lloyd-Jones, G. C.; Orpen, A. G.; OwenSmith, G. J. J.; Murray, P.; Hose, D. R. J.; Osborne, R.; Purdie, M. Organometallics 2010, 29, 6245.

(53) Ellis, D. D.; Haddow, M. F.; Orpen, A. G.; Watson, P. J. Dalton Trans. 2009, 10436.

(54) Taira, K.; Mock, W. L.; Gorenstein, D. G. J. Am. Chem. Soc. 1984, 106, 7831.

(55) Belyakov, A. V.; Dalhus, B.; Haaland, A.; Shorokhov, D. J.; Volden, H. V. J Chem Soc Dalton 2002, 3756.

(56) Slater, J. C. Quantum Theory of Molecules and Solids, Vol. 4: The SelfConsistent Field for Molecules and Solids; McGraw-Hill: New York, 1974.

(57) Becke, A. D. Phys Rev A 1988, 38, 3098.

(58) Perdew, J. P. Phys Rev B 1986, 34, 7406. 
(59) Perdew, J. P. Phys Rev B 1986, 33, 8822.

(60) Perdew, J. P.; Zunger, A. Phys Rev B 1981, 23, 5048.

(61) Hay, P. J.; Wadt, W. R. J Chem Phys 1985, 82, 270.

(62) Pyykko, P.; Mendizabal, F. Inorg. Chem. 1998, 37, 3018.

(63) Couty, M.; Hall, M. B. J Comput Chem 1996, 17, 1359.

(64) M.J. Frisch, G. W. T., H.B. Schlegel, G.E. Scuseria, M.A. Robb, J.R. Cheeseman, G. Scalmani, V.; Barone, B. M., G.A. Petersson, H. Nakatsuji, M. Caricato, X. Li, H.P. Hratchian, A.F. Izmaylov; J. Bloino, G. Z., J.L. Sonnenberg, M. Hada, M. Ehara, K. Toyota, R. Fukuda, J. Hasegawa, M.; Ishida, T. N., Y. Honda, O. Kitao, H. Nakai, T. Vreven, J.A. Montgomery Jr, J.E. Peralta, F.; Ogliaro, M. B., J.J. Heyd, E. Brothers, K.N. Kudin, V.N. Staroverov, R. Kobayashi, J.; Normand, K. R., A. Rendell, J.C. Burant, S.S. Iyengar, J. Tomasi, M. Cossi, N. Rega, J.M.; Millam, M. K., J.E. Knox, J.B. Cross, V. Bakken, C. Adamo, J. Jaramillo, R. Gomperts, R.E.; Stratmann, O. Y., A.J. Austin, R. Cammi, C. Pomelli, J.W. Ochterski, R.L. Martin, K. Morokuma,; V.G. Zakrzewski, G. A. V., P. Salvador, J.J. Dannenberg, S. Dapprich, A.D. Daniels, O” . Farkas, J.B.; Foresman, J. V. O., J. Cioslowski, D.J. Fox. ; Gaussian, Inc.: Willingford, CT, 2009. 


\section{Aromatic $\mathrm{C}-\mathrm{H}$ Activation and Catalytic Hydroarylation of Ethylene Using $\mathrm{TpRu}\left[\mathbf{P}\left(\mathrm{OCH}_{2}\right)_{2}\left(\mathrm{OCCH}_{3}\right)\right](\mathrm{NCMe}) \mathrm{Ph}$}

\subsection{Introduction}

Previously, our group has demonstrated that $\mathrm{TpRu}(\mathrm{L})(\mathrm{NCMe}) \mathrm{Ph}[\mathrm{L}=\mathrm{CO}$, or

$\left.\mathrm{P}\left(\mathrm{OCH}_{2}\right)_{3} \mathrm{CEt}\right]$ complexes are active for olefin hydroarylation. ${ }^{1-6}$ Expanded studies of $\mathrm{TpRu}(\mathrm{L})(\mathrm{NCMe}) \mathrm{Ph}$ where $\mathrm{L}=\mathrm{CO}, \mathrm{P}\left(\mathrm{OCH}_{2}\right)_{3} \mathrm{CEt}, \mathrm{PMe}_{3}$, or $\mathrm{P}(\mathrm{N} \text {-pyrrolyl })_{3}$ revealed important trends. ${ }^{3}$ It was shown through calculations and experimental data that the rate limiting step of the catalytic cycle is aromatic $\mathrm{C}-\mathrm{H}$ activation, and the $\mathrm{C}-\mathrm{H}$ activation step is promoted by more electron rich metal centers. In contrast, olefin insertion is more efficient with less electron rich metal centers. Our explanation of the trend in activation barrier for olefin insertion is based on metal-to-olefin $\pi$-backbonding. More electron deficient metals exhibit decreased backbonding into the $\pi^{*}$ orbitals of the olefin, making the olefin less tightly bound and, hence, facilitate insertion into the $\mathrm{Ru}-\mathrm{Ph}$ bond. Thus, a balance has to be struck between the electron richness of the metal center for these two key steps of the olefin hydroarylation catalytic cycle. In the case of electron rich metal centers such as $\mathrm{TpRu}\left(\mathrm{PMe}_{3}\right)(\mathrm{NCMe}) \mathrm{Ph}$, olefin $\mathrm{C}-\mathrm{H}$ activation competes with olefin insertion yielding a $\mathrm{Ru}$-vinyl species, which upon subsequent olefin insertion and isomerzation gives a stable $\mathrm{TpRu}\left(\mathrm{PMe}_{3}\right)\left(\eta^{3}-\mathrm{C}_{4} \mathrm{H}_{7}\right)$ complex incapable of catalytic olefin hydroarylation (Scheme 3.1$).{ }^{2}$ Even though $\mathrm{TpRu}\left[\mathrm{P}\left(\mathrm{OCH}_{2}\right)_{3} \mathrm{CEt}\right](\mathrm{NCMe}) \mathrm{Ph}$ is capable of catalytic olefin hydroarylation leading to approximately $10 \mathrm{TON}$ of ethylbenzene $\left(90^{\circ} \mathrm{C}\right.$, 25 psi of ethylene) before catalytic deactivation, it was found that the metal center was 
also too electron rich and olefin $\mathrm{C}-\mathrm{H}$ activation competes with olefin insertion leading to the deactivation product, $\mathrm{TpRu}\left[\mathrm{P}\left(\mathrm{OCH}_{2}\right)_{3} \mathrm{CEt}\right]\left(\eta^{3}-\mathrm{C}_{4} \mathrm{H}_{7}\right)($ Scheme 3.1).
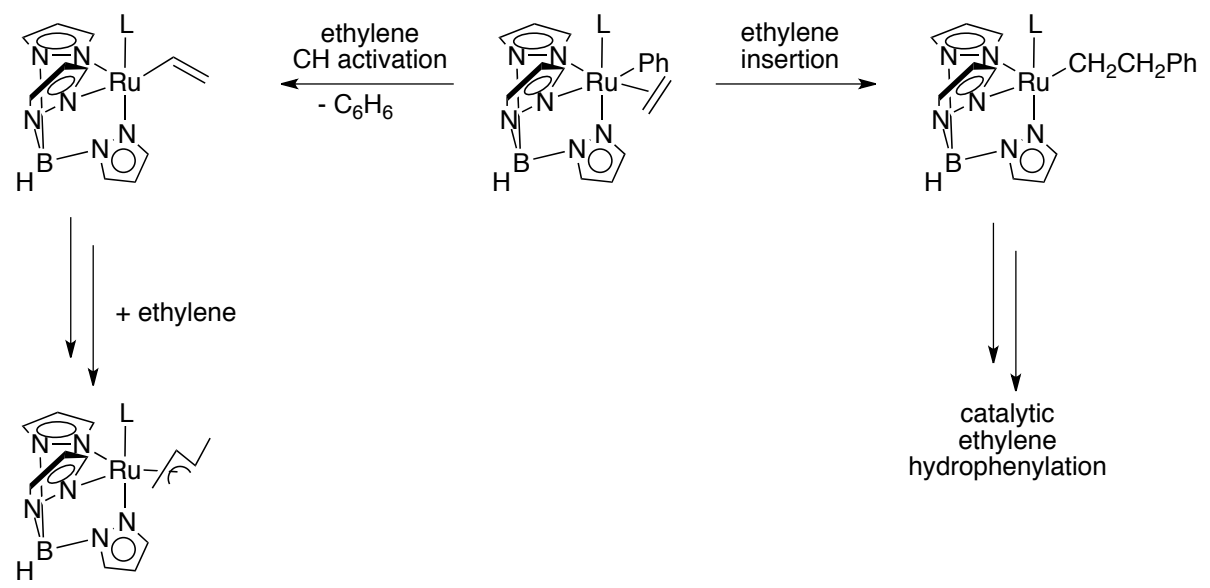

Scheme 3.1. Ethylene C-H activation vs ethylene insertion in olefin hydroaylation cycle.

Therefore, a long-lived catalyst cannot have strong phosphite donor ligands due to the competition between olefin $\mathrm{C}-\mathrm{H}$ activation and olefin insertion. Additionally, through studies it has been determined that although $\mathrm{C}-\mathrm{H}$ activation is the rate limiting step in the catalytic cycle, the difference in electron density of the metal center has a greater impact on olefin insertion rather than $\mathrm{C}-\mathrm{H}$ activation. ${ }^{3}$ Furthermore, a catalyst with larger steric bulk could potentially bias the olefin orientation upon coordination to the metal center, which could allow us to control linear to branched selectivity when $\alpha$ olefins are employed. Therefore, our group examined to $\mathrm{TpRu}\left[\mathrm{P}(\mathrm{pyr})_{3}\right](\mathrm{NCMe}) \mathrm{Ph}$, in hopes to increase linear to branched selectivity. Unfortunately, the $\mathrm{P}(\mathrm{pyr})_{3}$ ligand was too sterically bulky and olefin coordination was inhibited. 
The studies outlined in chapter 2 demonstrated that removing a methylene linker from the bicyclic phosphite $\mathrm{P}\left(\mathrm{OCH}_{2}\right)_{3} \mathrm{CEt}$ to yield $\mathrm{P}\left(\mathrm{OCH}_{2}\right)_{2}\left(\mathrm{OCCH}_{3}\right)$ leads to a decrease in donor ability as determined by cyclic voltammetry of Ru(II) complexes; however, cone angle calculations from crystallographic data showed that steric bulk of the two bicyclic phosphites is similar and significantly less than $\mathrm{P}(\mathrm{pyr})_{3}{ }^{7}$ The decrease in electron density in P-basicity for $\mathrm{P}\left(\mathrm{OCH}_{2}\right)_{2}\left(\mathrm{OCCH}_{3}\right)$ related to $\mathrm{P}\left(\mathrm{OCH}_{2}\right)_{3} \mathrm{CEt}$ has been proposed to result from the "hinge" effect described by John Verkade, which is a consequence of decreased p-orbital overlap between the $\mathrm{O}$ and $\mathrm{P}$ atom. Alternatively, our group has proposed that changes in $\mathrm{O}-\mathrm{P}-\mathrm{O}$ angles results in lower energy $\mathrm{P}-\mathrm{O} \sigma^{*}$ orbitals for $\mathrm{P}\left(\mathrm{OCH}_{2}\right)_{2}\left(\mathrm{OCCH}_{3}\right)$ which enhances $\pi$-acidity (see chapter 2 for a more detailed discussion). ${ }^{7-9}$ Hence, we desired to use the ligand $\mathrm{P}\left(\mathrm{OCH}_{2}\right)_{2}\left(\mathrm{OCCH}_{3}\right)$ to synthesize the catalyst precursor $\mathrm{TpRu}[$ $\left.\mathrm{P}\left(\mathrm{OCH}_{2}\right)_{2}\left(\mathrm{OCCH}_{3}\right)\right](\mathrm{NCMe}) \mathrm{Ph}$ for olefin hydroarylation.

\subsection{Results and Discussion}

\subsubsection{Synthesis of $\mathrm{TpRu}\left[\mathrm{P}\left(\mathrm{OCH}_{2}\right)_{2}\left(\mathrm{OCCH}_{3}\right)\right](\mathrm{NCMe}) \mathrm{Ph}$}

The initial attempt to synthesize $\mathrm{TpRu}\left[\mathrm{P}\left(\mathrm{OCH}_{2}\right)_{2}\left(\mathrm{OCCH}_{3}\right)\right](\mathrm{NCMe}) \mathrm{Ph}$ was by a similar route as the published procedure for $\mathrm{TpRu}\left[\mathrm{P}\left(\mathrm{OCH}_{2}\right)_{3} \mathrm{CEt}\right](\mathrm{NCMe}) \mathrm{Ph} .{ }^{1}$ Refluxing $\mathrm{TpRu}\left(\mathrm{PPh}_{3}\right)_{2} \mathrm{Cl}$ in benzene with excess $\mathrm{P}\left(\mathrm{OCH}_{2}\right)_{2}\left(\mathrm{OCCH}_{3}\right)$ led to displacement of one $\mathrm{PPh}_{3}$ and coordination of $\mathrm{P}\left(\mathrm{OCH}_{2}\right)_{2}\left(\mathrm{OCCH}_{3}\right)$, yielding $\mathrm{TpRu}\left(\mathrm{PPh}_{3}\right)\left[\mathrm{P}\left(\mathrm{OCH}_{2}\right)_{2}\left(\mathrm{OCCH}_{3}\right)\right.$ ]Cl. This is evident by the two sets of doublets in the ${ }^{31} \mathrm{P}\left\{{ }^{1} \mathrm{H}\right\}$ NMR spectrum (162.6 and 
$44.8 \mathrm{ppm}$ ) with a ${ }^{2} J_{\mathrm{PP}}=55 \mathrm{~Hz}$ (see Chapter 2, Figure 2.3 for NMR spectrum). However, attempts at metathesis reactions with chloride using a variety of triflate or phenyl sources (e.g., AgOTf, TMSOTf, HOTf, $\mathrm{Ph}_{2} \mathrm{Mg}[\mathrm{THF}]_{2}$, and $\mathrm{PhMgCl}$ ) agents were futile. The reactions with triflate sources were not clean and purificiation was difficult. In addition, attempted reactions of $\mathrm{TpRu}\left(\mathrm{PPh}_{3}\right)\left[\mathrm{P}\left(\mathrm{OCH}_{2}\right)_{2}\left(\mathrm{OCCH}_{3}\right)\right] \mathrm{Cl}$ with phenyl sources lead to no reaction. Therefore, another starting material was sought.

Given previous reports that $\left[\left(\eta^{6}\right.\right.$-arene $) \mathrm{Ru}(\mathrm{X})(\mu-\mathrm{X}]_{2}\left(\mathrm{X}=\mathrm{Cl}\right.$ or $\mathrm{Br} ; \eta^{6}$-arene $=$ benzene or cumene) complexes react with neutral two-electron donors to form $\left(\eta^{6}\right.$ arene) $\mathrm{RuX}_{2} \mathrm{~L}$ complexes, ${ }^{10-21}$ we considered the $\mathrm{Ru}(\mathrm{II})$ arene complexes as possible precursors to $\mathrm{TpRu}\left[\mathrm{P}\left(\mathrm{OCH}_{2}\right)_{2}\left(\mathrm{OCCH}_{3}\right)\right](\mathrm{NCMe}) \mathrm{Ph}$. Stirring $\left[\left(\eta^{6}-p\right.\right.$-cymene $) \mathrm{Ru}(\mathrm{Br})(\mu$ $\mathrm{Br}]_{2}$ and $\mathrm{P}\left(\mathrm{OCH}_{2}\right)_{2}\left(\mathrm{OCCH}_{3}\right)$ in $\mathrm{CH}_{2} \mathrm{Cl}_{2}$ leads to the formation of $\left[\left(\eta^{6}\right.\right.$-p-cymene $) \mathrm{Ru}[$ $\mathrm{P}\left(\mathrm{OCH}_{2}\right)_{2}\left(\mathrm{OCCH}_{3}\right) \mathrm{Br}_{2}(\mathbf{1})$ in 91\% isolated yield (Scheme 3.2, Figure 3.1, Figure 3.2). The ${ }^{1} \mathrm{H}$ NMR spectrum shows a symmetric complex with two downfield resonances for the $\left(\eta^{6}-p\right.$-cymene). The ${ }^{31} \mathrm{P}$ NMR spectrum of 1 shows a resonance at $140 \mathrm{ppm}$ for the $\mathrm{P}\left(\mathrm{OCH}_{2}\right)_{2}\left(\mathrm{OCCH}_{3}\right)$ ligand.
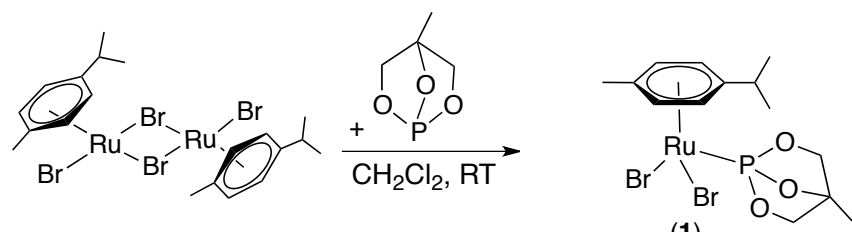

(1)

Scheme 3.2. Synthesis of $\left[\left(\eta^{6}-p\right.\right.$-cymene $) \mathrm{Ru}\left[\mathrm{P}\left(\mathrm{OCH}_{2}\right)_{2}\left(\mathrm{OCCH}_{3}\right)\right] \mathrm{Br}_{2}(\mathbf{1})$. 


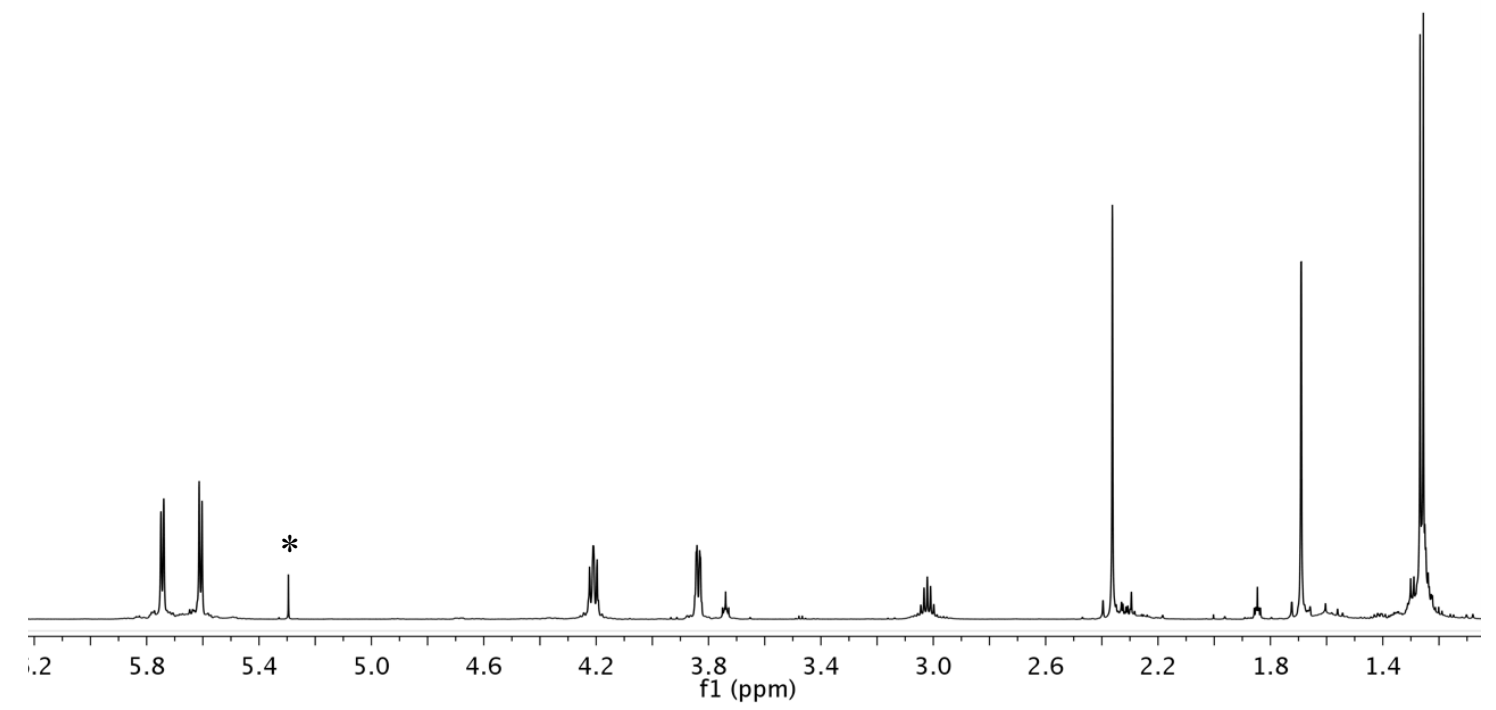

Figure 3.1. ${ }^{1} \mathrm{H}$ NMR spectrum of $\left(\eta^{6}-p\right.$-cymene $) \mathrm{Ru}\left[\mathrm{P}\left(\mathrm{OCH}_{2}\right)_{2}\left(\mathrm{OCCH}_{3}\right)\right] \mathrm{Br}_{2}$ (1) in $\mathrm{CDCl}_{3}$. (* = residual $\left.\mathrm{CH}_{2} \mathrm{Cl}_{2}\right)$.

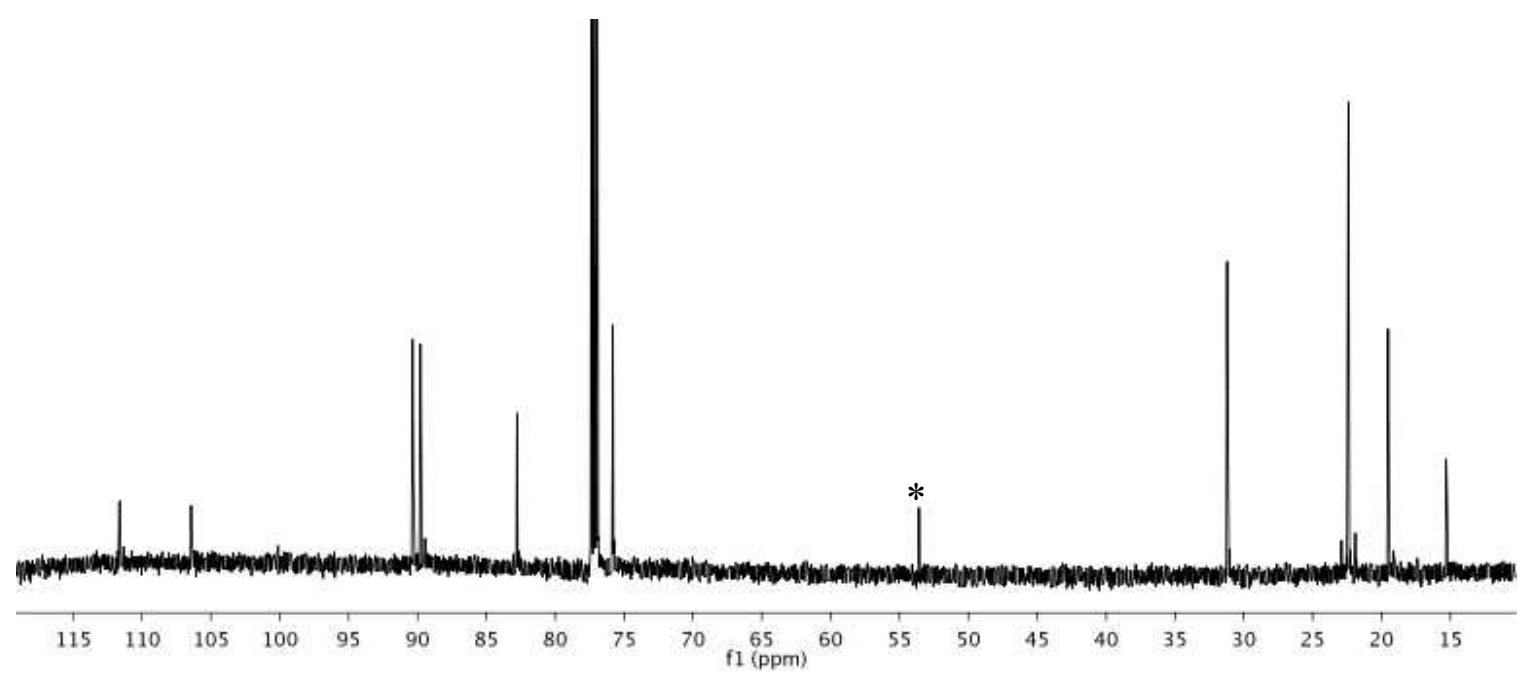

Figure 3.2. ${ }^{13} \mathrm{C}$ NMR spectrum of $\left(\eta^{6}-p\right.$-cymene $) \mathrm{Ru}\left[\mathrm{P}\left(\mathrm{OCH}_{2}\right)_{2}\left(\mathrm{OCCH}_{3}\right)\right] \mathrm{Br}_{2}$ (1) in $\mathrm{CDCl}_{3}$. (* = residual $\left.\mathrm{CH}_{2} \mathrm{Cl}_{2}\right)$.

Stirring 1 and one equivalent of $\mathrm{Ph}_{2} \mathrm{Mg}(\mathrm{THF})_{2}$ at room temperature gives the phenylated species $\left(\eta^{6}-p\right.$-cymene $) \mathrm{Ru}\left[\mathrm{P}\left(\mathrm{OCH}_{2}\right)_{2}\left(\mathrm{OCCH}_{3}\right)\right](\mathrm{Ph}) \mathrm{Br}(\mathbf{2})$. Complex 1 is only 
partially soluble in THF; however, upon the addition of $\mathrm{Ph}_{2} \mathrm{Mg}(\mathrm{THF})_{2}$ to complex $\mathbf{1}$, the reaction becomes bright yellow and homogeneous. The formation of $\mathbf{2}$ is evident by the ${ }^{31} \mathrm{P}$ NMR spectrum, which shows a downfield shift (155.5 ppm) of $\sim 15 \mathrm{ppm}$ relative to $\mathbf{1}$. Additionally, the ${ }^{1} \mathrm{H}$ NMR spectrum supports an asymmetric complex with four separate resonances for the aromatic hydrogens of the $\eta^{6}-p$-cymene ligand and the two doublets for the methyl groups of the $\left(\eta^{6}-p\right.$-cymene) isopropyl with ${ }^{3} J_{\mathrm{HH}}$ coupling constant of $7 \mathrm{~Hz}$ (Scheme 3.3, Figure 3.3, Figure 3.4).

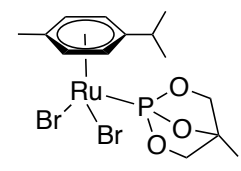

(1)

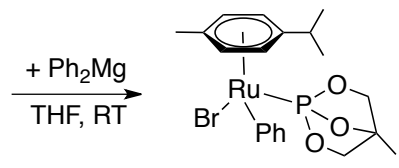

(2)

Scheme 3.3. Synthesis of $\left[\left(\eta^{6}-p\right.\right.$-cymene $) \mathrm{Ru}\left[\mathrm{P}\left(\mathrm{OCH}_{2}\right)_{2}\left(\mathrm{OCCH}_{3}\right)\right] \mathrm{PhBr}$.

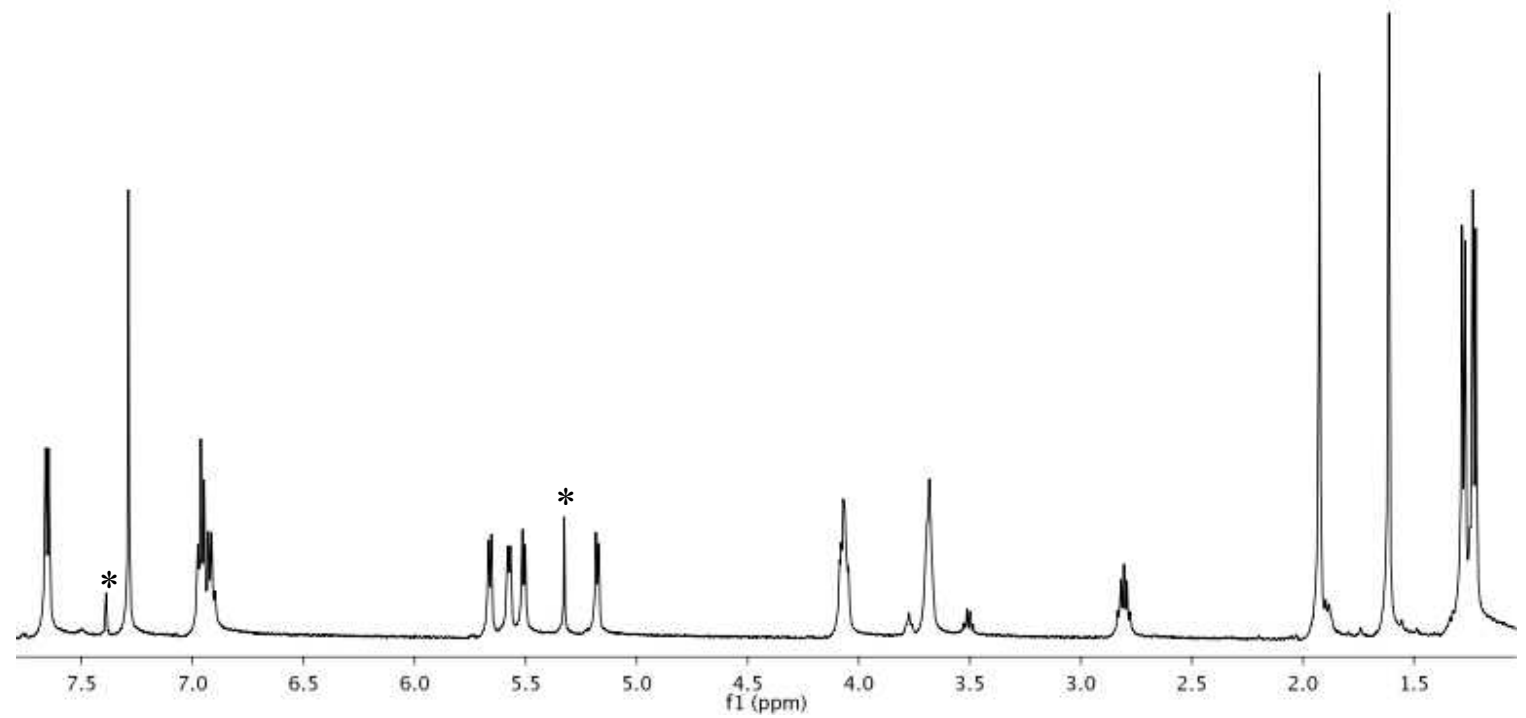

Figure 3.3. ${ }^{1} \mathrm{H}$ NMR spectrum of $\left(\eta^{6}-p\right.$-cymene $) \mathrm{Ru}\left[\mathrm{P}\left(\mathrm{OCH}_{2}\right)_{2}\left(\mathrm{OCCH}_{3}\right)\right](\mathrm{Ph}) \mathrm{Br}$ (2) in $\mathrm{CDCl}_{3}$. $\left(*=\right.$ residual $\mathrm{C}_{6} \mathrm{H}_{6}$ and residual $\left.\mathrm{CH}_{2} \mathrm{Cl}_{2}\right)$. 


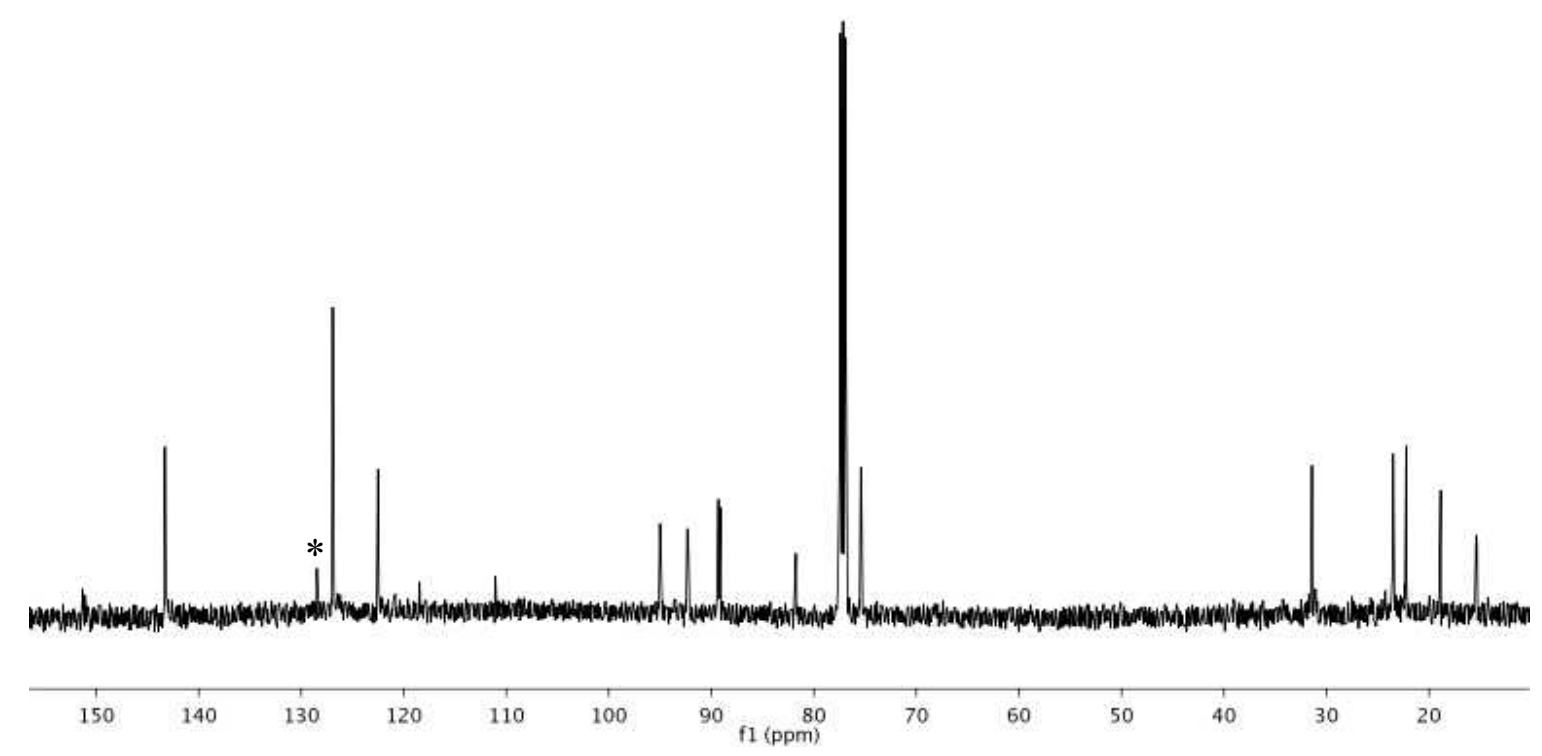

Figure 3.4. ${ }^{13} \mathrm{C}$ NMR spectrum of $\left(\eta^{6}-p\right.$-cymene $) \mathrm{Ru}\left[\mathrm{P}\left(\mathrm{OCH}_{2}\right)_{2}\left(\mathrm{OCCH}_{3}\right)\right](\mathrm{Ph}) \mathrm{Br}(2)$ in $\mathrm{CDCl}_{3} \cdot\left(*=\right.$ residual $\left.\mathrm{C}_{6} \mathrm{H}_{6}\right)$.

The $p$-cymene ligand can be displaced upon heating at $75^{\circ} \mathrm{C}$ for $4 \mathrm{~h}$ in $\mathrm{NCMe}$ to yield the putative complex $(\mathrm{NCMe})_{3} \mathrm{Ru}\left[\mathrm{P}\left(\mathrm{OCH}_{2}\right)_{2}\left(\mathrm{OCCH}_{3}\right)\right](\mathrm{Ph}) \mathrm{Br}(\mathbf{3})$, whose identity is supported by the distinct disappearance of the 2 doublets for the methyl groups of the $\eta^{6}$ $p$-cymene isopropyl group and the formation of free $p$-cymene. However, $(\mathrm{NCMe})_{3} \mathrm{Ru}[$ $\left.\mathrm{P}\left(\mathrm{OCH}_{2}\right)_{2}\left(\mathrm{OCCH}_{3}\right)\right](\mathrm{Ph}) \mathrm{Br}$ (3) has not been characterized beyond in situ ${ }^{1} \mathrm{H}$ NMR spectroscopy (Figure 3.5) due to difficulty in isolation and purification. Heating complex 3 and $\mathrm{KTp}$ in $\mathrm{CH}_{2} \mathrm{Cl}_{2}$ for $4 \mathrm{~h}$ at $75{ }^{\circ} \mathrm{C}$ produces $\mathrm{TpRu}\left[\mathrm{P}\left(\mathrm{OCH}_{2}\right)_{2}\left(\mathrm{OCCH}_{3}\right)\right](\mathrm{NCMe}) \mathrm{Ph}(4)$ in $44 \%$ isolated yield (Scheme 3.4, Figure 3.6). The ${ }^{1} \mathrm{H}$ NMR spectrum of 4 is consistent 
with an asymmetric complex with the presence of 9 unique Tp peaks. Cyclic voltammetry of complex 4 in NCMe shows a reversible redox couple at $\mathrm{E}_{1 / 2}=0.69 \mathrm{~V}$ (vs. NHE).

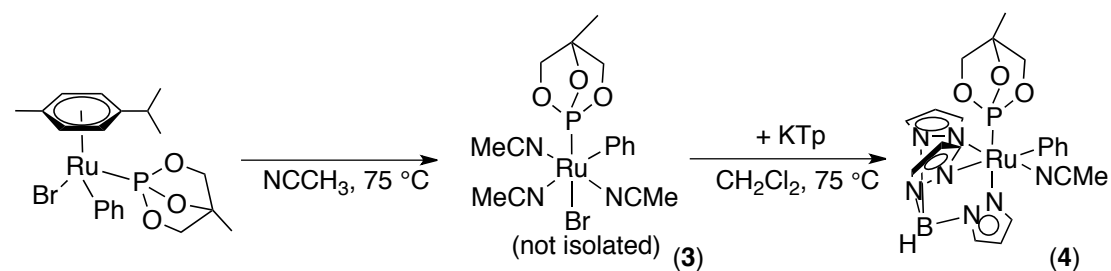

Scheme 3.4. Synthesis of $\mathrm{TpRu}\left[\mathrm{P}\left(\mathrm{OCH}_{2}\right)_{2}\left(\mathrm{OCCH}_{3}\right)\right](\mathrm{NCMe}) \mathrm{Ph}$ (4).

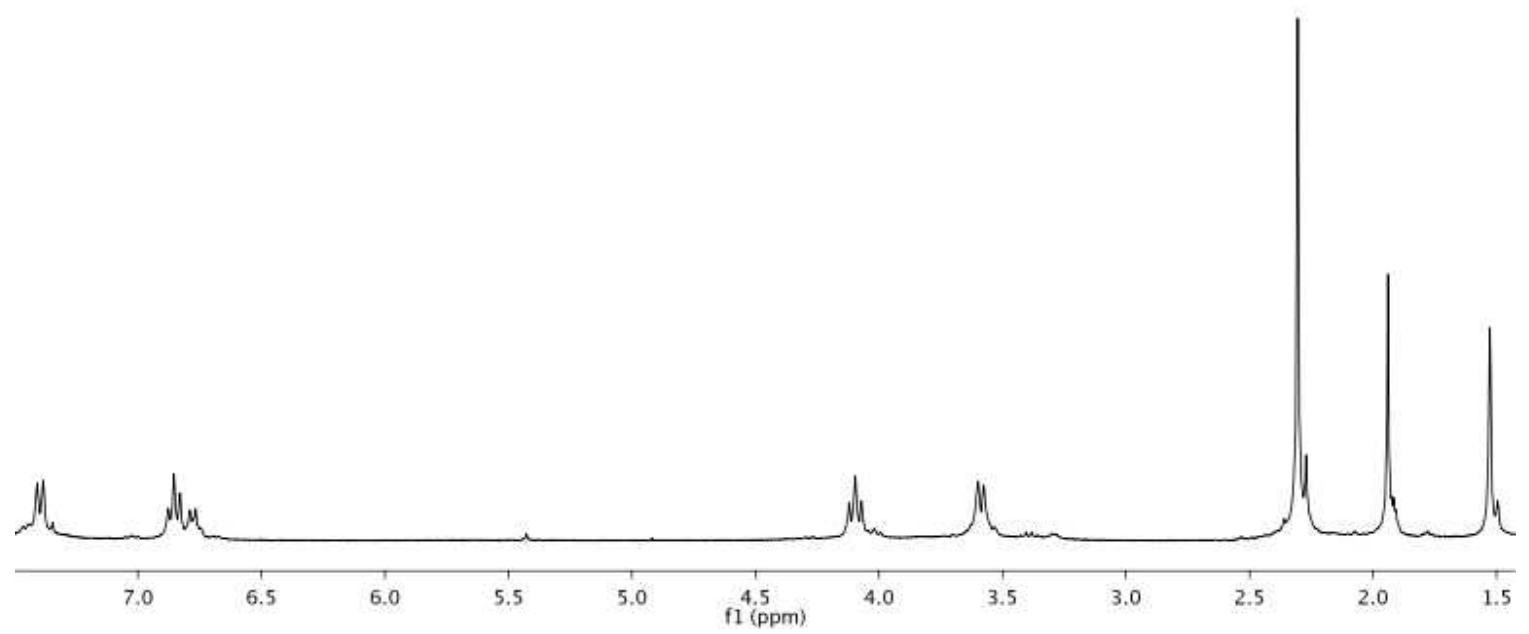

Figure 3.5. ${ }^{1} \mathrm{H}$ NMR spectrum of $(\mathrm{NCMe})_{3} \mathrm{Ru}\left[\mathrm{P}\left(\mathrm{OCH}_{2}\right)_{2}\left(\mathrm{OCCH}_{3}\right)\right] \mathrm{PhBr}(3)$ in $\mathrm{CD}_{3} \mathrm{CN}$. 


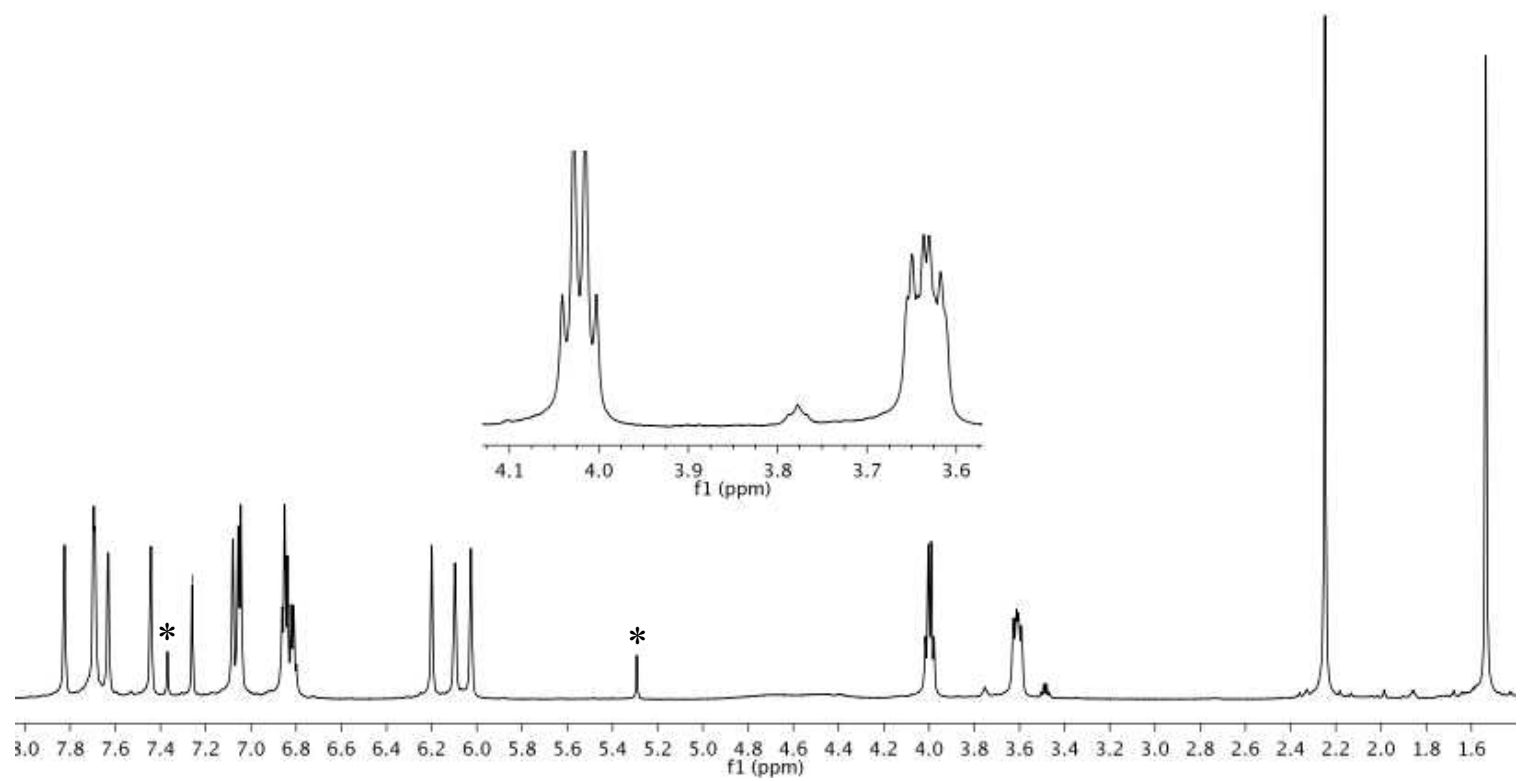

Figure 3.6. ${ }^{1} \mathrm{H} \mathrm{NMR}$ spectrum of $\mathrm{TpRu}\left[\mathrm{P}\left(\mathrm{OCH}_{2}\right)_{2}\left(\mathrm{OCCH}_{3}\right)\right](\mathrm{NCMe}) \mathrm{Ph}(4)$ in $\mathrm{C}_{6} \mathrm{D}_{6}$. $(*=$ residual $\mathrm{CH}_{2} \mathrm{Cl}_{2}$ and residual $\mathrm{C}_{6} \mathrm{H}_{6}$ ).

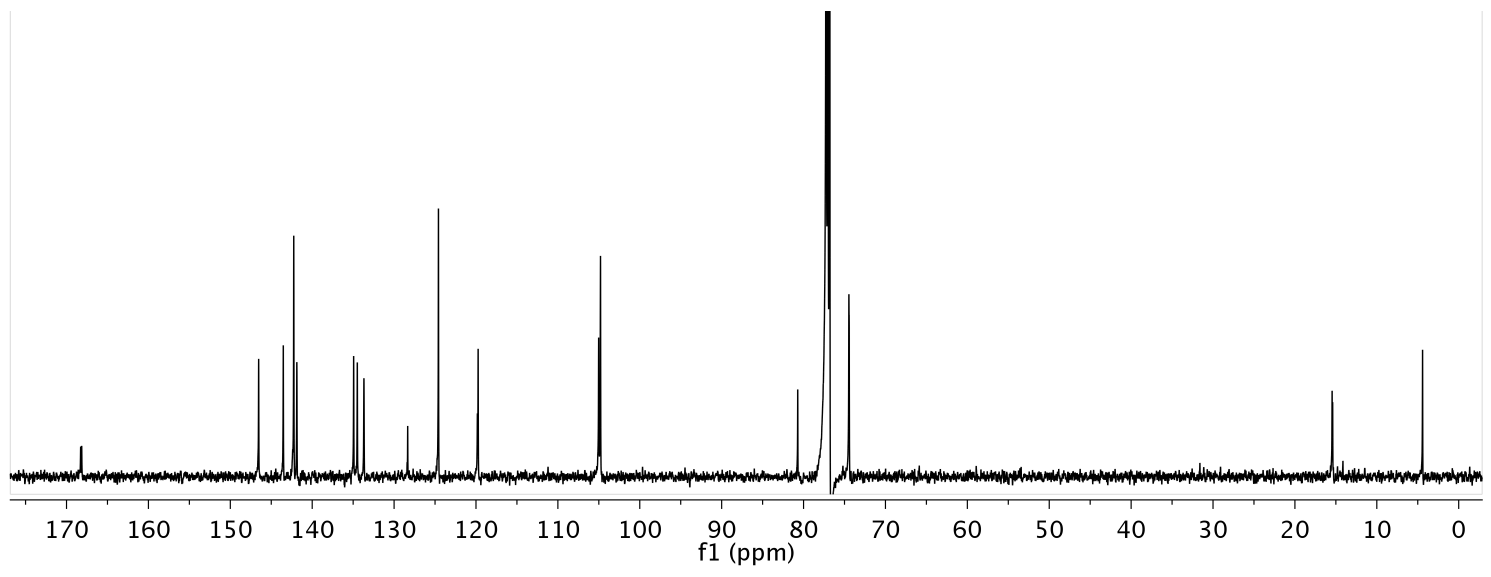

Figure 3.7. ${ }^{13} \mathrm{C}$ NMR spectrum of $\mathrm{TpRu}\left[\mathrm{P}\left(\mathrm{OCH}_{2}\right)_{2}\left(\mathrm{OCCH}_{3}\right)\right](\mathrm{NCMe}) \mathrm{Ph}(4)$ in $\mathrm{C}_{6} \mathrm{D}_{6}$.

A single crystal of 4 suitable for X-ray structure determination was obtained from slow evaporation of a $\mathrm{CH}_{2} \mathrm{Cl}_{2}$ :pentane $(\sim 1: 1 \mathrm{v}$ :v) solution at room temperature, and the 
resulting solid-state structure is shown in Figure 3.8 (Table 3.1). The phosphite has two smaller O-P-O angles of $93.76(1)^{\circ}$ and $93.56(1)^{\circ}$ and one larger angle at $100.27(2)^{\circ}$. The $\mathrm{P}-\mathrm{O}$ bond distance for the arm of the phosphite without a $\mathrm{CH}_{2}$ group is slightly longer at $1.643(2) \AA$ versus $1.628(2) \AA$ and $1.6290(2) \AA$ for $\mathrm{TpRu}\left[\mathrm{P}\left(\mathrm{OCH}_{2}\right)_{2}\left(\mathrm{OCCH}_{3}\right)\right](\mathrm{NCMe}) \mathrm{Ph}$ (4). The $\mathrm{C}-\mathrm{O}-\mathrm{P}$ bond angle is approximately $10^{\circ}$ less for the portion of the phosphite lacking the $\mathrm{CH}_{2}$ whereas the other $\mathrm{C}-\mathrm{O}-\mathrm{P}$ angles are $108.52(2)^{\mathrm{o}}$ and $107.95(2)^{\mathrm{o}}$.

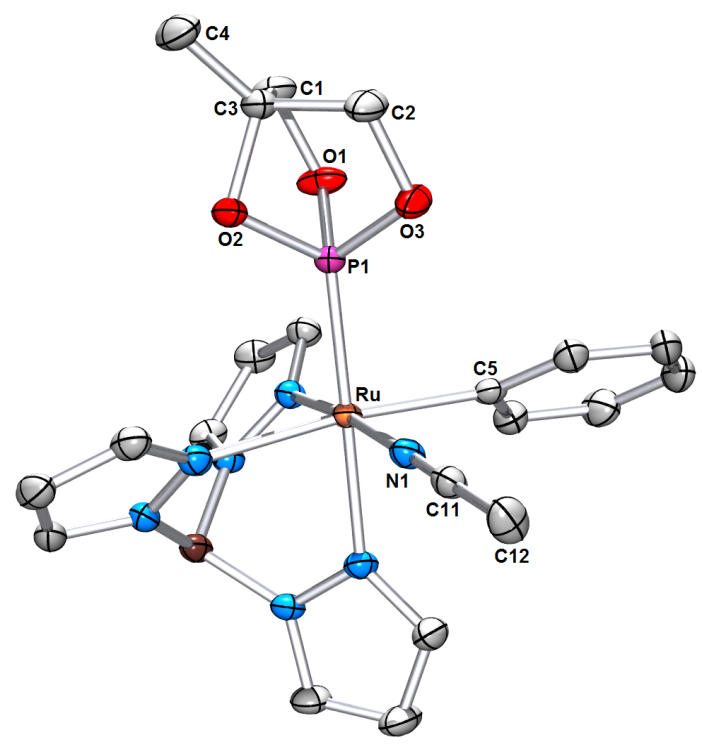

Figure 3.8. ORTEP of $\mathrm{TpRu}\left[\mathrm{P}\left(\mathrm{OCH}_{2}\right)_{2}\left(\mathrm{OCCH}_{3}\right)\right](\mathrm{NCMe}) \mathrm{Ph}$ (4) (50\% probability, hydrogen atoms omitted for clarity.) Selected bond lengths $(\AA)$ : Ru-N1, 2.009(2); RuC5, 2.092(2); N1-C11, 1.147(2); C11-C12, 1.445(4); Ru-P1, 2.1602(6); P1-O1, 1.628(2); P1-O2, 1.643(2); P1-O3, 1.629(2). Selected bond angles ( $\left.{ }^{\circ}\right)$ : N1-Ru-C5, 88.55(9); N1-Ru-P1, 92.58(6); C5-Ru-P1, 92.83(6); N1-C11-C12, 178.1(3); O3-P1$\mathrm{O} 1,100.27(2)$; O3-P1-O2, 93.76(1); O1-P1-O2, 93.56(1); O1-P1-Ru, 119.21(7); O3$\mathrm{P} 1-\mathrm{Ru}, 120.47(7)$; C1-O1-P1, 108.52(2); C3-O2-P1, 98.56(1); C2-O3-P1, 107.95(2). 
Table 3.1. Selective Crystallographic Data for $\mathrm{TpRu}\left[\mathrm{P}\left(\mathrm{OCH}_{2}\right)_{2}\left(\mathrm{OCCH}_{3}\right)\right]$ $(\mathrm{NCMe}) \mathrm{Ph} \bullet \mathrm{CH}_{2} \mathrm{Cl}_{2}(4)$.

\begin{tabular}{ll}
\hline empirical formula & $\mathrm{C}_{22} \mathrm{H}_{27} \mathrm{BCl}_{2} \mathrm{~N}_{7} \mathrm{O}_{3} \mathrm{PRu}$ \\
Fw & 8651.26 \\
cryst syst & Triclinic \\
space group & $\mathrm{P}-1$ \\
a, $\AA$ & $7.8849(2)$ \\
$\mathrm{b}, \AA$ & $12.4914(3)$ \\
$\mathrm{c}, \AA$ & $14.3261(3)$ \\
$\alpha, \mathrm{deg}$ & $81.278(1)$ \\
$\beta, \mathrm{deg}$ & $88.846(1)$ \\
$\gamma$, deg & $75.726(1)$ \\
$\mathrm{V}, \AA^{3}$ & $1351.43(6)$ \\
$\mathrm{Z}$ & 2 \\
$\mathrm{D}_{\text {calcd }}, \mathrm{mg} / \mathrm{m}^{3}$ & 1.600 \\
cryst size $(\mathrm{mm})$ & $0.42 \times 0.19 \times 0.08$ \\
$\mathrm{R} 1, \mathrm{wR} 2(\mathrm{I}>2(\mathrm{I}))$ & $0.0386,0.1110$ \\
$\mathrm{GOF}$ & 0.898 \\
\hline
\end{tabular}

\subsubsection{Stoichiometric Benzene Activation}

Based on mechanistic studies, we have suggested that benzene $\mathrm{C}-\mathrm{H}$ activation by $\mathrm{TpRu}(\mathrm{L})(\mathrm{NCMe}) \mathrm{Ph}\left[\mathrm{L}=\mathrm{CO}, \mathrm{PMe}_{3}, \mathrm{P}\left(\mathrm{OCH}_{2}\right)_{3} \mathrm{CEt}\right]$ complexes most likely involves dissociation of $\mathrm{NCMe}$, which gives an open coordination site for $\mathrm{C}_{6} \mathrm{D}_{6}$ coordination, followed by $\mathrm{C}-\mathrm{D}$ activation (Scheme 3.5). ${ }^{1,2,4}$ The reaction of complex 4 in $\mathrm{C}_{6} \mathrm{D}_{6}$ under pseudo-first order conditions results in benzene $\mathrm{C}-\mathrm{D}$ activation as described above for $\mathrm{TpRu}(\mathrm{L})(\mathrm{NCMe}) \mathrm{Ph}\left[\mathrm{L}=\mathrm{CO}, \mathrm{PMe}_{3}, \mathrm{P}\left(\mathrm{OCH}_{2}\right)_{3} \mathrm{CEt}\right]$ (Scheme 3.5, Scheme 3.6) Similar to the previously reported $\mathrm{TpRu}(\mathrm{L})(\mathrm{NCMe}) \mathrm{Ph}$ complexes, ${ }^{1,2,4,5}$ the addition of $\mathrm{NCMe}$ is necessary to inhibit decomposition and allow the $\mathrm{C}-\mathrm{D}$ activation to proceed in quantitative yield ( ${ }^{1} \mathrm{H}$ NMR spectroscopy). ${ }^{2}$ Monitoring a solution of 4 in $\mathrm{C}_{6} \mathrm{D}_{6}$ at $60{ }^{\circ} \mathrm{C}$ by ${ }^{1} \mathrm{H}$ NMR spectroscopy reveals the formation of benzene $\left(\mathrm{C}_{6} \mathrm{H}_{5} \mathrm{D}\right)$ and the disappearance of resonances for the phenyl ligand of 4 . The addition of one equivalent of 
NCMe to the solution results in clean conversion of 4 to $4-d_{5}$ with $>90 \%$ yield (by ${ }^{1} \mathrm{H}$ NMR spectroscopy). ${ }^{22}$ These observations are consistent with $\mathrm{C}-\mathrm{D}$ activation of $\mathrm{C}_{6} \mathrm{D}_{6}$ by complex 4 .

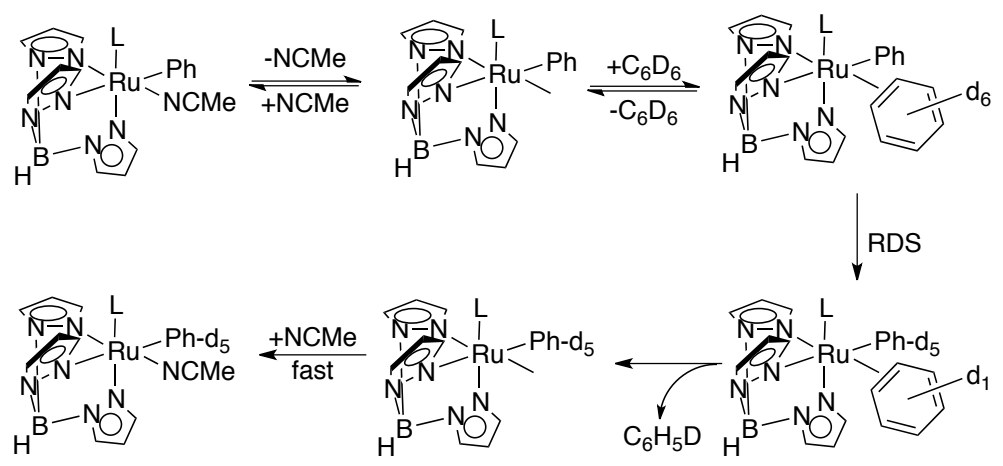

Scheme 3.5 Proposed mechanism for benzene $\mathrm{C}-\mathrm{H}$ activation by $\mathrm{TpRu}(\mathrm{L})(\mathrm{NCMe}) \mathrm{Ph}$.

In order to compare $\mathrm{C}_{6} \mathrm{D}_{6}$ activation by complex 4 to other $\mathrm{TpRu}(\mathrm{L})(\mathrm{NCMe}) \mathrm{Ph}$ complexes, the rate of reaction with $\mathrm{C}_{6} \mathrm{D}_{6}$ was determined under pseudo first order conditions (i.e., large excess of $\left.\mathrm{C}_{6} \mathrm{D}_{6}\right)$. A $k_{\mathrm{obs}}$ of $7.2(5) \times 10^{-6} \mathrm{~s}^{-1}\left(60^{\circ} \mathrm{C}\right)$ was found by fitting the plot concentration of perprotio-4 versus time to a first-order decay (Figure 3.9). The $k_{\mathrm{obs}}$ is an average of four independent kinetic experiments. Thus, the rate of $\mathrm{C}_{6} \mathrm{D}_{6}$ activation shared good reproducibility. The $k_{0 b s}$ values for $\mathrm{C}_{6} \mathrm{D}_{6}$ activation by $\mathrm{TpRu}(\mathrm{L})(\mathrm{NCMe}) \mathrm{Ph}\left(\mathrm{L}=\mathrm{CO}, \mathrm{PMe}_{3}\right.$ or $\left.\mathrm{P}\left(\mathrm{OCH}_{2}\right)_{3} \mathrm{CEt}\right)$ have been previously determined, ${ }^{3}$ and a plot of $k_{\text {obs }}$ for $\mathrm{C}_{6} \mathrm{D}_{6}$ activation vs. $\mathrm{Ru}(\mathrm{III} / \mathrm{II})$ redox potential for the $\mathrm{TpRu}(\mathrm{L})(\mathrm{NCMe}) \mathrm{Ph}$ complexes reveals a clear trend (Table 3.2, Figure 3.10). The rate of $\mathrm{C}_{6} \mathrm{D}_{6}$ activation decreases as $\mathrm{Ru}(\mathrm{III} / \mathrm{II})$ potential becomes more positive. The slowest $\mathrm{C}_{6} \mathrm{D}_{6}$ activation occurs with $\mathrm{TpRu}(\mathrm{CO})(\mathrm{NCMe}) \mathrm{Ph}$ with a $k_{\mathrm{obs}}=4.62(3) \times 10^{-6} \mathrm{~s}^{-1}$; whereas the most electron-rich metal center, $\mathrm{TpRu}\left(\mathrm{PMe}_{3}\right)(\mathrm{NCMe}) \mathrm{Ph}$, exhibits the fastest rate of 
$\mathrm{C}_{6} \mathrm{D}_{6}$ activation with $k_{\mathrm{obs}}=1.36(4) \times 10^{-5} \mathrm{~s}^{-1}$ (Table 3.2). The plot of $\mathrm{E}_{1 / 2}$ vs. $k_{\text {obs }}$ gives a linear correlation with an $\mathrm{R}^{2}$ value of 0.92 and a slope of $-1.29 \mathrm{~s}^{-1} \mathrm{~V}^{-1}$ (Figure 3.10). However, it is important to note that the in these experiments the rate of $\mathrm{C}-\mathrm{D}$ activation is being determined from $\mathrm{TpRu}(\mathrm{L})(\mathrm{NCMe}) \mathrm{Ph}$ rather than the proposed catalyst resting states $\mathrm{TpRu}(\mathrm{L})\left(\mathrm{CH}_{2} \mathrm{CH}_{2} \mathrm{Ph}\right)\left(\eta^{2}-\mathrm{C}_{2} \mathrm{H}_{4}\right)$. Since dissociation of ethylene, which is necessary for benzene activation in the catalytic cycle under conditions where $\mathrm{TpRu}(\mathrm{L})\left(\mathrm{CH}_{2} \mathrm{CH}_{2} \mathrm{Ph}\right)\left(\eta^{2}-\mathrm{C}_{2} \mathrm{H}_{4}\right)$ complexes are the resting state, might vary differently as a function of the ligand $\mathrm{L}$ compared to acetonitrile dissociation, it is not possible to definitively use the comparative rates of benzene activation by $\mathrm{TpRu}(\mathrm{L})(\mathrm{NCMe}) \mathrm{Ph}$ to make predictions about relative rates of catalysis.

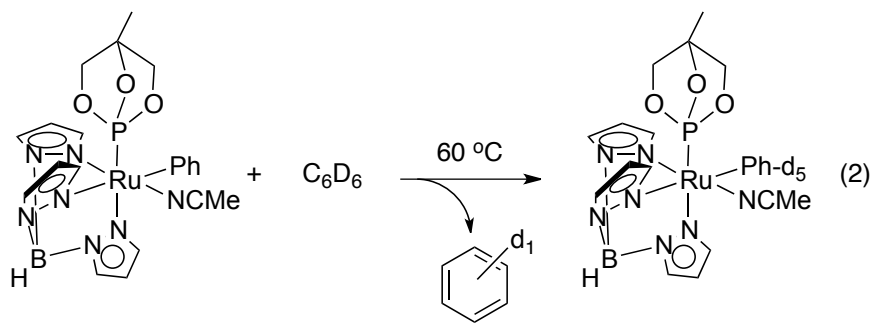

Scheme 3.6. Stoichiometric C-D benzene of complex 4 . 


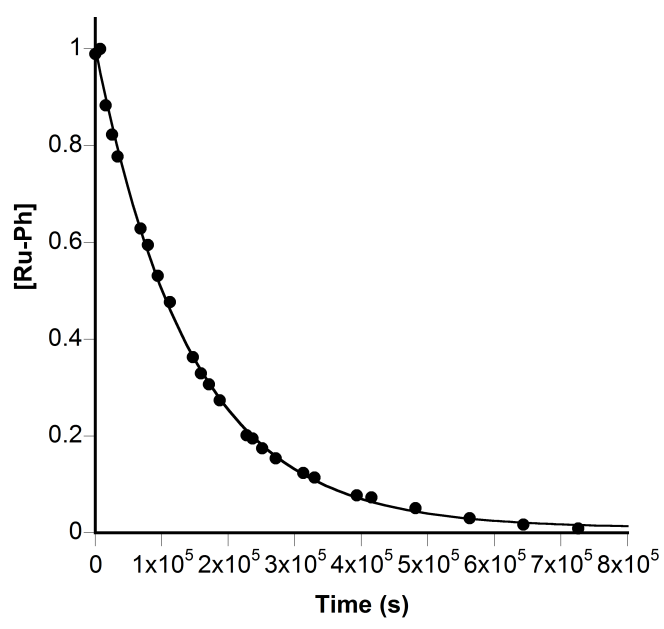

Figure 3.9. Representative plot of $\mathrm{C}-\mathrm{D}$ activation of $\mathrm{C}_{6} \mathrm{D}_{6}$ by $\mathrm{TpRu}\left[\mathrm{P}\left(\mathrm{OCH}_{2}\right)_{2}\left(\mathrm{OCCH}_{3}\right)\right.$ ](NCMe) $\mathrm{Ph}(4)$ in $\mathrm{C}_{6} \mathrm{D}_{6}$ at $60{ }^{\circ} \mathrm{C}$ monitored by ${ }^{1} \mathrm{H}$ NMR spectroscopy $\left(k_{\mathrm{obs}}=7.0(2) \times 10^{-6}\right.$ $\mathrm{s}^{-1}, \mathrm{R}^{2}=0.99$ ). The plot shows relative amount of protio-phenyl ligand (integrated against an internal standard) of $\mathbf{4}$ as a function of time.

Table 3.2. $\mathrm{Ru}(\mathrm{III} / \mathrm{II})$ Potentials and Rate Constants for the Activation of $\mathrm{C}_{6} \mathrm{D}_{6}$ at $60{ }^{\circ} \mathrm{C}$ by $\mathrm{TpRu}(\mathrm{L})(\mathrm{NCMe}) \mathrm{Ph} .^{a}$

\begin{tabular}{cccc}
\hline & $\begin{array}{c}\mathrm{Ru}(\mathrm{III} / \mathrm{II}) \text { Potentials } \\
\mathrm{L}\end{array}$ & $k_{\mathrm{obs}}\left(\mathrm{V} 10^{-5}, \mathrm{~s}^{-1}\right)^{a}$ & Relative $k_{\text {obs }}$ \\
\hline $\mathrm{PMe}_{3}$ & 0.29 & $1.36(4)$ & 3.0 \\
$\mathrm{P}\left(\mathrm{OCH}_{2}\right)_{3} \mathrm{CEt}$ & 0.54 & $1.20(2)$ & 2.6 \\
$\mathrm{P}\left(\mathrm{OCH}_{2}\right)_{2}\left(\mathrm{OCCH}{ }_{3}\right)$ & 0.69 & $0.72(5)$ & 1.6 \\
$\mathrm{CO}$ & 1.03 & $0.462(3)$ & 1
\end{tabular}




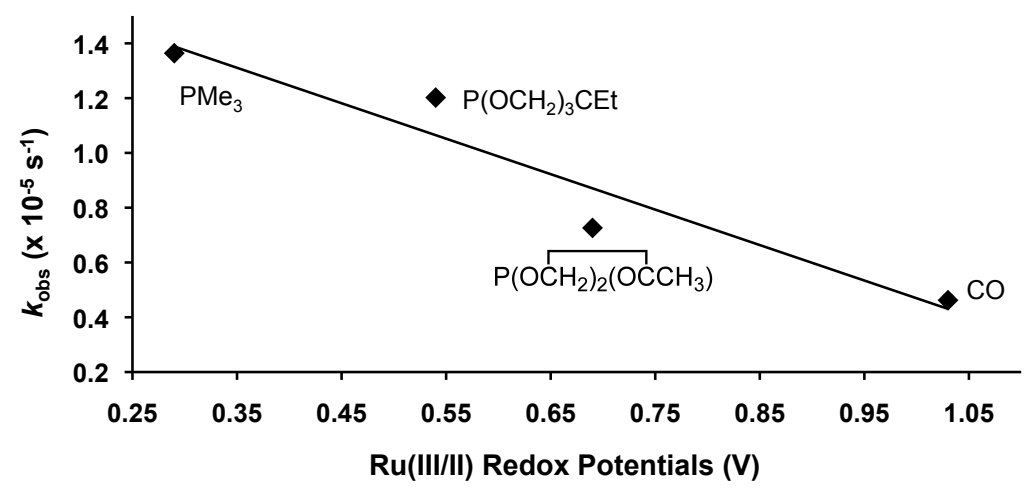

Figure 3.10. Linear fit for plot of $k_{\mathrm{obs}}\left(\mathrm{x} 10^{-5}, \mathrm{~s}^{-1}\right)$ values vs. $\mathrm{Ru}(\mathrm{III} / \mathrm{II})$ potentials (vs. $\mathrm{NHE}, \mathrm{V}$ ) for the $\mathrm{C}-\mathrm{D}$ activation of $\mathrm{C}_{6} \mathrm{D}_{6}$ by $\mathrm{TpRu}(\mathrm{L})(\mathrm{NCMe}) \mathrm{Ph}$ at $60{ }^{\circ} \mathrm{C}$ with 0.065 mmol of added NCMe $\left(\mathrm{R}^{2}=0.92, \mathrm{~m}=-1.29 \mathrm{~s}^{-1} \mathrm{~V}^{-1}\right)$.

\subsubsection{Catalytic Hydrophenylation of Ethylene by TpRu[ $\left.\mathrm{P}\left(\mathrm{OCH}_{2}\right)_{2}\left(\mathrm{OCCH}_{3}\right)\right]$ (NCMe)Ph (4)}

Scheme 3.7 shows the proposed catalytic cycle for ethylene hydrophenylation by $\mathrm{TpRu}(\mathrm{L})(\mathrm{NCMe}) \mathrm{Ph} \quad$ complexes. $^{1-3,5,23}$ Through experimental and computational mechanistic studies, it has been concluded that the active catalytic species is generated from $\mathrm{TpRu}(\mathrm{L})(\mathrm{NCMe}) \mathrm{Ph}$ by dissociation of NCMe. Subsequent coordination of ethylene to $\mathrm{Ru}$ followed by olefin insertion into the $\mathrm{Ru}-\mathrm{Ph}$ bond yields $\mathrm{TpRu}(\mathrm{L})\left(\mathrm{CH}_{2} \mathrm{CH}_{2} \mathrm{Ph}\right){ }^{5}$ Benzene coordination and $\mathrm{C}-\mathrm{H}$ activation releases ethylbenzene and regenerates the active catalyst. $^{3,1}$ The catalyst resting state has been identified as $\operatorname{TpRu}(\mathrm{L})\left(\eta^{2}-\right.$ $\left.\mathrm{C}_{2} \mathrm{H}_{4}\right)\left(\mathrm{CH}_{2} \mathrm{CH}_{2} \mathrm{Ph}\right),{ }^{3}$ and the rate-limiting step of the catalytic cycle is likely the aromatic $\mathrm{C}-\mathrm{H}$ bond activation event as determined by kinetic studies and kinetic isotope effects. 


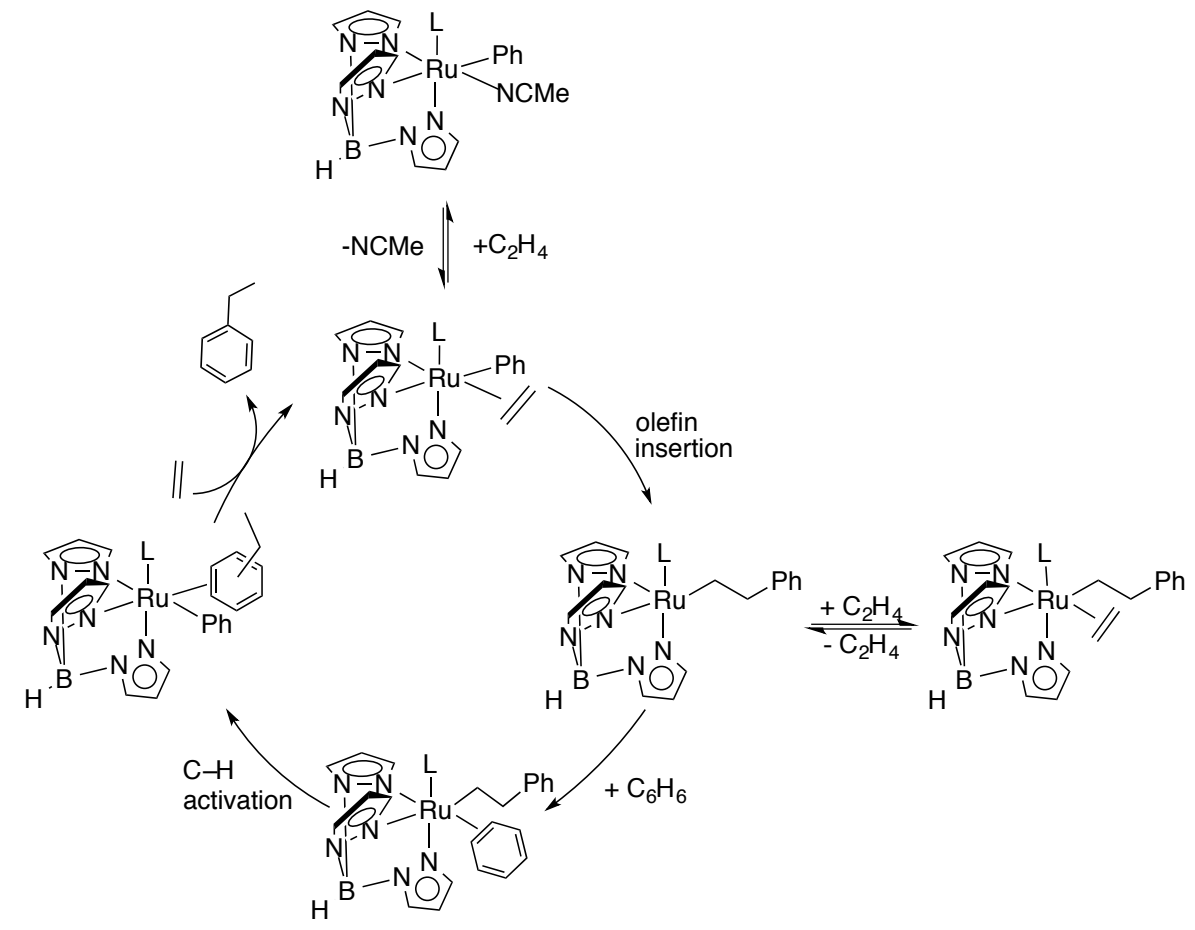

Scheme 3.7. Proposed Catalytic Cycle for the Hydrophenylation of Ethylene using $\mathrm{TpRu}(\mathrm{L})(\mathrm{NCMe})_{3} \mathrm{Ph}\left[\mathrm{L}=\mathrm{CO}, \mathrm{P}\left(\mathrm{OCH}_{2}\right)_{3} \mathrm{CEt}\right.$ or $\left.\mathrm{P}\left(\mathrm{OCH}_{2}\right)_{2}\left(\mathrm{OCCH}_{3}\right)\right]$.

Complex 4 catalyzes the hydrophenylation of ethylene using $0.025 \mathrm{~mol} \%$ (relative to benzene) of 4 at with 15 psi of ethylene results in 90 turnovers (TOs) of ethylbenzene after $50 \mathrm{~h}$. Similar to previously reported $\mathrm{Ru}(\mathrm{II})$ complexes,${ }^{25}$ the catalyst activity is inversely proportional to ethylene concentration (Figure 3.11). The proposed catalyst resting state is $\mathrm{TpRu}(\mathrm{L})\left(\eta^{2}-\mathrm{CH}_{2} \mathrm{CH}_{2}\right)\left(\mathrm{CH}_{2} \mathrm{CH}_{2} \mathrm{Ph}\right)$. Thus, ethylene removes the $\mathrm{Ru}$ catalyst from the catalytic cycle, which provides a rationalization for the inhibition of catalyst activity at higher ethylene concentrations. For example, at $90{ }^{\circ} \mathrm{C}$ after $8 \mathrm{~h}$, the TOs were 38 (15 psi), 29 (25 psi), 17 (50 psi), 7 (100 psi) and 5 (200 psi). The optimal conditions for catalysis are at $90{ }^{\circ} \mathrm{C}$ with $15 \mathrm{psi}$ of ethylene. Under most conditions, no 
diethylbenzene or styrene is detected. Increasing the temperature $\left(75^{\circ} \mathrm{C}, 90{ }^{\circ} \mathrm{C}\right.$ and 105 ${ }^{\circ} \mathrm{C}$ ) at 15 psi of ethylene increases the rate of ethylbenzene production (Figure 3.13).

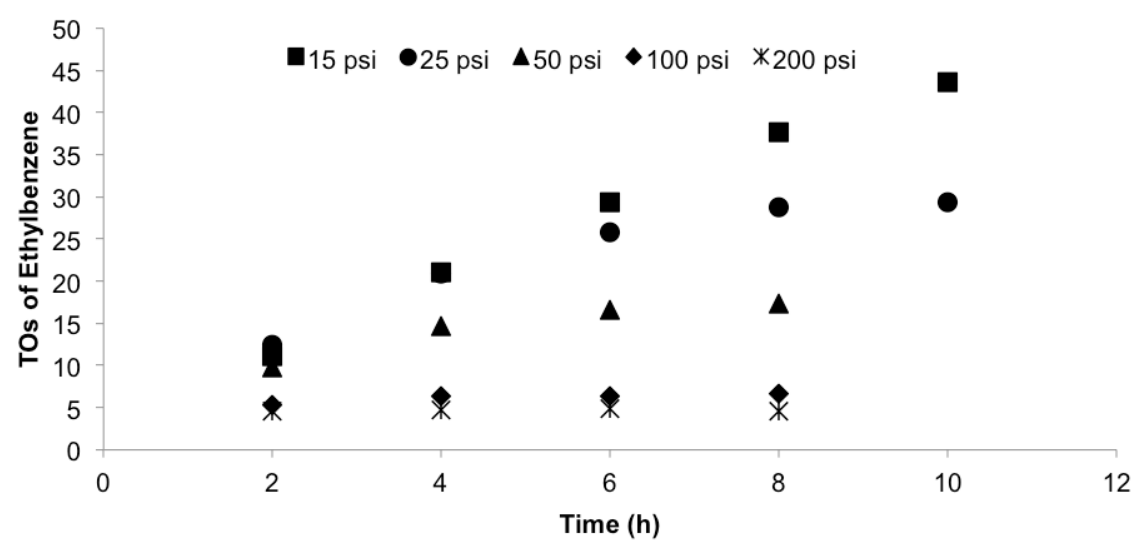

Figure 3.11. Comparison of catalytic hydrophenylation of ethylene by complex $4\left(90{ }^{\circ} \mathrm{C}\right)$ at variable ethylene pressures.

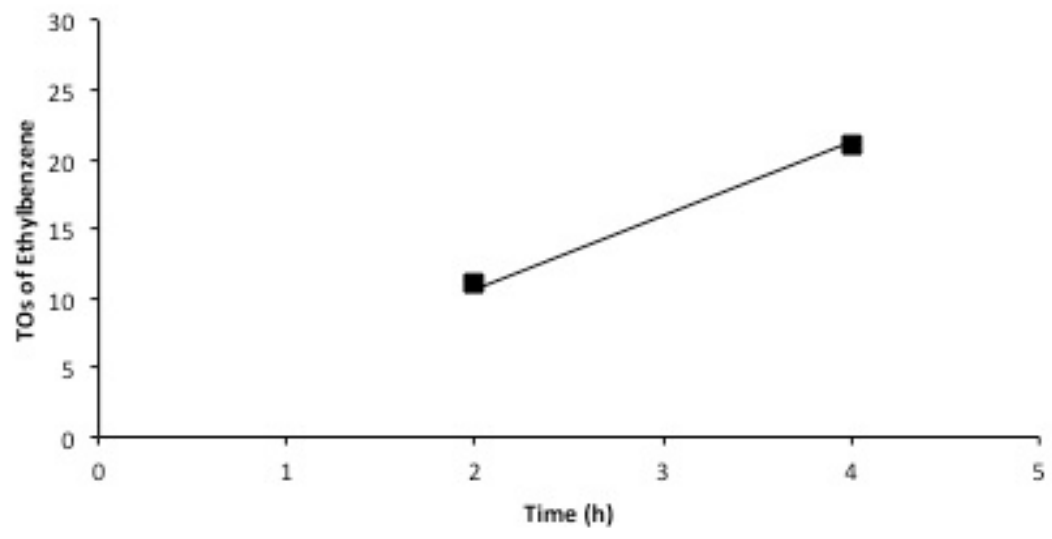

Figure 3.12. Comparison of catalytic hydrophenylation of ethylene by complex 4 (15 psi $\left.\& 90{ }^{\circ} \mathrm{C}\right)$ through $4 \mathrm{~h}$ with mininal decomposition of catalyst present $\left(\mathrm{R}^{2}=0.99\right.$ when trendline is forced through 0,0 ).

As seen in Figure 3.12, during the first $4 \mathrm{~h}$ of catalysis the slope of the change in TO over time is linear (i.e., minimal catalyst deactivation is observed). Therefore initial turnover frequency (TOF) were calculated at $4 \mathrm{~h}$ : TOF $=2.1 \times 10^{-4} \mathrm{~s}^{-1}$ at $75^{\circ} \mathrm{C}, 1.5 \times 10^{-3}$ 
$\mathrm{s}^{-1}$ at $90{ }^{\circ} \mathrm{C}$, and $3.5 \times 10^{-3} \mathrm{~s}^{-1}$ at $105{ }^{\circ} \mathrm{C}$. In comparison, the TOF using $\mathrm{TpRu}(\mathrm{CO})(\mathrm{NCMe}) \mathrm{Ph}\left(90^{\circ} \mathrm{C}\right.$, calculated after $4 \mathrm{~h}$ of catalysis) is $6.7 \times 10^{-3} \mathrm{~s}^{-1}$ (note: this TOF and the turnover number (TON) are different from previously published data ${ }^{5}$ as a result of different conditions). Thus, at $90{ }^{\circ} \mathrm{C}$ and 15 psi of ethylene $\mathrm{TpRu}[$ $\left.\mathrm{P}\left(\mathrm{OCH}_{2}\right)_{2}\left(\mathrm{OCCH}_{3}\right)\right](\mathrm{NCMe}) \mathrm{Ph}$ (4) is a less active catalyst than $\mathrm{TpRu}(\mathrm{CO})(\mathrm{NCMe}) \mathrm{Ph}$ by a factor of $\sim 4.5$.

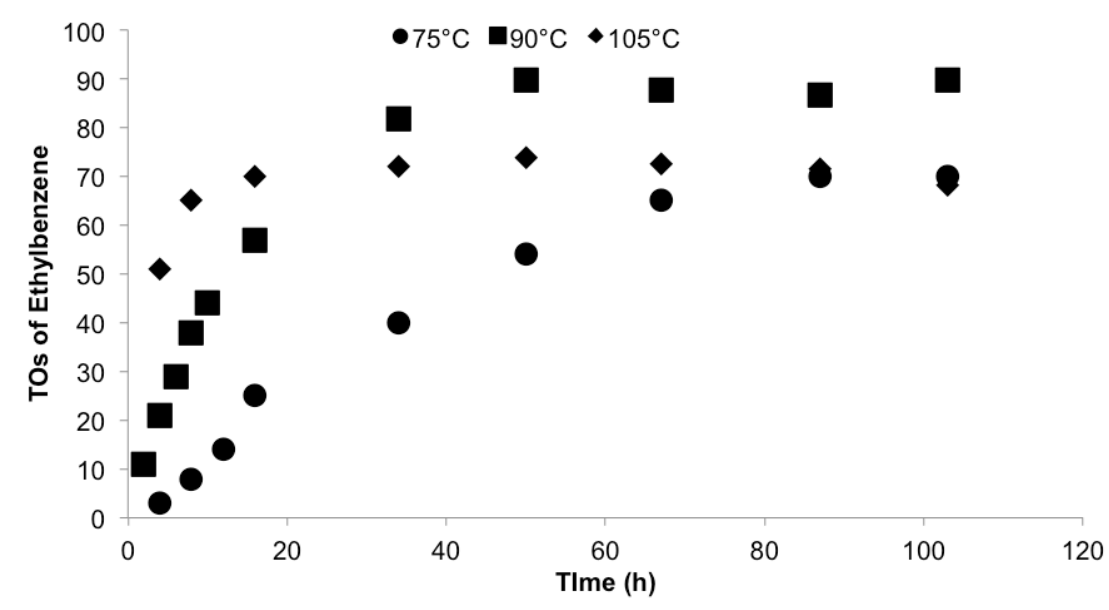

Figure 3.13. Comparison of catalytic hydrophenylation of ethylene by complex 4 at 15 psi of ethylene and variable temperature.

${ }^{1} \mathrm{H}$ NMR spectroscopy of the non-volatiles after catalyst deactivation indicates that the product of catalyst deactivation is the $\eta^{3}$-allyl complex $\mathrm{TpRu}\left[\mathrm{P}\left(\mathrm{OCH}_{2}\right)_{2}\left(\mathrm{OCCH}_{3}\right)\right.$ ]$\left(\eta^{3}-\mathrm{C}_{3} \mathrm{H}_{4} \mathrm{Me}\right)$ (5). Complex 5 has been isolated and characterized by ${ }^{1} \mathrm{H}$ NMR spectroscopy and mass spectrometry (Scheme 3.8, Figure 3.14, Figure 3.15). The ${ }^{1} \mathrm{H}$ NMR spectrum reveals minor impurities that we were not able to remove. GC-MS analysis of $\mathbf{5}$ shows the expected parent peak for complex $\mathbf{5}$ in addition to peaks for 
complexes with one and two additional equivalents of ethylene (Figure 3.16). Thus, we speculate that the minor impurities are allyl complexes with propyl and pentyl groups that result from insertion of one or two additional equivalents of ethylene (Scheme 3.8). The deactivation of 4 under catalytic conditions is identical to that observed for $\mathrm{TpRu}\left(\mathrm{PMe}_{3}\right)(\mathrm{NCMe}) \mathrm{Ph}$ and $\mathrm{TpRu}\left[\mathrm{P}\left(\mathrm{OCH}_{2}\right)_{3} \mathrm{CEt}\right](\mathrm{NCMe}) \mathrm{Ph}^{1,2}$ It has been shown previously that the allyl complex is formed due to an electron-rich $\mathrm{Ru}$ center, which results in olefin $\mathrm{C}-\mathrm{H}$ activation competing with ethylene insertion. ${ }^{3}$ This ultimately leads to the formation of an $\eta^{3}$-allyl species due to the formation of a Ru-vinyl species followed by olefin insertion and isomerization.

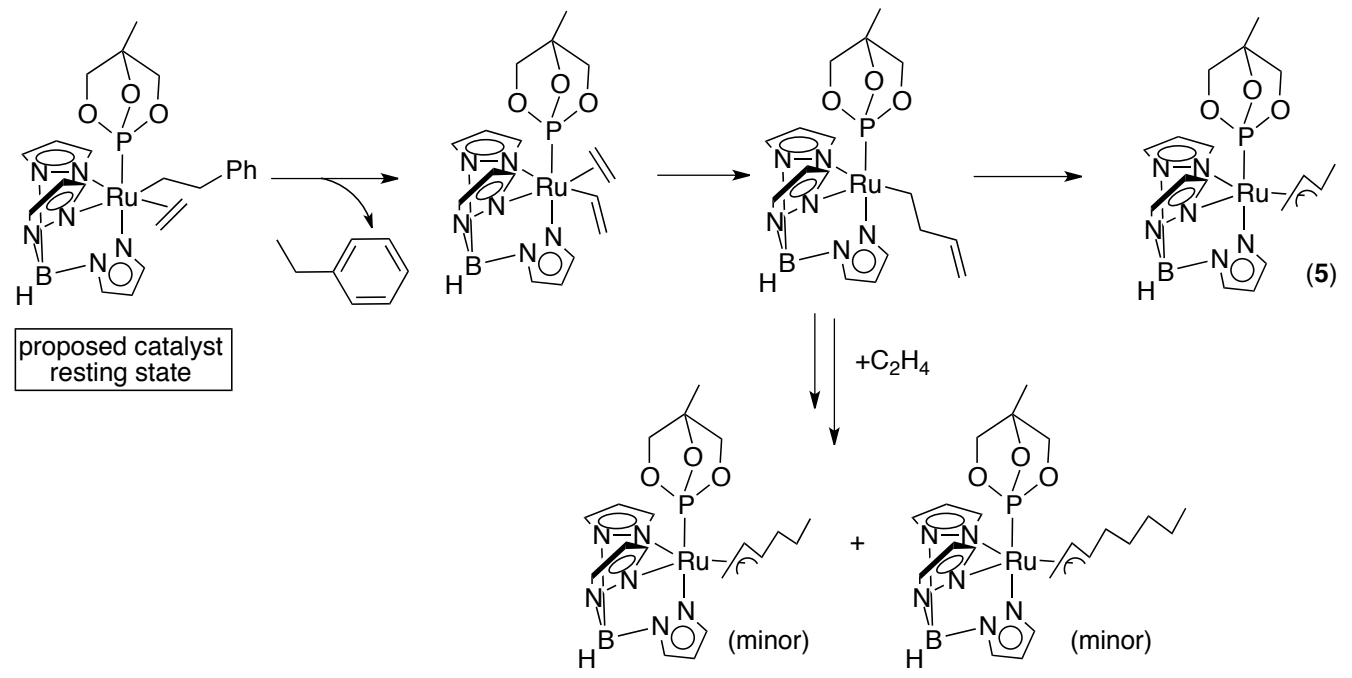

Scheme 3.8. $\mathrm{TpRu}\left[\mathrm{P}(\mathrm{OCH})_{2}\left(\mathrm{OCCH}_{3}\right)\right]\left(\eta^{3}-\mathrm{C}_{3} \mathrm{H}_{4} \mathrm{Me}\right)(5)$ and minor products caused by multiple ethylene insertions. 

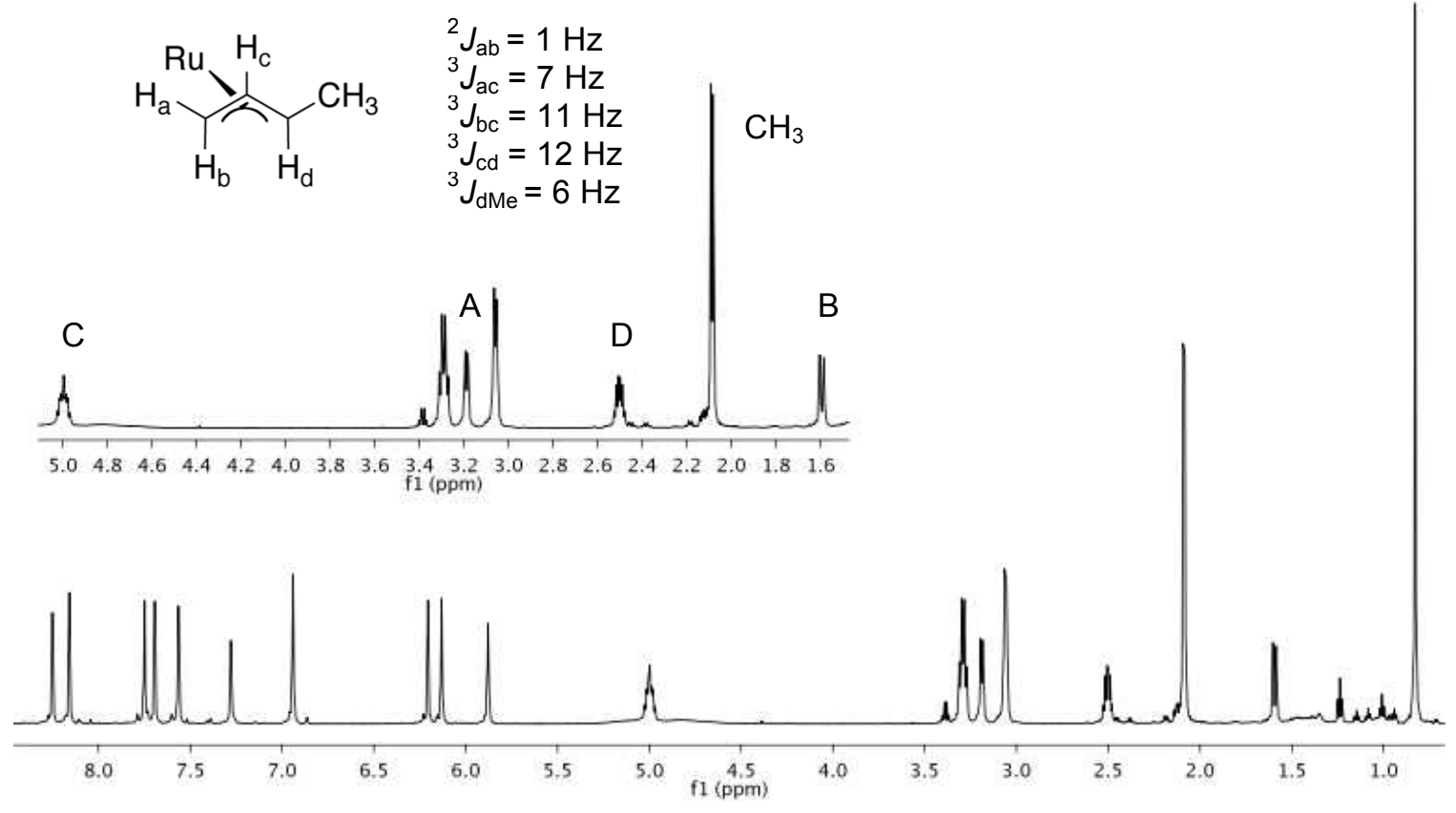

Figure 3.14. ${ }^{1} \mathrm{H}$ NMR spectrum of $\mathrm{TpRu}\left[\mathrm{P}\left(\mathrm{OCH}_{2}\right)_{2}\left(\mathrm{OCCH}_{3}\right)\right]\left(\eta^{3}-\mathrm{C}_{3} \mathrm{H}_{4} \mathrm{Me}\right)(\mathbf{5})$ in $\mathrm{C}_{6} \mathrm{D}_{6}$.

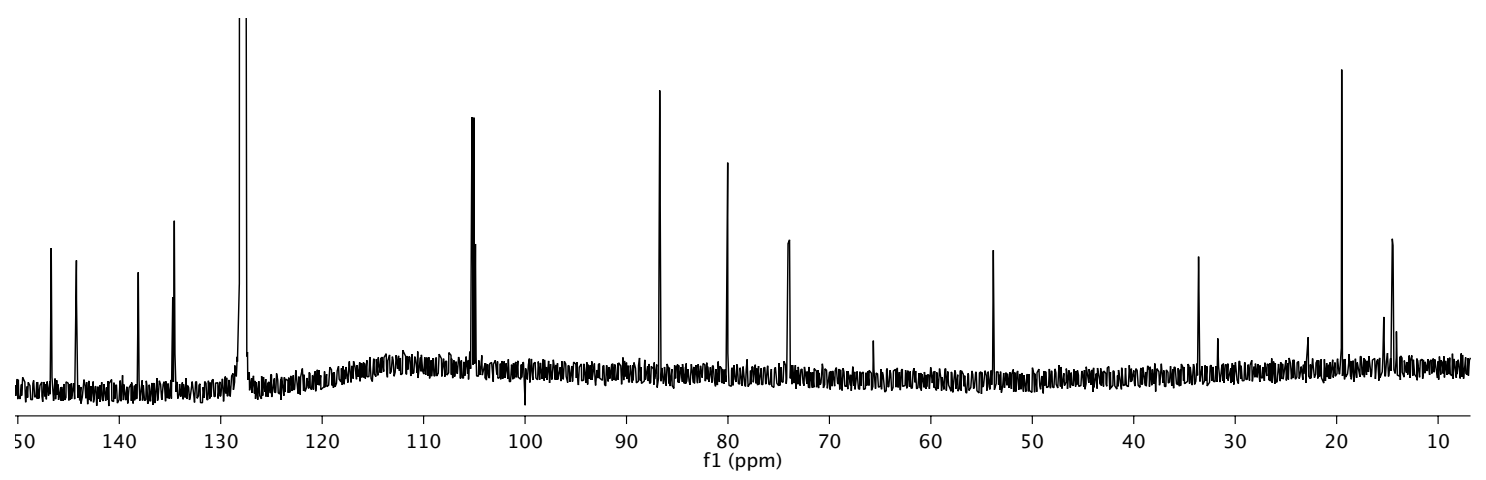

Figure 3.15. ${ }^{13} \mathrm{C}$ NMR spectrum of $\mathrm{TpRu}\left[\mathrm{P}\left(\mathrm{OCH}_{2}\right)_{2}\left(\mathrm{OCCH}_{3}\right)\right]\left(\eta^{3}-\mathrm{C}_{3} \mathrm{H}_{4} \mathrm{Me}\right)(\mathbf{5})$ in $\mathrm{C}_{6} \mathrm{D}_{6}$. 


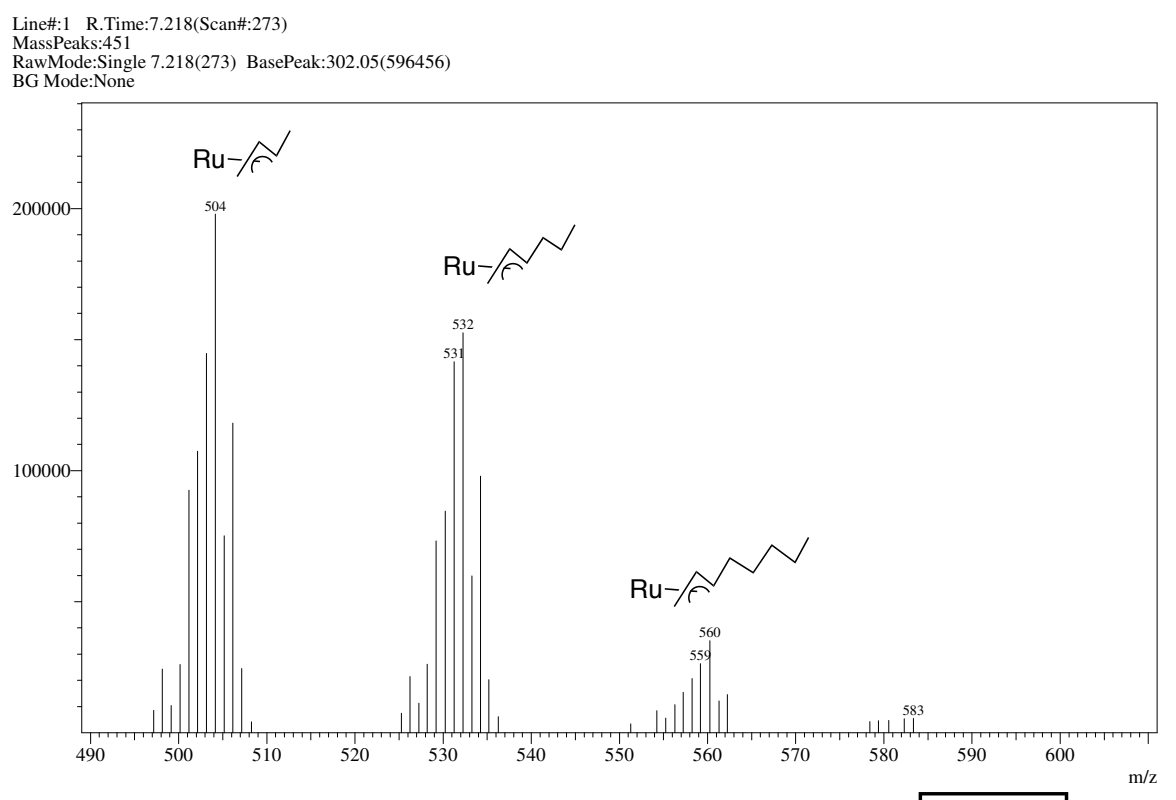

Figure 3.16. Low-Resolution Mass Spectrometry of TpRu[ $\left.\mathrm{P}\left(\mathrm{OCH}_{2}\right)_{2}\left(\mathrm{OCCH}_{3}\right)\right]\left(\eta^{3}-\right.$ $\left.\mathrm{C}_{3} \mathrm{H}_{4} \mathrm{Me}\right)(\mathbf{5})$ in $\mathrm{C}_{6} \mathrm{D}_{6}$ from $\mathrm{m} / \mathrm{z}=490$ to 600 .

\subsubsection{Catalytic Hydroarylation by $\mathrm{TpRu}\left[\mathrm{P}\left(\mathrm{OCH}_{2}\right)_{2}\left(\mathrm{OCCH}_{3}\right)\right](\mathrm{NCMe}) \mathrm{Ph}$ (4) using Ethylbenzene and Ethylene}

Regioselective production of dialkyl benzenes is a challenging reaction. FriedelCrafts catalysts generally give a mixture of 1,2-, 1,3- and 1,4-dialkyl benzenes. ${ }^{24}$ To determine if complex $\mathbf{4}$ exhibits selectivity for the production of diethylbenzene, ethylene hydroarylation studies were performed using ethylbenzene in the presence of ethylene. Upon the reaction of ethylbenzene and ethylene at $90{ }^{\circ} \mathrm{C}$ and 15 psi of ethylene with $0.025 \mathrm{~mol} \%$ of 4 , a $2: 1$ ratio of 1,3 - to 1,4-diethylbenzene ( 8 and 4 TOs after $4 \mathrm{~h}$, respectively) was observed (Scheme 3.9). No evidence for the formation of 1,2diethylbenzene was obtained. In the case of $\mathrm{TpRu}(\mathrm{CO})(\mathrm{NCMe}) \mathrm{Ph}$, the same 2:1 ratio of 1,3-diethylbenzene to 1,4-diethylbenzene is observed. ${ }^{35}$ The TOF for the formation of diethylbenzene after $4 \mathrm{~h}$ is $8.3 \times 10^{-4} \mathrm{~s}^{-1}$, which is 1.8 times slower than the formation of 
ethylbenzene from benzene and ethylene (see above). With Friedel-Crafts catalysts, ethylbenzene is generally more reactive than benzene, which renders selective monoalkylation challenging. ${ }^{3}$

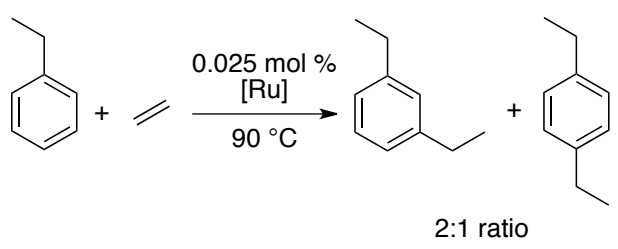

Scheme 3.9. Formation of 1,3- and 1,4-diethylbenzene.

\subsubsection{Attempted Hydrophenylation of Monosubstituted Olefins}

Hydrophenylation of 1-pentene (160 equivalents relative to 4) was attempted. Only minimal production of 2-phenylpentane ( $\sim 0.3 \mathrm{TOs})$ was observed after $8 \mathrm{~h}$. Increasing the amount of 1-pentene did not give increased production of phenylpentane. Additionally, catalytic hydrophenylation was unsuccessful with the substrates methyl acrylate, methyl vinyl ketone and propylene (at pressures from $25-150$ psi and temperatures of $90{ }^{\circ} \mathrm{C}$ or $\left.110^{\circ} \mathrm{C}\right)$.

\subsubsection{DFT Calculations of Ethylene Hydrophenylation by $T p R u[$ $\left.\mathrm{P}\left(\mathrm{OCH}_{2}\right)_{2}\left(\mathrm{OCCH}_{3}\right)\right](\mathrm{NCMe}) \mathrm{Ph}$}

Density Functional Theory (DFT) calculations were used to probe the conversion of $\mathrm{TpRu}\left[\mathrm{P}\left(\mathrm{OCH}_{2}\right)_{2}\left(\mathrm{OCCH}_{3}\right)\right](\mathrm{NCMe}) \mathrm{Ph}$ (4) and ethylene to ethylbenzene (Scheme 3.10). Comparison of the free energy surface for $\mathrm{L}=\mathrm{P}\left(\mathrm{OCH}_{2}\right)_{2}\left(\mathrm{OCCH}_{3}\right)$ with that previously reported for $\mathrm{PMe}_{3}, \mathrm{P}(\mathrm{pyr})_{3}, \mathrm{P}\left(\mathrm{OCH}_{2}\right)_{3} \mathrm{CEt}$ and $\mathrm{CO}$ shows little variation in the overall 
shape and energies of the intermediates and transition states for ethylene insertion (TS1, Scheme 3.10, Scheme 3.11) and benzene C-H activation (TS2, Scheme 3.10, Scheme 3.11). ${ }^{3}$ As seen for other $\pi$-acidic ligands (e.g., $\mathrm{P}\left(\mathrm{OCH}_{2}\right)_{3} \mathrm{CEt}$ and $\left.\mathrm{CO}\right)$, the coordination mode of benzene in $\mathrm{TpRu}(\mathrm{L})($ benzene $)\left(\mathrm{CH}_{2} \mathrm{CH}_{2} \mathrm{Ph}\right)\left(\mathrm{E}\right.$ in Scheme 3.10) is $\eta^{2}-\mathrm{C}=\mathrm{C}$, while for less $\pi$-acidic ligands an $\eta^{2}-\mathrm{C}-\mathrm{H}$ coordination mode of benzene was calculated to be most favorable. ${ }^{3}$ There is very little difference in calculated energetics starting from complex 4 compared to identical calculations for $\mathrm{TpRu}\left[\mathrm{P}\left(\mathrm{OCH}_{2}\right)_{3} \mathrm{CEt}\right](\mathrm{NCMe}) \mathrm{Ph}^{1}{ }^{1}$ In fact, calculated energies for the two phosphites differ by only $\sim 1 \mathrm{kcal} / \mathrm{mol}$, which is within the error of these calculations.

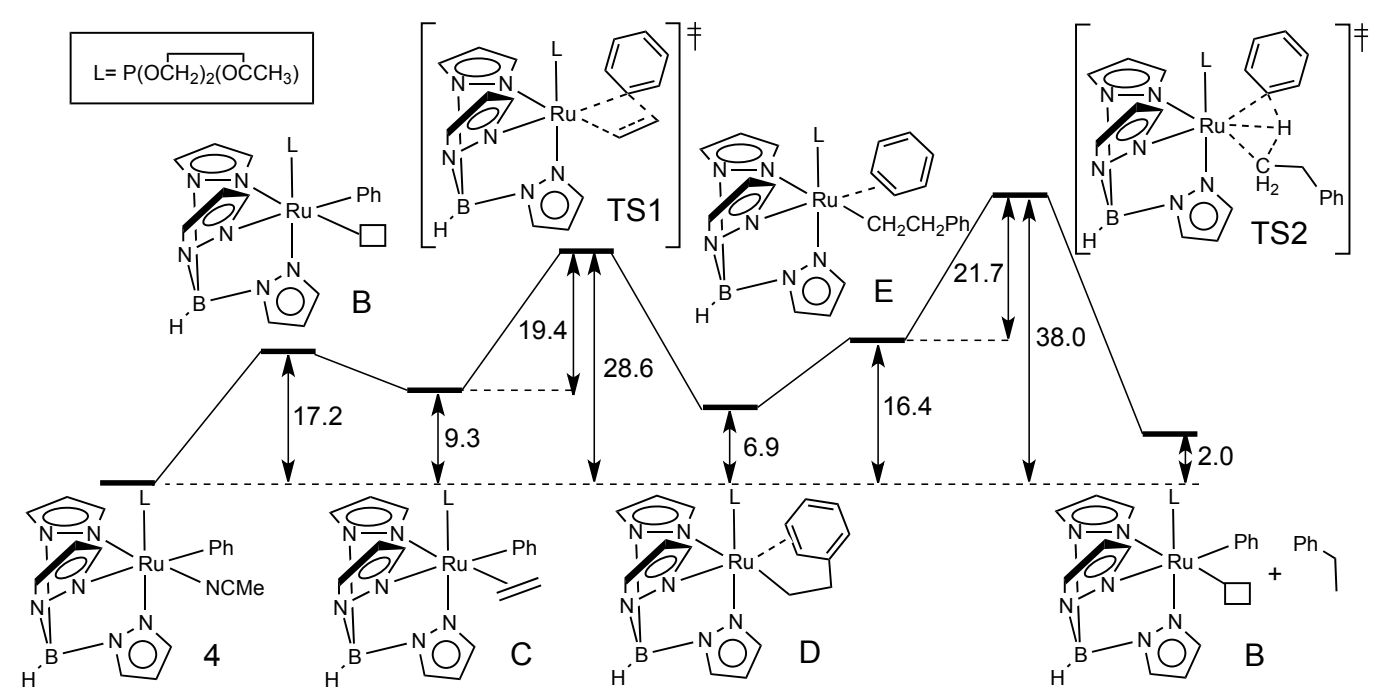

Scheme 3.10. Calculated Gibbs free energies $(\mathrm{kcal} / \mathrm{mol})$ for hydrophenylation of ethylene by $\mathrm{TpRu}\left[\mathrm{P}\left(\mathrm{OCH}_{2}\right)_{2}\left(\mathrm{OCCH}_{3}\right)\right](\mathrm{NCMe}) \mathrm{Ph}$.

Table 3.3 contains key bond distances for the calculated structures of TS2 (Scheme 3.10 and Table 3.3) for $\mathrm{TpRu}(\mathrm{L})(\mathrm{NCMe}) \mathrm{Ph}$ complexes $\left(\mathrm{L}=\mathrm{PMe}_{3}, \mathrm{P}\left(\mathrm{OCH}_{2}\right)_{3} \mathrm{CEt}\right.$, $\mathrm{P}\left(\mathrm{OCH}_{2}\right)_{2}\left(\mathrm{OCCH}_{3}\right), \mathrm{CO}, \mathrm{P}(\mathrm{pyr})_{3}$ or $\left.\mathrm{PF}_{3}\right)$. Little variation is observed structurally for the 
six transition states, and there are no obvious trends in the calculated bond distances relative to donor ability or steric bulk of L. We have previously reported that the calculated $\mathrm{Ru}-\mathrm{H}$ bond distances (c in Figure 3.17) in the transition state for benzene $\mathrm{C}-\mathrm{H}$ activation by $\mathrm{TpRu}(\mathrm{L})\left(\eta^{2}-\mathrm{C}_{6} \mathrm{H}_{6}\right) \mathrm{Ph}$ complexes are shorter for more strongly donating ligands L; however, a similar trend is not calculated here for benzene $\mathrm{C}-\mathrm{H}$ activation by $\operatorname{TpRu}(\mathrm{L})\left(\eta^{2}-\mathrm{C}_{6} \mathrm{H}_{6}\right)\left(\mathrm{CH}_{2} \mathrm{CH}_{2} \mathrm{Ph}\right)$ complexes. Despite the lack of a straightforward trend, the calculated transition states with the three less donating ligands (i.e., $\mathrm{CO}, \mathrm{PF}_{3}$ and $\left.\mathrm{P}(\text { pyr })_{3}\right)$ exhibit longer calculated $\mathrm{Ru}-\mathrm{H}$ bond distances (average $=1.629 \AA$ ) than the three complexes with more strongly donating ligands (i.e., $\mathrm{PMe}_{3}, \mathrm{P}\left(\mathrm{OCH}_{2}\right)_{3} \mathrm{CEt}$ and $\mathrm{P}\left(\mathrm{OCH}_{2}\right)_{2}\left(\mathrm{OCCH}_{3}\right) ;$ average $\left.=1.583 \AA\right)$.

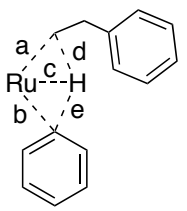

Figure 3.17. Transition state for benzene $\mathrm{C}-\mathrm{H}$ activation (TS2, Scheme 3.10) by $\mathrm{TpRu}(\mathrm{L})(\mathrm{NCMe}) \mathrm{Ph}$. See Table 3.3 for calculated distances.

Table 3.3. Calculated Distances $(\AA)$ for $\mathrm{C}-\mathrm{H}$ Activation Transition State (TS2, Scheme 3.10) for $\mathrm{TpRu}(\mathrm{L})(\mathrm{NCMe}) \mathrm{Ph}$ (see Figure 3.17 for labels).

\begin{tabular}{|c|c|c|c|c|c|}
\hline $\mathrm{L}$ & $\begin{array}{l}\mathrm{Ru}-\mathrm{C} \\
\text { (a) }\end{array}$ & $\begin{array}{l}\mathrm{Ru}-\mathrm{C} \\
\text { (b) }\end{array}$ & $\begin{array}{l}\mathrm{Ru}-\mathrm{H} \\
\text { (c) }\end{array}$ & $\begin{array}{l}\mathrm{C}-\mathrm{H} \\
\text { (d) }\end{array}$ & $\begin{array}{l}\mathrm{C}-\mathrm{H} \\
\text { (e) }\end{array}$ \\
\hline $\mathrm{PMe}_{3}$ & 2.249 & 2.170 & 1.584 & 1.739 & 1.649 \\
\hline $\mathrm{P}\left(\mathrm{OCH}_{2}\right)_{3} \mathrm{CEt}$ & 2.254 & 2.180 & 1.579 & 1.826 & 1.737 \\
\hline $\mathrm{P}\left(\mathrm{OCH}_{2}\right)_{2}\left(\mathrm{OCCH}_{3}\right)$ & 2.262 & 2.183 & 1.585 & 1.787 & 1.705 \\
\hline $\mathrm{P}(\mathrm{pyr})_{3}$ & 2.286 & 2.215 & 1.627 & 1.647 & 1.525 \\
\hline $\mathrm{PF}_{3}$ & 2.288 & 2.193 & 1.611 & 1.690 & 1.625 \\
\hline $\mathrm{CO}$ & 2.310 & 2.194 & 1.648 & 1.609 & 1.549 \\
\hline
\end{tabular}




\subsubsection{Comparison of $\mathrm{TpRu}(\mathrm{L})(\mathrm{NCMe}) \mathrm{Ph}$ Catalysts}

Based on $\mathrm{Ru}(\mathrm{III} / \mathrm{II}$ ) potentials (see Table 3.4), the relative Ru-based electron densities of the complexes $\mathrm{TpRu}(\mathrm{L})(\mathrm{NCMe}) \mathrm{Ph}$ can be assigned as $\mathrm{L}=\mathrm{PMe}_{3}>\mathrm{P}\left(\mathrm{OCH}_{2}\right)_{3} \mathrm{CEt}>$ $\mathrm{P}\left(\mathrm{OCH}_{2}\right)_{2}\left(\mathrm{OCCH}_{3}\right)>\mathrm{P}(\text { pyr })_{3}>\mathrm{CO}$. Table 3.4 provides a comparison of the results from hydrophenylation of ethylene using $\mathrm{TpRu}(\mathrm{L})(\mathrm{NCMe}) \mathrm{Ph}$ complexes.

Table 3.4. Comparison of TON and TOF for Ethylbenzene Production from Catalytic Hydrophenylation of Ethylene by $\mathrm{TpRu}(\mathrm{L})(\mathrm{NCMe}) \mathrm{Ph}$ Complexes.

\begin{tabular}{lccccc}
\hline & & & & Relative & $\mathrm{E}_{1 / 2}$ \\
$\mathrm{~L}$ & TON & Time & TOF $\left(\mathrm{s}^{-1}\right)^{\mathrm{c}}$ & TOF & $(\mathrm{V}$ vs. NHE $)$ \\
\hline $\mathrm{CO}$ & $415^{\mathrm{a}}$ & $40 \mathrm{~h}$ & $6.7 \times 10^{-3}$ & 14 & 1.03 \\
$\mathrm{P}(\mathrm{pyr})_{3}$ & 0 & --- & --- & --- & 0.76 \\
$\mathrm{P}\left(\mathrm{OCH}_{2}\right)_{2}(\mathrm{OCCH}$ & & & \\
$\mathrm{P}_{3}\left(\mathrm{OCH}_{2}\right)_{3} \mathrm{CEt}$ & $90^{\mathrm{b}}$ & $50 \mathrm{~h}$ & $1.5 \times 10^{-3}$ & 3 & 0.69 \\
$\mathrm{PMe}_{3}$ & $20^{\mathrm{b}}$ & $24 \mathrm{~h}$ & $4.8 \times 10^{-4}$ & 1 & 0.54 \\
& $0^{\mathrm{b}}$ & --- & --- & --- & 0.29
\end{tabular}

a Products from catalyst decomposition are unknown, but under most conditions $\mathrm{TpRu}(\mathrm{CO})\left(\eta^{3}-\mathrm{C}_{3} \mathrm{H}_{4} \mathrm{Me}\right)$ is not formed. ${ }^{b}$ Catalyst deactivation occurs by formation of $\mathrm{TpRu}(\mathrm{L})\left(\eta^{3}-\mathrm{C}_{3} \mathrm{H}_{4} \mathrm{Me}\right) .{ }^{\mathrm{c}}$ Calculated after $4 \mathrm{~h}$ at $90{ }^{\circ} \mathrm{C}$ with 15 psi ethylene and $0.025 \mathrm{~mol}$ $\%$ of catalyst.

For the three complexes $\mathrm{TpRu}(\mathrm{L})(\mathrm{NCMe}) \mathrm{Ph}\left(\mathrm{L}=\mathrm{P}\left(\mathrm{OCH}_{2}\right)_{3} \mathrm{CEt}\right.$, $\mathrm{P}\left(\mathrm{OCH}_{2}\right)_{2}\left(\mathrm{OCCH}_{3}\right)$ or $\left.\mathrm{CO}\right)$ that serve as catalysts for the hydrophenylation of ethylene, the catalyst activity and longevity vary as a function of the identity of L. The observed trends in $\mathrm{TON}$ and $\mathrm{TOF}$ for $\mathrm{TpRu}(\mathrm{L})(\mathrm{NCMe}) \mathrm{Ph}$ catalysts are inverse to the trend in relative rates of benzene activation by $\mathrm{TpRu}(\mathrm{L})(\mathrm{NCMe}) \mathrm{Ph}$. Our studies provide a clear rationalization for the trends in $\mathrm{TON}$. For $\mathrm{TpRu}(\mathrm{L})(\mathrm{NCMe}) \mathrm{Ph}$ complexes $(\mathrm{L}=$ $\mathrm{P}\left(\mathrm{OCH}_{2}\right)_{3} \mathrm{CEt}, \mathrm{P}\left(\mathrm{OCH}_{2}\right)_{2}\left(\mathrm{OCCH}_{3}\right), \mathrm{CO}$ or $\left.\mathrm{PMe}_{3}\right)$, a primary factor in the longevity of the 
catalyst is the relative rate of olefin insertion versus olefin $\mathrm{C}-\mathrm{H}$ activation. As previously reported and confirmed again here by our analysis of $\mathrm{TpRu}\left[\mathrm{P}\left(\mathrm{OCH}_{2}\right)_{2}\left(\mathrm{OCCH}_{3}\right)\right.$ ](NCMe)Ph, altering the donor ability of $\mathrm{L}$ has a relatively minor impact on the $\Delta G^{\ddagger \text { s }}$ for benzene and presumably, also ethylene $\mathrm{C}-\mathrm{H}$ activation. ${ }^{3}$ However, the identity of $\mathrm{L}$ has a substantial impact on the activation barrier for ethylene insertion into the $\mathrm{Ru}-\mathrm{Ph}$ bond of $\mathrm{TpRu}(\mathrm{L})\left(\eta^{2}-\mathrm{C}_{2} \mathrm{H}_{4}\right) \mathrm{Ph}$ complexes. With the exception of $\mathrm{TpRu}\left[\mathrm{P}(\mathrm{pyr})_{3}\right](\mathrm{NCMe}) \mathrm{Ph},{ }^{3}$ increased donor ability of $\mathrm{L}$ results in an increase in the calculated $\Delta G^{\ddagger}$ for olefin insertion from $\mathrm{TpRu}(\mathrm{L})\left(\eta^{2}-\mathrm{C}_{2} \mathrm{H}_{4}\right) \mathrm{Ph}$ complexes, which results in competition between ethylene $\mathrm{C}-\mathrm{H}$ activation and ethylene insertion into the $\mathrm{Ru}-\mathrm{Ph}$ bond (Scheme 3.1, Scheme 3.11). In the presence of excess ethylene, the $\mathrm{C}-\mathrm{H}$ activation of ethylene by $\operatorname{TpRu}(\mathrm{L})\left(\eta^{2}-\mathrm{C}_{2} \mathrm{H}_{4}\right) \mathrm{Ph}$ results in the formation of $\eta^{3}$-allyl complexes $\operatorname{TpRu}(\mathrm{L})\left(\eta^{3}-\right.$ $\mathrm{C}_{3} \mathrm{H}_{4} \mathrm{Me}$ ) [allyl complexes have been isolated for $\mathrm{L}=\mathrm{CO}, \mathrm{PMe}_{3}, \mathrm{P}\left(\mathrm{OCH}_{2}\right)_{3} \mathrm{CEt}$ and $\left.\mathrm{P}\left(\mathrm{OCH}_{2}\right)_{2}\left(\mathrm{OCCH}_{3}\right)\right]^{3}$

Table 3.5 shows the calculated $\Delta G^{\ddagger}$ s for ethylene insertion and the calculated $\Delta G^{\ddagger}$ for ethylene $\mathrm{C}-\mathrm{H}$ activation from $\mathrm{TpRu}(\mathrm{L})\left(\eta^{2}-\mathrm{C}_{2} \mathrm{H}_{4}\right) \mathrm{Ph}$ complexes. The difference in energies $\left(\Delta \Delta G^{\ddagger}\right)$ of ethylene insertion vs. ethylene activation demonstrates a clear trend that as the electron density of the metal increases the differences in these two values decreases. Additionally, the calculated $\Delta \Delta G^{\ddagger}$ for ethylene insertion $\left(\Delta \Delta G^{\ddagger}\right.$ of $\sim 6.2$ $\mathrm{kcal} / \mathrm{mol})$ is much larger than the $\Delta \Delta G^{\ddagger}$ for benzene $\mathrm{C}-\mathrm{H}$ activation $(\sim 4.4 \mathrm{kcal} / \mathrm{mol})$ as the ligand $\mathrm{L}$ is varied (Scheme 3.11). Therefore, varying the donor ability of $\mathrm{L}$ has a greater impact on the rate of olefin insertion compared to the rate of benzene $\mathrm{C}-\mathrm{H}$ activation. For 
$\mathrm{TpRu}\left(\mathrm{PMe}_{3}\right)(\mathrm{NCMe}) \mathrm{Ph}$, ethylene insertion does not compete with ethylene $\mathrm{C}-\mathrm{H}$ activation, and catalytic production of ethylbenzene is not observed (Scheme 3.1). ${ }^{45}$ For $\mathrm{TpRu}\left[\mathrm{P}\left(\mathrm{OCH}_{2}\right)_{3} \mathrm{CEt}\right](\mathrm{NCMe}) \mathrm{Ph}$, ethylene insertion is more rapid than ethylene $\mathrm{C}-\mathrm{H}$ activation, but the $\Delta \Delta G^{\ddagger}$ between the two processes is sufficiently small that ethylene C$\mathrm{H}$ activation competes and only 20 TON of ethylbenzene are obtained before the catalyst is deactivated to form $\mathrm{TpRu}\left[\mathrm{P}\left(\mathrm{OCH}_{2}\right)_{3} \mathrm{CEt}\right]\left(\eta^{3}-\mathrm{C}_{3} \mathrm{H}_{4} \mathrm{Me}\right)$. This suggests that $k_{\text {ins }} / k_{\text {act }}$ is $\sim 20$ for $\mathrm{TpRu}\left[\mathrm{P}\left(\mathrm{OCH}_{2}\right)_{3} \mathrm{CEt}\right](\mathrm{NCMe}) \mathrm{Ph}$ ( $k_{\text {ins }}$ is the rate constant for ethylene insertion and $k_{\text {act }}$ is the rate constant for ethylene $\mathrm{C}-\mathrm{H}$ activation). ${ }^{25}$ For $\mathbf{4}, k_{\text {ins }} / k_{\text {act }}$ is increased (to 90) relative to the $\mathrm{P}\left(\mathrm{OCH}_{2}\right)_{3} \mathrm{CEt}$ complex, and multiple TON of ethylbenzene production are observed. Thus, the modulation of $\Delta G^{\ddagger}$ for olefin insertion is a key factor in successful long-lived catalysis using $\mathrm{TpRu}(\mathrm{L})(\mathrm{NCMe}) \mathrm{Ph}$ complexes.

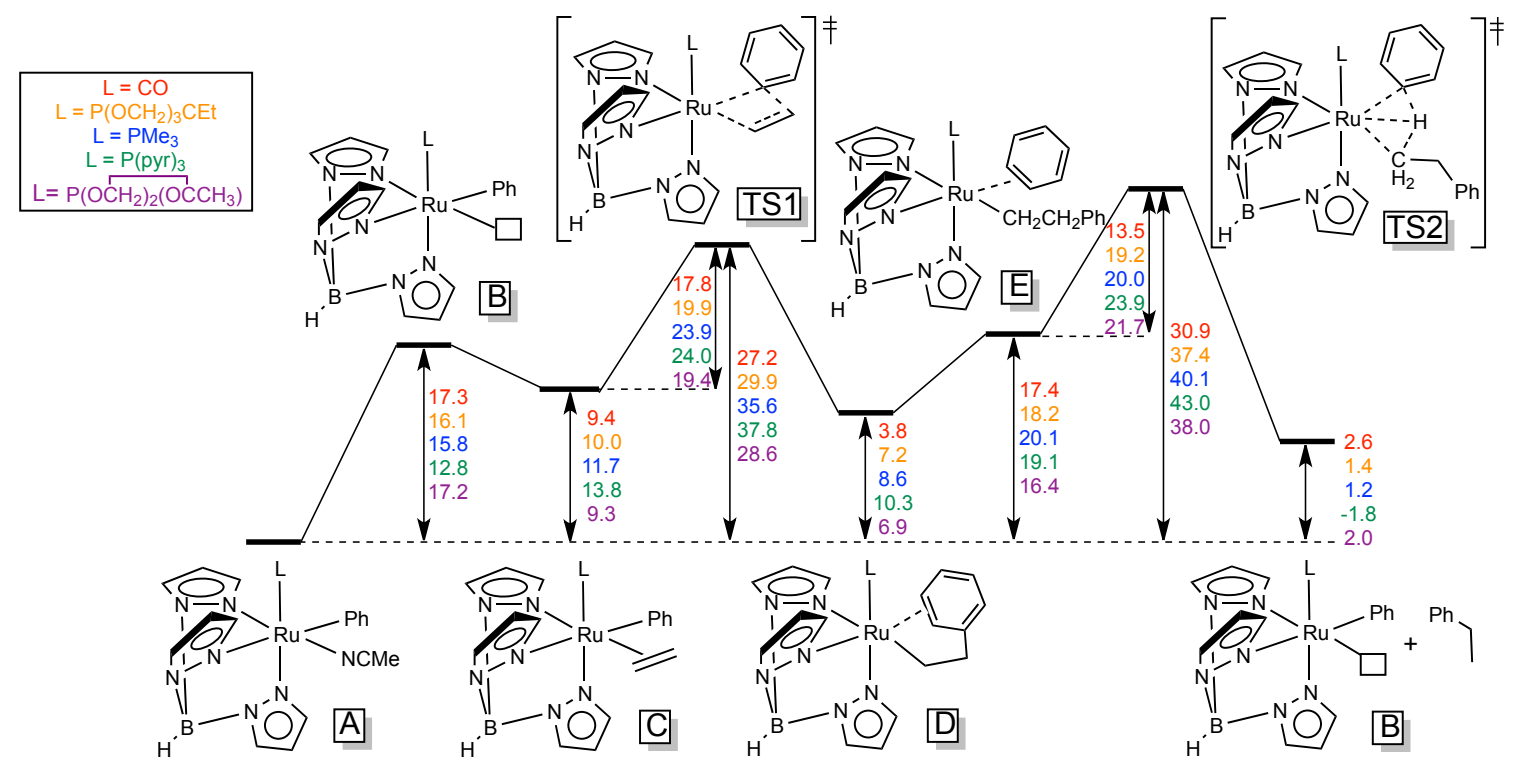

Scheme 3.11. Calculated Gibb's free energies $(\mathrm{kcal} / \mathrm{mol})$ for ethylene hydrophenylation catalytic cycle by $\mathrm{TpRu}(\mathrm{L})(\mathrm{NCMe}) \mathrm{Ph}\left[\mathrm{L}=\mathrm{CO}, \mathrm{PMe}_{3}, \mathrm{P}\left(\mathrm{OCH}_{2}\right)_{3} \mathrm{CEt}, \mathrm{P}(\text { pyr })_{3}\right.$ and $\mathrm{P}\left(\mathrm{OCH}_{2}\right)_{2}\left(\mathrm{OCCH}_{3}\right)$. 
Table 3.5. Calculated $\Delta G^{\ddagger}$ insertion $(\mathrm{kcal} / \mathrm{mol})$ for ethylene insertion (TS1, Scheme 3.10) and $\Delta G^{\ddagger}$ CH activation $(\mathrm{kcal} / \mathrm{mol})$ of ethylene for TpRu(L) $\left(\eta^{2}-\mathrm{C}_{2} \mathrm{H}_{4}\right) \mathrm{Ph}$ Complexes.

\begin{tabular}{lccc}
\hline $\mathrm{L}$ & $\begin{array}{c}\Delta G_{\text {insertion }}^{\ddagger} \\
\text { of } \mathrm{C}_{2} \mathrm{H}_{4}\end{array}$ & $\begin{array}{c}\Delta G^{\ddagger}{ }_{\text {C-H activation }} \\
\text { of C }_{2} \mathrm{H}_{4}\end{array}$ & $\Delta \Delta G^{\ddagger}$ \\
\hline $\mathrm{PMe}_{3}$ & 23.9 & 27.0 & 3.1 \\
$\mathrm{P}(\text { pyr })_{3}$ & 23.2 & 28.6 & 5.4 \\
$\mathrm{P}\left(\mathrm{OCH}_{2}\right)_{3} \mathrm{CEt}$ & 20.1 & 27.3 & 7.4 \\
$\stackrel{\mathrm{P}\left(\mathrm{OCH}_{2}\right)_{2}\left(\mathrm{OCCH}_{3}\right)}{ }$ & 19.4 & 28.3 & \\
$\mathrm{PF}_{3}$ & 18.3 & 28.0 & 8.9 \\
$\mathrm{CO}$ & 17.7 & 28.9 & 9.7 \\
& & & 11.2
\end{tabular}

The TOF for catalytic hydrophenylation of ethylene by $\mathrm{TpRu}(\mathrm{L})(\mathrm{NCMe}) \mathrm{Ph}$ complexes also varies as a function of the identity of L, and a plot of TOF vs. Ru(III/II) potential shows a good linear correlation (Figure 3.18). The TOFs were calculated after 4 $\mathrm{h}$ since there is no evidence of catalyst deactivation at this time point for any of the catalysts. Benzene $\mathrm{C}-\mathrm{H}$ activation is the proposed rate limiting step for the catalytic hydrophenylation of ethylene using $\mathrm{TpRu}(\mathrm{L})(\mathrm{NCMe}) \mathrm{Ph}$ complexes. ${ }^{3}$ Thus, given the relative rates of $\mathrm{C}_{6} \mathrm{D}_{6}$ activation by $\mathrm{TpRu}(\mathrm{L})(\mathrm{NCMe}) \mathrm{Ph}$ complexes, which are opposite to the observed rates for catalytic ethylene hydrophenylation, the trend in TOF is more difficult to rationalize than TON. One potential explanation for the inverse trend for rates of stoichiometric benzene activation and TOF for catalytic hydrophenylation is that the rate of benzene $\mathrm{C}-\mathrm{H}$ activation from proposed catalyst resting states, $\operatorname{TpRu}(\mathrm{L})\left(\eta^{2}-\right.$ $\left.\mathrm{C}_{2} \mathrm{H}_{4}\right)\left(\mathrm{CH}_{2} \mathrm{CH}_{2} \mathrm{Ph}\right)$, might be different from the observed relative rates of $\mathrm{C}_{6} \mathrm{D}_{6}$ activation by $\mathrm{TpRu}(\mathrm{L})(\mathrm{NCMe}) \mathrm{Ph}$ complexes. To probe this possibility, we calculated the energetics for benzene $\mathrm{C}-\mathrm{H}$ activation starting from $\mathrm{TpRu}(\mathrm{L})\left(\eta^{2}-\mathrm{C}_{2} \mathrm{H}_{4}\right)\left(\mathrm{CH}_{2} \mathrm{CH}_{2} \mathrm{Ph}\right)$ for the active catalysts $\mathrm{L}=\mathrm{CO}, \mathrm{P}\left(\mathrm{OCH}_{2}\right)_{3} \mathrm{CEt}$ and $\mathrm{P}\left(\mathrm{OCH}_{2}\right)_{2}\left(\mathrm{OCCH}_{3}\right)($ Scheme 3.12). 


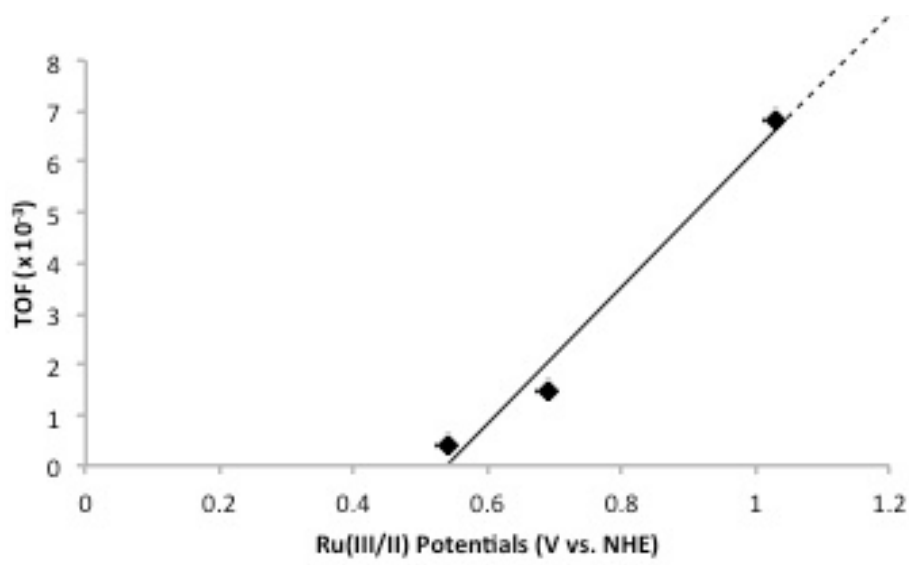

Figure 3.18. Plot of TOF vs. $\mathrm{Ru}(\mathrm{III} / \mathrm{II})$ potential for catalytic hydrophenylation of ethylene by $\mathrm{TpRu}(\mathrm{L})(\mathrm{NCMe}) \mathrm{Ph}\left(\mathrm{L}=\mathrm{P}\left(\mathrm{OCH}_{2}\right)_{3} \mathrm{CEt}, \mathrm{P}\left(\mathrm{OCH}_{2}\right)_{2}\left(\mathrm{OCCH}_{3}\right)\right.$ or $\left.\mathrm{CO}\right)$ using $0.025 \mathrm{~mol} \%$ of catalyst, $15 \mathrm{psi}$ of ethylene at $90{ }^{\circ} \mathrm{C}$. TOF calculated after 4 hours of reaction $\left(\mathrm{R}^{2}=0.97\right)$.

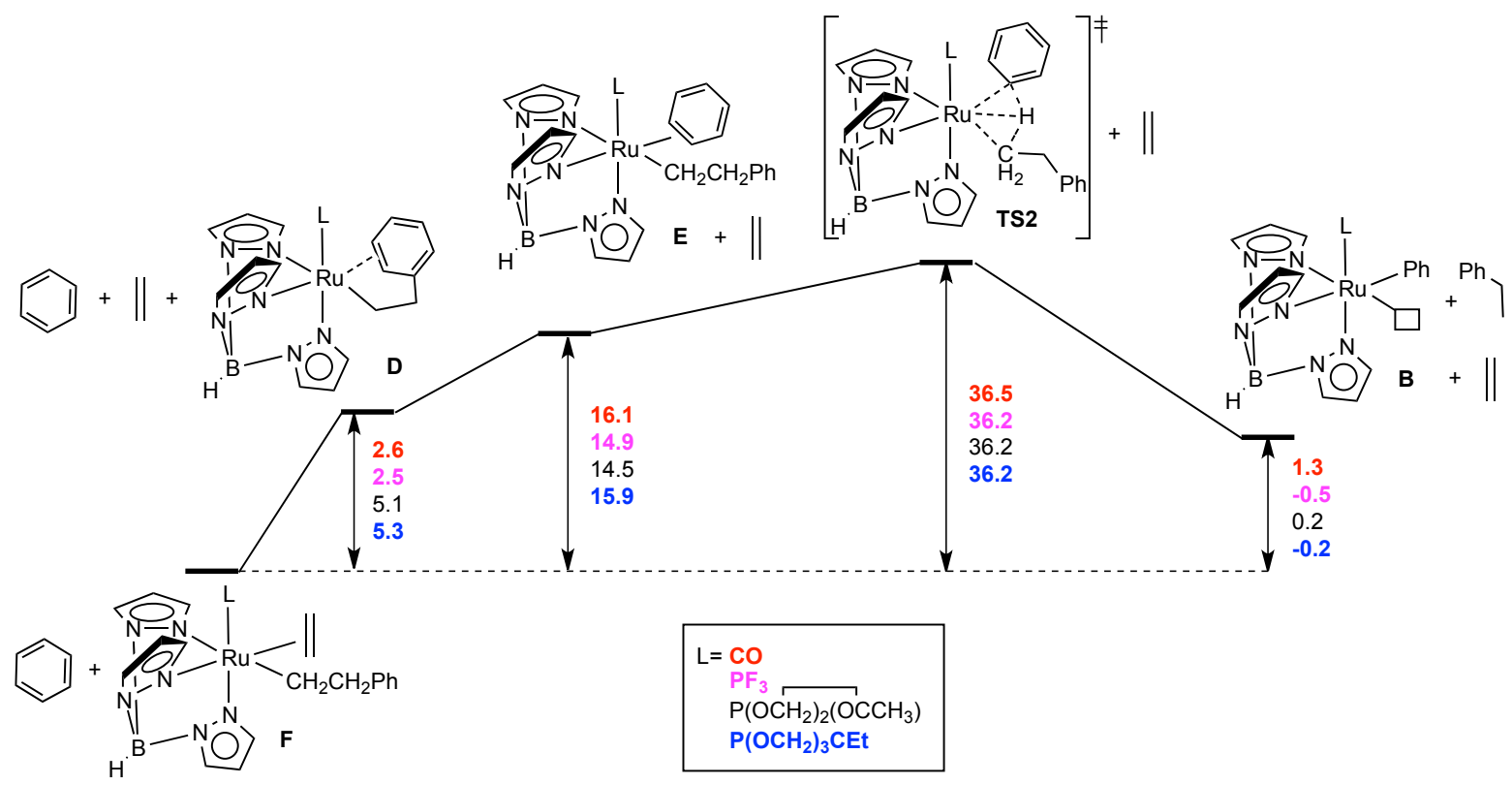

Scheme 3.12. Calculated Gibbs Free Energies ( $\mathrm{kcal} / \mathrm{mol}$ ) for benzene $\mathrm{C}-\mathrm{H}$ activation and formation of ethylbenzene by $\mathrm{TpRu}(\mathrm{L})\left(\eta^{2}-\mathrm{C}_{2} \mathrm{H}_{4}\right)\left(\mathrm{CH}_{2} \mathrm{CH}_{2} \mathrm{Ph}\right)$. 
As Scheme 3.12 shows, within the anticipated error, the calculations predict identical activation barriers for the production of ethylbenzene from all of the $\operatorname{TpRu}(\mathrm{L})\left(\eta^{2}-\right.$ $\left.\mathrm{C}_{2} \mathrm{H}_{4}\right)\left(\mathrm{CH}_{2} \mathrm{CH}_{2} \mathrm{Ph}\right)$ complexes. Although these results do not reproduce the experimental observations, they are not surprising given the small difference in activation barrier of $\sim 2$ $\mathrm{kcal} / \mathrm{mol}$ between the most and least active catalysts. Perhaps most informative is a comparison of the ethylene binding energy among the series of $\operatorname{TpRu}(\mathrm{L})\left(\eta^{2}-\right.$ $\left.\mathrm{C}_{2} \mathrm{H}_{4}\right)\left(\mathrm{CH}_{2} \mathrm{CH}_{2} \mathrm{Ph}\right)$ complexes. Comparison of the energetics for ethylene dissociation from $\mathrm{TpRu}(\mathrm{L})\left(\eta^{2}-\mathrm{C}_{2} \mathrm{H}_{4}\right)\left(\mathrm{CH}_{2} \mathrm{CH}_{2} \mathrm{Ph}\right)$ (F) to form $\mathrm{TpRu}(\mathrm{L})\left(\kappa^{3}-\mathrm{CH}_{2} \mathrm{CH}_{2} \mathrm{Ph}\right)$ (D) reveals that the phosphite complexes exhibit stronger binding energies of ethylene than the $\mathrm{CO}$ complex by 2.5 and $2.7 \mathrm{kcal} / \mathrm{mol}$, respectively, for $\mathrm{P}\left(\mathrm{OCH}_{2}\right)_{2}\left(\mathrm{OCCH}_{3}\right)$ and $\mathrm{P}\left(\mathrm{OCH}_{2}\right)_{3} \mathrm{CEt}$ (Scheme 3.12). This could be a result of the more strongly donating character of the phosphite ligands compared to $\mathrm{CO}$, which would enhance $\mathrm{Ru}$-to-ethylene $\pi$-backbonding. The difference in binding energies might also be due to sterics; however, the calculated binding energy of ethylene for $\mathrm{TpRu}\left(\mathrm{PF}_{3}\right)\left(\eta^{2}-\mathrm{C}_{2} \mathrm{H}_{4}\right)\left(\mathrm{CH}_{2} \mathrm{CH}_{2} \mathrm{Ph}\right)$ is identical to the $\mathrm{CO}$ complex (given the expected error in calculations), which is consistent with the electronic effect playing a dominant role. We believe that more strongly donating ligands enhance ethylene binding for the proposed resting states $\mathrm{TpRu}(\mathrm{L})\left(\eta^{2}-\mathrm{C}_{2} \mathrm{H}_{4}\right)\left(\mathrm{CH}_{2} \mathrm{CH}_{2} \mathrm{Ph}\right)$, which should increase the overall activation barriers for catalytic hydrophenylation of ethylene.

\subsection{Summary and Conclusions}

$\mathrm{TpRu}\left[\mathrm{P}\left(\mathrm{OCH}_{2}\right)_{2}\left(\mathrm{OCCH}_{3}\right)\right](\mathrm{NCMe}) \mathrm{Ph}$ (4) has been shown to catalyze the hydrophenylation of ethylene to yield $\sim 90$ TOs of ethylbenzene after $50 \mathrm{~h}$ at $90{ }^{\circ} \mathrm{C}$ with 
15 psi of ethylene. Complex 4 does not catalyze the hydrophenylation of propene or 1pentene. A comparison of catalytic hydrophenylation of ethylene, or in some cases the failure of the complex to catalyze the reaction, by the series of $\mathrm{TpRu}(\mathrm{II})$ complexes $\mathrm{TpRu}(\mathrm{L})(\mathrm{NCMe}) \mathrm{Ph}\left[\mathrm{L}=\mathrm{CO}, \mathrm{PMe}_{3}, \mathrm{P}(\mathrm{pyr})_{3}, \mathrm{P}\left(\mathrm{OCH}_{2}\right)_{3} \mathrm{CEt}\right.$ and $\left.\mathrm{P}\left(\mathrm{OCH}_{2}\right)_{2}\left(\mathrm{OCCH}_{3}\right)\right]$ allows some conclusions to be drawn:

1) Increasing the donor ability of the ligand $\mathrm{L}$ of $\mathrm{TpRu}(\mathrm{L})(\mathrm{NCMe}) \mathrm{Ph}$ complexes increases the overall rate of stoichiometric benzene $\mathrm{C}-\mathrm{H}$ activation.

2) The influence of the donor ability of $\mathrm{L}$ on the rate of ethylene insertion into $\mathrm{Ru}-$ phenyl bonds appears to be the most important factor that determines the TON for $\mathrm{Ru}(\mathrm{II})$ catalysts.

3) For $\mathrm{TpRu}(\mathrm{L})(\mathrm{NCMe}) \mathrm{Ph}$ catalysts, the steric profile of $\mathrm{L}$ plays an important role. For example, we have published data that suggest ethylene/NCMe exchange with $\mathrm{TpRu}\left[\mathrm{P}(\mathrm{pyr})_{3}\right](\mathrm{NCMe}) \mathrm{Ph}$ is unfavorable due to sterics. ${ }^{23}$

4) Although only three data points are available, the TOFs in Table 3.4 suggest that less electron-rich $\mathrm{Ru}(\mathrm{II})$ catalysts supported by poly(pyrazolyl) ligands are more active for ethylene hydrophenylation.

\subsection{Experimental}

General Methods. Unless otherwise noted, all synthetic procedures were performed under anaerobic conditions in a nitrogen-filled glovebox or by using standard Schlenk techniques. Glovebox purity was maintained by periodic nitrogen purges and was monitored by an oxygen analyzer $\left[\mathrm{O}_{2}(\mathrm{~g})<15 \mathrm{ppm}\right.$ for all reactions]. Tetrahydrofuran was dried by distillation from sodium/benzophenone. Pentane was distilled over $\mathrm{P}_{2} \mathrm{O}_{5}$. 
Acetonitrile and diethyl ether were dried by distillation from $\mathrm{CaH}_{2}$. Hexanes, benzene and methylene chloride were purified by passage through a column of activated alumina. Benzene- $d_{6}$, acetonitrile- $d_{3}$, methylene chloride- $d_{2}$ and chloroform- $d_{1}$ were stored under a nitrogen atmosphere over $4 \AA$ molecular sieves. ${ }^{1} \mathrm{H}$ NMR spectra were recorded on a Varian Inova $500 \mathrm{MHz}$ or Varian MRS $600 \mathrm{MHz}$ spectrometer, and ${ }^{13} \mathrm{C} \mathrm{NMR}$ spectra were recorded on a Varian Inova $500 \mathrm{MHz}$ or Varian MRS $600 \mathrm{MHz}$ spectrometer (operating frequency $126 \mathrm{MHz}$ or $151 \mathrm{MHz}$, respectively). All ${ }^{1} \mathrm{H}$ and ${ }^{13} \mathrm{C}$ NMR spectra are referenced against residual proton signals $\left({ }^{1} \mathrm{H} \mathrm{NMR}\right)$ or the ${ }^{13} \mathrm{C}$ resonances of the deuterated solvent $\left({ }^{13} \mathrm{C}\right.$ NMR $) .{ }^{31} \mathrm{P}$ NMR spectra were obtained on a Varian Mercury Plus $300 \mathrm{MHz}$ (operating frequency $121 \mathrm{MHz}$ ) spectrometer and referenced against an external standard of $\mathrm{H}_{3} \mathrm{PO}_{4}(\delta=0)$. Resonances due to the Tp ligand in ${ }^{1} \mathrm{H}$ NMR spectra are listed by chemical shift and multiplicity only (all coupling constants for the Tp ligand are $\sim 2 \mathrm{~Hz})$.

Electrochemical experiments were performed under a nitrogen atmosphere using a BAS Epsilon Potentiostat. Cyclic voltammograms were recorded in $\mathrm{CH}_{3} \mathrm{CN}$ using a standard three electrode cell from -1700 to $1700 \mathrm{mV}$ at $100 \mathrm{mV} / \mathrm{s}$ with a glassy carbon working electrode and tetrabutylammonium hexafluorophosphate as electrolyte. All potentials are reported versus NHE (normal hydrogen electrode) using ferrocene as the internal standard.

High-resolution electrospray ionization mass spectrometry (ESI-MS) analyses were obtained on a Bruker BioTOF-Q spectrometer at the University of Richmond. Samples were dissolved in acetonitrile, then mixed 3:1 with $0.1 \mathrm{M}$ aqueous sodium trifluoroacetate 
(NaTFA) using $\left[\mathrm{Na}(\mathrm{NaTFA})_{\mathrm{x}}\right]^{+}$clusters as an internal standard. These data are reported using the most intense peaks from the isotopic envelope for $[\mathrm{M}+\mathrm{Na}]^{+}$. The data are listed as $\mathrm{m} / \mathrm{z}$ with the intensity relative to the most abundant peak of the isotopic envelope given in parentheses for both the calculated and observed peaks. The difference between calculated and observed peaks is reported in ppm. Low-resolution mass spectra were acquired on a Shimadzu G-17A/QP-5050 GC-MS instrument operating in EI-directinlet-MS mode. Mass spectra are reported as $\mathrm{M}+$ for originally neutral samples. In all cases, observed isotopic envelopes were consistent with the molecular composition reported.

The preparation, isolation and characterization of $\mathrm{TpRu}\left[\mathrm{P}\left(\mathrm{OCH}_{2}\right)_{3} \mathrm{CEt}\right]\left(\mathrm{PPh}_{3}\right) \mathrm{Cl},{ }^{1}$ $\mathrm{TpRu}(\mathrm{CO}) \mathrm{Ph}(\mathrm{NCMe}){ }^{5}{ }^{\mathrm{T} p R u}\left[\mathrm{P}\left(\mathrm{OCH}_{2}\right)_{3} \mathrm{CEt}\right] \mathrm{Ph}(\mathrm{NCMe}),{ }^{1} \quad \mathrm{TpRu}\left[\mathrm{P}(\mathrm{pyr})_{3}\right] \mathrm{Ph}(\mathrm{NCMe}),{ }^{23}$ $\mathrm{Ph}_{2} \mathrm{Mg}[\mathrm{THF}]_{2},{ }^{26} \mathrm{P}\left(\mathrm{OCH}_{2}\right)_{2}\left(\mathrm{OCCH}_{3}\right)^{7}$ and $\mathrm{C}\left(\mathrm{CH}_{3}\right)(\mathrm{OH})\left(\mathrm{CH}_{2} \mathrm{OH}\right)_{2}{ }^{7}$ have been previously reported. $\mathrm{P}\left(\mathrm{OCH}_{2}\right)_{3} \mathrm{CEt}$ was obtained from a commercial source and purified by reconstitution in hexanes and filtration through Celite. The filtrate was concentrated to dryness to yield a white solid.

Calculations. Density functional theory calculations were performed using the Gaussian 09 suite of programs ${ }^{27}$ employing the hybrid functional B3LYP with the effective core potential basis set CEP-31G(d). ${ }^{28}$ Optimized geometries and transition states were confirmed by the presence of zero and one imaginary frequencies, respectively, with thermochemistry determined at $298.15 \mathrm{~K}$ and $1 \mathrm{~atm}$.

$\left(\eta^{6}-p\right.$-cymene $) \mathrm{Ru}\left[\quad \mathbf{P}(\mathbf{O C H})_{2}\left(\mathbf{O C C H}_{3}\right) \quad\right] \mathrm{Br}_{2} \quad$ (1). The complex $\left[\left(\eta^{6}-p\right.\right.$ cymene $) \mathrm{Ru}(\mathrm{Br})(\mu-\mathrm{Br})]_{2}{ }^{21}(1.36 \mathrm{~g}, 1.73 \mathrm{mmol})$ was dissolved in $150 \mathrm{~mL}$ of methylene 
chloride and added to a round bottom flask $(500 \mathrm{~mL})$ containing a benzene solution of $\mathrm{P}\left(\mathrm{OCH}_{2}\right)_{2}\left(\mathrm{OCCH}_{3}\right)\left(\sim 1.13 \mathrm{~g}, 6.90 \mathrm{mmol}, 200 \mathrm{~mL}\right.$ of $\left.\mathrm{C}_{6} \mathrm{H}_{6}\right)$. The reaction was stirred for 1 h. The reaction mixture was concentrated to $\sim 20 \mathrm{~mL}$ under vacuum. Hexanes were added, and the mixture was stirred for $1 \mathrm{~h}$. The hexanes were decanted through a fine porosity frit with $\sim 1 / 3$ inch of Celite, and the filtrate was discarded. The Celite was washed with methylene chloride, and this second filtrate was placed back into the reaction flask. All solvent was removed under vacuum. The resulting solid was placed on a fine porosity frit, washed with pentane, and dried in vacuo (1.67 g, 91\% yield). ${ }^{1} \mathrm{H}$ NMR (600 MHz, $\left.\mathrm{CDCl}_{3}\right) \delta 5.74\left(\mathrm{~d},{ }^{3} J_{\mathrm{HH}}=6 \mathrm{~Hz}, 2 \mathrm{H}, p\right.$-cymene: $\left.\mathrm{C}_{6} H_{4}\right), 5.61\left(\mathrm{~d}, 2 \mathrm{H},{ }^{3} J_{\mathrm{HH}}=6 \mathrm{~Hz}, p\right.$ cymene: $\left.\mathrm{C}_{6} H_{4}\right), 4.21\left(\mathrm{dt}, 2 \mathrm{H},{ }^{2} J_{\mathrm{HH}}=10 \mathrm{~Hz},{ }^{3} J_{\mathrm{HP}}=5 \mathrm{~Hz}, \mathrm{P}\left(\mathrm{OCH}_{2}\right)_{2}\left(\mathrm{OCCH}_{3}\right)\right), 3.86-$ $3.82\left(\mathrm{~m}, 2 \mathrm{H}, \mathrm{P}\left(\mathrm{OCH}_{2}\right)_{2}\left(\mathrm{OCCH}_{3}\right)\right), 3.02$ (sept, $1 \mathrm{H},{ }^{3} J_{\mathrm{HH}}=7 \mathrm{~Hz}, p$-cymene: $\left.\mathrm{CH}\left(\mathrm{CH}_{3}\right)_{2}\right)$, 2.36 (s, 3H, p-cymene: $\left.\mathrm{CH}_{3}\right), 1.69\left(\mathrm{~s}, 3 \mathrm{H}, \mathrm{P}\left(\mathrm{OCH}_{2}\right)_{2}\left(\mathrm{OCCH}_{3}\right)\right), 1.26\left(\mathrm{~d}, 6 \mathrm{H},{ }^{3} J_{\mathrm{HH}}=7 \mathrm{~Hz}\right.$, p-cymene: $\left.\mathrm{CH}\left(\mathrm{CH}_{3}\right)_{2}\right) .{ }^{13} \mathrm{C} \mathrm{NMR}\left(151 \mathrm{MHz}, \mathrm{CDCl}_{3}\right) \delta 111.6,106.4,90.4,90.3,89.8$, 89.8 (each a singlet, $\left.\mathrm{C}_{6} \mathrm{H}_{4}\right), 82.8\left(\mathrm{~s}, \mathrm{P}\left(\mathrm{OCH}_{2}\right)_{2}\left(\mathrm{OCCH}_{3}\right)\right), 75.86\left(\mathrm{P}\left(\mathrm{OCH}_{2}\right)_{2}\left(\mathrm{OCCH}_{3}\right)\right)$, $75.81\left(\mathrm{P}\left(\mathrm{OCH}_{2}\right)_{2}\left(\mathrm{OCCH}_{3}\right)\right), 31.2\left(\mathrm{~s}, \mathrm{C}_{6} \mathrm{H}_{4}-\mathrm{CH}\left(\mathrm{CH}_{3}\right)_{2}\right), 22.4\left(\mathrm{~s}, \mathrm{C}_{6} \mathrm{H}_{4}-\mathrm{CH}\left(\mathrm{CH}_{3}\right)_{2}\right), 19.5(\mathrm{~s}$, $\left.\mathrm{C}_{6} \mathrm{H}_{4}-\mathrm{CH}_{3}\right) 15.3\left(\mathrm{~d},{ }^{3} J_{\mathrm{CP}}=11 \mathrm{~Hz}, \mathrm{P}\left(\mathrm{OCH}_{2}\right)_{2}\left(\mathrm{OCCH}_{3}\right)\right) .{ }^{31} \mathrm{P}\left\{{ }^{1} \mathrm{H}\right\}$ NMR $(121 \mathrm{MHz}$ $\left.\mathrm{CDCl}_{3}\right) \delta$ 140.5. HRMS: [M+Na $]$ obs'd (\%), calc'd (\%), ppm: 548.85142 (20.2), 548.85313 (23.7), -3.1; 549.85263 (40.7), 549.85355 (45.5), -1.7; 550.85317 (57.1), 550.85257 (64.7), $1.1 ; 551.85322$ (46.3), 551.85251 (55), 1.3; 552.85149 (100), 552.85172 (100), -0.4; 553.85181 (29.1), 553.85252 (31.3), -1.3; 554.84983 (49.9), $554.85096(70.3),-2$. 
$\left(\eta^{6}-p\right.$-cymene $) \mathbf{R u}\left[\mathbf{P}\left(\mathbf{O C H _ { 2 } ) _ { 2 } ( \mathbf { O C C H }}\right)\right](\mathbf{P h}) \mathbf{B r}(\mathbf{2})$. The complex $\left(\eta^{6}-p\right.$-cymene $) \mathrm{Ru}[$ $\left.\mathrm{P}\left(\mathrm{OCH}_{2}\right)_{2}\left(\mathrm{OCCH}_{3}\right)\right] \mathrm{Br}_{2}(\mathbf{1})(0.543 \mathrm{~g}, 1.10 \mathrm{mmol})$ in $75 \mathrm{~mL}$ of THF and $\mathrm{Ph}_{2} \mathrm{Mg}[\mathrm{THF}]_{2}$ $(0.331 \mathrm{~g}, 1.10 \mathrm{mmol})$ in $50 \mathrm{~mL}$ of THF were combined to give a red solution. Over a period of 45 minutes the red solution turned yellow with formation of a light pink precipitate. The mixture was filtered through Celite. The filtrate was concentrated to dryness, reconstituted in benzene and filtered through Celite. The filtrate was loaded onto a $1 / 2$ inch plug of silica and washed with THF to elute a bright yellow band. The filtrate was reduced to $\sim 10 \mathrm{~mL}$, hexanes were added, and the mixture was reduced to dryness. The resulting yellow solid was collected, washed with pentane, and dried under vacuum. (0.228 g, 42\% yield). ${ }^{1} \mathrm{H}$ NMR $\left(500 \mathrm{MHz}, \mathrm{CDCl}_{3}\right) \delta 7.62\left(\mathrm{dd}, 2 \mathrm{H},{ }^{3} J_{\mathrm{HH}}=8 \mathrm{~Hz},{ }^{4} J_{\mathrm{HH}}=1\right.$ $\mathrm{Hz}$, ortho phenyl), $6.98-6.85$ (m, 3H, para and meta phenyl), $5.63\left(\mathrm{dd}, 1 \mathrm{H},{ }^{3} J_{\mathrm{HH}}=6 \mathrm{~Hz}\right.$, ${ }^{4} J_{\mathrm{HH}}=1 \mathrm{~Hz}, p$-cymene: $\mathrm{C}_{6} H_{4}$, fine coupling is observed for this resonance but other $p$ cymene resonances are too broad for resolution of fine coupling), $5.54\left(\mathrm{~d}, 1 \mathrm{H},{ }^{3} J_{\mathrm{HH}}=6\right.$ Hz, p-cymene: $\left.\mathrm{C}_{6} H_{4}\right), 5.48\left(\mathrm{~d}, 1 \mathrm{H},{ }^{3} J_{\mathrm{HH}}=6 \mathrm{~Hz}, p\right.$-cymene: $\left.\mathrm{C}_{6} H_{4}\right), 5.15\left(\mathrm{~d},{ }^{3} J_{\mathrm{HH}}=6 \mathrm{~Hz}\right.$, 1H, p-cymene: $\left.\mathrm{C}_{6} H_{4}\right), 4.04\left(\mathrm{td},{ }^{2} J_{\mathrm{HH}}=8 \mathrm{~Hz},{ }^{3} J_{\mathrm{HP}}=4 \mathrm{~Hz}, 2 \mathrm{H}, \mathrm{P}\left(\mathrm{OCH}_{2}\right)_{2}\left(\mathrm{OCCH}_{3}\right)\right), 3.70$ $-3.61\left(\mathrm{~m}, 2 \mathrm{H}, \mathrm{P}\left(\mathrm{OCH}_{2}\right)_{2}\left(\mathrm{OCCH}_{3}\right)\right), 2.78\left(\mathrm{sept}, 1 \mathrm{H},{ }^{3} \mathrm{~J}_{\mathrm{HH}}=7 \mathrm{~Hz}, p\right.$-cymene: $\left.\mathrm{CH}\left(\mathrm{CH}_{3}\right)_{2}\right)$, 1.89 (s, 3H, p-cymene: $\left.\mathrm{CH}_{3}\right), 1.58\left(\mathrm{~s}, 3 \mathrm{H}, \mathrm{P}\left(\mathrm{OCH}_{2}\right)_{2}\left(\mathrm{OCCH}_{3}\right)\right), 1.25\left(\mathrm{~d}, 3 \mathrm{H},{ }^{3} J_{\mathrm{HH}}=7 \mathrm{~Hz}\right.$, p-cymene: $\left.\mathrm{CH}\left(\mathrm{CH}_{3}\right)_{2}\right), 1.20\left(\mathrm{~d}, 3 \mathrm{H},{ }^{3} \mathrm{~J}_{\mathrm{HH}}=7 \mathrm{~Hz}, p\right.$-cymene: $\left.\mathrm{CH}\left(\mathrm{CH}_{3}\right)_{2}\right) \cdot{ }^{13} \mathrm{C}$ NMR $(126$ $\left.\mathrm{MHz}, \mathrm{CDCl}_{3}\right) \delta 151.3$ (s, ipso of phenyl), 143.3, 126.9, 122.5 (each a singlet, phenyl), 118.4 (s, Cy- $\mathrm{C}_{\text {quat }}$ ), 111.1 (s, $p$-cymene: $\mathrm{C}_{\text {quat }}$ ), 95.0 (s, $p$-cymene: $\left.C_{6} \mathrm{H}_{4}\right), 92.3\left(\mathrm{~d},{ }^{2} J_{\mathrm{PC}}=9\right.$ $\mathrm{Hz}, \quad$-cymene: $\left.C_{6} \mathrm{H}_{4}\right), 89.3,89.1$ (each a singlet, $p$-cymene: $\left.C_{6} \mathrm{H}_{4}\right), 81.7$ ( 
$\left.\mathrm{P}\left(\mathrm{OCH}_{2}\right)_{2}\left(\mathrm{OCCH}_{3}\right)\right), 75.4\left(\mathrm{P}\left(\mathrm{OCH}_{2}\right)_{2}\left(\mathrm{OCCH}_{3}\right)\right), 75.4\left(\mathrm{~s}, \mathrm{P}\left(\mathrm{OCH}_{2}\right)_{2}\left(\mathrm{OCCH}_{3}\right)\right), 31.4$ (s, p-cymene: $\left.\mathrm{CH}\left(\mathrm{CH}_{3}\right)_{2}\right), 23.5$ (s, p-cymene: $\left.\mathrm{CH}\left(\mathrm{CH}_{3}\right)_{2}\right), 22.2$ (s, p-cymene: $\left.\mathrm{CH}\left(\mathrm{CH}_{3}\right)_{2}\right)$, 18.9 (s, p-cymene: $\left.\mathrm{CH}_{3}\right), 15.35\left(\mathrm{~d},{ }^{3} J_{\mathrm{CP}}=10.7 \mathrm{~Hz}, \mathrm{P}\left(\mathrm{OCH}_{2}\right)_{2}\left(\mathrm{OCCH}_{3}\right)\right) .{ }^{31} \mathrm{P} \mathrm{NMR}(121$ $\left.\mathrm{MHz}, \mathrm{CD}_{2} \mathrm{Cl}_{2}\right) \delta$ 155.5. HRMS: [M+Na $\left.{ }^{+}\right]$obs'd (\%), calc'd (\%), ppm: 546.97455 (34.4), 546.97431 (34.6), 0.4; 547.97473 (65.1), 547.97492 (66), 0.3; 548.9739 (100), 548.97344 (100), 0.8; 549.97459 (53.5), 549.97293 (47.9), 3; 550.9734 (107.1), 550.97294 (104.5), 0.8; 551.97659 (85.5), 551.9763 (84.2), 0.5; 552.9734 (85.5), 552.97181 (84.2), 2.9.

TpRu[ P(OCH $)_{2}\left(\mathrm{OCCH}_{3}\right)$ ](NCMe)Ph (4). The complex ( $\eta^{6}-p$-cymene $) \mathrm{Ru}[$ $\left.\mathrm{P}\left(\mathrm{OCH}_{2}\right)_{2}\left(\mathrm{OCCH}_{3}\right)\right](\mathrm{Ph}) \mathrm{Br}(2)(0.228 \mathrm{~g}, 0.434 \mathrm{mmol})$ was taken up in approximately 15 $\mathrm{mL}$ of NCMe, added to a pressure tube and heated overnight at $75^{\circ} \mathrm{C}$. The reaction was brought into the glovebox and allowed to cool to room temperature. The mixture was filtered through Celite, and the filtrate was concentrated to dryness yielding ( $\mathrm{NCMe})_{3} \mathrm{Ru}[$ $\left.\mathrm{P}\left(\mathrm{OCH}_{2}\right)_{2}\left(\mathrm{OCCH}_{3}\right)\right](\mathrm{Ph}) \mathrm{Br}(3)$. Without any purification, the resulting solid was taken up in $\sim 10 \mathrm{~mL}$ of methylene chloride and added to a pressure tube along with a $5 \mathrm{~mL}$ solution of KTp (0.109 g, $0.434 \mathrm{mmol})$ in methylene chloride. The reaction was heated to $75^{\circ} \mathrm{C}$ for 4 hours. The reaction was brought into the glovebox and filtered through Celite. The filtrate was concentrated to dryness and then reconstituted in diethyl ether (partially soluble). The mixture was loaded onto an $1 / 2$ inch plug of silica and washed with $50 \mathrm{~mL}$ of diethyl ether. Methylene chloride $(\sim 100 \mathrm{~mL})$ was used to elute a light yellow solution. The eluent was concentrated to $\sim 5 \mathrm{~mL}$ and added to a stirring flask of hexanes. The mixture was concentrated to $\sim 5 \mathrm{~mL}$ of solvent, and the resulting solid was collected on a 
fine porosity frit. The solid was washed with pentane and dried in vacuo to yield an offwhite solid (0.109 g, 44\%). ${ }^{1} \mathrm{H}$ NMR (600 MHz, $\left.\mathrm{C}_{6} \mathrm{D}_{6}\right) \delta 8.27,8.00,7.55,7.38$ (each a d, each $1 \mathrm{H}$, Tp 3 and 5 positions), $7.70\left(\mathrm{dd}, 2 \mathrm{H},{ }^{3} \mathrm{~J}_{\mathrm{HH}}=8 \mathrm{~Hz},{ }^{4} \mathrm{~J}_{\mathrm{HH}}=1 \mathrm{~Hz}\right.$, ortho phenyl), $7.62-7.61$ (m, 1H, Tp 3 or 5 position), 7.58, (s, 1H, Tp 3 or 5 position), $7.31\left(\mathrm{t}, 2 \mathrm{H},{ }^{3} J_{\mathrm{HH}}\right.$ $=8 \mathrm{~Hz}$, meta of phenyl), $7.20-7.16(\mathrm{~m}, 2 \mathrm{H}$, para phenyl), $6.20-6.17(\mathrm{~m}, 1 \mathrm{H}, \mathrm{Tp} 4$ position), 6.03 (s, 1H, Tp 4 position), $5.96-5.95$ (m, 1H, Tp 4 position), 3.41 (td, $2 \mathrm{H}$, $\left.{ }^{2} J_{\mathrm{HH}}=7 \mathrm{~Hz},{ }^{2} J_{\mathrm{HP}}=3 \mathrm{~Hz}, \mathrm{P}\left(\mathrm{OCH}_{2}\right)_{2}\left(\mathrm{OCCH}_{3}\right)\right), 3.24\left(\mathrm{dd}, 1 \mathrm{H},{ }^{2} J_{\mathrm{HH}}=7 \mathrm{~Hz},{ }^{3} J_{\mathrm{HP}}=3 \mathrm{~Hz}\right)$, $3.17\left(\mathrm{dd}, 1 \mathrm{H},{ }^{2} J_{\mathrm{HH}}=7 \mathrm{~Hz},{ }^{3} J_{\mathrm{HP}}=3 \mathrm{~Hz}, \mathrm{P}\left(\mathrm{OCH}_{2}\right)_{2}\left(\mathrm{OCCH}_{3}\right)\right), 0.82(\mathrm{~s}, 3 \mathrm{H}$, $\left.\mathrm{P}\left(\mathrm{OCH}_{2}\right)_{2}\left(\mathrm{OCCH}_{3}\right)\right), 0.62\left(\mathrm{~s}, 3 \mathrm{H}, \mathrm{CH}_{3} \mathrm{CN}\right) .{ }^{13} \mathrm{C} \mathrm{NMR}\left(151 \mathrm{MHz}, \mathrm{CDCl}_{3}\right) \delta 168.4(\mathrm{~d}$, ${ }^{2} J_{\mathrm{CP}}=19 \mathrm{~Hz}$, ipso phenyl), 146.7, 128.5, 124.7 (each a singlet, phenyl), 143.7, 142.4, 142.0, 135.1, 134.6, 133.8 (each a singlet, Tp 3 and 5 positions), $119.9\left(\mathrm{NCCH}_{3}\right), 105.2$ (Tp 4 position), 104.9 (2C, overlapping Tp 4 positions), $80.8\left(\mathrm{P}\left(\mathrm{OCH}_{2}\right)_{2}\left(\mathrm{OCCH}_{3}\right)\right), 74.6$ $\left(\mathrm{d},{ }^{2} J_{\mathrm{CP}}=2 \mathrm{~Hz}, \mathrm{P}\left(\mathrm{OCH}_{2}\right)_{2}\left(\mathrm{OCCH}_{3}\right)\right), 74.6\left(\mathrm{~d},{ }^{2} J_{\mathrm{CP}}=2 \mathrm{~Hz}, \mathrm{P}\left(\mathrm{OCH}_{2}\right)_{2}\left(\mathrm{OCCH}_{3}\right)\right), 15.6(\mathrm{~d}$, $\left.J_{\mathrm{CP}}=10 \mathrm{~Hz}, \mathrm{P}\left(\mathrm{OCH}_{2}\right)_{2}\left(\mathrm{OCCH}_{3}\right)\right), 4.5\left(\mathrm{NCCH}_{3}\right) .{ }^{31} \mathrm{P} \mathrm{NMR}\left(121 \mathrm{MHz}, \mathrm{CDCl}_{3}, \delta\right):$ 164.6. HRMS: $\left[\mathrm{M}+\mathrm{Na}^{+}\right]$obs'd (\%), calc'd (\%), ppm: 587.08142 (42.6), 587.08084 (44.6), 1; 588.07974 (51.1), 588.08042 (54.7), -1.2; 589.07966 (73.8), 589.0809 (77.2), -2.1; 590.07876 (100), 590.07943 (100), -1.1; 591.08134 (40.4), 591.08228 (35.6), -1.6; 592.07975 (63.8), 592.08025 (54.6), -0.8; 593.08074 (10.6), 593.08269 (13.2), -3.3. Anal. Calcd. for $\mathrm{C}_{21} \mathrm{H}_{25} \mathrm{BN}_{7} \mathrm{O}_{3}$ PRu. C, 44.54; H, 4.45; N, 17.31. Found C, 44.10; H, 4.52; N, 16.56. CV (NCMe): $E_{1 / 2}=0.69 \mathrm{~V} \mathrm{Ru}(\mathrm{III} / \mathrm{II})$. 


\section{TpRu[ $\left.\quad \mathbf{P}\left(\mathbf{O C H}_{2}\right)_{2}\left(\mathbf{O C C H}_{3}\right) \quad\right]\left(\eta^{3}-\mathbf{C}_{3} \mathbf{H}_{4} \mathrm{Me}\right) \quad$ (5). $\quad \mathrm{TpRu}\left[\quad \mathrm{P}\left(\mathrm{OCH}_{2}\right)_{2}\left(\mathrm{OCCH}_{3}\right)\right.$}

](NCMe)Ph (4) (0.0384 g, $0.0678 \mathrm{mmol})$ was dissolved in $12 \mathrm{~mL}$ of benzene and placed in a stainless steel pressure reactor. The reactor was charged with $50 \mathrm{psi}$ of ethylene and heated to $90{ }^{\circ} \mathrm{C}$ for $20 \mathrm{~h}$. The volatiles were removed in vacuo. The residue was taken up in diethyl ether and loaded on a plug of silica gel and eluted with a 1:1 mixture of diethyl ether and pentane. The solvent was removed from the pale yellow filtrate in vacuo to give a beige solid (0.0162 g, 47\% yield). ${ }^{1} \mathrm{H}$ NMR (600 MHz, $\left.\mathrm{C}_{6} \mathrm{D}_{6}\right) \delta 8.23,8.14,7.73,7.67$, 7.55, 6.92 (each a d, each 1H, Tp 3 and 5 positions), 6.19, 6.11 (each a t, each 1H, Tp 4 position), $5.86\left(\mathrm{~s}, 1 \mathrm{H}, \mathrm{Tp} 4\right.$ position), $4.98\left(\mathrm{~m}, 2 \mathrm{H}, \mathrm{H}_{\mathrm{c}}\right.$ in Table 3.6), $3.27\left(\mathrm{dd}, 2 \mathrm{H},{ }^{3} J_{\mathrm{HP}}=\right.$ $\left.8 \mathrm{~Hz},{ }^{2} J_{\mathrm{HH}}=6 \mathrm{~Hz}, \mathrm{P}\left(\mathrm{OCH}_{2}\right)_{2}\left(\mathrm{OCCH}_{3}\right)\right), 3.17\left(\mathrm{~d}, 1 \mathrm{H},{ }^{3} J_{\mathrm{AC}}=7 \mathrm{~Hz}, \mathrm{H}_{\mathrm{a}}\right.$ in Table 3.6), 3.04 $\left(\mathrm{d}, 2 \mathrm{H},{ }^{2} J_{\mathrm{HH}}=6 \mathrm{~Hz}, 3 \mathrm{H}, \mathrm{P}\left(\mathrm{OCH}_{2}\right)_{2}\left(\mathrm{OCCH}_{3}\right)\right), 2.48\left(\mathrm{dq}, 1 \mathrm{H},{ }^{3} J_{\mathrm{DC}}=12 \mathrm{~Hz},{ }^{3} J_{\mathrm{DMe}}=6 \mathrm{~Hz}\right.$, $\mathrm{H}_{\mathrm{d}}$ in Table 3.6), $2.07\left(\mathrm{~d}, 3 \mathrm{H},{ }^{3} J_{\mathrm{MeD}}=6 \mathrm{~Hz}, \mathrm{CH}_{3}\right.$ in Table 3.6), $1.57\left(\mathrm{~d}, 1 \mathrm{H},{ }^{3} J_{\mathrm{AB}}=1 \mathrm{~Hz}\right.$, ${ }^{3} J_{\mathrm{BC}}=11 \mathrm{~Hz}, \mathrm{H}_{\mathrm{b}}$ in Table 3.6), $0.81\left(\mathrm{~s}, 3 \mathrm{H}, \mathrm{P}\left(\mathrm{OCH}_{2}\right)_{2}\left(\mathrm{OCCH}_{3}\right)\right) .{ }^{13} \mathrm{C}$ NMR $(151 \mathrm{MHz}$, $\left.\mathrm{C}_{6} \mathrm{D}_{6}\right) \delta 147.0,144.5,138.4,135.0,134.8,134.8$ (each a singlet, Tp 3 and 5 positions), 105.5, 105.3, 105.1 (each a singlet, Tp 4 positions), 87.0 (allyl- $\mathrm{CH}_{2} \mathrm{CHCHCH}_{3}$ ), 80.3 ( $\left.\mathrm{P}\left(\mathrm{OCH}_{2}\right)_{2}\left(\mathrm{OCCH}_{3}\right)\right), 74.3\left(\mathrm{~d},{ }^{2} J_{\mathrm{CP}}=7 \mathrm{~Hz}, \mathrm{P}\left(\mathrm{OCH}_{2}\right)_{2}\left(\mathrm{OCCH}_{3}\right)\right), 74.2\left(\mathrm{~d},{ }^{2} J_{\mathrm{CP}}=7 \mathrm{~Hz}\right.$, $\left.\mathrm{P}\left(\mathrm{OCH}_{2}\right)_{2}\left(\mathrm{OCCH}_{3}\right)\right), 54.1\left(\mathrm{~d},{ }^{2} J_{\mathrm{CP}}=3 \mathrm{~Hz}\right.$, allyl- $\left.\mathrm{CH}_{2} \mathrm{CHCHCH}_{3}\right), 33.8\left(\mathrm{~d},{ }^{2} J_{\mathrm{CP}}=4 \mathrm{~Hz}\right.$, allyl- $\left.\mathrm{CH}_{2} \mathrm{CHCHCH}_{3}\right), \quad 19.8$ (s, allyl- $\left.\mathrm{CH}_{2} \mathrm{CHCHCH}_{3}\right), 14.7$ (d, ${ }^{3} J_{\mathrm{CP}}=10 \mathrm{~Hz}$, $\left.\mathrm{P}\left(\mathrm{OCH}_{2}\right)_{2}\left(\mathrm{OCCH}_{3}\right)\right)$. ${ }^{31} \mathrm{P}$ NMR $\left(121 \mathrm{MHz}, \mathrm{C}_{6} \mathrm{D}_{6}\right) \delta$ 171.7. LRMS: obs'd m/z (obs'd \%)/calc'd \%): 501 (42.6/45.5); 502 (53.6/54.5); 503 (71.9/77.5); 504 (100/100); 505 $(33.8 / 32.1) ; 506(58.5 / 55.0)$. 
Table 3.6. Allyl Coupling Diagram for $\mathrm{TpRu}\left[\mathrm{P}\left(\mathrm{OCH}_{2}\right)_{2}\left(\mathrm{OCCH}_{3}\right)\right]\left(\eta^{3}-\mathrm{C}_{3} \mathrm{H}_{4} \mathrm{Me}\right)(\mathbf{5})$.

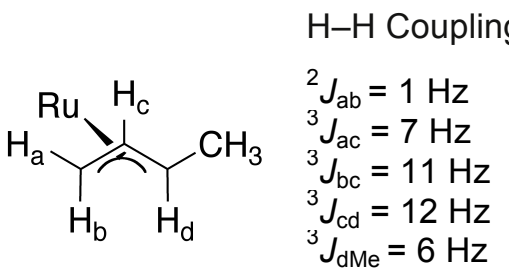

\section{Kinetic Studies: Rate Determination for Activation of $\mathrm{C}_{6} \mathrm{D}_{6}$ by $T p R u[$} $\left.\mathbf{P}\left(\mathrm{OCH}_{2}\right)_{2}\left(\mathrm{OCCH}_{3}\right)\right]$ l(NCMe)Ph (4). A solution of $\mathrm{TpRu}\left[\mathrm{P}\left(\mathrm{OCH}_{2}\right)_{2}\left(\mathrm{OCCH}_{3}\right)\right.$ ](NCMe)Ph (4) (0.0115 g, $0.0203 \mathrm{mmol})$, acetonitrile $(3.4 \mu \mathrm{L}, 0.070 \mathrm{mmol})$, and a crystal of hexamethylbenzene (as an internal standard) in $2 \mathrm{~mL}$ of $\mathrm{C}_{6} \mathrm{D}_{6}(22.6 \mathrm{mmol})$ was equally divided and transferred into four J. Young NMR tubes. The solutions were heated to 60 ${ }^{\circ} \mathrm{C}$ in a temperature-regulated oil bath. ${ }^{1} \mathrm{H}$ NMR spectra were periodically acquired through 3 half-lives (using a pulse delay of $5 \mathrm{~s}$ ). Relative to the internal standard hexamethylbenzene, the rates of $\mathrm{Ru}-\mathrm{Ph} / \mathrm{Ru}-\mathrm{Ph}-d_{5}$ exchange were followed by integration of the ortho phenyl resonance at $7.69 \mathrm{ppm}$.

Representative Catalytic Reaction. $\mathrm{TpRu}\left[\mathrm{P}\left(\mathrm{OCH}_{2}\right)_{2}\left(\mathrm{OCCH}_{3}\right)\right](\mathrm{NCMe}) \mathrm{Ph}$ (4) (0.0048 $\mathrm{g}, 0.0085 \mathrm{mmol}$ ) was dissolved in $3 \mathrm{~mL}$ benzene (with hexamethylbenzene as an internal standard). The homogeneous reaction mixture was transferred to a stainless steel pressure reactor, charged with 15 psi of ethylene followed by pressurization with nitrogen to give a total pressure of $120 \mathrm{psi}$. The reactor was heated to $90^{\circ} \mathrm{C}$. After $2 \mathrm{~h}, 4 \mathrm{~h}, 6 \mathrm{~h}, 8 \mathrm{~h}$ and 10 $\mathrm{h}$, the reaction was analyzed by GC/MS using peak areas of the products and the internal standard to calculate product yields. Ethylbenzene production was quantified using linear regression analysis of gas chromatograms of standard samples. A set of five known standards were prepared consisting of $2: 1,3: 1,4: 1,5: 1$ and $6: 1$ molar ratios of 
ethylbenzene to hexamethylbenzene in methylene chloride. A plot of peak area ratios versus molar ratios gave a regression line. For the GC/MS system, the slope and correlation coefficient for ethylbenzene were 0.68 and 0.99 , respectively.

\subsection{References}

(1) Foley, N. A.; Ke, Z. F.; Gunnoe, T. B.; Cundari, T. R.; Petersen, J. L. Organometallics 2008, 27, 3007.

(2) Foley, N. A.; Lail, M.; Lee, J. P.; Gunnoe, T. B.; Cundari, T. R.; Petersen, J. L. J. Am. Chem. Soc. 2007, 129, 6765.

(3) Foley, N. A.; Lee, J. P.; Ke, Z. F.; Gunnoe, T. B.; Cundari, T. R. Acc. Chem. Res. 2009, 42, 585.

(4) Lail, M.; Arrowood, B. N.; Gunnoe, T. B. J. Am. Chem. Soc. 2003, 125, 7506 .

(5) Lail, M.; Bell, C. M.; Conner, D.; Cundari, T. R.; Gunnoe, T. B.; Petersen, J. L. Organometallics 2004, 23, 5007.

(6) Andreatta, J. R.; McKeown, B. A.; Gunnoe, T. B. J. Organomet. Chem. 2011, 696, 305.

(7) Joslin, E. E.; McMullin, C. L.; Gunnoe, T. B.; Cundari, T. R.; Sabat, M.; Myers, W. H. Inorg. Chem. 2012, 51, 4791.

(8) Vande Griend, L. J.; Verkade, J. G.; Pennings, J. F. M.; Buck, H. M. J. Am. Chem. Soc. 1977, 99, 2459.

(9) Verkade, J. G. Coord. Chem. Rev. 1972, 9, 1.

(10) Werner, H.; Brauers, G.; Nurnberg, O. J. Organomet. Chem. 1993, 454, 247.

(11) Zelonka, R. A.; Baird, M. C. Can J Chemistry 1972, 50, 3063.

(12) Bennett, M. A.; Smith, A. K. J Chem Soc Dalton 1974, 233.

(13) Werner, H.; Werner, R. Chem Ber-Recl 1982, 115, 3766.

(14) Zelonka, R. A.; Baird, M. C. J. Organomet. Chem. 1972, 35, C43. 
(15) Elsegood, M. R. J.; Tocher, D. A. Polyhedron 1995, 14, 3147.

(16) Pigge, F. C.; Coniglio, J. J. Curr. Org. Chem. 2001, 5, 757.

(17) Serron, S.; Nolan, S. P.; Abramov, Y. A.; Brammer, L.; Petersen, J. L. Organometallics 1998, 17, 104.

(18) Hodson, E.; Simpson, S. J. Polyhedron 2004, 23, 2695.

(19) Furstner, A.; Liebl, M.; Lehmann, C. W.; Picquet, M.; Kunz, R.; Bruneau, C.; Touchard, D.; Dixneuf, P. H. Chem-Eur J 2000, 6, 1847.

(20) Elsegood, M. R. J.; Smith, M. B.; Sanchez-Ballester, N. M. Acta Crystallogr E 2006, 62, M2838.

(21) Mendoza-Ferri, M. G.; Hartinger, C. G.; Nazarov, A. A.; Eichinger, R. E.; Jakupec, M. A.; Severin, K.; Keppler, B. K. Organometallics 2009, $28,6260$.

(22) Percent yield was determined using ${ }^{1} H$ NMR spectroscopy versus an internal standard.

(23) Foley, N. A.; Lail, M.; Gunnoe, T. B.; Cundari, T. R.; Boyle, P. D.; Petersen, J. L. Organometallics 2007, 26, 5507.

(24) Olah, G. A.; Molnar, A. Hydrocarbon Chemistry; 2nd ed.; WileyInterscience: New York, 2003.

(25) Relative rates were determined by using experimental TOs.

(26) Lühder, K.; Nehls, D.; Madeja, K. Journal Fur Praktische Chemie 1983, $325,1027$.

(27) Frisch, M. J., et al.; Gaussian, Inc: Willingford, CT, 2009.

(28) Stevens, W. J.; Krauss, M.; Basch, H.; Jasien, P. G. Can J Chem 1992, 70, 612. 


\section{Catalytic Decomposition Pathway for $\mathrm{TpRu}(\mathrm{CO})(\mathrm{NCMe}) \mathrm{Ph}$}

\subsection{Introduction}

Our group has demonstrated that $\mathrm{TpRu}(\mathrm{CO})(\mathrm{NCMe}) \mathrm{Ph}$ is one of the most active olefin hydroarylation catalyst. ${ }^{1-4} \mathrm{TpRu}(\mathrm{CO})(\mathrm{NCMe}) \mathrm{Ph}(0.1 \mathrm{~mol} \%$ loading) catalyzes the formation of $51 \mathrm{TO}$ of ethylbenzene from benzene and ethylene (25 psi) after $4 \mathrm{~h}$ with a turnover frequency (TOF) of $3.5 \times 10^{-3} \mathrm{~s}^{-1}$. This TOF is an estimate since it is calculated using TO after 4 hours and some catalyst decomposition of $\mathrm{TpRu}(\mathrm{CO})(\mathrm{NCMe}) \mathrm{Ph}$ could have occured. ${ }^{1-3}$ Additionally, it was shown that catalysis with $\alpha$-olefins (e.g., propylene and hexene) using $\mathrm{TpRu}(\mathrm{CO})(\mathrm{NCMe}) \mathrm{Ph}$ is selective for the anti-Markovnikov product ( $n$-propylbenzene and $n$-hexylbenzene) over the Markovnikov product (cumene and 2phenylhexane) in a 1.6:1 ratio. The bias for anti-Markovnikov products supports a nonacid catalyzed process (i.e., Friedel-Crafts alkylation). Through experimental and computation studies, we determined that the mechanism for transition metal catalyzed hydroarylation includes two key steps: olefin insertion in a M-Ar bond and benzene $\mathrm{C}-\mathrm{H}$ activation (see Chapter 1). ${ }^{4}$ Initial studies suggested that the deactivation product of catalysis with $\mathrm{TpRu}(\mathrm{CO}) \mathrm{Ph}(\mathrm{NCMe})$ was a paramagnetic multinuclear $\mathrm{Ru}$ species; however, the identity of the product(s) of deactivation have not been definitely determined..$^{1-3}$

Chapter 3 describes the use of $\mathrm{TpRu}\left[\mathrm{P}\left(\mathrm{OCH}_{2}\right)_{2}\left(\mathrm{OCCH}_{3}\right)\right](\mathrm{NCMe}) \mathrm{Ph}$ as a catalyst for olefin hydroarylation. ${ }^{5}$ Due to a multiple step synthesis with a $17 \%$ overall yield for $\mathrm{TpRu}\left[\left(\mathrm{P}\left(\mathrm{OCH}_{2}\right)_{2}\left(\mathrm{OCCH}_{3}\right)\right](\mathrm{NCMe}) \mathrm{Ph}\right.$, reactions were performed initially at a lower catalyst loading than we typically used for $\mathrm{TpRu}(\mathrm{L})(\mathrm{NCMe}) \mathrm{Ph}$ catalysts $(0.025 \mathrm{~mol} \%$ 
rather than $0.1 \mathrm{~mol} \%)$. The optimal catalytic conditions for $\mathrm{TpRu}\left[\mathrm{P}\left(\mathrm{OCH}_{2}\right)_{2}\left(\mathrm{OCCH}_{3}\right)\right.$ ](NCMe) $\mathrm{Ph}$ are $0.025 \mathrm{~mol} \% \mathrm{Ru}, 90{ }^{\circ} \mathrm{C}$, and 1 atm of ethylene yielding $90 \mathrm{TON}$ of ethylbenzene. Therefore, to have a direct comparison for the $\operatorname{TpRu}(\mathrm{L})(\mathrm{NCMe}) \mathrm{Ph}[\mathrm{L}=$ $\mathrm{CO}, \mathrm{PMe}_{3}, \mathrm{P}\left(\mathrm{OCH}_{2}\right)_{2}\left(\mathrm{OCCH}_{3}\right)$, or $\left.\mathrm{P}\left(\mathrm{OCH}_{2}\right)_{3} \mathrm{CEt}\right]$ series, these previously reported catalysts were evaluated at the same conditions used for $\mathrm{TpRu}\left[\mathrm{P}\left(\mathrm{OCH}_{2}\right)_{2}\left(\mathrm{OCCH}_{3}\right)\right.$ ](NCMe) $\mathrm{Ph}\left(0.025 \mathrm{~mol} \% \mathrm{Ru}, 90^{\circ} \mathrm{C}\right.$ and $1 \mathrm{~atm}$ ethylene). Decreasing the catalyst loading for $\mathrm{TpRu}\left[\mathrm{P}\left(\mathrm{OCH}_{2}\right)_{3} \mathrm{CEt}\right] \mathrm{Ph}(\mathrm{NCMe})$ (25 psi ethylene) had no influence on the TON; however, an increase of $10 \mathrm{TON}$ was observed at lower ethylene concentration (1 atm vs $10 \mathrm{psi}$ ) compared to the previously reported values. A significant change in TON was observed for $\mathrm{TpRu}(\mathrm{CO})(\mathrm{NCMe}) \mathrm{Ph}$. $\mathrm{TpRu}(\mathrm{CO})(\mathrm{NCMe}) \mathrm{Ph}$ at $0.025 \mathrm{~mol} \%$ loading yielded $415 \mathrm{TON}$ yet, at $0.1 \mathrm{~mol} \% \mathrm{Ru}$ only $77 \mathrm{TON}$ were observed (Table 4.1 ). The large increase in turnovers at a lower concentration of $\mathrm{TpRu}(\mathrm{CO})(\mathrm{NCMe}) \mathrm{Ph}$ supports the hypothesis that the NMR silent decomposition product is a multinuclear species that forms by a second order process (see below). This chapter will describe the effects of catalyst loading and ethylene pressure on ethylene hydrophenylation catalyzed by $\mathrm{TpRu}(\mathrm{CO})(\mathrm{NCMe}) \mathrm{Ph}$ with a focus on routes of deactivation. 
Table 4.1. Comparison of TON and TOF for Ethylbenzene Production from Catalytic Hydrophenylation of Ethylene by $\mathrm{TpRu}(\mathrm{L})(\mathrm{NCMe}) \mathrm{Ph}$ Complexes.

\begin{tabular}{cccccc}
\hline & & & & Relative & $\mathrm{E}_{1 / 2}$ \\
$\mathrm{~L}$ & TON & Time & TOF $\left(\mathrm{s}^{-1}\right)^{\mathrm{a}}$ & TOF & $(\mathrm{V}$ vs. NHE $)$ \\
\hline $\mathrm{CO}$ & 415 & $40 \mathrm{~h}$ & $6.7 \times 10^{-3}$ & 14 & 1.03 \\
$\mathrm{P}\left(\mathrm{OCH}_{2}\right)_{2}\left(\mathrm{OCCH}_{3}\right)$ & $90^{\mathrm{b}}$ & $50 \mathrm{~h}$ & $1.5 \times 10^{-3}$ & 3 & 0.69 \\
$\mathrm{P}\left(\mathrm{OCH}_{2}\right)_{3} \mathrm{CEt}$ & $20^{\mathrm{b}}$ & $24 \mathrm{~h}$ & $4.8 \times 10^{-4}$ & 1 & 0.54
\end{tabular}

${ }^{\text {a }}$ Calculated after $4 \mathrm{~h}$ at $90{ }^{\circ} \mathrm{C}$ with 1 atm ethylene and $0.025 \mathrm{~mol} \%$ of catalyst (relative to benzene). ${ }^{b}$ Catalyst deactivation occurs by formation of $\mathrm{TpRu}(\mathrm{L})\left(\eta^{3}-\mathrm{C}_{3} \mathrm{H}_{4} \mathrm{Me}\right)$.

\subsection{Results and Discussion}

\subsubsection{Kinetics of Decomposition of $\mathrm{TpRu}(\mathrm{CO})(\mathrm{NCMe}) \mathrm{Ph}$ in $\mathrm{THF}$}

Monitoring the deactivation of $\mathrm{TpRu}(\mathrm{CO})(\mathrm{NCMe}) \mathrm{Ph}$ under catalytic conditions (i.e., in benzene under ethylene pressure) is complicated by competing processes (see below). Thus, we explored the decomposition of $\mathrm{TpRu}(\mathrm{CO})(\mathrm{NCMe}) \mathrm{Ph}$ in the absence of benzene and ethylene. $\mathrm{TpRu}(\mathrm{CO})(\mathrm{NCMe}) \mathrm{Ph}(0.03 \mathrm{M})$ was placed in THF- $d_{8}$, heated to $75{ }^{\circ} \mathrm{C}$ and monitored by ${ }^{1} \mathrm{H}$ NMR spectroscopy. As the reaction progressed, resonances for the starting material decreased and the appearance of broad resonances were observed in the ${ }^{1} \mathrm{H}$ NMR spectra. These broad resonances are consistent with the formation of a paramagnetic species and may be the same as one of the products of catalyst deactivation (see below). Plots of the $\ln ([\mathrm{TpRu}(\mathrm{CO})(\mathrm{NCMe}) \mathrm{Ph}])$ vs time and $[\mathrm{TpRu}(\mathrm{CO})(\mathrm{NCMe}) \mathrm{Ph}]^{-1}$ vs time (Figure 4.1, Figure 4.2) reveal that the decomposition pathway is likely second order in Ru. The rate of decomposition was determined using only the first 30,000 seconds due to larger error associated with the integrations at the end of the reaction. The rate of decomposition was determined to be $0.007(1) \mathrm{s}^{-1} \mathrm{M}^{-1}$ at $75^{\circ} \mathrm{C}$. 


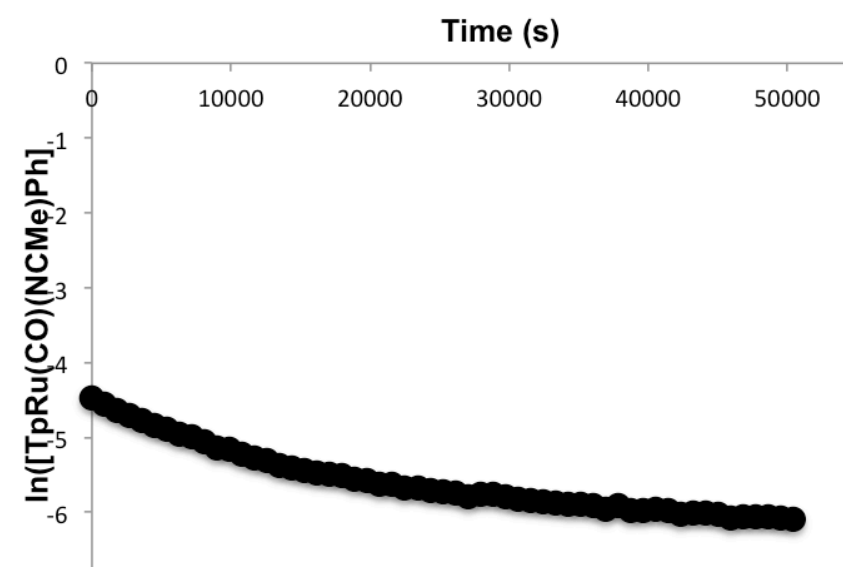

Figure 4.1. First order plot of $\ln ([\mathrm{TpRu}(\mathrm{CO})(\mathrm{NCMe}) \mathrm{Ph}])$ vs time determined from ${ }^{1} \mathrm{H}$ NMR spectroscopy (using the internal standard HMDS) for the decomposition of $\mathrm{TpRu}(\mathrm{CO})(\mathrm{NCMe}) \mathrm{Ph}$ in $\mathrm{THF}-d_{8}$ at $75^{\circ} \mathrm{C}$.

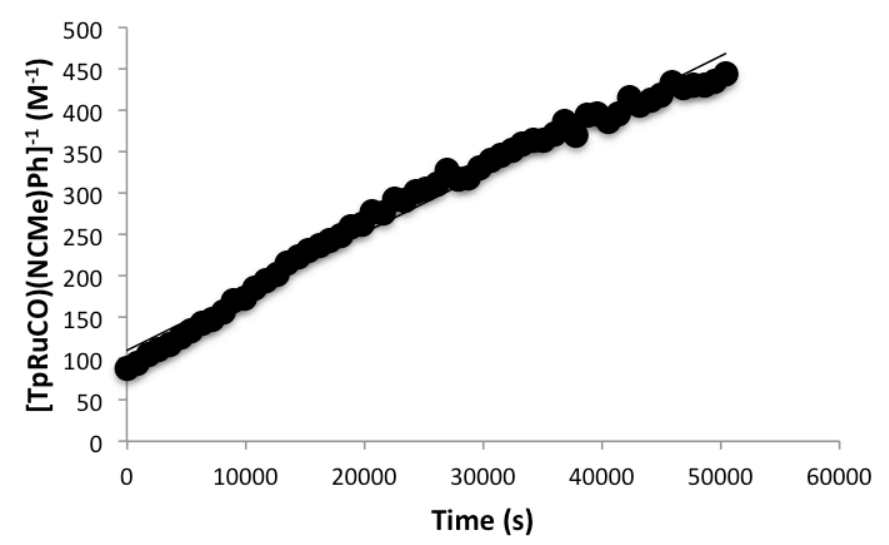

Figure 4.2. Second order plot of the $[\mathrm{TpRu}(\mathrm{CO})(\mathrm{NCMe}) \mathrm{Ph}]^{-1}$ vs time $\left(\mathrm{R}^{2}=0.98\right)$ determined from ${ }^{1} \mathrm{H}$ NMR spectroscopy (using the internal standard HMDS) for the decomposition of $\mathrm{TpRu}(\mathrm{CO})(\mathrm{NCMe}) \mathrm{Ph}$ in $\mathrm{THF}-d_{8}$ at $75^{\circ} \mathrm{C}$.

\subsubsection{Competing Decompostion Reactions: Dependence on Ethylene Concentration}

It has been shown that higher concentrations of ethylene decrease the rate of catalysis for the hydrophenylation of ethylene which has been explained by the resting state $\mathrm{TpRu}(\mathrm{CO})\left(\eta^{2}-\mathrm{H}_{2} \mathrm{C}=\mathrm{CH}_{2}\right)\left(\mathrm{CH}_{2} \mathrm{CH}_{2} \mathrm{Ph}\right)(\mathrm{Scheme} 4.1) .{ }^{2}$ Unlike $\mathrm{TpRu}(\mathrm{L})(\mathrm{NCMe}) \mathrm{Ph}$ $\left[\mathrm{L}=\mathrm{PMe}_{3}, \mathrm{P}\left(\mathrm{OCH}_{2}\right)_{2}\left(\mathrm{OCCH}_{3}\right)\right.$, or $\left.\mathrm{P}\left(\mathrm{OCH}_{2}\right)_{3} \mathrm{CEt}\right]$ where catalysis is halted by the 
formation of a $\mathrm{TpRu}(\mathrm{L})\left(\eta^{3}-\mathrm{C}_{4} \mathrm{H}_{7}\right),{ }^{3,5,6}$ previous analysis of the non-volatiles after deactivation of $\mathrm{TpRu}(\mathrm{CO})(\mathrm{NCMe}) \mathrm{Ph}$ revealed potential formation of a paramagnetic species and lack of evidence for the presence of $\mathrm{TpRu}(\mathrm{CO})\left(\eta^{3}-\mathrm{C}_{4} \mathrm{H}_{7}\right){ }^{7} \mathrm{TpRu}(\mathrm{CO})\left(\eta^{3}-\right.$ $\mathrm{C}_{4} \mathrm{H}_{7}$ ) has been synthesized by the reaction of $\mathrm{TpRu}(\mathrm{CO})(\mathrm{NCMe}) \mathrm{Ph}$ with ethylene (250 psi) in THF at $70{ }^{\circ} \mathrm{C} .{ }^{1}$ We anticipate that the pathway of deactivation of $\mathrm{TpRu}(\mathrm{CO})(\mathrm{NCMe}) \mathrm{Ph}$ [i.e., formation of paramagnetic complex or $\left.\mathrm{TpRu}(\mathrm{CO})\left(\eta^{3}-\mathrm{C}_{4} \mathrm{H}_{7}\right)\right]$ might depend on ethylene concentration. To examine the effect of ethylene concentration on catalyst deactivation, catalytic experiments were conducted using $0.01 \mathrm{~mol} \% \mathrm{Ru}$ loading at $90{ }^{\circ} \mathrm{C}$ with varied ethylene pressures ( $1 \mathrm{~atm}, 25$ or $50 \mathrm{psi}$ ). Also, if the formation of the paramagnetic deactivation product during catalysis is the same process as decomposition of $\mathrm{TpRu}(\mathrm{CO})(\mathrm{NCMe}) \mathrm{Ph}$ in $\mathrm{THF}$ (see above), it should be second order in $[\mathrm{TpRu}(\mathrm{CO})(\mathrm{NCMe}) \mathrm{Ph}]$.

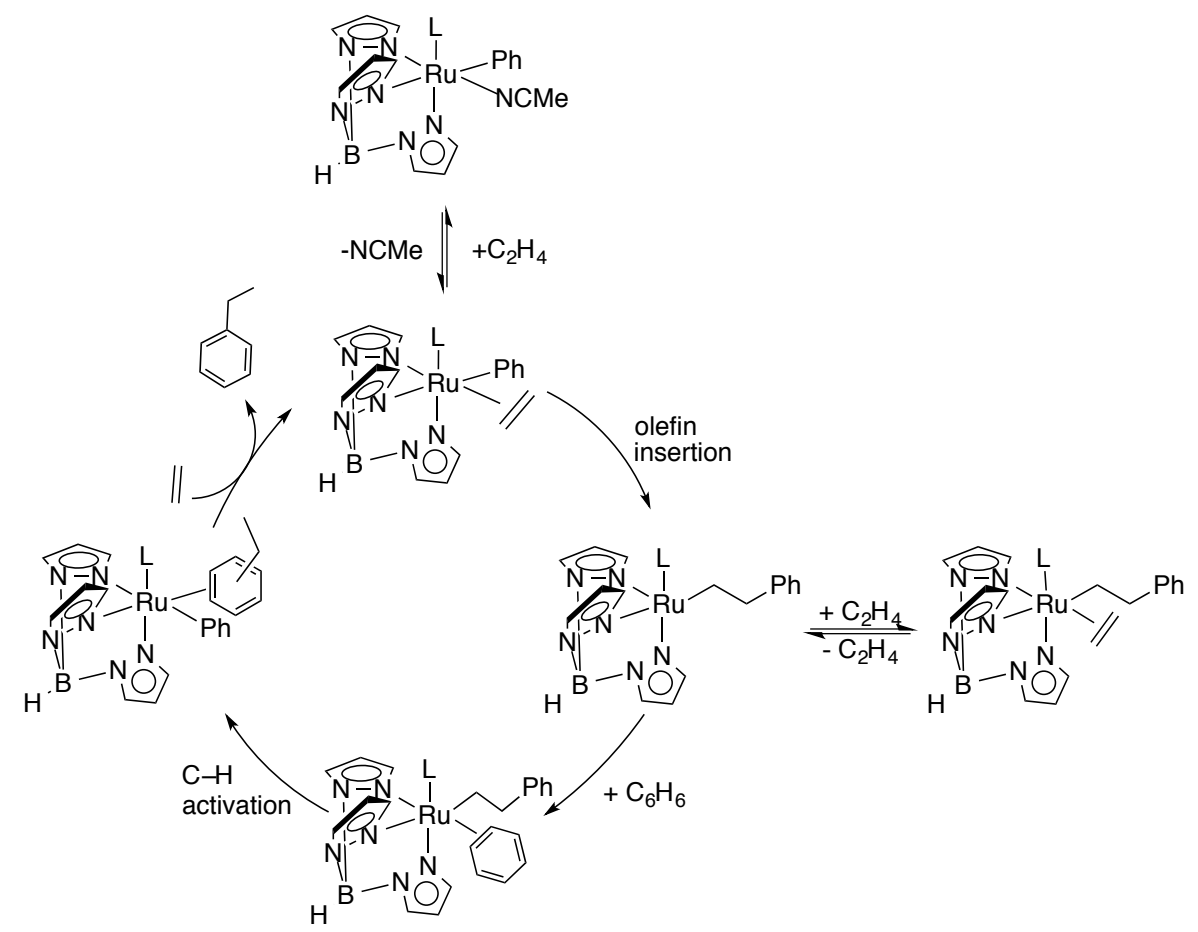

Scheme 4.1. Proposed catalytic cycle for olefin hydroarylation with $\mathrm{TpRu}(\mathrm{II})$ complexes. 
Catalytic reactions at $0.01 \mathrm{~mol} \% \mathrm{TpRu}(\mathrm{CO})(\mathrm{NCMe}) \mathrm{Ph}$ and 1 atm of ethylene show significant increase longevity and an increase in TON of ethylbenzene compared to reactions with higher ethylene pressure (Table 6.2). As ethylene pressure increases the longevity and TON of ethylbenzene decreases due to the increased formation of $\mathrm{TpRu}(\mathrm{CO})\left(\eta^{3}-\mathrm{C}_{4} \mathrm{H}_{7}\right)$. At ethylene pressures $\geq 25 \mathrm{psi}$, the formation of the allyl species $\mathrm{TpRu}(\mathrm{CO})\left(\eta^{3}-\mathrm{C}_{4} \mathrm{H}_{7}\right)$ is quantitative (Table 6.2). These results suggest at lower ethylene concentrations, deactivation via formation of the proposed paramagnetic complex (which are presumed to be independent of ethylene) and $\mathrm{TpRu}(\mathrm{CO})\left(\eta^{3}-\mathrm{C}_{4} \mathrm{H}_{7}\right)$ complete. But, at increased ethylene concentrations the rate of deactivation to form the ally complex $\mathrm{TpRu}(\mathrm{CO})\left(\eta^{3}-\mathrm{C}_{4} \mathrm{H}_{7}\right)$ dominates. Therefore, higher ethylene concentrations lead to more rapid catalyst deactivation. At $0.01 \mathrm{~mol} \% \mathrm{TpRu}(\mathrm{CO})(\mathrm{NCMe}) \mathrm{Ph}$ and 1 atm of ethylene the formation of $\mathrm{TpRu}(\mathrm{CO})\left(\eta^{3}-\mathrm{C}_{4} \mathrm{H}_{7}\right)$ is the predominate catalytic deactivation product (62\% yield) but the proposed paramagnetic species is also formed.

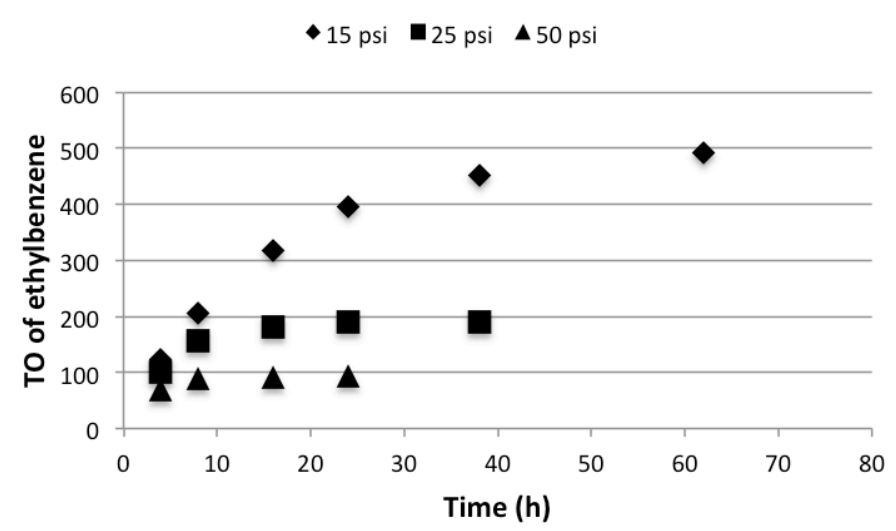

Figure 4.3. Comparison of catalytic hydrophenylation of ethylene at various pressures (1 atm, 25 and $50 \mathrm{psi})$ by $\mathrm{TpRu}(\mathrm{CO})(\mathrm{NCMe}) \mathrm{Ph}$ at $0.01 \mathrm{~mol} \% \mathrm{Ru}$ and $90{ }^{\circ} \mathrm{C}$. 
Table 4.2. Comparison of $\mathrm{TpRu}(\mathrm{CO})\left(\eta^{3}-\mathrm{C}_{3} \mathrm{H}_{4} \mathrm{Me}\right)$ yield during catalysis at $0.01 \mathrm{~mol} \%$ $\mathrm{Ru}$ at varying pressures of ethylene at $90^{\circ} \mathrm{C}$.

\begin{tabular}{c|c|c}
\hline Ethylene Pressure & TON & $\begin{array}{c}\text { \% yield } \\
\text { TpRu}(\mathrm{CO})\left(\eta^{3}-\mathrm{C}_{3} \mathrm{H}_{4} \mathrm{Me}\right)^{\mathrm{a}}\end{array}$ \\
\hline $1 \mathrm{~atm}$ & 490 & 62 \\
$25 \mathrm{psi}$ & 189 & 98 \\
$50 \mathrm{psi}$ & 94 & 100
\end{tabular}

${ }^{a} \%$ yield was determined by ${ }^{1} \mathrm{H}$ NMR spectroscopy using integrations versus an known concentration of internal standard HMDS.

\subsubsection{Competing Deactivation Pathways: Dependence on Catalyst Loading}

To further investigate the competition between the formation of $\operatorname{TpRu}(\mathrm{CO})\left(\eta^{3}-\right.$ $\mathrm{C}_{4} \mathrm{H}_{7}$ ) and the proposed paramagnetic $\mathrm{Ru}$ species, catalysis was performed with $\mathrm{TpRu}(\mathrm{CO})(\mathrm{NCMe}) \mathrm{Ph}$ using catalyst loadings between 0.001 and $0.3 \mathrm{~mol} \%, 1 \mathrm{~atm}$ of ethylene and $90{ }^{\circ} \mathrm{C}$. At lower concentrations of catalyst $(\leq 0.025 \mathrm{~mol} \% \mathrm{Ru})$ the TON of the catalyst is significantly increased compared to catalyst loadings greater than $0.05 \mathrm{~mol}$ $\%$. At lower catalyst loadings $(\leq 0.025 \mathrm{~mol} \% \mathrm{Ru})$, activity is generally maintained through approximately $40 \mathrm{~h}$ and the $\mathrm{TpRu}(\mathrm{CO})\left(\eta^{3}-\mathrm{C}_{4} \mathrm{H}_{7}\right)$ is formed in $\sim 60 \%$ yield. Higher Ru loadings increase the time during which activity is observed $(\sim 90 \mathrm{~h})$ but overall TON of ethylbenzene is decreased significantly. At higher concentration of Ru the proposed paramagnetic species dominates deactivation with only of $22 \%$ and $12 \%$ of $\mathrm{TpRu}(\mathrm{CO})\left(\eta^{3}-\mathrm{C}_{4} \mathrm{H}_{7}\right)$ observed at $0.1 \mathrm{~mol} \%$ and $0.2 \mathrm{~mol} \% \mathrm{Ru}$, respectively (Table 4.3 ). 


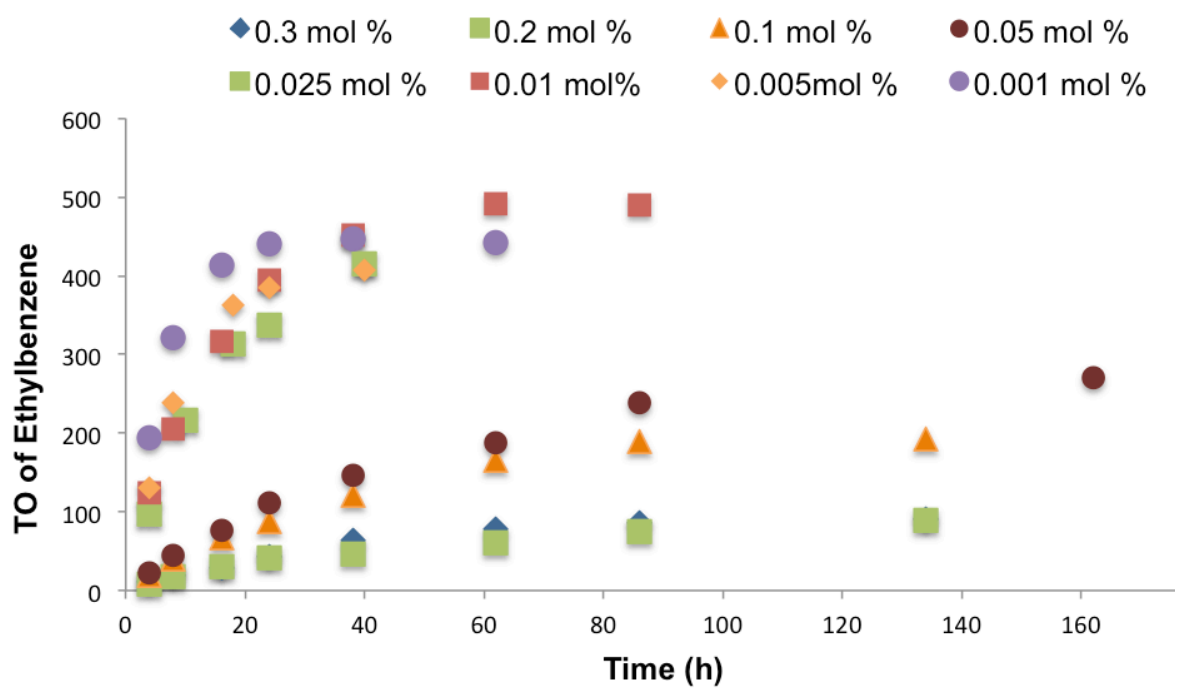

Figure 4.4. Comparison of catalytic hydrophenylation of ethylene at various $\mathrm{Ru}$ mol \% loadings $(0.001-0.3 \mathrm{~mol} \%)$ by $\mathrm{TpRu}(\mathrm{CO}) \mathrm{Ph}(\mathrm{NCMe})$ at 1 atm and $90{ }^{\circ} \mathrm{C}$.

Table 4.3. Comparison of $\mathrm{TpRu}(\mathrm{CO})\left(\eta^{3}-\mathrm{C}_{3} \mathrm{H}_{4} \mathrm{Me}\right)$ concentration during catalysis as a function of catalyst loading ${ }^{a}$

\begin{tabular}{c|c}
\hline $\begin{array}{c}\text { Mol \% yield } \\
\mathrm{Ru}\end{array}$ & $\mathrm{TpRu}(\mathrm{CO})\left(\eta^{3}-\mathrm{C}_{3} \mathrm{H}_{4} \mathrm{Me}\right)^{b}$ \\
\hline 0.2 & 12 \\
0.1 & 22 \\
0.025 & 60 \\
0.01 & 62 \\
0.005 & 59 \\
0.001 & 52
\end{tabular}

${ }^{a}$ Reactions conducted at 1 atm of ethylene and $90{ }^{\circ} \mathrm{C}{ }^{b} \%$ yield was determined by ${ }^{1} \mathrm{H}$ NMR spectroscopy using integrations versus a known concentration of internal standard, HMDS.

\subsection{Conclusions}

$\mathrm{TpRu}(\mathrm{CO})(\mathrm{NCMe}) \mathrm{Ph}$ has been observed to be an effective catalyst for ethylene hydrophenylation. Studies of the impact of catalyst loading and ethylene pressure were examined. Two competing deactivation pathways have been proposed based on these studies (Scheme 4.2). It was determined that ethylene concentration influences the catalyst longevity and the pathway to deactivation. At higher ethylene concentrations (i.e, 
25 or 50 psi and $0.01 \mathrm{~mol} \% \mathrm{Ru}$ ) the total TON was decreased compared to $1 \mathrm{~atm}$ of ethylene. Additionally, the only deactivation pathway observed was formation of $\mathrm{TpRu}(\mathrm{CO})\left(\eta^{3}-\mathrm{C}_{3} \mathrm{H}_{4} \mathrm{Me}\right)$ for 25 or $50 \mathrm{psi}$ of ethylene. At lower catalyst loadings $(\leq 0.025$ mol $\% \mathrm{Ru}$ ) approximately $60 \%$ yield of $\mathrm{TpRu}(\mathrm{CO})\left(\eta^{3}-\mathrm{C}_{3} \mathrm{H}_{4} \mathrm{Me}\right)$ is observed. However, at higher catalyst loadings (e.g., 0.1 and $0.2 \mathrm{~mol} \% \mathrm{Ru}$ ) the main decomposition product is a proposed paramagnetic $\mathrm{Ru}$ species with significantly less $\mathrm{TpRu}(\mathrm{CO})\left(\eta^{3}-\mathrm{C}_{3} \mathrm{H}_{4} \mathrm{Me}\right)$. It is surmised that immobilizing $\mathrm{TpRu}(\mathrm{CO})(\mathrm{NCMe}) \mathrm{Ph}$ on a solid support could eliminate the formation of the paramagnetic Ru species, and could improve catalyst longevity.

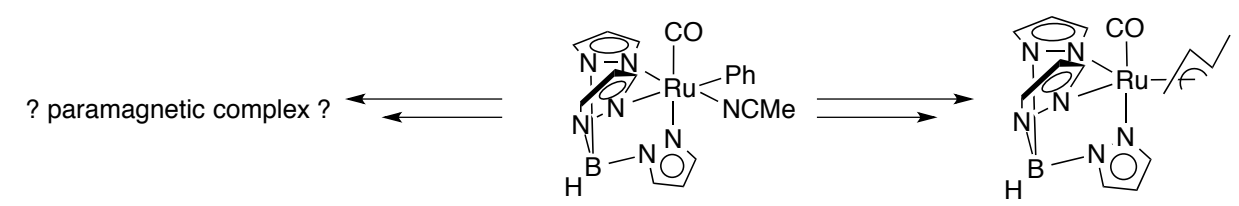

Scheme 4.2. Competing deactivation pathways during catalysis for $\mathrm{TpRu}(\mathrm{CO})(\mathrm{NCMe}) \mathrm{Ph}$.

\subsection{Experimental}

General Methods. The preparation, isolation and characterization of $\mathrm{TpRu}(\mathrm{CO}) \mathrm{Ph}(\mathrm{NCMe})$ have been previously reported. ${ }^{2}$ Benzene was purified by passage through a column of activated alumina. THF- $d_{8}$ was stored under a nitrogen atmosphere over $4 \AA$ molecular sieves. ${ }^{1} \mathrm{H}$ NMR spectra were recorded on a Varian MRS $600 \mathrm{MHz}$ spectrometer.

Kinetic Studies: Determination of Order of Deactivation for TpRu(CO)(NCMe)Ph. A THF- $d_{8}$ solution of $\mathrm{TpRu}(\mathrm{CO})(\mathrm{NCMe}) \mathrm{Ph}(0.0125 \mathrm{~g}, 0.0272$ mmol) and hexamethyldisiliane (as an internal standard) was made in a $1 \mathrm{~mL}$ volumetric 
flask. The solution was equally divided $(300 \mu \mathrm{L})$ and transferred into three J. Young NMR tubes. The NMR tube was placed into the temperature calibrated NMR probe (equilibrated at $76{ }^{\circ} \mathrm{C}$ ). The temperature was determined using a $80 \%$ Ethylene Glycol in DMSO- $d_{6}$ and the following equation provided by Bruker Instruments, Inc. VTCalibration Manual: $\mathrm{T}(\mathrm{K})=(4.218-\Delta) / 0.009132$, where $\Delta$ is the shift difference $(\mathrm{ppm})$ between $\mathrm{CH}_{2}$ and $\mathrm{OH}$ peaks of the ethylene glycol. Reaction progress was monitored by ${ }^{1} \mathrm{H}$ NMR spectroscopy using automated data acquisition. A single transient was used for each time point with $900 \mathrm{~s}$ delay between transients. The rate of the reaction was determined by monitoring the disappearance of the most upfield Tp resonance $(6.02 \mathrm{ppm})$ of the starting material. Each reaction was monitored through at least 3 half-lives.

Representative Catalytic Reaction. $\mathrm{TpRu}(\mathrm{CO})(\mathrm{NCMe}) \mathrm{Ph}(0.0103 \mathrm{~g}, 0.0224$ mmol, $0.1 \mathrm{~mol} \% \mathrm{Ru}$ relative to benzene) was dissolved in $2 \mathrm{~mL}$ of benzene. In a $25 \mathrm{~mL}$ volumetric flask decane $(0.199 \mathrm{~g}, 0.273 \mathrm{~mL}, 0.5 \mathrm{~mol} \%$ decane relative to benzene) was added to benzene solution. To generate $6 \mathrm{~mL}$ of a $0.025 \mathrm{~mol} \% \mathrm{Ru}$ catalyst solution: 1.5 $\mathrm{mL}$ of $[0.1 \mathrm{~mol} \%] \mathrm{Ru}$ solution, $1.5 \mathrm{~mL}$ of [0.5 mol \%] decane solution and $3 \mathrm{~mL}$ of benzene were transferred to a stainless steel pressure reactor. The reactor was charged with 15 psi of ethylene, degassed to reach a final pressure of 1 atm, pressurized with dinitrogen to a total pressure of $120 \mathrm{psi}$, and heated to $90{ }^{\circ} \mathrm{C}$. After a given duration the reactor was cooled to room temperature and an aliquot of the reaction mixture was removed. The reaction mixture was analyzed by GC/MS using peak areas of the products and the internal standard to calculate product yields. Ethylbenzene production was quantified using linear regression analysis of gas chromatograms of standard samples. A 
set of eight known standards were prepared consisting of 1:5, 3:5, 5:5, 7.5:5, 10:5, 50:5, 100:5 and 150:5 molar ratios of ethylbenzene to decane in methylene chloride. A plot of peak area ratios versus molar ratios gave a regression line. For the GC/MS system, the slope and correlation coefficient for ethylbenzene were 0.18 and 0.99 , respectively.

\section{Determination of Percent $\mathrm{TpRu}(\mathrm{CO})\left(\eta^{3}-\mathrm{C}_{3} \mathrm{H}_{4} \mathrm{Me}\right)$ Formation During}

Catalysis. A catalytic reaction was preformed as stated above. After completion of catalysis, the reactor was brought into the glovebox, the volume of the solution was determined, and the volatiles were removed in vacuo. The non-volatiles were dissolved in $\mathrm{C}_{6} \mathrm{D}_{6}(0.4 \mathrm{~mL})$ and placed in an NMR tube with $20 \mu \mathrm{L}$ of the $0.0049 \mathrm{M}$ HMDS solution. A ${ }^{1} \mathrm{H}$ NMR spectrum was collected (nt $=8$ and a pulse delay of $20 \mathrm{sec}$ ) and an allyl resonance corresponding to $\mathrm{TpRu}(\mathrm{CO})\left(\eta^{3}-\mathrm{C}_{3} \mathrm{H}_{4} \mathrm{Me}\right)(4.4 \mathrm{ppm})$ was integrated relative to the HMDS standard to calculate the percent yield of $\operatorname{TpRu}(\mathrm{CO})\left(\eta^{3}-\mathrm{C}_{3} \mathrm{H}_{4} \mathrm{Me}\right)$. 


\subsection{References}

(1) Lail, M.; Arrowood, B. N.; Gunnoe, T. B. J. Am. Chem. Soc. 2003, 125, 7506.

(2) Lail, M.; Bell, C. M.; Conner, D.; Cundari, T. R.; Gunnoe, T. B.; Petersen, J. L. Organometallics 2004, 23, 5007.

(3) Foley, N. A.; Lail, M.; Lee, J. P.; Gunnoe, T. B.; Cundari, T. R.; Petersen, J. L. J. Am. Chem. Soc. 2007, 129, 6765.

(4) Foley, N. A.; Lee, J. P.; Ke, Z. F.; Gunnoe, T. B.; Cundari, T. R. Acc. Chem. Res. 2009, 42, 585.

(5) Joslin, E. E.; McMullin, C. L.; Gunnoe, T. B.; Cundari, T. R.; Sabat, M.; Myers, W. H. Organometallics 2012, 31, 6851.

(6) Foley, N. A.; Ke, Z. F.; Gunnoe, T. B.; Cundari, T. R.; Petersen, J. L. Organometallics 2008, 27, 3007.

(7) Lail, M.,Thesis: Synthesis and Reactivity of Ruthenium Alkyl and Aryl Complexes and Their Applications towards Aromatic C-H Bond Activation and Olefin Hydroarylation, North Carolina State University, 2006. 


\section{Synthesis and Characterization of $(\mathrm{L}) \mathrm{Ru}(\mathrm{II})$ complexes $(\mathrm{L}=$ neutral 6-electron donor) for Olefin Hydroarylation}

\subsection{Introduction}

Tris(pyrazolyl)borate ligands, which are often called scorpionates were first reported by Trofimenko in the late 1960s..$^{1-3}$ Poly(pyrazolyl)borate ligands have been extensively studied, and more than 2,000 papers have been published containing this class of ligand. ${ }^{4}$ Their utility stems from the ease of altering electronic properties and steric profile by decorating the 3, 4, and/or 5-position of the pyrazolyl rings, adding substituents to boron, and replacing boron with carbon, silicon, phosphorous or gallium (Figure 5.1). ${ }^{3,5-9}$

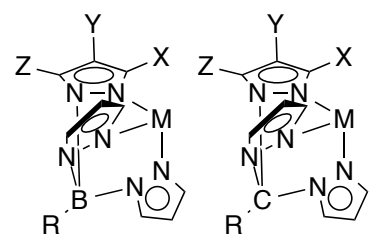

Figure 5.1. Examples of some scorpionate ligands

Our group has studied the use of tris(pyrazolyl)borate ligands on $\mathrm{Ru}(\mathrm{II})$ with the motif TpRu(L)(NCMe)Ph $\left[\mathrm{L}=\mathrm{CO}, \mathrm{PMe}_{3}, \mathrm{P}\left(\mathrm{OCH}_{2}\right)_{3} \mathrm{CEt}, \mathrm{P}(\mathrm{pyr})_{3}\right.$ and $\mathrm{P}\left(\mathrm{OCH}_{2}\right)_{2}\left(\mathrm{OCCH}_{3}\right)$ ]. ${ }^{10-14}$ The best catalyst developed from our studies on $\mathrm{TpRu}(\mathrm{L})(\mathrm{NCMe}) \mathrm{Ph}$ motif is $\mathrm{TpRu}(\mathrm{CO}) \mathrm{Ph}(\mathrm{NCMe})$, which yields with $415 \mathrm{TO}$ of ethylbenzene at $90{ }^{\circ} \mathrm{C}(0.025 \mathrm{~mol} \%$ Ru relative to benzene) with 15 psi of ethylene after 40 h. ${ }^{15}$ This catalyst functions by a mechanism that includes two key steps, olefin insertion into a $\mathrm{Ru}-\mathrm{Ph}$ bond and benzene $\mathrm{C}-\mathrm{H}$ activation. These two steps require a fine balance of electronics at the metal center. 
Whereas olefin insertion requires a less electron rich metal center, which decreases metal-to-olefin backbonding, benzene $\mathrm{C}-\mathrm{H}$ activation is promoted by more electron-rich metal centers. Experimental studies have found that the electron density of the metal center has a larger impact on the activation barrier for olefin insertion than the activation barrier for benzene $\mathrm{C}-\mathrm{H}$ activation. Results from catalysis demonstrate these effects. While $\mathrm{TpRu}\left(\mathrm{PMe}_{3}\right) \mathrm{Ph}(\mathrm{NCMe})$ activates benzene $\mathrm{C}-\mathrm{H}$ bonds most rapidly among the $\mathrm{TpRu}(\mathrm{L})(\mathrm{NCMe}) \mathrm{Ph}\left[\mathrm{L}=\mathrm{CO}, \mathrm{PMe}_{3}, \mathrm{P}\left(\mathrm{OCH}_{2}\right)_{3} \mathrm{CEt}, \mathrm{P}(\mathrm{pyr})_{3}\right.$ and $\left.\mathrm{P}\left(\mathrm{OCH}_{2}\right)_{2}\left(\mathrm{OCCH}_{3}\right)\right]$ series it is not a catalyst for olefin hydroarylation. ${ }^{10-14}$ The slow rate of ethylene insertion into the $\mathrm{Ru}-\mathrm{Ph}$ of $\mathrm{TpRu}\left(\mathrm{PMe}_{3}\right)\left(\eta^{2}-\mathrm{C}_{2} \mathrm{H}_{4}\right) \mathrm{Ph}$ allows ethylene $\mathrm{C}-\mathrm{H}$ activation to compete with catalytic turnover. Although benzene $\mathrm{C}-\mathrm{H}$ activation by $\mathrm{TpRu}(\mathrm{CO})(\mathrm{NCMe}) \mathrm{Ph}$ is slower than $\mathrm{TpRu}\left(\mathrm{PMe}_{3}\right)(\mathrm{NCMe}) \mathrm{Ph}$, the $\mathrm{CO}$ complex is a catalyst for olefin hydroarylation. $\mathrm{TpRu}\left[\mathrm{P}\left(\mathrm{OCH}_{2}\right)_{2}\left(\mathrm{OCCH}_{3}\right)\right] \mathrm{Ph}(\mathrm{NCMe})$ gives approximately 90 TON with 15 psi of ethylene at $90^{\circ} \mathrm{C}$. However, the metal center is still too electron rich, and olefin $\mathrm{C}-\mathrm{H}$ activation competes with olefin insertion, which reduces catalyst longevity. ${ }^{15,16}$ Thus, we sought an octahedral Ru(II) complex with similar electron density (or less) as $\mathrm{TpRu}(\mathrm{CO})(\mathrm{NCMe}) \mathrm{Ph}$ but without the $\mathrm{CO}$ ligand. Our goals were to improve selectivity for linear alkyl arenes (for olefin hydroarylation using $\alpha$-olefins) and to enhance catalyst stability (the $\mathrm{CO}$ ligand, which can bridge two $\mathrm{Ru}$ metals, might accelerate catalyst decomposition). Modulating the ligand set from the anionic tris(pyrazolyl)borates to the neutral poly(pyrazolyl)alkanes should provide us with a similar steric profile as our previously studied $\mathrm{TpRu}(\mathrm{L})(\mathrm{NCMe}) \mathrm{Ph}$ catalyst but would be less donating to the metal. 
The less donating poly(pyrazolyl)alkane allows the incorporation of more donating ligands but remain less electron rich than $\mathrm{TpRu}(\mathrm{CO}) \mathrm{Ph}(\mathrm{NCMe})$.

Our group has used $\mathrm{Ru}(\mathrm{III} / \mathrm{II})$ potentials (from cyclic voltammetry) to estimate electron density. We have previously shown that by replacing the $\mathrm{Tp}$ ligand in $\mathrm{TpRu}(\mathrm{CO})(\mathrm{NCMe}) \mathrm{Ph}$ with Ep (Ep = tris(pyrazolyl)ethane) shifts $\mathrm{Ru}(\mathrm{III} / \mathrm{II})$ potentials positive approximately $0.38 \mathrm{~V}$ (Figure 5.2). ${ }^{17,18}$ Using the predicted $0.38 \mathrm{~V}$ shift, $\mathrm{EpRu}\left[\mathrm{P}\left(\mathrm{OCH}_{2}\right)_{3} \mathrm{CEt}\right] \mathrm{Ph}(\mathrm{NCMe})$ should exhibit a $\mathrm{Ru}(\mathrm{III} / \mathrm{II})$ potential of $\sim 0.92 \mathrm{~V}$, which is similar to $\mathrm{TpRu}(\mathrm{CO}) \mathrm{Ph}(\mathrm{NCMe})(1.02 \mathrm{~V})$. This chapter describes the synthesis of a variety of $\mathrm{Ru}(\mathrm{II})$ complexes with neutral 6-electron donor ligands such as $\eta^{6}$ - $p$-cymene, $\mathrm{HC}(\mathrm{pz})_{3}\left(\mathrm{pz}{ }^{\prime}=3,5\right.$ dimethylpyrazolyl $)$ and $\mathrm{C}(\mathrm{pz})_{4}(\mathrm{pz}=$ pyrazolyl $)$ methane $)$ and their ability to catalyze olefin hydrophenylation.

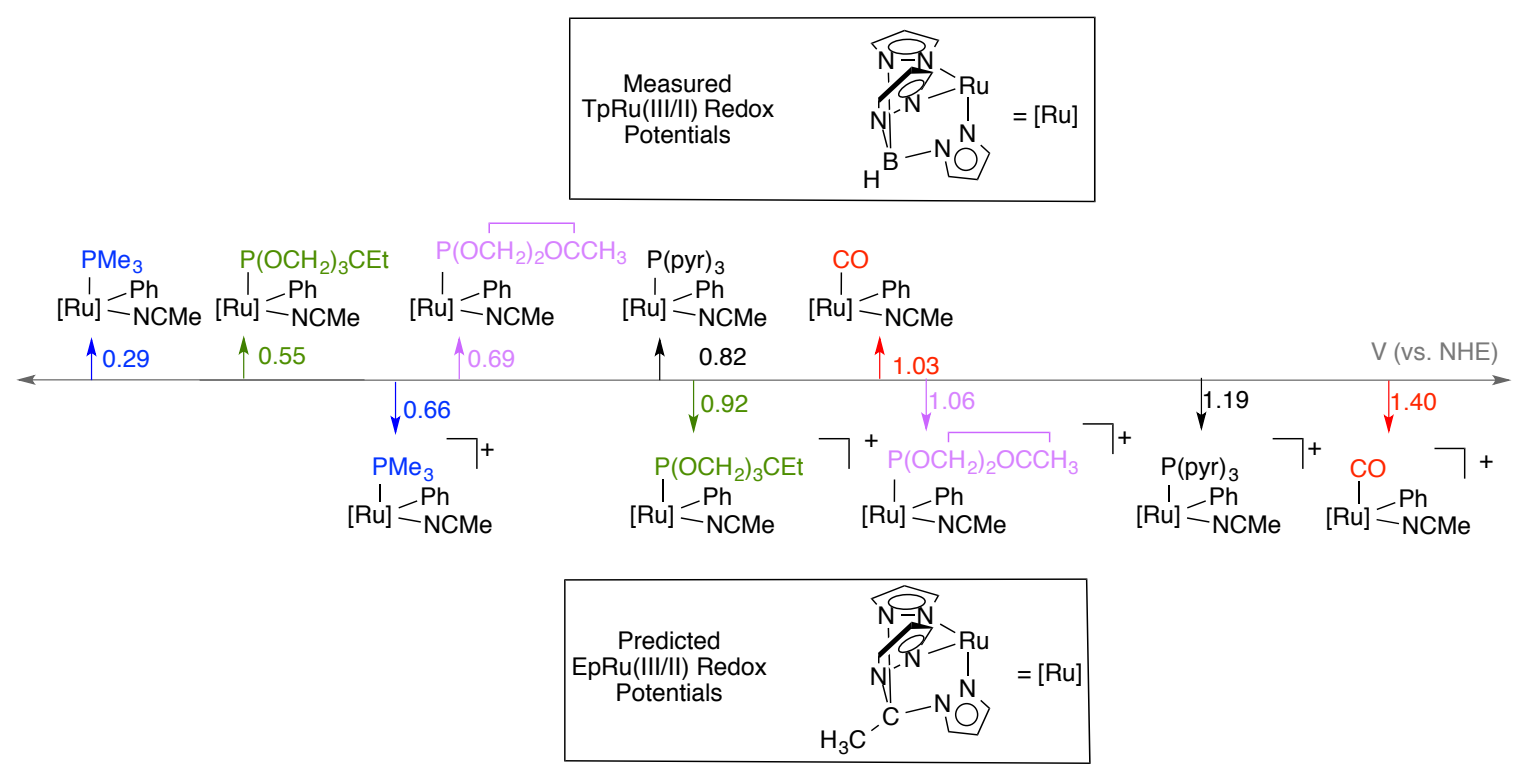

Figure 5.2. Comparison of experimental $\mathrm{Ru}(\mathrm{III} / \mathrm{II})$ (V vs NHE) potentials for $\mathrm{TpRu}(\mathrm{L}) \mathrm{Ph}(\mathrm{NCMe})$ to predicted $\mathrm{Ru}(\mathrm{III} / \mathrm{II})$ (V vs NHE) potentials for $\mathrm{EpRu}(\mathrm{L}) \mathrm{Ph}(\mathrm{NCMe})$. 


\subsection{Results and Discussion}

\subsubsection{Synthesis of $\left(\eta^{6}-p\right.$-cymene $) \operatorname{Ru}(\mathrm{L}) \mathrm{PhBr}$}

The synthesis of $\left[\left(\eta^{6}-p\right.\right.$-cymene $) \mathrm{Ru}\left[\mathrm{P}\left(\mathrm{OCH}_{2}\right)_{2}\left(\mathrm{OCCH}_{3}\right)\right] \mathrm{Br}_{2}$ and $\left[\left(\eta^{6}-p\right.\right.$ cymene $) \mathrm{Ru}\left[\mathrm{P}\left(\mathrm{OCH}_{2}\right)_{2}\left(\mathrm{OCCH}_{3}\right)\right] \mathrm{PhBr}$ were described in Chapter $3 .^{15}$ The complexes $\left(\eta^{6}-\right.$ $p$-cymene $) \mathrm{Ru}\left[\mathrm{P}\left(\mathrm{OCH}_{2}\right)_{3} \mathrm{CEt}\right] \mathrm{Br}_{2}(\mathbf{1}), \quad\left(\eta^{6}-p\right.$-cymene $) \mathrm{Ru}\left[\mathrm{P}\left(\mathrm{OCH}_{2}\right)_{3} \mathrm{CEt}\right] \mathrm{PhBr}(\mathbf{2}), \quad\left(\eta^{6}-p\right.$ cymene $) \mathrm{Ru}\left(\mathrm{PMe}_{3}\right) \mathrm{Cl}_{2}(3)$ and $\left(\eta^{6}-p\right.$-cymene $) \mathrm{Ru}\left(\mathrm{PMe}_{3}\right) \mathrm{Br}_{2}(4)$, were synthesized using a similar procedure. Complexes $\mathbf{1}$ and $\mathbf{3}$ were synthesized by the reaction of $\left[\left(\eta^{6}-p\right.\right.$ cymene $) \mathrm{Ru}(\mathrm{Br})(\mu-\mathrm{Br})]_{2}$ with excess $\mathrm{P}\left(\mathrm{OCH}_{2}\right)_{3} \mathrm{CEt}$ or $\mathrm{PMe}_{3}$, respectively, in methylene chloride (Scheme 5.1). The ${ }^{1} \mathrm{H}$ NMR spectra for both $\mathbf{1}$ and $\mathbf{3}$ are consistent with the presence of a mirror plane with two downfield resonances for the $\left(\eta^{6}-p\right.$-cymene) (Figure 5.3, Figure 5.5). The bicyclic phosphite ligand gives rise to a doublet for the methylene hydrogens and a quartet and triplet upfield for the ethyl group of the phosphite (Figure 5.3, Figure 5.5). The ${ }^{31} \mathrm{P}$ NMR spectrum of 1 shows a resonance at $110 \mathrm{ppm}$ for the $\mathrm{P}\left(\mathrm{OCH}_{2}\right)_{3} \mathrm{CEt}$ ligand. The ${ }^{1} \mathrm{H}$ NMR spectrum for complex 3 has a doublet with a ${ }^{2} J_{\mathrm{HP}}=$ $11 \mathrm{~Hz}$ for the phosphine group, and the ${ }^{31} \mathrm{P}$ NMR spectrum shows a downfield shift to $2.0 \mathrm{ppm}$ for the phosphine (Figure 5.5, Figure 5.6.) 


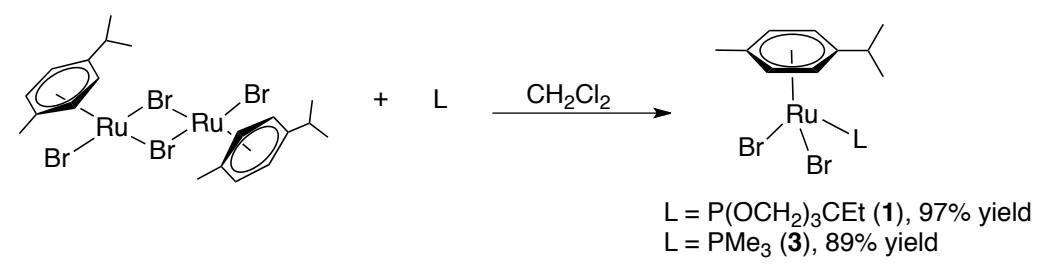

Scheme 5.1. Synthesis of $\left(\eta^{6}-p\right.$-cymene $) \mathrm{Ru}(\mathrm{L}) \mathrm{Br}_{2}\left[\mathrm{~L}=\mathrm{P}\left(\mathrm{OCH}_{2}\right)_{3} \mathrm{CEt}(\mathbf{1})\right.$ or $\left.\mathrm{PMe}_{3}(\mathbf{3})\right]$.

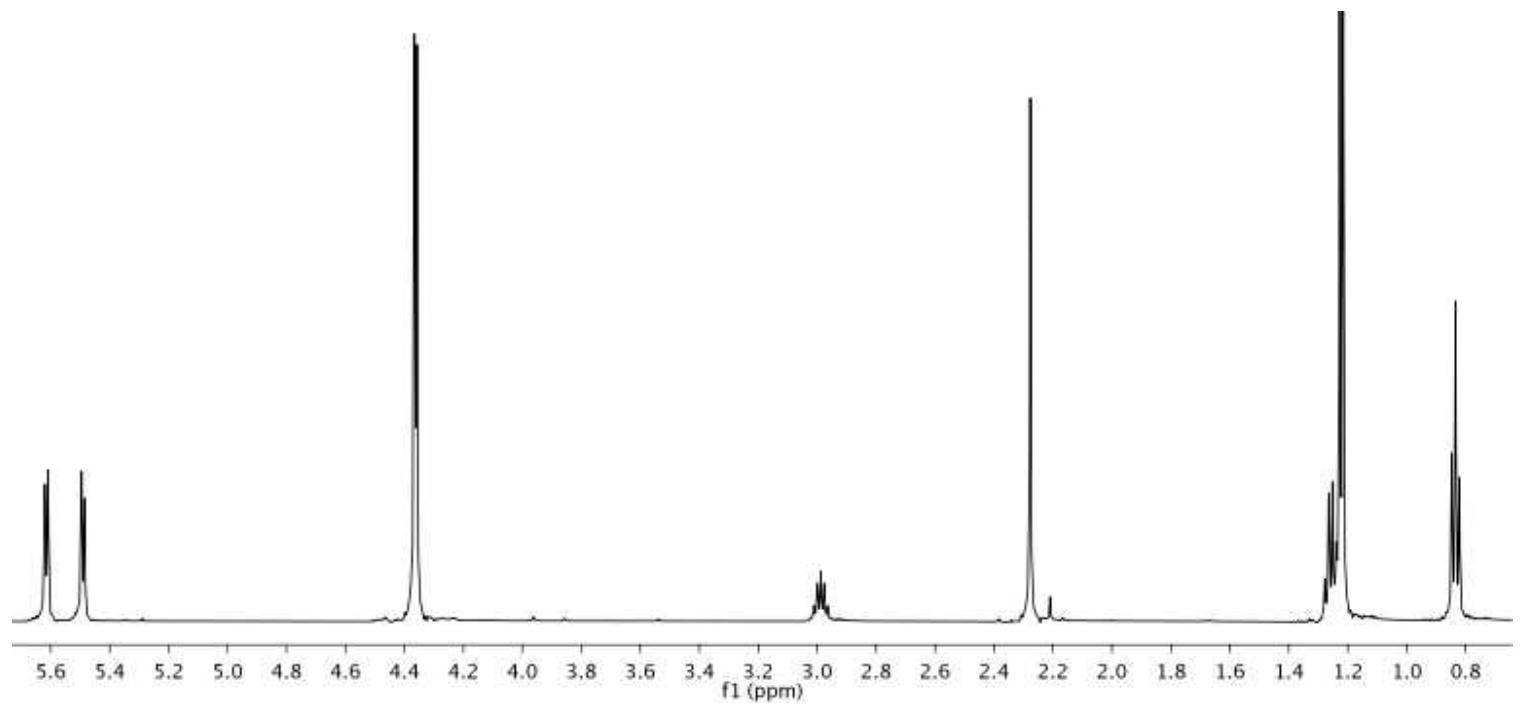

Figure 5.3. ${ }^{1} \mathrm{H}$ NMR spectrum of $\left(\eta^{6}-p\right.$-cymene $) \mathrm{Ru}\left[\mathrm{P}\left(\mathrm{OCH}_{2}\right)_{3} \mathrm{CEt}\right] \mathrm{Br}_{2}(\mathbf{1})$ in $\mathrm{CDCl}_{3}$. 


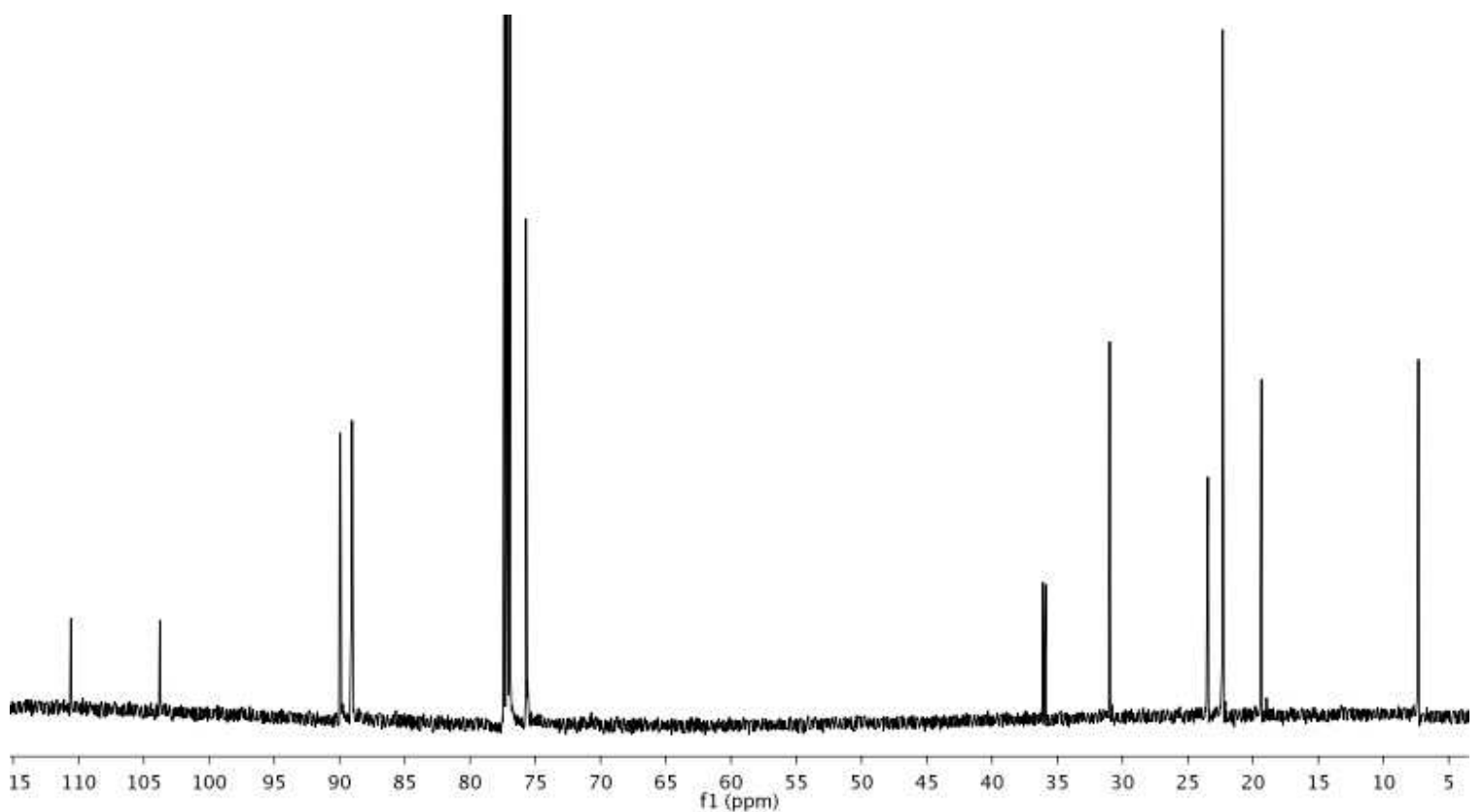

Figure 5.4. ${ }^{13} \mathrm{C}$ NMR spectrum of $\left(\eta^{6}-p\right.$-cymene $) \mathrm{Ru}\left[\mathrm{P}\left(\mathrm{OCH}_{2}\right)_{3} \mathrm{CEt}\right] \mathrm{Br}_{2}(\mathbf{1})$ in $\mathrm{CDCl}_{3}$.

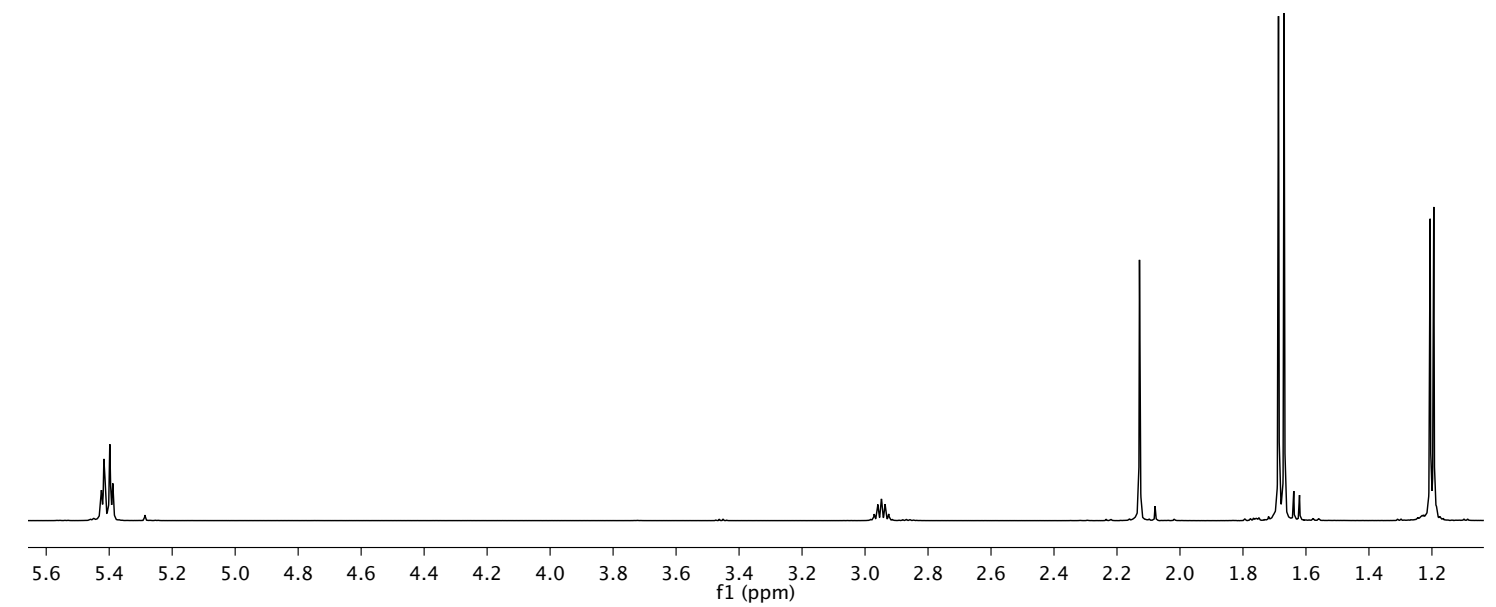

Figure 5.5. ${ }^{1} \mathrm{H}$ NMR spectrum of $\left(\eta^{6}-p\right.$-cymene $) \mathrm{Ru}\left(\mathrm{PMe}_{3}\right) \mathrm{Br}_{2}(3)$ in $\mathrm{CDCl}_{3}$. 


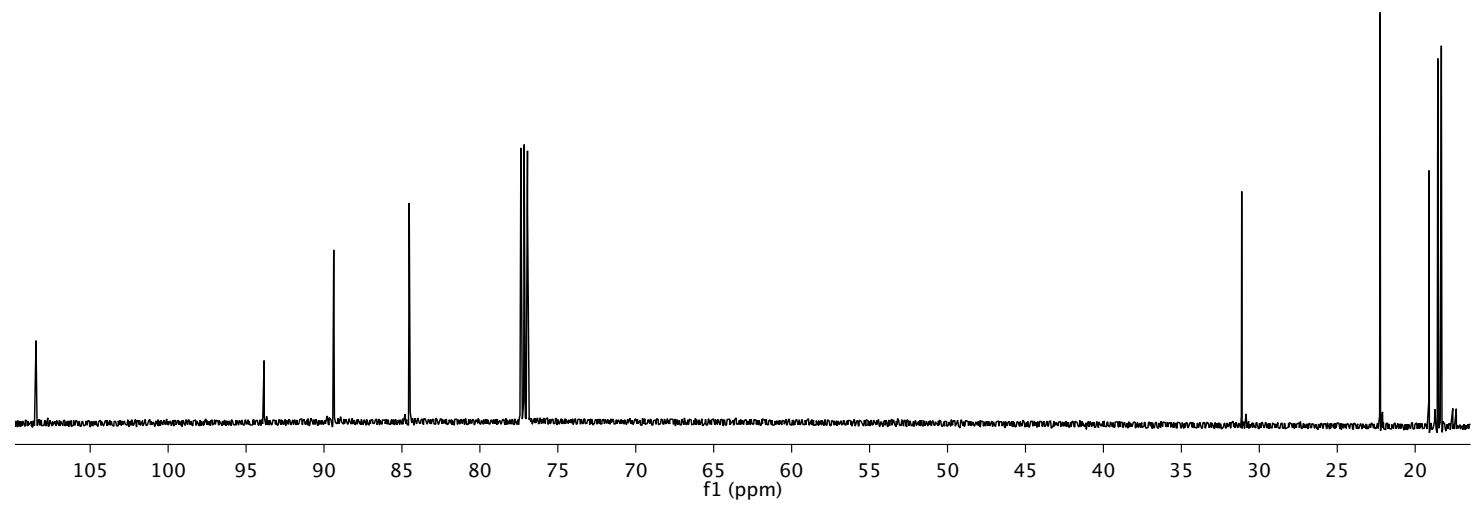

Figure 5.6. ${ }^{13} \mathrm{C}$ NMR spectrum of $\left(\eta^{6}-p\right.$-cymene $) \mathrm{Ru}\left(\mathrm{PMe}_{3}\right) \mathrm{Br}_{2}(3)$ in $\mathrm{CDCl}_{3}$

Complexes 1 and 3 can be phenylated using $\mathrm{Ph}_{2} \mathrm{Mg}[\mathrm{THF}]_{2}$ in THF. Both reactions begin as heterogeneous mixtures and as the product is formed, $\left(\eta^{6}-p\right.$ cymene) $\mathrm{Ru}\left[\mathrm{P}\left(\mathrm{OCH}_{2}\right)_{3} \mathrm{CEt}\right](\mathrm{Ph}) \mathrm{Br}$ (2) (Figure 5.7, Figure 5.8, Figure 5.9) or $\left(\eta^{6}-p\right.$ cymene) $\mathrm{Ru}\left(\mathrm{PMe}_{3}\right)(\mathrm{Ph}) \mathrm{Br}$ (4), (Figure 5.10, Figure 5.11, Figure 5.12), the reaction mixture becomes bright yellow and homogeneous (Scheme 5.2). The formation of the asymmetric complex 2 is apparent in the ${ }^{1} \mathrm{H}$ NMR spectrum with the appearance of 4 downfield resonances $(1 \mathrm{H}$ each) due to the $p$-cymene ligands and three resonances due to the phenyl ligands between 6.8 and $7.7 \mathrm{ppm}$. Additionally, the ${ }^{31} \mathrm{P}$ NMR spectrum shows a resonance at $124 \mathrm{ppm}$, which is a downfield shift of $13 \mathrm{ppm}$ compared to complex $\mathbf{1}$. Similar characteristics are observed in the ${ }^{1} \mathrm{H}$ NMR spectrum of complex 4 , and the phosphine peak in the ${ }^{31} \mathrm{P}$ NMR spectrum is shifted downfield by $\sim 6.6 \mathrm{ppm}$ to $4.5 \mathrm{ppm}$. Single crystals for both $\mathbf{2}$ and $\mathbf{4}$ suitable for X-ray structure determination were obtained by slow diffusion of $\mathrm{Et}_{2} \mathrm{O}$ into a THF solution of the complex (Table 5.1). The $\mathrm{Ru}-\mathrm{P}$ bond length $[2.3105(3) \AA]$ of $\left(\eta^{6}-p\right.$-cymene $) \mathrm{Ru}\left(\mathrm{PMe}_{3}\right) \operatorname{PhBr}(4)$ is longer than for $\left(\eta^{6}-p\right.$ cymene $) \mathrm{Ru}\left(\left[\mathrm{P}\left(\mathrm{OCH}_{2}\right)_{3} \mathrm{CEt}\right] \mathrm{PhBr}(2)[2.2144(3) \AA]\right.$; this could potentially be caused by 
the difference in back-bonding, with the phosphite, $\mathrm{P}\left(\mathrm{OCH}_{2}\right)_{3} \mathrm{CEt}$, being a stronger $\pi$-acid than $\mathrm{PMe}_{3}$. Additionally, sterics could also contribute to the longer $\mathrm{Ru}-\mathrm{P}$ bond distance of 4 since $\mathrm{PMe}_{3}$ has a Tolman's cone angle of $118^{\circ}$ and $\mathrm{P}\left(\mathrm{OCH}_{2}\right)_{3} \mathrm{CEt}$ has a smaller cone angle of $101^{\circ} \cdot{ }^{19}$

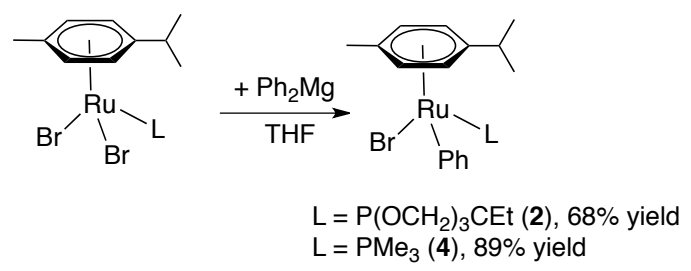

Scheme 5.2. Synthesis of $\left(\eta^{6}-p\right.$-cymene $) \mathrm{Ru}(\mathrm{L}) \mathrm{PhBr}\left[\mathrm{L}=\mathrm{P}\left(\mathrm{OCH}_{2}\right)_{3} \mathrm{CEt}(2)\right.$ or $\left.\mathrm{PMe}_{3}(4)\right]$.

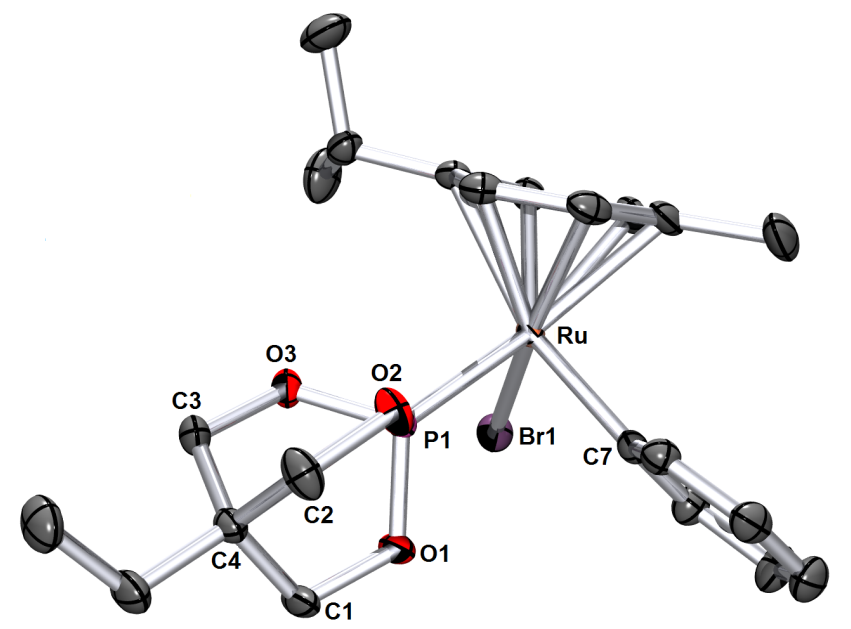

Figure 5.7. ORTEP of $\left(\eta^{6}-p\right.$-cymene $) \mathrm{Ru}\left[\mathrm{P}\left(\mathrm{OCH}_{2}\right)_{3} \mathrm{CEt}\right] \mathrm{PhBr}(2)$ (35\% probability with hydrogen atoms omitted.). Selected bond lengths (A): Ru-P1, 2.2144(3); P-O1, 1.6003(11); $\mathrm{P}-\mathrm{O} 2,1.602(1) ; \mathrm{P}-\mathrm{O} 3,1.6029(1)$. Selected bond angles $\left({ }^{\circ}\right)$ : O3-P1-O2, 102.31(6); O1-P1-O2, 101.88(6); O1-P1-O3, 101.89(6); O1-P1-Ru, 120.62(4); O2-P1$\mathrm{Ru}, 112.98(4) ; \mathrm{O} 3-\mathrm{P} 1-\mathrm{Ru}, 114.78(4)$. 


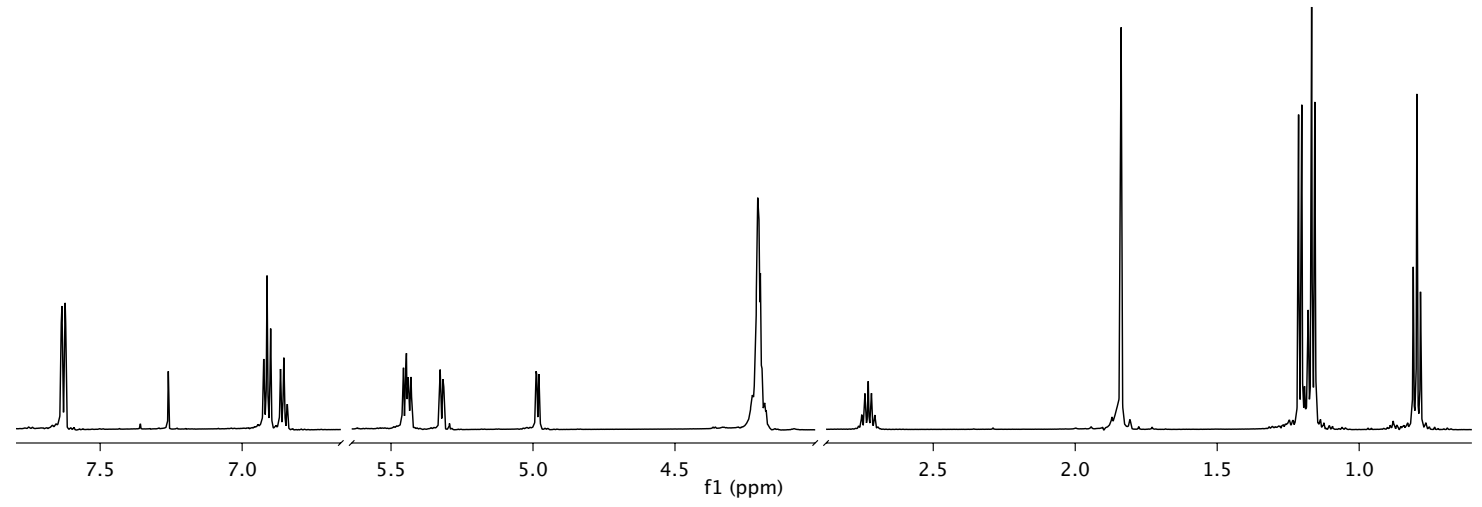

Figure 5.8. ${ }^{1} \mathrm{H}$ NMR spectrum of $\left(\eta^{6}-p\right.$-cymene $) \mathrm{Ru}\left[\mathrm{P}\left(\mathrm{OCH}_{2}\right)_{3} \mathrm{CEt}\right] \mathrm{PhBr}(\mathbf{2})$ in $\mathrm{CDCl}_{3}$.

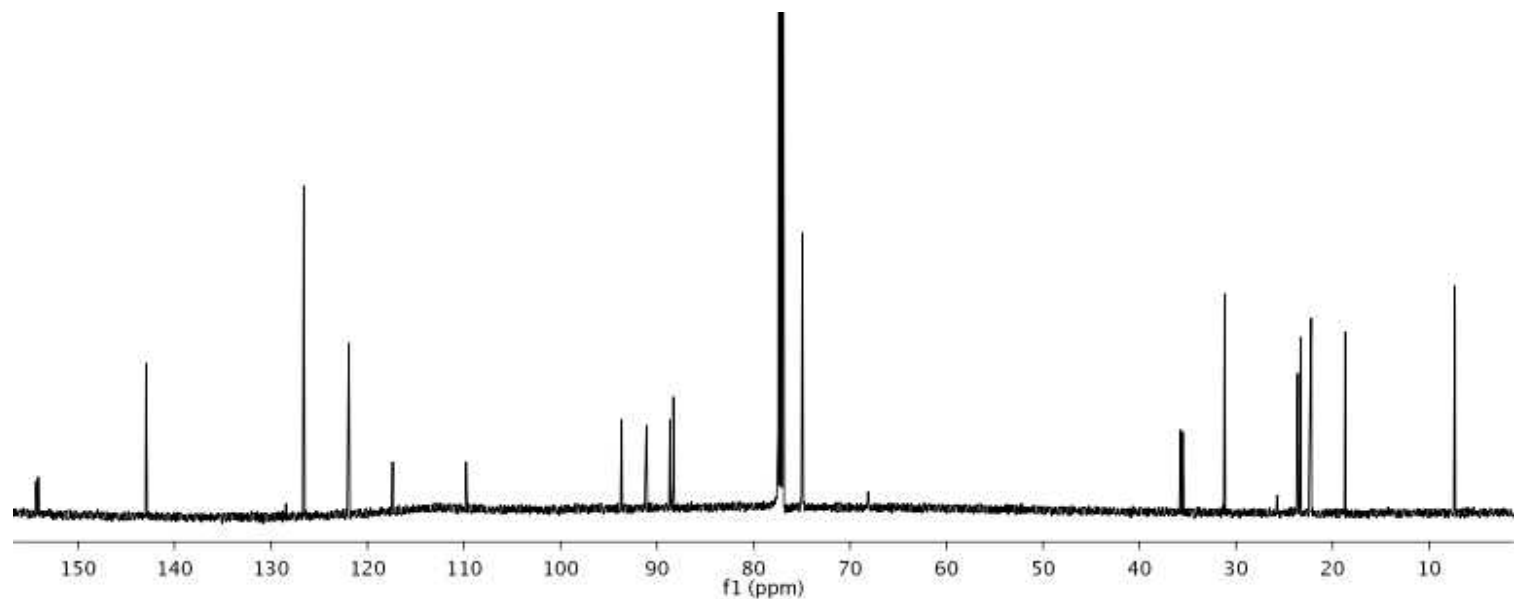

Figure 5.9. ${ }^{13} \mathrm{C}$ NMR spectrum of $\left(\eta^{6}-p\right.$-cymene $) \mathrm{Ru}\left[\mathrm{P}\left(\mathrm{OCH}_{2}\right)_{3} \mathrm{CEt}\right] \mathrm{PhBr}(2)$ in $\mathrm{CDCl}_{3}$. 


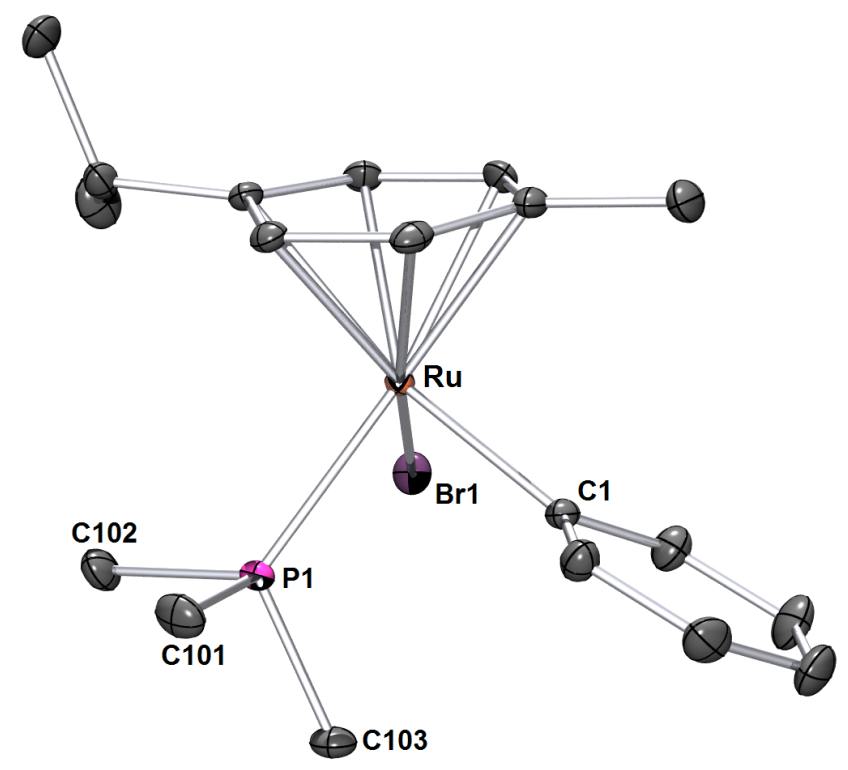

Figure 5.10. ORTEP of $\left(\eta^{6}-p\right.$-cymene $) \mathrm{Ru}(\mathrm{PMe} 3) \mathrm{PhBr}$ (4) (35\% probability with hydrogen atoms omitted.). Selected bond lengths $(\AA)$ : Ru-P1, 2.3105(5). Selected bond angles $\left({ }^{\circ}\right)$ : C101-P1-Ru, 118.19(8); C103-P1-Ru, 116.33(8); C102-P1-Ru, 114.28(8).

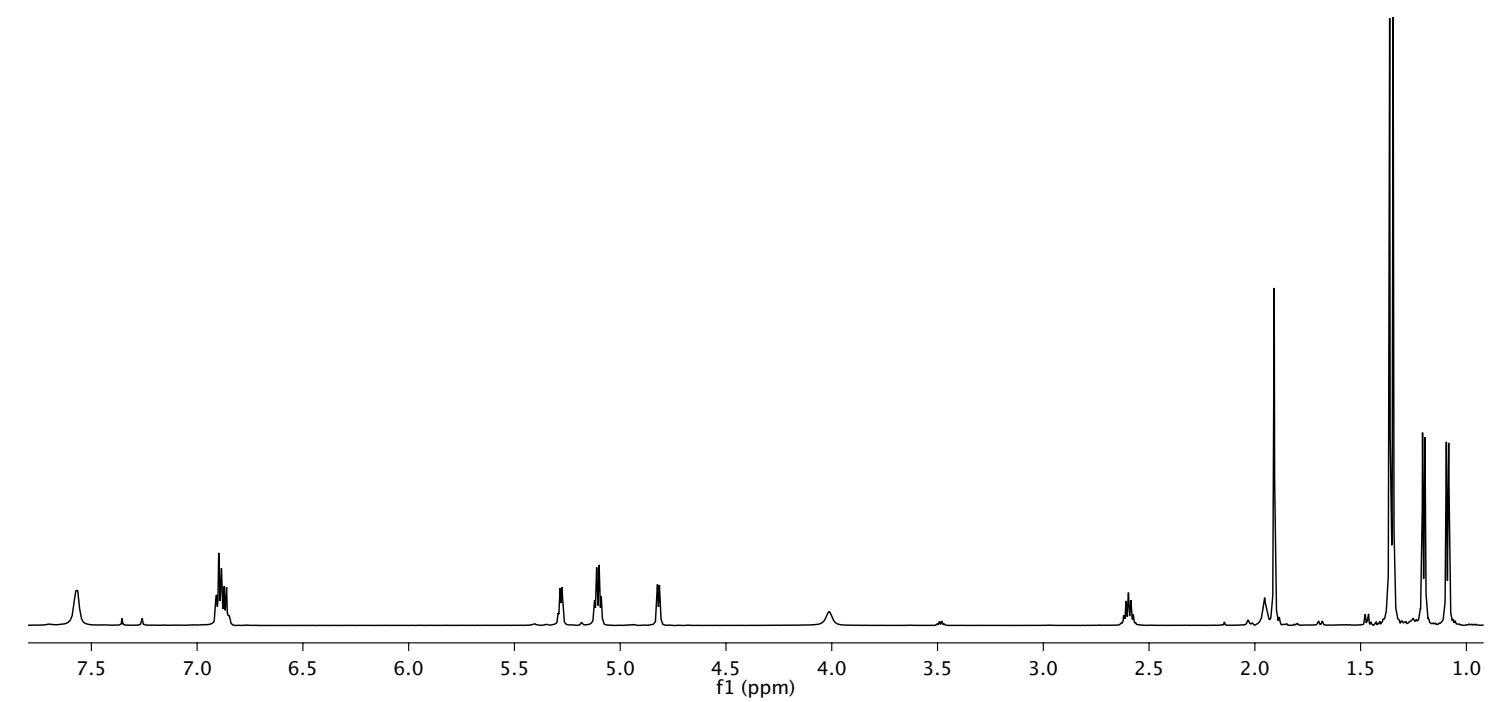

Figure 5.11. ${ }^{1} \mathrm{H} \mathrm{NMR}$ spectrum of $\left(\eta^{6}\right.$-p-cymene $) \mathrm{Ru}\left(\mathrm{PMe}_{3}\right) \mathrm{PhBr}(4)$ in $\mathrm{CDCl}_{3}$. 


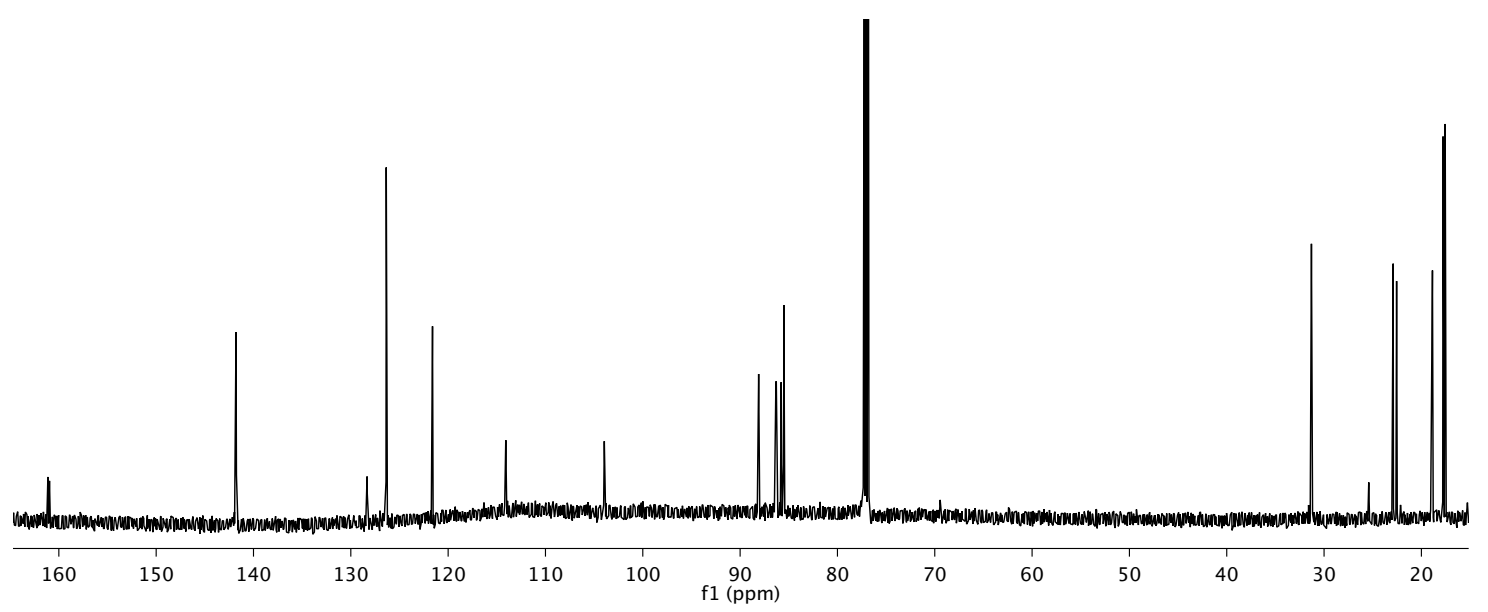

Figure 5.12. ${ }^{13} \mathrm{C}$ NMR spectrum of $\left(\eta^{6}-p\right.$-cymene $) \mathrm{Ru}\left(\mathrm{PMe}_{3}\right) \mathrm{PhBr}(4)$ in $\mathrm{CDCl}_{3}$.

Table 5.1. Selected Crystallographic Data for $\left(\eta^{6}-p\right.$-cymene $) \mathrm{Ru}\left[\mathrm{P}\left(\mathrm{OCH}_{2}\right)_{3} \mathrm{CEt}\right] \mathrm{PhBr}(\mathbf{2})$, and $\left(\eta^{6}-p\right.$-cymene $) \mathrm{Ru}\left(\mathrm{PMe}_{3}\right) \mathrm{PhBr}(4)$

\begin{tabular}{lll}
\hline & complex 2 & complex 4 \\
\hline empirical formula & $\mathrm{C}_{22} \mathrm{H}_{30} \mathrm{BrO}_{3} \mathrm{PRu}$ & $\mathrm{C}_{19} \mathrm{H}_{28} \mathrm{BrPRu}$ \\
Fw & 554.41 & 458.36 \\
cryst syst & monoclinic & monoclinic \\
space group & $P 2_{1} / \mathrm{n}$ & $P 2_{1} / \mathrm{n}$ \\
$\mathrm{a}, \AA$ & $7.1218(2)$ & $7.2196(4)$ \\
$\mathrm{b}, \AA$ & $13.8532(4)$ & $27.801(1)$ \\
$\mathrm{c}, \AA$ & $23.3707(7)$ & $9.6591(5)$ \\
$\beta$, deg & $94.316(1)^{\circ}$ & $92.812(1)$ \\
$\mathrm{V}, \AA^{3}$ & $2299.2(1)$ & $1936.4(2)$ \\
$\mathrm{Z}$ & 4 & 4 \\
$\mathrm{D}_{\text {calcd }}, \mathrm{mg} / \mathrm{m}^{3}$ & 1.602 & 1.607 \\
cryst size $(\mathrm{mm})$ & $0.42 \times 0.18 \times 0.18$ & $0.440 \times 0.340 \times 0.250$ \\
$\mathrm{R} 1, \mathrm{wR} 2(\mathrm{I}>2 \sigma(\mathrm{I}))$ & $0.0272,0.0598$ & $0.0192,0.0441$ \\
$\mathrm{GOF}$ & 1.036 & 1.336 \\
\hline
\end{tabular}

\subsubsection{Olefin hydrophenylation using $\left(\eta^{6}-p\right.$-cymene $) \mathrm{Ru}(\mathrm{L}) \mathrm{PhBr}$}

Initial attempts to isolate the cationic $\mathrm{Ru}(\mathrm{II})$ complexes $\left(\eta^{6}-p\right.$ cymene $) \mathrm{Ru}(\mathrm{L}) \mathrm{Ph}\left(\mathrm{L}^{\prime}\right)\left[\mathrm{BAr}{ }_{4}\right]$ and $\left(\eta^{6}-p\right.$-cymene $) \mathrm{Ru}(\mathrm{L}) \mathrm{Ph}(\mathrm{OTf})\left[\mathrm{L}=\mathrm{P}\left(\mathrm{OCH}_{2}\right)_{3} \mathrm{CEt}\right.$ or 
$\mathrm{PMe}_{3}, \mathrm{Ar}_{4}=3,5-\left(\mathrm{CF}_{3}\right)_{2}-\mathrm{C}_{6} \mathrm{H}_{3}$ and $\mathrm{L}^{\prime}=\mathrm{NCMe}$ or THF] were unsuccessful. For example, reactions were run with complex 2 and a range of halide abstracters (e.g., NaBAr' ${ }_{4}$, $\mathrm{AgBAr}_{4}$, NaOTf, TlOTf, KOTf) in THF or NCMe; however, all conditions lead to no reaction. This was due to being unable to abstract the halide under conditions that would not displace the $\left(\eta^{6}-p\right.$-cymene) ligand and cause decomposition. Therefore, ethylene hydrophenylation was attempted under catalytic conditions using complexes $\mathbf{2}$ or $\mathbf{4}$ in the presence of a halide abstractor (e.g., $\mathrm{NaBAr}_{4}, \mathrm{AgOTf}_{\text {or }} \mathrm{AgBAr}_{4}$ ). Both complexes gave irreproducible results with all of the halide abstractors. For example, four separate catalysis runs at $0.025 \mathrm{~mol} \%$ complex 2,25 psi of ethylene, and $<1$ equiv. $\mathrm{NaBAr}_{4}{ }_{4}$ at 90 ${ }^{\circ} \mathrm{C}$ gave an average of $13( \pm 16)$ TO of ethylbenzene. NMR scale reactions showed that free $p$-cymene is formed under conditions of catalysis. The lability of the $p$-cymene ligand has been shown with a similar species described in Chapter 3 . In the presence of NCMe the $p$-cymene ligand of $\left[\left(\eta^{6}-p\right.\right.$-cymene $) \mathrm{Ru}\left[\mathrm{P}\left(\mathrm{OCH}_{2}\right)_{2}\left(\mathrm{OCCH}_{3}\right)\right] \mathrm{PhBr}$ is displaced and $(\mathrm{NCMe})_{3} \mathrm{Ru}\left[\mathrm{P}\left(\mathrm{OCH}_{2}\right)_{2}\left(\mathrm{OCCH}_{3}\right)\right](\mathrm{Ph}) \mathrm{Br}$ is formed. Moreover, addition of free $p$ cymene does slow the rate of decomposition, but no catalysis was observed.

\subsubsection{Synthesis of $\left\{\left[\mathrm{C}(\mathrm{pz})_{4}\right] \mathrm{Ru}\left[\mathrm{P}\left(\mathrm{OCH}_{2}\right)_{3} \mathrm{CEt}\right] \mathrm{Ph}(\mathrm{NCMe})\right\}[\mathrm{Y}]$ Complexes}

In order to study the effect of having a charge neutral ligand similar to Tp, we sought to synthesize $\mathrm{C}(\mathrm{pz})_{4} \mathrm{Ru}(\mathrm{II})$ complexes where $\mathrm{C}(\mathrm{pz})_{4}=\kappa^{3}-N, N, N$-tetrakis $(1-$ pyrazolyl)methane. A potential synthetic route to the desired precatalyst, $\left[\mathrm{C}(\mathrm{pz})_{4}\right] \mathrm{Ru}\left[\mathrm{P}\left(\mathrm{OCH}_{2}\right)_{3} \mathrm{CEt}\right] \mathrm{Ph}(\mathrm{NCMe})\left[\mathrm{BAr}_{4}\right]$, is similar to the synthesis discussed in Chapter 3 for $\mathrm{TpRu}\left[\mathrm{P}\left(\mathrm{OCH}_{2}\right)_{2}\left(\mathrm{OCCH}_{3}\right)\right](\mathrm{Ph})(\mathrm{NCMe})$. The reaction of $\left(\eta^{6}-p\right.$ - 
cymene $) \mathrm{Ru}\left[\left(\mathrm{P}\left(\mathrm{OCH}_{2}\right)_{3} \mathrm{CEt}\right] \mathrm{PhBr}\right.$ with $\mathrm{NCMe}$ leads to the displacement of $p$-cymene and coordination of $\mathrm{NCMe}$ to form the tris-acetonitrile species $(\mathrm{NCMe})_{3} \mathrm{Ru}\left[\mathrm{P}\left(\mathrm{OCH}_{2}\right)_{3} \mathrm{CEt}\right] \mathrm{PhBr}(5)$ (Scheme 5.3, Figure 5.13).

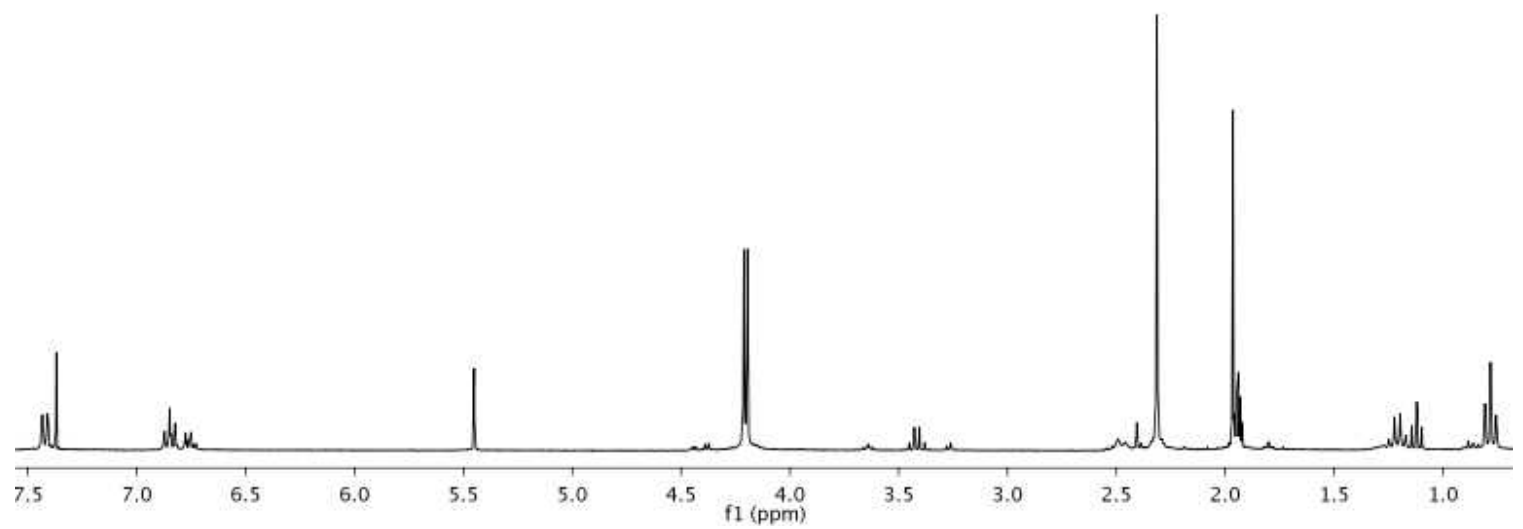

Figure 5.13. ${ }^{1} \mathrm{H}$ NMR spectrum of $(\mathrm{NCMe})_{3} \mathrm{Ru}\left[\mathrm{P}\left(\mathrm{OCH}_{2}\right)_{3} \mathrm{CEt}\right] \mathrm{PhBr}(\mathbf{5})$ in $\mathrm{CD}_{3} \mathrm{CN}$.

The reaction of complex 3 or complex 5 with $\mathrm{C}(\mathrm{pz})_{4}$ in $\mathrm{NCMe}$ leads to the formation of a new species. Following the reaction of complex $\mathbf{3}$ and $\mathrm{C}(\mathrm{pz})_{4}$ by ${ }^{1} \mathrm{H} \mathrm{NMR}$ spectroscopy reveals the formation of free $p$-cymene; however, the formation of free benzene and disappearance of the phenyl resonances were also observed (Figure 5.14). 


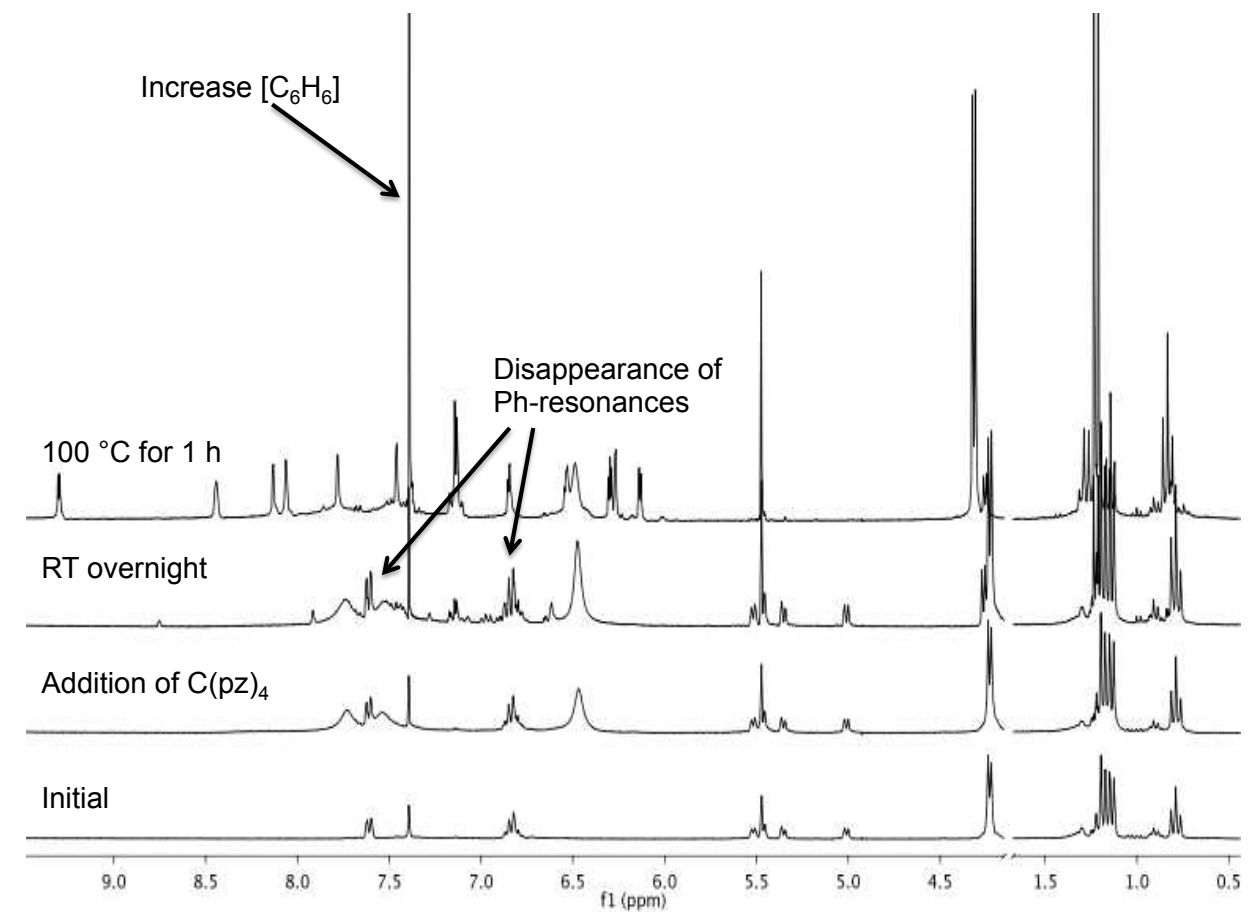

Figure 5.14. The reaction of $\left(\eta^{6}-p\right.$-cymene $) \mathrm{Ru}\left[\mathrm{P}\left(\mathrm{OCH}_{2}\right)_{3} \mathrm{CEt}\right] \mathrm{PhBr}(\mathbf{2})$ and $\mathrm{C}(\mathrm{pz})_{4}$ in NCMe at $90{ }^{\circ} \mathrm{C}$.

The formation of benzene upon reaction of 2 with $\mathrm{C}(\mathrm{pz})_{4}$ is clear evidence of a $\mathrm{C}-$ $\mathrm{H}$ activation process. ${ }^{1} \mathrm{H}$ NMR of the $\mathrm{Ru}$ product revealed only 11 resonances for the $\mathrm{C}(\mathrm{pz})_{4}$, yet 12 resonances were observed in ${ }^{13} \mathrm{C}$ NMR spectrum, with one of the pyrazolyl resonances split into a doublet with a ${ }^{2} J_{\mathrm{CP}}=18 \mathrm{~Hz}$. These data are consistent with $\mathrm{C}-\mathrm{H}$ activation of the 5-position of the pyrazolyl ring leading to the displacement of free benzene and the formation of a $\left(\kappa^{3}-N, C^{5}, N\right) \mathrm{C}(\mathrm{pz})_{4} \mathrm{Ru}\left[\mathrm{P}\left(\mathrm{OCH}_{2}\right)_{3} \mathrm{CEt}\right](\mathrm{NCMe}) \mathrm{Br}$ (6) (Scheme 5.3, Figure 5.15, and Figure 5.16). There are at least two previous examples of $\mathrm{C}-\mathrm{H}$ activation of the 5-position of the pyrazolyl ring. $\operatorname{Tp} \operatorname{Ir}\left(\mathrm{PPh}_{3}\right)\left(\mathrm{C}_{2} \mathrm{H}_{4}\right)$ and $\mathrm{HC}(\mathrm{pz})_{3} \operatorname{Ir}\left(\mathrm{PPh}_{3}\right)\left(\mathrm{C}_{2} \mathrm{H}_{4}\right)\left[\mathrm{BF}_{4}\right]$ in the presence of $\mathrm{PPh}_{3}$ in methylene chloride yield the 
cyclometalated species, $\left(N, C^{5}, N\right) \operatorname{TpIr}\left(\mathrm{PPh}_{3}\right)_{2} \mathrm{H}$ and $\left(N, C^{5}, N\right) \mathrm{HC}(\mathrm{pz})_{3} \operatorname{Ir}\left(\mathrm{PPh}_{3}\right)_{2} \mathrm{H}\left[\mathrm{BF}_{4}\right]$, respectively (Scheme 5.4). 19,20

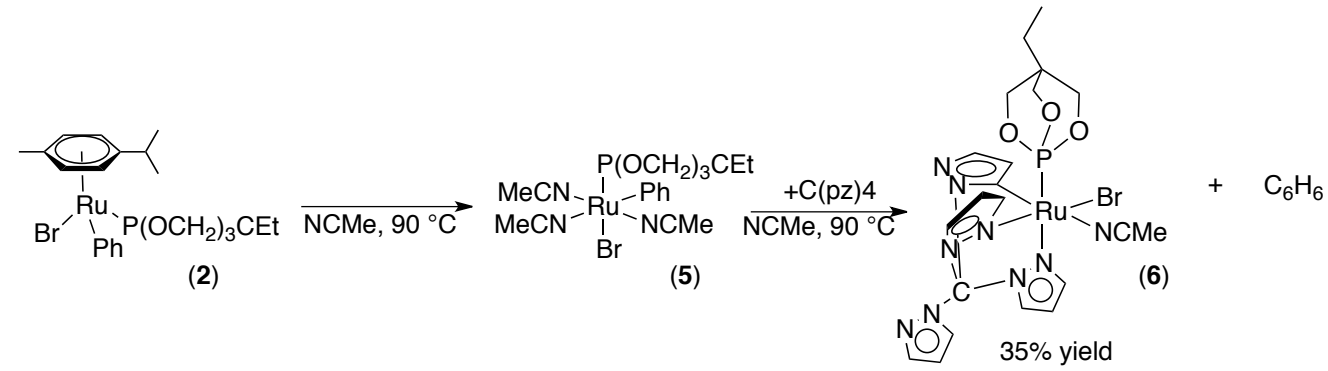

Scheme 5.3. Synthesis of $\left(\kappa^{3}-N, C^{5}, N\right) C(\mathrm{pz})_{4} \mathrm{Ru}\left[\mathrm{P}\left(\mathrm{OCH}_{2}\right)_{3} \mathrm{CEt}\right](\mathrm{NCMe}) \mathrm{Br}(\mathbf{6})$.

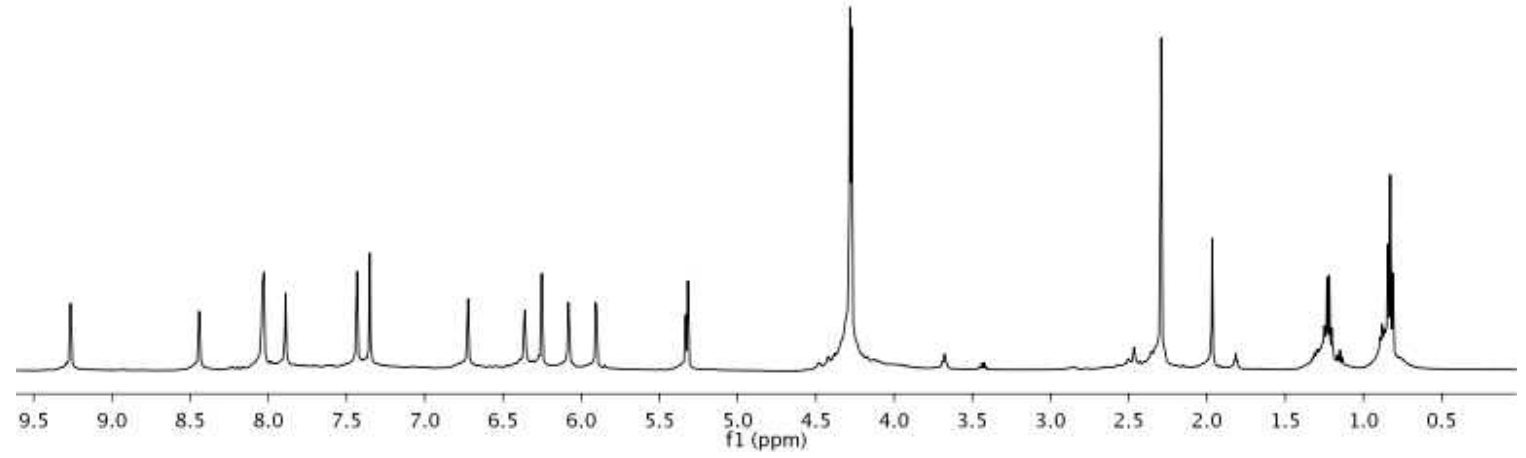

Figure 5.15. ${ }^{1} \mathrm{H}$ NMR spectrum of $\left(\kappa^{3}-N, C^{5}, N\right) \mathrm{C}(\mathrm{pz})_{4} \mathrm{Ru}\left[\mathrm{P}\left(\mathrm{OCH}_{2}\right)_{3} \mathrm{CEt}\right](\mathrm{NCMe}) \mathrm{Br}(\mathbf{6})$ in $\mathrm{CD}_{2} \mathrm{Cl}_{2}$. 

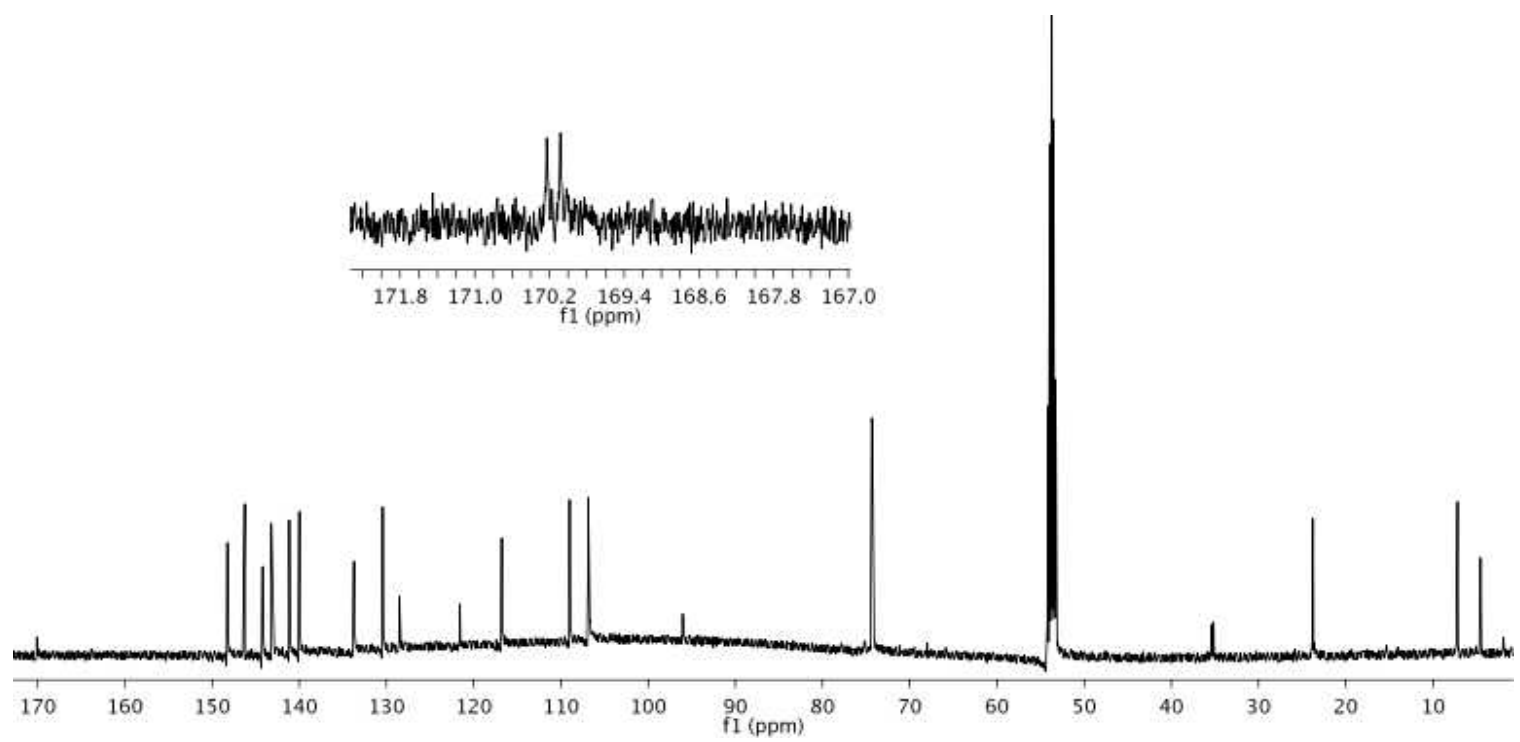

Figure 5.16. ${ }^{13} \mathrm{C}$ NMR spectrum of $\left(\kappa^{3}-N, C^{5}, N\right) \mathrm{C}(\mathrm{pz})_{4} \mathrm{Ru}\left[\mathrm{P}\left(\mathrm{OCH}_{2}\right)_{3} \mathrm{CEt}\right](\mathrm{NCMe}) \mathrm{Br}(\mathbf{6})$ in $\mathrm{CD}_{2} \mathrm{Cl}_{2}$.

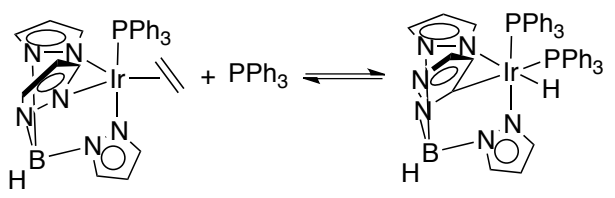

Scheme 5.4. C-H activation of 5-position of the Tp pyrazolyl ring in $\operatorname{Tp} \operatorname{Ir}\left(\mathrm{PPh}_{3}\right)\left(\mathrm{C}_{2} \mathrm{H}_{4}\right){ }^{19}$

Attempts to replace the bromide ligand of $\mathbf{6}$ with a phenyl or a triflate $\left(\mathrm{Ph}_{2} \mathrm{Mg}[\mathrm{THF}]_{2}, \mathrm{PhMgBr}, \mathrm{PhLi}, \mathrm{MeLi}\right.$, AgOTf, TlOTf, and TMSOTf $)$ under a variety of reaction conditions did not proceed cleanly or, in some cases, only starting material was recovered. Therefore, another synthetic route or an analogous complex of another neutral tris(pyrazoly)alkane was sought.

\subsubsection{Synthesis of $\left\{\left[\mathrm{HC}\left(\mathrm{pz}^{\prime}\right)_{3}\right] \mathrm{Ru}\left[\mathrm{P}\left(\mathrm{OCH}_{2}\right)_{3} \mathrm{CEt}\right] \mathrm{Ph}(\mathrm{NCMe})\right\}[Y]$ Complexes $\left(\mathrm{pz}^{\prime}=\right.$ 3,5-dimethyl-pyrazolyl and $\mathrm{Y}=\mathrm{Br}, \mathrm{BAr}_{4}^{\prime}, \mathrm{BF}_{4}$ or $\mathrm{PF}_{6}$ )}

Due to the undesirable $\mathrm{C}-\mathrm{H}$ activation of the 5-position on the pyrazolyl ring upon the reaction of $\mathbf{2}$ with $\mathrm{C}(\mathrm{pz})_{4}$, we targeted replacement of the hydrogen in the 5- 
position with a methyl group. Therefore, reactions were run using $\mathrm{HC}\left(\mathrm{pz}^{\prime}\right)_{3}\left(\mathrm{pz}^{\prime}=3,5-\right.$ dimethyl-pyrazolyl) as a neutral tridentate ligand. As stated above, refluxing complex 2 in $\mathrm{NCMe}$ yields $(\mathrm{NCMe})_{3} \mathrm{Ru}\left[\mathrm{P}\left(\mathrm{OCH}_{2}\right)_{3} \mathrm{CEt}\right] \mathrm{PhBr}(\mathbf{5})$. Heating complex 5 in methylene chloride in a sealed pressure tube with 1.2 equivalent of $\mathrm{HC}\left(\mathrm{pz}^{\prime}\right)_{3}$ for 1.5 hours leads to clean formation of $\left\{\left[\mathrm{HC}\left(\mathrm{pz}^{\prime}\right)_{3}\right] \mathrm{Ru}\left[\mathrm{P}\left(\mathrm{OCH}_{2}\right)_{3} \mathrm{CEt}\right] \mathrm{Ph}(\mathrm{NCMe})\right\}[\mathrm{Br}]$ (7). Heating complex 7 in deuterated acetonitrile results in the disappearance of the resonance at $1.41 \mathrm{ppm}$, which is assigned as coordinated NCMe. The product can be purified by removal of methylene chloride, washing the remaining solid with benzene, the solid was dissolved in methylene chloride and precipitating with pentane to yield a tan solid in 53\% yield (Scheme 5.5, Figure 5.17, Figure 5.18).

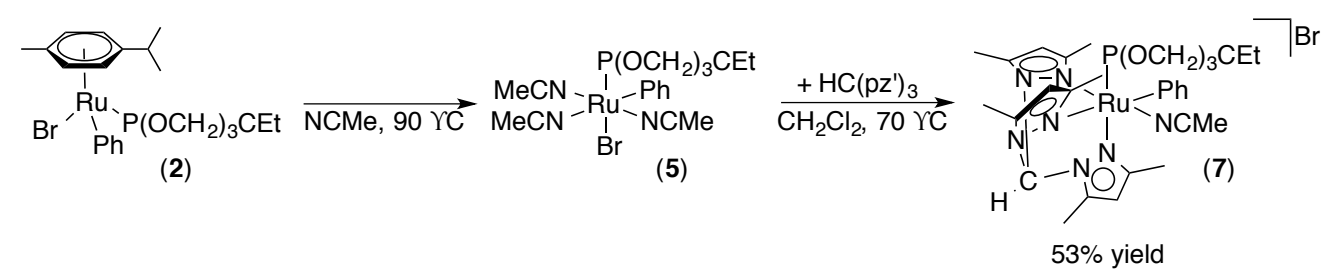

Scheme 5.5. Synthesis of $\left\{\left[\mathrm{HC}\left(\mathrm{pz}^{\prime}\right)_{3}\right] \mathrm{Ru}\left[\mathrm{P}\left(\mathrm{OCH}_{2}\right)_{3} \mathrm{CEt}\right] \mathrm{Ph}(\mathrm{NCMe})\right\}[\mathrm{Br}](7)$. 


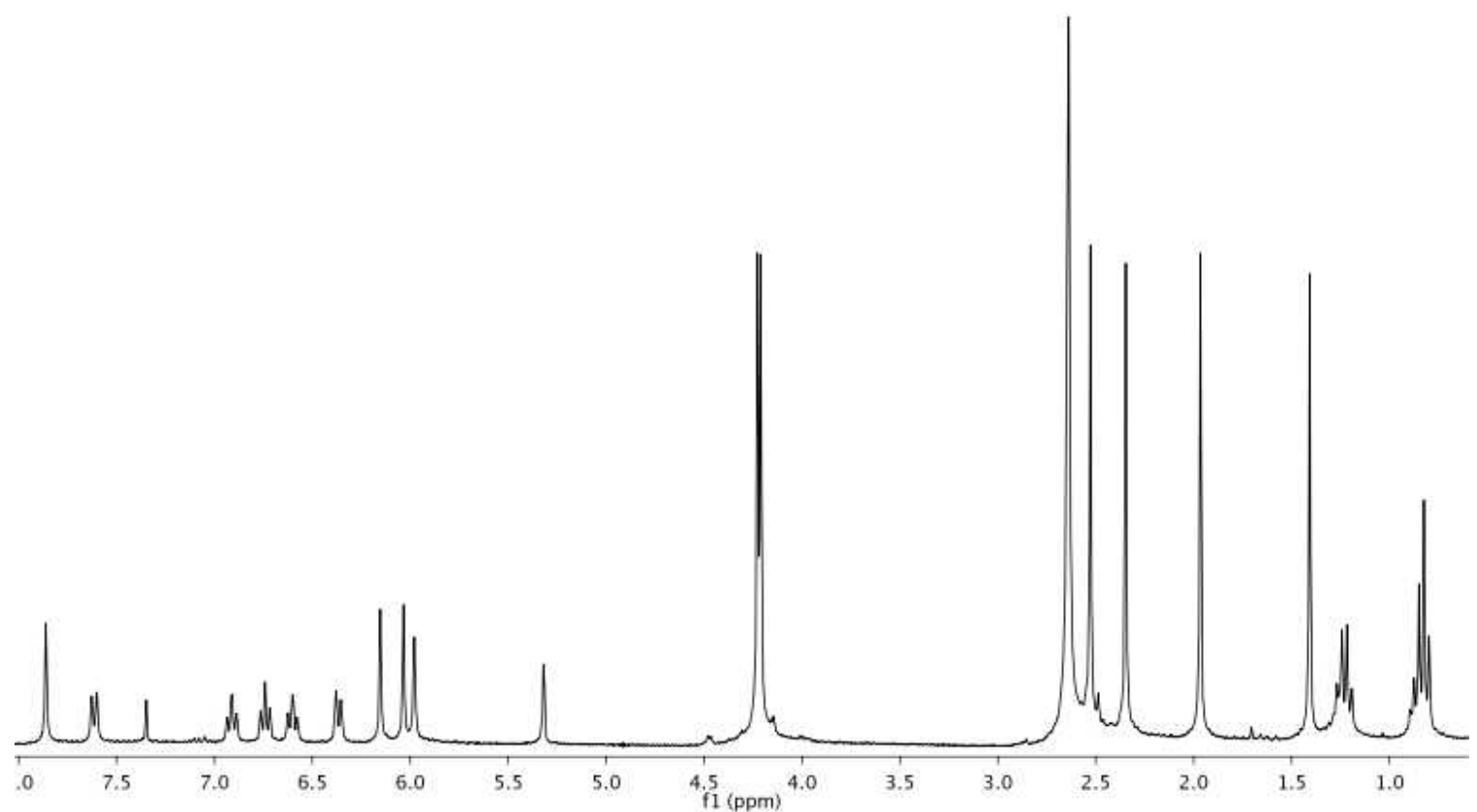

Figure 5.17. ${ }^{1} \mathrm{H}$ NMR spectrum of $\left\{\left[\mathrm{HC}\left(\mathrm{pz}^{\prime}\right)_{3}\right] \mathrm{Ru}\left[\mathrm{P}\left(\mathrm{OCH}_{2}\right)_{3} \mathrm{CEt}\right] \mathrm{Ph}(\mathrm{NCMe})\right\}[\mathrm{Br}](7)$ in $\mathrm{CD}_{2} \mathrm{Cl}_{2}$.

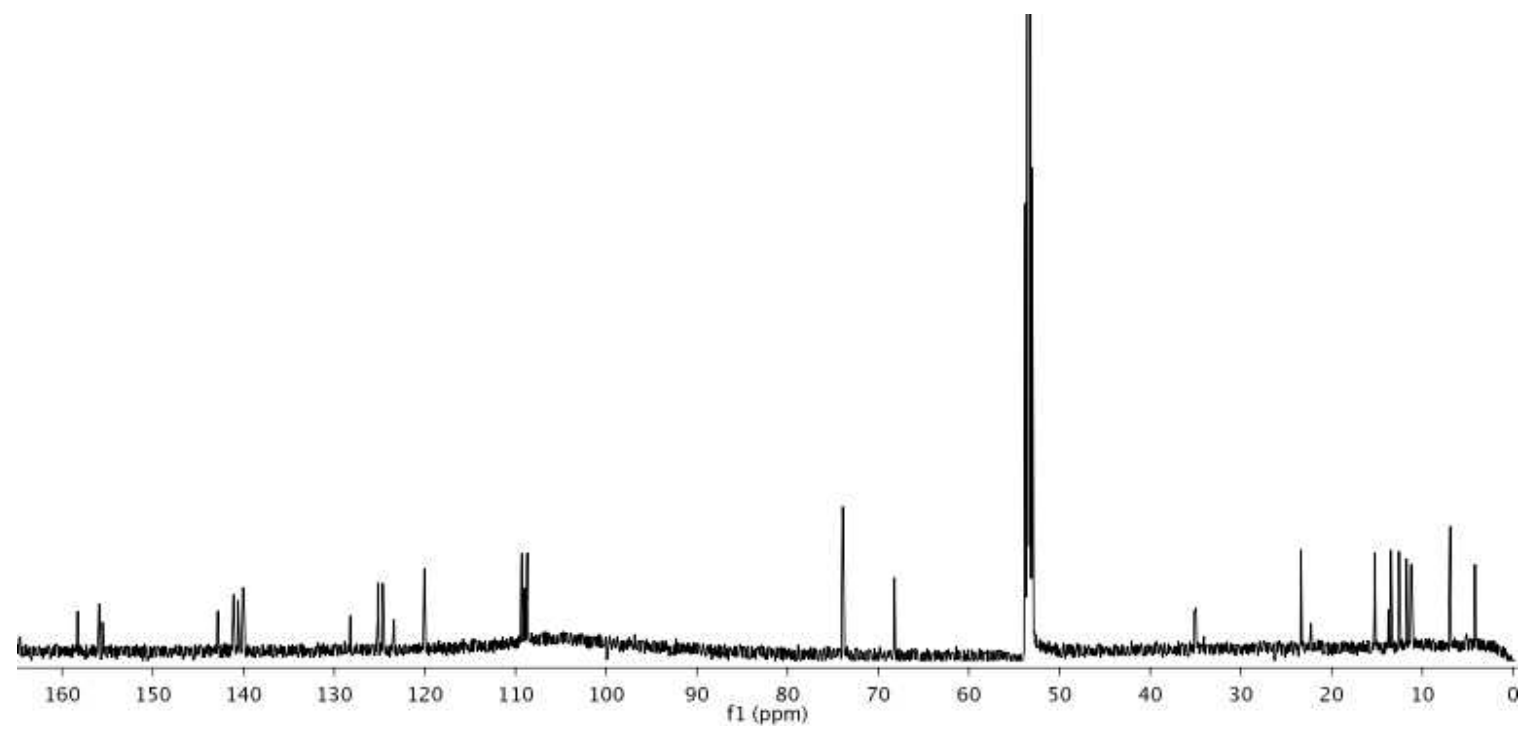

Figure 5.18. ${ }^{13} \mathrm{C}$ NMR spectrum for $\left\{\left[\mathrm{HC}\left(\mathrm{pz}^{\prime}\right)_{3}\right] \mathrm{Ru}\left[\mathrm{P}\left(\mathrm{OCH}_{2}\right)_{3} \mathrm{CEt}\right] \mathrm{Ph}(\mathrm{NCMe})\right\}[\mathrm{Br}](7)$ in $\mathrm{CD}_{2} \mathrm{Cl}_{2}$. 
The lack of solubility of complex 7 in benzene inhibited catalytic olefin hydroarylation. Therefore, the bromide counter-ion was replaced using $\mathrm{NaBAr}_{4}$ to increase the complex's solubility in benzene. Complex 7 in the presence of 1 equivalent of $\mathrm{NaBAr}_{4}$ in $\mathrm{THF}$ results in clean conversion to $\left\{\left[\mathrm{HC}\left(\mathrm{pz}^{\prime}\right)_{3}\right] \mathrm{Ru}\left[\mathrm{P}\left(\mathrm{OCH}_{2}\right)_{3} \mathrm{CEt}\right] \mathrm{Ph}(\mathrm{NCMe})\right\}\left[\mathrm{BAr}_{4}\right]$ (8) (Scheme 5.7, Figure 5.19, Figure 5.20). Complex 8 gives a Ru(III/II) $\mathrm{E}_{1 / 2}$ potential of $0.82 \mathrm{~V}$ vs NHE, which is close to the $\mathrm{Ru}(\mathrm{III} / \mathrm{II})$ potential $(1.02 \mathrm{~V})$ of $\mathrm{TpRu}(\mathrm{CO})(\mathrm{NCMe}) \mathrm{Ph}$ and is approximately a $0.13 \mathrm{~V}$ positive shift compared to $\mathrm{TpRu}\left[\mathrm{P}\left(\mathrm{OCH}_{2}\right)_{3} \mathrm{CEt}\right] \mathrm{Ph}(\mathrm{NCMe})(0.69 \mathrm{~V}$ vs NHE$) .{ }^{12}$ Although this is not as significant of a decrease in electron density as we expected (see above), this does provide a catalyst that is electronically identical to $\mathrm{TpRu}\left[\mathrm{P}(\mathrm{pyr})_{3}\right] \mathrm{Ph}(\mathrm{NCMe})^{10}$ but with a less sterically bulky two electron donor ligand (albeit, with a more bulky poly(pyrazolyl)ligand). Complex $\mathbf{8}$ demonstrated significantly increased solubility in benzene compared to complex 7. Therefore, ethylene hydrophenylation was attempted at $90{ }^{\circ} \mathrm{C}$ with both 15 and 25 psi of ethylene. Unfortunately, no production of ethylbenzene or styrene was observed. During attempted catalysis, complex 8 was observed to oil out of solution. Increasing the temperature to $105{ }^{\circ} \mathrm{C}$ with $25 \mathrm{psi}$ of ethylene or propylene yielded minimal TON of ethylbenzene and no $n$-propylbenzene or cumene, respectively.

Similar to the reaction with $\mathrm{NaBAr}_{4}^{\prime}$, the bromide counter-ion from complex 7 can be abstracted using $\mathrm{NaBF}_{4}$ or $\mathrm{NaPF}_{6}$ to yield $\left\{\left[\mathrm{HC}\left(\mathrm{pz}^{\prime}\right)_{3}\right] \mathrm{Ru}\left[\mathrm{P}\left(\mathrm{OCH}_{2}\right)_{3} \mathrm{CEt}\right] \mathrm{Ph}(\mathrm{NCMe})\right\}\left[\mathrm{BF}_{4}\right] \quad$ and $\left\{\left[\mathrm{HC}\left(\mathrm{pz}^{\prime}\right)_{3}\right] \mathrm{Ru}\left[\mathrm{P}\left(\mathrm{OCH}_{2}\right)_{3} \mathrm{CEt}\right] \mathrm{Ph}(\mathrm{NCMe})\right\}\left[\mathrm{PF}_{6}\right]$, respectively (Scheme 5.7). However, 
both complexes are insoluble in benzene. Therefore, the complexes could not be used for olefin hydrophenylation.

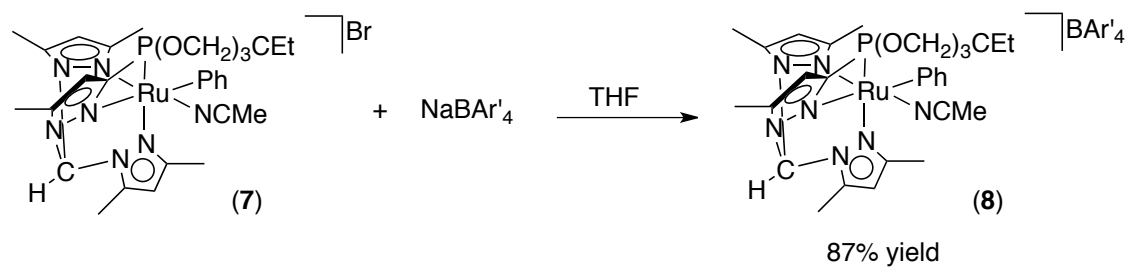

Scheme 5.6. Synthesis of $\left\{\left[\mathrm{HC}\left(\mathrm{pz}^{\prime}\right)_{3}\right] \mathrm{Ru}\left[\mathrm{P}\left(\mathrm{OCH}_{2}\right)_{3} \mathrm{CEt}\right] \mathrm{Ph}(\mathrm{NCMe})\right\}\left[\mathrm{BAr}_{4}\right](\mathbf{8})$.

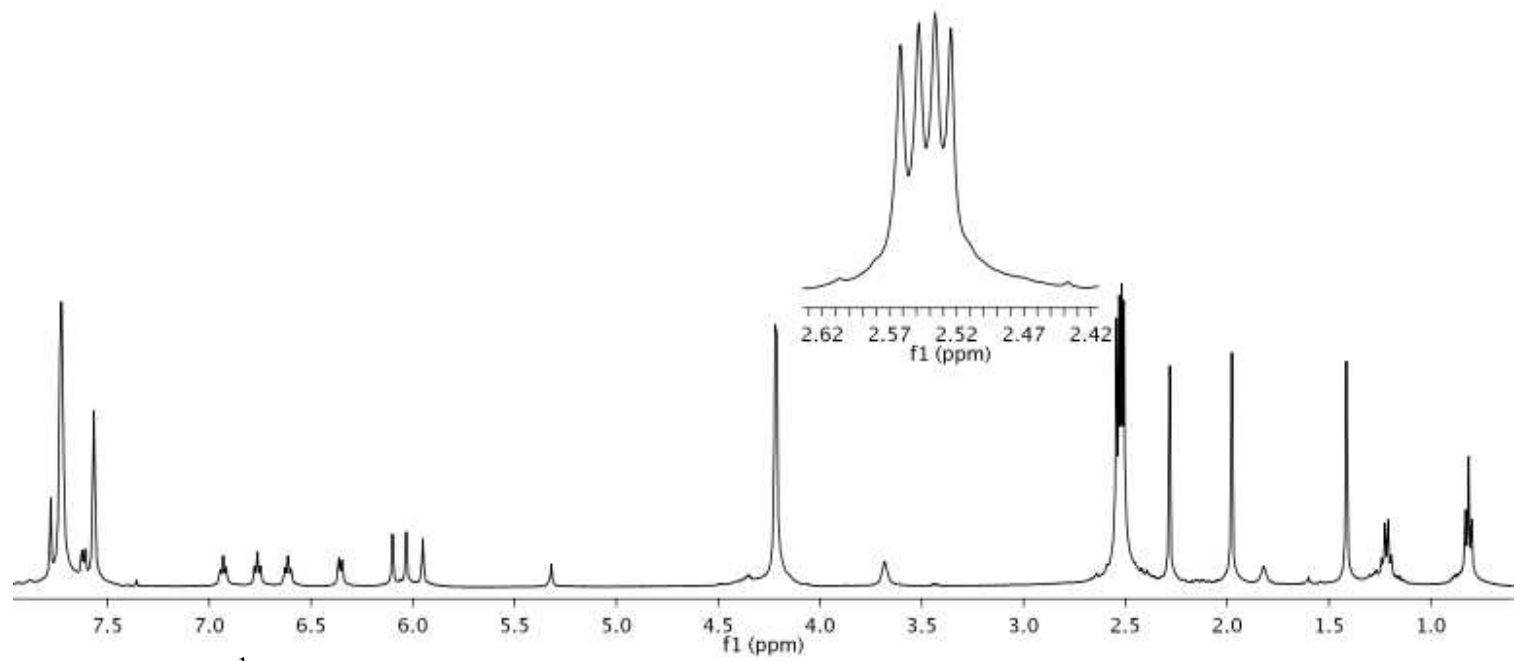

Figure 5.19. ${ }^{1} \mathrm{H}$ NMR spectrum of $\left\{\left[\mathrm{HC}\left(\mathrm{pz}^{\prime}\right)_{3}\right] \mathrm{Ru}\left[\mathrm{P}\left(\mathrm{OCH}_{2}\right)_{3} \mathrm{CEt}\right] \mathrm{Ph}(\mathrm{NCMe})\right\}\left[\mathrm{BAr}_{4}{ }_{4}\right](\mathbf{8})$ in $\mathrm{CD}_{2} \mathrm{Cl}_{2}$. 


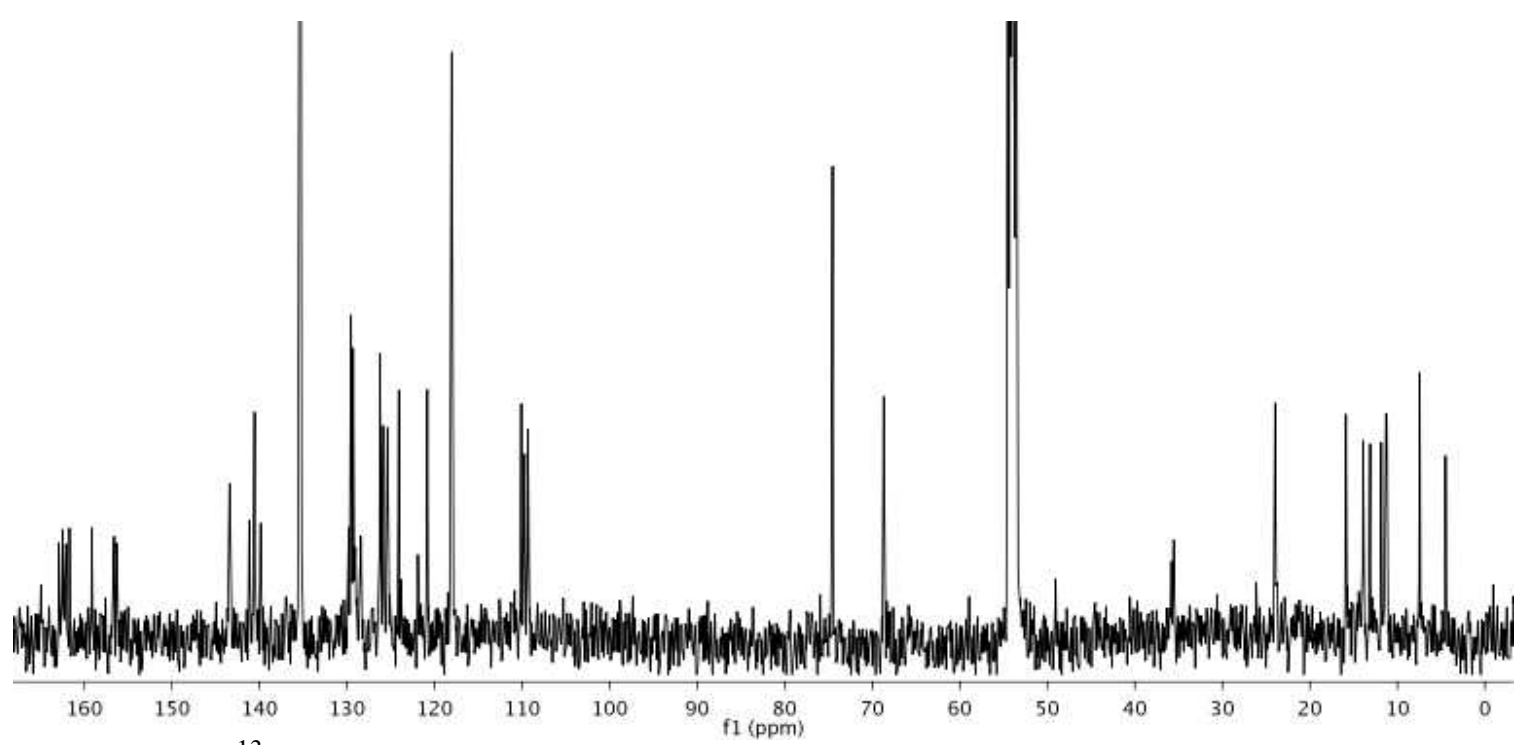

Figure 5.20. ${ }^{13} \mathrm{C}$ NMR spectrum of $\left\{\left[\mathrm{HC}\left(\mathrm{pz}^{\prime}\right)_{3}\right] \mathrm{Ru}\left[\mathrm{P}\left(\mathrm{OCH}_{2}\right)_{3} \mathrm{CEt}\right] \mathrm{Ph}(\mathrm{NCMe})\right\}\left[\mathrm{BAr}_{4}\right]$ (8) in $\mathrm{CD}_{2} \mathrm{Cl}_{2}$.

\subsubsection{Attempted Synthesis of $\left\{\left[\mathrm{C}(\mathrm{pz})_{4}\right] \mathrm{Ru}\left[\mathrm{P}\left(\mathrm{OCH}_{2}\right)_{3} \mathrm{CEt}\right] \mathrm{Ph}(\mathrm{NCMe})\right\}\left[\mathrm{BAr}_{4}{ }_{4}\right]$}

As stated above, the 5-position on the $\mathrm{C}(\mathrm{pz})_{4}$ pyrazolyl rings is susceptible to intramolecular $\mathrm{C}-\mathrm{H}$ activation. Therefore, an alternative synthetic route was attempted by adding the $\mathrm{C}(\mathrm{pz})_{4}$ ligand to a $\mathrm{Ru}$ complex which lacks an alkyl group. Refluxing $\mathrm{C}(\mathrm{pz})_{4}$ in the presence of $\mathrm{RuCl}_{2}\left(\mathrm{PPh}_{3}\right)_{4}$ in toluene overnight lead to the formation of $\left[\mathrm{C}(\mathrm{pz})_{4}\right] \mathrm{Ru}\left(\mathrm{PPh}_{3}\right) \mathrm{Cl}_{2}(9)$. Complex 9 precipitates out of toluene and to give a greenyellow solid in $79 \%$ yield. The presence of mirror symmetry is evident by the presence of nine $\mathrm{C}(\mathrm{pz})_{4}$ resonances in the downfield region with an integration of $1: 1: 1: 1: 1: 2: 2: 1: 2$ (Scheme 5.7, Figure 5.21, Figure 5.22). 


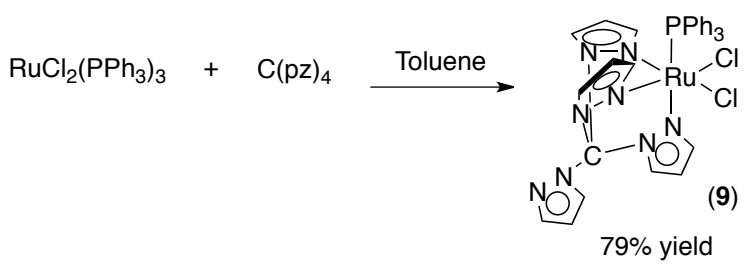

Scheme 5.7. Synthesis of $\left[\mathrm{C}(\mathrm{pz})_{4}\right] \mathrm{Ru}\left(\mathrm{PPh}_{3}\right) \mathrm{Cl}_{2}(9)$.

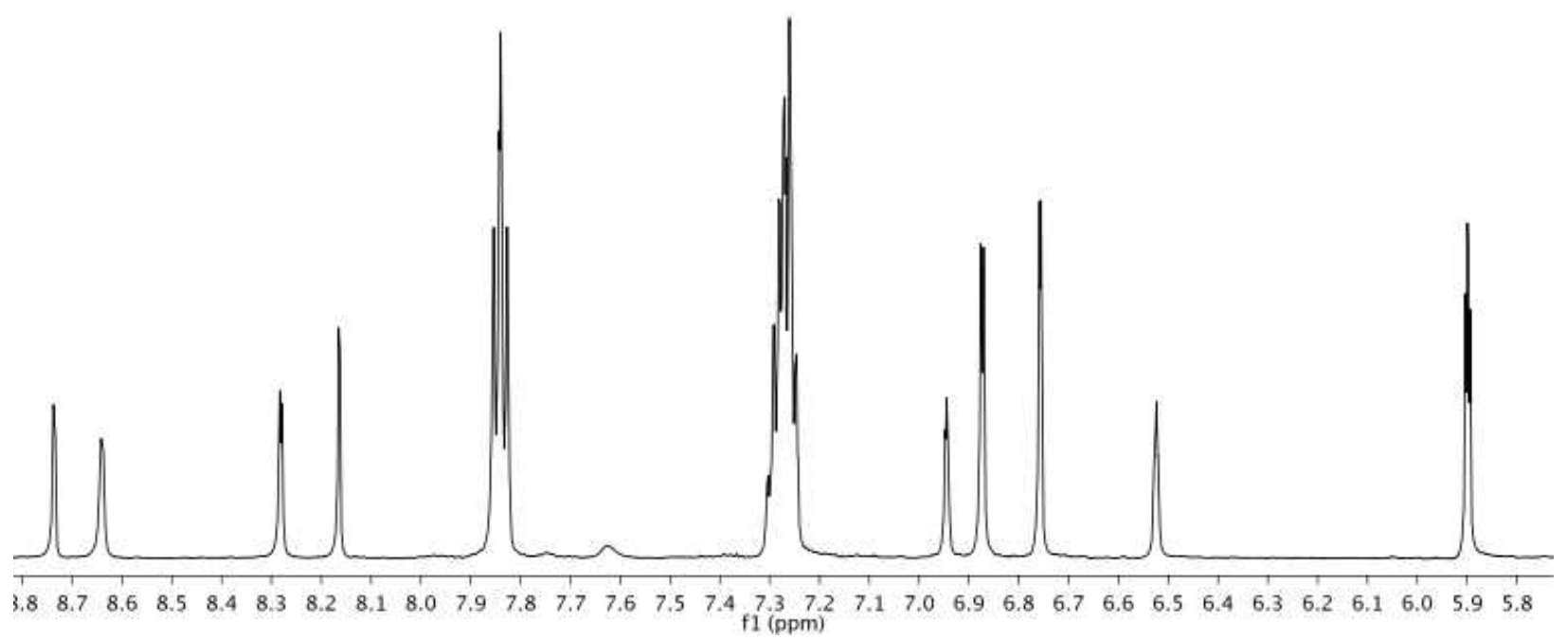

Figure 5.21. ${ }^{1} \mathrm{H} \mathrm{NMR}$ spectrum of $\left[\mathrm{C}(\mathrm{pz})_{4}\right] \mathrm{Ru}\left(\mathrm{PPh}_{3}\right) \mathrm{Cl}_{2}$ (9) in $\mathrm{CDCl}_{3}$.

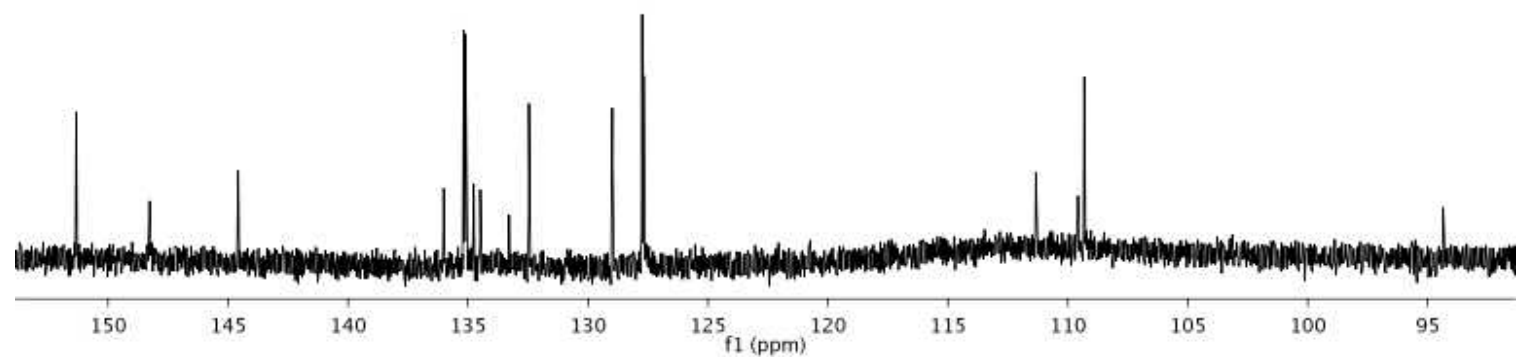

Figure 5.22. ${ }^{13} \mathrm{C}$ NMR spectrum of $\left[\mathrm{C}(\mathrm{pz})_{4}\right] \mathrm{Ru}\left(\mathrm{PPh}_{3}\right) \mathrm{Cl}_{2}(9)$ in $\mathrm{CDCl}_{3}$. 
The $\mathrm{PPh}_{3}$ ligand can then be displaced by refluxing 9 in chloroform in the presence of excess $\mathrm{P}\left(\mathrm{OCH}_{2}\right)_{3} \mathrm{CEt}$. Initially, both $\left[\mathrm{\kappa}^{2}-\mathrm{C}(\mathrm{pz})_{4}\right] \mathrm{Ru}\left[\mathrm{P}\left(\mathrm{OCH}_{2}\right)_{3} \mathrm{CEt}\right] \mathrm{Cl}_{2}$ and $\left[\kappa^{3}-\mathrm{C}(\mathrm{pz})_{4}\right] \mathrm{Ru}\left[\mathrm{P}\left(\mathrm{OCH}_{2}\right)_{3} \mathrm{CEt}\right] \mathrm{Cl}_{2}$ species are observed. The addition of hexanes to the reaction mixture, isolation of the precipate, followed by multiple rinses with hexanes to remove any free $\mathrm{PPh}_{3}$, and subsequent reconstitution in fresh chloroform and refluxing overnight yields $\left[\mathrm{\kappa}^{3}-\mathrm{C}(\mathrm{pz}) 4\right] \mathrm{Ru}\left[\mathrm{P}\left(\mathrm{OCH}_{2}\right)_{3} \mathrm{CEt}\right] \mathrm{Cl}_{2} \quad(\mathbf{1 0})$ as a yellow solid. The coordination of the $\mathrm{P}\left(\mathrm{OCH}_{2}\right)_{3} \mathrm{CEt}$ is apparent the disappearance of the resonance for coordinated $\mathrm{PPh}_{3}$ at $52 \mathrm{ppm}$ and the appearance of a downfield resonance at $128 \mathrm{ppm}\left({ }^{31} \mathrm{P}\right.$ NMR). Additionally, a phosphite resonance in the ${ }^{1} \mathrm{H}$ NMR spectrum is observed as a doublet for the methylene hydrogens and a triplet and quartet for the ethyl tail of the ligand (Scheme 5.8, Figure 5.24, Figure 5.25).

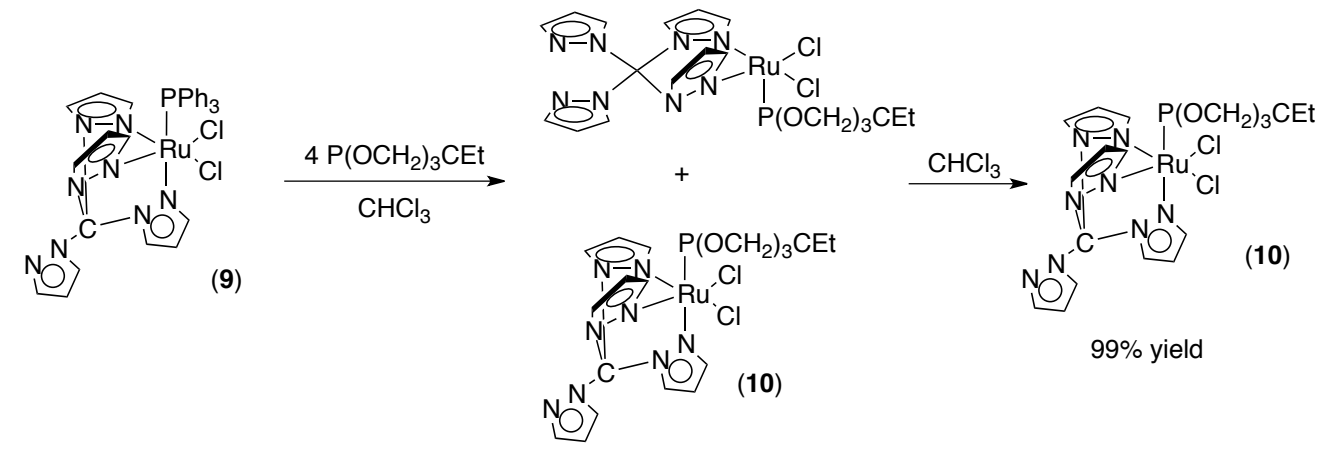

Scheme 5.8. Synthesis of $\left[\kappa^{2}-\mathrm{C}(\mathrm{pz})_{4}\right] \mathrm{Ru}\left[\mathrm{P}\left(\mathrm{OCH}_{2}\right)_{3} \mathrm{CEt}\right] \mathrm{Cl}_{2}$ and $\left[\kappa^{3}-\right.$ $\left.\mathrm{C}(\mathrm{pz})_{4}\right] \mathrm{Ru}\left[\mathrm{P}\left(\mathrm{OCH}_{2}\right)_{3} \mathrm{CEt}\right] \mathrm{Cl}_{2}(\mathbf{1 0})$. 


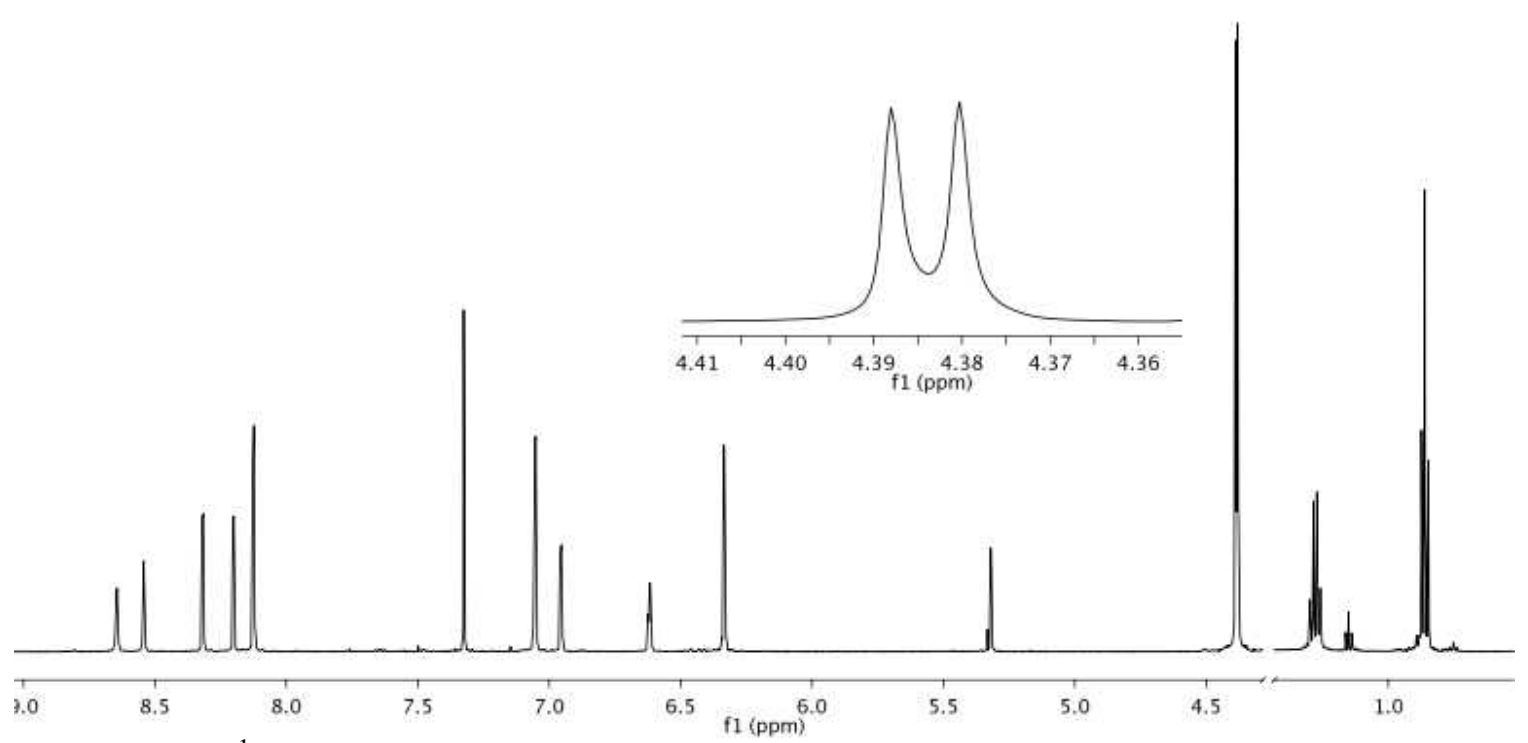

Figure 5.23. ${ }^{1} \mathrm{H}$ NMR spectrum of $\left[\mathrm{C}(\mathrm{pz})_{4}\right] \mathrm{Ru}\left[\mathrm{P}\left(\mathrm{OCH}_{2}\right)_{3} \mathrm{CEt}\right] \mathrm{Cl}_{2}(\mathbf{1 0})$ in $\mathrm{CD}_{2} \mathrm{Cl}_{2}$.

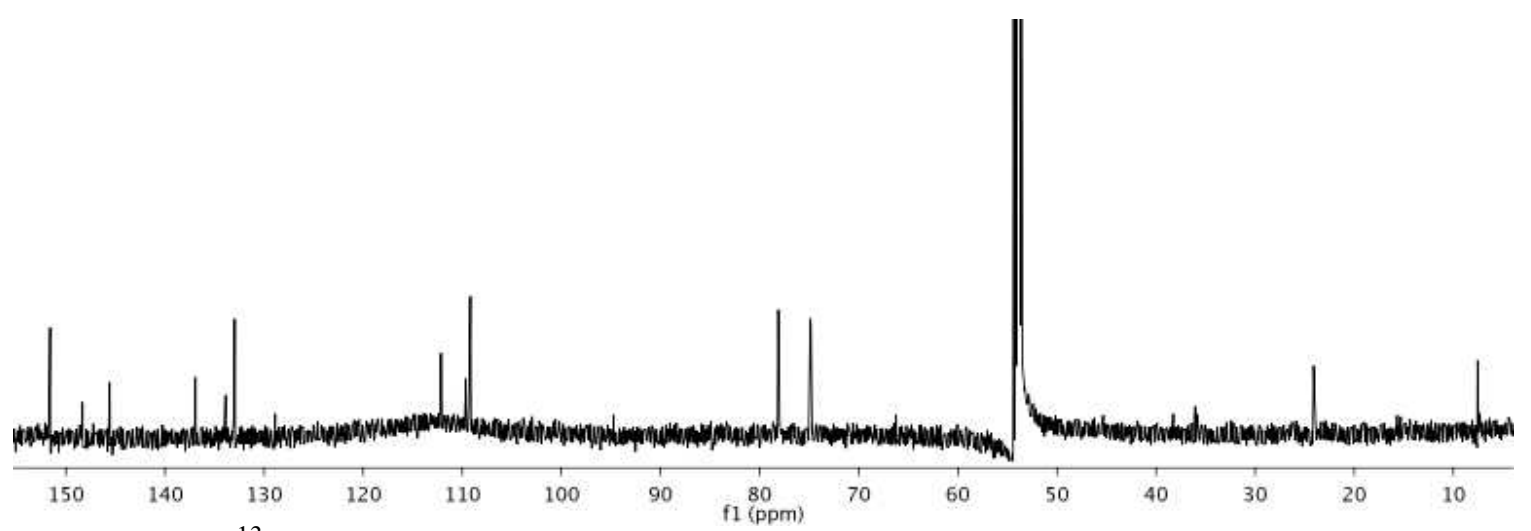

Figure 5.24. ${ }^{13} \mathrm{C}$ NMR spectrum of $\left[\mathrm{C}(\mathrm{pz})_{4}\right] \mathrm{Ru}\left[\mathrm{P}\left(\mathrm{OCH}_{2}\right)_{3} \mathrm{CEt}\right] \mathrm{Cl}_{2}(\mathbf{1 0})$ in $\mathrm{CD}_{2} \mathrm{Cl}_{2}$.

Refluxing complex $\mathbf{1 0}$ in acetonitrile overnight leads to conversion to the asymmetric $\left[\mathrm{C}(\mathrm{pz})_{4}\right] \mathrm{Ru}\left[\mathrm{P}\left(\mathrm{OCH}_{2}\right)_{3} \mathrm{CEt}\right] \mathrm{Cl}(\mathrm{NCMe})[\mathrm{Cl}](\mathbf{1 1})$ in approximately $71 \%$ yield. The coordination of NCMe is evident by a singlet at $2.59 \mathrm{ppm}$ in the ${ }^{1} \mathrm{H}$ NMR spectrum. The ${ }^{1} \mathrm{H}$ NMR spectrum demonstrates that complex $\mathbf{1 1}$ is asymmetric since twelve $\mathrm{C}(\mathrm{pz})_{4}$ resonances are observed. The reaction leads to one predominate product; however, there 
are some minor impurities, which are removed in the next step (Scheme 5.9, Figure 5.25, Figure 5.26).

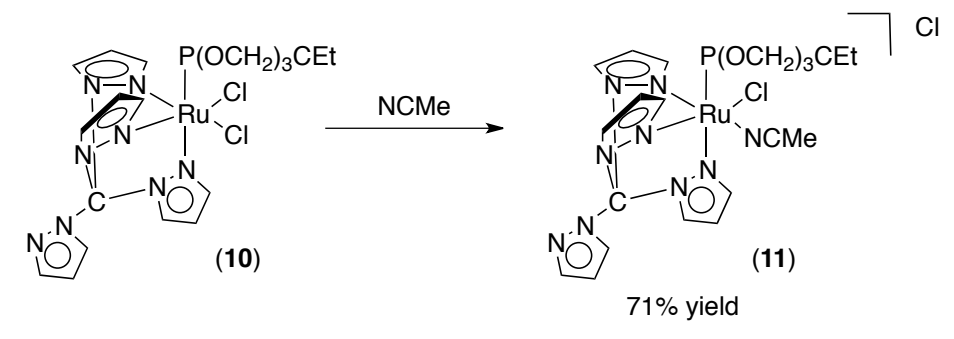

Scheme 5.9. Synthesis of $\left\{\left[\mathrm{C}(\mathrm{pz})_{4}\right] \mathrm{Ru}\left[\mathrm{P}\left(\mathrm{OCH}_{2}\right)_{3} \mathrm{CEt}\right] \mathrm{Cl}(\mathrm{NCMe})\right\}[\mathrm{Cl}](\mathbf{1 1})$.

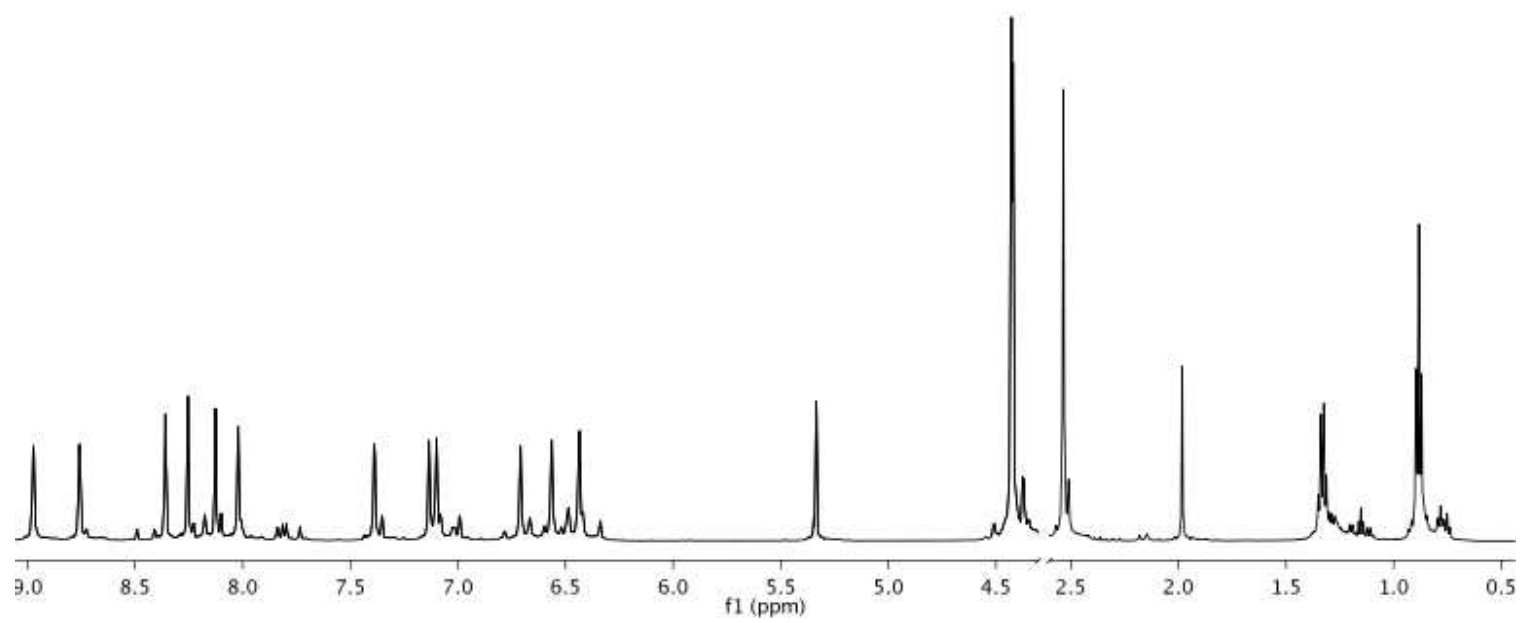

Figure 5.25. ${ }^{1} \mathrm{H}$ NMR spectrum of $\left\{\left[\mathrm{C}(\mathrm{pz})_{4}\right] \mathrm{Ru}\left[\mathrm{P}\left(\mathrm{OCH}_{2}\right)_{3} \mathrm{CEt}\right] \mathrm{Cl}(\mathrm{NCMe})\right\}[\mathrm{Cl}](\mathbf{1 1})$ in $\mathrm{CD}_{2} \mathrm{Cl}_{2}$. 


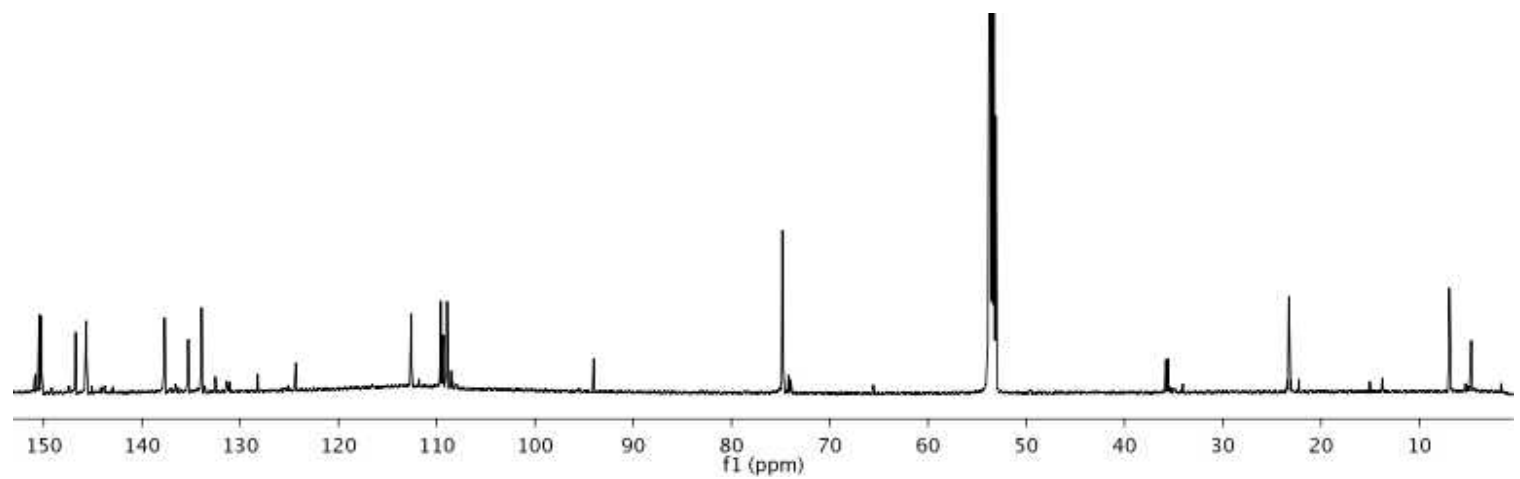

Figure 5.26. ${ }^{13} \mathrm{C}$ NMR spectrum of $\left\{\left[\mathrm{C}(\mathrm{pz})_{4}\right] \mathrm{Ru}\left[\mathrm{P}\left(\mathrm{OCH}_{2}\right)_{3} \mathrm{CEt}\right] \mathrm{Cl}(\mathrm{NCMe})\right\}[\mathrm{Cl}](\mathbf{1 1})$ in $\mathrm{CD}_{2} \mathrm{Cl}_{2}$.

The reaction of $\mathrm{NaBAr}_{4}{ }_{4}$ to a THF solution of complex 11 at room temperature, leads to the displacement of a chloride with BAr' ${ }_{4}$ yielding $\left\{\left[\mathrm{C}(\mathrm{pz})_{4}\right] \mathrm{Ru}\left[\mathrm{P}\left(\mathrm{OCH}_{2}\right)_{3} \mathrm{CEt}\right] \mathrm{Cl}(\mathrm{NCMe})\right\}\left[\mathrm{BAr}_{4}\right]$ (12). The presence of the $\mathrm{BAr}_{4}{ }_{4}$ is evident in the ${ }^{1} \mathrm{H}$ NMR spectrum by two singlets in the downfield region and a singlet in the ${ }^{19} \mathrm{~F}$ NMR spectrum at -63 ppm. Complex 12 can be purified on neutral alumina by first washing the plug with diethyl ether to remove the impurities followed by 1:1 mixture of $\mathrm{Et}_{2} \mathrm{O}: \mathrm{CH}_{2} \mathrm{Cl}_{2}$ to give the purified product in 57\% yield (Scheme 5.10, Figure 5.28, Figure 5.29). A single crystal of complex 12 was obtained by hexanes diffusion into a THF solution of complex 12 at $-30^{\circ} \mathrm{C}$ by Dr. Brandon Quillian (Figure 5.27, Table 5.2).

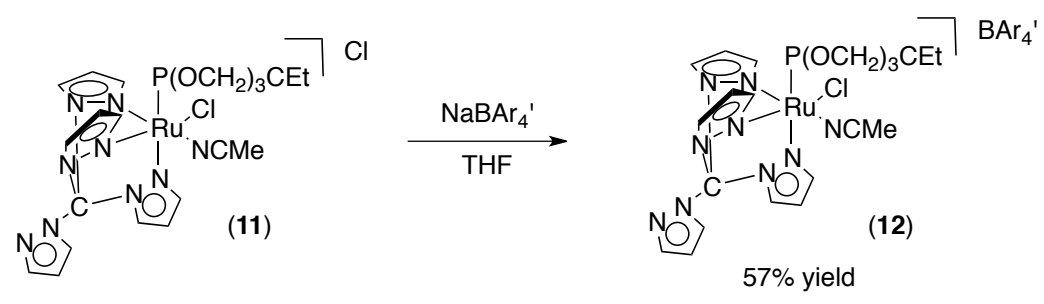

Scheme 5.10. Synthesis of $\left\{\left[\mathrm{C}(\mathrm{pz})_{4}\right] \mathrm{Ru}\left[\mathrm{P}\left(\mathrm{OCH}_{2}\right)_{3} \mathrm{CEt}\right] \mathrm{Cl}(\mathrm{NCMe})\right\}\left[\mathrm{BAr}_{4}\right]$ (12). 


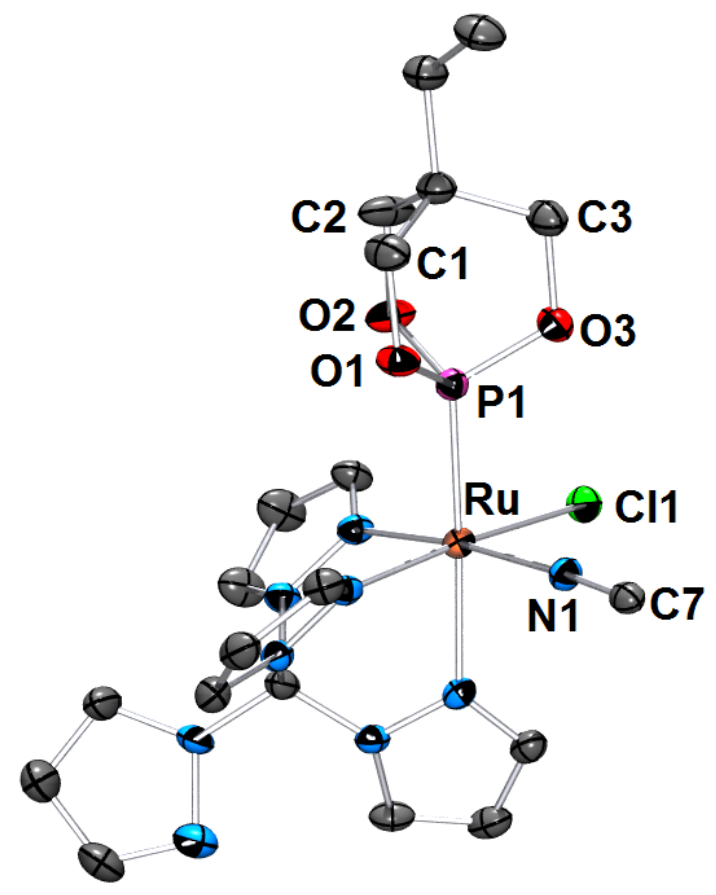

Figure 5.27. ORTEP of $\left\{\left[\mathrm{C}(\mathrm{pz})_{4}\right] \mathrm{Ru}\left[\mathrm{P}\left(\mathrm{OCH}_{2}\right)_{3} \mathrm{CEt}\right] \mathrm{Cl}(\mathrm{NCMe})\right\}\left[\mathrm{BAr}_{4}\right]$ (12) (35\% probability with hydrogen atoms and $\mathrm{BAr}_{4}{ }_{4}$ omitted.). Selected bond lengths $(\AA)$ : Ru-P1, 2.2053(15); P-O1, 1.594(4); P-O2, 1.599(5); P-O3, 1.595(4); $\mathrm{Ru}-\mathrm{Cl1}$, 2.397(2); $\mathrm{Ru}-\mathrm{N} 1$, 2.023(6). Selected bond angles $\left({ }^{\circ}\right)$ : O3-P1-O2, 102.2(2); O1-P1-O2, 101.7(2); O1-P1O3, 101.8(2); O1-P1-Ru, 115.12(15); O2-P1-Ru, 118.32(16); O3-P1-Ru, 115.35(17).

Table 5.2. Selected Crystallographic Data for $\left\{\left[\mathrm{C}(\mathrm{pz})_{4}\right] \mathrm{Ru}\left[\mathrm{P}\left(\mathrm{OCH}_{2}\right)_{3} \mathrm{CEt}\right] \mathrm{Cl}(\mathrm{NCMe})\right\}\left[\mathrm{BAr}_{4}\right](\mathbf{1 2})$.

\begin{tabular}{ll}
\hline & complex $\mathbf{1 2} \cdot 2 \mathrm{THF}$ \\
\hline empirical formula & $\mathrm{C}_{61} \mathrm{H}_{46} \mathrm{BClF}_{24} \mathrm{~N}_{9} \mathrm{O}_{5} \mathrm{PRu}$ \\
Fw & 1619.37 \\
cryst syst & monoclinic \\
space group & $P 2_{1} / \mathrm{c}$ \\
$\mathrm{a}, \AA$ & $11.5204(2)$ \\
$\mathrm{b}, \AA$ & $35.9819(7)$ \\
$\mathrm{c}, \AA$ & $16.6646(3)$ \\
$\beta$, deg & $99.818(1)$ \\
$\mathrm{V}, \AA^{3}$ & $6806.7(2)$ \\
$\mathrm{Z}$ & 4 \\
$\mathrm{D}_{\text {calcd }}, \mathrm{mg} / \mathrm{m}^{3}$ & 1.580 \\
cryst size $(\mathrm{mm})$ & $0.44 \times 0.16 \times 0.12$ \\
$\mathrm{R} 1, \mathrm{wR} 2(\mathrm{I}>2 \sigma(\mathrm{I}))$ & $0.0583,0.1721$ \\
GOF & 1.415 \\
\hline
\end{tabular}




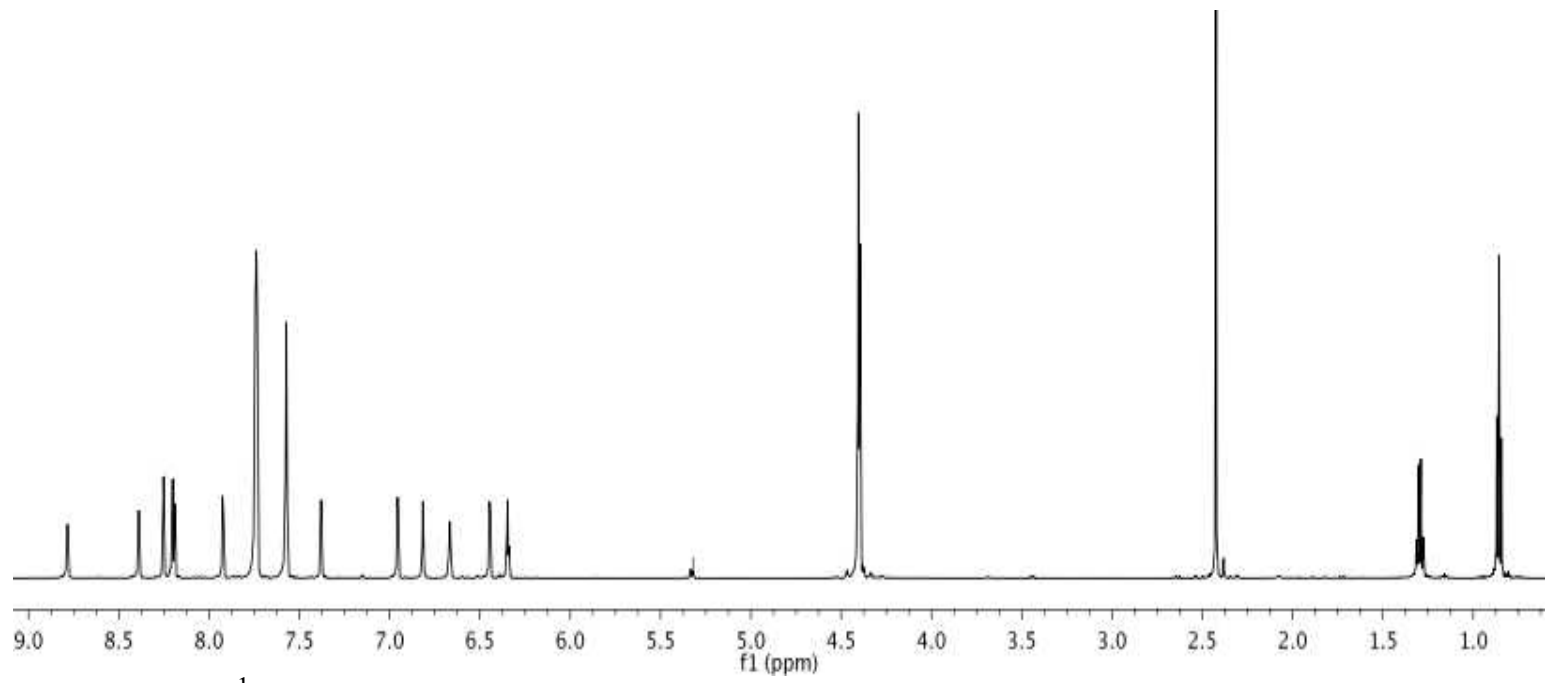

Figure 5.28. ${ }^{1} \mathrm{H}$ NMR spectrum of $\left\{\left[\mathrm{C}(\mathrm{pz})_{4}\right] \mathrm{Ru}\left[\mathrm{P}\left(\mathrm{OCH}_{2}\right)_{3} \mathrm{CEt}\right] \mathrm{Cl}(\mathrm{NCMe})\right\}\left[\mathrm{BAr}_{4}\right](\mathbf{1 2})$ in $\mathrm{CD}_{2} \mathrm{Cl}_{2}$.

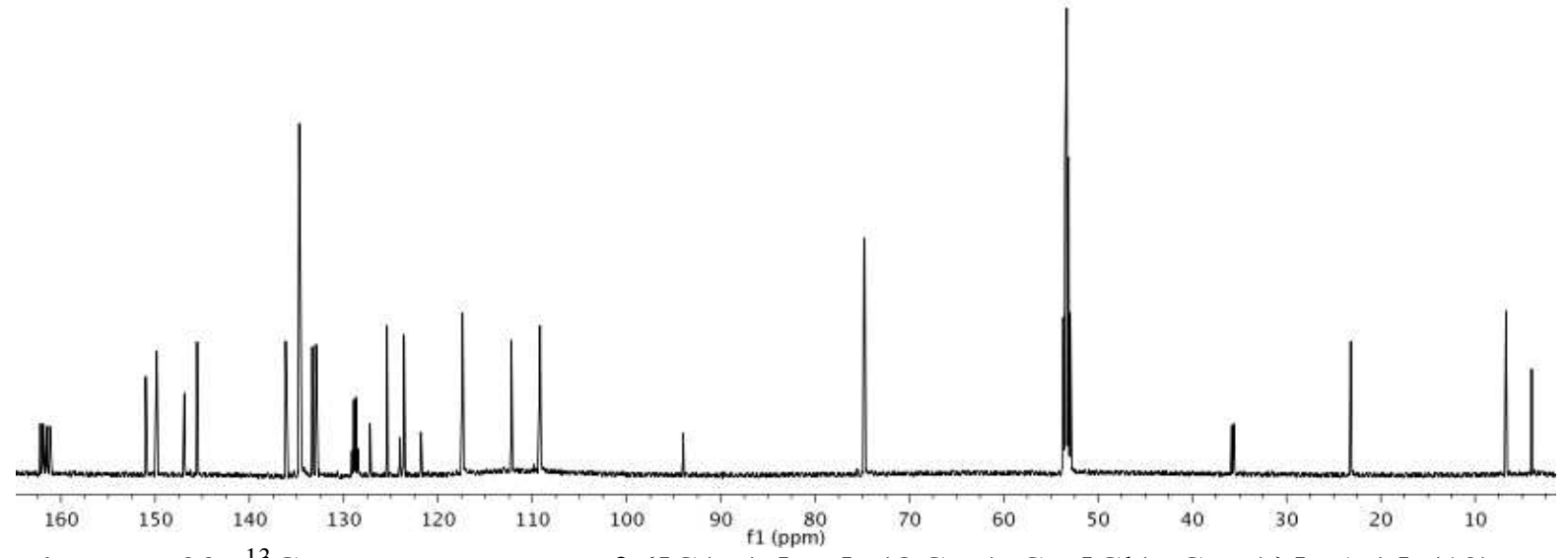

Figure 5.29. ${ }^{13} \mathrm{C}$ NMR spectrum of $\left\{\left[\mathrm{C}(\mathrm{pz})_{4}\right] \mathrm{Ru}\left[\mathrm{P}\left(\mathrm{OCH}_{2}\right)_{3} \mathrm{CEt}\right] \mathrm{Cl}(\mathrm{NCMe})\right\}\left[\mathrm{BAr}_{4}\right]$ (12) in $\mathrm{CD}_{2} \mathrm{Cl}_{2}$.

Direct alkylation of complex 12 was attempted with a range of reagents, temperatures and solvents (Table 5.3). However, all attempts led to no reaction or decomposition. Therefore, due to the better leaving ability of a triflate group, the chloride was replaced with a triflate group via a salt metathesis reaction. The removal of the chloride proved to 
be more difficult than expected. Multiple different triflate reagents were tested, and the only one that proved to be successful was TMSOTf in methylene chloride. The reaction of 12 and TMSOTf must be heated overnight at $100{ }^{\circ} \mathrm{C}$ to yield $\left\{\left[\mathrm{C}(\mathrm{pz})_{4}\right] \mathrm{Ru}\left[\mathrm{P}\left(\mathrm{OCH}_{2}\right)_{3} \mathrm{CEt}\right](\mathrm{OTf})(\mathrm{NCMe})\right\}\left[\mathrm{BAr}_{4}\right]$ (13) in an $84 \%$ isolated yield (Scheme 5.11, Figure 5.30, Figure 5.31). The coordination of triflate is evident by the singlet in the ${ }^{19} \mathrm{~F}$ NMR spectrum at $-79 \mathrm{ppm}$. Additionally, even in the presence of excess TMSOTf at high temperatures, the NCMe ligand appears to be tightly bound since an asymmetric complex was still observed with $12 \mathrm{C}(\mathrm{pz})_{4}$ resonances and a coordinated NCMe resonance in the ${ }^{1} \mathrm{H}$ NMR spectrum.

Table 5.3. Attempted alkylation of $\left\{\left[\mathrm{C}(\mathrm{pz})_{4}\right] \mathrm{Ru}\left[\mathrm{P}\left(\mathrm{OCH}_{2}\right)_{3} \mathrm{CEt}\right] \mathrm{Cl}(\mathrm{NCMe})\right\}\left[\mathrm{BAr}_{4}\right](\mathbf{1 2})$.

\begin{tabular}{|c|c|c|c|}
\hline Reagent & Solvent & Temperature $\left({ }^{\circ} \mathrm{C}\right)$ & Result \\
\hline $1 \mathrm{Me}_{2} \mathrm{Mg}$ & $\mathrm{THF}$ & $-78 \rightarrow \mathrm{RT}$ & Decomposition \\
\hline $2 \mathrm{Me}_{2} \mathrm{Mg}$ & THF & $-78 \rightarrow \mathrm{RT}$ & Decomposition \\
\hline $1.05 \mathrm{MeMgBr}$ & THF & $-78 \rightarrow 0 \rightarrow \mathrm{RT}$ & No Reaction \\
\hline $1.05 \mathrm{PhMgBr}$ & THF & $-78 \rightarrow 0 \rightarrow \mathrm{RT}$ & No Reaction \\
\hline $1.05 \mathrm{MeLi}$ & THF & $-78 \rightarrow \mathrm{RT}$ & Decomposition \\
\hline $1.05 \mathrm{PhLi}$ & THF & $-78 \rightarrow \mathrm{RT}$ & Decomposition \\
\hline $\begin{array}{c}1.3 \mathrm{PhSn}(\mathrm{n}-\mathrm{Bu})_{3} \\
0.65 \mathrm{CuOTf}\end{array}$ & THF & Reflux & Multiple Products \\
\hline $1 \mathrm{Me}_{2} \mathrm{Cu}$ & THF & $-78 \rightarrow \mathrm{RT}$ & No Reaction \\
\hline $0.75 \mathrm{Me}_{3} \mathrm{Al}$ & $\mathrm{C}_{6} \mathrm{D}_{6}$ & $\mathrm{RT}$ & Decomposition \\
\hline \multicolumn{4}{|c|}{$* \mathrm{RT}=$ room temperature } \\
\hline 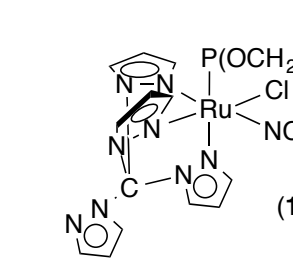 & & $\frac{\text { TMSOTf }}{\mathrm{CH}_{2} \mathrm{Cl}_{2}}$ & 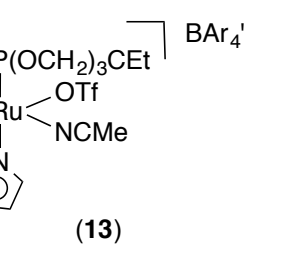 \\
\hline
\end{tabular}

Scheme 5.11. Synthesis of $\left\{\left[\mathrm{C}(\mathrm{pz})_{4}\right] \mathrm{Ru}\left[\mathrm{P}\left(\mathrm{OCH}_{2}\right)_{3} \mathrm{CEt}\right](\mathrm{OTf})(\mathrm{NCMe})\right\}\left[\mathrm{BAr}_{4}\right](\mathbf{1 3})$. 


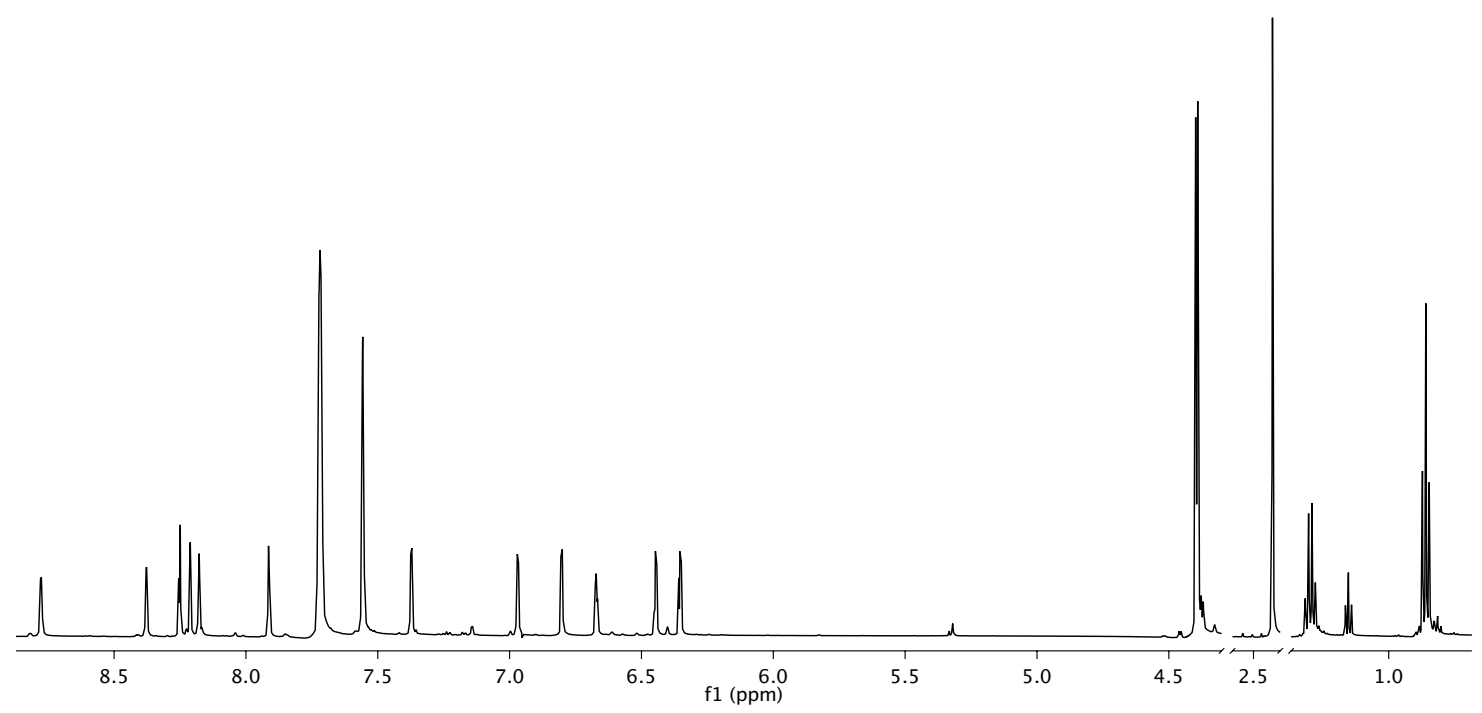

Figure 5.30. ${ }^{1} \mathrm{H}$ NMR spectrum of $\left\{\left[\mathrm{C}(\mathrm{pz})_{4}\right] \mathrm{Ru}\left[\mathrm{P}\left(\mathrm{OCH}_{2}\right)_{3} \mathrm{CEt}\right](\mathrm{OTf})(\mathrm{NCMe})\right\}\left[\mathrm{BAr}_{4}\right]$ (13) in $\mathrm{CD}_{2} \mathrm{Cl}_{2}$.

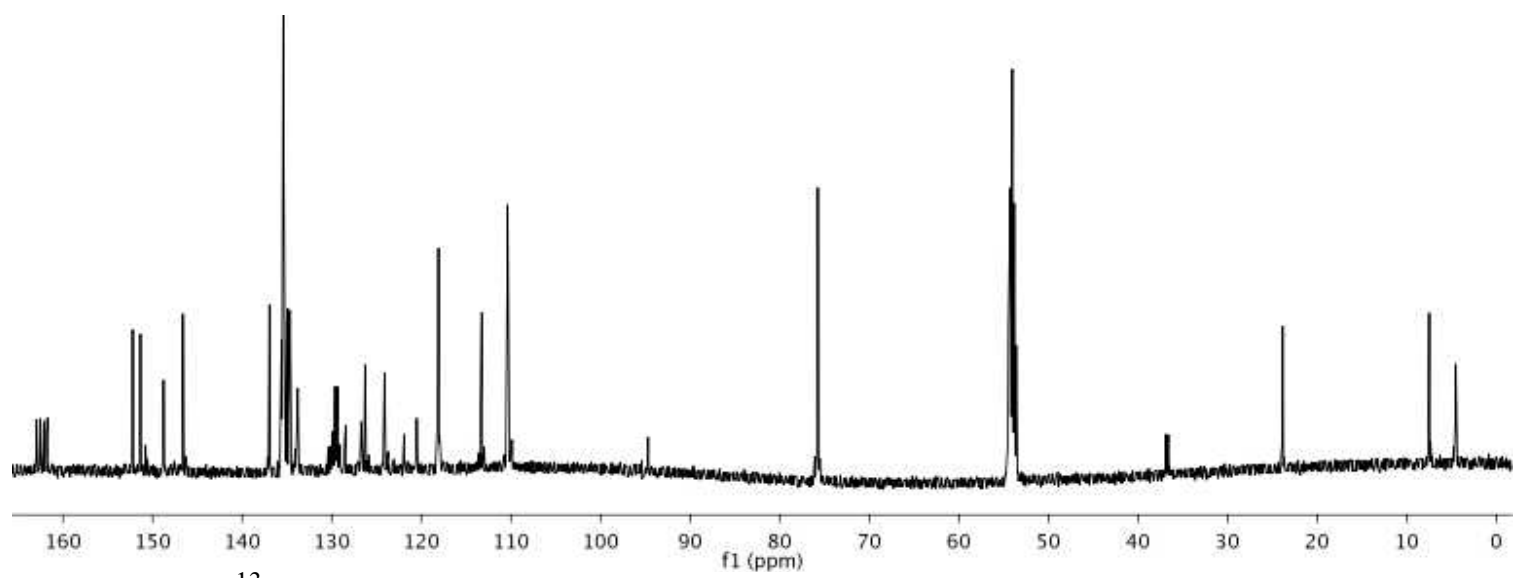

Figure 5.31. ${ }^{13} \mathrm{C}$ NMR spectrum of $\left\{\left[\mathrm{C}(\mathrm{pz})_{4}\right] \mathrm{Ru}\left[\mathrm{P}\left(\mathrm{OCH}_{2}\right)_{3} \mathrm{CEt}\right](\mathrm{OTf})(\mathrm{NCMe})\right\}\left[\mathrm{BAr}_{4}{ }_{4}\right]$ (13) in $\mathrm{CD}_{2} \mathrm{Cl}_{2}$.

The phenylation or methylation of complex 13 was attempted with a range of reagents, temperatures and solvent (Table 5.4). Most attempts led to decomposition except in the case of $\mathrm{PhLi}\left(\right.$ in $\left.\mathrm{Et}_{2} \mathrm{O}\right)$, and $\mathrm{PhSn}(n-\mathrm{Bu})_{3}$ with CuOTf in THF which yielded no reaction. However, methylation of complex 13 was accomplished with 1.5 
equivalents of $\mathrm{Me}_{3} \mathrm{Al}$ in benzene or diethyl ether to yield $\left\{\left[\mathrm{C}(\mathrm{pz})_{4}\right] \mathrm{Ru}\left[\mathrm{P}\left(\mathrm{OCH}_{2}\right)_{3} \mathrm{CEt}\right](\mathrm{Me})(\mathrm{NCMe})\right\}\left[\mathrm{BAr}_{4}\right]$ (14) in $67 \%$ yield. Complex 13 is sparingly soluble in benzene; however, methylation to give 14 improves solubility. The ${ }^{1} \mathrm{H}$ NMR spectrum of $\mathbf{1 4}$ is consistent with an asymmetric species with twelve resonances due to the $\mathrm{C}(\mathrm{pz})_{4}$ ligand. A doublet for the methyl group is observed at $0.79 \mathrm{ppm}$ with a ${ }^{3} J_{\mathrm{HP}}=1.7 \mathrm{~Hz}$. Additional evidence of a Ru-Me moiety was provided by treating complex 14 with one equivalent of $\mathrm{HCl} \cdot \mathrm{Et}_{2} \mathrm{O}$, which gave an insoluble complex identified as $\left\{\left[\mathrm{C}(\mathrm{pz})_{4}\right] \mathrm{Ru}\left[\mathrm{P}\left(\mathrm{OCH}_{2}\right)_{3} \mathrm{CEt}\right] \mathrm{Cl}(\mathrm{NCMe})\right\}\left[\mathrm{BAr}_{4}\right]$ (12). Moreover the production of $\mathrm{CH}_{4}$ was observed in ${ }^{1} \mathrm{H}$ NMR spectroscopy and GCMS.

Table 5.4. Attempted alkylation of $\left\{\left[\mathrm{C}(\mathrm{pz})_{4}\right] \mathrm{Ru}\left[\mathrm{P}\left(\mathrm{OCH}_{2}\right)_{3} \mathrm{CEt}\right](\mathrm{OTf})(\mathrm{NCMe})\right\}\left[\mathrm{BAr}_{4}\right]$ (13).

\begin{tabular}{|c|c|c|c|}
\hline Reagent & Solvent & Temperature $\left({ }^{\circ} \mathrm{C}\right)$ & Result \\
\hline $1.1 \mathrm{Me}_{2} \mathrm{Mg}$ & THF & $-78 \rightarrow \mathrm{RT}$ & Decomposition \\
\hline $1.1 \mathrm{Ph}_{2} \mathrm{Mg}$ & THF & $-78 \rightarrow \mathrm{RT} \rightarrow 50$ & Decomposition \\
\hline $2 \mathrm{Ph}_{2} \mathrm{Mg}$ & $\mathrm{THF}$ & RT & Decomposition \\
\hline $1.1 \mathrm{Ph}_{2} \mathrm{Mg}$ & $\mathrm{C}_{6} \mathrm{D}_{6}$ & RT & Decomposition \\
\hline $1 \mathrm{PhMgBr}$ & THF & $-78 \rightarrow 0 \rightarrow \mathrm{RT}$ & Decomposition \\
\hline Excess PhMgBr & THF & $-78 \rightarrow \mathrm{RT}$ & Decomposition \\
\hline $1 \mathrm{PhLi}$ & THF & $-78 \rightarrow \mathrm{RT}$ & Decomposition \\
\hline $\begin{array}{c}1.3 \mathrm{PhSn}(\mathrm{n}-\mathrm{Bu})_{3} \\
0.65 \mathrm{CuOTf}\end{array}$ & THF & Reflux & No Reaction \\
\hline $1 \mathrm{Me}_{2} \mathrm{Cu}$ & THF & $-78 \rightarrow \mathrm{RT}$ & Multiple Products \\
\hline $1.05 \mathrm{PhLi}$ & $\mathrm{Et}_{2} \mathrm{O}$ & $-78 \rightarrow \mathrm{RT}$ & No Reaction \\
\hline $1 \mathrm{Ph}_{3} \mathrm{Al}$ & $\mathrm{C}_{6} \mathrm{H}_{6}$ & RT & Decomposition \\
\hline $1 \mathrm{Me}_{3} \mathrm{Al}$ & $\mathrm{C}_{6} \mathrm{H}_{6}$ & RT & Product \\
\hline $1.5 \mathrm{Me}_{3} \mathrm{Al}$ & $\mathrm{Et}_{2} \mathrm{O}$ & $-78 \rightarrow \mathrm{RT}$ & Product \\
\hline
\end{tabular}

$* \mathrm{RT}=$ room temperature 


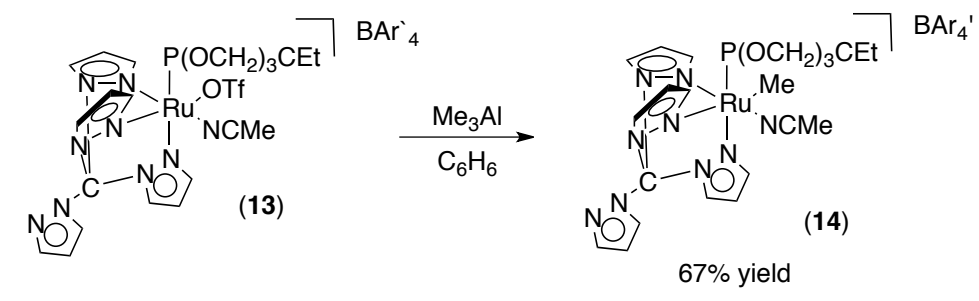

Scheme 5.12. Synthesis of $\left\{\left[\mathrm{C}(\mathrm{pz})_{4}\right] \mathrm{Ru}\left[\mathrm{P}\left(\mathrm{OCH}_{2}\right)_{3} \mathrm{CEt}\right](\mathrm{Me})(\mathrm{NCMe})\right\}\left[\mathrm{BAr}_{4}\right]$ (14).

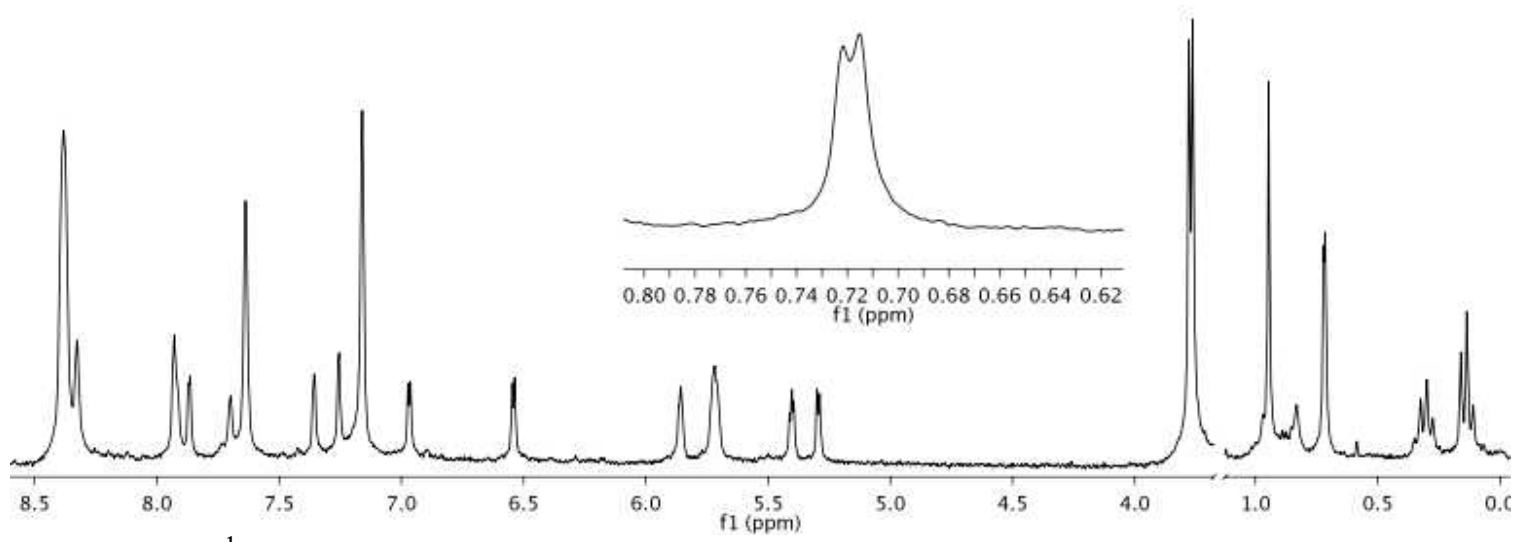

Figure 5.32. ${ }^{1} \mathrm{H}$ NMR spectrum of $\left\{\left[\mathrm{C}(\mathrm{pz})_{4}\right] \mathrm{Ru}\left[\mathrm{P}\left(\mathrm{OCH}_{2}\right)_{3} \mathrm{CEt}\right](\mathrm{Me})(\mathrm{NCMe})\right\}\left[\mathrm{BAr}_{4}\right]$ (14) in $\mathrm{C}_{6} \mathrm{D}_{6}$.

Heating $\mathrm{TpRu}(\mathrm{CO})(\mathrm{NCMe}) \mathrm{Me}$ in benzene results in $\mathrm{C}-\mathrm{H}$ activation to yield methane and $\mathrm{TpRu}(\mathrm{CO})(\mathrm{NCMe}) \mathrm{Ph} .{ }^{13,14}$ Unfortunately, heating complex $\mathbf{1 4}$ in benzene at $90{ }^{\circ} \mathrm{C}$ did not result in benzene $\mathrm{C}-\mathrm{H}$ activation. Due to lack of solubility, the complex oiled out of solution, and analysis of the oil did not show the phenylated complex. The same reaction was then attempted with a small amount of added NCMe, since it has been shown with $\mathrm{TpRu}(\mathrm{CO})(\mathrm{NCMe}) \mathrm{Me}$ that small amounts of $\mathrm{NCMe}$ does eliminate decomposition and increase the yield of the phenylated complex. When complex $\mathbf{1 4}$ is placed in benzene with one or more equivalents of NCMe conversion to a new product is observed. Unfortunately, intramolecular $\mathrm{C}-\mathrm{H}$ activation of the 5-position of the 
pyrazolyl ring occurs with release of $\mathrm{CH}_{4}$ to yield $\left\{\left(N, C^{5}, N\right) \mathrm{C}(\mathrm{pz})_{4} \mathrm{Ru}\left[\mathrm{P}\left(\mathrm{OCH}_{2}\right)_{3} \mathrm{CEt}\left[(\mathrm{NCMe})_{2}\right\}\left[\mathrm{BAr}_{4}\right]\right.\right.$ (15) (Scheme 5.13, Figure 5.33, Figure 5.34). The ${ }^{1} \mathrm{H}$ NMR spectrum in benzene shows two inequivalent NCMe groups, which indicates that one $\mathrm{NCMe}$ is trans to carbon-bound pyrazolyl ring while the other $\mathrm{NCMe}$ is trans to an $\mathrm{N}$-bound pyrazolyl ring. Only eleven resonances due to the pyrazolyl hydrogens are observed. However, the ${ }^{13} \mathrm{C}$ NMR spectrum displays twelve peaks for the pyrazolyl rings with one of them resonating as a doublet with a ${ }^{3} J_{\mathrm{CP}}=19.6$ $\mathrm{Hz}$ at $164.9 \mathrm{ppm}$. Ethylene hydrophenylation was attempted with complex $\mathbf{1 4}$ and complex $\mathbf{1 5}$, but due to poor solubility and poor stability upon heating in benzene there was no evidence for the production of ethylbenzene or styrene.

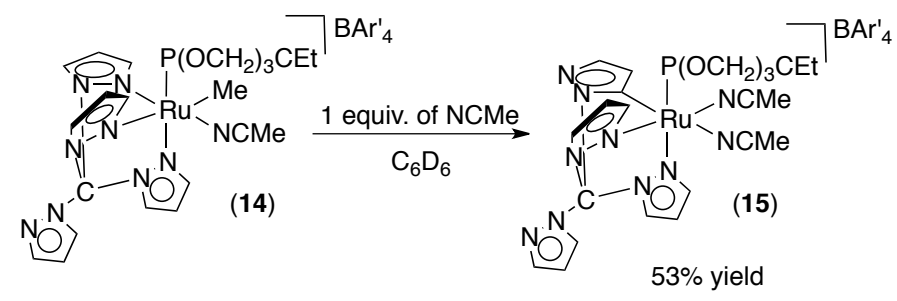

Scheme 5.13. Synthesis of $\left\{\left[\left(N, C^{5}, N\right) C(\mathrm{pz})_{4}\right] \mathrm{Ru}\left[\mathrm{P}\left(\mathrm{OCH}_{2}\right)_{3} \mathrm{CEt}\left[(\mathrm{NCMe})_{2}\right\}\left[\mathrm{BAr}_{4}\right]\right.\right.$ (15).

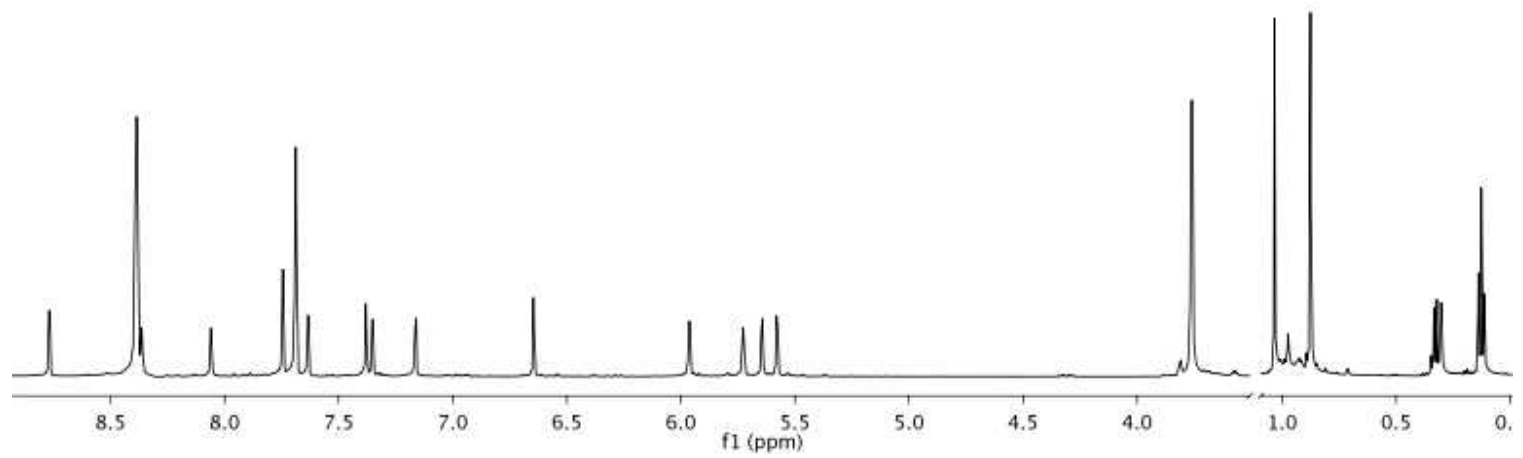

Figure 5.33. ${ }^{1} \mathrm{H} \mathrm{NMR}$ spectrum of $\left\{\left[\left(N, C^{5}, N\right) \mathrm{C}(\mathrm{pz})_{4}\right] \mathrm{Ru}\left[\mathrm{P}\left(\mathrm{OCH}_{2}\right)_{3} \mathrm{CEt}\left[(\mathrm{NCMe})_{2}\right\}\left[\mathrm{BAr}{ }_{4}\right]\right.\right.$ (15) in $\mathrm{C}_{6} \mathrm{D}_{6}$. 


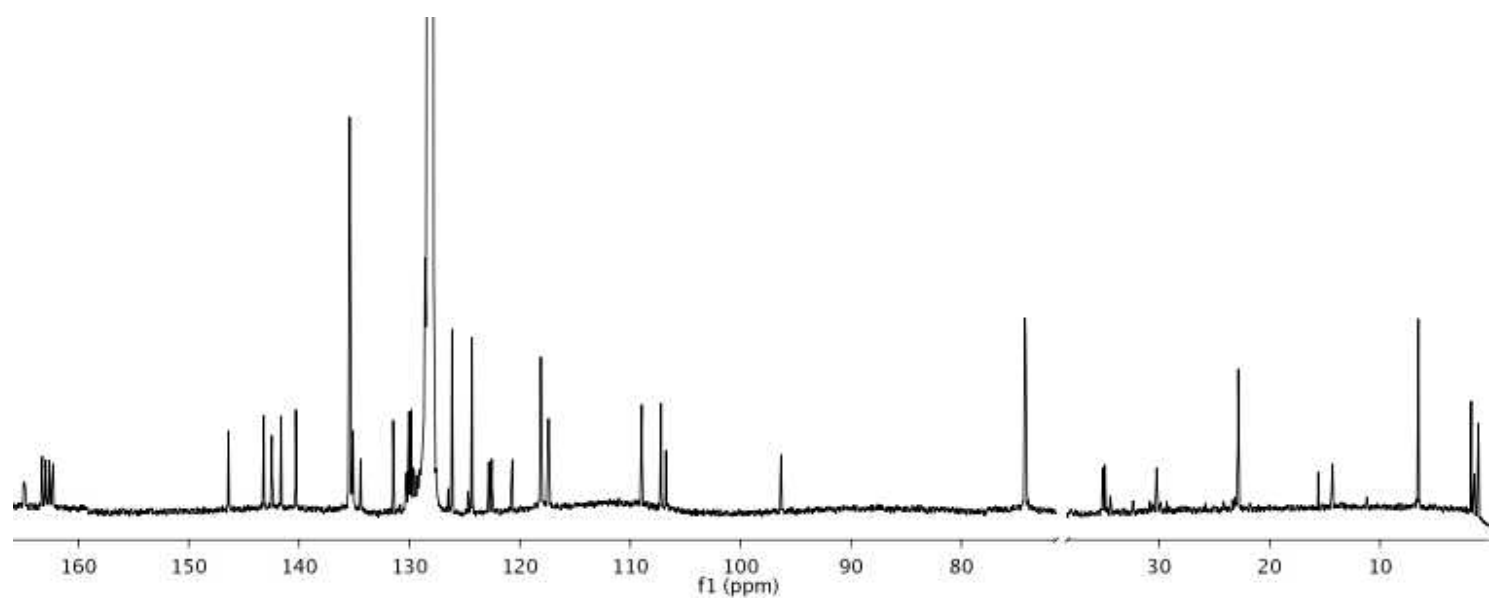

$\begin{array}{lllll}\text { Figure } & 5.34 & { }^{13} \mathrm{C} & \mathrm{NMR} & \text { spectrum }\end{array}$ $\left\{\left[\left(N, C^{5}, N\right) \mathrm{C}(\mathrm{pz})_{4}\right] \mathrm{Ru}\left[\mathrm{P}\left(\mathrm{OCH}_{2}\right)_{3} \mathrm{CEt}\left[(\mathrm{NCMe})_{2}\right\}\left[\mathrm{BAr}_{4}^{\prime}\right](\mathbf{1 5})\right.\right.$ in $\mathrm{C}_{6} \mathrm{D}_{6}$.

\subsection{Conclusions}

A variety of $\mathrm{Ru}(\mathrm{II})$ complexes with neutral 6-electron donor ligands [e.g., $\left(\eta^{6}-p\right.$ cymene, $\mathrm{C}(\mathrm{pz})_{4}$, and $\left.\mathrm{HC}\left(\mathrm{pz}^{\prime}\right)_{3}\right]$ where synthesized and characterized. These complexes were tested for olefin hydroarylation and were either unsuccessful or produced only minimal amounts of alkyl arenes. Additionally, it was found that $\mathrm{Ru}(\mathrm{II})$ complexes containing the $\mathrm{C}(\mathrm{pz})_{4}$ ligand are susceptible to intramolecular $\mathrm{C}-\mathrm{H}$ activation of the 5position on one of the pyrazolyl rings to produce an anionic 6-electron donor as observed in the formation of $\left\{\left(N, C^{5}, N\right) \mathrm{C}(\mathrm{pz})_{4} \mathrm{Ru}\left[\mathrm{P}\left(\mathrm{OCH}_{2}\right)_{3} \mathrm{CEt}\right](\mathrm{NCMe})_{2}\right\}\left[\mathrm{BAr}_{4}{ }_{4}\right]$ from $\left\{\mathrm{C}(\mathrm{pz})_{4} \mathrm{Ru}\left[\mathrm{P}\left(\mathrm{OCH}_{2}\right)_{3} \mathrm{CEt}\right](\mathrm{Me})(\mathrm{NCMe})\right\}\left[\mathrm{BAr}_{4}\right]$ with the release of methane in $\mathrm{C}_{6} \mathrm{H}_{6}$. Using cyclic voltammetry, it was found that replacement of the anionic Tp ligand with a neutral tris(pyrazolyl)alkane ligand in the case of $\left\{\mathrm{HC}\left(\mathrm{pz}^{\prime}\right)_{3} \mathrm{Ru}\left[\mathrm{P}\left(\mathrm{OCH}_{2}\right)_{3} \mathrm{CEt}\right] \mathrm{Ph}(\mathrm{NCMe})\right\}\left[\mathrm{BAr}_{4}\right]$ yields a less electron rich metal center than $\mathrm{TpRu}\left[\mathrm{P}\left(\mathrm{OCH}_{2}\right)_{3} \mathrm{CEt}\right] \mathrm{Ph}(\mathrm{NCMe})$. 


\subsection{Experimental Section}

General Methods. Unless otherwise noted, all synthetic procedures were performed under anaerobic conditions in a nitrogen-filled glovebox or by using standard Schlenk techniques. Glovebox purity was maintained by periodic nitrogen purges and was monitored by an oxygen analyzer $\left[\mathrm{O}_{2}(\mathrm{~g})<15 \mathrm{ppm}\right.$ for all reactions $]$. Tetrahydrofuran was dried by distillation from sodium/benzophenone. Pentane was distilled over $\mathrm{P}_{2} \mathrm{O}_{5}$. Acetonitrile and diethyl ether were dried by distillation from $\mathrm{CaH}_{2}$. Hexanes, benzene and methylene chloride were purified by passage through a column of activated alumina. Benzene- $d_{6}$, acetonitrile- $d_{3}$, methylene chloride- $d_{2}$ and chloroform- $d_{1}$ were stored under a $\mathrm{N}_{2}$ atmosphere over $4 \AA$ molecular sieves. ${ }^{1} \mathrm{H}$ NMR spectra were recorded on a Varian Mercury Plus $300 \mathrm{MHz}$ Spectrometer, a Varian Inova $500 \mathrm{MHz}$ Spectrometer, or a Bruker Avance DRX $600 \mathrm{MHz}$ spectrometer and ${ }^{13} \mathrm{C}$ NMR spectra were recorded on a Varian Inova $500 \mathrm{MHz}$ Spectrometer (operating frequency $125 \mathrm{MHz}$ ), a Bruker Avance

DRX $600 \mathrm{MHz}$ spectrometer (operating frequency $201 \mathrm{MHz}$ ). All ${ }^{1} \mathrm{H}$ and ${ }^{13} \mathrm{C}$ NMR spectra are referenced against residual proton signals $\left({ }^{1} \mathrm{H}\right.$ NMR) or the ${ }^{13} \mathrm{C}$ resonances of the deuterated solvent $\left({ }^{13} \mathrm{C}\right.$ NMR $) .{ }^{31} \mathrm{P}$ NMR spectra were obtained on a Varian $300 \mathrm{MHz}$ (operating frequency $121 \mathrm{MHz}$ ) spectrometer and referenced against an external standard of $\mathrm{H}_{3} \mathrm{PO}_{4}(\delta=0 \mathrm{ppm}) .{ }^{19} \mathrm{~F}$ NMR spectra were obtained on a Varian $300 \mathrm{MHz}$ (operating frequency $282 \mathrm{MHz}$ ) spectrometer and referenced against an external standard of hexafluorobenzene $(\delta=-164.9 \mathrm{ppm})$.

Electrochemical experiments were performed under a nitrogen atmosphere using a BAS Epsilon Potentiostat. Cyclic voltammograms were recorded in $\mathrm{NCCH}_{3}$ using a 
standard three electrode cell from -1700 to $1700 \mathrm{mV}$ at $100 \mathrm{mV} / \mathrm{s}$ with a glassy carbon working electrode and tetrabutylammonium hexafluorophosphate as electrolyte. All potentials are reported versus NHE (normal hydrogen electrode) using ferrocene as the internal standard. High resolution mass spectra were acquired in ESI mode, from samples dissolved in a 3:1 acetonitrile/water solution containing sodium trifluoroacetate (NaTFA). Mass spectra are reported for $\mathrm{M}^{+}$for monocationic complexes, or for $\left[\mathrm{M}+\mathrm{H}^{+}\right]$or $\left[\mathrm{M}+\mathrm{Na}^{+}\right]$ for neutral complexes, using $\left[\mathrm{Na}(\mathrm{NaTFA})_{\mathrm{x}}\right]^{+}$clusters as an internal standard. In all cases, observed isotopic envelopes were consistent with the molecular composition reported. For organic products, the monoisotopic ion is reported; for complexes, the major peaks in the isotopic envelope are reported. Spectra were collected on either a Bruker BioTOF-Q, a PerkinElmer Axion2 TOF, a Shimadzu IT-TOF, a Bruker MaXis Impact, an Agilent 6230 TOF, or a Waters Xevo G2Qtof. Elemental Analysis was performed by Atlantic Microlabs, Inc. Ethylene and propylene were used as received. The preparation, isolation and characterization of $\left[\left(\eta^{6}-p \text {-cymene }\right) \mathrm{Ru}(\mathrm{Br})(\mu-\mathrm{Br})\right]_{2}{ }^{21}, \mathrm{NaBAr}_{4}{ }^{22}, \mathrm{Ph}_{2} \mathrm{Mg}[\mathrm{THF}]_{2},{ }^{23}$ and $\mathrm{HC}\left(\mathrm{pz}^{\prime}\right)_{3}{ }^{24}$ have been previously reported. $\mathrm{P}\left(\mathrm{OCH}_{2}\right)_{3} \mathrm{CEt}$ was obtained from a commercial source and purified by dissolution in hexanes and filtration through Celite. The filtrate was concentrated to dryness to yield a white solid. All other reagents were used as purchased from commercial sources.

$\left(\eta^{6}-p\right.$-cymene $) \mathbf{R u}\left[\mathbf{P}\left(\mathbf{O C H}_{2}\right)_{3} \mathbf{C E t}\right] \mathrm{Br}_{2} \quad$ (1). The binuclear complex $\left[\left(\eta^{6}-p\right.\right.$ cymene $) \mathrm{Ru}(\mathrm{Br})(\mu-\mathrm{Br})]_{2}(2.726 \mathrm{~g}, 3.450 \mathrm{mmol})$ and $\mathrm{P}\left(\mathrm{OCH}_{2}\right)_{3} \mathrm{CEt}(1.4111 \mathrm{~g}, 8.692$ mmol) were combined in a $1 \mathrm{~L}$ round bottom flask with $400 \mathrm{~mL}$ of methylene chloride. The reaction mixture was stirred at room temperature for $2 \mathrm{~h}$. The volume of the solution 
was reduced in vacuo to $\sim 50 \mathrm{~mL}$. Hexanes were added to yield a reddish-orange precipitate. The solid was collected by filtration through a fine porosity frit and dried in vacuo to yield a reddish-orange solid $(3.7293 \mathrm{~g}, 97 \%) .{ }^{1} \mathrm{H} \mathrm{NMR}\left(600 \mathrm{MHz}, \mathrm{CDCl}_{3}\right) \delta$ $5.62\left(\mathrm{~d}, 2 \mathrm{H},{ }^{3} J_{\mathrm{HH}}=6 \mathrm{~Hz}, \mathrm{Cy}-\mathrm{C}_{\mathrm{Ar}}\right), 5.49\left(\mathrm{~d}, 2 \mathrm{H},{ }^{3} J_{\mathrm{HH}}=6 \mathrm{~Hz}, \mathrm{Cy}-\mathrm{C}_{\mathrm{Ar}}\right), 4.36\left(\mathrm{~d}, 2 \mathrm{H},{ }^{3} J_{\mathrm{HH}}=\right.$ $\left.5 \mathrm{~Hz}, \mathrm{P}\left(\mathrm{OCH}_{2}\right)_{3} \mathrm{CCH}_{2} \mathrm{CH}_{3}\right), 3.00$ (sept, $\left.\left.1 \mathrm{H}, \mathrm{Cy}-\mathrm{CH}\left(\mathrm{CH}_{3}\right)_{2}\right)\right), 2.28$ (s, 3H, Cy-CH3), 1.26 $\left(\mathrm{q},{ }^{3} J_{\mathrm{HH}}=8 \mathrm{~Hz}, \mathrm{P}\left(\mathrm{OCH}_{2}\right)_{3} \mathrm{CCH}_{2} \mathrm{CH}_{3}\right), 1.22\left(\mathrm{~d},{ }^{3} J_{\mathrm{HH}}=7 \mathrm{~Hz}, 6 \mathrm{H}, \mathrm{Cy}-\mathrm{CH}\left(\mathrm{CH}_{3}\right)_{2}\right), 0.83(\mathrm{t}$, $\left.{ }^{3} J_{\mathrm{HH}}=8 \mathrm{~Hz}, 3 \mathrm{H}, \mathrm{P}\left(\mathrm{OCH}_{2}\right)_{3} \mathrm{CCH}_{2} \mathrm{CH}_{3}\right) .{ }^{13} \mathrm{C} \mathrm{NMR}\left(151 \mathrm{MHz}, \mathrm{CDCl}_{3}\right) \delta 110.6,103.8$ (each a s, Cy-C $\left.\mathrm{Ar}_{\mathrm{Ar}}\right), 89.9\left(\mathrm{~d},{ }^{2} J_{\mathrm{CP}}=8 \mathrm{~Hz}, \mathrm{Cy}-\mathrm{C}_{\mathrm{Ar}}\right), 89.1\left(\mathrm{~d},{ }^{2} J_{\mathrm{CP}}=6 \mathrm{~Hz}, \mathrm{Cy}-\mathrm{C}_{\mathrm{Ar}}\right), 75.7(\mathrm{~d}$, $\left.\left.J_{\mathrm{HP}}=8 \mathrm{~Hz}, \mathrm{P}\left(\mathrm{OCH}_{2}\right)_{3} \mathrm{CCH}_{2} \mathrm{CH}_{3}\right)\right), 36.0\left(\mathrm{~d}, J=32 \mathrm{~Hz}, \mathrm{P}\left(\mathrm{OCH}_{2}\right)_{3} \mathrm{CCH}_{2} \mathrm{CH}_{3}\right), 30.98(\mathrm{~s}, \mathrm{Cy}-$ $\left.\mathrm{CH}\left(\mathrm{CH}_{3}\right)_{2}\right), 23.4$ (s, $\left.\mathrm{P}\left(\mathrm{OCH}_{2}\right)_{3} \mathrm{CCH}_{2} \mathrm{CH}_{3}\right), 22.3$ (s), 19.3 (s), 7.3 (s, $\left.\mathrm{P}\left(\mathrm{OCH}_{2}\right)_{3} \mathrm{CCH}_{2} \mathrm{CH}_{3}\right)$. ${ }^{31} \mathrm{P}$ NMR (121 MHz, $\left.\mathrm{CDCl}_{3}\right) \delta$ 110.5. Anal. Calcd. for $\mathrm{C}_{16} \mathrm{H}_{25} \mathrm{Br}_{2} \mathrm{O}_{3} \mathrm{PRu}$. C, 34.49; $\mathrm{H}$, 4.53; Found C, 34.48; H, 4.57.

\section{$\left(\eta^{6}\right.$-p-cymene $) \mathrm{Ru}\left[\mathrm{P}\left(\mathrm{OCH}_{2}\right)_{3} \mathrm{CEt}\right](\mathrm{Ph}) \mathrm{Br}$}

(2).

$\left(\eta^{6}-p-\right.$ cymene $) \mathrm{Ru}\left[\mathrm{P}\left(\mathrm{OCH}_{2}\right)_{3} \mathrm{CEt}\right] \mathrm{Br}_{2}(0.3551 \mathrm{~g}, 0.6373 \mathrm{mmol})$ was placed in $20 \mathrm{~mL}$ of $\mathrm{THF}$ in a round bottom flask yielding a heterogeneous mixture. $\mathrm{Ph}_{2} \mathrm{Mg}[\mathrm{THF}]_{2}(0.1641 \mathrm{~g}, 0.5085$ mmol) was dissolved in $20 \mathrm{~mL}$ of THF. The $\mathrm{Ph}_{2} \mathrm{Mg}$ solution was added to the round bottom flask containing the $\mathrm{Ru}$ complex. The reaction was stirred at room temperature for $1 \mathrm{~h}$, and the reaction slowly became bright yellow and homogeneous. The THF was removed in vacuo and $40 \mathrm{~mL}$ of benzene was added to the flask. The reaction was stirred for 15 minutes and then filtered through Celite. The benzene solution was eluted through $1 / 2$ inch of silica followed by THF washes. All solvent was removed, and $\sim 5 \mathrm{~mL}$ of methylene chloride was added, followed by hexanes to induce precipitation. The 
precipitate was collected on a fine porosity frit and dried in vacuo to yield a bright yellow solid (0.3362 g, 95\% yield). ${ }^{1} \mathrm{H}$ NMR (600 MHz, $\left.\mathrm{CDCl}_{3}\right) \delta 7.66-7.60$ (m, 2H, phenyl), $6.93-6.88\left(\mathrm{~m}, 2 \mathrm{H}\right.$, phenyl), $6.88-6.83\left(\mathrm{~m}, 1 \mathrm{H}\right.$, phenyl), $5.45\left(\mathrm{dd}, 1 \mathrm{H},{ }^{3} J_{\mathrm{HH}}=6 \mathrm{~Hz},{ }^{3} J_{\mathrm{HP}}\right.$ $\left.=1 \mathrm{~Hz}, \mathrm{Cy}-\mathrm{C}_{\mathrm{Ar}}\right), 5.44\left(\mathrm{dd}, 1 \mathrm{H},{ }^{3} J_{\mathrm{HH}}=6 \mathrm{~Hz},{ }^{3} J_{\mathrm{HP}}=1 \mathrm{~Hz}, \mathrm{Cy}-\mathrm{C}_{\mathrm{Ar}}\right), 5.32\left(\mathrm{dd}, 1 \mathrm{H},{ }^{3} J_{\mathrm{HH}}=6\right.$ $\left.\mathrm{Hz},{ }^{3} J_{\mathrm{HP}}=1 \mathrm{~Hz}, \mathrm{Cy}-\mathrm{C}_{\mathrm{Ar}}\right), 4.98\left(\mathrm{dd}, 1 \mathrm{H},{ }^{3} J_{\mathrm{HH}}=6 \mathrm{~Hz},{ }^{3} J_{\mathrm{HP}}=1 \mathrm{~Hz}, \mathrm{Cy}-\mathrm{C}_{\mathrm{Ar}}\right), 4.24-4.17$ (m, 6H, P(OCH $\left.)_{3} \mathrm{CCH}_{2} \mathrm{CH}_{3}\right), 2.73$ (sept, $1 \mathrm{H},{ }^{2} \mathrm{~J}_{\mathrm{HH}}=7 \mathrm{~Hz},\left(\mathrm{CH}_{3} \mathrm{C}_{6} \mathrm{H}_{4}(\mathrm{CH})\left(\mathrm{CH}_{3}\right)_{2}\right), 1.84$ (s, 3H, $\mathrm{C}_{6} \mathrm{H}_{4}-\mathrm{CH}_{3}$ ), 1.23 - 1.13 (overlapping m's, $8 \mathrm{H}$, coincidental overlap of $\mathrm{P}\left(\mathrm{OCH}_{2}\right)_{3} \mathrm{CCH}_{2} \mathrm{CH}_{3}$ and $\left.\mathrm{C}_{6} \mathrm{H}_{4}-\mathrm{CH}\left(\mathrm{CH}_{3}\right)_{2}\right), \quad 0.80 \quad\left(\mathrm{t}, \quad 3 \mathrm{H}, \quad{ }^{3} \mathrm{~J}_{\mathrm{HH}}=8 \mathrm{~Hz}\right.$, $\left.\mathrm{P}\left(\mathrm{OCH}_{2}\right)_{3} \mathrm{CCH}_{2} \mathrm{CH}_{3}\right) .{ }^{13} \mathrm{C} \mathrm{NMR}\left(151 \mathrm{MHz}, \mathrm{CDCl}_{3}\right) \delta 154.2\left(\mathrm{~d},{ }^{2} J_{\mathrm{CP}}=30 \mathrm{~Hz}\right.$, ipso of phenyl), $142.9\left(\mathrm{~d},{ }^{3} J_{\mathrm{PC}}=5 \mathrm{~Hz}\right.$, phenyl), 126.6 (s, phenyl), 121.9 (s, phenyl), $117.4\left(\mathrm{~d},{ }^{3} J_{\mathrm{PC}}\right.$ $=5 \mathrm{~Hz}$, ipso of Cy-C $\left.\mathrm{Cr}_{\mathrm{Ar}}\right), 109.8\left(\mathrm{~d},{ }^{3} J_{\mathrm{PC}}=5 \mathrm{~Hz}\right.$, ipso of Cy-C $\left.\mathrm{C}_{\mathrm{Ar}}\right), 93.6\left(\mathrm{~d},{ }^{2} J_{\mathrm{CP}}=4 \mathrm{~Hz}, \mathrm{Cy}-\right.$ $\left.\mathrm{C}_{\mathrm{Ar}}\right), 91.0\left(\mathrm{~d},{ }^{2} J_{\mathrm{CP}}=10 \mathrm{~Hz}, \mathrm{Cy}-\mathrm{C}_{\mathrm{Ar}}\right), 88.6\left(\mathrm{~d},{ }^{2} J_{\mathrm{CP}}=3 \mathrm{~Hz}, \mathrm{Cy}-\mathrm{C}_{\mathrm{Ar}}\right) 88.3\left(\mathrm{~s}, \mathrm{Cy}-\mathrm{C}_{\mathrm{Ar}}\right), 74.9$ $\left(\mathrm{d},{ }^{2} J_{\mathrm{CP}}=8 \mathrm{~Hz}, \mathrm{P}\left(\mathrm{OCH}_{2}\right)_{3} \mathrm{CCH}_{2} \mathrm{CH}_{3}\right), 35.6\left(\mathrm{~d},{ }^{3} J_{\mathrm{CP}}=32 \mathrm{~Hz}, \mathrm{P}\left(\mathrm{OCH}_{2}\right)_{3} \mathrm{CCH}_{2} \mathrm{CH}_{3}\right), 31.2(\mathrm{~s}$, $\left.\mathrm{C}_{6} \mathrm{H}_{4}-\mathrm{CH}\left(\mathrm{CH}_{3}\right)_{2}\right), \quad 23.6, \quad 23.3,22.2$ (all s, representing $\mathrm{Cy}-\mathrm{CH}\left(\mathrm{CH}_{3}\right)_{2}$ and $\left.\mathrm{P}\left(\mathrm{OCH}_{2}\right)_{3} \mathrm{CCH}_{2} \mathrm{CH}_{3}\right), 18.7\left(\mathrm{~s}, \mathrm{Cy}-\mathrm{CH}_{3}\right), 7.3\left(\mathrm{~s}, \mathrm{P}\left(\mathrm{OCH}_{2}\right)_{3} \mathrm{CCH}_{2} \mathrm{CH}_{3}\right) .{ }^{31} \mathrm{P} \mathrm{NMR}$ (121 $\left.\mathrm{MHz}, \mathrm{CDCl}_{3}\right) \delta$ 123.7. Anal. Calcd. for $\mathrm{C}_{22} \mathrm{H}_{30} \mathrm{BrO}_{3} \mathrm{PRu} . \mathrm{C}, 47.66 ; \mathrm{H}, 5.45$; Found $\mathrm{C}$, 46.62; H, 5.40. HRMS: [M+Na $\left.{ }^{+}\right]$obs'd (\%), calc'd (\%), ppm: 576.0067 (52), 576.0061 (60), 1.1; 577.0058 (92), 577.0053 (94), $0.9 ; 578.0063$ (42), 578.0060 (52.5), 0.5 ; 579.0054 (100), $579.0048(100), 1.1$.

$\left(\eta^{6}\right.$-p-cymene)Ru(PMe $) \mathrm{Br}_{2}$ (3). $\left[\left(\eta^{6}-p \text {-cymene }\right) \mathrm{Ru}(\mathrm{Br})(\mu-\mathrm{Br})\right]_{2}^{21} \quad(0.6352 \mathrm{~g}$, $0.8039 \mathrm{mmol}$ ) was dissolved in $20 \mathrm{~mL}$ of methylene chloride in a round bottom flask. $\mathrm{PMe}_{3}(0.18347 \mathrm{~g}, 2.416 \mathrm{mmol})$ was added to the solution in the round bottom flask via 
syringe. The reaction was allowed to stir for 30 minutes. The reaction mixture was concentrated to $\sim 5 \mathrm{~mL}$ under vacuum with slight warming. Hexanes were added to induce a precipitate. The precipitate was collected on a fine porosity frit and washed with pentane three times and dried under vacuum. (0.6724 g, 89\% yield) ${ }^{1} \mathrm{H}$ NMR (600 MHz, $\left.\mathrm{CDCl}_{3}\right) \delta 5.44-5.41\left(\mathrm{~m}, 2 \mathrm{H}, \mathrm{Cy}-\mathrm{C}_{\mathrm{Ar}}\right), 5.39\left(\mathrm{~d}, 2 \mathrm{H},{ }^{3} \mathrm{~J}_{\mathrm{HH}}=6 \mathrm{~Hz}, \mathrm{Cy}-\mathrm{C}_{\mathrm{Ar}}\right), 2.95($ sept, $1 \mathrm{H}$, $\left.{ }^{3} J_{\mathrm{HH}}=7 \mathrm{~Hz}, \mathrm{Cy}-\mathrm{CH}\left(\mathrm{CH}_{3}\right)_{2}\right), 2.13\left(\mathrm{~s}, 3 \mathrm{H}, \mathrm{Cy}-\mathrm{CH}_{3}\right), 1.68\left(\mathrm{~d}, 9 \mathrm{H},{ }^{2} J_{\mathrm{HP}}=11 \mathrm{~Hz}, \mathrm{PMe}_{3}\right)$, $1.20\left(\mathrm{~d}, 6 \mathrm{H},{ }^{3} J_{\mathrm{HH}}=7 \mathrm{~Hz}, \mathrm{Cy}-\mathrm{CH}\left(\mathrm{CH}_{3}\right)_{2}\right) \cdot{ }^{13} \mathrm{C} \mathrm{NMR}\left(151 \mathrm{MHz}, \mathrm{CDCl}_{3}\right) \delta 108.5(\mathrm{~s}$, C6H4), $93.8\left(\mathrm{~s}, \mathrm{Cy}-\mathrm{C}_{\mathrm{Ar}}\right), 89.4\left(\mathrm{~d},{ }^{2} J_{\mathrm{CP}}=5 \mathrm{~Hz}, \mathrm{Cy}-\mathrm{C}_{\mathrm{Ar}}\right), 84.5\left(\mathrm{~d},{ }^{2} J_{\mathrm{CP}}=6 \mathrm{~Hz}, \mathrm{Cy}-\mathrm{C}_{\mathrm{Ar}}\right)$, $31.1\left(\mathrm{~s}, \mathrm{Cy}-\mathrm{CH}\left(\mathrm{CH}_{3}\right)_{2}\right), 22.2\left(\mathrm{~s}, \mathrm{Cy}-\mathrm{CH}\left(\mathrm{CH}_{3}\right)_{2}\right), 19.1\left(\mathrm{~s}, \mathrm{Cy}-\mathrm{CH}_{3}\right), 18.4\left(\mathrm{~d},{ }^{2} J_{\mathrm{CP}}=34.4\right.$ $\left.\mathrm{Hz}, \mathrm{PMe}_{3}\right) .{ }^{31} \mathrm{P}\left\{{ }^{1} \mathrm{H}\right\} \mathrm{NMR}\left(121 \mathrm{MHz}, \mathrm{CDCl}_{3}\right) \delta-2.0 \mathrm{ppm}$. HRMS: $\left[\mathrm{M}+\mathrm{Na}^{+}\right]$obs'd (\%), calc'd (\%), ppm: 491.8850 (32), 491.8844 (45), 1.2; 492.8842 (52), 492.8834 (65), 1.6; 493.8841 (40), 493.8833 (55), 1.5; 494.8835 (100), 494.8826 (100), 1.9; 495.8839 (18), $495.8833(30), 1.3 ; 496.8825(60), 496.8818$ (70), 1.4.

( $\eta^{6}$-p-cymene)Ru(PMe $) \operatorname{PhBr} \quad$ (4). $\quad\left(\eta^{6}-p\right.$-cymene)Ru(PMe $) \mathrm{Br}_{2} \quad(0.3353 \quad \mathrm{~g}$, $0.7116 \mathrm{mmol}$ ) was combined with $20 \mathrm{~mL}$ of THF (heterogeneous) and added to a $100 \mathrm{~mL}$ round bottom flask. $\mathrm{Ph}_{2} \mathrm{Mg}[\mathrm{THF}]_{2}(0.1770 \mathrm{~g}, 0.5485 \mathrm{mmol})$ was dissolved in $20 \mathrm{~mL}$ THF and added to the round bottom flask containing the $\mathrm{Ru}$ mixture. The reaction was allowed to stir $\sim 1 \mathrm{~h}$ during which time the reaction slowly became homogeneous and bright yellow. All the solvent was removed in vacuo, and $\sim 30 \mathrm{~mL}$ of benzene were added to the flask. The solution was filtered through Celite. The filtrate was then eluted on a 1" silica plug; the plug was then washed with copious amounts of THF. The THF eluent was removed in vacuo to yield a bright yellow solid, which was collected on a fine 
porosity frit and washed with pentane. Dried in vacuo to yield a yellow solid $(0.2974 \mathrm{~g}$, 89\% yield). ${ }^{1} \mathrm{H}$ NMR (600 MHz, $\left.\mathrm{CDCl}_{3}\right) \delta 7.57$ (bs, 2H, phenyl), $6.95-6.82(\mathrm{~m}, 3 \mathrm{H}$, phenyl), $5.28\left(\mathrm{~d}, 1 \mathrm{H},{ }^{3} J_{\mathrm{HH}}=5.7 \mathrm{~Hz}, \mathrm{Cy}-\mathrm{C}_{\mathrm{Ar}}\right), 5.11\left(\mathrm{~m}, 2 \mathrm{H}, \mathrm{Cy}-\mathrm{C}_{\mathrm{Ar}}\right), 4.82(\mathrm{~d}, 1 \mathrm{H}, J=5.7$ $\left.\mathrm{Hz}, \mathrm{Cy}-\mathrm{C}_{\mathrm{Ar}}\right), 2.62\left(\mathrm{sept}, 1 \mathrm{H},{ }^{2} \mathrm{~J}_{\mathrm{HH}}=7 \mathrm{~Hz}, \mathrm{C}_{6} \mathrm{H}_{4}-\mathrm{CH}\left(\mathrm{CH}_{3}\right)_{2}\right), 1.91\left(\mathrm{~s}, 3 \mathrm{H}, \mathrm{Cy}-\mathrm{CH}_{3}\right), 1.35$ (d, $\left.9 \mathrm{H},{ }^{2} J_{\mathrm{HP}}=10 \mathrm{~Hz}, \mathrm{PMe}_{3}\right), 1.20\left(\mathrm{~d}, 3 \mathrm{H},{ }^{3} J_{\mathrm{HH}}=7 \mathrm{~Hz}, \mathrm{CH}\left(\mathrm{CH}_{3}\right)_{2}\right), 1.09\left(\mathrm{~d}, 3 \mathrm{H},{ }^{3} J_{\mathrm{HH}}=7 \mathrm{~Hz}\right.$, $\left.\mathrm{CH}\left(\mathrm{CH}_{3}\right)_{2}\right) .{ }^{13} \mathrm{C} \mathrm{NMR}\left(151 \mathrm{MHz}, \mathrm{CDCl}_{3}\right) \delta 161.2\left(\mathrm{~d},{ }^{2} J_{\mathrm{CP}}=25 \mathrm{~Hz}\right.$, ipso of phenyl), 141.9 $\left(\mathrm{d},{ }^{3} J_{\mathrm{PC}}=93.84 \mathrm{~Hz}\right.$, phenyl) 126.5 (s, phenyl), 121.7 (s, phenyl), $114.2\left(\mathrm{~d},{ }^{3} J_{\mathrm{PC}}=4 \mathrm{~Hz}\right.$, ipso of Cy-C $\left.\mathrm{Ar}_{\mathrm{Ar}}\right), 104.1\left(\mathrm{~s}, \mathrm{Cy}-\mathrm{C}_{\mathrm{Ar}}\right), 88.2\left(\mathrm{~d},{ }^{2} J_{\mathrm{CP}}=3 \mathrm{~Hz}, \mathrm{Cy}-\mathrm{CAr}\right), 86.4\left(\mathrm{~d},{ }^{2} J_{\mathrm{CP}}=6 \mathrm{~Hz}\right.$, Cy-C $\mathrm{Ar}), 85.9\left(\mathrm{~d},{ }^{2} J_{\mathrm{CP}}=4 \mathrm{~Hz}, \mathrm{Cy}-\mathrm{C}_{\mathrm{Ar}}\right), 85.6\left(\mathrm{~s}, \mathrm{Cy}-\mathrm{C}_{\mathrm{Ar}}\right) 31.4\left(\mathrm{~s}, \mathrm{Cy}-\mathrm{CH}\left(\mathrm{CH}_{3}\right)_{2}\right), 23.0(\mathrm{~s}$, $\left.\mathrm{Cy}-\mathrm{CH}\left(\mathrm{CH}_{3}\right)_{2}\right), 22.7\left(\mathrm{~s}, \mathrm{Cy}-\mathrm{CH}\left(\mathrm{CH}_{3}\right)_{2}\right), 19.0\left(\mathrm{~s}, \mathrm{Cy}-\mathrm{CH}_{3}\right) 17.8\left(\mathrm{~d},{ }^{2} J_{\mathrm{CP}}=33 \mathrm{~Hz}, \mathrm{PMe}_{3}\right)$. ${ }^{31} \mathrm{P}\left\{{ }^{1} \mathrm{H}\right\}$ NMR $\left(121 \mathrm{MHz}, \mathrm{CDCl}_{3}\right) \delta$ 4.5. HRMS: $\left[\mathrm{M}^{+} \mathrm{Na}^{+}\right]$obs'd (\%), calc'd (\%), ppm: 490.0054 (65), 490.0056 (61), -0.4; 491.0046 (95), 491.0048 (93.6), -0.4; 492.0053 (50), 492.0054 (49.1), -0.2; 493.0042 (100), 493.0043 (100), -0.2.

Tetrakis(1-pyrazolyl)methane. The synthesis of $\mathrm{C}(\mathrm{pz})_{4}$ has been previously reported. ${ }^{25,26}$ We used an alternate procedure. Pyrazolyl (13.437 g, $\left.0.19737 \mathrm{~mol}\right)$ and $\left[\mathrm{Bu}_{4} \mathrm{~N}\right]\left[\mathrm{HSO}_{4}\right](2.795 \mathrm{~g}, 0.008232 \mathrm{~mol})$ were dissolved in $\mathrm{CCl}_{4}(200 \mathrm{~mL})$ and transferred to a $500 \mathrm{~mL}$ round bottom flask. $\mathrm{K}_{2} \mathrm{CO}_{3}(27.90 \mathrm{~g}, 0.2013 \mathrm{~mol})$ was added in small portions with stirring. $\mathrm{KOH}$ flakes $(57.810 \mathrm{~g}, 1.0304 \mathrm{~mol})$ were added to the flask and the reaction was stirred at reflux (under nitrogen) for three days. The reaction was cooled and filtered through Celite $(\sim 1 / 2$ ’). The flask and Celite were washed with methylene chloride, yielding a reddish filtrate. The filtrate was then eluted through approximately 1 inch of silica, and the silica was washed with copious amounts of methylene chloride 
until the eluent was almost colorless. The yellow eluent was collected and reduced to dryness under reduced pressure. The yellow oil was reconstituted in diethyl ether and was reduced to dryness under reduced pressure. A minimal amount of diethyl ether was added to the flask, and the flask was placed in the freezer. A white solid precipitated. The solid was collected on a fine porosity frit, washed with a minimal amount of cold diethyl ether followed by pentane and dried under vacuum. A second batch could be isolated by reduction of filtrate, reconstitution in fresh ether and slow evaporate at room temperature (1.504 g, 11\% yield).

$\left(\kappa^{3}-\mathbf{N}, C^{5}, \mathbf{N}\right) \mathbf{C}(\mathbf{p z})_{4} \mathbf{R u}\left[\mathbf{P}(\mathbf{O C H})_{3} \mathbf{C E t}\right](\mathbf{N C M e}) \mathrm{Br} \quad(6)$. The complex $\left(\eta^{6}-p-\right.$ cymene $) \mathrm{Ru}\left[\mathrm{P}\left(\mathrm{OCH}_{2}\right)_{3} \mathrm{CEt}\right](\mathrm{Ph}) \mathrm{Br}(0.0747 \mathrm{~g}, 0.134 \mathrm{mmol})$ was dissolved in $\sim 5 \mathrm{~mL}$ of NCMe and added to a pressure tube. The reaction was heated for $19 \mathrm{~h}$ at $90{ }^{\circ} \mathrm{C}$. The reaction was brought into the glovebox and allowed to cool to room temperature. The mixture was filtered through Celite, and the yellow filtrate was reduced to dryness. The solid was washed with THF and benzene (both solutions discarded). The remaining solid was reconstituted in a minimal amount of methylene chloride and diethyl ether was added to induce a precipitate. The precipitate was collected on a fine porosity frit, washed with pentane and dried under vacuum to yield a yellow solid $(0.0321 \mathrm{~g}, 35 \%$ yield $) .{ }^{1} \mathrm{H}$ NMR $\left(497 \mathrm{MHz}, \mathrm{CD}_{2} \mathrm{Cl}_{2}\right) \delta 9.27\left(\mathrm{~d}, 1 \mathrm{H},{ }^{3} J_{\mathrm{HH}}=3 \mathrm{~Hz}, \mathrm{C}(\mathrm{pz})_{4}\right), 8.44\left(\mathrm{~s}, 1 \mathrm{H}, \mathrm{C}(\mathrm{pz})_{4}\right), 8.04(\mathrm{~m}$, 2H, overlapping $\left.\mathrm{C}(\mathrm{pz})_{4}\right), 7.89\left(\mathrm{~s}, 1 \mathrm{H}, \mathrm{C}(\mathrm{pz})_{4}\right), 7.43\left(\mathrm{t}, 1 \mathrm{H},{ }^{3} J_{\mathrm{HH}}=1.3 \mathrm{~Hz}, \mathrm{C}(\mathrm{pz})_{4}\right), 6.72(\mathrm{~s}$, $\left.1 \mathrm{H}, \mathrm{C}(\mathrm{pz})_{4}\right), 6.36\left(\mathrm{dt}, 1 \mathrm{H},{ }^{3} J_{\mathrm{HH}}=3.6,{ }^{3} J_{\mathrm{HH}}=1.6 \mathrm{~Hz}, \mathrm{C}(\mathrm{pz})_{4}\right), 6.25\left(\mathrm{t}, 1 \mathrm{H},{ }^{3} J_{\mathrm{HH}}=1.3 \mathrm{~Hz}\right.$, $\left.\mathrm{C}(\mathrm{pz})_{4}\right), 6.08\left(\mathrm{t}, 1 \mathrm{H},{ }^{3} J_{\mathrm{HH}}=3 \mathrm{~Hz}, \mathrm{C}(\mathrm{pz})_{4}\right), 5.91\left(\mathrm{~d}, 1 \mathrm{H},{ }^{3} J_{\mathrm{HH}}=3 \mathrm{~Hz}, \mathrm{C}(\mathrm{pz})_{4}\right), 4.28(\mathrm{~d}, 6 \mathrm{H}$, $\left.{ }^{3} J_{\mathrm{HP}}=4.6 \mathrm{~Hz}, \mathrm{P}\left(\mathrm{OCH}_{2}\right)_{3} \mathrm{CCH}_{2} \mathrm{CH}_{3}\right), 2.29\left(\mathrm{~s}, 3 \mathrm{H}, \mathrm{NCCH}_{3}\right), 1.23\left(\mathrm{q}, 2 \mathrm{H},{ }^{3} J_{\mathrm{HH}}=7.7 \mathrm{~Hz}\right.$, 
$\left.\mathrm{P}\left(\mathrm{OCH}_{2}\right)_{3} \mathrm{CCH}_{2} \mathrm{CH}_{3}\right), 0.83\left(\mathrm{t}, 3 \mathrm{H},{ }^{3} J_{\mathrm{HH}}=7.7 \mathrm{~Hz}, \mathrm{P}\left(\mathrm{OCH}_{2}\right)_{3} \mathrm{CCH}_{2} \mathrm{CH}_{3}\right) .{ }^{13} \mathrm{C}^{\mathrm{NMR}}(125$ $\left.\mathrm{MHz}, \mathrm{CD}_{2} \mathrm{Cl}_{2}\right) \delta 170.4\left(\mathrm{~d},{ }^{2} J_{\mathrm{CP}}=18 \mathrm{~Hz} \mathrm{Ru}-\mathrm{C}(\mathrm{pz})_{4}\right), 148.5,146.5,144.5,143.5,141.4$, $140.3,130.7,121.9,109.3,107.2,107.0$ (each a s, C(pz) $\left.)_{4}\right), 96.3\left(\mathrm{~s}, C(\mathrm{pz})_{4}\right), 74.6\left(\mathrm{~d},{ }^{2} J_{\mathrm{CP}}\right.$ $\left.=7.2 \mathrm{~Hz}, \mathrm{P}\left(\mathrm{OCH}_{2}\right)_{3} \mathrm{CCH}_{2} \mathrm{CH}_{3}\right), 35.6\left(\mathrm{~d},{ }^{3} J_{\mathrm{CP}}=31 \mathrm{~Hz}, \mathrm{P}\left(\mathrm{OCH}_{2}\right)_{3} \mathrm{CCH}_{2} \mathrm{CH}_{3}\right), 24.0(\mathrm{~s}$, $\left.\mathrm{P}\left(\mathrm{OCH}_{2}\right)_{3} \mathrm{CCH}_{2} \mathrm{CH}_{3}\right), 7.5\left(\mathrm{~s}, \mathrm{P}\left(\mathrm{OCH}_{2}\right)_{3} \mathrm{CCH}_{2} \mathrm{CH}_{3}\right), 4.8\left(\mathrm{~s}, \mathrm{NCCH}_{3}\right) .{ }^{31} \mathrm{P} \mathrm{NMR}(121 \mathrm{MHz}$, $\left.\mathrm{CD}_{2} \mathrm{Cl}_{2}\right) \delta 133.4$

$\left\{\left[\mathbf{H C}\left(\mathbf{p z}^{\prime}\right)_{3}\right] \mathbf{R u}\left[\mathbf{P}\left(\mathrm{OCH}_{2}\right)_{3} \mathbf{C E t}\right] \mathbf{P h}(\mathbf{N C M e})\right\}[\mathbf{B r}] \quad$ (7). The complex $\quad\left(\eta^{6}-p-\right.$ cymene $) \mathrm{Ru}\left[\mathrm{P}\left(\mathrm{OCH}_{2}\right)_{3} \mathrm{CEt}\right](\mathrm{Ph}) \mathrm{Br} \quad(0.2854 \mathrm{~g}, \quad 0.5151 \mathrm{mmol})$ was dissolved in approximately $15 \mathrm{~mL}$ of $\mathrm{NCMe}$, added to a pressure tube and heated for $2 \mathrm{~h}$ at $70{ }^{\circ} \mathrm{C}$. The reaction was brought into the glovebox and allowed to cool to room temperature. The mixture was filtered through Celite, and the filtrate was concentrated to dryness yielding $(\mathrm{NCMe})_{3} \mathrm{Ru}\left[\mathrm{P}\left(\mathrm{OCH}_{2}\right)_{3} \mathrm{CEt}\right](\mathrm{Ph}) \mathrm{Br}(3)$. Without any purification, the resulting solid was dissolved in $\sim 10 \mathrm{~mL}$ of methylene chloride and added to a pressure tube along with a 5 $\mathrm{mL}$ methylene chloride solution of $\mathrm{HC}\left(\mathrm{pz}^{\prime}\right)_{3}(0.1452 \mathrm{~g}, 0.4870 \mathrm{mmol})$. The reaction was heated to $70^{\circ} \mathrm{C}$ for $2 \mathrm{~h}$. The reaction was brought into the glovebox and filtered through Celite. The filtrate was concentrated to dryness. Benzene was added, and the mixture was stirred.. The mixture was filtered through Celite, and the filtrate was discarded. The remaining solid in the flask was reconsitituted in methylene chloride and filtered through Celite, concentrated to $\sim 2 \mathrm{~mL}$, and hexanes were added to induce a precipitate. The precipitate was collected on a fine porosity frit. The solid was washed with pentane and dried in vacuo to yield a tan solid $(0.2065 \mathrm{~g}, 53 \%$ yield $) .{ }^{1} \mathrm{H} \mathrm{NMR}\left(600 \mathrm{MHz}, \mathrm{CD}_{2} \mathrm{Cl}_{2}\right) \delta$ $7.87\left(\mathrm{~s}, 1 \mathrm{H}, H \mathrm{C}(\mathrm{pz})_{3}\right), 7.62\left(\mathrm{~d}, 1 \mathrm{H},{ }^{3} J_{\mathrm{HH}}=7.6 \mathrm{~Hz}\right.$, ortho-phenyl), $6.91\left(\mathrm{t}, 1 \mathrm{H},{ }^{3} J_{\mathrm{HH}}=7.4\right.$ 
$\mathrm{Hz}$, meta-phenyl), $6.74\left(\mathrm{t}, 1 \mathrm{H},{ }^{3} J_{\mathrm{HH}}=7.2 \mathrm{~Hz}\right.$, para-phenyl), 6.60 (t, $1 \mathrm{H}, J=7.4 \mathrm{~Hz}$, metaphenyl), $6.37\left(\mathrm{~d}, 1 \mathrm{H},{ }^{3} J_{\mathrm{HH}}=7.6 \mathrm{~Hz}\right.$, ortho-phenyl), 6.15, 6.04, 5.98 (each a s, $1 \mathrm{H}$, $\mathrm{HC}\left(\mathrm{pz}^{\prime}\right)_{3} ;$ 4-positions $), 4.22\left(\mathrm{~d}, 6 \mathrm{H},{ }^{3} \mathrm{~J}_{\mathrm{HP}}=4.6 \mathrm{~Hz}, \mathrm{P}\left(\mathrm{OCH}_{2}\right)_{3} \mathrm{CCH}_{2} \mathrm{CH}_{3}\right), 2.64$ (overlapping s, 9H, $\mathrm{HC}\left(\mathrm{pz}^{\prime}\right)_{3} ; 3,5$-methyl positions), 2.53, 1.97, 1.41 (each a s, 3H, $\mathrm{HC}\left(\mathrm{pz}^{\prime}\right)_{3} ; 3,5$-methyl positions), $2.35\left(\mathrm{~s}, 3 \mathrm{H}, \mathrm{NCCH}_{3}\right), 1.23\left(\mathrm{q}, 2 \mathrm{H},{ }^{3} J_{\mathrm{HH}}=7.6 \mathrm{~Hz}\right.$, $\left.\mathrm{P}\left(\mathrm{OCH}_{2}\right)_{3} \mathrm{CCH}_{2} \mathrm{CH}_{3}\right), 0.83\left(\mathrm{t}, 3 \mathrm{H},{ }^{3} J_{\mathrm{HH}}=7.7 \mathrm{~Hz}, \mathrm{P}\left(\mathrm{OCH}_{2}\right)_{3} \mathrm{CCH}_{2} \mathrm{CH}_{3}\right) .{ }^{13} \mathrm{C} \mathrm{NMR}^{(151}$ $\left.\mathrm{MHz}, \mathrm{CD}_{2} \mathrm{Cl}_{2}\right) \delta 165.3\left(\mathrm{~d},{ }^{2} J_{\mathrm{CP}}=19 \mathrm{~Hz}\right.$, ipso of phenyl) $158.9,156.5,156.1,141.2$, 140.6, 140.5 (each a s, $\mathrm{HC}\left(\mathrm{pz}^{\prime}\right)_{3}-\mathrm{CCH}_{3}$ ), 143.46 (phenyl), 141.7 (phenyl), 125.8 (phenyl), 125.2 (phenyl), 124.0 (s, $\mathrm{NCCH}_{3}$ ), 120.6 (phenyl), 109.9, 109.6, 109.3 (each a s, $\mathrm{HC}\left(\mathrm{pz}^{\prime}\right)_{3}-\mathrm{CH}$ group), $74.5\left(\mathrm{~d},{ }^{2} J_{\mathrm{CP}}=7.2 \mathrm{~Hz}, \mathrm{P}\left(\mathrm{OCH}_{2}\right)_{3} \mathrm{CCH}_{2} \mathrm{CH}_{3}\right), 68.8\left(\mathrm{~s}, H \mathrm{C}(\mathrm{pz})_{3}\right)$, $35.6\left(\mathrm{~d},{ }^{3} J_{\mathrm{CP}}=30.8 \mathrm{~Hz}, \mathrm{P}\left(\mathrm{OCH}_{2}\right)_{3} \mathrm{CCH}_{2} \mathrm{CH}_{3}\right), 24.0\left(\mathrm{~s}, \mathrm{P}\left(\mathrm{OCH}_{2}\right)_{3} \mathrm{CCH}_{2} \mathrm{CH}_{3}\right)$ 15.8, 14.0, 13.1, 12.3, 11.9, 11.8 (each a s, $\mathrm{HC}\left(\mathrm{pz}^{\prime}\right)_{3}-\mathrm{CH}_{3}$ group), $7.5\left(\mathrm{~s}, \mathrm{P}\left(\mathrm{OCH}_{2}\right)_{3} \mathrm{CCH}_{2} \mathrm{CH}_{3}\right), 4.8$ (s, $\left.\mathrm{NCCH}_{3}\right) .{ }^{31} \mathrm{P} \mathrm{NMR}\left(121 \mathrm{MHz}, \mathrm{CD}_{2} \mathrm{Cl}_{2}\right) \delta 137.4$.

\section{$\left\{\left[\mathrm{HC}\left(\mathrm{pz}^{\prime}\right)_{3}\right] \mathrm{Ru}\left[\mathrm{P}\left(\mathrm{OCH}_{2}\right)_{3} \mathrm{CEt}\right] \mathrm{Ph}(\mathrm{NCMe})\right\}\left[\mathrm{BAr}^{\prime}{ }_{4}\right]$}

(8). $\left\{\left[\mathrm{HC}\left(\mathrm{pz}^{\prime}\right)_{3}\right] \mathrm{Ru}\left[\mathrm{P}\left(\mathrm{OCH}_{2}\right)_{3} \mathrm{CEt}\right] \mathrm{Ph}(\mathrm{NCMe})\right\}[\mathrm{Br}] \quad(7) \quad(0.0487 \mathrm{~g}, 0.0641 \mathrm{mmol})$ was dissolved in approximately $5 \mathrm{~mL}$ of THF (heterogeneous) in a round bottom flask. $\mathrm{NaBAr}_{4}^{\prime}(0.0569 \mathrm{~g}, 0.0641 \mathrm{mmol})$ was dissolved in $2 \mathrm{~mL}$ of THF and added to the round bottom flask. The reaction was allowed to stir at room temperature for $2 \mathrm{~h}$. The solution was filtered through Celite, and the filtrate was concentrated to dryness. The solid was reconstituted in methylene chloride and all the volatiles were removed yielding a lowdensity yellow solid (0.0866 g, 87\% yield). ${ }^{1} \mathrm{H}$ NMR $\left(500 \mathrm{MHz}, \mathrm{CD}_{2} \mathrm{Cl}_{2}\right) \delta 7.80(\mathrm{~s}, 1 \mathrm{H}$, $\left.H \mathrm{C}\left(\mathrm{pz}^{\prime}\right)_{3}\right), 7.74\left(\mathrm{~s}, 8 \mathrm{H}, \mathrm{BAr}_{4}{ }_{4}\right.$ ortho position), $7.64\left(\mathrm{~d}, 1 \mathrm{H},{ }^{3} J_{\mathrm{HH}}=7.6 \mathrm{~Hz}\right.$, ortho-phenyl)), 
$7.58\left(\mathrm{~s}, 4 \mathrm{H}, \mathrm{BAr}_{4}{ }_{4}\right.$ para position), $6.95\left(\mathrm{t}, 1 \mathrm{H},{ }^{3} J_{\mathrm{HH}}=7.4 \mathrm{~Hz}\right.$, meta-phenyl), $6.78(\mathrm{t}, 1 \mathrm{H}$, ${ }^{3} J_{\mathrm{HH}}=7.2 \mathrm{~Hz}$, para-phenyl), $6.63\left(\mathrm{t}, 1 \mathrm{H}, J=7.5 \mathrm{~Hz}\right.$, meta-phenyl), $6.37\left(\mathrm{~d}, 1 \mathrm{H},{ }^{3} J_{\mathrm{HH}}=\right.$ 7.7 Hz, ortho-phenyl), 6.12, 6.05, 5.97 (each a s, 1H, $\mathrm{HC}\left(\mathrm{pz}^{\prime}\right)_{3}-4$ positions), 4.23 (d, 6H, $\left.{ }^{3} J_{\mathrm{HP}}=4.7 \mathrm{~Hz}, \mathrm{P}\left(\mathrm{OCH}_{2}\right)_{3} \mathrm{CCH}_{2} \mathrm{CH}_{3}\right), 2.56,2.55,2.54,2.52,2.00,1.43$ (each a s, $3 \mathrm{H}$, $\mathrm{HC}\left(\mathrm{pz}^{\prime}\right)_{3^{-}}$3,5 methyl positions), 2.30 (s, $\left.3 \mathrm{H}, \mathrm{NCCH}_{3}\right), 1.24$ (q, $2 \mathrm{H},{ }^{3} \mathrm{~J}_{\mathrm{HH}}=7.7 \mathrm{~Hz}$, $\left.\mathrm{P}\left(\mathrm{OCH}_{2}\right)_{3} \mathrm{CCH}_{2} \mathrm{CH}_{3}\right), 0.83\left(\mathrm{t}, 3 \mathrm{H},{ }^{3} J_{\mathrm{HH}}=7.6 \mathrm{~Hz}, \mathrm{P}\left(\mathrm{OCH}_{2}\right)_{3} \mathrm{CCH}_{2} \mathrm{CH}_{3}\right) .{ }^{13} \mathrm{C} \mathrm{NMR}(151$ $\left.\mathrm{MHz}, \mathrm{CD}_{2} \mathrm{Cl}_{2}\right) \delta 164.9$ (four line pattern, ${ }^{2} J_{\mathrm{CP}}=21 \mathrm{~Hz}$, ipso of phenyl), $162.3\left(\mathrm{q},{ }^{1} J_{\mathrm{CB}}=\right.$ $\left.50 \mathrm{~Hz}, \mathrm{BAr}_{4}\right)^{1}$ 159.1, 156.6, 156.3, 140.6, 140.5, 139.8 (each a s, $\left.\mathrm{HC}\left(\mathrm{pz}^{\prime}\right)_{3}-\mathrm{CCH}_{3}\right), 143.4$ (phenyl), 141.1 (phenyl), 135.3 (s, BAr' $\left.{ }_{4}\right), 129.1$ (q, $\left.{ }^{1} J_{\mathrm{CF}}=32 \mathrm{~Hz}, \mathrm{BAr}_{4}^{\prime}\right), 125.1$ (q, ${ }^{1} J_{\mathrm{CF}}=$ $273 \mathrm{~Hz}, \mathrm{BAr}_{4}$ ), 125.9 (phenyl), 125.4 (phenyl), 123.8 (s, $\mathrm{NCCH}_{3}$ ), 120.8 (phenyl), 118.0 (s, BAr' $\left.{ }_{4}\right) 110.1,109.7,109.3$ (each a s, $\mathrm{HC}\left(\mathrm{pz}^{\prime}\right)_{3}-\mathrm{CH}$ group), $74.5\left(\mathrm{~d},{ }^{2} J_{\mathrm{CP}}=7.3 \mathrm{~Hz}\right.$, $\left.\mathrm{P}\left(\mathrm{OCH}_{2}\right)_{3} \mathrm{CCH}_{2} \mathrm{CH}_{3}\right), 68.7$ (s, $\left.\mathrm{HC}\left(\mathrm{pz}^{\prime}\right)_{3}\right), 35.7\left(\mathrm{~d},{ }^{3} J_{\mathrm{CP}}=30.9 \mathrm{~Hz}, \mathrm{P}\left(\mathrm{OCH}_{2}\right)_{3} \mathrm{CCH}_{2} \mathrm{CH}_{3}\right)$, $24.0\left(\mathrm{~s}, \mathrm{P}\left(\mathrm{OCH}_{2}\right)_{3} \mathrm{CCH}_{2} \mathrm{CH}_{3}\right)$ 15.8, 13.9, 13.1, 11.8, 11.3, 11.2 (each a s, $\mathrm{HC}\left(\mathrm{pz}^{\prime}\right)_{3}-\mathrm{CH}_{3}$ group), 7.4 (s, $\left.\mathrm{P}\left(\mathrm{OCH}_{2}\right)_{3} \mathrm{CCH}_{2} \mathrm{CH}_{3}\right), 4.5\left(\mathrm{~s}, \mathrm{NCCH}_{3}\right) .{ }^{31} \mathrm{P} \mathrm{NMR}\left(121 \mathrm{MHz}, \mathrm{CD}_{2} \mathrm{Cl}_{2}\right) \delta$ 134.4. ${ }^{19} \mathrm{~F}$ NMR (282 MHz, $\left.\mathrm{CD}_{2} \mathrm{Cl}_{2}\right) \delta$-63.3. CV (NCMe): $E_{1 / 2}=0.82 \mathrm{~V} \mathrm{Ru}(\mathrm{III} / \mathrm{II})$.

$\left[\mathbf{C}(\mathbf{p z})_{4}\right] \mathbf{R u}\left(\mathbf{P P h}_{3}\right) \mathbf{C l}_{2}$ (9). C(pz) $)_{4}(0.3095 \mathrm{~g}, 1.104 \mathrm{mmol})$ and $\mathrm{RuCl}_{2}\left(\mathrm{PPh}_{3}\right)_{3}$ $(1.001 \mathrm{~g}, 1.045 \mathrm{mmol})$ were combined in a $50 \mathrm{~mL}$ round bottom flask and dissolved in 25 $\mathrm{mL}$ of toluene. The reaction was refluxed overnight. The brown solution gradually turned tan-yellow, and a large quantity of yellow precipitate formed. The flask was removed from heat and allowed to cool to room temperature. Hexanes $(10 \mathrm{~mL})$ were added complete precipitation. The yellow solid was collected on a fine porosity frit and washed with a small quantity of toluene $(5 \mathrm{~mL})$ followed by washing with pentane. The yellow 
solid was dried on the frit to yield a brownish-yellow powder $\left(0.5883 \mathrm{~g}, 79 \%\right.$ yield). ${ }^{1} \mathrm{H}$ NMR $\left(600 \mathrm{MHz}, \mathrm{CDCl}_{3}\right) \delta 8.74\left(\mathrm{~d}, 1 \mathrm{H},{ }^{3} J_{\mathrm{HH}}=2 \mathrm{~Hz}, \mathrm{C}(\mathrm{pz})_{4}\right), 8.64\left(\mathrm{~s}, 1 \mathrm{H}, \mathrm{C}(\mathrm{pz})_{4}\right), 8.28$ $\left(\mathrm{d}, 1 \mathrm{H},{ }^{3} J_{\mathrm{HH}}=3 \mathrm{~Hz}, \mathrm{C}(\mathrm{pz})_{4}\right), 8.16\left(\mathrm{~d}, 1 \mathrm{H},{ }^{3} J_{\mathrm{HH}}=2 \mathrm{~Hz}, \mathrm{C}(\mathrm{pz})_{4}\right), 7.90-7.79\left(\mathrm{~m}, 6 \mathrm{H}, \mathrm{PPh}_{3}\right.$, overlapping ortho protons), $7.33-7.19\left(\mathrm{~m}, 9 \mathrm{H}, \mathrm{PPh}_{3}\right.$, overlapping signals for meta and para protons), $6.94\left(\mathrm{vt}, 1 \mathrm{H}, \mathrm{C}(\mathrm{pz})_{4}\right), 6.87\left(\mathrm{~d}, 2 \mathrm{H},{ }^{3} J_{\mathrm{HH}}=3 \mathrm{~Hz}, \mathrm{C}(\mathrm{pz})_{4}\right), 6.76(\mathrm{~m}, 2 \mathrm{H}$, $\left.\mathrm{C}(\mathrm{pz})_{4}\right), 6.52\left(\mathrm{~d}, 1 \mathrm{H},{ }^{3} J_{\mathrm{HH}}=2 \mathrm{~Hz}, \mathrm{C}(\mathrm{pz})_{4}\right), 5.90\left(\mathrm{dd}, 2 \mathrm{H},{ }^{3} J_{\mathrm{HH}}=3.0 \mathrm{~Hz},{ }^{3} J_{\mathrm{HH}}=2.3 \mathrm{~Hz}\right.$, $\left.\mathrm{C}(\mathrm{pz})_{4}\right) .{ }^{13} \mathrm{C}$ NMR $\left(151 \mathrm{MHz}, \mathrm{CDCl}_{3}\right) \delta 151.3,148.3,144.6,136.0,134.8,134.5,111.3$, 109.6, 109.3 (each a s, C(pz) $), 135.1\left(\mathrm{~d},{ }^{2} J_{\mathrm{CP}}=9 \mathrm{~Hz}\right.$, ortho- $\left.\mathrm{PPh}_{3}\right), 132.5\left(\mathrm{~s}\right.$, ipso- $\left.\mathrm{PPh}_{3}\right)$, $129.0\left(\mathrm{~s}\right.$, para $\left.-\mathrm{PPh}_{3}\right), 127.7\left(\mathrm{~d},{ }^{3} J_{C p}=9 \mathrm{~Hz}\right.$, meta $\left.\left.-\mathrm{PPh}_{3}\right), 94.4(\mathrm{~s}, C(\mathrm{pz}))_{4}\right) .{ }^{31} \mathrm{P}$ NMR (121 $\left.\mathrm{MHz}, \mathrm{CD}_{2} \mathrm{Cl}_{2}\right) \delta 52.4$.

$\left[\mathbf{C}(\mathbf{p z})_{4}\right] \mathbf{R u}\left[\mathbf{P}(\mathbf{O C H})_{3} \mathbf{C E t}\right] \mathbf{C l}_{2} \quad$ (10). $\quad \mathrm{C}(\mathrm{pz})_{4} \mathrm{Ru}\left(\mathrm{PPh}_{3}\right) \mathrm{Cl}_{2} \quad$ (9) $\quad\left(\begin{array}{llll}0.457 & \mathrm{~g}, & 0.639\end{array}\right.$ mmol) and $\mathrm{P}\left(\mathrm{OCH}_{2}\right)_{3} \mathrm{CEt}(0.415 \mathrm{~g}, 2.56 \mathrm{mmol})$ were combined in a round bottom flask with $20 \mathrm{~mL}$ of chloroform. The reaction was refluxed overnight. The solution initially turned dark brown, then upon additional heating a yellow precipate formed. The reaction mixture was reduced to $\sim 5 \mathrm{~mL}$ and hexanes were added to induce a precipitate. The precipitate was collected on a fine frit and washed with hexanes. The yellow precipitate was placed back into a round bottom flask with $10 \mathrm{~mL}$ of chloroform and the reaction refluxed for $6 \mathrm{~h}$. After cooling to room temperature, the resulting solid was collected on a fine frit and washed with $\sim 5 \mathrm{~mL}$ of chloroform and pentane. The yellow solid was dried under vacuum to yield a yellow solid. (0.392 g, 99\% yield) ${ }^{1} \mathrm{H}$ NMR (600 MHz, $\left.\mathrm{CD}_{2} \mathrm{Cl}_{2}\right) \delta 8.65\left(\mathrm{dt}, 1 \mathrm{H},{ }^{3} J_{\mathrm{HH}}=1.8 \mathrm{~Hz},{ }^{4} J_{\mathrm{HP}}=0.7 \mathrm{~Hz}, \mathrm{C}(\mathrm{pz})_{4}\right), 8.54\left(\mathrm{dd}, 1 \mathrm{H},{ }^{3} J_{\mathrm{HH}}=1.9\right.$ $\left.\mathrm{Hz},{ }^{4} J_{\mathrm{HP}}=0.7 \mathrm{~Hz}, \mathrm{C}(\mathrm{pz})_{4}\right), 8.32\left(\mathrm{~d}, 1 \mathrm{H},{ }^{3} J_{\mathrm{HH}}=2.8 \mathrm{~Hz}, \mathrm{C}(\mathrm{pz})_{4}\right), 8.20\left(\mathrm{~d}, 1 \mathrm{H},{ }^{3} J_{\mathrm{HH}}=1.7\right.$ 
$\left.\mathrm{Hz}, \mathrm{C}(\mathrm{pz})_{4}\right), 8.13\left(\mathrm{dd}, 2 \mathrm{H},{ }^{3} J_{H H}=2.2 \mathrm{~Hz},{ }^{4} J_{\mathrm{HP}}=0.9 \mathrm{~Hz}, \mathrm{C}(\mathrm{pz})_{4}\right), 7.06\left(\mathrm{dd}, 2 \mathrm{H},{ }^{3} J_{\mathrm{HH}}=3.2\right.$ $\left.\mathrm{Hz},{ }^{4} J_{\mathrm{HP}}=0.9 \mathrm{~Hz}, \mathrm{C}(\mathrm{pz})_{4}\right), 6.95\left(\mathrm{dd}, 1 \mathrm{H},{ }^{3} J_{\mathrm{HH}}=2.9 \mathrm{~Hz},{ }^{3} J_{\mathrm{HH}}=1.8 \mathrm{~Hz}, \mathrm{C}(\mathrm{pz})_{4}\right), 6.62(\mathrm{dt}$, $\left.1 \mathrm{H},{ }^{3} J_{\mathrm{HH}}=2.8,{ }^{3} J_{\mathrm{HH}}=1.8 \mathrm{~Hz}, \mathrm{C}(\mathrm{pz})_{4}\right), 6.33\left(\mathrm{dd}, 2 \mathrm{H},{ }^{3} J_{\mathrm{HH}}=3.2,{ }^{3} J_{\mathrm{HH}}=2.2 \mathrm{~Hz}, \mathrm{C}(\mathrm{pz})_{4}\right)$, $4.38\left(\mathrm{~d}, 6 \mathrm{H},{ }^{3} J_{\mathrm{HP}}=4.5 \mathrm{~Hz}, \mathrm{P}\left(\mathrm{OCH}_{2}\right)_{3} \mathrm{CCH}_{2} \mathrm{CH}_{3},\right), 1.28\left(\mathrm{q}, 2 \mathrm{H},{ }^{3} J_{\mathrm{HH}}=7.8 \mathrm{~Hz}\right.$, $\left.\mathrm{P}\left(\mathrm{OCH}_{2}\right)_{3} \mathrm{CCH}_{2} \mathrm{CH}_{3}\right), 0.86\left(\mathrm{t}, 3 \mathrm{H},{ }^{3} \mathrm{~J}_{\mathrm{HH}}=7.7 \mathrm{~Hz}, \mathrm{P}\left(\mathrm{OCH}_{2}\right)_{3} \mathrm{CCH}_{2} \mathrm{CH}_{3}\right) .{ }^{13} \mathrm{C}$ NMR $(151$ $\left.\mathrm{MHz}, \mathrm{CD}_{2} \mathrm{Cl}_{2}\right) \delta 151.6,148.3,145.6,136.9,133.9,133.0,112.1,109.6,109.2\left(\mathrm{~s}, \mathrm{C}(\mathrm{pz})_{4} 4\right.$ position), $94.7\left(\mathrm{~s}, C(\mathrm{pz})_{4}\right), 74.9\left(\mathrm{~d},{ }^{2} J_{\mathrm{CP}}=7 \mathrm{~Hz}, \mathrm{P}\left(\mathrm{OCH}_{2}\right)_{3} \mathrm{CCH}_{2} \mathrm{CH}_{3}\right), 24.1$ (s, $\left.\mathrm{P}\left(\mathrm{OCH}_{2}\right)_{3} \mathrm{CCH}_{2} \mathrm{CH}_{3}\right), 7.5\left(\mathrm{~s}, \mathrm{P}\left(\mathrm{OCH}_{2}\right)_{3} \mathrm{CCH}_{2} \mathrm{CH}_{3}\right) .{ }^{13} \mathrm{C} \mathrm{NMR}\left(75 \mathrm{MHz}, \mathrm{CD}_{3} \mathrm{NO}_{2}\right) \delta$ $152.3,148.9,146.7,138.5,135.6,134.7,112.9,110.0,109.7$, (each a s, C(pz) 4$), 95.6(\mathrm{~s},-$ $\left.C(\mathrm{pz})_{4}\right), \quad 75.4\left(\mathrm{~d},{ }^{2} J_{C P}=8 \mathrm{~Hz}, \quad \mathrm{P}\left(\mathrm{OCH}_{2}\right)_{3} \mathrm{CCH}_{2} \mathrm{CH}_{3}\right), \quad 36.5\left(\mathrm{~d},{ }^{3} J_{C P}=31 \mathrm{~Hz}\right.$, $\left.\mathrm{P}\left(\mathrm{OCH}_{2}\right)_{3} \mathrm{CCH}_{2} \mathrm{CH}_{3}\right), 24.3$ (s, $\left.\mathrm{P}\left(\mathrm{OCH}_{2}\right)_{3} \mathrm{CCH}_{2} \mathrm{CH}_{3}\right), 7.5$ (s, $\left.\mathrm{P}\left(\mathrm{OCH}_{2}\right)_{3} \mathrm{CCH}_{2} \mathrm{CH}_{3}\right) .{ }^{31} \mathrm{P}$ NMR (121 MHz, $\left.\mathrm{CD}_{2} \mathrm{Cl}_{2}\right) \delta$ 128.1. HRMS: $\left[\mathrm{M}^{+} \mathrm{Na}^{+}\right]$obs'd (\%), calc'd (\%), ppm: 635.9969 (61), 635.9951 (64), 2.9; 636.9961 (100), 636.9942 (100), 2.9; 637.9963 (47), 637.9943 (52), 3.1; 638.9954 (94), 638.9935 (94), 3.0.

$\left\{\left[\mathbf{C}(\mathbf{p z})_{4}\right] \mathbf{R u}\left[\mathbf{P}\left(\mathbf{O C H}_{2}\right)_{3} \mathbf{C E t}\right] \mathbf{C l}(\mathbf{N C M e})\right\}[\mathbf{C l}] \quad$ (11). $\mathrm{C}(\mathrm{pz})_{4} \mathrm{Ru}\left[\mathrm{P}\left(\mathrm{OCH}_{2}\right)_{3} \mathrm{CEt}\right] \mathrm{Cl}_{2}$ (10) $(0.8550,1.391 \mathrm{mmol})$ was dissolved in NCMe $(25 \mathrm{~mL})$ (heterogenous) and refluxed overnight. During heating the mixture becomes homogenous. The initial yellow color changed to green-yellow, then brown, and finally back to yellow. The solution was filtered through Celite. The filtrate was reduced in vacuo to $\sim 2 \mathrm{~mL}$, and $\sim 2 \mathrm{~mL}$ of methylene chloride were added followed by the addition of diethyl ether to induce precipitation. The off-white solid was collected over a fine porosity frit, washed with diethyl ether and pentane and dried on the frit under reduced pressure $(0.6486 \mathrm{~g}, 71 \%$ 
yield). Note: contains a small amount of a second product; however, in the next step (reaction with $\left.\mathrm{NaBAr}_{4}\right)$ the second product is removed. ${ }^{1} \mathrm{H} \mathrm{NMR}\left(600 \mathrm{MHz}, \mathrm{CD}_{2} \mathrm{Cl}_{2}\right) \delta$ $8.96\left(\mathrm{~d}, 1 \mathrm{H},{ }^{3} J_{\mathrm{HH}}=3.2 \mathrm{~Hz}, \mathrm{C}(\mathrm{pz})_{4}\right), 8.74,8.34,8.24,8.01\left(\mathrm{~s}, 1 \mathrm{H}, \mathrm{C}(\mathrm{pz})_{4}\right), 8.11(\mathrm{~d}, 1 \mathrm{H}$, $\left.{ }^{3} J_{\mathrm{HH}}=2.2 \mathrm{~Hz}, \mathrm{C}(\mathrm{pz})_{4}\right), 7.37\left(\mathrm{~d}, 1 \mathrm{H},{ }^{3} J_{\mathrm{HH}}=3.2 \mathrm{~Hz}, \mathrm{C}(\mathrm{pz})_{4}\right), 7.12\left(\mathrm{~d}, 1 \mathrm{H},{ }^{3} J_{\mathrm{HH}}=3.0\right.$ $\left.\mathrm{Hz}, \mathrm{C}(\mathrm{pz})_{4}\right), 7.08,6.69,6.55,6.42\left(\mathrm{~s}, 1 \mathrm{H}, \mathrm{C}(\mathrm{pz})_{4}\right), 4.41\left(\mathrm{~d}, 6 \mathrm{H},{ }^{3} J_{\mathrm{HP}}=4.4 \mathrm{~Hz}\right.$, $\left.\mathrm{P}\left(\mathrm{OCH}_{2}\right)_{3} \mathrm{CCH}_{2} \mathrm{CH}_{3}\right), \quad 2.43$ (s, $\left.3 \mathrm{H}, \quad \mathrm{NCCH}_{3}\right), \quad 1.32 \quad\left(\mathrm{q}, \quad 2 \mathrm{H}, \quad{ }^{3} J_{\mathrm{HH}}=7.7 \mathrm{~Hz}\right.$, $\left.\mathrm{P}\left(\mathrm{OCH}_{2}\right)_{3} \mathrm{CCH}_{2} \mathrm{CH}_{3}\right), 0.87$ (t, 3H, $\left.{ }^{3} J_{\mathrm{HH}}=7.5 \mathrm{~Hz}, \mathrm{P}\left(\mathrm{OCH}_{2}\right)_{3} \mathrm{CCH}_{2} \mathrm{CH}_{3}\right) .{ }^{13} \mathrm{C}$ NMR $(151$ $\left.\mathrm{MHz}, \mathrm{CD}_{2} \mathrm{Cl}_{2}\right) \delta 151.0,150.8,147.3,146.2,138.2,135.8,134.5,134.4,113.1,110.1$, 109.9, 109.5 (each a s, $\left.\mathrm{C}(\mathrm{pz})_{4}\right), 124.9\left(\mathrm{~s}, \mathrm{NCCH}_{3}\right), 94.6\left(\mathrm{~s}, \mathrm{C}(\mathrm{pz})_{4}\right), 75.3\left(\mathrm{~d},{ }^{2} J_{\mathrm{CP}}=7 \mathrm{~Hz}\right.$, $\left.\mathrm{P}\left(\mathrm{OCH}_{2}\right)_{3} \mathrm{CCH}_{2} \mathrm{CH}_{3}\right), \quad 36.1 \quad\left(\mathrm{~d},{ }^{3} J_{\mathrm{CP}}=31.9 \mathrm{~Hz}, \quad \mathrm{P}\left(\mathrm{OCH}_{2}\right)_{3} \mathrm{CCH}_{2} \mathrm{CH}_{3}\right), 23.8$ (s, $\left.\mathrm{P}\left(\mathrm{OCH}_{2}\right)_{3} \mathrm{CCH}_{2} \mathrm{CH}_{3}\right), 7.5\left(\mathrm{~s}, \mathrm{P}\left(\mathrm{OCH}_{2}\right)_{3} \mathrm{CCH}_{2} \mathrm{CH}_{3}\right) 5.3\left(\mathrm{~s}, \mathrm{NCCH}_{3}\right) .{ }^{31} \mathrm{P} \mathrm{NMR}(121 \mathrm{MHz}$, $\left.\mathrm{CD}_{2} \mathrm{Cl}_{2}\right) \delta$ 128.1. HRMS: [M+] obs'd (\%), calc'd (\%), ppm: 617.0645 (23), 617.0640 (33.5), $0.8 ; 618.0636$ (29), 618.0630 (38.5), 1; 619.0640 (52), 619.0634 (59.5), 1; 620.0633 (100), 620.0625 (100), 1.3; 621.0640 (27), 621.0634 (36), 1; 622.0631 (70), $622.0623(75), 1.4$.

\section{$\left\{\left[\mathrm{C}(\mathrm{pz})_{4}\right] \mathrm{Ru}\left[\mathrm{P}\left(\mathrm{OCH}_{2}\right)_{3} \mathrm{CEt}\right] \mathrm{Cl}(\mathrm{NCMe})\right\}\left[\mathrm{BAr}_{4}{ }_{4}\right]$}

(12). $\left\{\left[\mathrm{C}(\mathrm{pz})_{4}\right] \mathrm{Ru}\left[\mathrm{P}\left(\mathrm{OCH}_{2}\right)_{3} \mathrm{CEt}\right] \mathrm{Cl}(\mathrm{NCMe})\right\}[\mathrm{Cl}](\mathbf{1 1})(0.700 \mathrm{~g}, 1.06 \mathrm{mmol})$ and $\mathrm{NaBAr}_{4}$ $(0.4783 \mathrm{~g}, 0.5397 \mathrm{mmol})$ were combined in THF $(15 \mathrm{~mL})$. The reaction was stirred at room temperature for $3 \mathrm{~h}$. The solution was filtered through Celite, and the filtrate was reduced to dryness. The solid was reconstituted in diethyl ether and loaded on a plug of neutral alumina. The plug was washed with diethyl ether. This portion was discarded. The plug was then washed with a 50/50 solution of methylene chloride/diethyl ether. The 
eluate was collected and dried under reduced pressure to yield a yellow oil. The yellow oil was dissolved in a minimal amount of methylene chloride and placed under vacuum to afford a pale-yellow solid (0.8957 g, 57\% yield). ${ }^{1} \mathrm{H}$ NMR $\left(800 \mathrm{MHz}, \mathrm{CD}_{2} \mathrm{Cl}_{2}\right) \delta 8.78$, $8.38\left(\right.$ each a s, $\left.1 \mathrm{H}, \mathrm{C}(\mathrm{pz})_{4}\right), 8.26\left(\mathrm{~d}, 1 \mathrm{H},{ }^{3} J_{\mathrm{HH}}=2.5 \mathrm{~Hz}, \mathrm{C}(\mathrm{pz})_{4}\right), 8.22,8.18($ each a s, $1 \mathrm{H}$, $\left.\mathrm{C}(\mathrm{pz})_{4}\right), 7.93\left(\mathrm{~m}, 1 \mathrm{H}, \mathrm{C}(\mathrm{pz})_{4}\right), 7.72\left(\mathrm{~s}, 8 \mathrm{H}, \mathrm{BAr}_{4}{ }_{4}\right.$ ortho position), 7.55 (s, 4H, BAr' ${ }_{4}$ para position), $7.37\left(\mathrm{~d}, 1 \mathrm{H},{ }^{3} J_{\mathrm{HH}}=3.0 \mathrm{~Hz}, \mathrm{C}(\mathrm{pz})_{4}\right), 6.98\left(\mathrm{~m}, 1 \mathrm{H}, \mathrm{C}(\mathrm{pz})_{4}\right), 6.80\left(\mathrm{~d}, 1 \mathrm{H},{ }^{3} J_{\mathrm{HP}}=\right.$ $\left.3.0 \mathrm{~Hz}, \mathrm{C}(\mathrm{pz})_{4}\right), 6.68\left(\mathrm{~s}, 1 \mathrm{H}, \mathrm{C}(\mathrm{pz})_{4}\right), 6.45,6.36\left(\right.$ each a m, $\left.1 \mathrm{H}, \mathrm{C}(\mathrm{pz})_{4}\right), 4.40\left(\mathrm{~d}, 6 \mathrm{H},{ }^{3} J_{\mathrm{HP}}\right.$ $\left.=4.0 \mathrm{~Hz}, \mathrm{P}\left(\mathrm{OCH}_{2}\right)_{3} \mathrm{CCH}_{2} \mathrm{CH}_{3}\right), 2.43\left(\mathrm{~s}, 3 \mathrm{H}, \mathrm{NCCH}_{3}\right), 1.30$ (q, $2 \mathrm{H},{ }^{3} J_{\mathrm{HH}}=7.7 \mathrm{~Hz}$, $\left.\mathrm{P}\left(\mathrm{OCH}_{2}\right)_{3} \mathrm{CCH}_{2} \mathrm{CH}_{3}\right), 0.87\left(\mathrm{t}, 3 \mathrm{H},{ }^{3} \mathrm{~J}_{\mathrm{HH}}=7.7 \mathrm{~Hz}, \mathrm{P}\left(\mathrm{OCH}_{2}\right)_{3} \mathrm{CCH}_{2} \mathrm{CH}_{3}\right) .{ }^{13} \mathrm{C} \mathrm{NMR}(201$ $\left.\mathrm{MHz}, \mathrm{CD}_{2} \mathrm{Cl}_{2}\right) \delta 162.3$ (four line pattern, ${ }^{1} J_{\mathrm{CB}}=50 \mathrm{~Hz}, \mathrm{BAr}_{4}^{\prime}$ ), 151.7, 150.5, 147.6, $146.3,136.8,135.1,134.0,133.6,112.9,110.0,109.9,109.8$ (s, each a s, C(pz) 4$) 135.3$ $\left(\mathrm{s}, \mathrm{BAr}_{4}^{\prime}\right), 129.4\left(\mathrm{q},{ }^{1} J_{\mathrm{CF}}=32 \mathrm{~Hz}, \mathrm{BAr}_{4}{ }_{4}\right), 125.1\left(\mathrm{q},{ }^{1} J_{\mathrm{CP}}=273 \mathrm{~Hz}, \mathrm{BAr}_{4}^{\prime}\right), 124.7(\mathrm{~s}$, $\left.\mathrm{NCCH}_{3}\right), 118.0\left(\mathrm{~s}, \mathrm{BAr}_{4}^{\prime}\right), 94.7\left(\mathrm{~s}, \mathrm{C}(\mathrm{pz})_{4}\right), 75.4\left(\mathrm{~d},{ }^{2} J_{\mathrm{CP}}=7 \mathrm{~Hz}, \mathrm{P}\left(\mathrm{OCH}_{2}\right)_{3} \mathrm{CCH}_{2} \mathrm{CH}_{3}\right)$, $36.4\left(\mathrm{~d},{ }^{3} J_{\mathrm{CP}}=32 \mathrm{~Hz}, \mathrm{P}\left(\mathrm{OCH}_{2}\right)_{3} \mathrm{CCH}_{2} \mathrm{CH}_{3}\right), 23.9\left(\mathrm{~s}, \mathrm{P}\left(\mathrm{OCH}_{2}\right)_{3} \mathrm{CCH}_{2} \mathrm{CH}_{3}\right), 7.5$ (s, $\left.\mathrm{P}\left(\mathrm{OCH}_{2}\right)_{3} \mathrm{CCH}_{2} \mathrm{CH}_{3}\right), 4.8\left(\mathrm{~s}, \mathrm{NCCH}_{3}\right) .{ }^{31} \mathrm{P} \mathrm{NMR}\left(121 \mathrm{MHz}, \mathrm{CD}_{2} \mathrm{Cl}_{2}\right) \delta 128.3 .{ }^{19} \mathrm{~F} \mathrm{NMR}$ $\left(282 \mathrm{MHz}, \mathrm{CD}_{2} \mathrm{Cl}_{2}\right) \delta$-63.7. Anal. Calc'd. for $\mathrm{C}_{53} \mathrm{H}_{38} \mathrm{BClF}_{24} \mathrm{~N}_{9} \mathrm{O}_{3} \mathrm{PRu}$ : C, 42.92; $\mathrm{H}, 2.58$; N, 8.50. Found: C, 42.85; H, 2.70; N, 8.30.

\section{$\left\{\left[\mathrm{C}(\mathrm{pz})_{4}\right] \mathrm{Ru}\left[\mathrm{P}\left(\mathrm{OCH}_{2}\right)_{3} \mathrm{CEt}\right](\mathrm{OTf})(\mathrm{NCMe})\right\}\left[\mathrm{BAr}_{4}^{\prime}\right]$}

(13). $\left\{\left[\mathrm{C}(\mathrm{pz})_{4}\right] \mathrm{Ru}\left[\mathrm{P}\left(\mathrm{OCH}_{2}\right)_{3} \mathrm{CEt}\right](\mathrm{Cl})(\mathrm{NCMe})\right\}\left[\mathrm{BAr}_{4}\right] \quad$ (12) (0.8796 g, $\left.0.5932 \mathrm{mmol}\right)$ was dissolved in $40 \mathrm{~mL}$ of methylene chloride in a thick walled pressure tube, and TMSOTf (1.318 g, $1.07 \mathrm{~mL}, 5.932 \mathrm{mmol})$ was added by syringe. The reaction was heated at 100 ${ }^{\circ} \mathrm{C}$ overnight. The reaction was brought back into the glovebox and allowed to cool to 
room temperature. The reaction mixture was added to $100 \mathrm{~mL}$ of hexanes and allowed to stir for 30 minutes. The desired product oiled out of solution. The hexanes solution was filtered through Celite, and the filtrate was discarded. The Celite was washed with methylene chloride, and the filtrate was placed in the flask with the oil. The methylene chloride was removed in vacuo to yield an oil. The oil was dissolved in a minimal amount of methylene chloride and placed in a vial, and the solvent was removed. After removing the solvent in vacuo, a minimal amount of diethyl ether was added, followed by removal of the volatiles to yield a yellow solid (0.7976 g, 84\% yield). ${ }^{1} \mathrm{H}$ NMR (600 $\left.\mathrm{MHz}, \mathrm{CD}_{2} \mathrm{Cl}_{2}\right) \delta 8.82,8.43\left(\mathrm{~m}, 1 \mathrm{H}, \mathrm{C}(\mathrm{pz})_{4}\right), 8.30\left(\mathrm{~d}, 1 \mathrm{H},{ }^{3} J_{\mathrm{HH}}=2.9 \mathrm{~Hz}, \mathrm{C}(\mathrm{pz})_{4}\right), 8.26(\mathrm{~d}$, $\left.1 \mathrm{H},{ }^{3} J_{\mathrm{HH}}=1.7 \mathrm{~Hz}, \mathrm{C}(\mathrm{pz})_{4}\right), 8.23\left(\mathrm{dd}, 1 \mathrm{H},{ }^{3} J_{\mathrm{HH}}=2.2 \mathrm{~Hz},{ }^{4} J_{\mathrm{HP}}=0.8 \mathrm{~Hz}, \mathrm{C}(\mathrm{pz})_{4}\right), 7.96(\mathrm{~m}$, $\left.1 \mathrm{H}, \mathrm{C}(\mathrm{pz})_{4}\right), 7.77$ (s, 8H, BAr' ${ }_{4}$ ortho position), 7.60 (s, 4H, BAr' ${ }_{4}$ para position), 7.42 $\left(\mathrm{dd}, 1 \mathrm{H},{ }^{3} J_{\mathrm{HH}}=3.2 \mathrm{~Hz},{ }^{4} J_{\mathrm{HP}}=0.8 \mathrm{~Hz}, \mathrm{C}(\mathrm{pz})_{4}\right), 7.02\left(\mathrm{dd}, 1 \mathrm{H},{ }^{3} J_{\mathrm{HH}}=2.8 \mathrm{~Hz},{ }^{4} J_{\mathrm{HH}}=1.8\right.$ $\left.\mathrm{Hz}, \mathrm{C}(\mathrm{pz})_{4}\right), 6.85\left(\mathrm{dd}, 1 \mathrm{H},{ }^{3} J_{\mathrm{HH}}=3.4 \mathrm{~Hz},{ }^{4} J_{\mathrm{HP}}=0.9 \mathrm{~Hz}, \mathrm{C}(\mathrm{pz})_{4}\right), 6.72\left(\mathrm{dt}, 1 \mathrm{H},{ }^{3} J_{\mathrm{HH}}=3.5\right.$ $\left.\mathrm{Hz},{ }^{4} J_{\mathrm{HH}}=1.9 \mathrm{~Hz}, \mathrm{C}(\mathrm{pz})_{4}\right) 6.49\left(\mathrm{dd}, 1 \mathrm{H},{ }^{3} J_{\mathrm{HH}}=3.4 \mathrm{~Hz},{ }^{4} J_{\mathrm{HH}}=2.2 \mathrm{~Hz}, \mathrm{C}(\mathrm{pz})_{4}\right), 6.40(\mathrm{dd}$, $\left.1 \mathrm{H},{ }^{3} J_{\mathrm{HH}}=3.2 \mathrm{~Hz},{ }^{4} J_{\mathrm{HH}}=2.2 \mathrm{~Hz}, \mathrm{C}(\mathrm{pz})_{4}\right) 4.45\left(\mathrm{~d}, 6 \mathrm{H},{ }^{3} J_{\mathrm{HP}}=4.6 \mathrm{~Hz}\right.$, $\left.\mathrm{P}\left(\mathrm{OCH}_{2}\right)_{3} \mathrm{CCH}_{2} \mathrm{CH}_{3}\right), \quad 2.43 \quad\left(\mathrm{~s}, \quad 3 \mathrm{H}, \quad \mathrm{NCCH}_{3}\right), \quad 1.34 \quad\left(\mathrm{q}, \quad 2 \mathrm{H}, \quad{ }^{3} J_{\mathrm{HH}}=7.7 \mathrm{~Hz}\right.$, $\left.\mathrm{P}\left(\mathrm{OCH}_{2}\right)_{3} \mathrm{CCH}_{2} \mathrm{CH}_{3}\right), 0.91\left(\mathrm{t}, 3 \mathrm{H},{ }^{3} J_{\mathrm{HH}}=7.7 \mathrm{~Hz}, \mathrm{P}\left(\mathrm{OCH}_{2}\right)_{3} \mathrm{CCH}_{2} \mathrm{CH}_{3}\right) .{ }^{13} \mathrm{C} \mathrm{NMR}(125$ $\left.\mathrm{MHz}, \mathrm{CD}_{2} \mathrm{Cl}_{2}\right) \delta 162.3$ (four lined pattern, ${ }^{1} J_{\mathrm{CB}}=50 \mathrm{~Hz}, \mathrm{BAr}_{4}{ }_{4}$ ), 152.2, 151.3, 148.7, 146.6, 136.9, 134.9, 134.6, 133.8, 113.2, 110.2 (each a s, $\mathrm{C}(\mathrm{pz})_{4}$, one resonances missing due to coincidental overlap), $129.5\left(\mathrm{q},{ }^{1} J_{\mathrm{CF}}=32 \mathrm{~Hz}, \mathrm{BAr}_{4}{ }_{4}\right), 125.2\left(\mathrm{q},{ }^{1} J_{\mathrm{CP}}=273 \mathrm{~Hz}\right.$, $\left.\mathrm{BAr}_{4}{ }_{4}\right), 135.4\left(\mathrm{~s}, \mathrm{BAr}^{\prime}{ }_{4}\right), 126.7\left(\mathrm{~s}, \mathrm{NCCH}_{3}\right), 118.1\left(\mathrm{~s}, \mathrm{BAr}_{4}\right), 94.6\left(\mathrm{~s}, C(\mathrm{pz})_{4}\right), 75.7$ (d, $\left.{ }^{2} J_{\mathrm{CP}}=7 \mathrm{~Hz}, \mathrm{P}\left(\mathrm{OCH}_{2}\right)_{3} \mathrm{CCH}_{2} \mathrm{CH}_{3}\right), 36.7\left(\mathrm{~d},{ }^{3} J_{\mathrm{CP}}=32 \mathrm{~Hz}, \mathrm{P}\left(\mathrm{OCH}_{2}\right)_{3} \mathrm{CCH}_{2} \mathrm{CH}_{3}\right), 23.8(\mathrm{~s}$, 
$\left.\mathrm{P}\left(\mathrm{OCH}_{2}\right)_{3} \mathrm{CCH}_{2} \mathrm{CH}_{3}\right), 7.5\left(\mathrm{~s}, \mathrm{P}\left(\mathrm{OCH}_{2}\right)_{3} \mathrm{CCH}_{2} \mathrm{CH}_{3}\right), 4.5\left(\mathrm{~s}, \mathrm{NCCH}_{3}\right) .{ }^{31} \mathrm{P} \mathrm{NMR}(121 \mathrm{MHz}$, $\left.\mathrm{CD}_{2} \mathrm{Cl}_{2}\right) \delta$ 127.7. ${ }^{19} \mathrm{~F}$ NMR $\left(282 \mathrm{MHz}, \mathrm{CD}_{2} \mathrm{Cl}_{2}\right) \delta-63.2\left(\mathrm{BAr}_{4}{ }_{4}\right),-78.9$ (OTf). Anal. Calc'd. for $\mathrm{C}_{54} \mathrm{H}_{38} \mathrm{BF}_{27} \mathrm{~N}_{9} \mathrm{O}_{6} \mathrm{PRuS}$ : C, $40.62 \mathrm{H}, 2.40$; N, 7.89. Found: C, 39.81; H, 2.62; N, 7.79. HRMS: [M+] obs'd (\%), calc'd (\%), ppm: 731.0476 (24), 731.0471 (35), 0.6; 732.0469 (32), 732.0463 (42.5), 0.8; 733.0476 (48), 733.0469 (55), 0.9; 734.0467 (100), 734.046 (100), 1.0; 735.0485 (19), 735.0479 (30), 0.9; 736.0472 (48), 736.0465 (55), 1.0 .

\section{$\left\{\left[\mathrm{C}(\mathrm{pz})_{4}\right] \mathrm{Ru}\left[\mathrm{P}\left(\mathrm{OCH}_{2}\right)_{3} \mathrm{CEt}\right](\mathrm{Me})(\mathrm{NCMe})\right\}\left[\mathrm{BAr}_{4}{ }_{4}\right]$}

(14). $\left\{\left[\mathrm{C}(\mathrm{pz})_{4}\right] \mathrm{Ru}\left[\mathrm{P}\left(\mathrm{OCH}_{2}\right)_{3} \mathrm{CEt}\right](\mathrm{OTf})(\mathrm{NCMe})\right\}\left[\mathrm{BAr}_{4}\right]$ (13) $(0.1296 \mathrm{~g}, 0.08118 \mathrm{mmol})$ was placed in a round bottom flask in $15 \mathrm{~mL}$ of benzene (heterogeneous-oil was observed). $\mathrm{Me}_{3} \mathrm{Al}(0.043 \mathrm{~mL}, 0.085 \mathrm{mmol})$ was added by syringe in two portions with 15 minutes stirring between each addition during which the reaction became bright yellow and homogeneous. The reaction was allowed to stir for 30 minutes followed by filtration through a plug of Celite. The benzene filtrate was then concentrated and transferred to a pre-weighed vial. The solvent was removed to yield a yellow low density solid. $(0.0801$ g, 67\% yield). ${ }^{1} \mathrm{H}$ NMR (500 MHz, $\left.\mathrm{C}_{6} \mathrm{D}_{6}\right) \delta 8.38$ (br s, $8 \mathrm{H}, \mathrm{BAr}_{4}{ }_{4}$ ortho position), 7.95 (d, $\left.1 \mathrm{H},{ }^{3} J_{\mathrm{HH}}=1.9 \mathrm{~Hz}, \mathrm{C}(\mathrm{pz})_{4}\right), 7.92\left(\mathrm{~d}, 1 \mathrm{H},{ }^{3} J_{\mathrm{HH}}=3.0 \mathrm{~Hz}, \mathrm{C}(\mathrm{pz})_{4}\right), 7.88\left(\mathrm{~d}, 1 \mathrm{H},{ }^{3} J_{\mathrm{HH}}=2.0\right.$ $\left.\mathrm{Hz}, \mathrm{C}(\mathrm{pz})_{4}\right), 7.65\left(\mathrm{~s}, 4 \mathrm{H}, \mathrm{BAr}_{4}{ }_{4}\right.$ para position), $7.38\left(\mathrm{~d}, 1 \mathrm{H},{ }^{3} J_{\mathrm{HH}}=2.1 \mathrm{~Hz}, \mathrm{C}(\mathrm{pz})_{4}\right), 7.30$ $\left(\mathrm{d}, 1 \mathrm{H},{ }^{3} J_{\mathrm{HH}}=1.8 \mathrm{~Hz}, \mathrm{C}(\mathrm{pz})_{4}\right), 7.00\left(\mathrm{~d}, 1 \mathrm{H},{ }^{3} J_{\mathrm{HH}}=3.0 \mathrm{~Hz}, \mathrm{C}(\mathrm{pz})_{4}\right), 6.57\left(\mathrm{~d}, 1 \mathrm{H},{ }^{3} J_{\mathrm{HH}}=\right.$ $\left.2.9 \mathrm{~Hz}, \mathrm{C}(\mathrm{pz})_{4}\right), 5.90\left(\mathrm{dd}, 1 \mathrm{H},{ }^{3} J_{\mathrm{HH}}=2.8 \mathrm{~Hz},{ }^{4} J_{\mathrm{HH}}=1.8 \mathrm{~Hz}, \mathrm{C}(\mathrm{pz})_{4}\right), 5.78(\mathrm{~m}, 1 \mathrm{H}$, $\left.\mathrm{C}(\mathrm{pz})_{4}\right), 5.74\left(\mathrm{~d}, 1 \mathrm{H},{ }^{3} J_{\mathrm{HH}}=2.6 \mathrm{~Hz}, \mathrm{C}(\mathrm{pz})_{4}\right), 5.44\left(\mathrm{~m}, 1 \mathrm{H}, \mathrm{C}(\mathrm{pz})_{4}\right), 5.35\left(\mathrm{~d}, 1 \mathrm{H},{ }^{3} J_{\mathrm{HH}}=3.2\right.$ $\left.\mathrm{Hz}, \mathrm{C}(\mathrm{pz})_{4}\right), 3.79\left(\mathrm{~d}, 6 \mathrm{H},{ }^{3} \mathrm{~J}_{\mathrm{HP}}=4.3 \mathrm{~Hz}, \mathrm{P}\left(\mathrm{OCH}_{2}\right)_{3} \mathrm{CCH}_{2} \mathrm{CH}_{3}\right), 0.98\left(\mathrm{~s}, 3 \mathrm{H}, \mathrm{NCCH}_{3}\right), 0.71$ $\left(\mathrm{d}, 3 \mathrm{H},{ }^{3} J_{\mathrm{HP}}=2.0 \mathrm{~Hz}, \mathrm{CH}_{3}\right), 0.35\left(\mathrm{q}, 2 \mathrm{H},{ }^{3} J_{\mathrm{HH}}=7.7 \mathrm{~Hz}, \mathrm{P}\left(\mathrm{OCH}_{2}\right)_{3} \mathrm{CCH}_{2} \mathrm{CH}_{3}\right), 0.17(\mathrm{t}$, 
$\left.3 \mathrm{H},{ }^{3} J_{\mathrm{HH}}=7.7 \mathrm{~Hz}, \mathrm{P}\left(\mathrm{OCH}_{2}\right)_{3} \mathrm{CCH}_{2} \mathrm{CH}_{3}\right){ }^{13} \mathrm{C} \mathrm{NMR}\left(125 \mathrm{MHz}, \mathrm{C}_{6} \mathrm{D}_{6}\right) \delta 162.8$ (four line pattern, $\left.{ }^{1} J_{\mathrm{CB}}=50 \mathrm{~Hz}, \mathrm{BAr}_{4}{ }_{4}\right), 148.2,147.0,144.6,144.0,136.0,133.8,131.9,131.6$, 111.0, 108.8, 108.4, 108.1 (each a s, C $(\mathrm{pz}) 4), 135.4\left(\mathrm{~s}, \mathrm{BAr}_{4}^{\prime}\right), 130.0\left(\mathrm{q},{ }^{1} J_{\mathrm{CF}}=32 \mathrm{~Hz}\right.$, $\left.\mathrm{BAr}_{4}^{\prime}\right), 126.3\left(\mathrm{~s}, \mathrm{NCCH}_{3}\right), 118.1\left(\mathrm{~s}, \mathrm{BAr}_{4}^{\prime}\right), 94.0 \quad\left(\mathrm{C}(\mathrm{pz})_{4}\right), \quad\left(\mathrm{d},{ }^{2} J_{\mathrm{CP}}=7 \mathrm{~Hz}\right.$ $\left.\mathrm{P}\left(\mathrm{OCH}_{2}\right)_{3} \mathrm{CCH}_{2} \mathrm{CH}_{3}\right), 23.0\left(\mathrm{~s}, \mathrm{P}\left(\mathrm{OCH}_{2}\right)_{3} \mathrm{CCH}_{2} \mathrm{CH}_{3}\right), 6.7$ (s, $\left.\mathrm{P}\left(\mathrm{OCH}_{2}\right)_{3} \mathrm{CCH}_{2} \mathrm{CH}_{3}\right), 2.2$ (s, $\mathrm{NCCH}_{3}$ ). Due to solubility some of the resonances could not be resolved. ${ }^{31} \mathrm{P}$ NMR (121 $\left.\mathrm{MHz}, \mathrm{CD}_{2} \mathrm{Cl}_{2}\right) \delta 135.1 .{ }^{19} \mathrm{~F}$ NMR $\left(282 \mathrm{MHz}, \mathrm{CD}_{2} \mathrm{Cl}_{2}\right) \delta-62.8$. HRMS: $[\mathrm{M}+]$ obs'd (\%), calc'd (\%), ppm: 597.1183 (40.7), 597.1186 (39.0), -0.5; 598.1175 (47.7), 598.1178 (44.0), -0.4; 599.1183 (58.1), 599.1185 (56), -0.3; 600.1175 (100), 600.11758 (100), 0.0; 601.1190 (32), 601.1199 (27.5), -1.4; 602.1179 (58.1), 602.1183 (55), -0.6.

\section{$\left\{\left(N, C^{5}, N\right) C(p z)_{4} \operatorname{Ru}\left[\mathbf{P}\left(\mathrm{OCH}_{2}\right)_{3} \mathrm{CEt}\left[\left(\mathrm{NCMe}_{2}\right\}\left[\mathrm{BAr}_{4}{ }_{4}\right]\right.\right.\right.$}

(15). $\left\{\left[\mathrm{C}(\mathrm{pz})_{4}\right] \mathrm{Ru}\left[\mathrm{P}\left(\mathrm{OCH}_{2}\right)_{3} \mathrm{CEt}\right](\mathrm{Me})(\mathrm{NCMe})\right\}\left[\mathrm{BAr}_{4}\right] \quad$ (14) $(0.055 \mathrm{~g}, 0.5140 \mathrm{mmol})$ and $\mathrm{NCMe}(0.00314 \mathrm{~g}, 0.0766 \mathrm{mmol}, 4 \mathrm{~mL})$ were combined in a pressure tube with $3 \mathrm{~mL}$ of benzene. The reaction was heated at $75^{\circ} \mathrm{C}$ for 3 hours. The solution was filtered through Celite. The filtrate was reduced to yield an oil to which $\sim 0.5 \mathrm{~mL}$ of pentane was added. The solvent was removed in vacuo to yield a pale yellow low density solid $(0.0271 \mathrm{~g}$, $53 \%$ yield). ${ }^{1} \mathrm{H}$ NMR $\left(600 \mathrm{MHz}, \mathrm{C}_{6} \mathrm{D}_{6}\right) \delta 8.77\left(\mathrm{~d}, 1 \mathrm{H},{ }^{3} J_{\mathrm{HH}}=2.8 \mathrm{~Hz}, \mathrm{C}(\mathrm{pz})_{4}\right), 8.39(\mathrm{~s}, 8 \mathrm{H}$, BAr' $_{4}$ ortho position), $8.06\left(\mathrm{~d}, 1 \mathrm{H},{ }^{3} J_{\mathrm{HH}}=2.9 \mathrm{~Hz}, \mathrm{C}(\mathrm{pz})_{4}\right), 7.75\left(\mathrm{~d}, 1 \mathrm{H},{ }^{3} J_{\mathrm{HH}}=1.7 \mathrm{~Hz}\right.$, $\left.\mathrm{C}(\mathrm{pz})_{4}\right), 7.69$ (s, 4H, BAr' ${ }_{4}$ para position), $7.63\left(\mathrm{~d}, 1 \mathrm{H},{ }^{3} J_{\mathrm{HH}}=2.2 \mathrm{~Hz}, \mathrm{C}(\mathrm{pz})_{4}\right), 7.38(\mathrm{~d}$, $\left.1 \mathrm{H},{ }^{3} J_{\mathrm{HH}}=1.7 \mathrm{~Hz}, \mathrm{C}(\mathrm{pz})_{4}\right), 7.35\left(\mathrm{~d}, 1 \mathrm{H},{ }^{3} J_{\mathrm{HH}}=2.0 \mathrm{~Hz}, \mathrm{C}(\mathrm{pz})_{4}\right), 6.65\left(\mathrm{~d}, 1 \mathrm{H},{ }^{3} J_{\mathrm{HH}}=1.5\right.$ $\left.\mathrm{Hz}, \mathrm{C}(\mathrm{pz})_{4}\right) 5.96\left(\mathrm{dd}, 1 \mathrm{H},{ }^{3} J_{\mathrm{HH}}=2.9 \mathrm{~Hz},{ }^{4} J_{\mathrm{HP}}=1.8 \mathrm{~Hz}, \mathrm{C}(\mathrm{pz})_{4}\right), 5.73\left(\mathrm{t}, 1 \mathrm{H},{ }^{3} J_{\mathrm{HH}}=2.5\right.$ $\left.\mathrm{Hz}, \mathrm{C}(\mathrm{pz})_{4}\right), 5.64\left(\mathrm{~m}, 1 \mathrm{H}, \mathrm{C}(\mathrm{pz})_{4}\right), 5.58\left(\mathrm{~d}, 1 \mathrm{H}^{3} J_{\mathrm{HH}}=3.1 \mathrm{~Hz}, \mathrm{C}(\mathrm{pz})_{4}\right), 3.76\left(\mathrm{~d}, 6 \mathrm{H},{ }^{3} J_{\mathrm{HP}}=\right.$ 
$\left.4.2 \mathrm{~Hz}, \mathrm{P}\left(\mathrm{OCH}_{2}\right)_{3} \mathrm{CCH}_{2} \mathrm{CH}_{3}\right), 1.03\left(\mathrm{~s}, 3 \mathrm{H}, \mathrm{NCCH}_{3}\right), 0.88$ (s, 3H, $\left.\mathrm{NCCH}_{3}\right), 0.0 .33$ (q, 2H, $\left.{ }^{3} J_{\mathrm{HH}}=7.6 \mathrm{~Hz}, \mathrm{P}\left(\mathrm{OCH}_{2}\right)_{3} \mathrm{CCH}_{2} \mathrm{CH}_{3}\right), 0.13\left(\mathrm{t}, 3 \mathrm{H},{ }^{3} J_{\mathrm{HH}}=7.7 \mathrm{~Hz}, \mathrm{P}\left(\mathrm{OCH}_{2}\right)_{3} \mathrm{CCH}_{2} \mathrm{CH}_{3}\right) .{ }^{13} \mathrm{C}$ NMR (201 MHz, $\left.\mathrm{C}_{6} \mathrm{D}_{6}\right) \delta 164.6$ (four lined pattern, $\left.{ }^{2} J_{\mathrm{CP}}=19.6 \mathrm{~Hz} \mathrm{Ru}-C(\mathrm{pz}) 4\right), 162.5$ (q, $\left.{ }^{1} J_{\mathrm{CB}}=50 \mathrm{~Hz}, \mathrm{BAr}_{4}{ }_{4}\right), 146.4,143.2,142.5,141.6,140.3,135.1,131.5,117.4,108.9$, 107.2, 106.7 (each a s, C(pz) 4$) 135.4\left(\mathrm{~s}, \mathrm{BAr}_{4}^{\prime}\right), 130.0\left(\mathrm{q},{ }^{1} J_{\mathrm{CF}}=32 \mathrm{~Hz}, \mathrm{BAr}_{4}^{\prime}\right), 126.1(\mathrm{~s}$, $\left.\mathrm{NCCH}_{3}\right), 124.3\left(\mathrm{~s}, \mathrm{NCCH}_{3}\right), 118.1\left(\mathrm{~s}, \mathrm{BAr}_{4}^{\prime}\right), 75.4\left(\mathrm{~d},{ }^{2} J_{\mathrm{CP}}=7 \mathrm{~Hz}, \mathrm{P}\left(\mathrm{OCH}_{2}\right)_{3} \mathrm{CCH}_{2} \mathrm{CH}_{3}\right)$, $36.4\left(\mathrm{~d},{ }^{3} J_{\mathrm{CP}}=32 \mathrm{~Hz}, \mathrm{P}\left(\mathrm{OCH}_{2}\right)_{3} \mathrm{CCH}_{2} \mathrm{CH}_{3}\right), 23.9\left(\mathrm{~s}, \mathrm{P}\left(\mathrm{OCH}_{2}\right)_{3} \mathrm{CCH}_{2} \mathrm{CH}_{3}\right), 7.5$ (s, $\left.\mathrm{P}\left(\mathrm{OCH}_{2}\right)_{3} \mathrm{CCH}_{2} \mathrm{CH}_{3}\right), 4.8\left(\mathrm{~s}, \mathrm{NCCH}_{3}\right) .{ }^{31} \mathrm{P} \mathrm{NMR}\left(121 \mathrm{MHz}, \mathrm{CD}_{2} \mathrm{Cl}_{2}\right) \delta 133.8 .{ }^{19} \mathrm{~F} \mathrm{NMR}$ $\left(282 \mathrm{MHz}, \mathrm{CD}_{2} \mathrm{Cl}_{2}\right) \delta-62.4$.

\subsection{Acknowledgements for High-Resolution Mass Spectroscopy Data}

We acknowledge the following with gratitude for help with the acquisition of highresolution mass spectra on some of the compounds and complexes described: Avinash Dalmia and Nicole Elliott, PerkinElmer, Shelton, CT; Jeffrey Dahl, Shimadzu Scientific Instruments, Columbia, MD; Anjali Alving, Bruker Daltonics, Billerica, MA; Joe Hedrick, Agilent Technologies, Wilmington, DE; and Gordon Fujimoto \& Besnik Bajrami, Waters Corporation, Beverly, MA.

\subsection{References}

(1) Trofimenko, S. J. Am. Chem. Soc. 1967, 89, 3170.

(2) Trofimenko, S. J. Am. Chem. Soc. 1966, 88, 1842.

(3) Trofimenko, S. Scorpionates: The Coordination Chemistry of Polypyrazolylborate Ligands; Imperial College Press: London, 1999.

(4) De Bari, H.; Zimmer, M. Inorg. Chem. 2004, 43, 3344. 
(5) Yoshimoto, S.; Mukai, H.; Kitano, T.; Sohrin, Y. Anal. Chim. Acta 2003, 494, 207.

(6) Rheingold, A. L.; Liable-Sands, L. M.; Incarvito, C. L.; Trofimenko, S. J Chem Soc Dalton 2002, 2297.

(7) Goodman, M. A.; Nazarenko, A. Y.; Casavant, B. J.; Li, Z.; Brennessel, W. W.; DeMarco, M. J.; Long, G.; Goodman, M. S. Inorg. Chem. 2011, 51, 1084.

(8) Jayaratna, N. B.; Gerus, I. I.; Mironets, R. V.; Mykhailiuk, P. K.; Yousufuddin, M.; Dias, H. V. R. Inorg. Chem. 2013, 52, 1691.

(9) Reger, D. L.; Grattan, T. C.; Brown, K. J.; Little, C. A.; Lamba, J. J. S.; Rheingold, A. L.; Sommer, R. D. Journal of Organometallic Chemistry 2000, 607,120 .

(10) Foley, N. A.; Lail, M.; Gunnoe, T. B.; Cundari, T. R.; Boyle, P. D.; Petersen, J. L. Organometallics 2007, 26, 5507.

(11) Foley, N. A.; Lail, M.; Lee, J. P.; Gunnoe, T. B.; Cundari, T. R.; Petersen, J. L. J. Am. Chem. Soc. 2007, 129, 6765.

(12) Foley, N. A.; Ke, Z. F.; Gunnoe, T. B.; Cundari, T. R.; Petersen, J. L. Organometallics 2008, 27, 3007.

(13) Lail, M.; Arrowood, B. N.; Gunnoe, T. B. J. Am. Chem. Soc. 2003, 125, 7506.

(14) Lail, M.; Bell, C. M.; Conner, D.; Cundari, T. R.; Gunnoe, T. B.; Petersen, J. L. Organometallics 2004, 23, 5007.

(15) Joslin, E. E.; McMullin, C. L.; Gunnoe, T. B.; Cundari, T. R.; Sabat, M.; Myers, W. H. Organometallics 2012, 31, 6851.

(16) Joslin, E. E.; McMullin, C. L.; Gunnoe, T. B.; Cundari, T. R.; Sabat, M.; Myers, W. H. Inorg. Chem. 2012, 51, 4791.

(17) Foley, N. A.,Thesis: Synthesis and Compariative Studies of Ru(II) Complexes for Metal-Mediated C-H Activation and Olefin Hydroarylation Catalyst, North Carolina State University, 2008.

(18) Fujisawa, K.; Ono, T.; Ishikawa, Y.; Amir, N.; Miyashita, Y.; Okamoto, K.; Lehnert, N. Inorg. Chem. 2006, 45, 1698.

(19) Wiley, J. S.; Oldham, W. J., Jr.; Heinekey, D. M. Organometallics 2000, 19,1670 . 
(20) Heinekey, D. M.; Oldham, W. J., Jr.; Wiley, J. S. J. Am. Chem. Soc. 1996, 118,12842 .

(21) Mendoza-Ferri, M. G.; Hartinger, C. G.; Nazarov, A. A.; Eichinger, R. E.; Jakupec, M. A.; Severin, K.; Keppler, B. K. Organometallics 2009, $28,6260$.

(22) Yakelis, N. A.; Bergman, R. G. Organometallics 2005, 24, 3579.

(23) Lühder, K.; Nehls, D.; Madeja, K. Journal Fur Praktische Chemie 1983, $325,1027$.

(24) Neves, P.; Gago, S.; Balula, S. S.; Lopes, A. D.; Valente, A. A.; CunhaSilva, L.; Paz, F. A. A.; Pillinger, M.; Rocha, J.; Silva, C. M.; Gonçalves, I. S. Inorg. Chem. 2011, 50, 3490.

(25) Trofimenko, S. J. Amer. Chem. Soc. 1970, 92, 5118.

(26) Julia, S.; Del, M. J. M.; Avila, L.; Elguero, J. Org. Prep. Proced. Int. 1984, 16, 299. 


\section{Summary and Future Outlook}

\subsection{Olefin Hydroarylation with $\mathrm{TpRu}(\mathrm{L})(\mathrm{NCMe}) \mathrm{Ph}$}

Our group has previously demostrated that $\mathrm{TpRu}(\mathrm{L})(\mathrm{NCMe}) \mathrm{Ph}\left(\mathrm{L}=\mathrm{CO}, \mathrm{PMe}_{3}\right.$, $\mathrm{P}(\text { pyr })_{3}$, and $\left.\mathrm{P}\left(\mathrm{OCH}_{2}\right)_{3} \mathrm{CEt}\right)$ complexes are capable of olefin hydroarylation with simple olefins (i.e., ethylene and propylene). ${ }^{1-6}$ These experimental studies along with computational studies by Professor Tom Cundari's group at the University of North Texas revealed important aspects and trends to olefin hydroarylation using these complexes. In order for a catalyst to be capable of catalytic olefin hydroarylation it has be to able to preform two key steps, olefin insertion into a $\mathrm{M}-\mathrm{Ar}$ bond and preference for arene $\mathrm{C}-\mathrm{H}$ activation over olefin $\mathrm{C}-\mathrm{H}$ activation. These two key step require two different electronic properties. $\mathrm{C}-\mathrm{H}$ activation of benzene, which was determined to be the rate limiting step of the reaction (for the $\mathrm{TpRu}(\mathrm{CO}) \mathrm{NCMe}$, is promoted by electron rich metal centers (see Chapter 1); alternatively, olefin insertion is more facile with electron poor metal centers. An important trend that was observed when systematically altering the electron density of the metal center from an electron rich metal center $(\mathrm{L}=$ $\left.\mathrm{PMe}_{3}\right)$ to an electron poor metal center $(\mathrm{L}=\mathrm{CO})$ is that the difference in the electron density of the metal center has a greater impact on the rate of olefin insertion compared to the rate of arene $\mathrm{C}-\mathrm{H}$ activation.

The most active and longest lived catalyst to date is $\mathrm{TpRu}(\mathrm{CO})(\mathrm{NCMe}) \mathrm{Ph}$ with approximately $415 \mathrm{TO}$ at $90{ }^{\circ} \mathrm{C}, 15 \mathrm{psi}$ and $0.025 \mathrm{~mol} \% \mathrm{Ru}$ and a TOF of $6.7 \times 10^{-3} \mathrm{~s}^{-1}$ (see Chapter 2). Previously, catalysis was run at $0.1 \mathrm{~mol} \% \mathrm{TpRu}(\mathrm{CO})(\mathrm{NCMe}) \mathrm{Ph}$ at 90 ${ }^{\circ} \mathrm{C}$ and 25 psi of ethylene which gave a significantly lower TON of 77 . The increased 
TON supported our hypothesis that lowering the catalyst loading would increase the TON because the route of decomposition is proposed to like to be a binuclear pathway leading to an NMR silent species. Chapter 4, discusses the decomposition and catalysis results through altering the catalyst loadings and ethylene pressure when $\mathrm{TpRu}(\mathrm{CO})(\mathrm{NCMe}) \mathrm{Ph}$ is employed as the catalyst. ${ }^{1} \mathrm{H}$ NMR spectroscopy experiments watching the rate of decomposition of $\mathrm{TpRu}(\mathrm{CO}) \mathrm{Ph}(\mathrm{NCMe})$ in $\mathrm{THF}-d_{8}$ at $90{ }^{\circ} \mathrm{C}$ yielded second order kinetics in $\mathrm{Ru}$ which supports a bi-nuclear decomposition pathway. Systematically changing the $\mathrm{Ru}$ catalyst loadings demonstrated the presence of competing decomposition pathways. At higher catalyst loadings and lower ethylene pressures the dominate decomposition product is the hypothesized multinuclear Ru species; however, at lower concentrations of $\mathrm{Ru}$, decomposition was observed through the allyl-species $\operatorname{TpRu}(\mathrm{CO})\left(\eta^{3}-\mathrm{C}_{4} \mathrm{H}_{7}\right)$. Therefore, it is hypothesized that by attaching $\mathrm{TpRu}(\mathrm{CO})(\mathrm{NCMe}) \mathrm{Ph}$ to a solid support (Figure 6.1) the binuclear decomposition pathway could be shutdown and the catalyst longevity and TON of alylkybenzenes could increase, similar to what being seen by our group's studies comparing the molecular system to the heterogeneous ('bpy)Pt(Ph)(THF)[BAr' $\left.{ }_{4}\right]^{7}$ system.

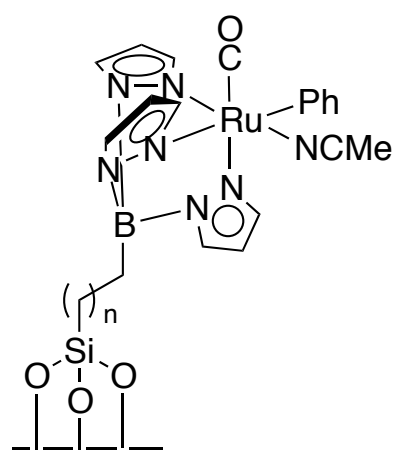

Figure 6.1. MSM supported $\mathrm{TpRu}(\mathrm{CO}) \mathrm{Ph}(\mathrm{NCMe})$ 
In order to shut down the decomposition pathway caused by olefin $\mathrm{C}-\mathrm{H}$ activation competing with olefin insertion we wanted to investigate a less electron rich metal center than when $\mathrm{L}=\mathrm{PMe}_{3}$ or $\mathrm{P}\left(\mathrm{OCH}_{2}\right)_{3} \mathrm{CEt}$. We synthesized a phosphite where a methylene group was removed from one of the phosphite tethered arms to yield $\mathrm{P}\left(\mathrm{OCH}_{2}\right)_{2}\left(\mathrm{OCCH}_{3}\right)$. Chapter 2, explores the electronics and structural properties of $\mathrm{P}\left(\mathrm{OCH}_{2}\right)_{2}\left(\mathrm{OCCH}_{3}\right)$ compared to carbon monoxide and a variety of phosphites and phosphines. The $\mathrm{Ru}(\mathrm{II})$ complexes studied were of the motif $\mathrm{TpRu}(\mathrm{L}) \mathrm{PPh}_{3} \mathrm{Cl}, \quad\left(\eta^{6}-\mathrm{C}_{6} \mathrm{H}_{6}\right) \mathrm{Ru}(\mathrm{L}) \mathrm{Cl}_{2}, \quad\left(\eta^{6}-p-\right.$ cymene $) \mathrm{Ru}(\mathrm{L}) \mathrm{Cl}_{2}$ where $\mathrm{L}=$ neutral two-electron donor). It was hypothesized that removal of a methylene group from one of the phosphite tethered arms would make $\mathrm{P}\left(\mathrm{OCH}_{2}\right)_{2}\left(\mathrm{OCCH}_{3}\right)$ a poor electron donor. Chapter 2 demonstrates that removal of the methylene linker does decrease the electron density of the metal center determined by cyclic voltammetry and crystal data. However, even though $\mathrm{P}\left(\mathrm{OCH}_{2}\right)_{2}\left(\mathrm{OCCH}_{3}\right)$ decreases the electron density at the metal center the metal center is still more electron rich than when $\mathrm{L}=\mathrm{CO}{ }^{8}$

Due to decreased electron density at the metal center when $\mathrm{P}\left(\mathrm{OCH}_{2}\right)_{2}\left(\mathrm{OCCH}_{3}\right)$ is employed as the neutral two electron donor, we sought to study this effect on olefin hydroarylation, which is examined in Chapter 3. TpRu[P(OCH$\left.)_{2}\left(\mathrm{OCCH}_{3}\right)\right](\mathrm{NCMe}) \mathrm{Ph}$ was synthesized and tested for olefin hydroarylation. 9 TpRu[ $\mathrm{P}\left(\mathrm{OCH}_{2}\right)_{2}\left(\mathrm{OCCH}_{3}\right)$ ](NCMe) $\mathrm{Ph}$ is capable of breaking aromatic $\mathrm{C}-\mathrm{H}$ bonds but is slower by a factor of two compared to $\mathrm{L}=\mathrm{PMe}_{3}$, which is to be expected since $\mathrm{C}-\mathrm{H}$ activation is promoted by 
more electron rich metal centers. TpRu[ $\left.\mathrm{P}\left(\mathrm{OCH}_{2}\right)_{2}\left(\mathrm{OCCH}_{3}\right)\right](\mathrm{NCMe}) \mathrm{Ph}$ produces approximately $90 \mathrm{TO}$ of ethylbenzene at $90^{\circ} \mathrm{C}$ and $15 \mathrm{psi}$ of ethylene before deactivation. However, the metal center is still too electron rich (similar to $\mathrm{L}=\mathrm{PMe}_{3}$ and $\left.\mathrm{P}\left(\mathrm{OCH}_{2}\right)_{3} \mathrm{CEt}\right)$ and olefin $\mathrm{C}-\mathrm{H}$ activation completes with olefin insertion leading to a $\mathrm{TpRu}\left[\mathrm{P}\left(\mathrm{OCH}_{2}\right)_{2}\left(\mathrm{OCCH}_{3}\right)\right]\left(\eta^{3}-\mathrm{C}_{4} \mathrm{H}_{7}\right)$ complex. Therefore, it is proposed that future work needs to examine a $\mathrm{Ru}(\mathrm{II})$ metal center that would have a similar electronic profile as $\mathrm{L}=$ CO. In order to achieve this one should look at neutral 6-electron donors rather than the anionic Tp ligand. This would enable us to vary the catalyst motif without drastic changes to the sterics. Although not as well studied at the tris(pyrazolyl)borates, tris(pyrazolyl)alkanes (Figure 6.2) have been synthesized and shown that the metal center is less electron rich. ${ }^{10}$

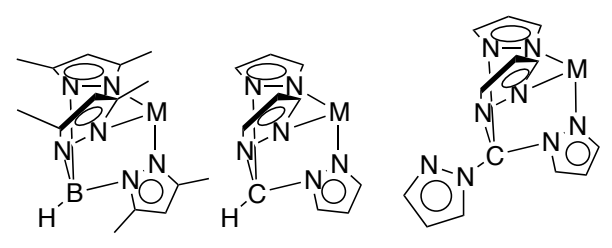

Figure 6.2. Examples of tris(pyrazolyl)alkanes.

\subsection{Olefin Hydroarylation with $R u(I I)$ Complex contain neutral 6-electron donor ligands.}

Chapter 5 discusses $\mathrm{Ru}(\mathrm{II})$ complexes with a variety of neutral 6-electron donors such $\left(\eta^{6}-p\right.$-cymene), $\mathrm{C}(\mathrm{pz})_{4}$, and $\mathrm{HC}\left(\mathrm{pz}^{\prime}\right)_{3}$. It was demonstrated that removing the anionic Tp ligand with a neutral ligand does reduce the electron density at the metal center. $\left\{\left[\mathrm{HC}\left(\mathrm{pz}^{\prime}\right)_{3}\right] \mathrm{Ru}\left[\mathrm{P}\left(\mathrm{OCH}_{2}\right)_{3} \mathrm{CEt}\right] \mathrm{Ph}(\mathrm{NCMe})\right\}\left[\mathrm{BAr}_{4}{ }_{4}\right]$ has a reversible $\mathrm{Ru}(\mathrm{III} / \mathrm{II})$ potential of $0.82 \mathrm{~V}$ where the analogous $\mathrm{Tp}$ complexes has a $\mathrm{Ru}(\mathrm{III} / \mathrm{II})$ potential of $0.69 \mathrm{~V}$. 
$\left\{\left[\mathrm{HC}\left(\mathrm{pz}^{\prime}\right)_{3}\right] \mathrm{Ru}\left[\mathrm{P}\left(\mathrm{OCH}_{2}\right)_{3} \mathrm{CEt}\right] \mathrm{Ph}(\mathrm{NCMe})\right\}\left[\mathrm{BAr}^{\prime}\right]$ has an identical $\mathrm{Ru}(\mathrm{III} / \mathrm{II})$ as $\mathrm{TpRu}\left[\mathrm{P}(\mathrm{pyr})_{3}\right] \mathrm{Ph}(\mathrm{NCMe})$ which was incapable of olefin hydroarylation due to the $\mathrm{P}(\mathrm{pyr})_{3}$ ligand being too sterically bulky and inhibiting olefin coordination. Therefore, the $\left\{\left[\mathrm{HC}\left(\mathrm{pz}^{\prime}\right)_{3}\right] \mathrm{Ru}\left[\mathrm{P}\left(\mathrm{OCH}_{2}\right)_{3} \mathrm{CEt}\right] \mathrm{Ph}(\mathrm{NCMe})\right\}\left[\mathrm{BAr}_{4}{ }_{4}\right]$ complex gives us an opportunity to test a $\mathrm{Ru}(\mathrm{II})$ catalyst that is of similar electron donor ability as $\mathrm{TpRu}\left[\mathrm{P}(\mathrm{pyr})_{3}\right] \mathrm{Ph}(\mathrm{NCMe})$ but with less steric bulk from the phosphine ligand. $\left\{\left[\mathrm{HC}\left(\mathrm{pz}^{\prime}\right)_{3}\right] \mathrm{Ru}\left[\mathrm{P}\left(\mathrm{OCH}_{2}\right)_{3} \mathrm{CEt}\right] \mathrm{Ph}(\mathrm{NCMe})\right\}\left[\mathrm{BAr}_{4}{ }_{4}\right]$ was incapable of olefin hydroarylation at $25 \mathrm{psi}$ and $90{ }^{\circ} \mathrm{C}$. This is potentially due to the increase steric bulk caused by the methyl group on the 3-position of the pyrazolyl ring which could inhibit olefin coordination. However, steric bulk of the $\mathrm{HC}\left(\mathrm{pz}^{\prime}\right)_{3}$ ligand still remains problematic, a potential way to eliminate this issue is to replace the 3-position of the pyrazolyl with a less bulky ligand such as a halide. However, the synthesis of a mono, di, or tri-substituted fluorinated or chlorinated pyrazole has only been studied via calculations. ${ }^{9}$ This is potentially due to the experimental hazard of using $\mathrm{Cl}_{2}$ or $\mathrm{F}_{2}$ for the synthesis of these complexes. The tris-brominated pyrazole has been synthesized, along with the $\mathrm{TpBr}_{3}{ }^{10}$ and on going work to synthesis the $\mathrm{HC}\left(\mathrm{pz}^{\mathrm{Br} 3}\right)_{3}$ is currently underway. Once the ligand is synthesized and coordinated to the metal center catalytic studies with olefin hydroarylation will be explored.

\subsection{Onward to Rhodium}

Due to our group's extensive studies with $\mathrm{Ru}(\mathrm{II})$ and $\mathrm{Pt}(\mathrm{II})$ complexes it is hypothesized that moving to $\mathrm{Rh}(\mathrm{I})$ complexes (Figure 6.4) could potential enhance selectivity for olefin hydroarylation..$^{1,3-7,11-13}$ Computation studies by the Cundari group 
have predicted that $[(\mathrm{bpy}) \mathrm{Rh}(\mathrm{Ph})]^{+}$will have a lower activated barrier by a $\Delta \Delta \mathrm{G}^{\ddagger}=7.3$ $\mathrm{kcal} / \mathrm{mol}$ (Figure 6.3) compared to the analogus Pt system.

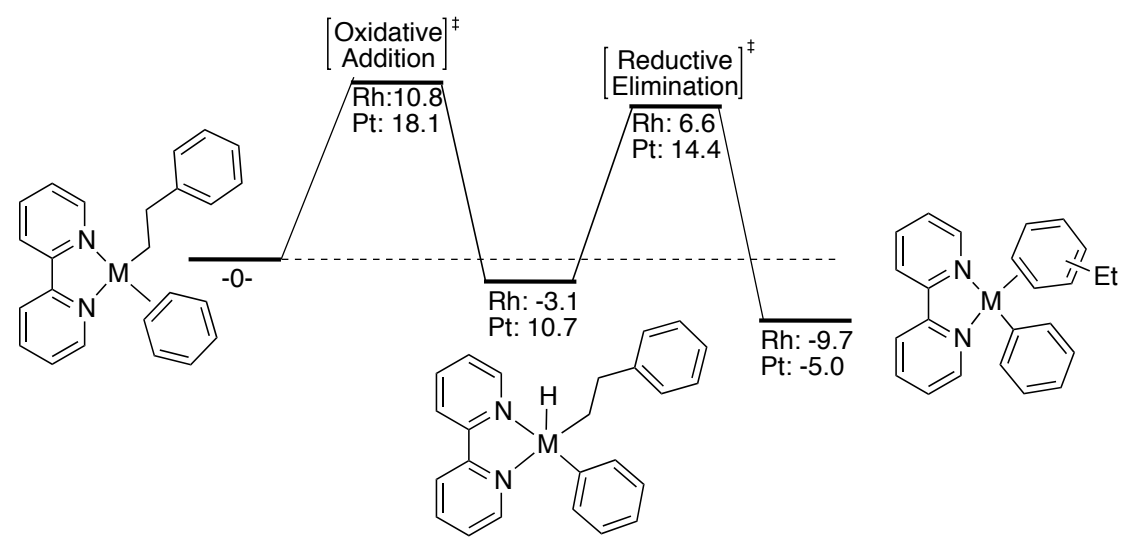

Figure 6.3. Calculated $\Delta \mathrm{G}^{\ddagger}(\mathrm{kcal} / \mathrm{mol})$ for benzene $\mathrm{C}-\mathrm{H}$ activation via a two-step reaction for $\mathrm{M}=\mathrm{Rh}$ or $\mathrm{Pt}$.

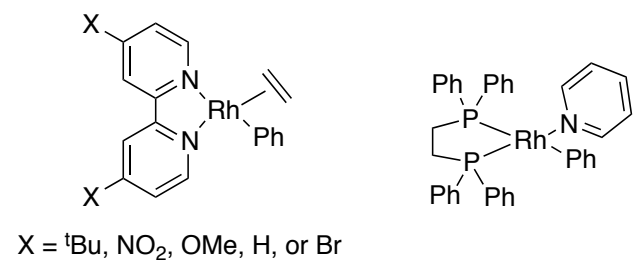

Figure 6.4. Potential $\mathrm{Rh}(\mathrm{I})$ catalyst for olefin hydroarylation.

One advantage to using the bpy ligand framework is the ability to do similar studies with Rh as our group has done with $\mathrm{Pt}^{13}$ By varying the 4,4' positions of the bpy the electronics of the metal center can be altered without changing the sterics surrounding the metal center. Hartwig et al. has published that a (DPPE)Rh(pyridine)(p-tolyl) [DPPE $=1,2$-bis(diphenylphosphino)ethane] is capable of the insertion reaction with electronpoor imines and aldehydes. ${ }^{14}$ This is an appealing starting complex since if the pyridine is significantly labile in the presence of ethylene, ethylene could displace the pyridine and 
lead to our desired $\mathrm{Rh}(\mathrm{I})$ (ethylene)(phenyl) complex. Additionally, it is thought that moving from $\mathrm{Ru}$ to $\mathrm{Rh}$ the metal center would be less $\pi$-basic; therefore, the olefin would be less tightly bound and the olefin would insert more readily into the $\mathrm{M}-\mathrm{Ph}$ bond which would shut down the decomposition pathway seen with the $\mathrm{TpRu}(\mathrm{II})$ complexes where olefin $\mathrm{C}-\mathrm{H}$ activation is competitive with olefin insertion.

\subsection{References}

(1) Lail, M.; Arrowood, B. N.; Gunnoe, T. B. J. Am. Chem. Soc. 2003, 125, 7506.

(2) Lail, M.; Bell, C. M.; Conner, D.; Cundari, T. R.; Gunnoe, T. B.; Petersen, J. L. Organometallics 2004, 23, 5007.

(3) Foley, N. A.; Lail, M.; Gunnoe, T. B.; Cundari, T. R.; Boyle, P. D.;

Petersen, J. L. Organometallics 2007, 26, 5507.

(4) Foley, N. A.; Lail, M.; Lee, J. P.; Gunnoe, T. B.; Cundari, T. R.; Petersen, J. L. J. Am. Chem. Soc. 2007, 129, 6765.

(5) Foley, N. A.; Ke, Z. F.; Gunnoe, T. B.; Cundari, T. R.; Petersen, J. L. Organometallics 2008, 27, 3007.

(6) Foley, N. A.; Lee, J. P.; Ke, Z. F.; Gunnoe, T. B.; Cundari, T. R. Acc. Chem. Res. 2009, 42, 585.

(7) McKeown, B. A.; Foley, N. A.; Lee, J. P.; Gunnoe, T. B. Organometallics 2008, 27, 4031.

(8) Joslin, E. E.; McMullin, C. L.; Gunnoe, T. B.; Cundari, T. R.; Sabat, M.; Myers, W. H. Inorg. Chem. 2012, 51, 4791.

(9) Aullon, G.; Gorun, S. M.; Alvarez, S. Inorg. Chem. 2006, 45, 3594.

(10) Rheingold, A. L.; Liable-Sands, L. M.; Incarvito, C. L.; Trofimenko, S. J Chem Soc Dalton 2002, 2297.

(11) Andreatta, J. R.; McKeown, B. A.; Gunnoe, T. B. J. Organomet. Chem. 2011, 696, 305. 
(12) McKeown, B. A.; Gonzalez, H. E.; Friedfeld, M. R.; Gunnoe, T. B.; Cundari, T. R.; Sabat, M. J. Am. Chem. Soc. 2011, 133, 19131.

(13) McKeown, B. A.; Gonzalez, H. E.; Friedfeld, M. R.; Brosnahan, A. M.; Gunnoe, T. B.; Cundari, T. R.; Sabat, M. Organometallics 2013, 32, 2857.

(14) Krug, C.; Hartwig, J. F. Organometallics 2004, 23, 4594. 